\title{
Estrutura eletrônica e efeitos magneto-quânticos em super-redes semicondutoras degeneradas
}

\author{
Luiz Carlos Donizetti Gonçalves
}

Banca examinadora:

Dra. Ana Maria de Paula

Dr. André Bohomoletz Henriques (orientador) Amerfueusino

Dr. Nelson Studart

Dr. Paulus Maria Koenraad

Dr. Valdir Bindilatti

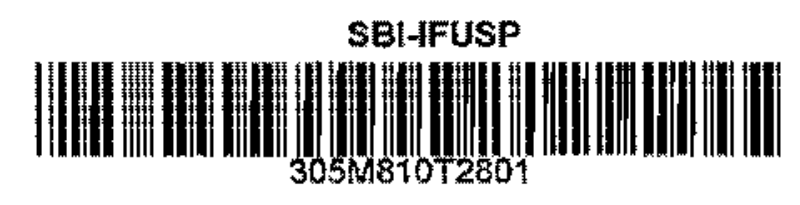

Tese apresentada a Instituto de Física da Universidade de Sáo Paulo para a obtenção do título de Doutor em Ciênciats

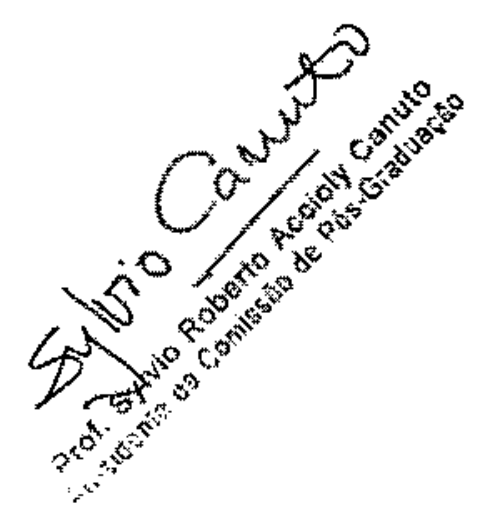

SÃO PAULO

1998

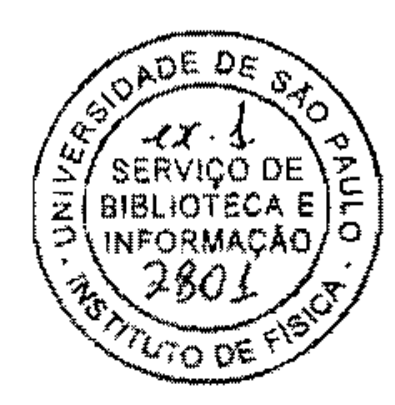




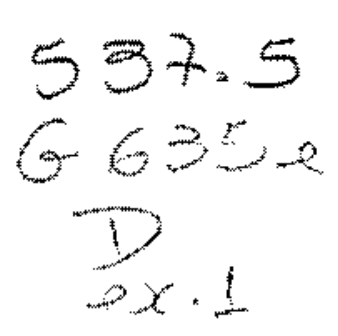

FICHA CATALOGRÁFICA

Preparada pelo Serviço de Biblioteca e Informação do Instituto de Fisica da Universidade de São Paulo

Gonçalves, Luiz Carlos Donizetti

Estrutura Eletrônica e Efeitos Magneto-Quânticos em Super-Redes Semicondutoras Degeneradas.

São Paulo, 1998.

Tese (Doutoramento) Universidade de Sāo Paulo. Instituto de Fisica - Departamento de Física dos Materiais e Mecânica.

Area de Concentração: Fisica do Estado Sólido Orientador: Prof. Dr. André Bohomoletz Henriques

Unitermos: 1. Estrutura Eletrônica; 2. Super Redes;

3. Mobilidade Eletrônica; 4. Shubnikov de Haas;

5. Capacitäncia-Voltagem. 
$"$ [... pedi que os quatro homens arrancassem os arbustos com as raizes [..., onde, suponho, deveria encontrar-se a maravilhosa oliveira, da qual ulisses preparou sua cama e, em torno desse local, construiu seu quarto de dormir (Od. XXI, 183-204).

Na parte interna do pátio cresceu uma oliveira alta [...]. En torno dela, construi [...] o aposento conjugal, [...] cortei os galhos da frondosa oliveira e aparei a superfície do tronco a partir das raízes. [...] construí toda a cama, cobri com ouro, prata e marim, e na parte interna estiquel correias de couro de boi, tingido de cor púrpur brilhante."

Porérn, encontramoz somente scombros de tellas e panelas. Numa profundidade de 66 crn resolve mos deixar de lado esse rochedo. Nele havia muitas fendas, nas quais as raizes de oliveira poderian ter penetrado. Mas todas as minhas esperanças de encontrar ali objetos arqueológicos desapareceram.

Pedi para escavarem o chäo logo ao lado, pois havia descoberto dois blocos de pedra, os quais, pelo que me parece, tinharn pertencido am muro. Após tres horas de trabalbo, os ajudantes trouxeram à luz do dia as duas lajes inferiores de um pequeno edificio com 3 m de latgura e $4,75 \mathrm{~m}$ de comprimento. A abertura da porta tinha uma largura de $1 \mathrm{~m}$. As pedras estavan bem talhadas e tinham $33 \mathrm{~cm}$ de comprimento de largura. Elas estavam unidas com bastante cimento, branco como a neve, do qual level alguns pedaços para casa. Mesmo abaixo da camada inferior de pedras, havia uma espessa laje de cimento, que, por estar ali, năo deixa dúvidas que esse edificio foi contruido no minimo sete séculos depois da Guerra de Tróia, pois eu nunca havia percebido a presença de cirnento nas construçöes da época dos heröis.

No local escavado encontramos ainda muitos destroços de telhas tortas, levemente queimadas, e até uma tella inteira com $66 \mathrm{~cm}$ de comprimento e de mesma largura, bem como muitos outros cacos.

Ethquanto meus ajudantes estavam ocupados com essa escavacäa, pesquisei com muta atençăo todo o terreno do palácio, e quando encontrel ama grande pedra, cuja extremidade parecia descrevet uma curva, aproximadamente a centésima parte de uma cincunferência, tirế com uma faca a terra que estava na pedra e vi que formava uma semi-circunferencia. Quando continuei a escavar com a faca, percebi logo que era possivel completar a outra metade da circunferencia empilhando camadas de pedras, que formava um muro ao pedaços, por assim dizer. A principio, eu queria tirar essas camadas com a faca, mas, näo atingi o meu objetivo, pois a terra estava misturada com uma substancia branca, que reconheci como sendo cinzas de ossos carbonizados, e que tava tào dura quanto a própria pedra. Então comecei a escavar com a picareta. Mas mal tinha escavado $10 \mathrm{~cm}$ de profundidade, quando quebrei am lindo vaso, bem pequeno, cheio de cinzas humanas. Continuei a escavar com o major cuidado e encontrel cerca de 20 yasos diferentes de formas bizatras. Alguns estavam deitados e outros, em pé. Infelizmente, quebrei a maioria ao retirálos devido à dureza da terra e à falta de boas fsramentas. Consegui levar somente cinco a salvo. 0 maior deles nano tinha mais de $11 \mathrm{~cm}$ de altura. $O$ diametro da sua abertura $e$ de $1 \mathrm{~cm}$. Um outro tern a abertura de apenas $6 \mathrm{~mm}$. Dois desses yasos tinham uma pintura realmente bonita ao puxámlos da terra, mas ficaram praticamente irreconheciveis, assim que os expus ao sol. Espero que esfregando com álcool água elas voltem a aparecer rapidamente.

Todos esses vasos estão preenchidos com as cinzas de onsadas humanas.

Além disso, encontrei nesse pequeno cenitério familiar a lämina torta de uma faca de sacrifícios, com $13 \mathrm{~cm}$ de comprimento, bern enferrujada, mas, de um modo geral, razoavelmente bem conservada. Tinha tarnbém um idolo de baro que representa uma deusa com duas flautas na boca: os destrogos de uma espada de ferro, um dente de um javali, muitos ossos pequenos de avimaís por fim, am motivo de fos de bronze batidos uns aos outros. Daria cinco anos da minha vida por uma inscriçäo mas, infelizmente, näo havia nenhuma!

Embora seja diffoil determinar a idade desses objetos, tenho certeza de que os vazos säo bern mais velhos que os mais antigos vasos de Cumae, no museu de Nápoles, e é bern possivel, que du guarde nas minhas cinco pequenas urnas as cinzas de Ulisses, de Penélope ou seus destendentes. 
Depois que escavei a abertura redonda até o fundo, comprovei através de mediçōes que sua profundidade no lado sul é de $76 \mathrm{~cm}$, do lado norte, $92,5 \mathrm{~cm}$ e seu diâmetro é de 1,25 m.

Nada provoca mais sede que o árduo trabalho de escar sob um calor de $52^{\circ} \mathrm{C}$. Na verdade, tínhamos levado três jarras enormes cheias de água e uma garrafa grande com quatro litros de vinho. $O$ vinho foi o suficiente para nós, pois o vinho de Ítaca, como eu já havia dito, é três vezes mais forte que o vinho Bordeux, mas a nossa provisão de água logo foi esgotada e por duas vezes fomos obrigados a renová-las.

Meus quatro ajudantes tinham terminado a escavação da casa pós-homérica, ao mesmo tempo em que eu terminei a escavação do pequeno cemitério circular. Com certeza tive mais sucesso do que eles. Mas não os repreendi por isso, visto que eles tinham trabalhado para valer, e mais mil anos podem passar antes que o espaço escavado seja novamente preenchido com pó atmosférico.

O meio-dia chegou e nós não tinhamos comido nada desde as $\mathbf{5}$ horas da manhā. Fizemos entāo nossa refeição sob uma oliveira entre os dois muros, uns $15 \mathrm{~m}$ para baixo do topo. Nossa refeiçāo era composta de pão seco, vinho e água, cuja temperatura nāo estava abaixo dos $30^{\circ} \mathrm{C}$. Mas eram produtos do solo de Ítaca, os quais eu saboreava e precisamente no pátio do palácio de Ulisses, talvez no mesmo lugar onde ele derramou lágrimas quando viu novamente o seu cachorro predileto, Argos, que morreu de felicidade ao reconhecer o seu dono após vinte anos de ausência. Também onde o divino pastor de porcos disse as famosas palavras: 'Pois Júpiter, o todo-poderoso, retira a metade do valor do homem, assim que os dias de servidão o alcançam'.

Posso bem dizer que nunca na minha vida comi com tanto apetite como nessa refeição frugal no palácio de Ulisses.

Após a refeição, os meus ajudantes descansaram uma hora e meia, enquanto eu, com a picareta na māo, pesquisava o terreno da construçāo do palácio entre os muros, para fazer novas descobertas. Em todos os lugares onde a aparência do solo mostrava a possibilidade de encontrar algo, eu fazia uma marcação, para continuar uma escavaçāo depois. Às duas horas começaram novamente a trabalhar e foram até às cinco horas; mas sem o mínimo sucesso. Como queria recomeçar as escavaçōes na manhā do dia seguinte, deixamos as ferramentas no local e voltamos para Vathy, onde chegamos às sete horas da noite.

As cordiais senhoritas Triantafyllides cuidaram de preparar um almoço para mim. Mas, quāo grande foi minha consternaçāo, quando colocaram à mesa nada mais que batatas cozidas, sal e pão. Então perguntei a elas se nāo estavam brincando comigo. Com espanto, responderam: $O$ senhor é cristāo e quer comer carne na sexta-feira? - Mas por todos os deuses da Grécia, repliquei, se as senhoritas, com cuidado com a salvação da minha alma, nāo querem servir carne, por que não me servem ao menos peixe?- Alguém já viu alguma vez- responderam elas - um cristão que no dia de jejum comeu peixe? E mesmo se quiséssemos servir peixe, não poderíamos, pois, nenhum pescador joga a sua rede às sextas ou às quartas-feiras, porque ninguém iria comprar os seus peixes. E nenhum açougueiro abre a sua loja nestes dias, pois seria maltratado pela população.

As caras sérias com as quais elas me deram esta explicaçāo, provou claramente que exprimiam a sua inteira convicção e que consideravam um crime contra os mandamentos de Deus que alguém comesse carne nos dias de jejum. Fiquei quieto e saí para conseguir presunto ou manteiga. mas embora perguntasse em diversas lojas. nảo havia nada disso na ilha de Ítaca. Com muito esforço recebi um pouco de óleo para untar as batatas. Essa mais do que modesta refeiçāo não produziu: de modo algum, mal-estar. E nunca me senti tão bem nas viagens, mesmo quando tinha que me contentar com pão e água."

Heinrich Schliemann em Ítaca. o Peloponeso e Tróia 


\section{Resumo}

É apresentado um estudo da estrutura eletrônica e de processos de espalhamento em superredes semicondutoras degeneradas. Os processos de espalhamento foram estudados em termos do seu efeito sobre os fenômenos magneto-oscilatórios (em particular, o efeito Shubnikov-de Haas), tanto no aspecto térico como no experimental.

Foi desenvolvida uma metodologita que permite a extraçäo dos parâmetros fundamentais para super-redes $\delta$-dopadas (o período $d$, a densidade de dopagem por periodo, $N_{\mathrm{d}}$, e a expessura das camadas dopadas $\Delta_{d}$ ) com base em medidas de Shubrikov-de Hass $(\$ d H)$ com o campo magnético aplicado paralelarnente aos eixos de crescimento das supet-redes e em medidas de Capacitância-Voltagem(CV). Foi demonstrado que os periodos de oscilaçato CV correspondem aos periodos de dopagem $d$. A partir da transformada de Fourier das oscilaçoes de SdH são obtidas as áreas extremas da superfície de Fermi que, via a estrutura eletrônica calculada, fornecem os demais parânetros $N_{\mathrm{d}}$ e $\Delta_{\mathrm{d}}$.

As oscilações de SdH devidas a cada una das minibandas populadas foram isoladas do restante do espectro através de téenicas de transformada de Fourier. A partir de um modelo desenvolvido recentemente, o qual inclui a estrutura eletrônica das super-redes na forma de linha das oscilaçōes de SdH, as mobilidades quânticas associadas aos tempos de meia vida no nível de Fermi nas várias minibandas eletrônicas foram determinadas. Os estudos foram efetuados em funçäo do periodo da super-rede, os quais determinam o grau de acoplamento entre poços vizinhos. Uma posterior comparaçäo das mobilidades quânticas obtidas a partir do espectro de SdH com a teoria Fandom Phase Approximation(RPA) desenvolvida para o espalhamento por centros coulombianos blindados em sistemas periodicamente $\delta$-dopados, com espessura das camadas dopadas praticamente nula, mostrou um acordo bastante bom.

Adicionalmente, cálculos teóricos em sistemas $\delta$-dopados indicam que as mobilidades qquẫntica e de transporte são sẹnsíveís à espessura e distribuição espacial da camada dopada e à concentração de aceitadores residuais em sistemas realisticos. Também foram efetuados cálculos teóricos para as mobilidades quântíca e de transporte ern estruturas $\delta$-dopadas submetidas à aplicaçäo de um potencial externo as quais mostram que, no estado atual da teoria na literatura para sistemas com muiltiplas subbandas, a teoria RPA é aquela de escolha para a descrição dos fenomenos de espalharnento por impurezas ionizadas em sistemas bi-dimensionais.

Por firm, alguns tópicos que abordam a obtençâo das mobilidades de transporte em sistemas $\delta$-dopados são discutidos. 


\section{Abstract}

It is presented a study of the electronic structure and scattering processes in degenerate semiconductor superlattices. The scattering processes were studied in terms of their effect on the magneto-oscillatory phenomena (in particular, the Shubnikov-de Hass effect), both theoretical and experimentally.

An approach was developed to allow the extraction of the fundamental parameters for $\delta$-doped superlattices (the period $d_{2}$ the doping density per period, $N_{\mathrm{d}}$, and the doped layers thicknesses $\Delta_{d}$ ) from Shubnikov-de Haas (SdH) measurements with magnetic field applied along the superlattice growth axis and from Capacitance-Voltage(CV) measurements. It was demonstrated that the CV oscillation periods correspond to the doping period $d$. From the Fourier transform of StH oscillations the extremal cross sectional areas of the Fermi surface are obtained and, together with the calculated electronic structure, provide the additional paraneters $N_{\mathrm{d}}$ and $\mathrm{A}_{\mathrm{d}}$.

The oscillations due to each populated miniband were isolated from the rest of the spectrum by Fourier transform techniques. By means of a recently developed model, which indudes the superlattice electronic structure in the lineshape of the SdH oscillations, the quantum mobilities associated to the quantum lifetimes at the Fermi level for sach miniband were determined. The behaviour of the quanturn mobilities were studied as a function of the superlattice period, which determines the coupling strength between adjacent wells. The comparison between the quantum mobilities obtained from the SdH spectrum and the Random Phase Approximation(RPA) theory developed for the screened Coulomb centers in systems periodically $\delta$-doped, with vanishing thickness of the doped layen, showed a very good agreenent.

Furthermore, theoretical calculations in $\delta$ doped systems show that the quantum and the transport mobilities are sensible to the thickness and to the spatial profile of the doped layer, and to the concentration of residual acceptors in realistic systems. The quantum and the transpor mobilities were calculated for gated d-doped structures and it's shown that; in the actual state-of-art of the theory for systems with multiple subbands, the RPA theory is that of choice to describe the scattering phenomena by ionized impurities in two-dimensional systems.

Finally, some topics involving the extraction of transport mobilities for multiple subbands systems are discussed. 


\section{Agradecimentos}

Como não poderia faltar em qualquer tese, enumerem-se e atribuam-se aqui os agradecimentos às pessoas que contribuíram direta ou indiretamente para o desenvolvimento desta tese de doutorado. A ordem en que as pessoas são citadas năo necessariamente representa a ordem de importância para este trabalho ou de qualquer outro critério logicamente estabelecido.

Primeiramente, e principalmente, agradeço aos meus pais pois sem eles eu nä́o conseguitia nem ter começado a fazer esta tese.

Agradeço novamente ao meu orientador por sua paciencia infinita e por todos estes anos de 'diversẫo' prolongada. Afinal, Work is muthe more fun than fun.

Ao Nestor Pestana in memoriam, ao Barney, que encheram de alegria os eventuais momentos de minha vida.

Aos meus colegas da pós-graduaçào pelas suas úteis sugestôes a atitudes cooperativas.

Ao Marcelo e ao Renato pela sua disponibilidade para o meu enriquecimento de cultura eletrônica, Windows e de redes.

Aos Profs. Nei de Oliveira e Valdir Bindilatti, ao pessoal da criogenia pela assistência prestada a esclarecímentos sobre a correta utilizaçäo da linha de Hélio. Em particular, ao Rui e Paula pela colaboraçăo prestada e pela espirituosidade de praxe. Igualmente, a todo o pessoal da oficina mecámica do Departamento, aos técnicos Eronides Olimpio. A Carla e ao Iran pela prestatividade e eficiencia.

A Profa. Patrícia Lustoza de Souza, deo Centro de Estudos em Telecomunicascos da PUC $\mathrm{RJ}$, pela hospitalidade e discussöes elucidativas proporcionadas e pelo fornecimento das amostras utilizadas neste trabaho. Ao Dr. Koenraad, da Eindhoven University of Technology, pelo fabrico de uma máscara e pelas medidas efetuadas em uma das amostras analisadas neste trabalho.

A Natacha pelo bom humor e coopenacâno prestada no trabalho no que diz respetito a sua celeridade.

Aos meus irmãos.

Aos meus colegas de apartamento pela sua cordialidade, hospitalidade fratamidade.

Igualmente importante, os cálculos de mobilidade constantes neste traballio foram efetuados utilizando-se os recursos do Laboratório Central de Computação A vançada da Universidade de São Paulo (LCCA-USP).

Os recursos utilizados para as medidas envolvendo campos magnéticos efetuadas (e a bolsa) contaram com apoio indispensavel do PRONEX. FAPESP. CNPq e CAPES.

Enfm, a todos que acharam que seus nomes aqui não constam e deveriam estar: a esses agradeço duas vezes. 


\section{Índice}

$\begin{array}{lr}\text { Resumo } & 1\end{array}$

Abstract $\quad 2$

$\begin{array}{ll}\text { Agradecimentos } & 3\end{array}$

$\begin{array}{lc}\text { Introduçāo } & 6\end{array}$

I Detalhes experimentais 9

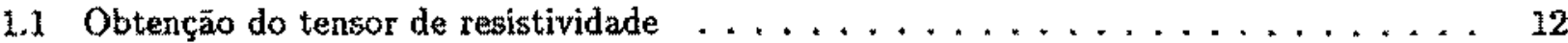

2 A estrutura eletrônica de poços e super-redes $\vec{\alpha}$

2.1 Estrutura eletrónica autoconsistente de poços $\delta \ldots \ldots \ldots \ldots$

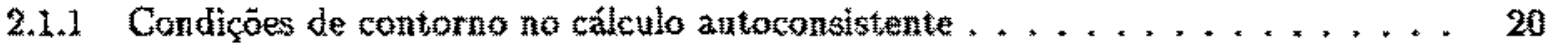

2.2 Estrutura eletronica semíclássica de poços

2.2 .1 Uma dedução simples para perfis de potencial de Thomas-Fermi . . . . . . 21

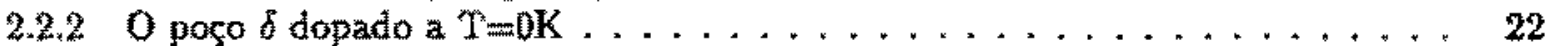

2.3 Estrutura eletrônica de super-redes $\delta$ periódicas $\ldots \ldots \ldots \ldots \ldots \ldots$

2.4 Procedimento numérico para o cálculo da estrutura eletrônica $\ldots \ldots \ldots \ldots$

3 Determinaçäo do periodo de super-redes por medidas CV 28

3.1 Resultados. . . . . . . . . . . . . . . . . . . . . 32

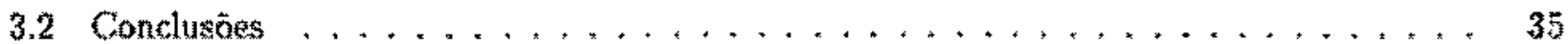

4. Determinaçäo experimental dos parâmetros caracteristicos de poços e super-redes (5) 36

4.1 Resultados numéricos $\ldots \ldots \ldots \ldots \ldots \ldots \ldots \ldots$

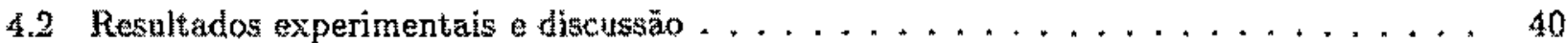

4.3 Medidas $\mathrm{CV} \ldots \ldots \ldots \ldots \ldots \ldots \ldots \ldots \ldots \ldots \ldots$

4.4 Conclusöes $\ldots \ldots \ldots \ldots \ldots \ldots \ldots \ldots \ldots \ldots$

5 Teoria para alindagem e mobilidades eletrônicas em tistemas $2 \mathrm{D}$ e quasi-3D 45

5.1 Teoria RPA para a mobilidade de sistemas $2 \mathrm{D} \ldots \ldots \ldots \ldots \ldots$

5.1.1 Blindagem eletrostática em um sistema $2 \mathrm{D} \ldots \ldots \ldots \ldots \ldots \ldots \ldots$

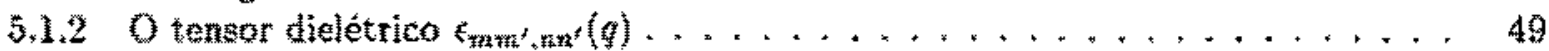

5.1.3 Simetrias e propriedades de $T_{n n^{2} m n^{\prime}} \ldots \ldots \ldots \ldots \ldots$

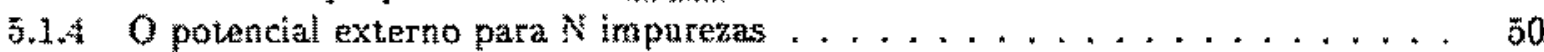

5.1 .5 Média configuracional $\ldots \ldots \ldots \ldots \ldots \ldots$

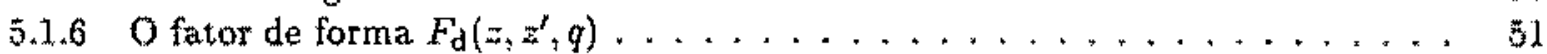


5.1 .7 Resumo ........................... $\ldots \ldots$

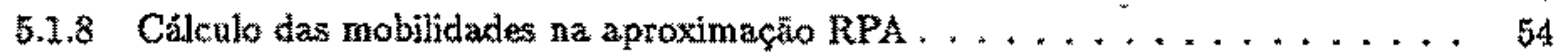

5.1 .9 Resultados para $\mathrm{T}=0 \ldots \ldots \ldots \ldots \ldots \ldots$

5.2 Teoria TF-2D para a blindagem e mobilidates eletrónchas $\ldots \ldots \ldots \ldots$

5.3 Teoria RPA para a blindagem e mobilidades quänticas em super-redes periódicas . . . 58

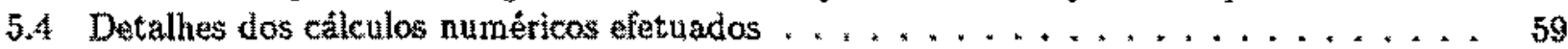

5.5 Teoria para a obtenção experimental das mobilidades quântînas . . . . . . . . 59

6 Mobilidades quäntica e de transporte em poços $\hat{\delta}$

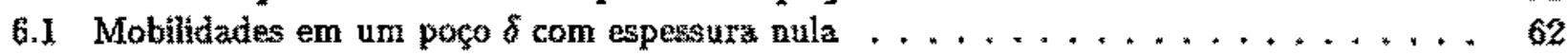

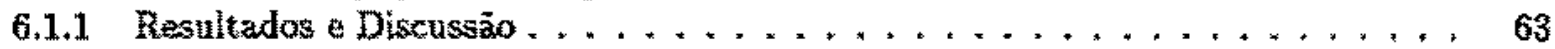

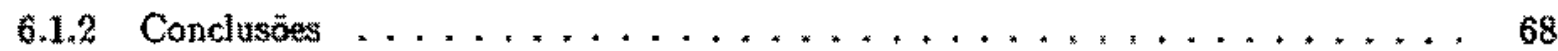

6.2 Influência do perfil de dopantes aceitadores residuais $\ldots \ldots \ldots \ldots$

6.2 .1 Resultados e Discusstäo . . . . . . . . . . . . . . . . 69

6.2 .2 Conchusöes $\ldots \ldots \ldots \ldots \ldots \ldots \ldots$

7 Comparaçăo das mobilidades em sỉstemas $2 \mathrm{D}-3 \mathrm{D}$ com a teoria 77

7.1 Resultados $\ldots \ldots \ldots \ldots \ldots \ldots \ldots \ldots \ldots \ldots$

7.1 .1 Caracterização $C V$ das super-redes . . . . . . . . . . . 77

7.1.2 Determinação da populaçäo de portadores a parămetros das mintibandas . . . 78

7.1.3 lsolamento das contribuiçōes intdividuais das nintbandas à magnetoresistência * 81

7.1 .4 Estimativa experimental para as mobilidades quänticas .......... 83

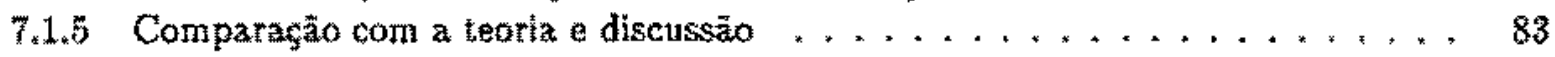

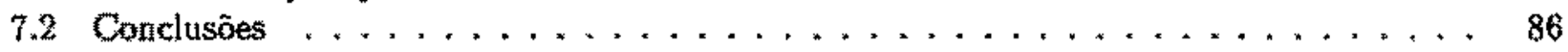

8 Mobilidades de transporte em sistemas 8 dopados 87

8.1 Populaços e mobilidade individuais de transporte via medidas Hall . . . . . . . 88

8.2 Transformaçāo do tensor de magnetoresistividade $\ldots \ldots \ldots \ldots \ldots \ldots$

8.30 espectro de mobilidade $\ldots \ldots \ldots \ldots \ldots \ldots \ldots$

8.4 A região classica da magnetoresistência $\ldots \ldots \ldots \ldots \ldots \ldots \ldots \ldots$

8.5 O efeito da pasição e do tamanho dos contatos na obtançăa do tensor de resistividade 95

8.6 O tensor de condutividade em sistemas $2 \mathrm{D} \ldots \ldots \ldots \ldots$

8.6.1 A interpretaçăo do espectro de mobilidade em sistemas $2 D \ldots \ldots \ldots$

8.6 .2 Resultados e discussão .......................... 98

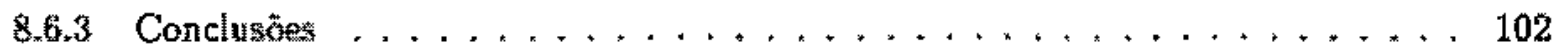

Apêndice - Apêndice - Sistema atômico efetịo 103

Apêndice - Determinação das componentes de $p$ em geometria retangular 105

$\begin{array}{lr}\text { Bibliografia } & 108\end{array}$

$\begin{array}{ll}\text { Trabalhos publicados } & 112\end{array}$ 


\section{Introdução}

A técnica de dopagem $\delta$ foi originalmente idealizada[1] como um meio de formecer elétrons livres em estruturas semicondutoras crescidas epitaxialmente de modo a maximizar a mobilidade dos portadores. Desde entào, a tecnologia de crescimento foi optimizada de modo a serem obtidas estruturas $\delta$-dopadas que permitissem a fabricaçäo de transistores com alto desempenho em relação à freqüếncia de operaçäo[2] ou que possuíssern planos de dopagem de Si extremamente finos como canal de fornecimento de elétrons para estruturas do tipo HEMT(High Electron Mobility Transistor) ou transtitores HBT(Heterojunction Bipolar Transistor) [3]. Mais recentemente, estruturas de InP z-dopadas extremamente finas, com espessura da carnada de dopantes de cerca de 8 A foram crescidas pela técnica LP-MOVPE Low Pressure-MataloOrganic Vapar Pressure Ephary)[4]. As estruturas $\delta$ dopadas exibem interessantes pro priedades físicas que tem sido estudadas nestas últimas duas décadas $[5,6]$. Város estudos nestes tipos de sistema visam o entendimento da dependência dos mecanismos de transporte. Num estudo recente, Schmidt et afly], analisararn o transporte em estruturas $\delta$-nipi de modo incluir correçöes locais de troca-correlação na teoria RPA para esses sistemas, de modo a melhor comparar os seus resultados experimentais de magnetotransporte com a teoria.

Num semicondutor com um único poço fo dopado com doadores rasos do tipo ni tipicamente localizados dentro de algurnas monocamadas do cristal hospedeiro, os elétrons säo líberados pelas impurezas e ficam confinados por um potencial autoconsistente em formato de $\mathrm{V}$. Esse potencial desdobra a banda de conduçäo em um conjunto de subbandas eletrônicas descritas por funçōes de onda cuja localização em torno da camada b decresce com o índice da subbanda. A medida em que várias dessas camadas de impureza são justapostas de maneira igualmente espaçada obtém-se uma super-rede ${ }^{2}$ periódica. Analogamente ao caso do poço isolado, os elétrons sẫo liberados pelas impurezas mas, devido ao fato da sobreposição das várias subbandas de poços vizinhos, dấ-se origem às minibandas eletrônicas.

O surgimento de populaço distintas de portadores com comportamento bi ou tridimensional em uma mesma amostra pôde ser constatado a partir da observaçăo do comporta-

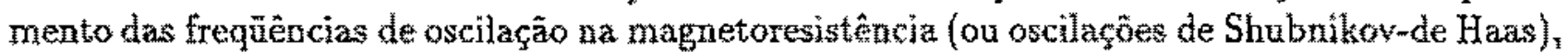
em amostras de GaAs periodicamente dopadas, quando o campo magnético era orientado obliquamente em relação ao eixo de crescimento [8,9]. A sobreposição das varias subbandas de poços adjacentes depende, por um lado, da própria distăneia entre poços. Por outro lado, a energia de ligaçấto do elétron à camada dopada depende também da densidade planar de impurezas depositadas: quanto maior a densidag̉e. mais próximo aes poços estaräo os elétrons das varias minibandas. Un terceiro fator determinante nas propriedades de uma super-rede periodicamente $\delta$-dopada concentração de dopantes, más rracamente o elétron estará ligado ao particular plano dopado.

0 acoplarnento entre as vârias funçōes de onda de planos adjacentes, em amostras perio- 
dicamente $\delta$-dopadas, então determinado essencialmente pela densidade de portadores por periodo, $N_{S}$, pela espessura das camadas a $_{\text {a }}$ e pelo periodo da da estrutura. E de se esperar também que a maior ou menor proxinidade dos elétrons ena relaçäo aos planos de impurezas determine assim uma maior ou menor probabilidade de espalhamento desses portadores, por exemplo, conforme teterminado teoricamente por Hai et al, l10] no ármbito da aproximaçäo RPA e experimentalmente por Yamada Makimoto [11] em estruturas com um único poso $\$$. O mesmo efeito de reduça ou aumento de mobilìdade é de se esperar quando os elétrons sä́o afastados das impurezas por uma polarizaçäo da amostra, ou seja, quando parte dos elétrons säo transferidos para a superfície por um potencial externo aplicado. Na literatura, o sfeito de polarização foi estudado dentro de uma ótica semi-elássica[12] que, no nível de aproxímaçäo envolvido, despreza os efeitos de localização das funçôes de onda. Posterionmente foram comparados por Gonzalez et al.[13] vários enfoques que conduzissem à obtençâo das mobilidades eletrớnicas, havendo esses autores concluído que a aproximaçấo semi-clássica, a um nível semelhante aquela utilizada por Mecrin e Shik[12], conduz a uma super-estimaçäo dos efeitos de blindagem, fornecendo assim valores menores para as mobilitades eletrônicas do que aqueles obtidos experimentalmente e pela aproximação RPA.

De modo a preencher algumas lacunas existentes na literatura, este trabalho propoe-se a dar um passo inicial no entendimento dos mecanismos que determinam as mobilidades quânticas para as várias minibandas em uma super-rede $\delta$-dopada e complementar alguns resultados para estruturas com um único pogo 0 .

Para tanto, podemos dividir o presente texto em duas partes:

- apresentar uma metodologia para a caracterizaçăo experimental da estrutura eletrónica de super-redes e posos $\delta$ dopados, ou equivalentemente, dos parâmetros característicos desse tipo de estrutura: a densidade de portadores $N_{S}$, a espessura da camada dopada $\Delta_{d}$ e o periodo da estrutura 4 . Essa metodologia de caracterizacäo baseia-se na anảlise das oscilaçōes de SaH em campo paralelo ao eixo de crescimento da super-rede e na análíse de resultados de medidas $\mathrm{CV}$;

- a partir do conhecimento da estrutura eletrônica dessas amostras, modelar a comportamento das mobilidades cuanticas e de transporte, com a posterior comparação aos respectivos valores obtidos experimentalmente.

Na prineira parte desta tese seräo incluidos alguns resultados bem conlectdos da literatura, de maneira a que o leitor extre em contato com a informaçă condensada a respeito do cálculo da estrutura eletronica de super-redes e poços $\delta$ e obtençäo de seus perfis de potencial e de suas funçòes de onda, o que é primário para o entendimento das propriedades desses sistemas.

No Capitulo 1. alguns detalhes experimentais do crescimento das amostras e das respectivas caracterizaçôes são colocados.

No Capitulo 2 apresentado o formalismo para a obtença da estrutura eletrónica de poços e super-redes o são discutidos alguns aspectos técnicos da obtençăo numéricu dersa estrutura.

No Capitulo 3 apresenta-se a metodologia para a obtençẫo dos períodos de dopagem a a interpretaçầo de medidas de Capacitancia-Voltagem (CV) de super-redes ódopadas.

No Capitulo 4 é apresentada uma metodologia para a obtençầ dos parametros caracteristicos de uma amostra. $N_{\mathrm{s}}$. $\mathrm{A}$ e $d$ a partir do emprego da análise das oscilaçōes de Shubnikovide Haas e de medidas CV. 
Na segunda parte do trabalho, a partir da estrutura eletrônica obtida para amostras com constantes caracteristicas $N_{\mathrm{d}}, \Delta$ e $d_{\text {q }}$ seräo obtidas as mobilidades quănticas e de transporte numérica experimentalmente, para sistemas bi e quasi bi-dimensionais.

No Capítulo 5 é desenvolvido oformalismo para a obtenção teónica das mobilidades quântica e de transporte para sistemas bi-dimensionais em funçäo da extrutura eletrônica obtida para estes sistemas, na aproximaçâno RPA e numa teoria do tipo Thomas-Fermi. A deterninação teớrica para as mobilidades quântica de transporte em super-redes na aproximaçê RPA é apresentada como também a teoria necessária para a extraçăo das mobilidades quânticas da parte oscilatória da magnetoresistencia.

No Capitulo 6 é avaliado taoricamente o impacto que os parâmetros característicos das amostras exercem sobre as mobilidades quânticas e de transporte em sistemas com um único pogo, como passo preliminar para o extendimento do comportamento das mobilidades quânticas ern estruturas periódicas.

No Capítulo 7 , os resultados obtidos experimentalmente pare as mobilidades quântica em super-redes de InP sằ apresentados e discutidos segundo os resultados teóricos obtidos.

No Capitulo 8, alguns tópicos apresentados mostram as dificuldades enfrentadas para a obtençâo das mobilidades de transporte em sistemas $\delta$-dopados. 


\section{Capítulo 1}

\section{Detalhes experimentais}

As estruturas $\delta$-dopadas de InP, utilizadas neste trabalho, foram crescidas pela técnica LP-MOVPE (Low Pressure-Metalo-Organic Vapour Pressure Epitaxy) e pré-Caracterizadas por medidas CV no Centro de Estudos em Telecomunicaçoes da Pontificia Universidade Católica do Rio de Janeiro, pelo grupo da Profa. Patrícia Lustoza de Souza.

As estruturas foram crescidas a $640^{\circ} \mathrm{C}$ num reator AIX 200 , sob pressöes de 20 mbar. As fontes utilizadas eram fosfna $\left(\mathrm{PH}_{3}\right.$, a $100 \%$ ), trimetil Índio (TMIn) a 1 \% de silano (SiH,) diluído em $\mathrm{H}_{2}$. A taxa total de fluxo, a fraça molar de TMIn e fraça V/III utilizada eram de 7 1/ $\mathrm{min}, 2,5 \times 10^{-6}$ e 360, respectivamente. A conjunça do desses fatores (pressato, temperatura e proporçóes entre fontes de organo-metalicos) produzirem uma taxa de crescimento de $4,5 \mathrm{~A} / \mathrm{s}$. O tluxo de SiH, foi escolhido de modo a produzir o máximo nivel de dopagem para uma amostra-teste homogeneamente dopada sem que o regime de saturaçäo fosse atingido.

As amostras foram crescidas em substratos de InP isolantes dopados com Fe, na direção (100). Antes dos planos de silício serem depositados, uma camada espessa näo dopada de InP de 3000 A foi crescida em cima do substrato, de modo a que as imperfeiçoes do substrato (de menor qualidade que o material crescido por MOVPE) não se propagassern para as super-redes $\delta$. Após o crescimento da super-redes, estruturas com 5 a 10 poços $\delta$ com períodos de 100 a $300 \AA$, uma carnada de $550 \AA$ foi depositada seja para que as estruturas ficassem protegidas mecanicarnente, seja para minimizar suas degradaçoes por oxidação ou para minimizar os efeitos de superficie.

As medidas CV realizadas para as estruturas b-dopadas foram efetuadas ntilizando-se um medidot eletroquímico de perfis CV PN4300, onde um contato Schottky e formado entre o semicondutor e eletrolito (HCl 0,5 molar). Para as estruturas periódicas, os perfis CV foram obtidos alternando-se medidas com corrosão da superfície de modo a que os poços mais profundos pudessem ser detectados. $O$ resultados das medidas $C V$ indicam que a largura a meia altura da distribuiçăo de doparites, $\Delta_{d}$, para as super-redes consideradas neste trabalho, é de aproximadamente 7,8 A. Maiores detalhes a respeito do crescimento e da caracterizaça $\mathrm{CV}$ podem ser encontrados na Ref. [4].

As amostras contendo as super-redes crescidas por MOY $\mathrm{PE}$ foram cortadas em quadrados, com lados de aproximadamente $4 \mathrm{~mm}$, e submetidas am tratamento químico a base de acetona e de álcool metilico para a limpeza de suas superficies. Posteriormente, foram foitos contatos nos cantos das amostras. Esses contatos possuiam áreas menores que $1 \%$ da área total das anostras e foram labricados difundindo-se fndio a $400^{\circ} \mathrm{C}$ mum forno Biorad $\mathrm{RC} 2400$ durante 
4 minutos, em atmosfera de Hëlio sem oxigênio.

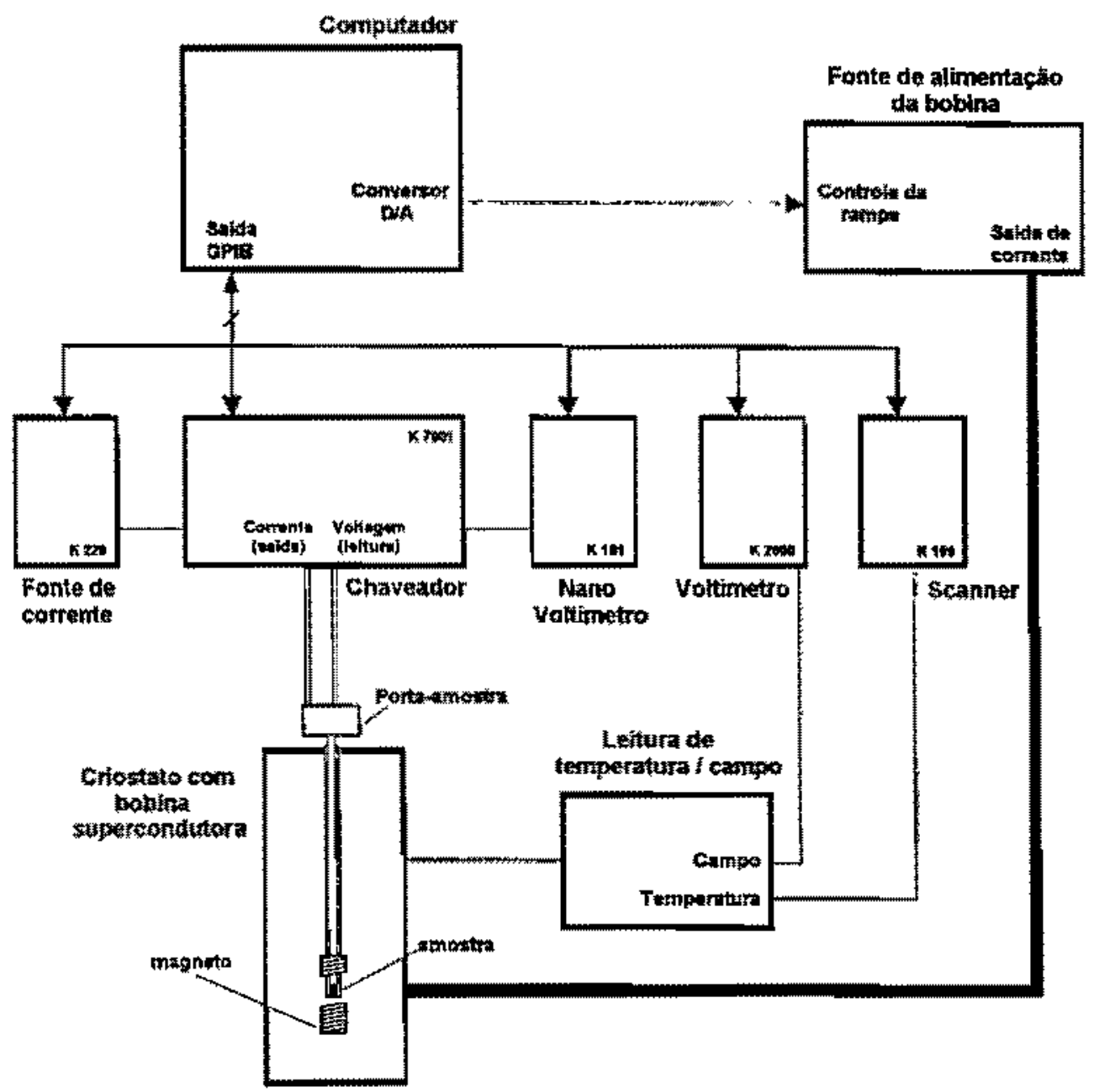

Figura 1.1: Diagrama da montagem experimental.

Na Fig. 1.1 e apresentada, de modo esquematizado, a montagem para as medidas Shubnikovde Haas realizadas nas amostras estudadas. Para a determinação experimental da magnetoresistência das amostras foi projetado e construido um porta amostra que permilia o acesso aos contatos das amostras, situadas em um banho de Helo liquido que as conserveva à temperatura constante de $4.2 \mathrm{~K}$, obtida a partir de uma resistencia de carbono colocada próxima a anostra. Essa resisténcia de carbono era alimentada por uma fonte de corrente de fabricaça caseira que, a despeito de sua simplicidade e baixo custo, tem alta rejeiçăo a ruido e muito estável, com variaça menor que 0,01 \% na corrente de saida. Os detalhes dessa fonte podern ser encontrados na Ref. [8]. 


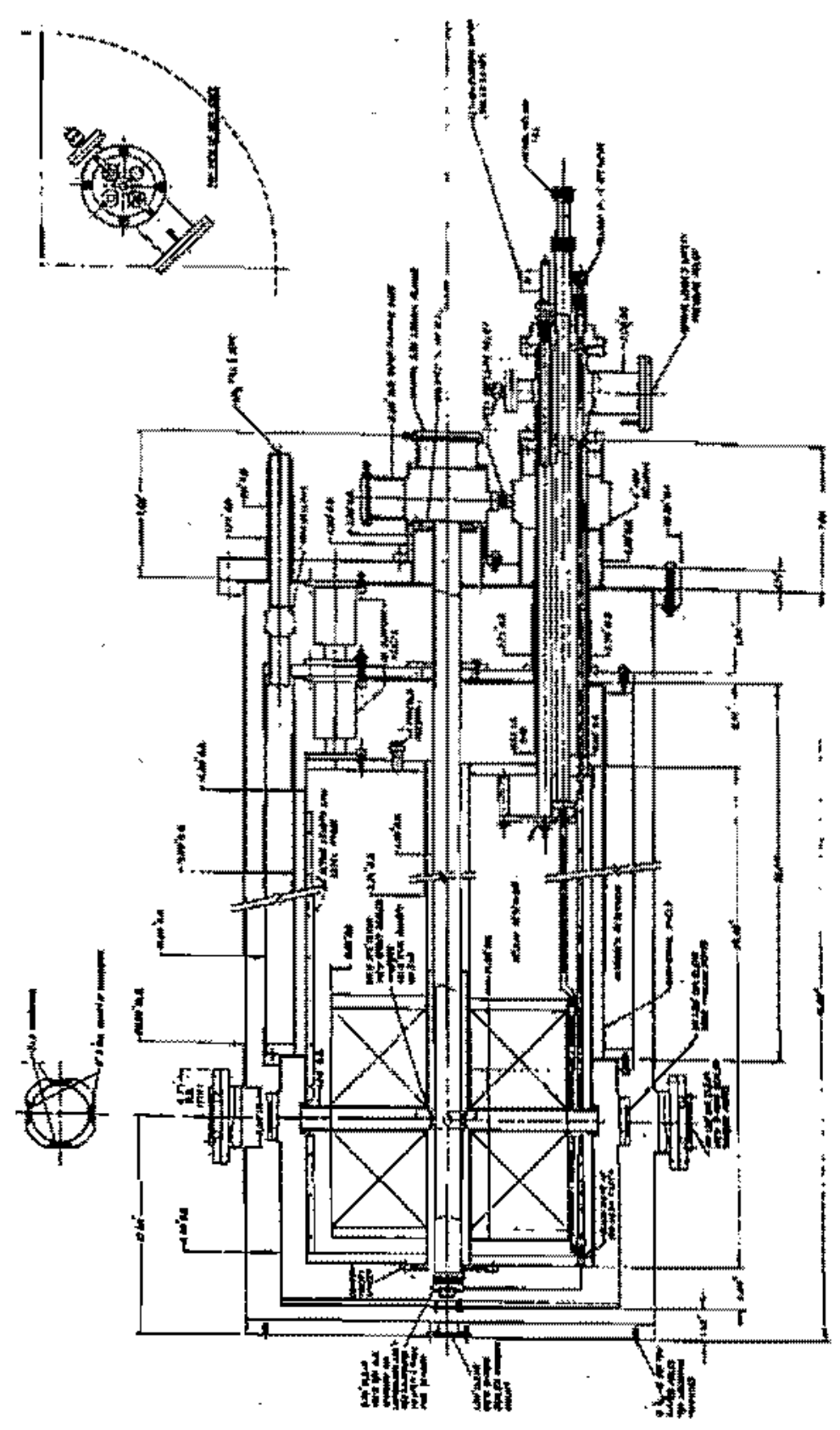

Figura 1,2: Criostato utilizado para as medidas de magneto-resistência.

Anteriormente ao inicio das medidas de magneto-resistência, jả no banho de Helio líquido, as amostras eram iluminadas por um led vermelho, de comprimento de onda inferior a banda proibida do $\ln \mathrm{P}_{\text {, de }}$ modo a que a infuéncia dos aceitadores ionizados fosse minimizada. As medidas de magneto-resistência eram efetuadas após o desligamento do led, quando a voltagem medida nas arnostras, devida a passagem de uma corrente externa pelas mesmas, atingia um patamar constante.

As medidas de magneto-resistencia foram efetuadas em uma bobina supercondutora Janis modelo 20CNRD/SC. imersa em Hélio liquido, capaz de fornecer carrpos de 0 a 1 la Teslas. A 
voltagem nos terminais das amostras a intensidade do campo magnético puderam ser lidas respectivamente partir de um Nano-Voltimetro Keithley $\mathrm{K} 181$ e de urn Multimetro Keithley 2000.

A corrente nas amostras, fornecida por uma fonte de corrente constante Keithley programátel 15220 , era mantida constante no decorrer das experiências de magneto-resistencía. Adicionalmente, fim de que efeitos näo lineares, como o aquecimento das minibandas ("hot electron effects"), näo fossem observados nas arnplitudes das oscilaçoes SdH, utillizaram-se corm rentes de no máximo $8 \mu \mathrm{A}$ por poço[14].

Os confatos por onde eram passadas as correntes e lidas as voltagens eram chaveados por um aparelho de chaveamento Keithley 7001.

Por fim, as medidas de magneto-resistividade foram efetuadas de maneira automatizada, utilizando-se uma interface GPIB entre os instrumentos de mediçào e computador. Todas as ferramentas de tratamento de dados, aquisiçấo e cálculos de estrutura eletrônica foram desenvolvidas nos últimos 8 anos e compiladas no programa SMP, escrito em Turbo Pascal e recentemente adaptado para Delphi 3 .

\subsection{Obtenção do tensor de resistividade}

A magneto resistencia das amostras foi extraida utilizando-se montagem da Fig. 1.3, pastando-se uma corrente constante por dois contatos (formecida pela fonte Keithley K220) e lendomse a voltagem por outros dois (pelo Nanovoltimetro K181). Todas as amostras utilizadas neste trabalho eram aproximadamente quuadradas, e em seu vértices foram dilundidos contatos de Índio.

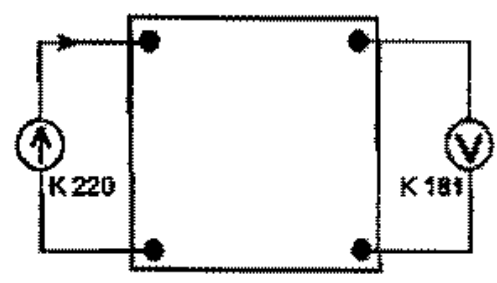

Figura 1.3* Djagrama simplificado da montagem utilizada para a obtençăo da magnetom resistência.

De acordo com Periofl[15] e Chwang[16], essa montagem garante gue o valor da resistência obtido seja, com boa precisão, proporcional a componente $\rho_{x x}(B)$ do tensor de resistividade dezde que os contatos näo excedam $1 \%$ da área total da amostra. Essa proporçäo pode ser obtida a partir de campo nulo com a metodologia de van der Pauvili], a qual elimina o problema da geometria da amostra na obtençäo do tensor de resistividade se os contatos estiverem na

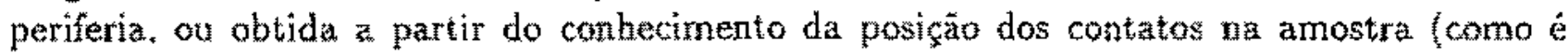
mostrado no Apendicel.

Para testar a prectisäo do método da obtençăo do tensor de resistividade em amostras com quatro contatos, utilizou-se uma amostra (118), preparada pelo grupo do Dr. Koenraad, da Eindhoven University of Technology. Holanda. aonde foi feita uma Hall bar[18]. 


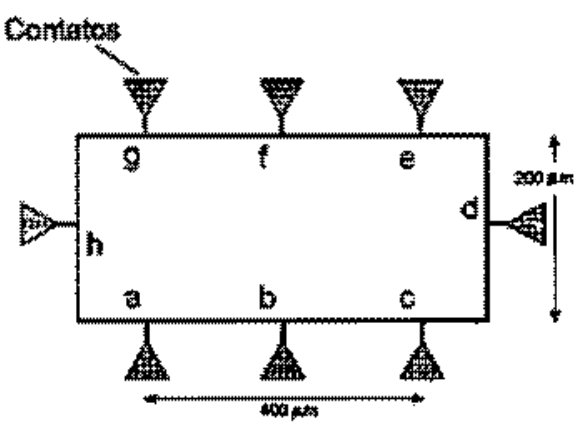

(a)
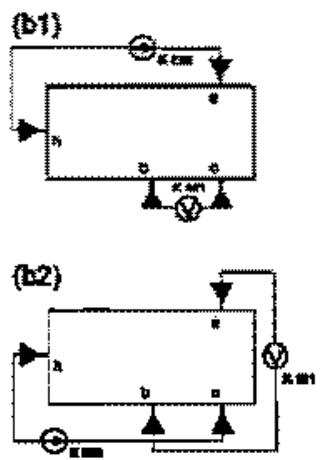

(cI)

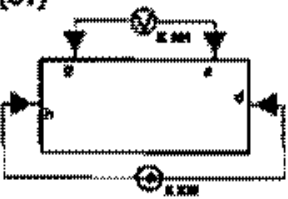

(e)

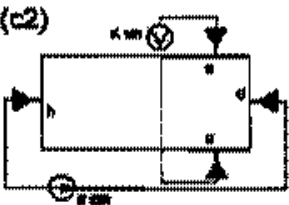

Figura 1.4: Obtençäo do tensor de resistividade. (a) Diagrama da amostra 118 preparada

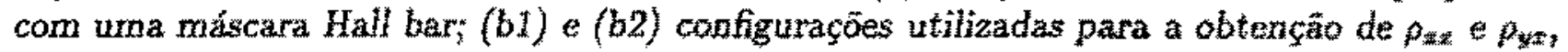
respectivamente, a partir de duas leituras em campo; (c1) e (c2) configuraçoes utilizadas para a obtenção de $\rho_{z x}$ e $\rho_{y x}$, respectivamente, a partir de uma leitura em campo, utilizando-se uma configuração geométrica ótima.

Na Figura 1.5 sầ comparados os resultados obtidos para a amostra 118 (um pogo $\delta$ isolado) utilizando-se uma geometria otimizada do tipo Hall bar ou a partir de duas varreduras de campo (Fig. 1.4), estando ambas as medidas em bon acordo.
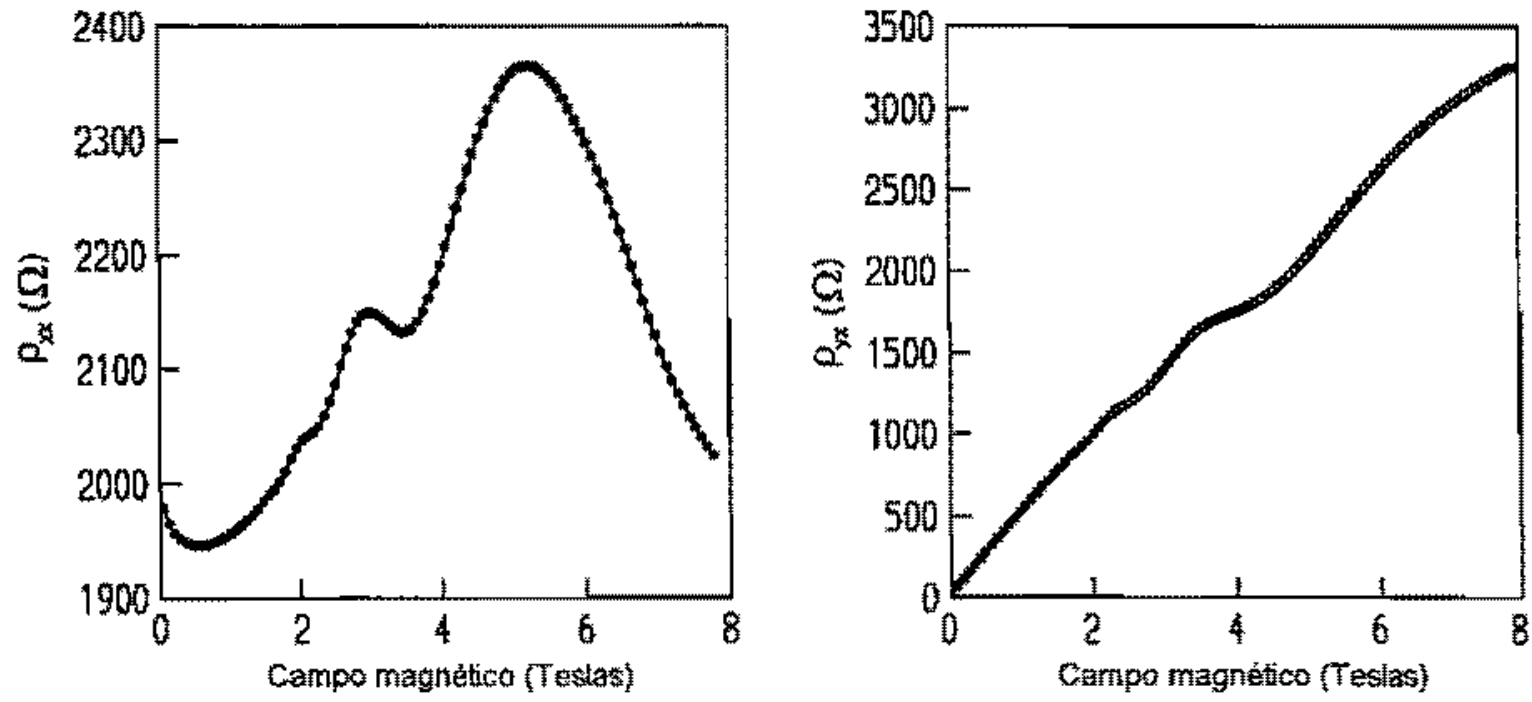

Figura 1.5: Componentes do tensor de magnetoresistividade obtidos para a amostra 118 fpoço

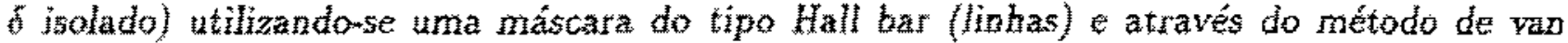
der Pauw. considerando-se os contatos puntuaks e na periferia da amostra[17]. A diferencá minima é observada apenas para a componetute $x y$.

A watagem da utilizaçào da geometria Hall bar para a obtença das componentes do tensor de resiatividade é a necessidade de apenas uma varredura em campo magnético, ao contrário da medida de van der Pauw que necessita de duas varreduras[18]. 
Na maior parte dos casos deste trabalho, entretanto, apenas os períodos de oscilaçäo e as mobilidades extraídas a partir do espectro de Fourier de campo inverso eram de interesse. Como essas grandezas independem do valor absoluto da resistividade em campo nulo, a magnetoresistência das amostras foram obtidas apenas com uma varredura a partir de amostras com quatro contatos, como mostrado na Fig. 1.3. Este procedimento torna mais eficiente o procedimento experimental ja que, na montagem utilizada, leva-se em torno de 40 minutos para uma varredura de 0 a 14 Tesias. 


\section{Capítulo 2}

\section{A estrutura eletrônica de poços e super-redes $\delta$}

Em sistemas bì-dimensionais, dentro da aproximaçẫo de massa efetiva, a equaçă para os estados de uma super-rede 6 dada por

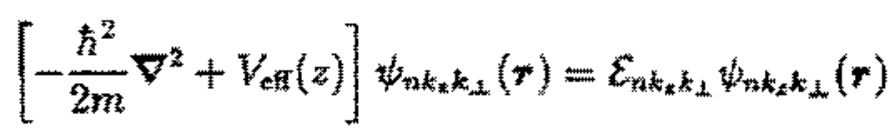

onde $n, k_{z}$ e $k_{1}$ representam os trếs nưmeros quânticos mais convenientes para esses tipos de sistemas: o indice da minibanda ou subbanda $n$, o vetor de onda paralelo ao eixo de crescimento $k_{z}$ e $a$ vetor de onda perpendicular a esse eixo $k_{\perp}$. $\varepsilon_{n k_{*} k_{\perp}}$ representa os autovalores da hamiltoniana e $V_{e f}(z)$ é o potencial confinarte dos portadores.

As funçóes de onda mais gerais para esse tipo de sistema bi-dirnensional podem ser definidas segundo o ensatz

$$
\psi_{n k_{x} k_{\perp}}(r)=\psi_{n k_{x} k_{\perp}}(\varrho, z)=\frac{1}{\sqrt{S}} e^{i k_{\perp} \cdot k} \chi_{n n k_{x}}(z)
$$

sendo normalizadas pela área da amostra $S . g$ é o vetor de posição no plano zy, $Q=(x, y)$, e $k_{\perp}$ é o vetor de onda desse mesmo plano $k_{\perp}=\left(k_{x}, k_{y}\right)$.

O ansat $z$ escolhido separa a Eq. (2.1), sendo apenas necessária a resoluçăo da equaçăo

$$
\left[-\frac{\hbar^{2}}{2 m} \frac{d^{2}}{d z^{2}}+V_{\mathrm{eft}}(z)\right] \chi_{n k_{z}}(z)=\left[\mathcal{E}_{n k_{z} k_{1}}-\frac{\hbar^{2} k_{\perp}^{z}}{2 m_{k}}\right]_{\lambda_{n} k_{*}}(z)
$$

sendo $k_{z}$ independente de $\boldsymbol{k}_{ \pm}$.

Definindo, por conveniencia $E_{n k_{2}}$, tal que

$$
\varepsilon_{\mathrm{rk}_{k_{2} k_{1}}}=E_{m k_{2}}+\frac{\hbar^{2} \hbar_{1}^{2}}{2 m}
$$

tem-se finalmente que

$$
\left[-\frac{h^{2}}{2 m b} \frac{d^{2}}{d z^{2}}+V_{\mathrm{eff}}(z)\right] \lambda_{n k_{z}}(z)=E_{n k_{z} \lambda_{n+k_{z}}(z)}
$$


A formulaçäo dada pelas Equaçoes $(2.2)$ (2.,4) é a mais geral possivel, dentro da aproximaçâo de massa efetiva, para sistemas com dopagem planaz num cristal hospedeiro sem variação de composiçāo. Nas seçôes que se seguem, essa formulação sera particularizada para a descriçäo dos estados e espectro energético de super-redes e poços $\delta$-dopados.

\subsection{Estrutura eletrônica autoconsistente de poços $\delta$}

A estrutura eletrônica de poços $\delta$ pode ser calculada a partit da simplificaçäo da Eq. (2.4) no sentido de que o elétron não possui a priorio grau de liberdade do deslocamento na direção $z$. Isso quer dizer que os elétrons possuirão apenas movimentação livre ao longo do plano de impurezas e estatâo confinados no eixo perpendicular a esse plano. Ou seja, a função de onda nẫo possuirá qualquer dependência no vetor de onda $k_{z}$. Logo, a equação de onda genérica (2.4) simplifica-se em

$$
\left[-\frac{\hbar^{2}}{2 m} \frac{d^{2}}{d z^{2}}+V_{\mathrm{H}}(z)+V_{\mathrm{x}}(z)\right] \chi_{n}(z)=E_{\mathrm{n}} X_{n}(z)
$$

onde $V_{H}(z)$ é o potencial autoconsistente de Hartree e $V_{x c}(z)$ é a correção de trocamcorrelação a potencial confinante. A relação de disperstîn para as subbandas é dada, a partir da equaçäo $(2,3)$, por

$$
\mathcal{E}_{n k_{j}}=E_{n}+\frac{\hbar^{2} k_{L^{2}}^{2}}{2 m}
$$

As funçóes de onda na enésima subbanda podem ser escritas como

$$
\psi_{n k_{\perp}}(e, s)=\frac{1}{\sqrt{S}} e^{i k_{\perp} Q} \chi_{n}(z)
$$

O potencial autoconsistente de Hartree é obtido pela solução da equaçāo de Poisson

$$
\frac{d^{2} V_{\mathrm{H}}}{d z^{2}}=-\frac{4 \pi \kappa e}{c} p(z)
$$

onde

$$
\rho(z)=e[-n(z)+n(z)]
$$

é a distribuiçăo espacial total composta pela nuvern eletrônica dos portadores

$$
\begin{aligned}
n(w) & =\sum_{n} N_{n}\left|x_{n}(z)\right|^{2} \\
N_{n} & =\frac{m k_{\mathrm{B}} T}{\pi \hbar^{2}} \ln \left[1+\exp \left(\frac{E_{\mathrm{F}}-E_{n}}{k_{\mathrm{B}} T}\right)\right]
\end{aligned}
$$

sendo $N_{n}$ o número de elétrons por unidade de área na enésima subbanda, $E_{F}$ é o potencial químico. $n_{1}(z)$ é a densidade espacial de impurezas ionizadas dada por

$$
n_{\mathrm{I}}(z)=n_{\mathrm{d}}(z)-n_{\mathrm{B}}(z)
$$

sendo $n_{a}(z)$ a densidade espacial de doadores $e n_{m}(t)$ a densidade espuctal de aceitadores ioni zados. 


\section{Distribuição de aceitadores ionizados}

Nos estudos que serão fêttos, quando considerados, os aceitadores seräo residuais, homoge-

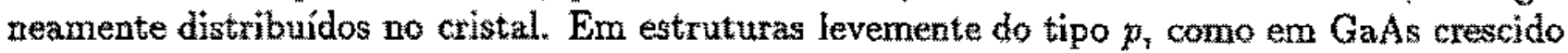
por MBE(Molecular Beam Epitazy), esses aceitadores residuais podem ser considerados ionizados dentro de uma regiäo de depleção de comprimento $\Delta_{\mathbf{a}}$.

Esse comprimento de depleçato pode ser estimado[19] primeiramente considerando-se que, como um senicondutor em questäo esteja em equilibrio termodinâmico, o potencial químico deva ser constante em todo o semicondutor. Por um lado, para aceitadores residuais do tipo $p$, o potencial químico deve coincidir com os niveis aceitadores em regióes afastadas da modulaçâa imposta pela dopagem intencional de impurezas doadoras. Por outro lado, na região de modulaçäo de dopagem o potencial quínico deve coincidir com aquele obtido pelo resultado do cálculo auto-consistente.

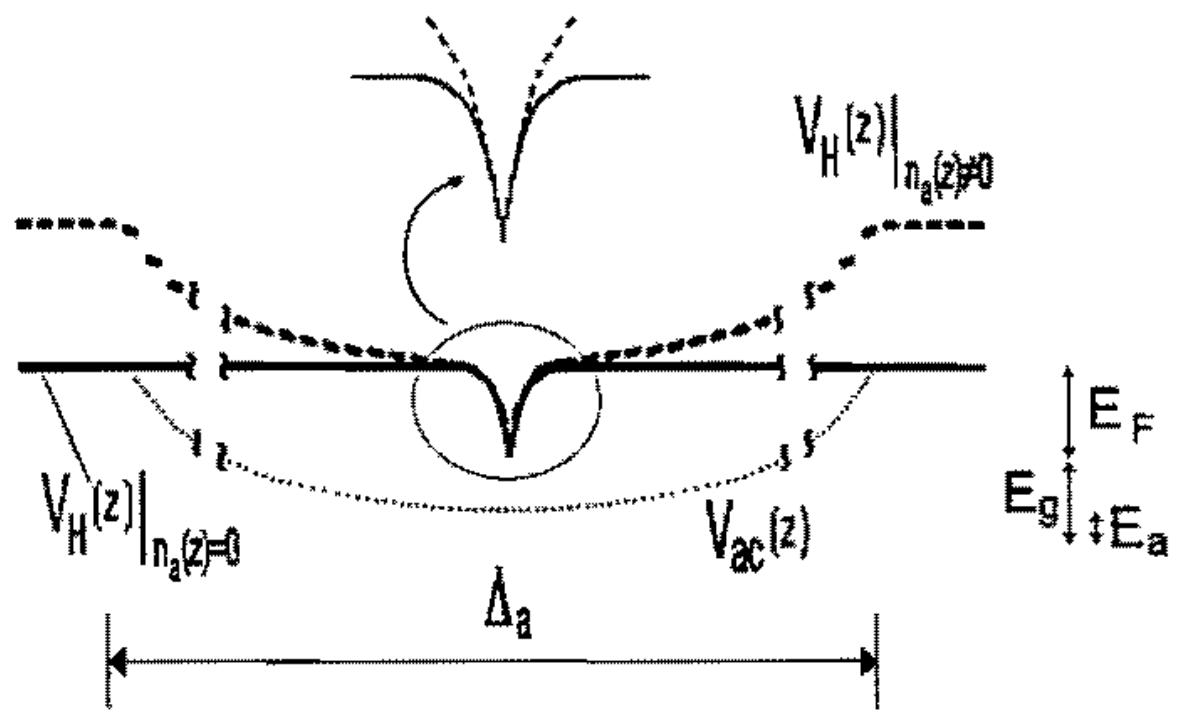

Figura 2.1: Deformaçào do potencial devido à presença de aceitadores residuais jonizados na regiäo de depleção de tamanho $\Delta_{\mathbf{a}}$. O potencial químico, na regiăo de modulaçäo é E Enquanto em regiöes afastadas coincide com a energia de aceitadores $E_{\mathrm{a}}$.

Na aproximação do comprimento de depleçâ, considerarse que as mudanças introduzidas pelos aceitadores nos niveis de energia e nas funçóes de onda dos elétrons sejam pequenas. Formalmente deduz-se que a variação do potencial autoconsistente. devido à contribuição dos aceitadores, é o próprio potencial dos aceitadores, ou

$$
\left.\left.V_{H}(z)\right|_{n_{\alpha}(z) \neq 0} \approx V_{b}(z)\right|_{n_{3}(z)=0}+l_{a c}(z)
$$

onde $V_{a c}(z)$ é o potencial gerado pelos aceitadores.

Resolvendo-se o problema eletrostático resultante, utilizando-se a origen $z=0$ como referència de campo elétrico nulo de $V_{\mathrm{at}}(z)$, obtém-se;

$$
\frac{d V_{\mathrm{ac}}(z)}{d z}=\frac{4 \pi \kappa \epsilon^{2}}{t} z
$$


para $z<\Delta_{n} / 2$, ou seja, dentro da regiào de depleçăo. Essa ủltima equação, integrada novamente, formece

$$
\left.V_{\operatorname{atat}(z)}\right|_{0} ^{z}=\frac{2 \pi \kappa \epsilon^{2}}{\epsilon} z^{2}
$$

A Eq. (2.13) avalizada entre 0 e $z=\Delta_{\mathrm{A}} / 2$ reflete diferença de potencial entre regiōes afastadas da regiäo de modulação de dopagern e a região de modulaçäo de dopagem. Conforme dito anteriormente, essa diferenga deve equivaler à diferença entre potenciais químicos entre ambas as regióes para que um potencial quimico constante no semicondutor possa ser estabelecido. Ou seja, para $\mathrm{T}=0 \mathrm{~K}$, a diferenca em energia das duas regioes deve ser aproximadamente $E_{\mathrm{G}}+E_{\mathrm{F}}-E_{\mathrm{a}}$ onde $E_{\mathrm{G}}$ é a largura da faixa proibida do semicondutor hospedeiro, $E_{\mathrm{a}}$ é o nivel de energia para aceitadores $E_{F}$ é a energia de Fermi na região de modulaçäo, Isso pode ser traduzido por

$$
\left.V_{\mathrm{at}}(z)\right|_{0} ^{\Delta_{\mathrm{x}} / 2}=E_{\mathrm{G}}+E_{\mathrm{F}}-E_{\mathrm{a}}=\frac{\pi e^{2}}{2 \xi} \Delta_{\mathrm{m}}^{2}
$$

Para semicondutores de banda proibida larga com dopagens tipicas, $E_{\mathrm{G}} \approx 1,4 \mathrm{eV}, E_{\mathrm{F}} \approx$ 0.15 eV e $E_{\mathrm{a}} \approx \mathrm{z}$ meV. Portanto, em boa aproxinação, obtérn-se para a largura da regiâo de depležrä,

$$
\Delta_{\mathrm{a}}=\sqrt{\frac{2 E_{\mathrm{G}}}{\pi N_{\mathrm{a}}} \frac{1}{a_{\mathrm{a}} H}}
$$

onde $N_{\mathrm{a}}$ é a concentraçāo volumétrica de aceitadores, an é rajo de Bohr efetivo a $H$ é o Hartree efetivo. Este valor para $\Delta_{\mathrm{a}}$ está tipicatnente na faixa de 1 a 10 mm, considerando-se densidades de dopagem residuais na ordem $d e 10^{14} \mathrm{~cm}^{-4}$, ou seja, a regiäo de depleção é da ordem do tamanho de uma amostra real.

Adicionalmente, a neutralidade elétrica do semicondutor garantida fazendo-se a carga total nula

$$
\int_{-\infty}^{+\infty} \mathrm{d} z\left[-n(z)+n_{\mathrm{d}}(z)-n_{\mathrm{a}}(z)\right]=0
$$

o que conduz a

$$
N_{\mathrm{S}}=N_{\mathrm{d}}-N_{\mathrm{a}} \Delta_{\mathrm{a}}=N_{\mathrm{d}}-\sqrt{\frac{2 E_{\mathrm{G}} N_{\mathrm{a}}}{\pi} \frac{a_{\mathrm{B}}}{H}} \approx N_{\mathrm{d}}
$$

sendo $N_{\mathrm{d}}$ a concentração areal de doadores ionizados e $N_{\mathrm{S}}$ o número total de impurezas ionizadas.

\section{Distribuição de doadores ionizados}

As distribuiçōes de doadores ionizados poden assumir vários formatos aproximados caracterizados pelas distribuicoes espaciais unitánas $g_{d}(z)$. Em particular, para of cátculos autoconsistentes que serão efetuados neste trabalho. seräo considerados três tipos de distribuiçoes unitúlues: 
- Distribuiçăo gaussiana[20]:

$$
g_{\mathrm{d}}(z)=\frac{1}{\sqrt{\pi \beta^{2}}} \mathrm{e}^{-z^{2} / \beta^{z}}
$$

onde $\Delta_{\mathrm{d}}=2 \beta \sqrt{\ln 2}$ é a largura total da gaussiana a meia altura (FWHM),

- Distribuiçẫo uniforme no intervalo $\left[\Delta_{\mathrm{d}} / 2,-\Delta_{\mathrm{d}} / 2\right]$ :

$$
g_{d}(z)= \begin{cases}1 / \Delta_{\mathrm{d}} & |z|<\Delta_{\mathrm{d}} / 2 \\ 0 & \text { caso contrário }\end{cases}
$$

- Distribuição de espessura nula ou $\delta$

$$
g_{d}(z)=\delta(z)
$$

onde $\delta(z)$ é a funçäo $\delta$ de Dirac.

A partir das distribuiçôes unitárias; a distribuição de doadores $n_{\mathrm{d}}(z)$ é calculada por

$$
n_{\mathrm{d}}(z)=N_{\mathrm{d}} g_{\mathrm{d}}(z)
$$

\section{Potencial de troca-correlação}

PaIa obtençẫo do potencial de troca-correlação, esquemas locais ou não-locais podern ser utilizados. Nos cálculos que seräo efetuados seră utilizada uma correção local, parametrizada na literatura para um gás de elétrons tri-dimensional por vários autores.

No caso dos estudos que serẫo apresentados, a parametrização de escolha é aquela de Hedin e Lundquist[21]

$$
V_{\mathrm{xc}}(z)=-\frac{H}{\pi \alpha r_{s}(z)}\left[1+0,7734 x \ln \left(1+x^{-1}\right)\right]
$$

onde

$$
\begin{aligned}
\alpha & =\left(\frac{4}{9 \pi}\right)^{1 / 3} \\
r_{3}(z) & =\left(\frac{4 \pi n(z)}{3}\right)^{1 / 3} a_{\mathrm{E}} \\
z & =\frac{r_{\mathrm{s}}(z)}{23}
\end{aligned}
$$

onde $H$ é o Hartree efetivo en(z) é a densidade total eletrônica local. 


\subsubsection{Condiçōes de contorno no cálculo autoconsistente}

Finalmente, para os cálculos que seră efetuados no presente texto, serăo consideradas as condiçôe de contorno para um poço com sem a aplicaçẩo de um potencial externo, ou seja, quando parte de sua carga eletronica é ou não transferida para a superfície.

Numa estrutura polarizada(biased structure), uma fraçăo $s \neq 0$ da carga total $N_{\mathrm{d}}$ é trans. ferida para a porta(gote) situada na superficie da amostra, por exemplo, en $z=-L$. Neste caso, a soluçäo das equağoses (2.5) -(2.8) serão sujeitas à condiçăo de contorno

$$
\left.\frac{d V}{d z}\right|_{z=-d}=-4 \pi s N_{d}
$$

devida ao campo elétrico gerado pela acumulaçăo de $s N_{\mathrm{d}}$ elétrons por unidade de áfea na porta.

No caso de uma estrutura näo polarizada (unbiased structure), $s=0$ e, portanto, anterion fica

$$
\left.\frac{d V}{d z}\right|_{z=-\infty}=0
$$

por näo haver elétrons na porta, ou seja, o campo elétrico é nulo na superfície.

Adicionalmente, para os casos de estruturas polarizadas ou näo, uma condiçäo de contorno extra considerada para uma única camada de doadores de espessura nula:

$$
\left.\frac{d V}{d z}\right|_{z=z^{\prime}+\varepsilon}-\left.\frac{d V}{d z}\right|_{z=x^{i}-t}=4 \pi N_{\mathrm{d}}
$$

sendo $\varepsilon$ uma grandeza infinitesimal e $z^{\prime}$ é a posiçäo da camada planar no eixo de crescimento.

\subsection{Estrutura eletrônica semi-clássica de poços $\delta$}

A aproximação semt-clássica de Thomas-Fermi, em geral mostra-se de bastante valia já que consegue fornecer algumas propriedades eletrönicas qualitativa ou mesmo quantitativamente. Em particular, para um sistema dopado, um perfil semiclássico de potencial pode ser determinado analiticamente para $\mathrm{T}=\mathrm{OK}$, evitando-se assim o cálculo automconsistente ou mesmo utilizando-o como uma aproximaçấ inicial de boa qualidade que diminua o numero de iteraçöes necessatrias para a obtençâo do perfil quântico do cálculo auto-consistente. Foi mostrado por loriatti[22] que a estrutura de bandas para concentraços suhcientemente elevadas de porta dores é praticamente equivalente àquela fornecida pelo calculo auto-consistente de Hartree sem a inclusấo da parte do potencial de troca-correlaçâo. Outros autores estudaram a estrutura eletrônica fornecida pelo cálculo semíclássico em super-redes de composiçăo de modo que as descontinuidades introduzidas pelas diferenças de potencial fossem consideradas[23, 24. 25]. A teoria semiclássica de Thomas-Fermi que pode ser encarada como a teoria do funcional densidade onde são ignorados termos an $\nabla V$, foi objeto de alguns estudos onde sẫo consideradas correçōes de gradiente de potencial $[26,27]$ e correçöes devidas a quantização da população eletronica[28], com bons resultados.

Nesta seçäo, será mostrado o formalismo que conduz à obtenção de perfís de potencial de Thomas-Fermi park o poço $\delta$ a $T=0 K$. 


\subsubsection{Uma dedução simples para perfis de potencial de Thomas- Fermi}

A literatura à respeito da dedução de perfis de potencial na aproximação de Thomas-Fermi é relativamente vasta, podendo ser encontrada em vários livros-texto (por exemplo, no livro de Davidov[29] ou no livro de Mahan[30]) ou em algumas revisöes (como, por exemplo, na revisão de March[31]).

Uma dedução simples pode ser obtida considerando-se primeiramente que podemos preencher o espaço de fase, a partir de estados com menores momentos, colocando dois portadores com spins opostos em cada célula de volume $h^{3}$, onde $h$ é a constante de Planck. $O$ espaço de momentos é então ocupado até o momento máximo $p_{\circ}(\boldsymbol{r})$. Loga, o volume do espaço de fase ocupado correspondente ao volume ocupado no espaço de posiçôes será

$$
\frac{4 \pi}{3} p_{0}^{3}(r)
$$

e, portanto, a densidade eletrônica seră dada por

$$
n(\boldsymbol{r})=\frac{1}{3 \pi^{2} h^{3}} z_{0}^{3}(\boldsymbol{r})
$$

A hamiltoniana clássica para o portador màs rápido pode ser escrita como

$$
\frac{p_{0}^{2}(r)}{2 m}+V(r)=E_{F}
$$

onde $V(r)$ é a energia potencial e $E_{F}$ é a energia de Fermi. Resolvendo as Eqs. (2.17) e (2.18) em $n(\boldsymbol{r})$ e $V(\boldsymbol{r})$, obtém-se

$$
n(\boldsymbol{r})=\frac{1}{3 \pi^{2} \hbar^{3}}(2 m)^{3 / 2}\left[E_{\mathrm{F}}-V(\boldsymbol{r})\right]^{3 / 2} \Theta\left[E_{\mathrm{F}}-V(\boldsymbol{r})\right]
$$

que é denominada como densidade eletrônica de Thomas-Femi. A funçăo $\Theta(x)$ fol introduzida de maneira a que estados acina do nivel de Fermi não sejarn populados.

Para que a energia potencial seja determinada, o requisito da autoconsistência deve ser invocado, ou seja, a energia potencial deve ser originada por meios eletrostáticos. Ou seja, a energia potencial deve obedecer à equaçẫo de Poisson

$$
-\nabla^{2} \frac{V(r)}{\varepsilon}=\frac{4 \pi \kappa}{\epsilon} \rho(r)
$$

onde $e$ é a carga do portador e $\rho(r)$ é a densidade espacial de cargas dada por $\rho(r)=e n(r)$. Ou seja,

$$
\nabla^{2} V(r)=-\frac{4 \pi \kappa e^{2}}{\epsilon} n(r)
$$

Combinando este resultado com a Eq. (2.19) resulta na eqquaçăo de Thomas-Fermi para at energia potencial

$$
\nabla^{2}\left[E_{\mathrm{F}}-V(r)\right]=\frac{8 \sqrt{2} \kappa e^{2}}{3 \pi \hbar^{3}} m^{3 / 2}\left[E_{\mathrm{F}}-V(\boldsymbol{r})\right]^{3 / 2} \Theta\left[E_{\mathrm{F}}-V(\boldsymbol{r})\right]
$$


Como explicado na Secăo 2.1 , em estruturas com dopagem planar, a densidade eletrônica de carga e dada por

$$
\rho(z)=-e n(z)+e n_{d}(z)-e n_{a}(z)
$$

e a equaça de Thomas-Fermi $(2.20)$ fica

$$
\frac{d^{2}}{d z^{2}}\left[E_{\mathrm{F}}-V(z)\right]=\frac{8 \sqrt{2} \kappa e^{2}}{3 \pi \epsilon \hbar^{3}} m^{3 / 2}\left[E_{\mathrm{F}}-V(z)\right]^{3 / 2} \Theta\left[E_{\mathrm{F}}-V(z)\right]-4 \pi e^{2} n_{\mathrm{d}}(z)+4 \pi e^{2} n_{\mathrm{a}}(z)
$$

Finalmente, os resultados da aproximaçäo semiclássica obtidos para sistemas bidimensionais podem ser sumarizados como

$$
\frac{d^{2}}{d z^{2}}\left[E_{\mathrm{F}}-V(z)\right]=\frac{8 \sqrt{2}}{3 \pi}\left[E_{\mathrm{F}}-V(z)\right]^{3 / 2} \theta\left[E_{\mathrm{F}}-V(z)\right]-4 \pi n_{\mathrm{d}}(z)+4 \pi n_{\mathrm{a}}(z)
$$

e

$$
n(z)=\frac{1}{3 \pi^{2}}\left[E_{F}-V(z)\right]^{3 / 2} \Theta\left[E_{F}-V(z)\right]
$$

em unidades atômicas efetivas.

\subsection{2 $\mathrm{O}$ poço $\delta$ dopado a $\mathrm{T}=0 \mathrm{~K}$}

Como já mencionado, os perfis do potencial de pocos o podem ser determinados utilizando a aproximação serni-clássica de Thomas-Fermi. Será mostrada aqui a solução da equação de Thomas-Fermi para poços $\delta$ de espessura nula, a $T=0 K$, na ausendia de aceitadores residuais.

Utilizando como origem da escala de energia o nivel de Fermi, $E_{\mathrm{F}}$, a equaçato diferencial (2.21) de Thomas-Fermi para o potencial confinante ficari dada por[22]

$$
\frac{d^{2}}{d z^{2}}[-V(z)]=\frac{8 \sqrt{2}}{3 \pi}[-V(z)]^{3 / 2} \Theta[-V(z)]-4 \pi N_{d} \delta(z)
$$

Em estruturas onde uma fraçào s da carga eletrónica foi transterida para a superficie, situada em $z=-d$, a solução da equaçào diferencial (2.23) para $z>0$ é dada por

$$
V(z)=-\frac{1}{2} \frac{\alpha^{2}}{(\alpha|z|+\beta)^{4}}
$$

$\operatorname{com} \alpha=2 / 15 \pi$

$$
B=\left(\frac{\alpha^{3}}{\pi N_{d}}\right)^{1 / 3}\left(1-s^{2}\right)^{-1 / 3}
$$

A profundidade do poģo de potencial, $\%$, é dade por

$$
H_{0}=V_{0}\left(1-s^{2}\right)^{4 / 5}
$$


onde $\overline{V_{0}}$ representa a profundidade do potencial do poço para uma estrutura sem polarização (i.e. $s=0$ )

$$
\bar{V}_{0}=\frac{1}{2}\left(\frac{m^{2} N_{d}^{2}}{\alpha}\right)^{2 / s}
$$

Para $z<0_{2}$ o potencial é determinado numericamente pela equaça diferencial

$$
\frac{d V(z)}{d z}=-\sqrt{16 \sqrt{2} \alpha|V(z)|^{5 / 2} \Theta[-V(x)]+\left(4 \pi s N_{d}\right)^{2}}
$$

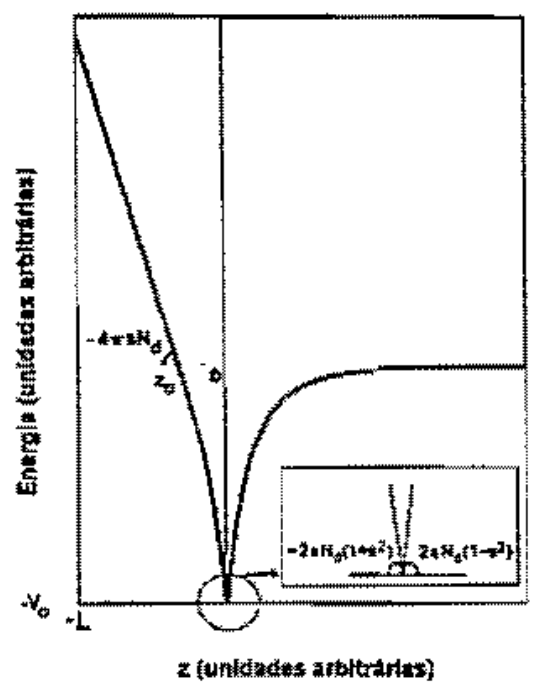

Figura 2.2: Perfil de urn poço $\delta$ dopado sujeito a um potencial externo aplicado, onde uma fraça $s$ da carga eletrônica fö transferida par superficie em $z=-d$. o potencial de Th é obtido a partir das relaçöes $(2.24)$ e $(2.28), z>0$ e para $z<0$, respectivamente $O$ potencial de

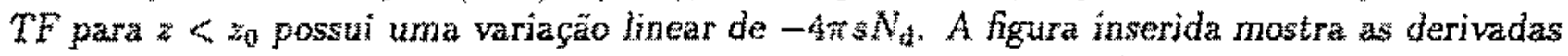
do potencial em $z=0$, obtidas a partir das condjocos de contorno (2.15) e (2.16).

Para estruturas sem polurizaçăo, o perfll de potencial de Thomas-Fermi será dado pela equaçāo (2.24) para todo o $z$, fazzendo-se $s=0$.

\section{$2.3 \quad$ Estrutura eletrônica de super-redes $\delta$ periódicas}

Quando os elétrons sẽo confinados num potencial perióthico ao longo de um eixo (a direção de crescimento $*$ ), os estados eletrónicos säo quantirados em minibandas de energias $\varepsilon_{n k_{*} k_{1}}$

$$
\varepsilon_{n k_{z} k_{1}}=E_{n k_{\sharp}}+\frac{\hbar k_{1}^{2}}{2 m}
$$


onde $k_{\perp}$ e $k_{2}$ săo, respectivamente, os vetores de onda perpendicular e paralelo aos poços confinantes e $E_{n k_{z}}$ é a relaçăo de dispersäo da enésima minibanda. $O$ s estados eletronicos correspondentes às energias $E_{n k_{z}}$ sào descritos pelas funçố de onda

$$
\psi_{n k_{z} k_{\perp}}(e, z)=\frac{1}{\sqrt{S}} \mathrm{e}^{i k_{\perp} \cdot e} \chi_{n k_{s}}(z)
$$

onde $\chi_{n k_{*}}(z)=u_{n k_{z}}(z) e^{i k_{*} t}$ e $u_{n k_{z}}(z)$ sâto funçöes de Bloch normalizadas no tamanho da superrede. A funçōes $\chi_{n} z_{*}(z)$ săo soluçöes da equação de Schrödinger

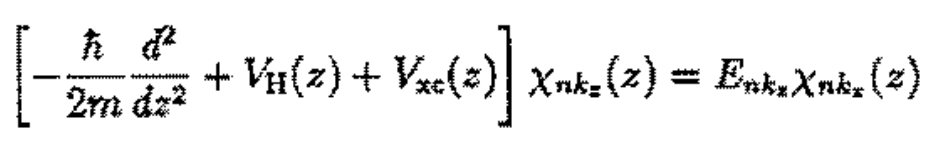

$V_{1}(x)$ é o potencial auto-consistente de Hartree, obtido pela solução numérica da equação de Poisson (2.8) com

$$
\begin{aligned}
& n(z)=\sum_{n} N_{n k_{z}}\left|u_{n k_{x}}(z)\right|^{2} \\
& N_{n+k_{z}}=\frac{m k_{\mathrm{B}} T}{\pi \hbar^{2}} \ln \left[1+\exp \left(\frac{E_{\mathrm{F}}-E_{n k_{z}}}{k_{\mathrm{B}} T}\right)\right]
\end{aligned}
$$

sendo $n(z)$ a densidade de portadores livres e $E_{\mathrm{F}}$ a energia de Fermi.

O restante do cálculo da estrutura eletrónica de super-rede periódicas segue raciocinio análogo a cálculo da estrutura eletrónica de paços $\delta$. E de mencionatr-se que a distribuiça de doadores ionizados $n_{\mathrm{d}}(z)$, assumindo-se o formato de uma camada dopada como sendo uma funçüo normalizada $g a(z)$,

$$
\int_{-\infty}^{+\infty} d z g_{d}(z)=1
$$

é calculada a partir de

$$
n_{d}(z)=N_{d} \sum_{n=-\infty}^{+\infty} \xi_{d}(z-n d)
$$

onde $d$ é o periodo da super-rede e $N_{d}$ é a densidade planar de doadores em cada plano $\delta$-dopado.

\subsection{Procedimento numérico para o cálculo da estrutura eletrônica}

A estrutura eletrontica quântica de super-redes ôn-kopadas e poços $\delta$ é obtida a partir do cálculo auto consistente das equaçôes de Poisson e Schrödinger. utilizando-se, por exemplo. o potencial de Thomas-Fermi como ponto de partida.

Na implementaçõo do procedimento auto consistente, três métodos diferentes podem ser utilizados para se resolver a equaçào de Schrödinger: 
- Expandindo-se o potencial confinante e as funções de onda envoltórias em série de Fourier e resolvendo-se o problema de auto-valores resultante; (por exemplo, como descrito na Ref. [32]).

- Utilizando-se o método da matriz de transferência, considerando-se o potencial constante por intervalos (Ref. [33]);

- Resolvendo-se a equação de Schrölinger pelo método das diferenças finitas.

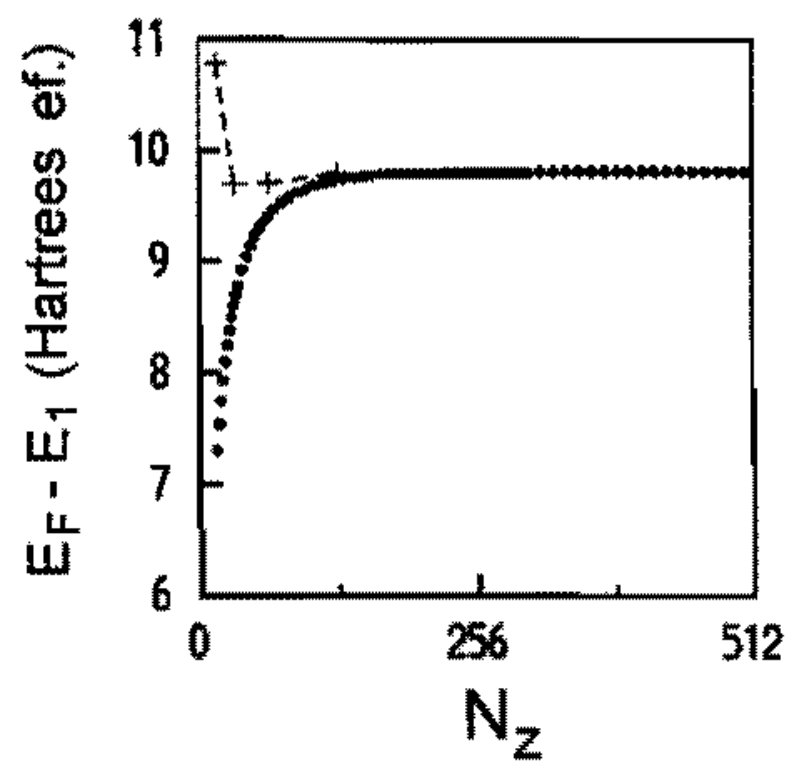

Figura 2.3: Energia de Fermi relativa ao minimo da subbanda E1, calculada em funçào do número de ondas planas utilizadas para a expansâa do potencial confinante por uma série discreta de Fourier (t) para uma super-rede com parâmetros $\Lambda_{\mathrm{d}}=5 a_{\mathrm{B}}^{-2}, d=12 a_{\mathrm{B}} e \Delta=0,1 a_{B}$. Os círculos cheios representam os resultados obtidos pelo método das diferenças finitas.

Os dois últimos métodos produzem resultados equivalentes. sendo que a utilizaçâo do método de diferenças finitas é vantajosa, no que diz respeito à velocidade da obtenção do potencial, para o cálculo da estrutura eletrônica de poços isolados.

No caso dos dois primeiros métodos, o potencial periódico e a função de distribuição de doadores são amostradas em $N_{z}$ pontos equidistantes em cada periodo da super-rede; para o método (1), $N_{z}$ será também o número de ondas planas utilizadas na expansão de Fourier do potencial confinante. Na medida em que $N_{*}$ cresce, o potencial numérico e a função de distribuição dos doadores são melhor aproximadas pelos valores da amostragem, e os resultados dos cálculos convergem.

Estudou-se a convergència em função de $N_{z}$ para urna situação numérica extrema: uma supernrede com alta dopagem por periodo $\left(N_{\mathrm{d}}=5 a_{B}^{-2}\right)$ com periodo muito grande $(d=$ $\left.12 a_{B}\right)$ e com uma distribuiçäo de doadores gaussiana bastante aguda $\left(\Delta=0,1 a_{B}\right)$. Para tais 
parâmetros, somente os elétrons em minibandas acima da quinta estarão acoplados com os poços adjucentes: esses elétrons perfazem apenas $0,5 \%$ do total, portanto os poços säo efetivamente desacoplados. A energia de Fermi $E_{F}$ fol escolhida como o parâmetro de convergència; esta escolha fol baseada no fato de que $E_{F}$ e muito sensivel a qualquer mudança no formato dos perfis dos poços, sendo axsirn uma escolha ideal para o teste de convergencia. A posição calculada do nível de Fermi a partir do mínimo da primeira subbanda, $E 1$, como funçẫo de $N_{t}$ é mostrada na Fig. 2.3. As cruzes na Fig. 2.3 indicam a soluçào obtida utalizando-se o método de Fourier de expansảo em ondas planas, enquanto os círculos representam as resultados obtidos pelo método da matriz de transferência. A Fig. 2.3 mostra que o método de solução que emprega a expansão de Fourier converge mais rapidamente que aquele da maţriz de transferéncia; isto pode ser atribudo ao fato de que axpansão $\operatorname{com} N_{z}$ ondas planas representa melhor o potencial do que uma aproximaçäo do mesmo por $N_{*}$ segmentos constante (que é o caso do método da matriz de transferência).

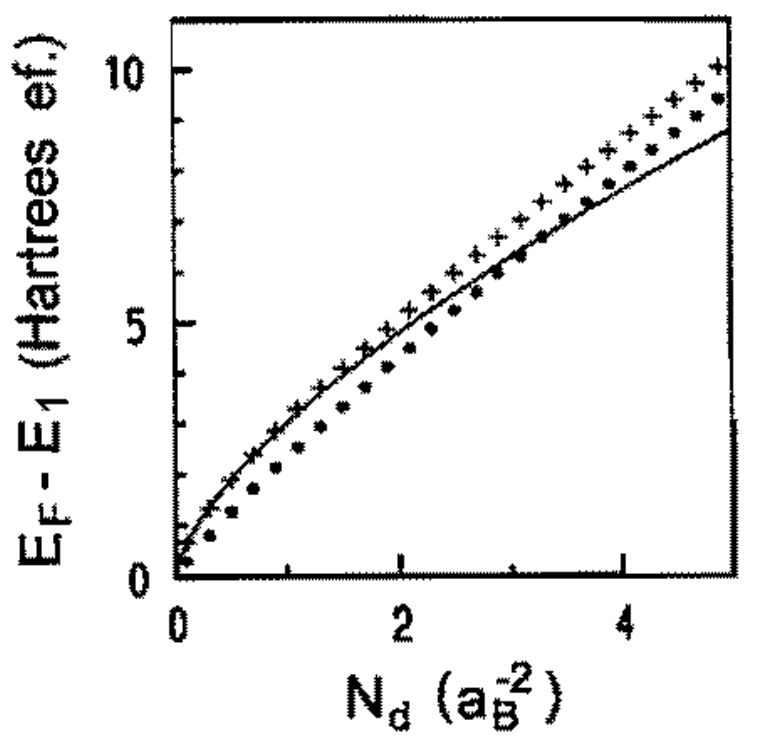

Figura 2.1: Energia de Femi calculada para uma superwede com paránetros $d=2 a$ em funçäo de $N_{d}(+)$. A linha cheia é dependência de Er para un gras de elétrons $3 \mathrm{D}$. Os circulos representam dependencia de $E_{F}$ na aproximação bindimensional de Thomas-Fermi. obtida da soluçấo numérica do potencial dado pela Eq. (2.24)

Para os parâmetros considerados na obtençào da Fig. 2.3, uma expansăo com $12 \mathrm{~S}$ ondas planas fornece uma energia de Fermi com um desvio de menos de $0.3 \%$ do vator obtido 512 on. das planas. Pata urn forte acoplamento entre poços atjacentes. um baixo nivel de dopagem ou uma distribuiçăo de doadores mais larga, o potencial confonante serâ mais suave que aquele considerado na Fig. 2.3, e será melhor aproximado pelo mesmo número de ondas planas. Portanto, para o cálculo dos potenciais de super-redes. utilizaremos um número máximo de 128 ondas planas. Como mostraco isto produzira uma estrutura eletrônica de boa qualidade numérica 
para sua posterior utilização na obtençäo de propriedades derivadas como as mobilidades das mini-bandas e espectros CV.

A Fig. 2.4 mostra a dependência da energia de Fermi em funçäo da dopagen planar aș sumida, $N_{d}$, calculada para una super-rede de período $d=2 a_{B}$ e $\Delta=0,2 a_{B}$ (cruzes). $\mathrm{Na}$ Fig. 2.4 tambẻm é mostrada a dependência da energia de Fermi em $N_{\mathrm{d}}$ para um gás de elétrons livres, $E_{\mathrm{F}}^{3 D}=\frac{1}{2}\left(3 \pi^{2} N_{\mathrm{d}} / d\right)^{2 / 3}$ (linha cheia), e a dependencia da energia de Fermi em $N_{\mathrm{d}}$ obtida da soluçäo numérica da equaçäo de Schrödinger ntilizando-se o potencial de Thomas-Fermi (Eq. (2.24)) (circulos). Para pequenos valores de $N_{\text {di }}$ os pocos säo rasos e acoplamento entre poços adjacentes forte; portanto $E_{F}$ segue a dependetucia do gás de elétrons livres $E_{F}^{3 D}$. Em alta concentraçäo, o acoplamento entre poços adjacentes diminul e a dependéncia de $E_{\mathrm{F}}$ em $N_{\mathrm{d}}$ torna-se linear como a aproximação de Thomas-Fermi para um poço isolado. $O$ comportamento bi-dimensional em alta concentração $N_{\mathrm{d}}$ ilustra o fato de que em altos niveis de dopagem, os poços $\delta$ são desacoplados mesmo para super-redes com períodos muito curtos, como mostrado por cálculos $a b$ initio [34]. 


\section{Capítulo 3}

\section{Determinação do período de super-redes por medidas CV}

A técnica de caracterizaçầo CV (capacitância-voltagem) foi originalmente desenvolvida para deteminar a distribuiçäo espacial de impurezas em heterojunçöes semicondutoras e é descrita em alguns livros texto, como por exemplo na Ref. [35].

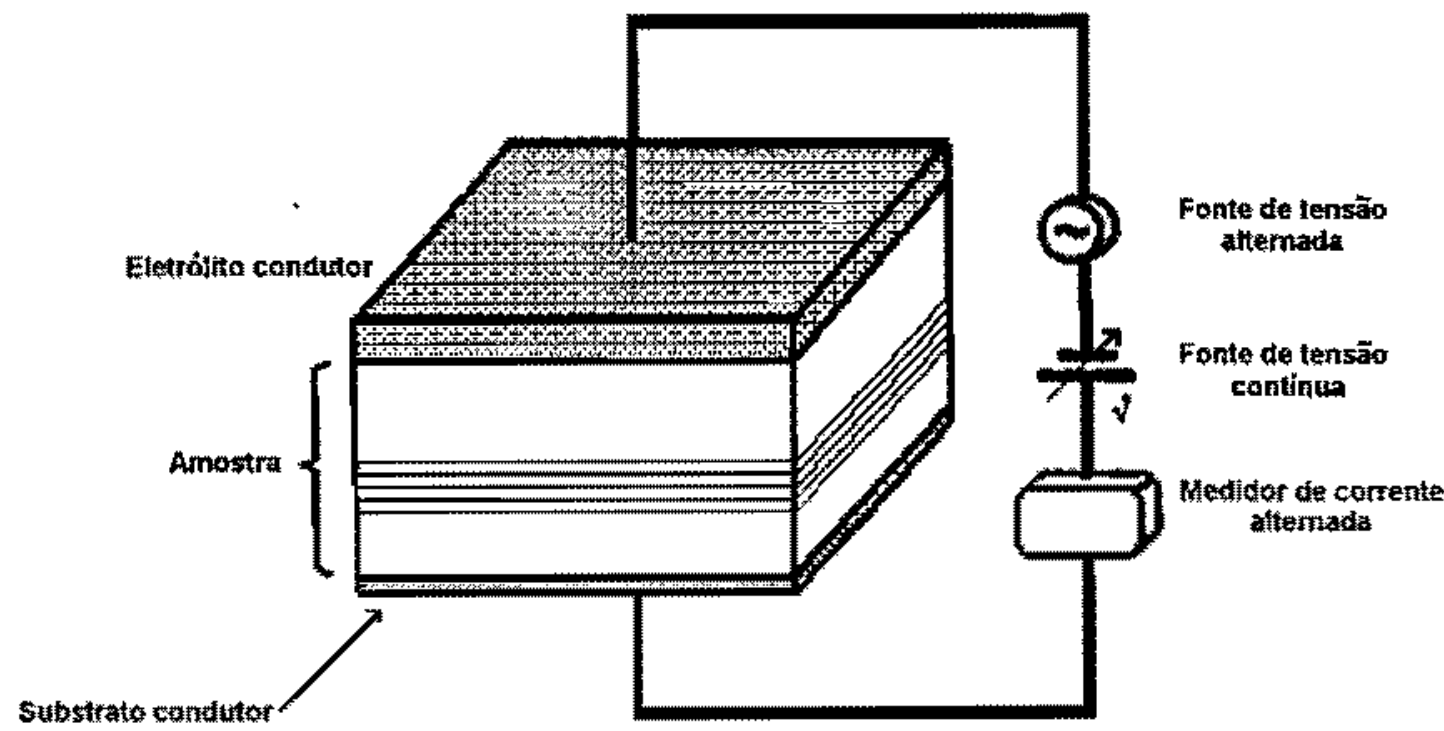

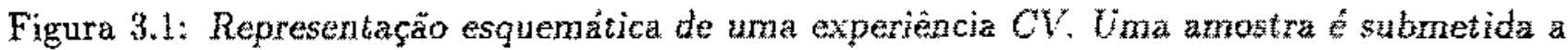

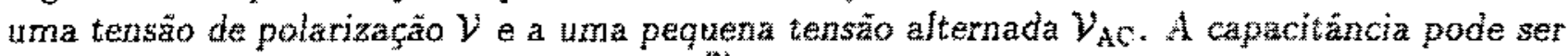
obtida, para cada valor de $\mathcal{V}$ por $i_{\mathrm{AC}}=\mathrm{C} \frac{\mathrm{M}_{\mathrm{A}} \text {. }}{\mathrm{a}}$.

A técnica CV pode tambérn ser aplicada em sistemas semicondutores bidimensionais[36. 37] tais como sistemas a-dopados. Para um único poço 0 mostra-se que a análise do espectro CV 
pode ser utilizada para deterninar a localizaçäo das impurezas do plano fo com uma precisão da ordem do tamanho da constante de rede do cristal hospedeiro[38].

A fim de que se obtenha um espectro $\mathrm{CV}$, uma tensão de polarização $v$ é aplicada no contato Schottky feito na superficie do semicondutor a capacitância diferencial C é medida adicionando-se urna pequena voltagem alternada à tensão de polarização, como esquematizado na Figura 3.1 .

Utilizandomse o sistema adimensional de unidades, onde as unidades de comprimento, energia e massa säo, respectivamente, o raio de Bohr efetivo, o Hartree efetivo e a massa efetiva, o espectro CV é definido como sendo a concentraçăo $C V$ definida por

$$
N_{\mathrm{OV}}=4 \pi C^{3} \frac{d V}{d C}
$$

versus a profundidade $C V$ definida por

$$
z_{\mathrm{CV}}=\frac{1}{4 \pi C}
$$

Para sistemas com um único poço $\delta$, gráfico $N_{\mathrm{CV}} \times z_{\mathrm{CV}}$ é caracterizado por ser uma curva em forma de sino.

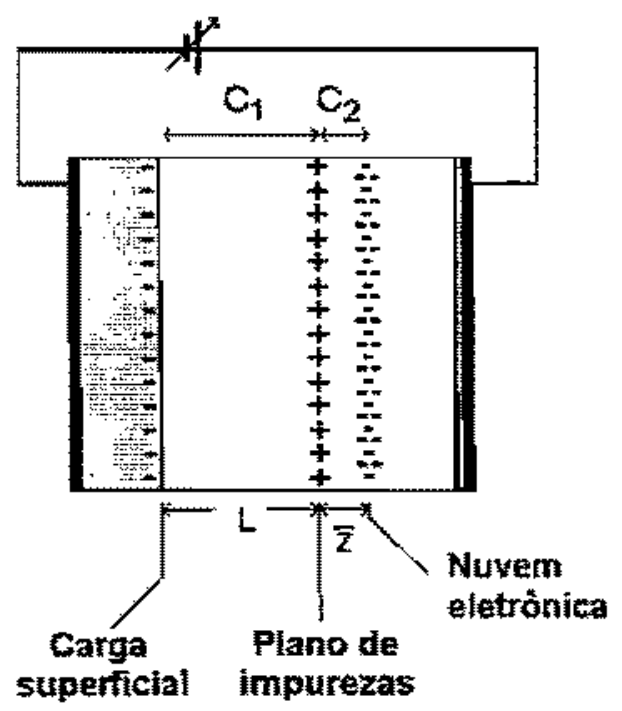

Figura 3.2: Representacão da localizaço espacial das cargas envolvidas na medida CV. A capacitancia total $C$ pode ser obtida por $\frac{1}{C}=\frac{1}{C_{1}}+\frac{1}{C_{2}}$ ou, equivalentemente, z $\mathrm{Cv} \approx L+Z$

O processo fisico que determina o formato do espectro $\mathrm{Cl}$ poda ser entendido a partir de uma breve discussão. Quando da aplicaçăo de uma tensão de polarizaçăo parte da carga eletrônica é transferida do poço para o contato Schottky. Como mostrado na Figura 3.2. se tomarmos como aproximadamente constante intensidade do campo elétrico existente trutre 0 contato Schottky e o poço $\delta$, a capacitância total será

$$
\frac{1}{C}=\frac{1}{C_{1}}+\frac{1}{C_{2}}
$$


com $1 / C=4 \pi \mathrm{C}_{\mathrm{V}}, 1 / \mathrm{C}_{1}=4 \pi L$ e $1 / C_{2} \approx 4 \pi \ddot{z}$. Substituãndo-se esses resultados na relaçấ (3.2) tem-se, portanto,

$$
z_{\text {CV }} \approx L+\bar{z}
$$

onde $L$ é a distancia entre a superficie e o poço $\delta$ e $\bar{z}$ é a posiçầ esperada da carga letrônica, medida a partir do centro do plano de impurezas. Portanto; o espectro CV será determinado pela dependencia de $\frac{d z}{d}$ na tensão de polarizaçăo $V$.

Para pequenos valores de $\mathcal{V}, \bar{z}$ aumenta rapidamente devido $\mathbf{s}$ contribuiçôes das sabbandas de energia mais altas (Fig. 3.3a e 3.3b), posto que estas são caracterizadas por um comprimento de ligação grande (ou seja, fracamente ligadas ao plano de carga positiva) e que säo extremamente sensiveis à intensidade do campo elétrïco externo aplicado. Em valores intermediários de $V$ (Fig. $3.3 \mathrm{c}$ ), apenas subbandas forternente ligadas to plano $\delta$ permanecem populadas a dependência de $\bar{z}$ em $\mathcal{V}$ torna-se mais fraca. Finalmente, para valores mais altos de $\mathcal{V}$, a força de ligaça do potencial de confinamento dimimui (Figura $3.3 \mathrm{~d}$ ), devido ao aumento de importancia da repulsão da carga confinada pelas cargas superficiais, o que se reflete novamente num rápido aumento de $\bar{z} \operatorname{com} \mathcal{V}$. Essa dependência em forma de degrau de $z$ ern $\mathcal{V}$ conduz a um espectro CV em forma de sino (Fig. 3.3e e 3.3f). Ju que as mudanças erm zäo muito menores que o valor de $L$, a posiçảo do pico CV será aproximadamente a distấncia da superfície ao plano $\delta$.

Como mostrado por Schubert, a largura do pico CV é proporcional à extensäo espacial da funçăo de onda de uma partícula do estado fundamental (ou seja, do sístema sem campo

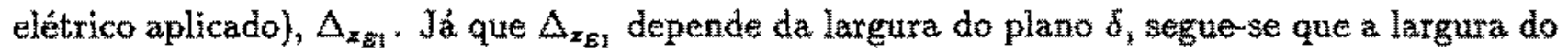
espectro CV de um semicondutor 8 -dopado reftete a dispersāo das impurezas ao redor do plano 5. Se a densidade planar dos átomos da impureza conhecida, a largura do plano o pode ser estimada calculando-se auto-consistentemente o espectro CV teórico[38]. Num calculo deste thpo, a largura do plano $\delta$ é a variável de entradaj a largura real do plano $\delta$ é tomada como sendo igual ao valor do parâmetro que conduz ao espectro CV teórico que esteja em melhor acordo com o experimental $[4,6,20]$.

Neste capitulo, mostramos como a análise do espectro $C V$ pode ser extendida a semicondutores periodicamente $f$ dopados. $O$ espectro $\mathrm{CV}$ foi medido para super-redes InP:Si perio dicamente dopadas e foram observadas oscilaçes. Os espectros CV teoricos foram calculados, demonstrando qque os periodos das oscilaçôes constituem uma medida precisa da periodicidade de dopagem. A gama de parametros, nivel de dopagern e período, nos quais a técnica CV é de valia para a determinação do periodo $d$, também foi avaliada. 


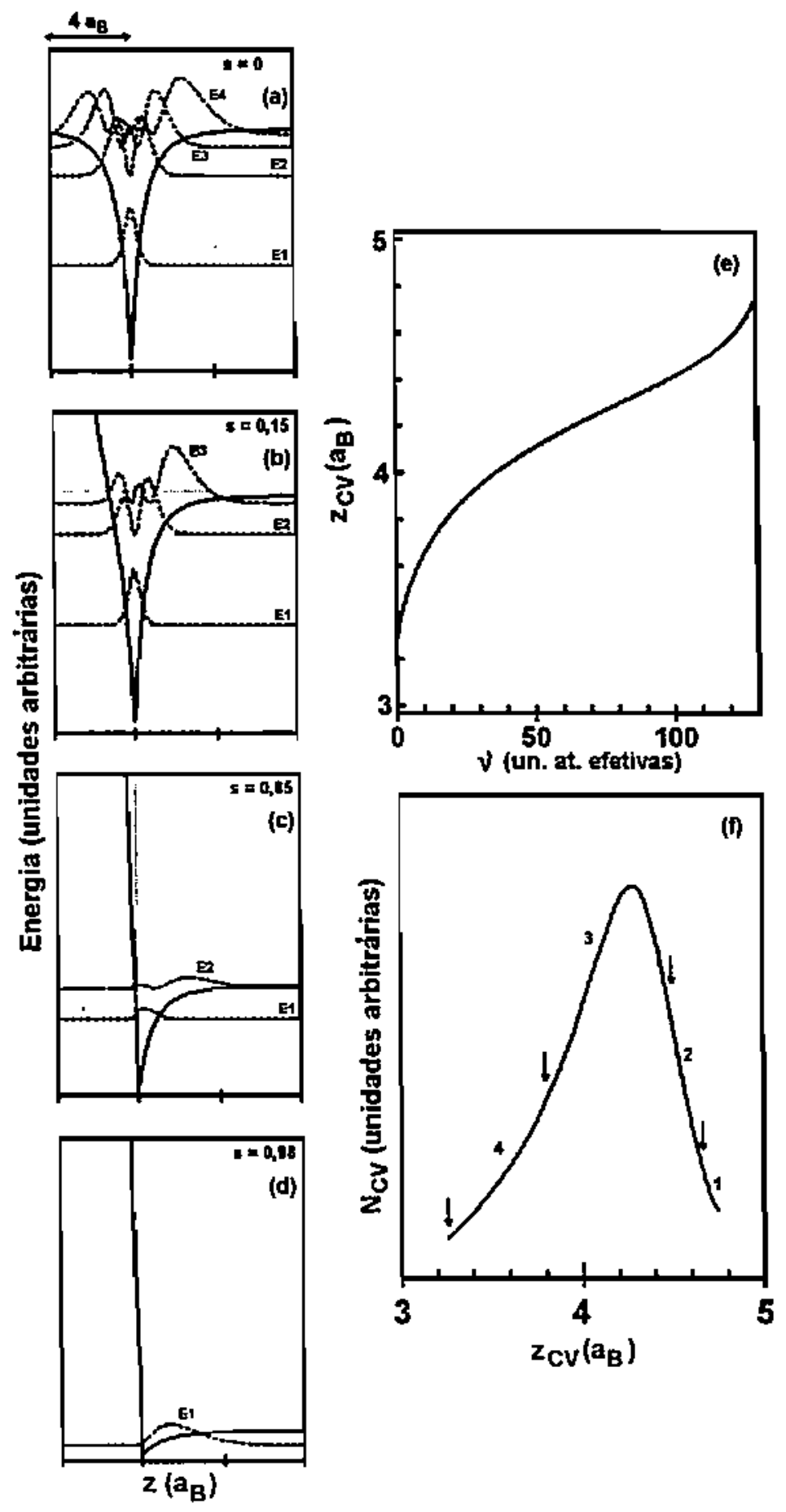

Figura 3.3: (a)-(d) Evoluçāo do potencial confinante de um poço $\delta$ com a voltagem externa aplicada. a $4 a_{\mathrm{B}}$ abaixo da superfície da amostra. São mostrados as funções de onda e os níveis energéticos correspondentes às subbandas $E 1$ a $E 4$ (linhas tracejadas) e a fraçāo de carga situada na superfície (s). As linhas pontilhadas vertical e horizontal indicam a posição do plano de impurezas e ao nivel de Fermi para $s=0$. respectivamente. (e) $z_{\mathrm{CV}}$ em função da voltagem $\mathcal{V}$ aplicada. (f) Espectro CV. Entre as setas é indicado o número de subbandas ocupadas. 


\subsection{Resultados}

A Fig. 3.4 mostra o espectro CV experimental para três amostras de InP estudadas. Os espectros CV säo carecterizálos por possuirem uma seqüência de picos com um espaçamento constante que é aproximadamente igual ao espaçamento nominal entre os planos $\delta$. Pela figura, pode-se observar também que para espaçamentos menores entre os planos $\delta$, os picos vistos no espectro CV sãto menos bem resolvidos.

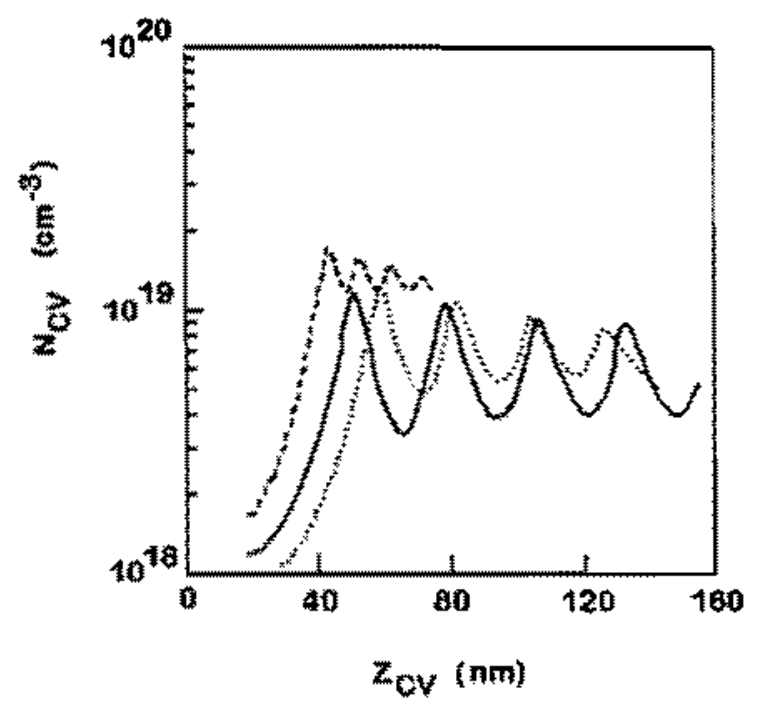

Figura 3.4: Espectros CV experimentais super-fedes $\delta$ periódicas com períodos de $280 A$ (linha cheia), $250 A$ (linha ponthlida) e $100 A$ (linha tracejada), medidos a $300 \mathrm{~K}$. A densidade de portadores é aproximadamente igual a $4.5 \times 10^{12} \mathrm{~cm}^{-2}$, por período de dopagem, para todas as amostras. As amostras continharn, respectivarnente, 5,10 e 10 poços $\delta$.

Para que os espectros CV experimentais possam set interpretados, espectros CV teóricos foram gerados resolvendo-se auto-consistentemente as equaçōes de Schrödinger e Poisson para super-redes $\delta$ dopadas submetidas à tensöes de polarizaçăo (̧os detalhes do cálculo autoconsistente podem ser apreciados no Capítulo 2)[39]. As estruturas téricas consistiam em cinco poços $\delta$ igualmente espaçados e form utilizadats 25 subbandas para o cálculo auto-consistente. Assumiu-se também que as impurezas estavam distribudas de acordo com uma distribuiçâo

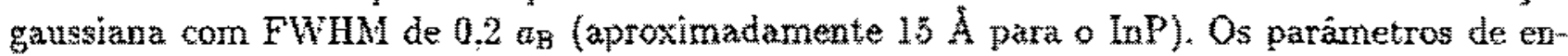
trada nos cálculos foram o periodo de dopagem d a densidade planar de átomos da impureza em cada plano dopado $N_{3}$. Foram estudados tambern os efeitos de impurezas aceitadoras residuais com concentraçóes na raixa de $N_{2}<10^{-4} a_{\mathrm{B}}^{-3}\left(N_{\mathrm{m}}<2,1 \times 10^{-14} \mathrm{~cm}^{-3}\right.$ para o InP). Entretanto, os espectros CV calculados mostratam una pequena dependencia na densidade de uctudadores residuais e nos calculos que seräo mostrados. aera desprezado esse efeito. Finalmente, os espectros CV teóricos foram calculados utlizando-se as equaçôes Eqs. (3.1) e (3.2).

Na. Figura Fig. 3.5 et mostrado o potencial confinante e a distribuição eletrônica de carga obtidos a partit do câtculo auto-consistente das equaçôs de Schrödiager e Poisson em função da tensäo de polarizaçäo aplicada para uma estrutura periodicamente $\delta$-dopada com parámetros $N_{\mathrm{d}}=2.5 \mathrm{ag}_{\mathrm{B}}^{-2}\left(4.0 \times 10^{12} \mathrm{~cm}^{-2}\right.$ para o InP $), d=a_{\mathrm{B}}(79 A$ para o InP $)$ e $\mathrm{T}=300 \mathrm{~K}$. 

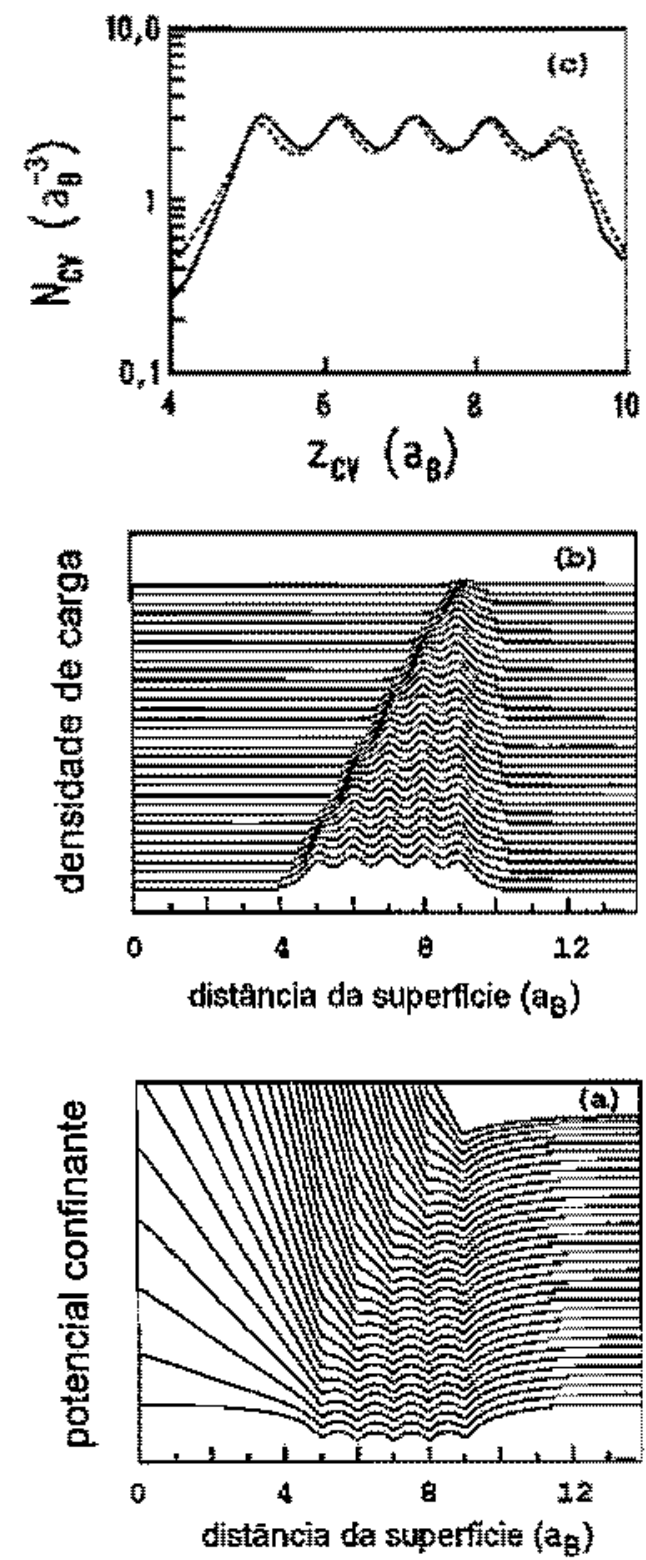

Figura 3.5: (a) Dependência do potencial confinante auto-consistente de um sernicondutor periodicamente f-dopado pela polarizaçāo aplicada; a curva abaixo de toda corresponde

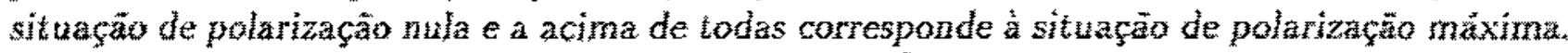
Os parametros foram tomados comosendo $\Lambda_{\mathrm{d}}=2.5 \mathrm{a}_{\mathrm{B}}^{-2}$ : $\mathrm{d}=\mathrm{a \textrm {B }}$ e $\mathrm{T}=300 \mathrm{~K}$. $O$ contato $5 \mathrm{choth}$

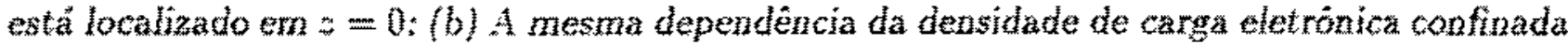
ara estrutura: (c) $O$ espectro $C V$ calculado para a mesma estrutura (curva cheia). A curva tracejada representa a soma de espectros Cl teóricos associados com amostras contento uma

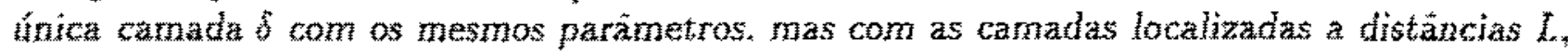
$L+4, L+2 d, \ldots$ abaixo da superficie.

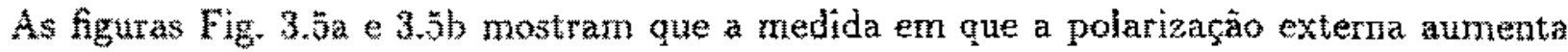
a estrutura semicondutora e progressivamenta depletada. Essa depleção progressiva acontece. 
entretanto, primeiramente no poço $\delta$ mais próximo da superfície sendo que o próximo começará a ser depletado somente quando que o anterior já estiver completamente vazio. Isto sugere que o espectro CV de um sistema periodicamente $\delta$-dopado possa ser aproximado pela sobreposiça de curvas CV associadas a estruturas $\delta$-dopadas com um thico plano de impurezas localizados as distancias $L, L+d, L+2 d, \cdots$ da superfície da amostra. Portanto o espaçamenio entre picos CV sert igual à distancia entre planos $\delta$ adjacentes. Como pode ser visto pela Fig. 3.5c, a sobreposiçäo de curvas CV associadas a planos $\delta$ aproxima-se bastante bem o espectro CV para a estrutura periodicamente $\delta$-dopada.

Entretanto, a resoluçu dos picos CV será possivel somente se o espaçamento entre planos for maior que largura a meia altura (FWHM) do pico CV de um plano que o espaçamento entre picos seja igual ao período de dopagem $d$ e a FWHM de um pico CV individual igual a localizaçầo espacial da subbanda do estado fundarnental $\Delta z_{\text {za }}[0,20]$, para observarem-se oscilaçôes no espectro CV a condiçäo que deve ser satisfeita

$$
d>\Delta z_{E}
$$

Cabe ressaltar que, nesta gama de periodos de dopagem, o acoplamento extre elétrons localizados em poços adjacentes e pertencentes a minibanda fundamental é fraco. Neste caso, a depleçào de carga da estrutura sobre polarização é um processo seqüencial lou seja, um dado poço começa a ser depletado somente quando todos os poços mais próximos da porta ja o forum ), o que, pelos argumentos já expostos, garante que a distancia entre picos CV é urna boa medida do periodo de dopagem da estrutura de um semicondutor periodicamente todopado.

A extensäo espacial da função de onda do estado fundamental, $\Delta z_{E_{1}}$, depende principalmente de dois parâmetros da amostra: da densidade planar eletrônica em cada poço, $N_{d}$, e da espessura da camada dopada por átomos doadores, $\Delta_{\mathrm{d}}$. Para um poço $\delta$ ideal, ou seja, com camada dopada de espessura nula, $\Delta_{\mathrm{x}}=0$, a extensão espacial $\Delta z_{2}$ pode ser estimada a partir da regra de quantização de Bohr-Sommerfeld,

$$
\int \mathrm{d} z p(x)=2 \pi\left(n+\frac{1}{2}\right)
$$

escrita em unidades atômicas fotivas.

A energia de um estado ligado, $E_{n}$, pode ser obtida pela substituiçâo

$$
p(\xi)=\sqrt{2\left[E_{n}-V(z)\right]}
$$

onde $V(z)$ é a equaçăo conhecida para o potencial confinante. A extensäo espacial do enésimo estado é igual ż distância entre os pontos de retorno clássicos. sendo assim determinados pela condiçāo $V(z)=E_{\mathrm{n}}$. Nas proximidades do plano de impurezas, o potencial confrnante pode ser aproximado por

$$
V(x) \approx 2 \pi N a
$$

Nessa aproximaçäo a extensão espacial do estado andamental $(n=0$. que foi denotado por El) é dada por

$$
\Delta z_{E 1}=\left(\frac{3 \pi^{1 / 2}}{2^{5 / 2}}\right)^{2 / 3} k_{d}^{n-1 / 3}
$$


Portanto, para planos $\delta$ muito estreìtos, a condiçäo para que o spectro CV apresente uma estrutura oscilatória, cujo período seja igual ao espaçamento entre os planos de dopante, será

$$
d>\left(\frac{3 \pi^{1 / 2}}{25 / 2}\right)^{2 / 3} N_{\mathrm{i}}^{-1 / 3}
$$

\subsection{Conclusöes}

Em suma, fol mostrado que o espectro CV de uma estrutura periodicamente $\delta$-dopada pode ser descrito, em boa aproximaçăo como uma combinaçäo linear de espectros CV associados com uma seqüência de poços $\delta$ individuais igualmente deslocados espacialmente da superficie da amostra. Para trềs super-redes reais de InP:Si consideradas, com dopagens planares de 4,5x $10^{12} \mathrm{~cm}^{-7}$, os perfodos de dopagem obtidos dos espectros CV foram de 92,225 e $280 \mathrm{~A}$, os quais em concordấncia excelente com o periodos intencionais de 100,250 e $280 \AA$, respectivamente.

A técnica CV pode ser útil para que sejam determinados os periodos de dopagem somente nos casos em que o período de dopagem seja maior que a FWHM do espectro CV associado com un plano individual de impurezas.

A técnica pode ser aplicada a uma estrutura com um número arbitrário de periodos e densidades planares. A avalanche elétrica (electric breakdown) pode ser evitada se as medidas CV forem feitas no modo de corrosäo (etching mode), ou seja, se a superfície da amostra for sendo corroida gradativamente. Entretanto, o procedimento de corrosão introduz um alargamento dos picos CV (cujos detalhes podem ser vistos, por exemplo, na Ref. [40]), e, como conseqüència, o espectro CV experimental mostrará apenas um número finito de oscilações associadas com os planos $\delta$ mais próximos da superfície da amostra. 


\section{Capítulo 4}

\section{Determinação experimental dos parâmetros característicos de poços e super-redes $\delta$}

Os parâmetros característicos de uma super-rede $\delta$ dopada ideal sâo a densidade de átomos doadores nas camadas dopadas, $N_{\mathrm{d}}$, e o periodo de dopagem, d. Estes dois parânetros determinam inteiramente as propriedades optoeletrónicas de um semicondutor com dopagem periódica e espessura nula da camada de dopagem. Em amostras reais, entzetanto os átomos doadores estão dífundidos en torno do plano idealizado e a distribuiçāo dezses atomos pode ser aproximada, por exemplo, por uma funçẫo gaussiana com largara a meia altura $\Delta_{\mathrm{d}}[20]$. Recentemente, a partir de medidas de difractometria de raios-X foi possivel a determinaç艹o da flutuaça no periodo de super-zedes $\delta$-GaAs, alérn de ter sỉdo deduzido por esta técnica que todos os átomos de Si ocupam posiçôes substituindo o Ga[41], em concentraçôes de Si muito menores que aquela

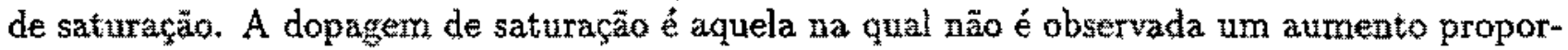
cional na concentraçäo de portadores e, para o GaAs, está na faixa de $2 \times 10^{-13} \mathrm{~cm}^{-2}$, conforme verificado por Droopad ei al. [42] a partir de medidas de magnetotransporte, Conforme verificado experimentalmente por Droopad et al e teoricamente por [43], a expessura nâo nula das camadas dopadas reflete-se no espectro energetico e no preenchimeato das minibandas de uma super-rede[43]. Adicionalmente, presença de aceitadores residuais ionizados também tem uma pẹuzena influência na estrutura eletrônica das \$ubbandas maìs excitadas; estas impurezas podem ser neutralizadas iluminando-se amostra em baxas temperaturas; [44]. Portanto, para a gama de densidades abaixo do limite crítico determinado por Droopad al al, pode-se tomar como boa aproximação que a densidade planar de portadores livres por periodo da super-rede seja igual à densidade de doadores, ou seja $N_{\mathrm{S}}=N_{\mathrm{a}}$.

Os parâmetros caracteristicos de uma super-rede $f$ tem grande influência nas propriedades ópticas e elétricas. Por exemplo. em Gas com uma densidade planar fixa de $1.2 \times 10^{12} \mathrm{~cm}^{-2}$, quando o periodo de dopagem decresce de 500 para $100 \mathrm{~K}$. o espectro de lotoluminescéncia associado com a presença das camadas $\delta$ muda de uma banda de emissäo estreita com uma energia de corte proxima ao topo da banda para uma banda de emissão larga com energia de corte cerca de 60 meV ucima do gap renomalizado do GaAs $[43,40$. Similarmente, para um periocio fxo de dopagem, o limiar de absorçäo é aumentado quando o periodo da super-rede diminui[9]. Estas observaçôe estäo em bom acordo com os resultados teóricos efetuados dentro 
da aproximaça de massa efetiva e utilizando-se os parâmetros caracteristicos das amostras como entrada[47]. Medidas de $\mathrm{SdH}$ em ángulo obliquo mostraram o efeito de acoplamento entre poços of adjacentes no formato da Superfície de Fermi [42]; as áreas extremas de corte da Superficie de Fermi em campo magnético oblíquo sào também reproduzidas pelo mesmo

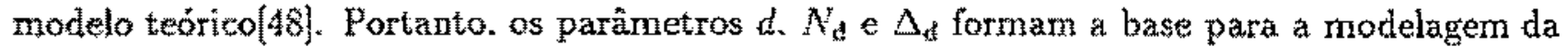
estrutura eletronica de ama super-rede $\delta$ e o conhecimento dos mesmo é un pré-requisito para 0 entendimento das propriedades ópticas e eletrônicas de uma dada amostra.

Apresentaromos neste capítulo uma maneira de conectar resultados experimentais com a estrutura eletronica de uma amostra $\delta$-dopada. Em particular, a conexäo entre os resultados do calculo auto-consistente, de medidas CV e os resultados de nedidas de Shubnikov-de Haas transversais ( quando o campo magnético é aplicado paralelamente à direçäo de crescimento da super-mrede).

\subsection{Resultados numéricos}

Quando graficada em funçâo do inverso de campo magnetico aplicado, a parte oscilatónia

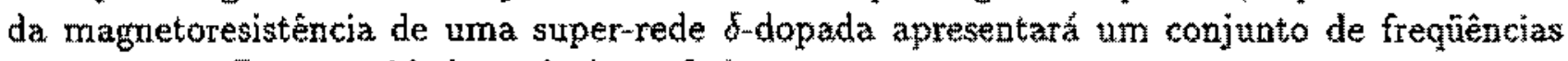
superpostas, $B_{i}$, em unidades atômicas efetivas,

$$
B_{i}=E_{\mathrm{F}}-E_{i}
$$

onde $i$ é o indice da minibanda e $E_{\text {; }}$ é a limiar da lésima minibanda[49], no sistema adimensional. Portanto, a cada minibanda preenchida corresponderá um período nas oscilaçōes da magnetoresistência. Os parâmetros $N_{\mathrm{d}}$, e $\Delta_{\mathrm{d}}$ de uma dada amostra são aqueles que fornecem melhor acordo simultâneo entre as frequências de $\mathrm{SdH}$ calculadas as medidas. 


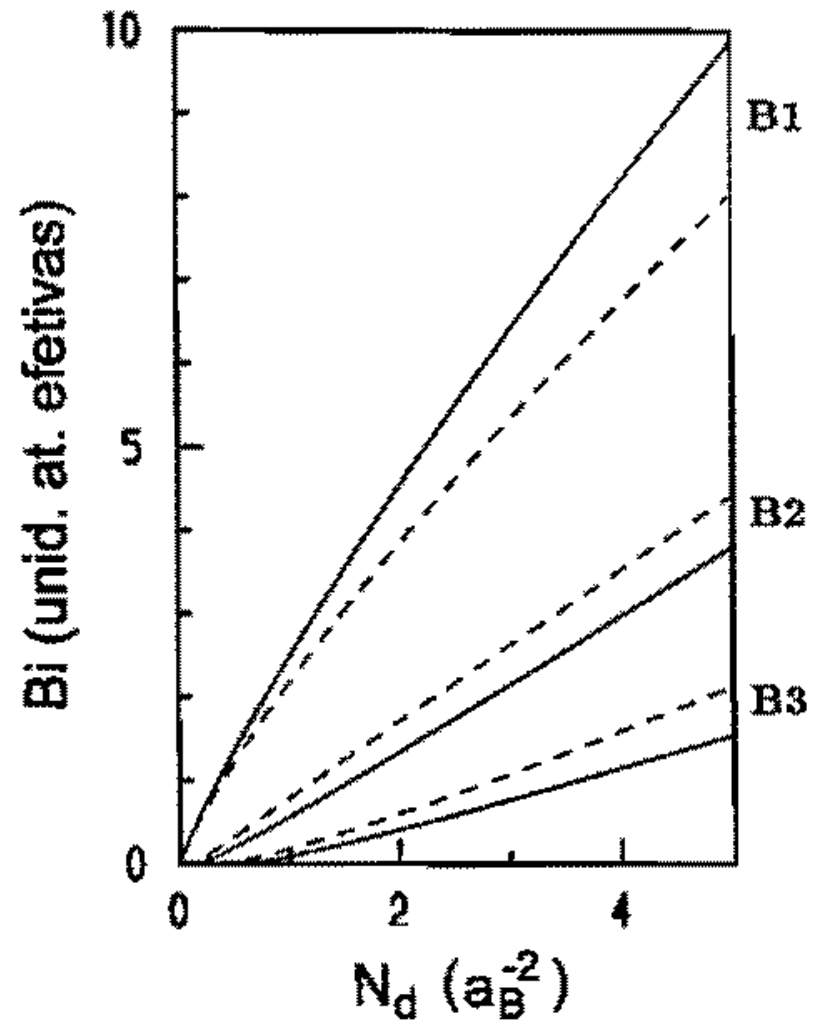

Figura 4.1: Freqüërcias das oscilaçöes de $S d H$ (Bi) calculadas para um poço $\delta$ isolado. As linhas cheias correspondem a $\Delta_{\mathrm{d}}=0,1 a_{\mathrm{B}}$ e as linhas tracejadas a $\Delta_{\mathrm{d}}=1,0 a_{\mathrm{B}}$.

Para um poço isolado, a Eq. (4.1) assume a forma usual, ern unidades atôrnicas efetivas,

$$
B_{i}=\pi N_{i}
$$

onde $N_{i}$ é a densidade planar de portadores na lésima subbanda. Ajustando-se os parâmetros de entrada, $N_{\mathrm{d}} \in \Delta_{d}$, no modelo teórico até que as freqüencias preditas coincidissern com as obtidas experimentalmente, Koenraad deterninou ambos os parâmetros de entrada para uma amostra de GaAs com um único poço $\delta[44]$.

A Fig. 4.1 mostra a dependència de $B_{i}$ en funçâo da densidade planar de portadores para uma amostra corn um único poso $\delta$ tom $\Delta_{\mathrm{d}}=0.1 a_{\mathrm{B}}$ (linha cheia) e $\Delta_{\mathrm{d}}=1.0 a_{\mathrm{B}}$ (linha tracejada). Quando a largura do plano de impurezas é aumentada o poço $\delta$ toma-se mais largo; consequentemente, a diferença em energia entre os mínimos das subbandas decresce, resultando em uma transferència de elétrons da subbanda E1 para E2 e E3. Observa-se que freqüências das oscilaçoes $S d H$ caiculadas mostram unoa substancial sensibilidade à largura $\Delta_{d}$ : para uma variaçào de $\Delta_{A}$ de $0.1 a_{B}$ para $1.0 a_{e}$ para $N_{d}=2.0 a_{B}$ a mudançá nas frequêencias B1 calculadas é maior do que 0,7 u.a. Considerando que Bi pode ser detectada experimentalmente com uma precisăo de $\pm 0.2 \mathrm{~T}$ [44], e tomando a massa efetiva e a constante dielétrica do GaAs respectivamente como $m=0,0665 m_{0}$ e $t=12.6$. espera-se que a análise da oscilaçoes $\mathrm{SdH}$ forneçam valores de $\Delta_{\mathrm{d}}$ com uma incerteza de cerca de $\pm 5 \mathrm{~A}$. 
No caso do poço isolado. calculamos zumericamente a relaçäo entre $B i$ e $N_{d}$ para uma distribuiçăo gaussiana de impurezas. Verificamos que essa relação numérica pode ser muito bem aproximada pela simples relação empírica, em unidades atômitas efetivas,

$$
B i\left(\Lambda_{d}\right)=a i\left(\Delta_{d}\right)\left[N_{d}-b i\left(\Delta_{d}\right)\right]^{c i\left(\Delta_{d}\right)}
$$

onde ai, bi e ci säa polinômios de segundo grau dados pela Tabela 4.1

$$
\begin{array}{lrl}
\mathrm{a} 1(\mathrm{x})= & 2,53113-3,77296 \cdot 10^{-1} x+2,57351 \cdot 10^{-2} x^{2} \\
\mathrm{~b} 1(x)= & 0 & \\
\mathrm{c} 1(\mathrm{x})= & 8,60743 \cdot 10^{-1}-5,17878 \cdot 10^{-2} x+3,21415 \cdot 10^{-3} x^{2} \\
\mathrm{a} 2(x)= & 6,73469 \cdot 10^{-1}+3,11760 \cdot 10^{-1} x-6,37959 \cdot 10^{-2} x^{2} \\
\mathrm{~b} 2(x)= & 1,85360 \cdot 10^{-1}-5,20661 \cdot 10^{-2} x+5,52679 \cdot 10^{-3} x^{2} \\
\mathrm{c} 2(\mathrm{x})= & 1,08469-9,74060 \cdot 10^{-2} x+6,67422 \cdot 10^{-3} x^{2} \\
\mathrm{a} 3(x)= & 2,84099 \cdot 10^{-1}+2,04100 \cdot 10^{-2} x+3,94370 \cdot 10^{-2} x^{2} \\
\mathrm{~b} 3(x)= & 6,64766 \cdot 10^{-1}-3,34956 \cdot 10^{-1} x+7,90960 \cdot 10^{-2} x^{2} \\
\mathrm{c} 3(x)= & 1,13174+1,35237 \cdot 10^{-1} x-6,78180 \cdot 10^{-2} x^{2}
\end{array}
$$

Tabela 4.1: Polinômios utilizados para gerar a Fig. 4.1 attravés da relaçăo (4.2)

A Fig. 4.2 apresenta as freqüûncias de $\mathrm{SdH}$ calculadas em funçâo de $N_{\mathrm{d}}$ utilizando um valor fixo da largura do plano de dopantes, $\Delta_{\mathrm{d}}=0,2 a_{\mathrm{B}}$, para periodos de super-rede $d=1,5 a_{\mathrm{B}}$ e $d=2,0 \mathrm{c}_{\mathrm{B}}$. Na medida en que o periodo da super-rede torna-se mais curto, um maior valor de dopagem $N_{d}$ é necessário para popular as minibandas excitadas; por esta razâo, na medida em que $d$ diminui, as funçòes $B i\left(N_{\mathrm{a}}\right)$ para as minibandas excitadas intersectam o eixo horizontal en valores mais altos de $N_{\mathrm{d}}$. 


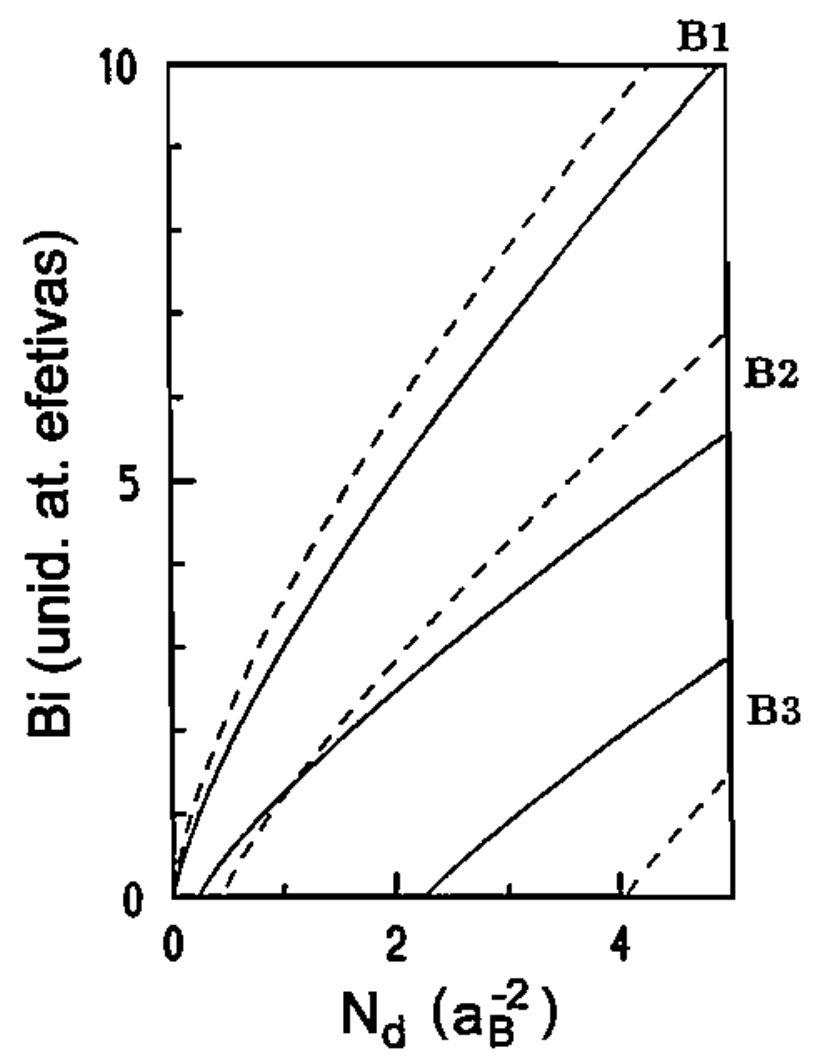

Figura 4.2: Freqüências das oscilações de $S d H(B i)$ calculadas para uma uma super-rede $d=2,0$ $a_{\mathrm{B}}$ (curva cheia) e $d=1,5 a_{\mathrm{B}}$ (curva tracejada). Os cálculos foram feitos tomando-se $\Delta_{\mathrm{d}}=0,2$ $a_{\mathrm{B}}$.

\subsection{Resultados experimentais e discussão}

Apresentamos nesta seção, como exemplo para o cálculo dos parâmetros característicos da amostra, três amostras $\delta$-dopadas de InP. Essas amostras foram sujeitas a campos magnéticos variando de 0 a 14 Teslas. a $4.2 \mathrm{~K}$, e foram efetuadas medidas de magnetoresistência com o campo magnético paralelo aos planos de doadores. Anteriormente à medição da magnetoresistência, as amostras foram iluminadas com um led vermelho de modo a que as impurezas residuais ionizadas fossem neutralizadas.

Uma dessas amostras (No 124) continha um único poço $\delta$. As outras duas amostras continham 20 poços $\delta$ (No 120 e 121). As amostras foram crescidas de tal modo que a densidade nominal de doadores na amostra No 121 fosse a mesma que a da amostra No 124 . e que a amostra No 120 possuísse uma dopagem menor. 

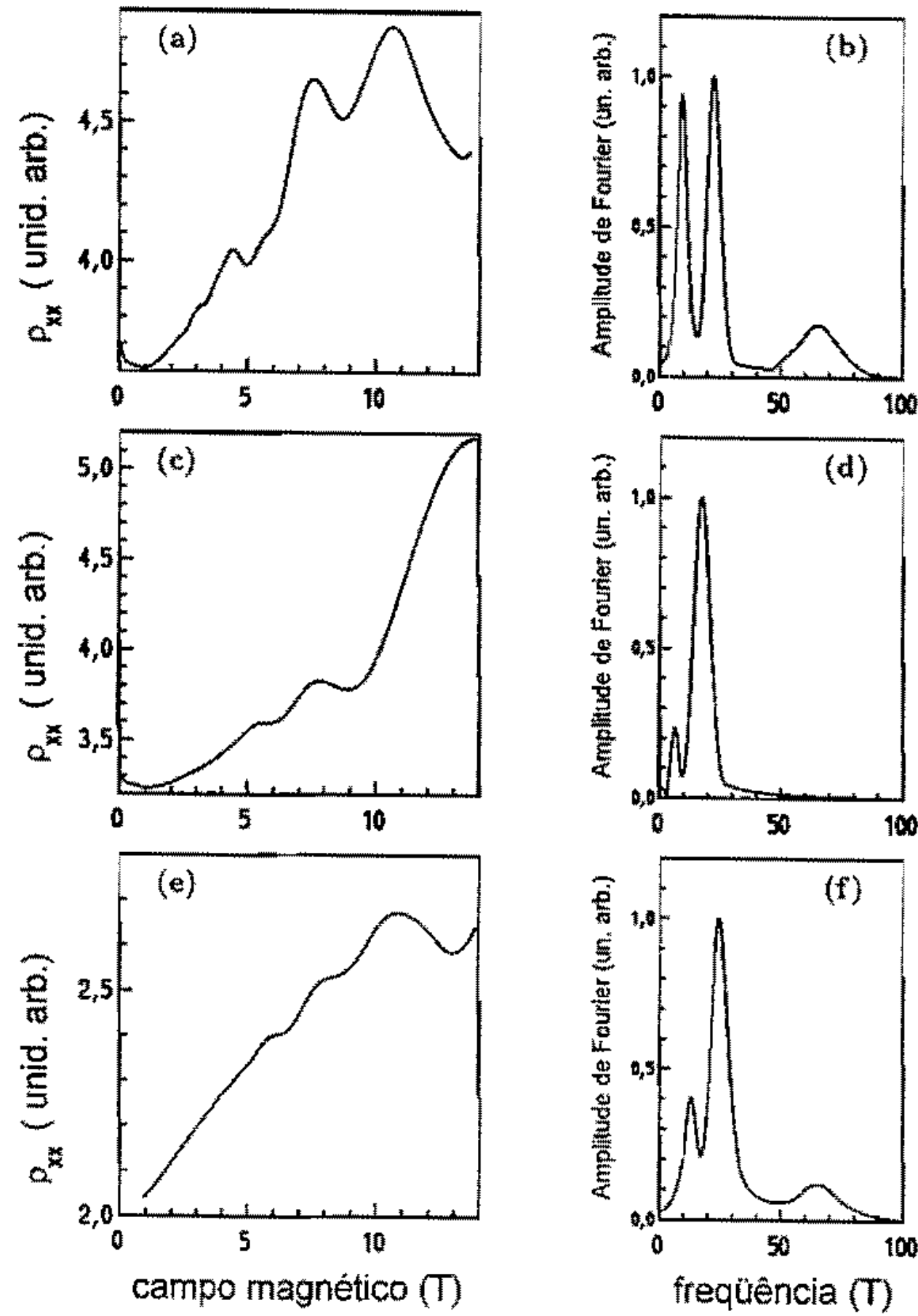

Figura 4.3: Espectro de SdH (a) e sua transformada de Fourier de campo inverso (b) para a amostra No. 124: igualmente, (c) e (d) para a amostra No. 120 ; (e) e (f) para a amostra No. 121 . 
A Figura 4.3(a) mostra o espectro de Shubnikov-de Haas para a amostra No 124 e a Figura 4.3(b) mostra a transformada de Fourier de (a) em campo inverso. Os picos vistos em 9.5 . 22,6 e em $65,6 \mathrm{~T}$ correspondem respectivamente à ocupaçào das subbandas E3, E2 e E1. Como mostrado por Skuras at al [50]. a largura a meia altura de um pico de Fourier pode ser associado à mobilidade quântica dos portadores na subbanda correspondente: o decréscino gradativo na largura quando observa-se a seqüência a partir cle E3 até El reflete uma mobilidade crescente dos portadores, em concordância com observaçôes prévias de alguns autores [11, 44]. Esse efeito é responsável por uma pequena incerteza nas posiçôes medidas para os picos na transformada de Fourier associados às minibandas matis excitadas, conforme pode ser visto na Tabela 4.2.

\begin{tabular}{|c|c|c|c|c|c|c|c|c|c|c|}
\hline \multirow[b]{2}{*}{ Amoutra } & \multirow[b]{2}{*}{ Camadas } & \multirow[b]{2}{*}{ d } & \multicolumn{3}{|c|}{ Mosididos } & \multicolumn{3}{|c|}{ Calculados } & \multirow[b]{2}{*}{ 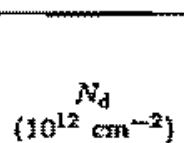 } & \multirow[b]{2}{*}{$\Delta_{4}$} \\
\hline & & & $\begin{array}{l}\mathrm{B1} \\
\text { (T) }\end{array}$ & $\begin{array}{l}\text { B2 } \\
(T)\end{array}$ & $\begin{array}{l}\mathrm{B3} \\
\mathrm{CT}\end{array}$ & $\begin{array}{l}B 1 \\
(T)\end{array}$ & $\begin{array}{l}\mathrm{B} 2 \\
{[\mathrm{~T})}\end{array}$ & $\begin{array}{l}\mathrm{Sa} \\
(\mathrm{T})\end{array}$ & & \\
\hline 124 & 1 & $-m$ & $65,6 \pm 1,9$ & $22,5=0,5$ & $6, \pm 0,1$ & 65,2 & $255_{1}^{4}$ & 9,3 & $4,9 \pi \pm 0,05$ & $30 \pm 6$ \\
\hline 120 & 20 & 270 & $19,6 \pm 1,1$ & $8,1 \pm 0,3$ & - & 10,6 & 8,1 & - & $1,14 \pm 0,06$ & $33 \pm 15$ \\
\hline 121 & 23 & 400 & $04 \pm 19$ & $23,6 \pm 1,2$ & 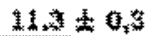 & 64,4 & 25,7 & 11,0 & $4, x^{3} \pm 0,01$ & $39 \pm 7$ \\
\hline
\end{tabular}

Tabela 4.2: Frequếncias das oscilą̧öes na magnetoresistência de estruturas $\delta$-dopadas In P:Si. Os valores experimentais säo médias experimentajs de cinco medidas efetuadas a $4,2 \mathrm{~K}$. Os valores de $N_{\mathrm{d}}$ e $\Delta_{\mathrm{d}}$ e suas incertezas foram estimados de cada valor medido para $B$ i

Nas super-redes, entretanto, os elétrons nas minibandas mais excitadas estão deslocalizados podendo ocorrer uma maior sobreposiçăo das funçöes de onda com os planos de impureza adjacentes. Isso pode implicar numa diminuição da mobilidade da eventual minibanda cornparativamente ao caso do poco isolado [51, 52]. Nos casos analisados aqui, os picos de Fourier são mais alargados comparativamente ao poço isolado e conseqüentemente a incerteza relativa comparada para as mixibandas é maior, como pode ser visto na tabela 4.2 .

De modo a comparar os resultados experimentais às prediçōes teóricas, a massa efetiva $e$ a constante dielétrica para o InP foram tomados da literatura como sendo $m=0,08 m_{0}[53]$ e $\varepsilon=11,8[54]$, respectivamente. Utilizando a densidade de portadores por periodo da super-rede $N_{\mathrm{d}}$ e a dispersão característica dos dopantes ao redor do plano de dopagem $\Delta_{\mathrm{d}}$ como parâmetros de entrada, as frequiencias teóricas previstas para o espectro de Shubnikov-de Haas Bi foram calculadas numericamente. Os parámetros de entrada $\left(N_{\mathrm{d}} \mathrm{e} \Delta_{\mathrm{d}}\right)$ nos cálculos numéricos foram variadas até que as freqüềncias de $\mathrm{SdH}$ calculadas concordassem com as frequéencias observadas experimentalmente. Os valores para $N_{\mathrm{d}}$ e $\Delta_{\mathrm{d}}$ para cada amostra foram tomados como sendo aqueles que forneciam a melhor concordância, no sentido de mínimos quadrados. entre as freqüências experimentais e teóricas. Ou seja, dada a funç̧ão

$$
X^{z}=\sum_{i}\left(\frac{B i \mathrm{EXP}-B i_{\mathrm{F}}^{\mathrm{EOO}}}{\Delta B i \mathrm{EP}}\right)^{z}
$$

os valores de $N_{d}$ e $\Delta_{d}$ ideais para descreverem o espectro energético de uma certa estrutura sāo aqueles que minimizam $\mathcal{X}^{2}$.

As incertezas nos valores de $N_{d}$ e $\Delta_{d}$ foram estimadas a partir das incertezas experimentais para os valores $\mathrm{Bj}$. A Tabela 4.2 resume os resultados da experiência e dos cálculos para as amostras em questäo: uma comparaçâo entre as trequêñcias de oscilaçăo de SdH medidas e calculadas, eos melhores valores ajustados para $N_{d} \in \Delta_{l}$. 
A espessura característica para os planos $\delta$-dopados estimada da analise do espectro SdH é consistente para todas as amostras. $O$ valor ligeiramente maior de $\delta$ e a maior incerteza obtida foram para amostra No 120, se comparados amostras No 121 e 1 io 124 , e provavelmente devido a que, para essa amostra, apenas dois picos são observados nà transformada de Fourier das oscilaçôes do $5 \mathrm{dH}$. Isso torna o procedimento de ajuste para a extração de $N_{d}$ e $\lambda_{\mathrm{d}}$ menos confável se comparado ao procedimento para as amostras No 121 e No 124.

\subsection{Medidas CV}

A Figura 4.4(a) mostra o perfil CV para a amostras No 121 obtido pela medida CV com corrosāo. Do perfll CV, o período da super-rede fó determinado como sendo $400 \pm 15 \AA$.
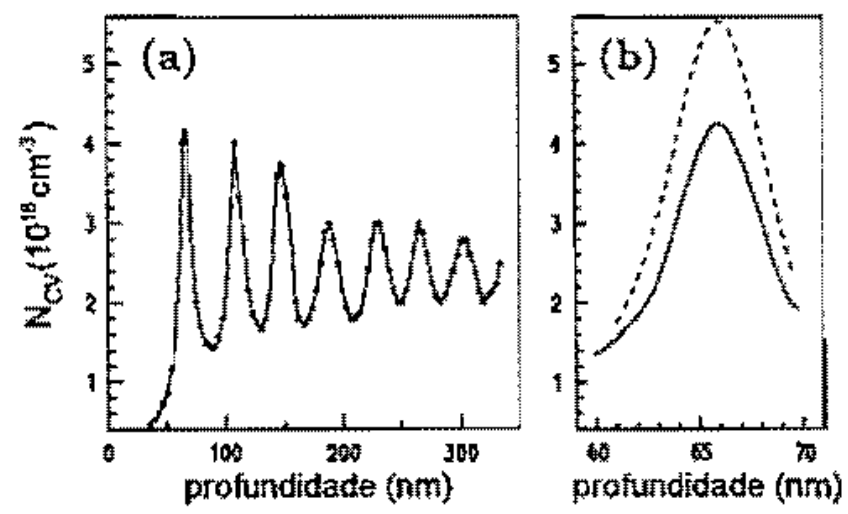

Figura 4.4: Espectro CV para a mostra No. 121: (a) é o resultado obtido alternando corrosäo da amostra e a tomada de dados $(V$. (b) é o espectro $C V$, sem a corrosäo da amostra, $O$ qual permite visualizar a distribuiça de carga ao redor do primeiro plano de dopante: a linha tracejada $e$ resultado do cálculo teórico utilizando os valores de $N_{a}$ e $\Delta_{\mathrm{d}}$ obtidos do espectro de $\mathrm{SdH}$

$O$ espectro CV mostrado pela limha cheia fo obtido de um varrimento $\mathrm{CV}$ da amostra qual fó corroida anteriormente to começo da medida. A curva tracejada na Figura 4.4 é o espactro CV teórico para a amostra No. 121, gerado com os parametros dados na Tabela 4.2. utilizando-se a relaçầo

$$
N_{C V}=4 \pi C^{3} \frac{d \nu}{d C}
$$

A discrepancia entre os valores absolutos térico experimental de $N$ cu como pode ser observado na Fig. $4.4(b)$ tem como origem provável o fato the que as medidas (CV serem realizadas à temperatura ambiente, enquanto que as medidas de SaH foram realizadas a 4.2 İ. e também que $N_{d}$ possa exibir alguma dependencía com a tempetatura. Essa discrepancia pode ter origem também no fato de que o espectro CV ebtido a partit de uma corrosảo prévia da superfície: essa técnica de corrosão introduz uma incerteza na area do contato Schottky entre o semicondutor e o eletrólito líquido. Como conseqüencia da incerteza da área do contato 
Schottky, uma incerteza experimental no valor de $N_{\mathrm{CV}}$ é introduzida[18]. Apesar disso, a largura a meia altura do espectro CV näo deve ser dependente dessas fontes de erro, e mesmo pode fornecer uma estimativa independente da espessura do plano de doadores, que por sua vez pode ser utilizada para avaliar a precisão de $\Delta_{d}$ extraído a partir da análise do espectro de $S d H$ da amostra.

A largura a meia altura do pico $\mathrm{CV}$ da Fig. $4.4(\mathrm{~b})$ e de $70 \mathrm{~A}$; a largura do espectro teónico, mostrado na Fig. 4.4 pela linha tracejada, reproduz esse resultado. Portanto, a largura característica da camada de doadores estimada do espectro SdH está em excelente acordo com aquela obtita a partir do espectro $\mathrm{CV}$.

\subsection{Conclusões}

Foi mostrado que a experiència de $\$ \mathrm{dH}$ pode servir para o propósito de determinar os parânetros característicos de uma super-rede: a distribuiça de portadores pelas vátas minibandas eletronicas, a espessura da camada dopada e o período da super-rede. Neste Capítulo, a análise do espectro de SdH foi restringida à estimativa da densidade de portadores $N_{d}$ e à estimativa da espessura da camada dopada, $\Delta_{\mathfrak{d}}$, sendo o periodo da super-rede o valor obtido a partir das medidas CV. $\mathrm{O}$ valor de $\Delta_{\mathrm{d}}$ obtido da auálise do espectro de $\mathrm{SAH}$ está ern bom acordo com o valor predito pela técnica $\mathrm{CV}$. 


\section{Capítulo 5}

\section{Teoria para a blindagem e mobilidades eletrônicas em sistemas $2 \mathrm{D}$ e quasi-3D}

Admita-se, inicialmente, que uma partícula positivamente carregada é posta em um gás de elétrons: ela atrairá os elétrons para a sua vizinhança, criando assim una região de excesso de carga negativa em seu redor, o qual irá diminuir a intensidade do campo da carga positiva em refiöes mais afastadas. A essa diminuição da intensidade do campo por acúrnulo de cargas chams-se blindagern eletrostática.

Qutando o potencial em sistemas semicondutores degenerados é bi-dimensional, ocorre uma distribuição da populaçäo eletronica, liberada pelas impurezas, em minibandas ou subbandas. Devido ao caráter quantizante do potencial, é esperado que a posição média das funçōes de onda correspondentes às populaçóes distintas de portadores varie em relaçäo aos centros espalhadores. Por outro lado, a própria atenuação do potencial coulombiano dos centros espalhadores por populaços mais localizadas em suas proximidades (menos energéticas) reflete-se em populaçöes menos localizadas(mais energéticas).

A observaçăo deste tipo de fenomeno é relativamente recente em semicondutores e foi praticamente possível de ser abservado a partir do advento das técnicas de dopagem planar. Até então, em sistemas com dopagem uniforme, somente era esperado que o espalhamento de um portador fosse dependente de sua energia e nào da sua localização espacial, já que as funçoes de onda nesses sistemas tri-dimensionais são totalmente deslocalizadas na rede cristalina.

$O$ fenomeno de blindagem eletrostática em sistemas tri-dimensionais foi bastante estudado e hoje faz parte da maioxia dos livros textos de Estado Solido (por exemplo, o livro de Ashcroft e Mermim[05]). Fisse assunto é geralmente tratado a partir de um enfocue semi-clássico, como a aproximaçăo de Thomas-Fermi. ou a partir de um enfoque quântico, como a aproximaçăo de Lindhatd ou RPA (Rantom-phas aprotimation).

En sistemas bi-dimensionais. comparativamente aos tri-dimensionais. tanto a literatura como a quantidade de dados experimentais acumulados relativamente esassa, sendo que as

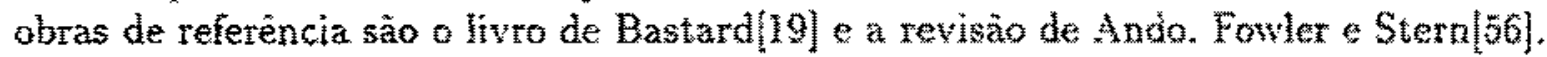

O objetivo do presente capitulo é apresentar uma sintese das duas teorias citadas. Tanto a teoria de Thomas-Fermi quanto a teoria RPA conduzem a formatos de blindagem eletrostática bastante diferentes. Os resultados obtidos para ambas as teorias serâto entäo comparados nos capítulos posteriores. 


\subsection{Teoria RPA para a mobilidade de sistemas $2 \mathrm{D}$}

O formato to potencjal blindado devido a uma impureza. ToT ( 2 ), podo ser scparado em duas componentes: a primeira, que se chama de potencial externo a que é o potencial devido apenas à carga positiva isolada, $\zeta^{\mathrm{EXT}}(r)$. e a segunda que chama-se de potencial induzido. $p^{\mathrm{ND}}(r)$, tal que

$$
\psi^{\mathrm{TOT}}(r)=\varphi^{\mathrm{EXT}}(r)+\psi^{\mathrm{IND}}(r)
$$

O potencial externo satisfaz a equaçăo de Poisson

$$
-\nabla^{2} \psi^{E X T}(r)=\frac{4 \pi *}{\epsilon} \rho^{\operatorname{EXT}}(\tau)
$$

onde $p^{\mathrm{EXT}}(\boldsymbol{r})$ a densidade de carga positiva. O potencial total, $\varphi^{\mathrm{Tr}}(\boldsymbol{r})$, produzido pela carga positiva e cargas negativas, analogamente, satisfaz

$$
-\nabla^{2} \rho^{T O T}(r)=\frac{4 \pi \kappa}{\epsilon} p^{\mathrm{TOT}}(r)
$$

$\operatorname{com}$

$$
\rho^{\mathrm{TOT}}(r)=\rho^{\mathrm{EXT}}(r)+p^{\mathrm{EDO}}(r)
$$

sendo $\rho^{\text {Tor }}(r)$ a carga total e $p^{\mathrm{IND}}(r)$ a carga induzida.

$O$ potencial blindado TTT $^{\text {TOT }}(\tau)$ pode ser obtido através da soluça da hamiltoniana total

$$
\left[-\frac{\hbar^{2}}{2 m^{*}} \nabla^{2}+V_{s c}(r)+V^{\mathrm{TOT}}(r)\right] \Xi_{\xi}^{\mathrm{TOT}}(\boldsymbol{r})=E_{\xi}^{\mathrm{TOT}} \equiv_{\xi}^{\mathrm{TOT}}(\boldsymbol{r})
$$

onde $V^{\text {ToT }}(r)=-e c^{T o t}(r)$ e $V_{\text {se }}^{*}(r)$ é o potencial autoconsistente bi-dimensional no qual a impureza está inersa. $O$ potencial autoconsistente $V_{\text {se }}(r)$ possui como hamiltoniana

$$
\left[-\frac{\hbar^{2}}{2 m^{*}} \Gamma^{2}+1_{s c}(r)\right] \equiv_{f}(r)=E_{\xi} \Xi_{\xi}(r)
$$

As autofunçoes $\Xi_{\xi}^{\text {TOT }}(r)$, em termos das autofuncỏes $\Xi_{\xi}(r)$, soluçoes da hamiltoniana do potencial autoconsistente. em serre perturbativa alé primeira ordem. serão dadas por

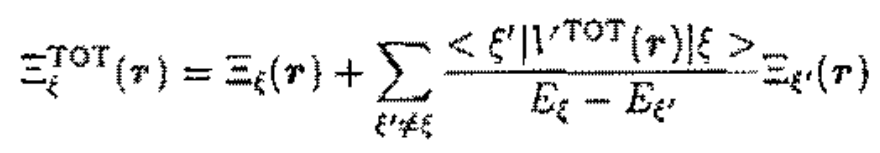

onde $\Xi_{\ell}(r)=\mid \xi>$

A carga induzida será dada pela diferença entre a carga total a carga externa

$$
f^{\mathrm{ND}}(r)=-e \sum_{\xi}\left(\left|\Xi_{\xi}^{\mathrm{ToT}}(r)\right|^{2}-\left|E_{\xi}(r)\right|^{2}\right) f\left(E_{\xi}\right)
$$


Substituindo $=$ ToT ( $)$ pelo resultado da Ea. (5.2), e ignorando os termos de ordem superior ou igual a dois en $V$ Tot $(r)$, obtém-se

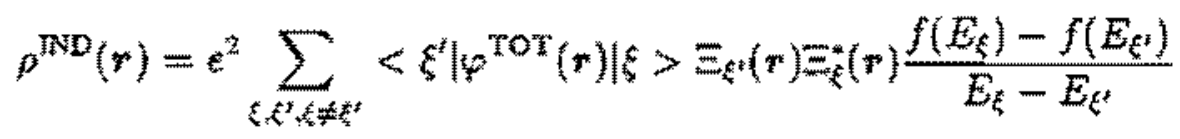

A partit da relaçäo eletrostática entre o potencial induzido e a carga induzida

$$
\varphi^{\mathrm{ND}}(r)=\mathrm{r}^{3} r^{*} \frac{p^{\mathrm{IND}}\left(r^{\prime}\right)}{\varepsilon\left|r-r^{\prime}\right|}
$$

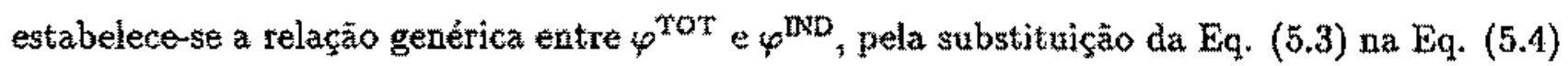

$$
\varphi^{\mathrm{TND}}(\boldsymbol{r})=\kappa \epsilon^{2} \sum_{\xi \xi^{\prime}, \xi \neq \xi^{\prime}}<\xi^{\prime}\left|\varphi^{\mathrm{TOT}}(\boldsymbol{r})\right| \xi>\frac{f\left(E_{\xi}\right)-f\left(E_{\xi^{\prime}}\right)}{E_{\xi}-E_{\xi^{\prime}}} \int \mathrm{d}^{3} \boldsymbol{r}^{\prime} \frac{\Xi_{\xi^{\prime}}(\boldsymbol{r}) \Xi_{\xi}^{*}(\boldsymbol{r})}{\epsilon\left|\boldsymbol{r}-\boldsymbol{r}^{\prime}\right|}
$$

\subsubsection{Blindagem eletrostática em um sistema 2D}

Na introdução deste capítulo calculoumse genericamente a relação entre o potencial induzido e o potencial total. Nesta seçào aplicaremos os resultados obtidos para o caso particular de um sistema bi-dimendional. Num sistema $2 \mathrm{D}$, as funçỏes de onda, soluções de uma hamiltoniana do tipo (5.1), podem ser escritas como

$$
|\xi>=| n k_{\perp} \sigma>=\frac{e^{i k_{\perp} \cdot Q}}{\sqrt{5}} \chi_{n}(z)
$$

e, a relaçäo de dispersāo, de energia é dada por

$$
E_{\xi}=E_{n}\left(k_{1}\right)=E_{n}+\frac{\hbar^{2} k_{\perp}^{2}}{2 m}
$$

Substituindo estas relaçōes na Eq. (5.5), obtém-se para o potericial induzido a expressão

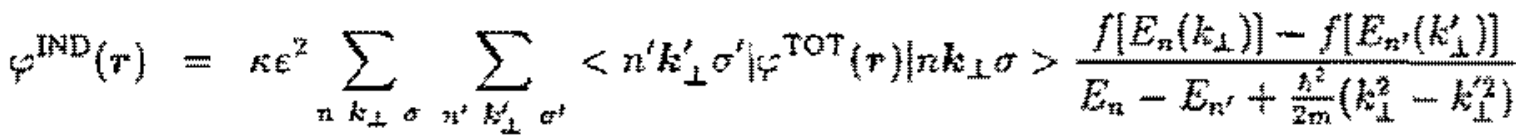

$$
\begin{aligned}
& x \int \frac{d^{3} r^{*}}{\left|r-r^{*}\right|} \frac{e^{i k_{1} \cdot e^{2}}}{\sqrt{S}} x_{n}\left(z^{z}\right) \frac{\mathrm{e}^{-i k_{1}^{*} \cdot Q^{*}}}{\sqrt{S}} x_{n}^{*}\left(z^{z}\right)
\end{aligned}
$$

Re-arranjando a expressâo, levando em conta que $\left\langle\sigma \mid \sigma^{*}\right\rangle=\delta_{*} \sigma^{*}$ tem-se que

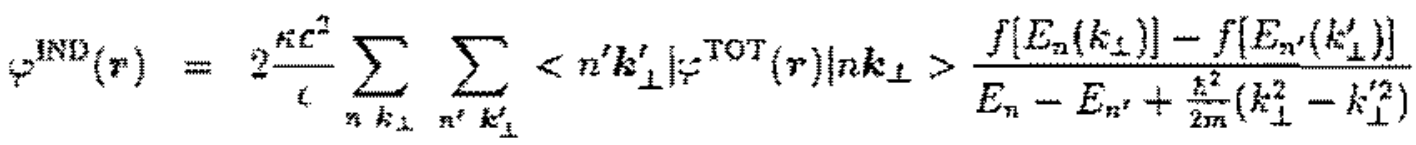

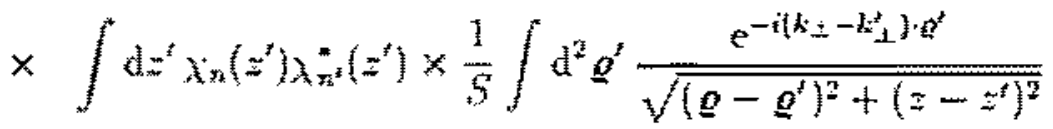

Introduzindo a variảel $g=k_{\perp}-k_{\perp}^{z}$ juntamente com a notação

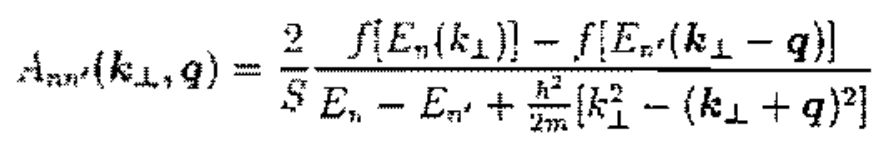


e com o resultado

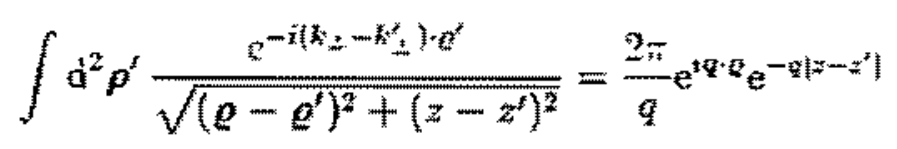

a. E. $(5, \pi)$ reduz-se a

$$
\begin{aligned}
& \varphi^{\mathrm{IND}}(r)=\frac{2 \kappa e^{2}}{\varepsilon S} \sum_{n k_{\perp}} \sum_{n^{\prime} q}\left\langle n^{\prime} k_{\perp}+q\left|\varphi^{\mathrm{TOT}}(r)\right| n k_{\perp}>A_{n n^{\prime}}\left(k_{\perp}, q\right) e^{\mathrm{T} q{ }^{\prime} \ell} \times\right.
\end{aligned}
$$

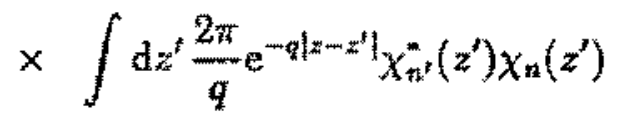

O elemento de matriz

$$
{ }_{\mathrm{nu}^{\prime}}^{\mathrm{TO}}=\left\langle n^{\prime} k_{2}+q\left|\varphi^{\mathrm{TOT}}(r)\right| n k_{\perp}\right\rangle
$$

pode ser escrito como

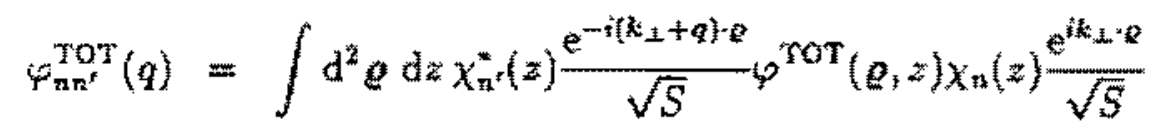

$$
\begin{aligned}
& =\int \mathrm{d} z \chi_{n^{n}}^{*}(z) \chi_{n}(z) \varphi^{\mathrm{TOT}}(q, z)
\end{aligned}
$$

onde

$$
\varphi^{\text {Tot }}(q, z)=\frac{1}{S} \int \mathrm{d}^{2} g \mathrm{e}^{-i q \cdot \varphi_{\varphi} \operatorname{ToT}^{\mathrm{T}}\left(\rho_{1} z\right)}
$$

Substituindo o resultado da equaça Eq. (5.11) na Eq. (5.9), obtém-se que

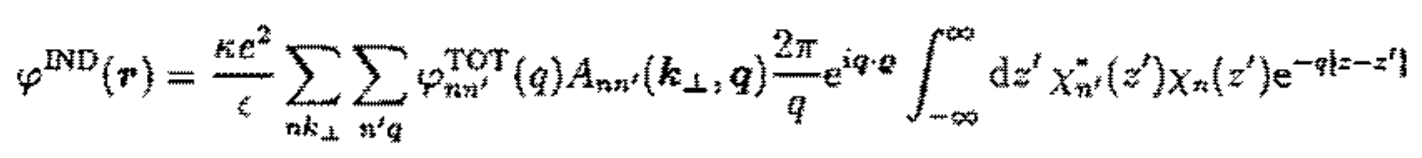

ou

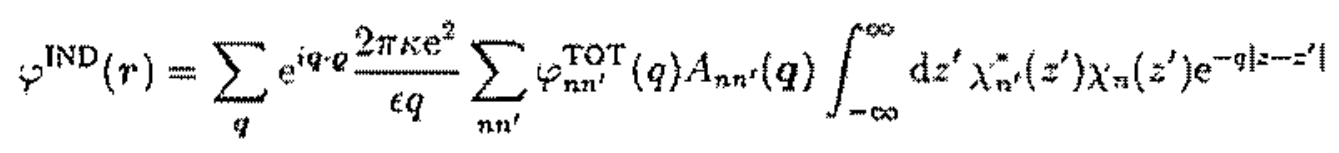

onde

$$
A_{n n^{\prime}}(q)=\sum_{k_{\perp}} A_{n n^{\prime}}\left(k_{\perp}, q\right)
$$

Introduzindo aqui a transformada de Fourier bi-dimensional ke $\gamma^{\mathrm{NND}} / \mathrm{r}$ )

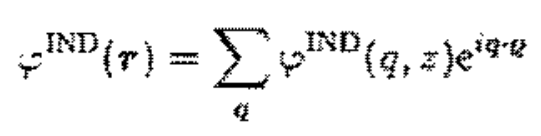


e comparando esta relaçäo com a Eq. (5.12) obtemos

$$
\varphi^{\mathrm{HND}}(q, z)=\frac{2 \pi k \mathrm{E}^{2}}{E q} \sum_{n n^{\prime}} \varphi_{n n^{\prime}}^{\mathrm{TOT}}(q) A_{n, n^{\prime}}(q) \int_{-\infty}^{\infty} \mathrm{d} z^{\prime} X_{n^{\prime}}^{\prime}\left(z^{\prime}\right) \chi_{n}\left(z^{\prime}\right) \mathrm{e}^{-q\left|z-z^{\prime}\right|}
$$

Definindo-se $\varphi_{\mathrm{mm}}^{\mathrm{IND}}(q)$ por

$$
\varphi_{m, m^{2}}^{\mathrm{IND}}(q)=\int_{-\infty}^{\infty} \mathrm{d} z X_{m}^{*}(z) X_{m}(z) \varphi^{\mathrm{IND}}(q, z)
$$

e introduzindo o fator de forma coulombtano $T_{\mathrm{mm}^{7}, \mathrm{an}^{1}}(q)$ como

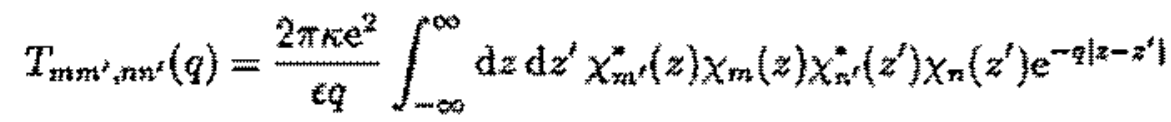

obtém-se

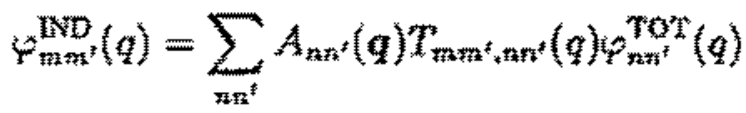

\subsubsection{O tensor dielétrico $\epsilon_{m n^{2}, n m^{3}}(q)$}

Tendo em conta que

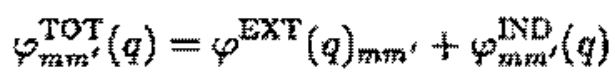

é conveniente introduzir-se a noção e definiçăo do tensor dielétrico $\varepsilon_{\mathrm{mm}^{\prime} \mathrm{n}^{\prime}, \mathrm{mn}^{\prime}}(q)$,

$$
F_{m m^{\prime}}^{\operatorname{ExT}}(q)=\sum_{n n^{\prime}} \epsilon_{m n m_{*}^{*} n n^{\prime}}(q) \varphi_{n n^{\prime}}^{\operatorname{ToT}}(q)
$$

onde $\epsilon_{m_{m} m^{t}, x n^{t}}(q)$ é dado por

$$
\begin{aligned}
\varepsilon_{m m^{\prime}, n n^{\prime}}(q) & =\delta_{n n^{\prime}, m m^{\prime}}-A_{n n^{\prime}}(q) T_{n m^{\prime}, n n^{r}}(q) \\
\delta_{n n^{\prime}, m m^{2}} & =\delta_{n m b} \delta_{n^{\prime} r a^{t}}
\end{aligned}
$$

onde $\delta_{\alpha \beta}$ é o símbolo de lironecker.

\subsubsection{Simetrias e propriedades de $T_{n n^{t} \cdot m m^{t}}$}

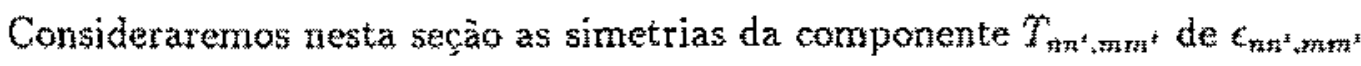

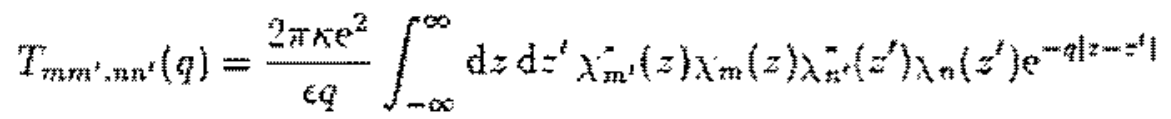

Por inspeçà $T$ possui as simetrias

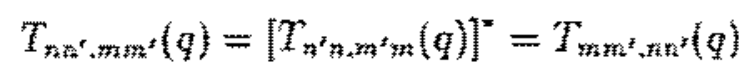


Para funçós de onda reais, tem-se que $T_{n H_{*}^{*}+m^{\prime}}(q)$ é invariante por trocas entre seus indices. Adicionalmente para funços de onda reais com paridade em relaça a um ponto do eixo $z$

$$
T_{\pi n^{2}+m+x^{2}}(\varphi)=0
$$

para $n+n^{\prime}+m+m^{\prime}=$ número impar.

Estas simetrias e propriedades são importantes levando-se em conta o custo computacional de um cálculo típico para uma estrutura. Em particular, o custo computacional na avaliação de $T$ é significativo já que säo calculadas integrais duplas em função do módulo do vetor de onda $q$.

\subsubsection{O potencial externo para $\mathrm{N}$ impurezas}

Nos cảlculos efetuados até entäo pressupos-se que o espalhamento era efetuado por um centro espalhador com carga unitária. Esse resultado pode ser generalizado se considerarmos

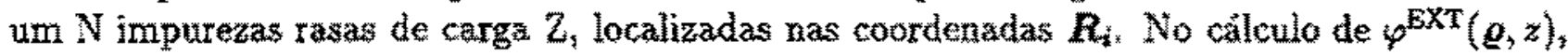
ou seja, na ausencia de blindagem eletrônica, consideremos ntầ sse conjunto de impurezas rasas. $\log 0$

$$
p^{\mathrm{EXT}}(r)=\sum_{i=1}^{N} \frac{k Z e}{\left(\sqrt{\left(\varrho-\underline{a}_{i}\right)^{2}+\left(z-z_{i}\right)^{2}}\right.}
$$

que, utilizando o resultado da Eq. (5.8), transforma-se em

$$
\varphi^{\operatorname{EXT}}(q, z)=\frac{2 \pi \kappa Z e}{\epsilon q S} \sum_{i} \mathrm{e}^{-i q \cdot Q_{i}} \mathrm{e}^{-q] z-z_{i} \mid}
$$

\subsubsection{Média configuracional}

Um resultado que será utilizado quando do cálculo das mobilidades é a grandeza

$$
\left.\operatorname{lot}_{n \rightarrow}^{\operatorname{TOT}}(a)\right|^{2}
$$

onde

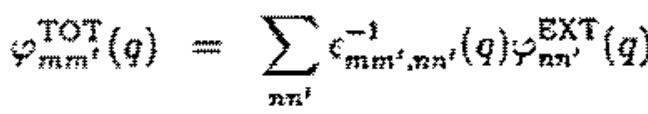

$$
\begin{aligned}
& v_{n+3}^{\operatorname{EXT}}(q)=\psi_{n n^{i}}^{\operatorname{EXT}}\left(q R_{1} \cdots R_{N}\right)
\end{aligned}
$$

e é determinado a partir da locajizaçäo espacial especifica de $N$ impurezas, cada uma con coordenadas $R_{i}=(\varrho z)_{i}$.

Pode-se proceder ao cálculo de $\left|i_{n n^{\prime}}^{\mathrm{TO}}(q)\right|^{2}$ utilizando-se o fato de que as impurezas estẫo aleatoriamente dispostas no cristal hospedeiro segundo uma certa distribuiç̧⿸厃㔾 do probabilidades. Em particular. seja $\boldsymbol{P}\left(\boldsymbol{R}_{1} \cdots \boldsymbol{R}_{N}\right) \mathrm{d}^{3} \boldsymbol{R}_{1} \cdots \mathrm{d}^{3} \boldsymbol{R}_{N}$ a probabilidade da impureza 1 ser encontrada no volume $\mathrm{d}^{3} \boldsymbol{R}_{1}$, da impureza 2 no volume $\mathrm{d}^{3} \boldsymbol{R}_{2}$ e assim por diante. 0 integral de uma grandeza $\mathcal{S}\left(\boldsymbol{R}_{1} \cdots \boldsymbol{R}_{N}\right)$ pode ser calculado "estatisticamente" por

$$
\left.<S\left(\boldsymbol{R}_{1} \cdots \boldsymbol{R}_{N}\right)\right\rangle_{\text {med }}=\overline{S\left(\boldsymbol{R}_{1} \cdots \boldsymbol{n}_{N}\right)}=\int \mathrm{d}^{3} \boldsymbol{R}_{1} \cdots \mathrm{d}^{3} \boldsymbol{R}_{N} P\left(\boldsymbol{R}_{1} \cdots \boldsymbol{R}_{N}\right) S\left(\boldsymbol{R}_{2} \cdots \boldsymbol{R}_{N}\right)
$$


onde $\langle\mathcal{S}\rangle_{\text {med }}$ é a médía estatística ou configuractonal de $S\left(\boldsymbol{R}_{1} \cdots \boldsymbol{R}_{N}\right)$. Para uma densidade de impurezas suficientemente baixw, de tal modo que possamos corsiderar que a probabilidade de uma impureza ser colocada num determinado sítio $i$ independe da connguraçăo das outras impurezas (impurezas näo correlacionadas),

$$
P\left(\boldsymbol{R}_{1} \ldots \boldsymbol{R}_{N}\right)=P\left(\boldsymbol{R}_{1}\right) \cdots P\left(\boldsymbol{R}_{N}\right)
$$

A condição de normalização para uma dopagem do tipo bi-dimensional é

$$
\begin{aligned}
P\left(\boldsymbol{R}_{1} \cdots \boldsymbol{R}_{N}\right) & =\frac{1}{S} g(z) \\
\int \mathrm{d} z g(z) & =1
\end{aligned}
$$

onde $S$ é a áré da base do cristal.

Para que o cálculo de $\left|\varphi_{n=7}^{\text {ToT }}(q)\right|^{2}$ seja efetuado de forma independente das coordenadas espaciais das Impurezas, essa grandeza será substituida por sua média estatística. Essa aproximaçäo é justificada em sistemas con uma concentraçäo grande de impurezas[57].

Utilizando-se os resultados desta seção. chega-se a

$$
\begin{aligned}
& \overline{\left|\gamma_{m m^{2}}^{\text {TOT }}(q)\right|^{2}}=\overline{\left|\sum_{n n^{2}} \varepsilon_{m m^{2}, n n^{\prime}}^{-1}(q) \psi_{n n^{2}}^{\mathrm{EXT}}(q)\right|^{2}}
\end{aligned}
$$

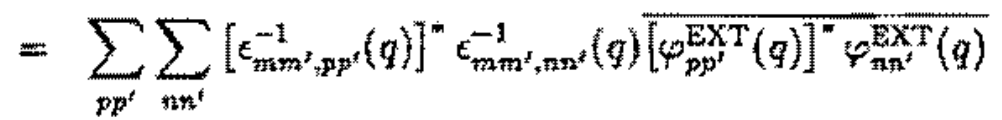

Fazendo

$$
S\left(\boldsymbol{R}_{1} \cdots \boldsymbol{R}_{N}\right)=\left[\varphi_{p p^{\prime}}^{\mathrm{EXT}}(q)\right]^{*} \psi_{n w^{i}}^{\mathrm{EXT}}(q)
$$

obtéñ-se a média estatística para o potencial total

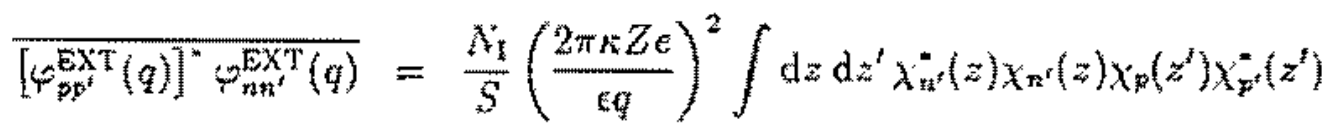

$$
\begin{aligned}
& \times F_{d}\left(q, z, z^{*}\right)
\end{aligned}
$$

onde $F_{d}\left(q_{2}, z^{\prime}\right)$ é o fator de forma da listribuiça de imputezas definido como

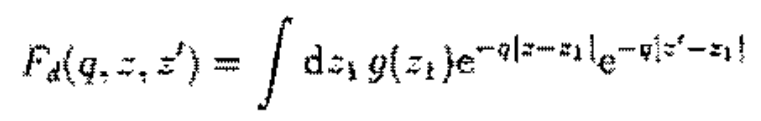

\subsubsection{O fator de forma $F_{\mathrm{d}}\left(z, z^{\prime}, q\right)$}

Nesta seçäo, alguns resultados para distribuiçòes de impurezas possiveis em um cristal hospedeiro serāo considerados. Em particular. estando os átomos doadores localizados em um plano de espessura nula no cristal. distribuidos segundo uma distribuição gaussiana e segundo uma distribuigäo uniforme num intervalo finito. 


\section{Propriedades de simetria}

Como referido na seção anterior émportante considerarmos todas as possiveis propriedades de simetria das grandezas envolvidas no cálculo numérico das mobilidades devido ao alto custo computacional deste processo. No caso do fator de forma $F_{\mathrm{d}}\left(q, z, z^{t}\right)$, definido como

$$
F_{d}\left(q, z, z^{\prime}\right)=\int_{-\infty}^{+\infty} d z_{1} g\left(z_{1}\right) e^{-q\left|x-z_{1}\right|} e^{-g\left|z^{\prime}-z_{1}\right|}
$$

tem-se, como propriedade geral

$$
F_{\mathrm{d}}\left(q, z, z^{\prime}\right)=F_{\mathrm{d}}\left(q, z^{\prime}, z\right)
$$

e, em particulat para funçöes de distribuiçăo $g d(z)$ pares, como será considerado posteriormente,

$$
F_{\mathrm{d}}\left(q,-z,-z^{\prime}\right)=F_{\mathrm{d}}\left(q, z, z^{\prime}\right)
$$

\section{Distribuiçấo \& ideal}

Num semicondutor $\delta$-dopado ideal, os átomos doadores estaräo localizados num plano no cristal hospedeiro. Neste sistema idealizado, a distribuiçäo unitária das impurezas é dada por

$$
g_{d}(z)=\delta(z)
$$

que conduz a um fator de forma de impureza

$$
F_{d}\left(a, z, z^{\prime}\right)=\mathrm{e}^{-Q\left\{\left[z|-| z^{2} \mid\right\}\right.}
$$

\section{Distribuição gaussiana}

Entretanto, em sistemas reais, o perfll de dopagem será de espessura nấ nula devido efeitos de difusäo térmica das impurezas quando do crescimento. Una abordagem realistica é distribuir as impurezas em tomo do plano $z=0$ por uma funçäo gaussiana de largura a meia altura (FWHM) $\Delta_{d}=2 \beta \sqrt{\ln 2}$

$$
g_{\mathrm{d}}(z)=\frac{1}{\sqrt{\pi \beta^{2}}} \mathrm{e}^{-\vec{z}^{2} / \beta^{2}}
$$

onde $\beta=2 \sqrt{D T}$. sendo $D$ o cofficiente e $\tau$ otempo de difusạolo $]$. Para essa distribuiçăo de doadores: o fator de forma de impureza fica

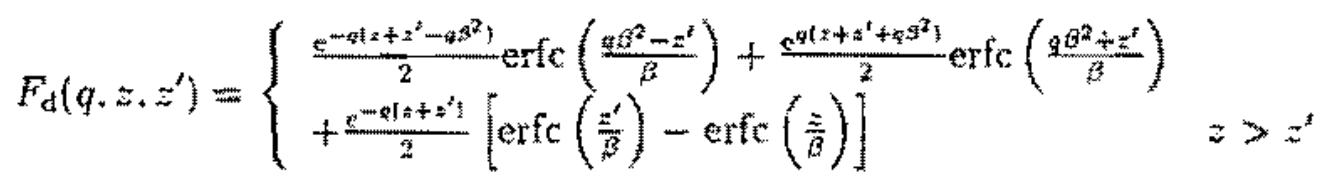

sendo que $F_{d}\left(q . \approx z^{*}\right)$ para $z<z^{*}$ e obtido comatandonse $z$ com $z^{r}$. 


\section{Distribuiçã̃o uniforme em um intervalo}

Outra abordagerm plausivel a ser considerada é o perfil de dopatgem ser retangular com uma certal espessura, de modo que

$$
g_{\mathrm{d}}(A)= \begin{cases}1 / \Delta_{\mathrm{d}} & |z|<\Delta_{\mathrm{d}} / 2 \\ 0 & \text { caso contrário }\end{cases}
$$

Neste caso, o fator de forma de impureza fica [58]

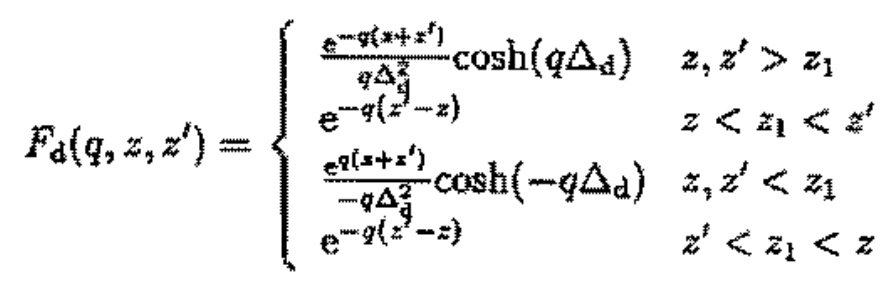

\subsubsection{Resumo}

Podemos sumarizar os resultados obtidos até agora como se segue.

Da aproximaçäo RPA:

$$
\varphi_{m m^{2}}^{\operatorname{EXT}}(q)=\sum_{m n^{2}} \epsilon_{m n^{2}, m n^{2}}(q) \varphi_{m n^{2}}^{\mathrm{TOT}}(q)
$$

onde

$$
\begin{aligned}
\epsilon_{m m^{\prime}, m n^{\prime}}(q) & =\delta_{n n^{\prime}, m m^{\prime}}-A_{n n^{\prime}}(q) T_{m n^{\prime}, n n^{\prime}}(q) \\
A_{n n^{\prime}}(q) & =\frac{2}{S} \sum_{k_{\perp}} \frac{f\left[E_{n}\left(k_{\perp}\right)\right]-f\left[E_{n^{\prime}}\left(k_{\perp}-q\right)\right]}{E_{n}-E_{n^{\prime}}+\frac{\hbar^{2}}{2 m}\left(k_{\perp}^{2}-\left(k_{\perp}+q\right)^{2}\right)} \\
T_{m m m^{\prime}, n n^{\prime}}(q) & =\frac{2 \pi n \mathrm{e}^{2}}{\epsilon q} \int_{-\infty}^{\infty} \mathrm{d} z \mathrm{~d} z^{\prime} \chi_{m}^{*}(z) X_{m}(z) \chi_{n^{\prime}}^{*}\left(z^{\prime}\right) \chi_{n}\left(z^{\prime}\right) \mathrm{e}^{-\xi\left|z-x^{\prime}\right|}
\end{aligned}
$$

e

$$
\begin{aligned}
\varphi_{m m^{\prime}}(q) & =\int_{-\infty}^{\infty} \mathrm{d} z X_{m^{\prime}}^{*}(z) \chi_{\mathrm{m}}(z) \varphi(q, z) \\
\varphi_{m m^{\prime}}(q, z) & =\frac{1}{S} \int \mathrm{d}^{2} g \mathrm{e}^{-i q \cdot \theta} \varphi(Q, z)
\end{aligned}
$$

onde $\varphi$ pode ser $\psi^{\text {TOT }}, \psi^{\text {LND }}$ on $\psi^{\text {EXT }}$.

Da aproximação estatística:

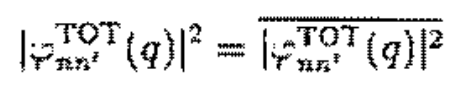

$\mathrm{com}$

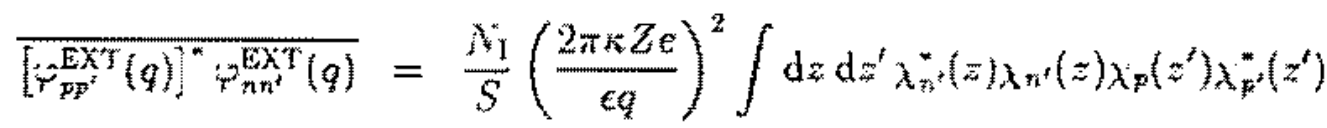

$$
\begin{aligned}
& \times F_{\mathrm{d}}\left(q, z, z^{\prime}\right)
\end{aligned}
$$

e

$$
F_{d}\left(q, z, z^{\prime}\right)=\int \mathrm{d} z_{1} g_{d}\left(z_{1}\right) e^{-q\left|z-z_{1}\right|} e^{-q\left|z^{*}-z_{1}\right|}
$$




\subsubsection{Cálculo das mobilidades na aproximaçäo RPA}

Utilizando a regra de ouro de Fermi. o tempo de mein-vida de un estado eletrônico pertencente à enésima subbanda com mornento $k_{\perp}$ é dado por[29, 57]

$$
T_{Q}^{-1}\left(n, k_{\perp}\right)=\frac{2 \pi}{\hbar} \sum_{n^{\prime} k_{\perp}^{*} \sigma^{\prime}}\left|<n^{\prime} k_{\perp}^{\prime} \sigma^{\sigma}\right|-\left.e \varphi^{\mathrm{TOT}}(r)\left|n k_{\perp} \sigma\right\rangle\right|^{2} \delta\left[E_{n}\left(k_{\perp}\right)-E_{n^{\prime}}\left(k_{\perp}^{\prime}\right)\right]
$$

Como anteriormente, efetuando a mudança de variável $q=k_{\perp}-k_{\perp}^{t}$, teremos

$$
\tau_{Q}^{-1}\left(n, k_{\perp}\right)=\frac{2 \pi e^{2}}{\hbar} \sum_{z^{\prime} q}\left|<n^{\prime} k_{\perp}+q\right| \varphi^{\mathrm{TOT}}(r)\left|n k_{\perp}>\right|^{2} \delta\left[E_{n}\left(k_{\perp}\right)-E_{n^{\prime}}\left(k_{\perp}+q\right)\right]
$$

Pelas Eqgs. $(5.10)$ e (5.11), isto pode ser pode ser escrito como

$$
r_{Q}^{-1}\left(n, k_{\perp}\right)=\frac{2 \pi e^{2}}{\hbar} \sum_{n^{\prime} \varphi}\left|\psi_{n n^{T}}^{\mathrm{TOT}}(q)\right|^{2} \delta\left[E_{n}\left(k_{\perp}\right)-E_{n^{\prime}}\left(k_{\perp}+q\right)\right]
$$

ou, equivalentemente,

$$
\tau_{Q}^{-1}\left(n, k_{\perp}\right)=\frac{2 \pi \varepsilon^{2}}{\hbar} \sum_{n^{\prime} k_{\perp}^{k_{1}}} \varphi_{n k^{t}}^{\mathrm{TOT}}\left(\left|k_{\perp}-k_{\perp}^{\prime}\right|\right) \varphi_{n^{\prime} n}^{\mathrm{TTT}}\left(\left|k_{\perp}-k_{\perp}^{\prime}\right|\right) \delta\left[E_{n}\left(k_{\perp}\right)-E_{n^{\prime}}\left(k_{\perp}^{\prime}\right)\right]
$$

onde levou-se em conta o resultado advindo da Eq. (5.11)

$$
\left[\varphi_{n n^{\prime}}^{\mathrm{TOT}}(q)\right]^{*}=\varphi_{n^{\prime} \pi}^{\mathrm{TOT}}(q)
$$

A soma em $k_{\perp}^{t}$ pode ser substituída por

$$
\sum_{k^{2} \perp} \rightarrow \int \frac{d^{2} k^{\prime} \perp}{(2 \pi / S)^{2}}
$$

$e \delta\left[E_{n}\left(k_{\perp}\right)-E_{n^{2}}\left(k_{\perp}^{2}\right)\right]$ por

$$
\delta\left[E_{n}\left(k_{1}\right)-E_{n^{2}}\left(k_{\perp}\right)\right]=\frac{m k_{\perp o}^{\prime}}{\hbar^{2}} \delta\left(k_{\perp}-k_{\perp 0}^{\prime}\right)
$$

onde $k_{1 o}^{\prime}$ é a raiz positiva da equação

$$
E_{n}\left(k_{1}\right)=E_{n}\left(k_{\perp}^{\prime}\right)
$$

Substituindo estes resultados na Eq. (5.20), teremos

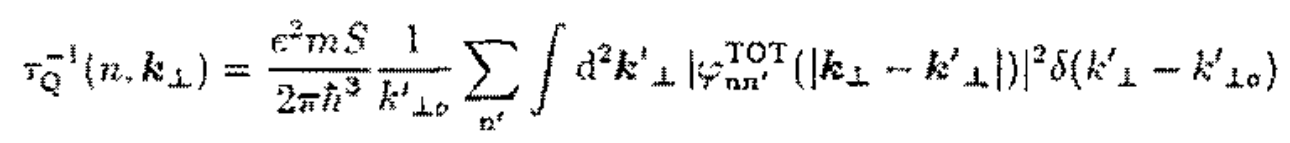




\subsubsection{Resultados para $\mathrm{T}=0$}

Até agora os resultados obtidos. dentro tas aproximacóos efetuadas. $s a ̈ n$ os matis gerais possinteis e seräo particularizados para $T=0$. Essa particularização é importante devido ao fato de que obtençâo das mobilidades quấnticas é praticamente possivel em baixas temperaturas a partir da análise da parte oscilatónia da magneto-resistência. Esse fenômeno quả̃ntico, como tantos outros, dependem da densidade de estados na energia de Fermi com o campo magnético: quanto mais fortes forem as singularidades de van Hove originadas pela quantizaça proveniente do campo magnético mais fortes serǟo os efeitos magneto-oscilatórios.

Em sistemas bi-dimensionais, os elétrons que contribuem para a condução săo aqueles da superficie de Fermi. Portanto, doravante, o vetor de de onda $k_{F}$ energia $E_{F n}$ seräo denomi nados como, respectivamente, vetor de onda de Fermi e energia de Fermi da enesima subbanda. Definindo-se o ângulo entre os vetores $k_{F_{n}}$ e $k_{n_{n^{\prime}}}$ por $\phi$, teremos finalmente que

$$
\tau_{Q}^{-1}\left(n, k_{\perp}\right)=\frac{e^{2} m S}{2 \pi \hbar^{3}} \sum_{n^{*}} \int_{0}^{2 \pi} \mathrm{d} \phi\left|\varphi_{n=1}^{\mathrm{TO} T}(\phi)\right|^{2}
$$

onde

$$
q=\left(\frac{2 m}{\hbar^{2}}\right)^{2}\left[E_{F n^{2}}+E_{F n^{*}}-2 \sqrt{E_{F_{n}} E_{F n^{*}}} \cos \phi\right]^{1 / 2}
$$

on

$$
q=\left(k_{F_{n}}^{2}+k_{F_{n^{r}}}^{2}-2 k_{F_{n}} k_{F_{n^{t}}} \cos \phi\right)^{1 / 2}
$$

As mobilidades de transporte das subbandas eletrônicas, Tr( $(0)$, são obtidas, de acordo com Siggia e Kwok [58], da solução do sistema de equaçöes

$$
\sum_{i^{\prime}} \kappa_{i i^{\prime}} \tau_{T}\left(i^{\prime}\right)=E_{\mathrm{F} i}
$$

onde

$$
K_{i i^{2}}=\delta_{i i^{*}} \sum_{j} K_{i j}^{(1)}-K_{i i^{*}}^{(j)}
$$

$\operatorname{com}$

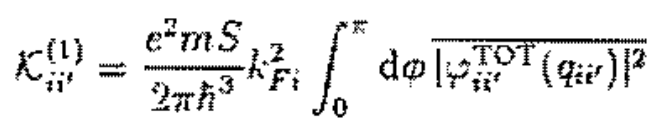

e

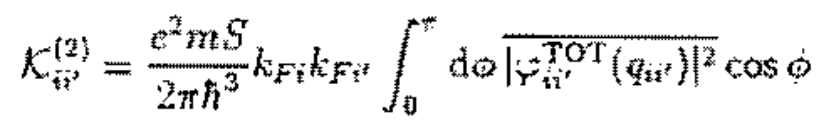

onde qiz é dado pela equaçäo (5.23). 
Cálculo de $A_{n n}(q)$ para $T=0$

É facil a verificaçăo de que $A_{n n^{\prime}}(q)=A_{n n^{\prime}}(q)$. Parte-se da relaçăo

$$
A_{n n^{\prime}}\left(q^{\prime}\right)=\frac{2}{S} \sum_{k_{\perp}} \frac{f\left[E_{n}\left(k_{\perp}\right)\right]-f\left[E_{n^{\prime}}\left(k_{\perp}-q^{\prime}\right)\right]}{E_{n}-E_{n^{r}}+\frac{h^{2}}{2 m}\left(k_{\perp}^{2}-\left(k_{\perp}+q^{\prime}\right)^{2}\right)}
$$

onde $q^{\prime}=\mathcal{O} \cdot q$, sendo $\mathcal{O}$ uma operação unitária de rotaçăo do vetor $q$. Fazendo-se a transformaçâo arbitrária da variável muda $k_{\perp}=0 \cdot k_{\perp}^{\prime}$, obtém-se que

$$
A_{n \mathrm{~m}^{\prime}}\left(q^{\prime}\right)=A_{\mathrm{rn}}(q)
$$

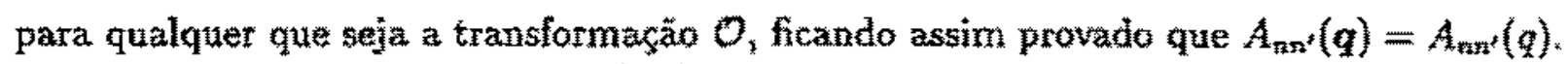

Outro resultado importante é obtido transformando-se a Eq. (5.28) em

$$
A_{n n^{\prime}}(q)=\frac{2}{S}\left\{\sum_{k_{\perp}} \frac{f\left[E_{n}\left(k_{\perp}\right)\right]}{E_{n}-E_{n^{\prime}}+\frac{\hbar^{2} q^{2}}{2 m}-\frac{\hbar^{2}}{m} k_{\perp} \cdot q}+\frac{f\left[E_{n^{\prime}}\left(k_{\perp}\right)\right]}{E_{n^{\prime}}-E_{n}+\frac{\hbar^{2} q^{2}}{2 m}-\frac{\hbar^{2}}{m} k_{\perp} \cdot q}\right\}
$$

Por inspeçäo, deste resultado temos que

$$
A_{n^{n} n}(q)=A_{n n^{\prime}}(q)
$$

O cálculo de $A_{\pi n}(q)$ fornece, para $\mathrm{T}=0 \mathrm{~K}$, quando

$$
f\left[E_{n}\left(k_{\perp}\right)\right]=\Theta\left(E_{F_{n}}-\frac{\hbar^{2} k_{\perp}^{2}}{2 m}\right)
$$

um resultado exato[59]:

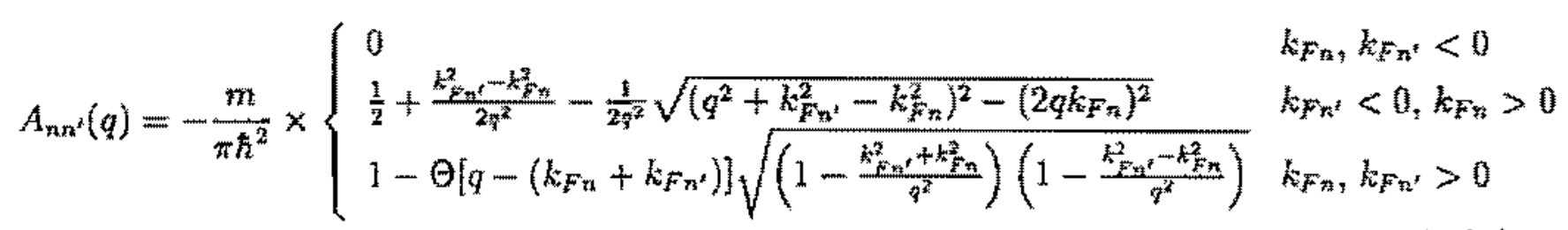

\subsection{Teoria TF-2D para a blindagem e mobilidades eletrônicas}

Na aproximação TF-2D, o potencial blindado de uma impureza com carga positiva. situada em $\left(\varphi_{i}, 0\right)$ pode ser calculada para uma carga de blindagem. localizada em $z=0$ e o resultado é[60, 36,19$]$

$$
\operatorname{VTOT}^{\operatorname{To}}\left(q, p_{i}\right)=\frac{e^{-q \cdot p_{1}}}{S} \frac{2 \pi}{q+q s} e^{-q|z|}
$$

onde $q_{s}=2$ é o vetor de onda de blindagem de Thomas-Fermi. o quual caracteriza uma resposta de blindagem independente da densidade de uma catga eletrónica estritamente bj-dimendional. 
De rrodo a calcular as mobilidades nas subbandas utilizando a Eq. (5.22) e as Eqs. (5.24)$(5.27)$, é necessário definir as funçöes de onda das subbandas $\chi_{i}(z)$ e respectivas energias $E_{i}$. Nos estudos que serào feitos das mobilidades no Cap. 6 para poços isolados, as funçòes de onda e energias, serão obtidas resolvendo-se numericamente a equaŗäo (2.5) com o potencial confinante sevdo aquele obtido da aproximaçào de Thomas-Fermi (2.24). Utilizando-se as funçōes de onda obtidas desta maneira, a média estatística do potencial eletrostático blindado na distribuição de doadores de carga positiva pode ser calculada como

$$
\overline{\left|V_{i i^{\prime}}^{T O T}(q)\right|^{2}}=\frac{N_{\mathrm{S}}}{S}\left(\frac{2 \pi}{q+q_{s}}\right)^{2}\left|\int_{-\infty}^{+\infty} \mathrm{d} z \chi_{i^{*}}^{*}(z) \chi_{i}(z) e^{-q|z| z \mid}\right|^{2}
$$

Substituindo as Eqs. (5.30) na Eq. (5.24), obtém-se para $i \neq z^{t}$

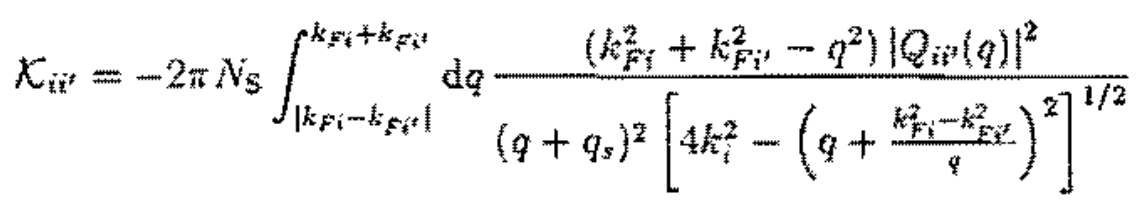

e para os elementos diagonais

$$
\begin{aligned}
& \mathcal{K}_{i j}=2 \pi N_{S} \int_{0}^{2 k_{F v}} d q \frac{q^{2} \mid Q_{i i}(q)^{2}}{\left(q+q_{s}\right)^{2}\left[4 k_{F i}^{2}-q^{2}\right]^{1 / 2}}+ \\
& 4 \pi N_{S} k_{F i}^{2} \sum_{i \neq i} \int_{\left|k_{F i}-k_{F i}\right|}^{k_{F i}+k_{F_{i} i}} \mathrm{~d} q \frac{\left(q+q_{*}\right)^{-2}\left|Q_{i i}(q)\right|^{2}}{\left[4 k_{F i}^{2}-\left(q+\frac{k_{F i}^{2}-k_{F i}^{2}}{q}\right)^{2}\right]^{1 / 2}}
\end{aligned}
$$

onde

$$
Q_{i}(\eta)=\int_{-\infty}^{+\infty} \mathrm{d} z X_{i}(z) X_{j}(z) e^{-q|z|}
$$

As equacōes (5.31) e (5.32) estão na forma obtida por Mezrin e Shik [61], e são convenientes para o cáltulo numérico das mobilidades quântica de transporte de uma subbanda pelo uso das relaçöes $(5.24)-(5.27)$ e (5.22)

Na aproximação $T F-2 D$, a largura nằo nula da carga de blindagem não ê levada em conta, ao contrário do que ocorre na aproximação RPA. Esta diferença pode ser apreciada pelo exarne da equação (5.30), a qual conduz a um tensor dielétrico diagonal

$$
\left.\epsilon_{i i^{\prime} m m^{2}}^{T F} t q\right)=\left(1+\frac{2 \pi}{q} \frac{d N_{\mathrm{S}}}{d E_{\mathrm{F}}}\right) \delta_{i \mathrm{~m}} \delta_{i^{\prime} m^{*}}
$$

A Eq. (5.33) é independente do formato da carga de blindagem, en contraste ao tensor dielétrico RPA dado pela Eq. (5.14). É bem conhecido que o limite $q \rightarrow 0$ da aproximaçāo RPA para um sistema quântico confinado conduz a uma aproximaçăo de Thomas-Fermi para um sisterna bj-dimensional estrito. A Eq.(5.33) pode ser obtida tomando-se o limite $q \rightarrow 0$ das equaçóes RPA que conduzern à Eq. (5.14) (mas näo da Eq. (5.14) diretamente) e assumindo $N_{\mathrm{d}}=E_{F} / \pi_{1}$ o que é válido para um sistema estritarnente bi-dimensional, o qual é caracterizado por possuir a carga de blindagem restrita a oupar o plano das impurezas. 
Quando comparados os dois modelos, será visto entäo a näo adequaçäo do modelo TF-2D, apesar de sua simplicidade, para a determinaçăo das mobilidades quântica e de transporte. justamente pelo fato de que o modelo $T F-2 D$ não leva em conta a espesstra fintita da camada de blindagem e subestima a localização das funçöes de onda das subbandas, prevendo assim mobilidades muito menores do que aquelas obtidas experimentalmente.

\subsection{Teoria RPA para a blindagem e mobilidades quânticas em super-redes periódicas}

Os resultados da teotia RPA para a blindagem e mobilidades eletrönicas em supermedes periódicas assemelham-se bastente aqueles para sistemas bi dimensionais.

A taxa de espallamento de elétrons de un dado estado quâtutico, para $T=0 \mathrm{~K}$, pode ser obtida da regra de ouro de Fermi, assumindo que a interaçăo coulombiana entre elétrons e impurezas ionizadas como sendo o únjco processo de espalhamento. Utilizando as funçós de onda para uma super-rede periódica,,$\chi_{n k}(z)$, e considerando os processos de espalhamento de portadores como ocorrendo na superficie de Femmi, obtém-se para o tempo de meia vida do estado $k$ da enésima minibanda (em unidades atônicas etetivas, o tempo de meia-vida quântico é igual à rnobilidade quântica $f a)$ :

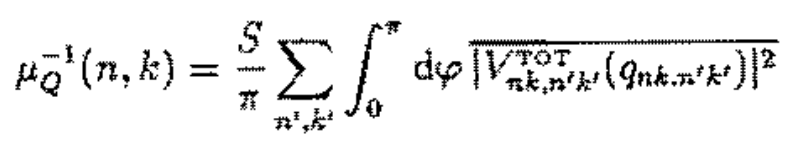

onde o somatóño extenderse sobre os estados quânticos $\left(n^{t}, k^{t}\right)$ abaixo do nivel de Fermi (lie. $\left.\phi_{n}{ }^{\prime},>0\right)$.

O vetor de onda $q_{n+n_{1} n^{2} k^{t}}$ é dado por

$$
q_{n k, k^{i} k^{*}}=2^{1 / 2}\left[\dot{\phi}_{n k}+\phi_{n^{\prime} k^{*}}-2 \sqrt{\phi_{n k} \phi_{n^{*} k^{k}}} \cos \varphi\right]^{1 / 2}
$$

A variável de integraçöo $\varphi$ é a ângulo de espalhamento entre os vetores $k_{1}$ e $k_{1}^{\prime}$ :

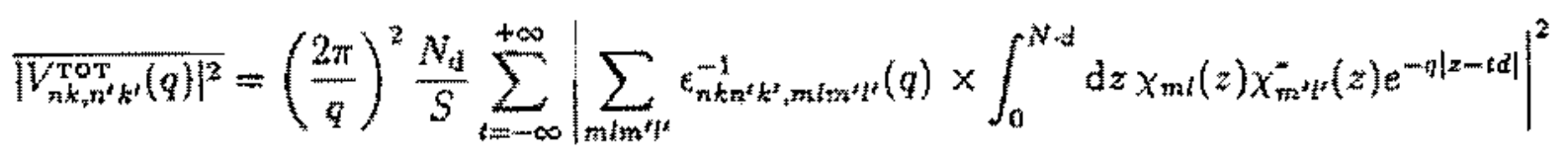

representa a média estatistica dos alementos de matriz da transformada bi-dimensional de Fourier do potencial espalhador; os índices das funçoes de onda $\chi_{n k}(z)$ representam o índice da minibanda e vetor de onda perpendicular à direçäo de crescimento, respectivamente. Na última aquação, a soma extende-se sobre todos os niveis de energia eletrônicos, $N_{\mathrm{a}}$ é a densidade por unidade de área de átomos doadores com uma carga ionizada em cada período de dopagem, com distribuiçăo de espessura nula na direçào $z$, 1 é o periodo da super-rede, $N \cdot d$ é o período

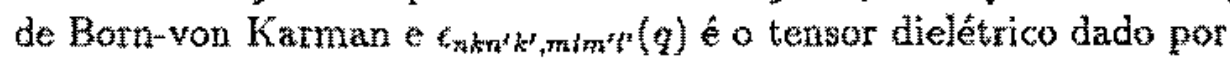

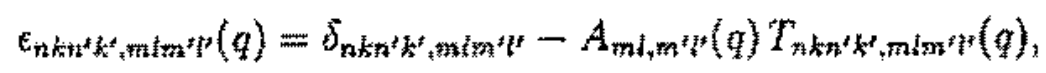

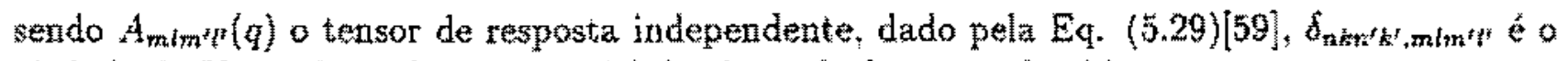
símbolo de Krönecker e $T_{n} k^{*} k^{\prime}, m i m^{\prime} t(a)$ é o fator de forma coulombiano

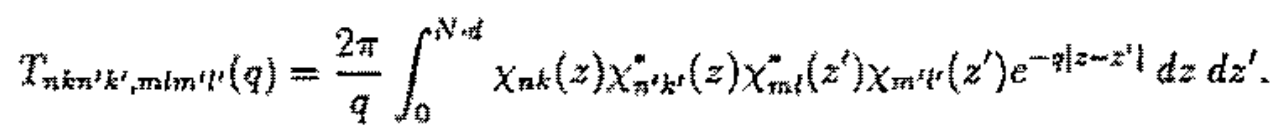




\subsection{Detalhes dos cálculos numéricos efetuados}

Para o cálculo das mobilidades que serảo efetuados nos capitulos posteriores, serào utilizadas as funçôes de onda e estrutura de minibandas de energia numéricas obtidas a partir dos parâmetros de uma amostra $\delta$-dopada. como visto no Capítulo 2. A partir dessas funçōes de onda, para o cálculo das mobilidades, a teoria apresentada no Capítulo 5 será utilizada com a simplificação que se segue. O tensor dielétrico contém contribuiçôs de subbandas acima do nivel de Fermi. Taís contribuiçôes foram estudadas por Hai et al.[10], en sisteraas com um único poço $\delta$, e foi mostrado que essas contribuiçōes afetam apenas um pouco a mobilidade da subbanda mais energética, a qual acomoda cerca de $5 \%$ do total da população eletrônica. Os resultados experimentais para as mobilidades quanticas em super-redes $\delta$-dopadas, como será visto, mostram um bom acordo com a previsào teórica e não houve a necessidade de tal correção. Em sisternas com um único poço, os resultados obtidos por nós para as mobilidades de transporte sugerem que tal correção deva ser investigada novamente juntamente com os efeitos de temperatura nesses sistemas, como será mostrado no cap̧ítulo final.

\subsection{Teoria para a obtençāo experimental das mobili- dades quânticas}

De rnodo a testar a teoria desenwolvida nas seçóes anteriores, urna comparação com a mobilidade quåntica obtida experimentalmente é necessária. A mobilidade quântica dos portadores nas minibandas pode ser extraída do espectro de SdH. Como mostrado nas Refs. [47, 49], numa supet-rede semicondutora, cada minibanda manifesta-se na experiência de SdH como um conjunto de componentes oscilatórias independertes. Cada minibanda pode ser classificada em uma das três categorias: aquelas de caráter bi-dimensional, com largura de banda xula, $W_{n}=0$; aquelas de caráter quasi bi-dirnensional, descritas por uma pequena dispersẫo e com banda estreita, $W_{n}<\phi_{n}$; e aquelas que são efetivamente tri-dimensionais, $W_{n}>\phi_{n}$, onde $\phi_{n}$ representa a distâucia em energia entre o nivel de Fermi e o limiar da minibanda.

A contribuiçăo à magnetoresistencia de uma minibanda cuja largura de banda é menor que a sua energia de Fermi, ou seja, $W_{n}<\dot{\phi}_{n}$, será descrita por[49]

$$
\begin{aligned}
& \frac{\Delta \rho_{z z}}{\rho_{0}} \approx-\frac{X}{\operatorname{senh} X} e^{-\alpha_{n} u}\left\{2 J_{0}\left(\beta_{n} u\right) \cos \xi_{n} u\right. \\
& \left.+8 \epsilon_{n} \Im \mathrm{m}\left[e^{-i \beta_{n} u t} \Phi\left(1 / 2,2,2 i \beta_{n} u\right)\right] \operatorname{sen} \omega_{n} u\right\},
\end{aligned}
$$

onde $X=2 \pi^{2} T / B, T$ é a temperatura em unidades de $h^{2} / k_{B} m^{*} a_{B}^{2}, u=1 / B, \alpha_{n}=\pi / t_{O}(n)$. $\mu_{Q}(n)$ é a mobilidade quântica na enésima minibanda. $J_{Q}$ é a funçäo de Bessel de primeiro tipo, $\Phi$ é a função hipergeométrica degeneradal62], $\phi_{n}=\pi \Delta_{n}, \omega_{n}=2 \pi\left(\phi_{n}-\Delta_{n}\right)$ e $\epsilon_{n}$ é un parâmetro adimensional o qual é obtido ajustândo-se a relaçào de dispersâo numérica da minibanda, $E_{n}(k)$, à expressão

$$
E_{n}(k)=\frac{\Delta_{n}}{2}(1-\cos k d)-\hbar_{n} \frac{\Delta_{n}}{2}(1-\cos 2 k d),
$$

A Equação (5.35) foi obtida assumindo-se que a mobilidade quântica é constante numa minibanda. 
Quando o espaçamento entre os planos dopados aumenta muito $(d \rightarrow \infty)$ a largura das minibandas vai a zero $\left(\Delta_{r_{i}} \rightarrow 0\right)$. e a Eq. (3.35) assume a forma familiar associada a um gts de elétrons confinado em duas dimensòes $[$ by|:

$$
\frac{\Delta p_{x x}}{p_{0}} \sim-2 \frac{X}{\operatorname{senh} X} e^{-\alpha_{\pi} *} \cos 2 \pi \phi_{n} u \text {. }
$$

No caso mais geral, a Eq. (5.35) será caracterizada por duas componentes oscilatórias, correspondentes às órbitas extremas de cintura e de pescoço da mini superfície de Fermi associada à minibanda. Entretanto, como mostrado na Ref.[49], em sistemas periodicamente $\delta$-dopados a órbita de pescoço näo è detectada. Esta conclusä́ é baseada na observaçầo de que a fim de que a órbita de pescoco seja detectada o alargamento dos niveis de energia deve ser menor que a largura da minibanda e também menor que o mini faixa de energia proibida entre a minibanda atual e a proxima em ordem de energia. Entretanto. em sisternas prdopados estas duas condiçôs não săo simultaneamente sabisfeitas e, portanto, cada minibanda manifesta-se através de uma única componente oscilatória, devida à órbita de cintura. Esta asserçăo leva a concluir-se que, no caso de semicondutores periodicamente $\delta$-dopados, a mobilidade quantica que comparece na Eq. (5.35) é aquela da órbita de cintura. Portanto, se se desejar testar a teoria da mobilidade quântica desenvolvida nas seçöes anteriores. a mobilidade quântica obtida pelo ajuste da Eq. (5.35) aos dados experimentais deve ser comparada com o valor de saida da Eq. (5.22) no vetor de onda associado a órbita de cintura tou seja, $k=0$ para as minibandas $E 1, E 3, \ldots$ e $k=\pi / d$ para as minibandas $E 2, E 4 \ldots$ ).

Para aquelas minibandas cuja largura de banda é maior que a energia de Fermi, ou seja quando $W_{n}>\phi_{n}$, as ascilaçöes na magnetoresistencia podem ser aproximadas pela expressão usual associada a um gás de elétrons livres em três dimensöes[63]

$$
\frac{\Delta \rho_{x z}}{\rho_{0}} \sim-2 \frac{X}{\operatorname{senh} X} \frac{e^{-\alpha_{n} u}}{\sqrt{u}} \cos \left(2 \pi \phi_{n} u-\frac{\pi}{4}\right)
$$

A mobilidade quántica, neste caso, pode ser similarmente obtida pelo ajuste da Eq. (5.38) à componente magneto-oscilatớt isolada. 


\section{Capítulo 6}

\section{Mobilidades quântica e de transporte em $\operatorname{poços~} \delta$}

Neste capitulo tenta-se estabelecer um procedimento de calculo teórico confível para as mobilidades quântica e de transporte em super-redes.

Vários níveis de aproximação sẫo possiveis para a obtençăo das mobilidades eletrônicas em estruturas de modulaçäo de dopagem: desde o uso de um modelo do tipo Thomas-Fermi para a blindagem que ignore totalmente a espessura da camada de blindagem até um modelo que inclua todos os ingredientes da estrutura eletrôníca de una super-rede, como a espessura e perfil do plano de dopagem, a espessura näo nula da camada de dopagem via suas funçôes de onda e a deformação imposta ao potencial pela presença de aceitadores ionizados. Com o aumento de complexidade introduzido por um modelo particular e pelo grau de aproximacäo envolvido aumenta o custos computacional devido à complexidade do cálculo numérico necessário para a obtenção das mobilidades eletrônicas de uma estrutura.

Para que as mobilidades eletronicas possam ser obtidas numericamente e comparadas com a experiencia é necessário que se conheçam os parâmetros característicos desses tipos de sistemas, os quais podem ser obtidos, por exemplo, a partir da análise das oscilaçōes de Shubnikov-de Haas como já discutido.

A partir dos periodos de SdH foi mostrado que é possivel a determinação dos parâmetros $N_{\mathrm{d}} \mathrm{e} \Delta_{\mathrm{d}}$. Embor o formato da distribuiçăo dos dopantes nảo seja univocamente conhecido, outras técnicas como a microscopia de tunelamentol64 sảo eficazes na determinaçáo do pertil da distribuiçño dos dopantes. A partir de medilas de reflectividade de raios- $X$ mostrou-se poskivel a determinaçă dos perfis de distribuição de dopagem, além da concentraçäo nos planos de Si em amostras de CaAs[bo].

Vários autores modelaram o cálculo das mobilidades quânticas e de transporte nas subbandas individuais a mobilidade Hall em estruturas contendo um único poço of utilizando vários graus de aproximaţă $110,13,61]$

Na Ref. [13] foi mostrado oue o modelo no qual a mobilidede é limitada pelo espalhamento coulombiano dos doadores ionizados. incluindo a blindagem do potencial espalhador naproxtmaçăo RPA, fornece valores para a mobilidade compativeis am uma ordem de magnitude com os valores experimentais. Em seus cálculos, os autores da Ref. [13] desprezaram a largura finita do plano de dopantes e as funçós de onda envoltórias para as subbandas foram obtidas por um princípio variacional. 
Recentemente [10], um cálculo mais realístico das mobilidades eletrônicas das subbandas fô efetuado onde os autores utilizaram as funçoes de onda obtidas pela solução auto-consistente das equaçóes de Schrödinger e de Poisson para a estrutura $f$ e a largura da camada de dopantes foi incorporada no modelo teórico. A distribuição dos átomos doadores na direçäo de crescimento foi considerada uniforme num determinado intervalo.

Em outro artigo[66], o autor determina a influencia do tipo de distribuição dos atomos dopantes, além do efeito dos aceitadores residuais ionizados. A presença de aceitadores ionizados apropriada para descrever cristais hospedeiros com caracteristicas de tipo p (como ocorre em GaAs crescido por MBE) foi levada em conta no que diz respeito ao seu eféto na mudança do formațo do poço $\delta$. As mobilidades obtidas teoricamente desta maneira estäo em bom acordo com as medidas obtidas experimentalmente, embora algums desacordos entre a teoria $e$ a experiência existam para as mobilidades das aubbandas excitadas.

Neste capitulo setăo discutidos os resultados teóricos para as mobilidades quantica e de transporte baseadas na soluçăo auto-consistente das equą̧öes de Schrödinger e de Poisson para um semicondutor $\delta$-dopado atilizando-se a aproximaçäo RP 1 para descrever os efeitos de blindagem. $O$ perfil da distribuiçäo dos átomos doadores será considerada e serão comparados os resultados obtidos para a distribuiçăo uniforme e retangular. A presença de aceitadores de fundo foi incorporaña nos cálculos das mobilidades das subbandas. Juntamente ao efeito dos aseitadores ionizados no formato do potencial confinante, o espalhamento por esses centros foi incluido no tálculo teórico das mobilidades.

En resumo, serão comparados alguns fatores importantes na determinação das mobilidades quảntica e de trunsporte:

- o perfil de dopagem, caraterizado por $\Delta_{\mathrm{t}}$

- o modelo para blindagem mais adequado para a reproduço dos dados experimentais

- a influència dos aceitadores residuais na determinaça das mobilidades

\subsection{Mobilidades em um poço $\delta$ com espessura nula}

Para uma estrutura $\delta$-dopada polarizada, a mobilidade dos portadores nas subbandas eletrônicas foi estudada, num primeiro momento, dentro da aproximação de Thomas- Fermi [12]. $O$ interesse nas propriedades de trausporte de estruturas polarizadas vem de suas aplicaçón tecnológicas, corno por exemplo o transistor $\delta$-EET [67]. A estrutura $\delta$-dopada polarizada é também um sistema conveniente para o estudo de efeitos da proxirnidade da superficie nas propriedades do gás de elétrons confinados [68], já que aplicando-se a polarizaçầo ao sistema com a porta, a regiào proxima à superficie pode ser depletada de portadores. Por esses motivos, parece apropriado que o tratamento quântico completo seja aplicado a estruturas do dopadas com polarizaçāo, o que será visto nesta seçăo.

As mobilidades dos portadores foram calculadus utilizando-se o modelo de Thomas-Fermi para o potencial juntamente com a descriçato prevista pelo modelo TF-2D para a carga de bindagem, a partir do tratamento quântico da carga de blindagem e do potencial.

A confiabilidade do cálculo quântico apresentado estát baseada no fato do seu sucesso para a descricấa de estruturas $\delta$ năo polarizadas. Os resultados mostratẫo que embora o modelo 
TF-2D apresente grande simplicidade e requetra um pequeno esforço computacional, ele consegue apenas prever adequadamente a mobllidade dos portadores pertencentes à subbanda fundamental.

\subsubsection{Resultados e Discussão}

As mobilidades quantica e de transporte para as subbandas individuais numa estrutura $\delta$-dopada com uma porta em funçào da voltagem de polarizaçào aplicada foram calculadas na aproximaçăo RPA e na aproximação de Thomas-Fermt. Os cálculos foram efetuados para uma. estrutura f-dopada com concentracöos de doadores $N_{S}=2,5$ e $10 a_{\mathrm{B}}^{-2}$. 0 efeito da polarizaçä̀ é apresentado através da fraçäo $\$$ do número total de elétrons na estrutura $N_{\$}$ que é transferida para a superfície dia amostra quando uma diferença de potencial é aplicada entre a porta e o substrato. Os resultados para as mobilidades quânticas e de transporte em funça do são apresentados na Fig. 6.

\section{Resultados em polarização nula}

Primeiramente discutiremos os resultados quando a voltagem de polarização ê nula à luz das teorizs RPA e TF-2D. A diferença mais patente entre as duas teorias é o aumento das mobilidades com o indice da subbanda na teoria RPA enquanto na teoria TF-2D as mobilidades são quantitativamente similares. Por outro lado, a mobilidade obtida para os portadores da subbanda fundamental, E1, é aproximadamente a mesma para ambas as teorias. $O$ resultado do tratamento quântico para polarizaçăo nula está em acordo quantitativo com os resultados experimentais de Koenrazd et al.699]. Os autores dessa referencia obtiveram para as mobilidades quânticas na iésima subbanda, $\mu_{\mathrm{Q}}\left(E_{i}\right), \mu_{\mathrm{Q}}\left(E_{2}\right) \sim 4 \mu_{\mathrm{Q}}\left(E_{1}\right)$ para $N_{\mathrm{s}}-2$ e $\mu_{\mathrm{O}}\left(E_{2}\right) \sim 3 \mu_{\mathrm{Q}}\left(E_{1}\right)$ para $N_{s} \approx$ 5. Esses resultados săo bem reproduzidos pelos nossos cálculos RPA, e indicam o calculo RPA como a teoria de escolha.

Os cálculos baseiam-se em duas quantidades de entrada: o espectro eletrônico e potencial eletrostático blindado de urn plano de impurezas ionizadas de espessura nula. Para um plano de doadores com espessura nula, o espectro eletrônico obtido pela solução auto-consistente das equaçồ de Schrö́dinger e de Poisson (Eqs. 2.5 e 2.8) é praticamente idêntico àquele obtido pela soluç̆o da equaçäo de Schrödinger utilizando-se o potencial de Thomas-Fermi (Eq. 2.24). Este resultado está em acordo com a conclusäo da Ref. [22], onde é mostrado que, em polarização mula, o potencial confinante de TF conduz a resultados que são equivalentes àqueles obtidos pela solução autoconsistente das equaçốes de Schrödinger de Poisson.

Portanto, as diferenças entre as mobilidades das subbandas obtidas pelos cálculos RPA a TF-2D não podem ser explicadas pelas diferenças entre os espectros eletrônicos e devem ser analisadas segundo as diferenças nos modelos utilizados para o potencial eletrostático blindado utilizado em cada caso. No modelo RPA, a espessura nằo nula da camada de blindagem é levada en conta. Isto implica que a intensidade do campo elétrico do plano de impurezas carregadas entraquecerá rapidamente à medida em que nos afastamos de $z=0$. Portanto, elétrons ocupando estados em subbendas mais energeticas, descritos por funçōes de onda menos localizadas em torno de $z=0$, seräo espalhados menos eficientemente a, portanto, terăo mobilidades maiores. Em contrapartida, no modelo TF-2D a carga de blindagem é assumida como possuindo expessura nula e, por conseguinte, o campo eletrico da placa de impurezas carregada 
varia muito mais lentamente a medida am que nos afastamos de $z=0$ do que pelo modelo RPA.
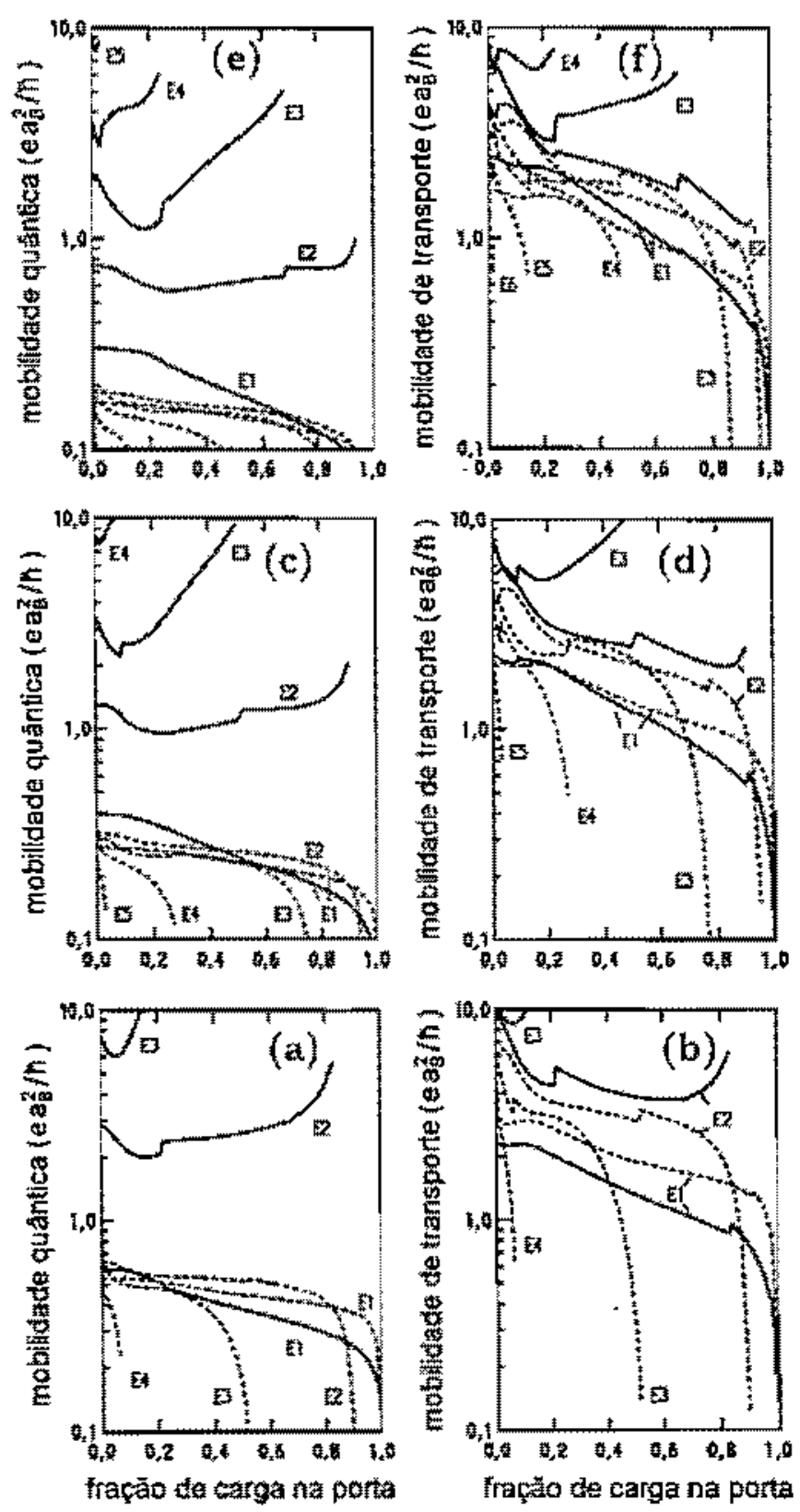

Figura 6.1: Mobilidades quântica e de transporte calculadas para $N_{\$}=2$ (fa) e (b)); $N_{\mathrm{S}}=5$ (lc) e (d)); a $N_{s}=10$ ((e) e (f)) em funçäo da fração $s$ do numero total de portadores da estrutura transferidos para a porta. As linhas cheias correspondem ao resultado da teoria RPA, enquanto as linhas tracejadas representam o resultado da aproximaçäo TF $2 \mathrm{D}$. Os rótulos indicam o indice da subbanda correspondente a cada curva.

Lsso é equivalente também ao fato de que os eletrons em todas as subbandas são espalhados com quase igual eficiencia por isso, exibirä́c mobilidades parecidas. Ern outras palavras, 
a distância médía entre a carga eletrônica e a placa de impurezas carregada mostra-se de fundamental importância no modelo RPA mas não no modelo TF-2D. De fato, como pode ser observado na Fig. 6.1, a teoria TF-2D prediz algumas vezes que a moblidade alecresce com o indice da subbanda. o que é una consequêencia de um vetor de onda de Fermì que decresce, 0 que favorece uma taxa de probabilidade de espalhamento maior.

\section{Resultados em polarizaçäo não nula}

Quando um potencial externo é aplicado. uma parte da sarga eletrônica é transferida do poço $\delta$ para a superficie. A subbanda mais excitada é esvaziada até que para $s \sim 0,95$ somente a subbanda fundamental permanece populada. Sempre quando uma subbanda é esvaziada completamente. as mobilidades nas subbandas restantes, que permanecern populadas, experimentam um salto, o que é conseqüência de uma brusca mudança na densidade de estados na energia de Fermi; tais saltos seräo atenuados em temperaturas finitas, quando a laixa de energia dos elétrons de condução é alargada.
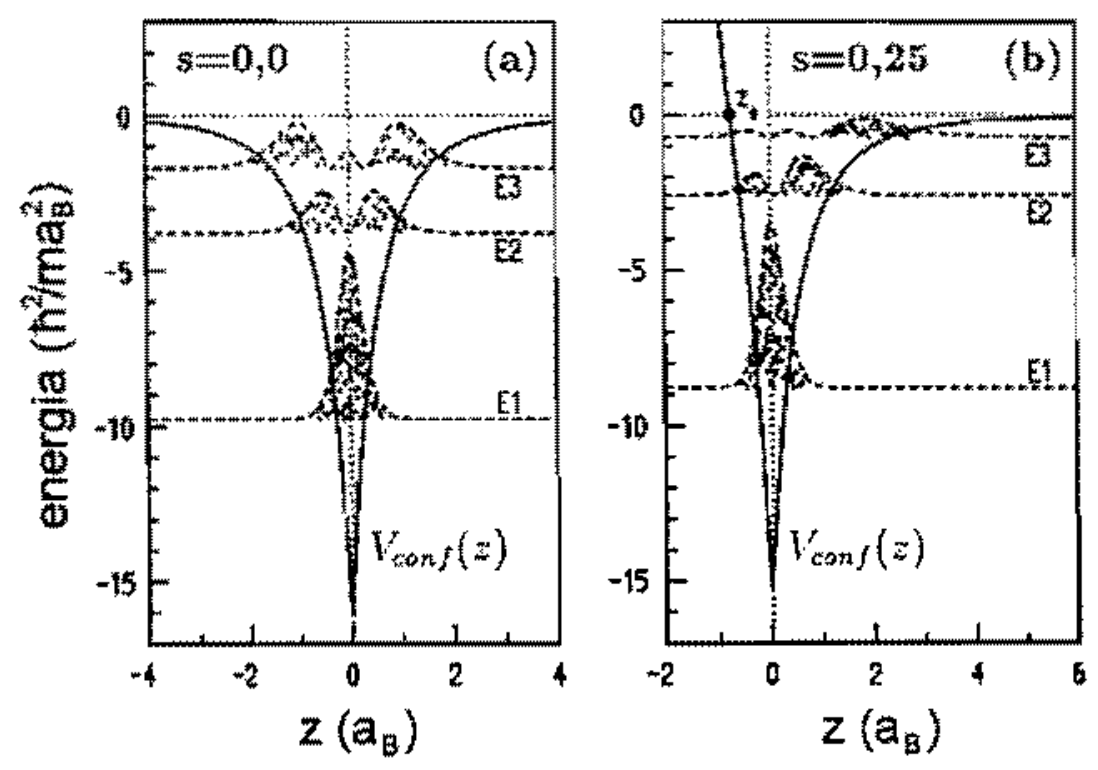

Figura 6.2: Poço $\delta$ obtido da aproximaca de Thomas-Fermi (linha cheia) para $s=0$ (a) e $s=0,25$ (b). A origem da escala de energia fol escolhida como sendo a energia de Fermi. As Hinhas tracejadas representam a carga eletronica correspondente à subbanda indicada por um rótulo.

Com o aumento da polarizaçăo, a densidade dos elétrons que permanecen confinados no poço, $(1-s) N_{5}$, decresce. Segundo o modelo RPA, isso quer dizer que a capacidade de blindagem dos elétrons confinados no poço $\delta$ decresce a, portanto, o potencial eletrostático das impurezas carregadas toma-se mais intenso implicando numa major eficiencia de espalhamento 2. numa menor mobilidade do portador. Este comportamento (uma mobilidade decrescente com a polarização) é vista nas mobilidades quântica e de transporte obtidas do cálculo RPA no 
limite de pequenas polarizaçoes. Entretanto, para valores grandes da voltagem de polarizaçăo, as moblidades RPA nas subbandas excitadas aumentam. Quando a polarização é aplicada, as subbandas mais energéticas afastam-se do plano de impurezas devido ao fato a carga eletronica é repelida pela carga negativa situada na superficie da amostra.

Isto ilustrado na Fig. 6.2 a qual mostra o poso $\delta$ com $N_{S}=2.0$ e as funçóes de onda das subbandas em polarização rula e para $s=0,25$. Em polarizaçäo nula, os valores esperados säo $\langle z>=0$ para todas as subbandas. En $s=0,25$, o valor esperado para os elétrons fortemente ligados da subbanda El cresce ligeiramente para $\angle z>B=0,05 ;$ para as subbandas E2 $\mathrm{E}$ E3, uma mudança grande para $\langle z\rangle_{E Z}=0,53$ e $\left.<z\right\rangle_{E 3}=1,82$. respectivamente, é obtida. Portanto, com o aumento da polarização, os elétrons ocupando estados em subbandas rnais energéticas distanciar-se-äo para longe do plano de impurezas. No modelo RPA, tal separaçäo espacial dos elétrons e impurezas implica que a mobilidade nas subbandas excitadas aumentará com a polarização.

Na. Ref. [66] foi mostrado que a mobilidade eletrônica numa subbanda $E_{\text {i }}$ correlaciona-se com o recobrimento da densidade de una particula, $|x \in(z)|^{2}$, com uma funçăo de distribuiçào que caracteriza o perfil de dopagem do poço $\delta$. Para um perfil de dopagem de largura nula, como apresentado, tal recobrimento será dado simplesmente por $\left\{\left.x \in(0)\right|^{2}\right.$.

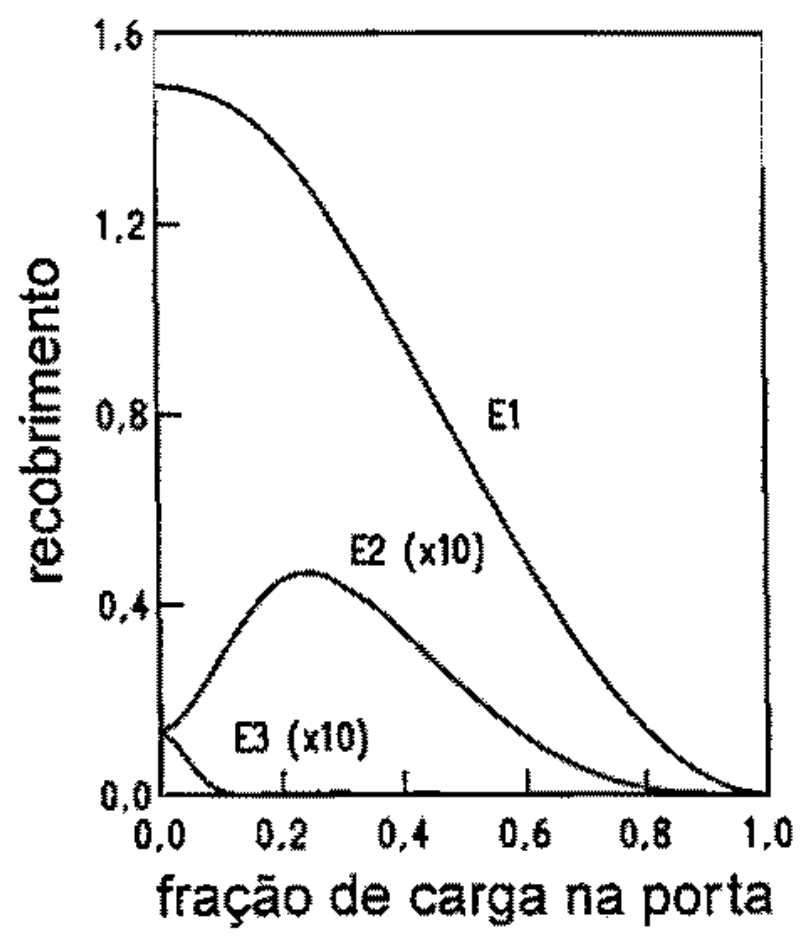

Figura 6.3: Recobrirnento $|X(0)|^{2}$ em funçăo da tensão de polarização para $N_{s}=2$. Os rótulos indicam o irdice da subbanda correspondente a cada curva, $O$ fator pelo qual o recobrimento calculado é multiplicado é apresentado ao lado dos rótulos.

A figura 6.3 mostra os recobrimentos calculados en funçäo da polarizaçäo para um poço $8 \mathrm{com} N_{\mathrm{S}}=2,0$. Uma comparaça da Fig. 6.3 com as Figs. 6.1(a) e 6.1(b) mostra que 
existe cortelaçăo entre o recobrimento e a polarizaçă aplicada e a mobilidade obtida pela teoria RPA para as subbandas $E$ i: quando o recobrimento aumenta a mobilidade diminui $e$ vice versa. Essa correlaça entre o recobrimento e a mobilidade näo é verificada apenas para a subbanda fundamental, a qual esta fortemente ligada ao plano de impurezas. näo variando de modo significativo a sua posiça aro relação a plano de impurezas, Portanto para a subbanda fundamental, a diminuiçäo de mobilidade com a polarizaçäo é praticamente função da diminuiçäo do momento de Fermi, analogamente an que acontece no modelo de Thomas Fermi. A correlaça entre as subbandas mais energeticas com o recobrimento prova que as mobilidades obtidas pelo modelo RPA săo sensiveis à distäncia média entre à carga eletrônica e o plano dopado.

Em contraste, como a Fig. 6.1 mostra, no modelo TF-2D, as mobilidades individuais nas subbandas sempre decrescem com o polarizaçăo aplicada; nesse caso, entretanto, o comprimento de blindagem é independente da densidade e, logo, o decréscimo na mobilidade não pode ser atribuido à mudança na eficiência do espalhamento. Como mencionado acima. as mobilidades TF-2D são também insensiveis à localizaçāo da funçăo de onda s, portanto, o entortarnento do poço $\delta$ tem apenas um pequeno efeito sobre o valor absoluto das mobilidades nas subbandas. $\mathrm{O}$ descréscino das mobilidades nas subbandas com polarizaça, obtido pelo modelo TF-2D dominado pelo decréscimo no vetor de onda de Fermi quando o poço 0 é esvaziado de portadores, o que conduz a uma maior probabilidade de espalhamento e. portanto a mobilitades menores.

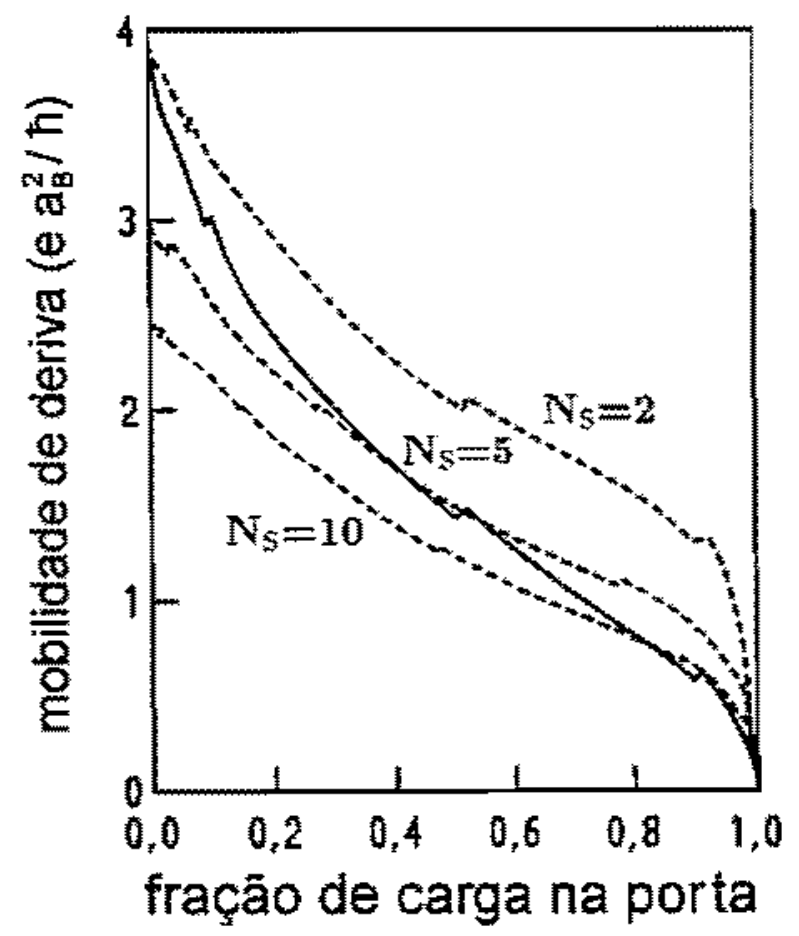

Figura 6.4: Mobilidades médias calculadas pelo modelo RPA (linha cheia) e pelo modelo TF 20 (linhas tracejadas) em função da tensão de polarização aplicada. A densidade total de portadores na estrutura ê indicada para cada curva. 
Um resultado adicional dos cálculos teóricos é a mobilidade média de deriva, $\mu_{\mathrm{av}}$, para o transporte paralelo ao plano dopado. A mobilidade média de deriva é dada pela média ponderada das mobilidades de transporte nas subbandas, utilizando-se como peso a densidade de portadores na subbanda correspondente

$$
\mu_{\mathrm{av}}=\frac{\sum_{\mathrm{i}} \mu_{T}(i) E_{\mathrm{i}}}{\sum_{i} E_{\mathrm{i}}}
$$

Os resultados dos cálculos são mostrados na Fig. 6.4 em função da polarização aplicada; a linha cheia corresponde ao resultado RPA com $N_{\mathrm{S}}=5$ (para $N_{\mathrm{S}}=2,0$ e $N_{\mathrm{S}}=10$, o modelo RPA conduz a resultados similares àqueles de $N_{\mathrm{S}}=5$ ); as mobilidades médias de deriva obtidas pelo modelo TF-2D são mostradas para $N_{\mathrm{S}}=2,5$ e 10 por linhas tracejadas.

$\dot{E}$ interessante observar que a dependência da mobilidade média de deriva em função da polarização é aproximadamente a mesma em ambos os modelos. Já que a maior parte da carga eletrônica no poço ocupa estados da subbanda fundamental. a mobilidade média de deriva será dominada pela mobilidade da subbanda E1. cujo comportamento é similar em ambos os modelos. RPA ou TF-2D. Este fato foi observado na Ref. [61], cujos autores mostram que a mobilidade média de deriva, obtida dentro da aproximação TF-2D, concorda favoravelmente com valores experimentais para estruturas $\delta$ nào polarizadas.

\subsubsection{Conclusões}

As mobilidades quânticas e de transporte das subbandas individuais de um semicondutor com dopagem $\delta$ foram calculadas nas aproximaçôes RPA e TF-2D em função da polarização externa. Os resultados das teorias TF-2D e RPA mostram concordância apenas nos resultados da subbanda fundamental, o que pode ser explicado pelo pequeno comprimento de blindagem para portadores nessa subbanda. Para subbandas excitadas, as mobilidades aumentam com o índice da subbanda na aproximaçāo RPA. enquanto permanecem praticamente inalteradas pelo modelo TF-2D. Esta diferença baseia-se no fato de que na aproximação RPA, a mobilidade é muito sensivel à distância média entre a carga eletrônica e os centros espalhadores, o que não é o caso na teoria TF-2D. Pelo fato de que a mobilidade média de deriva para o transporte paralelo ao plano dopado ser dominada pelos portadores da subbanda fundamental, a mobilidade média de deriva no modelo TF-2D está em razoável acordo com o mesmo valor previsto pela teoria RPA. O resultado dos cálculos RPA, assumido como confiável devido ao sucesso da teoria RPA em descrever estruturas $\delta$ nāo polarizadas, mostra que há correlaçāo entre a mobilidade em função da polarização com o recobrimento entre funções de onda e a regiảo aonde os átomos doadores estão situados.

\subsection{Influência do perfil de dopantes e aceitadores resi- duais}

Na literatura, vários autores calcularam teoricamente as mobilidades quântica e de transporte das subbandas eletrônicas e a mobilidade Hall de semicondutores $\delta$-dopados utilizando vários graus de aproximação[10, 13,61]. 
Na Ref. [13], foi mostrado que o modelo no qual a mobilidade é limitada pelo espatharnento coulombiano dos doadores ionizados, incluindo a blindagem do potencial espalhador na aproximaça RPA. fornece valores de mobilidade que concordam dentro de uma ordem de magnitude corn as observaçöes experimentais. Em seus cálculos. os autores dessa referência desprezaram a largura do plano de dopantes e os formatos das funçōes de onda envoltórias que descrevem as subbandas eletrónicas eram variacionais,

Num cálculo mais realista, os autores da Ref. [10] utilizaram as funçōes numéricas obtidas da solução auto-consistente das equaçōes de Schrödinger e de Poisson para uma estrutura do tipo $\delta$, onde a espessura raăo nula da camada de dopante fỏ levada em consideraçâo nu modelo teórico. A distribuição dos doadores foi aproximada por uma funçăo reţangular. A presença de aceitadores residuais ionizados, apropriada para descrever um cristal hospedeiro do tipo $p$ (por exemplo, GaAs crescido por MBE), foi levada em conta somente no que respeita ao seu efeito na mudança do perfil do potencial do poço $\delta$. As mobilidades teóricas obtidas desta maneira estão em bom acordo com observaçoes experimentais. embora algum desacordo entre teoria e experiència exista para as mobilidades nas subbandas mais excitadas.

Nesta seção, serảo mostrados os resultados do câlculo teórico para as mobilidades quântica \& de transporte que utilizarm a estrutura eletronica auto-ensistente advinda das equações de Poisson e de Schrödinger, juntamente com a utilizaçāo da aproximação RPA para descrever os efeitos de blindagem. Adjcionalmente, seräo comparados os resultados teóricos obtidos as distribuiçöes reiangular e ganssiana. A presença de aceitadores residuais foi incorporada nos cálculos das mobilidades nas subbandas. Juntamente ao efeito dos aceitadores residuais ionizados na mudança do perfil do poço, o espalhamento por eles produzido foi incluido nos cálculos.

\subsubsection{Resultados e Discussäo}

Os cálculos teóricos foram efetuados para três densidades de dopagem, nomeadamente $N_{\mathrm{d}}=2,0,5,0$ e $8,0 \mathrm{a}_{\mathrm{B}}^{-2}$ (aproximadamente $2,0,5,0$ e $8,0 \times 10^{12} \mathrm{~cm}^{-2}$ para o GaAs). A densidade de aceitadores residuais foi fixada em $1,0 \times 10^{-4} a_{\mathrm{B}}^{-3}$ (aproximadamente $10^{14} \mathrm{~cm}^{-3}$ para $\circ \mathrm{GaAs}$ ). Para esta densidade de aceitadores residuais, os que estäo ionizados estão na faixa de uma densidade areal de aproximadamente $0.05 a_{\mathrm{B}}^{-2} \mathrm{e}$, portanto, a densidade de portadores livres será praticamente igual à densidade de doadores $N_{\mathrm{d}}$.

Os resultados teóricos para as mobilidades quântica e de transporte nas subbandas em funçăo da espessura dos planos de dopante, tomados tanto como tendo distribuiçắo gaussiana como retangular. são mostrados na Figura $6.5(a)-(f)$. 

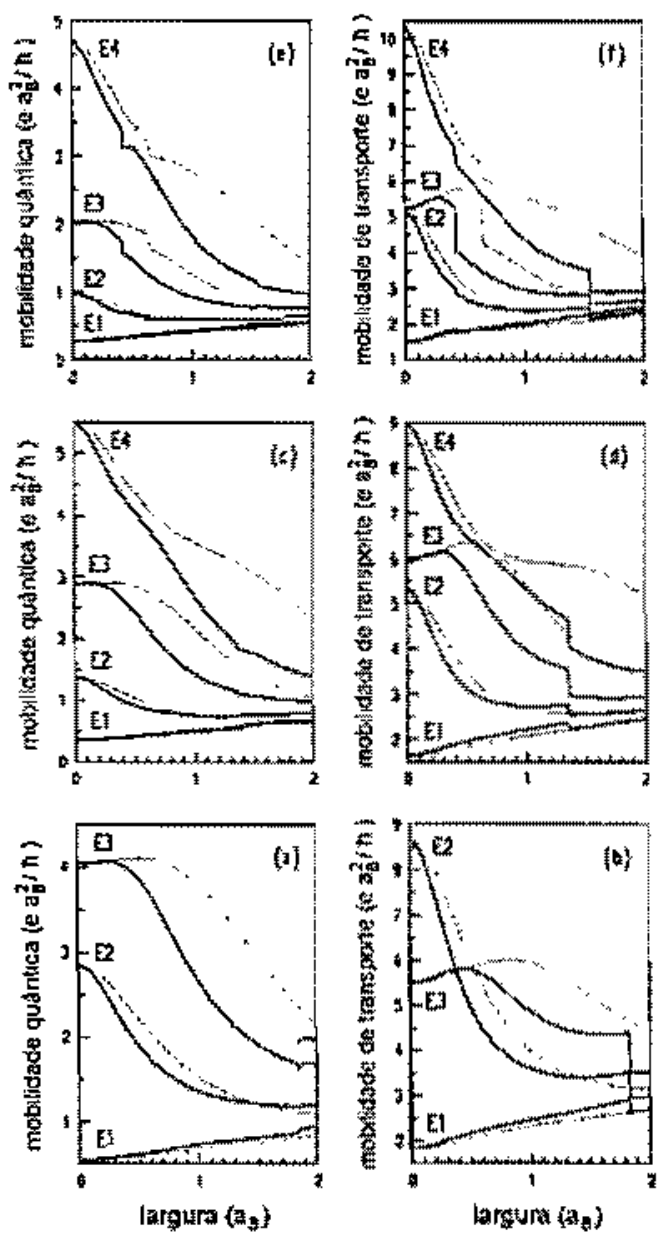

Figura 6.5: Mobilidades quântica e de transporte para as subbandas para $N_{\mathrm{d}}=2,0$ (abaixo), 5,0 (no centro) e $8,0 a_{\mathrm{B}}^{-2}$ (acima). As linhas cheias correspondern a perfis gaussianos de dopagem, enquanto as tracejadas a perfis retangulares. A densidade de aceitadores residuais foi fixada em $N_{a}=1,0 \times 10^{-4} a_{\mathrm{B}}^{-3}$. Os rótulos indicam o indice da subbanda correspondente a cada curva.

A unidade de mobilidade eletrônica é $\epsilon u_{\mathrm{B}}^{2} / \hbar$, aproximadamente $1500 \mathrm{~cm}^{2} / \mathrm{V}$ s para o GaAs. O gráfico da mobilidade média de deriva calculada

$$
\mu_{\mathrm{av}}=\frac{\sum_{i} \mu \mu_{\mathrm{T}}(i) E_{\mathrm{F} i}}{\sum_{w i} E_{\mathrm{F} i}}
$$

em função da largura do plano de dopantes é mostrada na Fig. 6.6 

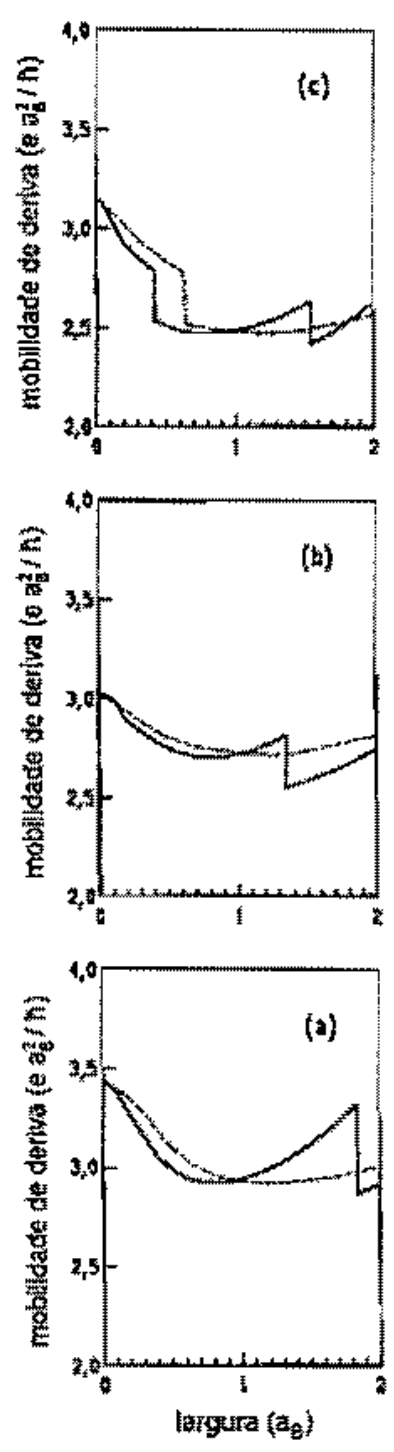

Figura 6.6: Mobilidade média de deriva calculada para $N_{0}=2,0(a), 5,0(b)$ and 8,0 a $a^{-2}(c)$. A densidade de aceitadores foi fixa em $1.0 \times 10^{-4} \mathrm{a}_{\mathrm{B}}^{-3}$. As linhas cheias foram obtidas levando-se en conta o perfil de dopagem gaussiano, enquanto que a linhe tracejada o perfll foi considerado retangular.

\section{Infiuência da largura do perfil de dopagem nas mobilidades}

A medida em que a lartura $\Delta_{d}$ do plano de dopantes torna-se maior, a tendencia geral das mobilidades é decrescer, à exceção da subbanda El. Outra caracteríticica notória é a presença de descontinuidades para certos valores de $\mathrm{A}_{\mathrm{d}}$. As discontinuidades ocorrem quando - limiar de una subbanda cruza o nivel de Fermit. o que introduz uma mudança brusca na densidade de estados en $E=E_{F} e$, portanto, uma mudança na taxa de espallamento dos portadores responsáveis pela condutividade a $T=0 \mathrm{~K}$. Tais discontinuidades serão atenuadas 
a temperaturas finitas, quando a gama de energias possíveis para os elétrons de condução é aumentada. As mudanças na mobilidade quando $\Delta_{d}$ aumenta correlaciona-se com as mudanças no recobrimento entre as funções de onda eletrônicas e a regiäo dopada.

E interessante notar que para planos estreitos de dopante, tanto a mobilidade de transporte quanto a quantica correspondente a subbanda E3 tornam-se menores que as respectivas mobilidades da subbanda E2, o que pode ser visto na Figura 6.5(b) e também na Figura $6.9(\mathrm{~b})$. Isto ocorre devido a que a subbanda E2 é descrita por uma funçầo de onda impar (anula-se em $z=0$, portanto), e esse futo acarreta numa reduçäo do recobrimento entre a funçäo de onda $e$ a regita dopada. Entretanto, à medida em que $\Delta_{d}$ aumenta, o recobrimento da funçäo de onda E2 com o plano de dopante cresce mais rapidamente que para a subbanda E3 e a mobilidade na subbanda E2 torna-se menor que a da subbanda E3 para perfis de dopagem mais alargados. Por outro lado, de se notar que as mobilidades eletronicas na subbanda E3 crescen com $\Delta_{a}$ na regiăo de perfis de dopugem estreitos, o que também respeita ao tamanho do recobrimento entre a funço de onda eletrônica desta subbanda com a regiáo dopada.

\section{Influëncia do perfil de dopagem nas mobilidades}

Para perfis de dopagem estreitos, os resultados teóricos obtidos para uma distribuiçăo gaussiana de doadores coincidern com aqueles obtidos para uma distribuçào retangular. A medida em que a largura da camada dopada aumenta, as mobilidades eletrônicas calculadas para as distribuiçöes gutussiana e retangular modificam o sen comportarnento.

As maiores diferença entre as distribuiçôs gaussiana e retangular säo observadas nas mobilidades quântica de transporte nas subbandass mais energúticas. Novamente, isto pode ser explicado em termos do recobrimento entre as funçōes de ondas das subbandas e a distribuiçấ normalizada de doadores. Para uma dada largura $\Delta_{d}$ da camada de doadores, a distributç̧ăo gaussiana possui uma extensão espacial maion que a retangular ao redor do centro da distribuição. Portanto, o recobrimento da regiăo dopada com as funçós de onda eletrônicas para as subbandas excitadas, as quais extendem-se para longe da camada dopada, é maior para uma distribuiçäo gaussiana do que para uma retangular. Em contrapartida, as subbandas menos energéticas säo descritas por funçoes de onda fortemente localizadas ao redor de $z=0$ e, portanto, menos sensiveis ao perfl exato da distribuiçäo de doadores.

Ao invés de decrescerem, as mobilidades quâticica de transporte da subbanda fundarnental mostram um pequeno aumento quando a espessura da camada dopada aumenta, dado que o recobrimento da funçăo de onda correspondente a esta subbanda com a regiäo dopada torna-se menor quando os átomos doadores estāo distribuitos de maneira mais esparsa.

Para ilustrar a correlaçăo entre as mobilidades eletrônicas e o recobrimento entre a funça de onda com a camada dopada, o tecobrimento calculado $\int \mathrm{d} z g_{\mathrm{d}}(z)\left|\chi_{\mathrm{i}}(\mathrm{z})\right|^{2}$ é mostrado na Figura 6.7 para as distribuiçôs gaussiana e retangular em funçäo de $\Delta_{\mathrm{d}}$, no caso onde $N_{\mathrm{d}}=5,0 a_{\mathrm{B}}^{-2}$.

Cormparando-se as Figuras $6.5(\mathrm{c})$ e (d) con a Figura 6.7 , verifica-se que para cada subbanda uma mudança no tecobrimento com a regiăo dopada é acompanhado por uma mudança oposta na mobilidade: quando $\int \mathrm{d} z g_{\mathrm{d}}(z)\left|\chi_{i}(z)\right|^{2}$ aumenta, $\mu(i)$ diminui vice versa. 


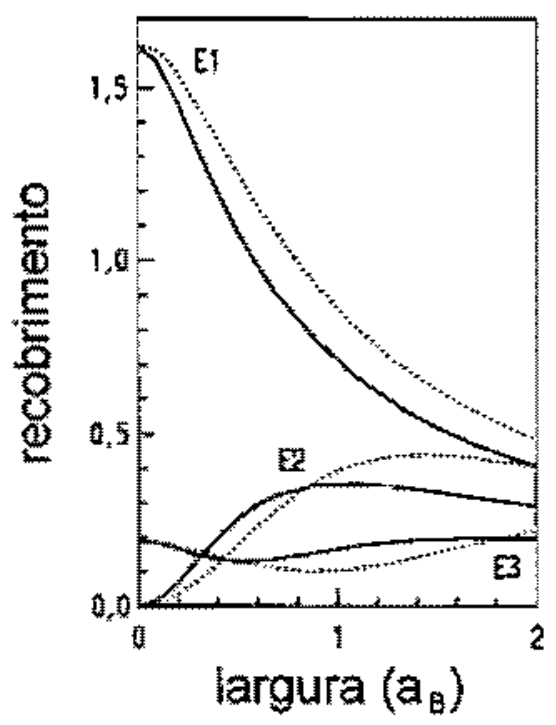

Figura 6.7: Recobrimento $\int_{-\infty}^{+\infty} \mathrm{d} z g_{\mathrm{d}}\left({ }_{\mathrm{u}}\right)\left|\chi_{i}(z)\right|^{2}$ em função da espessura da camada dopada calculado para um perfil gaussiano (linhas cheias) e para um retangular (linha pontilhada), para uma densidade de doadores de $N_{\mathrm{d}}=5,0 \mathrm{a}_{\mathrm{B}}^{-2}$. A densidade de aceitadores residuais foi tomada como sendo $N_{\mathrm{a}}=1,0 \times 10^{-4} a_{\mathrm{B}}^{-3}$. Os rótulos referem-se ao indice da subbanda correspondente a cada curva.

\section{Influência das impurezas aceitadoras nas mobilidades}

Outro aspecto importante a ser considerado é o papel das impurezas residuais carregadas que normalmente existem em sistemas reais: GaAs rââ dopado, crescido por MBE, é normalmente levenente do tipo p. Na Rel. [70], os autores demonstraram que os aceitadores residuais tem uma infuência significativa no formato do potencial confinante, já que as mobilidades eletrônicas são diminuidas se comparadas aos valores obtidos quando da năo consideração da presença dos mesmos aceitadores.

A medida em que a densidade dos doadores torna-se maior, a carga eletrônica contrabalanceia cada vez menos a carga dos doadores ionizados, conduzindo a um potencial cada vez mais confinante. Conseqüentemente. os elétrons são comprimidos cada vez mais para o centro da regiâo dopada, portanto aumentando a eficiência de espalhamento dos átomos doadores e reduzindo a mobilidade eletrônica. Isto é ilustrado na. Figura 6.8 para densidades de fundo de $N_{\mathrm{a}}=1,0 \times 10^{-4} a_{\mathrm{B}}^{-3}$ (linhas cheias) e $N_{\mathrm{a}}=5,0 \times 10^{-4} \mathrm{a}_{\mathrm{B}}^{-3}$, mostrando que para valores majores de densidades de aceitadores residuais, as funçöes de onda das subbandas tornam-se mais localizadas ao redor de $z=0$. sendo esse efeito maior para subbandas majs energéticas. 


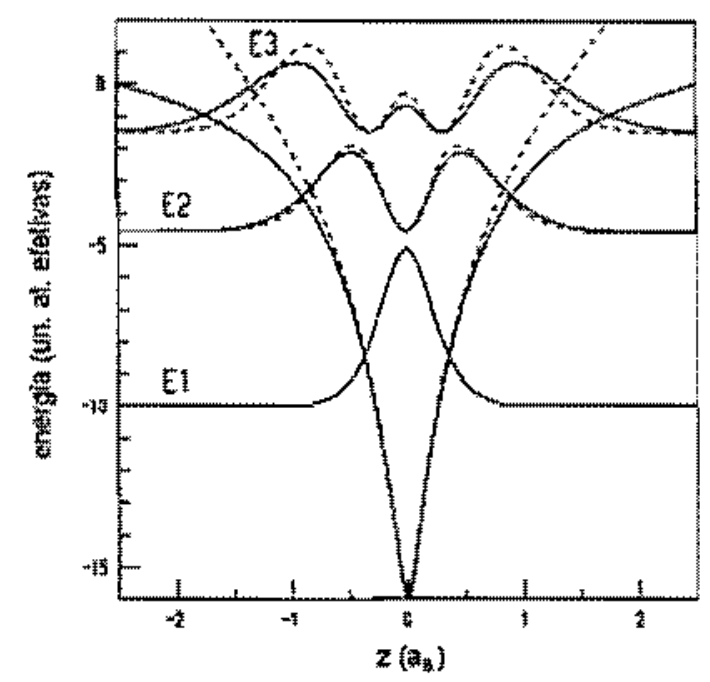

Figura 6.8: Potencial confinante e densidades das subbandas eletronicas para um semicondutor 8-dopado com $N_{\mathrm{d}}=5,0 \mathrm{a}_{\mathrm{B}}^{-2}$. Als linhas cheia e tracejada correspondem a densidades de aceitadores residuais de $N_{\mathrm{a}}=1,0 \times 10^{-4}$ e $N_{\mathrm{a}}=5 \times 10^{-3} a_{\mathrm{B}}^{-3}$, respectivanzente. A origem da escala de energia foi escolhida como sendo o nivel de Fermi, Os rótulos indicam a qual subbanda cada curva corresponde.
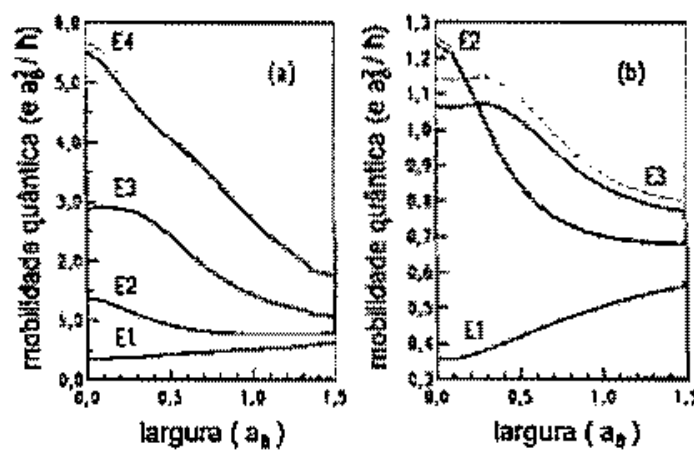

Figura 6.9: Mobilidades quâticas para um semicondutor 6 -dopado com $N_{\mathrm{d}}=5,0 \mathrm{a}_{\mathrm{B}}^{-2}, \mathrm{~N}_{\mathrm{a}}=$ $1,0 \times 10^{-4} \mathrm{ag}_{\mathrm{g}}^{-3}(\mathrm{a})$ e $N_{\mathrm{a}}=5,0 \times 10^{-3} \mathrm{a}_{\mathrm{q}}^{-3}(\mathrm{~b})$. As linhas pontihadas e cheias foram calculadas incluindo e ignorando o espalhamento pelos aceitadores residuais, respectivamente. $O$ fndice da subbanda correspondente a cada curva e indicado por um rótulo.

Como resultado da compressão do poço $\delta$, o número de subbandas ocupadas decresce de 4 para 3 , neste caso, quando a densidade de aceitadores residuais muda de $N_{\mathrm{a}}=1,0 \times 10^{-4}$ para 
$N_{\mathrm{a}}=5 \times 10^{-3} a_{\mathrm{B}}^{-3}$, A Figura 6.8 mostra que a funçăo de onda para a subbanda E3 é a mais afetada pela localizaça induzida pelos aceitadores. As mobilidades nas subbandas, obtidas a partir dos cálculos para os pocos $\delta$ mostrados a a Fig. 6.8, podem ser vistas nas Figs. 6.9(a) e (b).

A medida em que $N_{a}$ aumenta de $1,0 \times 10^{-4}$ para $5,0 \% 10^{-3} a_{\mathrm{B}}^{-3}$, nenhuma mudança signt ficativa ocorre nas mobilidades quânticas para as subbandas El e E2. Entretanto, o efeito de localiazço induzida por aceitadores na mobilidade da subbanda E3 é dramatico: a mobilidade é reduzida por um fator de aproximadamente 2.5 e que a mobilidade de E3 passa a ser menor do que a mobilidade de E2 para perfis de dopagem estreitos.

Adicionalmente à redução das mobilidades eletronicas através de uma forte localizaçäo de portadores livres, a presença de aceitadores residuais ionizados reduz a mobilidade eletrônica total simplismente pelo acréscimo do número total de centros espalhadores presentes no semicondutor. $\mathrm{O}$ efeito de espalhamento por aceitador nas mobilidades eletrônicas é sabido ser pequeno, já que para niveis de dopagern típicos de impurezas residuais, a carga de superfície dos aceitadores e suas densidades sấo muito menores que os mesmos valores para os doadores. Entretanto, devido a complexidade do modelo teórico a não é possivel, à partida, excluír o fato de

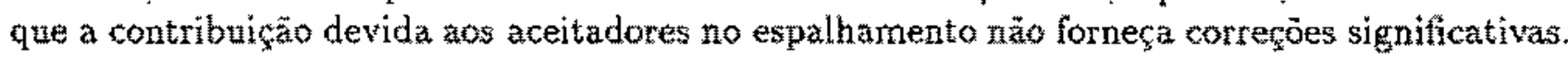

Uma estimativa quantitativa da contribuiçào dos aceitadores residuaís e seu efeito sobre o espalharnento total não foi feitza em trabalhos anteriores. $O$ espalhamento por aceitadores ionizados foi levalo em conta calculando-se a taxa de espalhamento utilizando-se o formalismo apresentado no Capitulo 5 , sendo que sua distribuiçẫo eै retangular. A Fig. 6.9 mostra as mobilidades quanticas para $N_{\mathrm{a}}=1,0 \times 10^{-4}$ e $3,0 \times 10^{-3} a_{\mathrm{B}}^{-3}$ (aproximadamente $1,0 \times 10^{14} \mathrm{e}$ $5,0 \times 10^{15} \mathrm{~cm}^{-3}$, respectivamente) com e sem a inclusão de do espalhamento por aceitadores residuais na teoria. $\mathrm{Da}$ Fig. 6.9 pode ser visto que o espalhamento por aceitadores residuais causa algum impacto nos valores das mobilidades quânticas das subbandas mais energetticas, enquanto que as subbandas de menor energia sảo praticanente insensiveis a esse efeito. Os resultados dos cálculos mostraram que as propriedades de transporte săo menos afetadas que as mobilidades quanticas. Como a Fig. 6.9 mostra, apenas a mobilidade quântica da subbanda E3 mostra alguma sensibilidade à incorporaça do espalhamento por aceitadores na teoria. A maior sensibilidade da subbanda E3 vem de seu maior recobrimento com a regiäo depletada, já que a subbanda E3 extende-se por un grande volume ao redor da camada $\delta$. como mostra a Fig. 6.8. As funçôes de onda das subbandas menos energéticas (E1 e E2) säo mais localizadas e suas mobilldades são dominadas ern maitor grau pelo espalhamento por doadores.

Digno de nota e fato de que a contribuição por aceitadores carregados na taxa de espathamento dos eltrons de E3 cresce muito lentamente com a densidade de aceitadores: na Fig. $6.9(b)$, a densidade de aceitadores foi tomada como sendo so vezes maior que na Fig. 6.9(a); de qualquer modo, as mobilidades teóricas obtidas com e sem a indusão do espalhamento por aceitadores residuais carregados permanece praticamente iguais. A pequena sensibilidade mostrada pela taxa de espalhamento eletronica nesse aumento de 50 veres na densidade de aceitadores residuats é devido a dois fatores:

- primeiramente, a densidade planar de aceitadores, a qual representa o múmero total de centros espalhadores incluidos na teoria. é proporcional à raiz quadrada da densidade volumétrita de aceitadores, portanto com crescimento sub-linear com $\mathrm{N}_{\mathrm{a}}$.

- em segundo lugar, devido ao fato de que para um maior valor de $N_{\mathrm{a}}$ o poço quâutico 
torna-se mais confinante.

Portanto, enquanto a densidade de portadores aumenta, o recobrimento da funça de onda de E3 com o volume ocupato pelos aceitadores ionizados decresce; conseqüentemente, a eficiencia de espalhamento dos aceitadores ionizados năo aumenta à mesma proporctăo da densidade planar de catga.

\subsubsection{Conclusōes}

A dependência das mobilidades das subbandas eletrónicas pelo formato das distribuiçôes de doadores correlaciona-se com o recobrimento entre as funçôes de onda e a regiäo espacial na qual os átomos doadores estäo situados. Foi mostrado que o formato da distribuiçäo de doadores é um ingrediente importante num cálculo realístico das mobilidades quântica e de transporte para um semicondutor dopado.

A dependencia a mobilidade pela espessura da regiăo dopada nas subbandas menos energéticas, $\mathrm{El}$ e E2. nảo mostra uma sensibilidade acentuada com o formato exato da distribuição de doadores. Em contrapartida, a dependencia das mobilidades com $\Delta_{d}$ para as subbandas excitadas é fortemente afetada pelo pernl exato da distribuicäo de toadores. Para a distribuiça gaussiana, as mobilidades das subbandas $\mathrm{E} 3$ on mais energeticas, decrescem mais rapidamente $\operatorname{com} \Delta_{\mathrm{d}}$ que para uma distribuigäo retangular, 0 que pode ser um ingrediente importante para um melhor acordo entre a teoria e a experiência. Porém, para distribuiçós de dopagem suficientemente estreitas (menos que $0,5 \mathrm{a}_{\mathrm{B}}$ ), o que pode ser obtido pelas técnicas modernas de crescimento epitaxial. o perfil exato da distribuição de dopantes é de pouca relevância, podendo ser aproximado por um plano ideal.

$O$ efeito do espalhamento por aceitadores residuais carregados foi igualmente examinado e uma estimativa qualitativa foi feita, demonstrando que para níveis típicos de dopagem residual por aceitadores, o espalbamento contribui somente com uma correçäo pequena para a mobim lidade quântica nas subbandas mais energéticas. A inclusão do espalhamento por aceitadores na teoria aumenta a cute computacional e deve ser somente justificado quando uma pequena correçầ à mobilidade quăntica nas subbandas mais excitadas for relevante. 


\section{Capítulo 7}

\section{Comparação das mobilidades em sistemas 2D-3D com a teoria}

Do ponto de vista teórico, os cálculos das mobilidades eletrônicas em amostras com um único poço $\delta$ foram feitos utilizando-se o modelo de Thomas-Fermi $[12,13,61]$ ou a aproximação RPA $\{10,13,69,66,70\}$ para descrever a interaçüo blindada entre os portadores confinados e as impurezas ionizadas. Os cálculos téricos feitos utilizando-se a aproximação RPA mostram um bom acordo com as estimativas experimentais $[10,69]$, enquanto o acordo é ruim quando o modelo de Thomas-Fermi é utilizado. Neste capitulo, o tratamento RPA, aplicado a poços isolados, será extendido a super-redes de modulaçäo de dopagem.

Até a publicação do artigo de Henriques et al. [5l], cálculos para as mobilidades em sistemas 8-dopados periódicos ainda năo haviam sido feitos. Nesse tipo de sistemas, as mobilidades teónicas săo calculadas a partir das mesmas grandezas das quais sāo extraídas as mobilidades para sistemas com um único poço $f$, ou seja, a partir de seus espectros energéticos e funçöes de onda juntamente a um modelo para o potencial eletrostático das impurezas ionizadas.

Neste capitulo serão apresentados os resultados teónicos para as mobilidades eletrônicas das minibandas de super-redes oflopadas, deseritz por extados de Bloch em contraste ao poco isolado, cujas funcões de onda săo espacialmente localizadas ao redor da camada dopada.

\subsection{Resultados}

\subsubsection{Caracterização CV das super-redes}

Foi mostrado por Ulrich et al.[38] que o espectro CV de um semicondutor $\delta$-dopado é muito sensivel à dispersẫo dos átomos da impureza. De modo a estimar a largura caracteristica da camada dopada em nossas amostras, procedeu-se de acordo com o que segue. A amostra No. 187 , contendo urn único poço $\&$ de $\mathrm{Si}$, foj crescida nas mesmas condiçốs utilizadas para - crescimento das amostras que continham super-redes. De modo a tomar vantagern do fato de que a técnica CV apresenta uma resolução maior para maiores concentraçöes na camada dopada, a arnostra No. 187 foi mais fortemente dopada que as outras amostras utiliatadas neste trabalho. A densidade por unidade de área dos portadores confinados nesta amostra foi obtida do espectro de $\mathrm{SAH}$, segundo a prescrição do Capítulo 4 . Utilizando a densidade de portadores obtidas do espectro de $\mathrm{SdH}$, perfis teóricos CV foram gerados resolvendo-se 
auto-consistentemente as equaçöes de Schrödinger e Poisson para a estrutura sob polariaação; nos cáloulos do espectro CV. o perfil de distribuiçäo de impurezas foi assumido como sendo gaussiano e a FWH da gaussiana foi variada até que o espectro CV teórico obtido estivesse no melhor acordo com o espectro CV experimental.
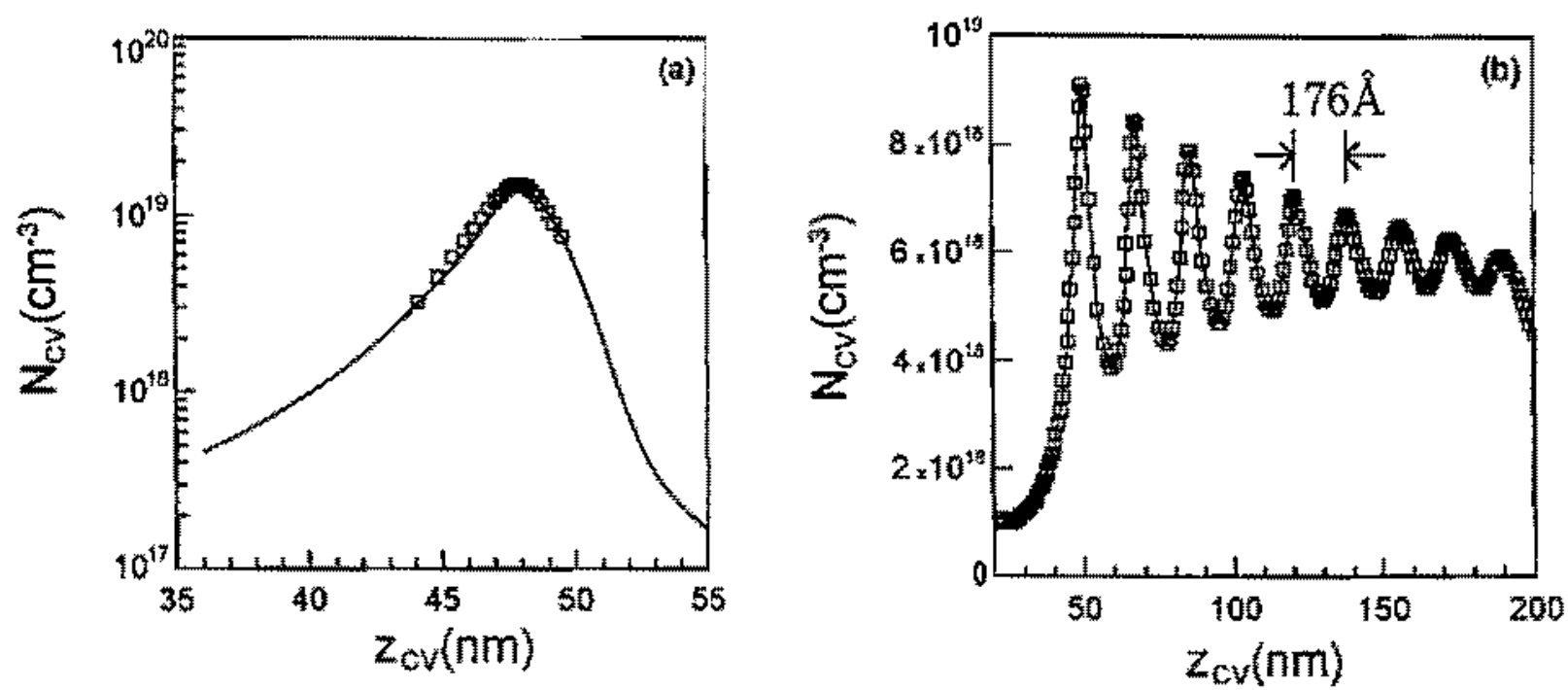

Figura 7.1: (a)Perfil de capacitancia-voltagen medido para a amostra 187 (quadrados) para $T=300 \mathrm{~K} . \mathrm{O}$ espectro $\mathrm{CV}$ teórico (linha cheia) foi gerado assumindo $N_{\mathrm{S}}=8,3 \times 10^{12} \mathrm{~cm}^{-2}$ e os átomos de Si distribudós de acordo com uma funçăo gaussiana de largura a meia altura de $8 \AA$. (b) Perfil de capacitanciamvoltagern para a amostra 200. A periodicidade dos picos indica que o periodo de dopagem para essa estrutura é $176 \mathrm{~A}$.

A Figura 7.1 (a) mostra o espectro $C V$ para a amostra No. 187. A curva térica mostrada na Figura 7.1 (a) foi calculada assumindo que a FWH do poço fosse igual a 8 , e reproduz bastante bem o espectro $\mathrm{CV}$ experimental. Isto demonstra que os átomos de Si nas amostras que utilizamos para esse trabalho estäo limitadas a uma dispersăo de apenas 2 monocamadas de $\ln P$.

Para determinarem-se os periodos de dopagem da várias amostras, seus espectros CV foram medidos. Como exemplo, ospectro (V para amostra No. 200 é mostrado na Figura 7.1(b). A concentração CV, $N_{C V}$, apresenta oscilaçoes em funçăo da profundidade CV, zCV. As oscilaçöes vistas na Figura $\mathrm{i} .1(\mathrm{~b})$ mostram uma periodicidade de $176 \mathrm{~A}$, a qual tornamos como sendo igual ao periodo de dopagem desta estrutura, de acordo com o apresentado no Capítulo 3 ; os periodos de dopagen obtidos para todas as amostras, do mesmo modo, säo mostrados na Tabela 7.1 .

\subsubsection{Determinaçäo da população de portadores e parâmetros das minibandas}

A concentração planar total de portadores $N_{S}$ para cada amostra foi extraida a partir do espectro SdH. A Figura 7.2(a) mostra o espectro de magnetoresistência para amostra No. 196 
e a Figura $7.2(b)$ mostra a transformada de Fourier das oscilaçôes SdH tomadas em campo inverso.
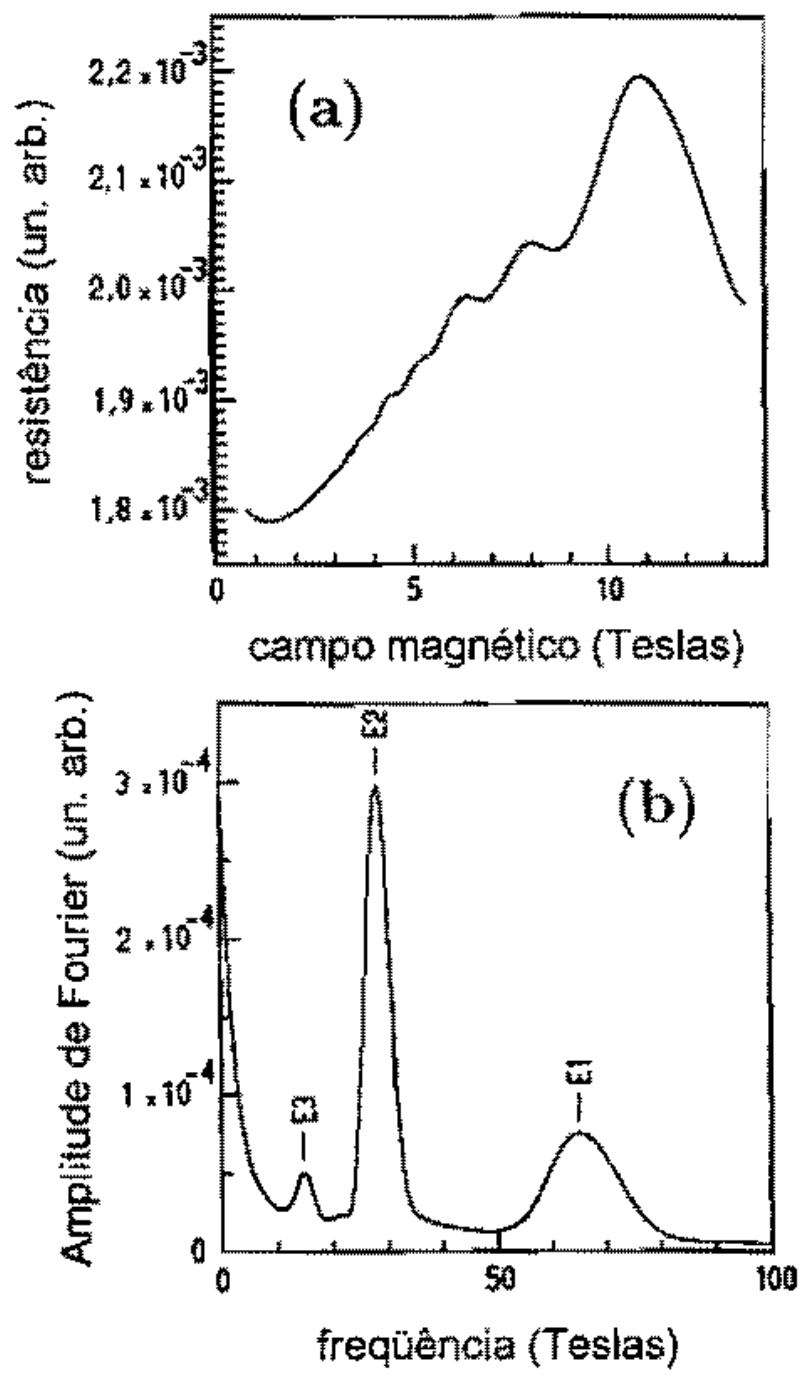

Figura 7.2: (a) Espectro de Shubnikov-de Has para a amostra 196 (b) Transformada de Fourjer do espectro de Shubnikoy de Haas tomado en campo inverso l/ 8 e derivado, para a arnostra

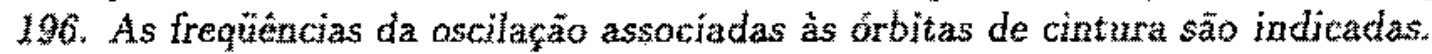

Antes de se efetuar a transformada de Fourier com o objetivo de reduzir a infuencia do fundo magnetoresistivo no qual as oscilaçōes de SdH estäo superpostas, as curvas de magnetoresistencia foram derivadas. Cada un dos picos vistos na Fig. 7.2 corresponde a uma órbita de cintura de uma das minibandas populatias; a posição do pico determina as seçôes de corte extremas da mini superficie de Fermi, em unidades de $h / 2 \pi e$.

Para determinarem-se os valores de $N_{S}$, foi necessário resolverem-se auto-consistentemente as equaçöes de Schrödinger e Poisson (como visto no Capitulo 2) para cada amostra. No cálculo, o período de dopagem foi fixado como sendo o valor obtido pelas medidas CV, os ătomos de Si foram tomados como sendo distribuídos de acordo com uma funçăo gaussiana com 
FWHM de $8 \AA$, como deduzido do espectro CV. O inico parâmetro adicional neste cálculo, a concentraçẫo de portadores $N_{\S}$, foi variado até que todas a freạieñncias de oscilação calculadas. ou seja, as frequëencias de oscilaçäo correspondentes às órbitas de cintura aproximassem-se simultaneamente de todas as frequềncias obtidas a partir do espectro de SdH. como prescrito em detalhe no Capitulo A. Os resultados da análise dos espectros $\mathrm{CV}$ e das oscilaçōes de SdH estào sumarizados na Tabela 7.1 .

\begin{tabular}{|c|c|c|c|c|c|c|c|c|c|}
\hline \multirow[t]{2}{*}{ Amostra } & \multirow{2}{*}{$\begin{array}{l}\text { No. de } \\
\text { periodos }\end{array}$} & \multirow{2}{*}{$\stackrel{d}{(A)}$} & \multicolumn{3}{|c|}{ SdH Experiência ( $\mathrm{T}$ ) } & \multicolumn{3}{|c|}{ Calculado (T) } & \multirow{2}{*}{$\begin{array}{c}N_{S} \\
\left(\mathrm{~cm}^{-2}\right)\end{array}$} \\
\hline & & & $B_{E !}^{S d H}$ & $B^{\text {SadK }}$ & $B_{E 3}^{S d A}$ & $B_{E 1}^{T E D}$ & $B_{E 2}^{T \& O}$ & $B_{F}^{T=0}$ & \\
\hline 194 & 5 & 92,0 & 85,4 & 43.1 & - & 86,3 & 42,3 & - & $4,27 \times 10^{12}$ \\
\hline 206 & 10 & $10 \%$ & 89.7 & 47,9 & - & 90,3 & 48,7 & - & $3,08 \times 10^{12}$ \\
\hline 198 & 5 & 128 & 74,9 & 38,6 & - & 75,4 & 40,2 & - & $4,50 \times 10^{12}$ \\
\hline 207 & 10 & 133 & $80 . \bar{T}$ & 46.0 & - & 79.2 & 46,2 & - & $5,08 \times 10^{12}$ \\
\hline 200 & 10 & 176 & 62,2 & 32.2 & - & 63,8 & 32,4 & 9,1 & $4,27 \times 10^{12}$ \\
\hline 197 & 5 & 225 & 73.7 & 33.8 & - & 73,7 & 34,9 & 17,0 & $5,38 \times 10^{12}$ \\
\hline 199 & 10 & 245 & 73,1 & 25,9 & 11.1 & 7,6 & 27,2 & 11,2 & $5,26 \times 10^{12}$ \\
\hline 196 & 5 & 278 & 65,4 & 28.1 & 15,0 & 68.2 & 28,4 & 15,9 & $4,98 \times 10^{12}$ \\
\hline 164 & single & - & 69,6 & 24,0 & 6,8 & 70,8 & 24,5 & 6,7 & $5,07 \times 10^{12}$ \\
\hline
\end{tabular}

Tabela 7.1: Parâmetros das amostras estudadas. O perídodo de dopagen $d$ foi obtido a partir

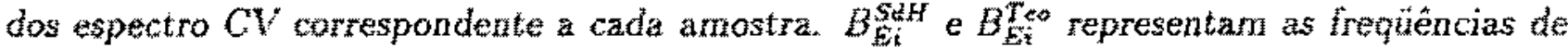
oscilaçäo experimental e teórica associadas à órbita de cintura no espaço $k$. A concentração total de portadores $N_{\mathrm{S}}$ mostrada é aquela que fornece o melhor acordo da teoria com a experiencia.

Para amostras com periodos menores que $200 \mathrm{~A}$, as oscilaşôs quânticas associadas com a minibanda $E_{3}^{3}$ aăo foram observadas. Isto é uma indicacäo que nesta gama de períodos de dopagem, o minigap entre as minibandas E2 e E3 é menor que o alargamenio dos niveis de energia, o que quer dizer que para os fins práticos, as minibandas E3 e E2 são uma só. Nestas circunstâncias, apenas á órbita de cintura associada à minibanda E2 se manifestará através das oscilaçóes na magnetoresistència, o que é uma caracteristica de um comportamento trídimensional, como visto na Sec. 5.5 . Fn períodos ainda menores $(d<150 \AA)$, a minibanda E3 é esvaziada de portadores.

Adicionalmente a concentraçăo de portadores livres, os cálculos auto-consistentes fornecem como saída a energia de Fermi $\Phi_{n}$, a largura $W_{n}$ e o fator de dispersão $\varepsilon_{n}$ para todas as minibandas. Os parämetros obtidos sāo mostrados na Tabeia 7.2. 


\begin{tabular}{|c|c|c|c|c|c|c|c|c|c|}
\hline Amostra & $\begin{array}{c}W_{1} \\
(m e V)\end{array}$ & $\begin{array}{c}\dot{\phi}_{1} \\
(\mathrm{meV}) \\
\end{array}$ & $\epsilon_{1}$ & $\begin{array}{c}W_{2} \\
\left(\mathrm{meV}^{2}\right)\end{array}$ & $\begin{array}{c}\phi_{2} \\
(\mathrm{meV})\end{array}$ & $\varepsilon_{2}$ & $\begin{array}{c}W_{3} \\
(\mathrm{meV})\end{array}$ & $\begin{array}{c}\phi_{3} \\
\text { (meV) }\end{array}$ & $\epsilon_{3}$ \\
\hline 194 & 43,7 & 127,0 & 0.21 & 152,9 & 57.5 & $=$ & - & 0,0 & - \\
\hline 200 & 26.4 & 130.2 & 0,16 & 105.8 & 68.8 & $=$ & - & 0,0 & - \\
\hline 198 & 14.8 & 107.8 & 0.12 & 69.4 & 56.9 & - & - & 0.0 & - \\
\hline 207 & 11,0 & 118,3 & 0,09 & 61,0 & 64,0 & - & - & 0,0 & - \\
\hline 200 & 3,2 & 91.4 & 0,03 & 31.7 & 44,7 & 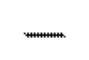 & عسm & 0,0 & - \\
\hline 197 & 2,8 & $10 \%, 1$ & 0,00 & 11,4 & 45,4 & - & س & 0,0 & - \\
\hline 190 & 1,4 & 102,3 & 0,00 & 8,1 & 41.2 & $\ldots$ & - & 22,4 & - \\
\hline 196 & 0,0 & 95,5 & 0,00 & 4.6 & 35,9 & 0,11 & 19,9 & 19,0 & - \\
\hline 164 & 0,0 & 96.7 & 0,00 & 0,0 & 37,2 & 0,00 & 0,0 & 11,4 & 0,0 \\
\hline
\end{tabular}

Tabela 7.2: Parâmetros para as minibandas obtidas do modelo teórico. A largura en energia $e$ a energia de Fermi para cada ninibanda, respectivamente $W_{n}$ and $\phi_{n}$. săo os valores obtidos da soluçấo auto-consistente das equaçöes de Schrödinger e Poisson utilizando-se d e $N_{\mathrm{S}}$ da Tabela 7.1. O parâmetro $\epsilon_{n}$ fọi obtido ajustândo-se a relação de dispersẫo numérica, $E_{n}(k)$, com a Equação (5.36), e é indicado para minibardas que obedecem o comportanento quasi-2D (Eq. (5.35)).

\subsubsection{Isolamento das contribuiçōes individuais das minibandas à magnetoresistëncia}

As componentes oscilatórias individuais foram separadas do espectro de magnetoresistência aplicando-se um filtro de banda passante gaussiano no espectro de Fourier. Os parâmetros desse filtro eram a frequêencia do pico e a largura at meia altura (FWHM). Isso é ilustrado nas Figuras 7.3(a)-(d) para a amostra No. 196. A amostra No. 196 foi escolhida para exemplificar os resultados do procedimento de filtragem devido a que nesta amostra cada minibanda está associada a um tipo de caracteristica que pode ser exibida pelas componentes magneto-oscilatórias em semicondutores periodicamente d-dopados:

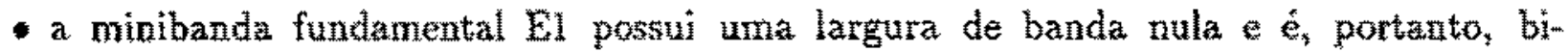
dimensional, fornecendo uma contribuição à magnetoresistência que obedece a Eq. (5.37);

- a minibanda E2 possui uma largura de banda pequena, $W_{2}<\Phi_{2}$, o que corresponde a uma dimensionalidade intermediária entre 2 e 3 , e suas oscilações na magnetoresistência obedecerä̀ a relação Eq. (5.35);

- a minibanda $\mathrm{E}_{3}$, que possuj uma grande largura de banda, $W_{3}>{ }_{3}$, efetivamente tridimensional, o que implica que as ostilaçöes na magnetoresistència seráo descritas pela Eq. (5.38)

Portanto, a amostra No. 196 serve ao propósito de ilustrar o procedimento de filtragem utilizado e os procedimentos de ajuste das oscilaçoes individuais à teoria sobre qualquer circunstância que possa ocorrer em qualquer tipo de sistema com dopagem periódica. 

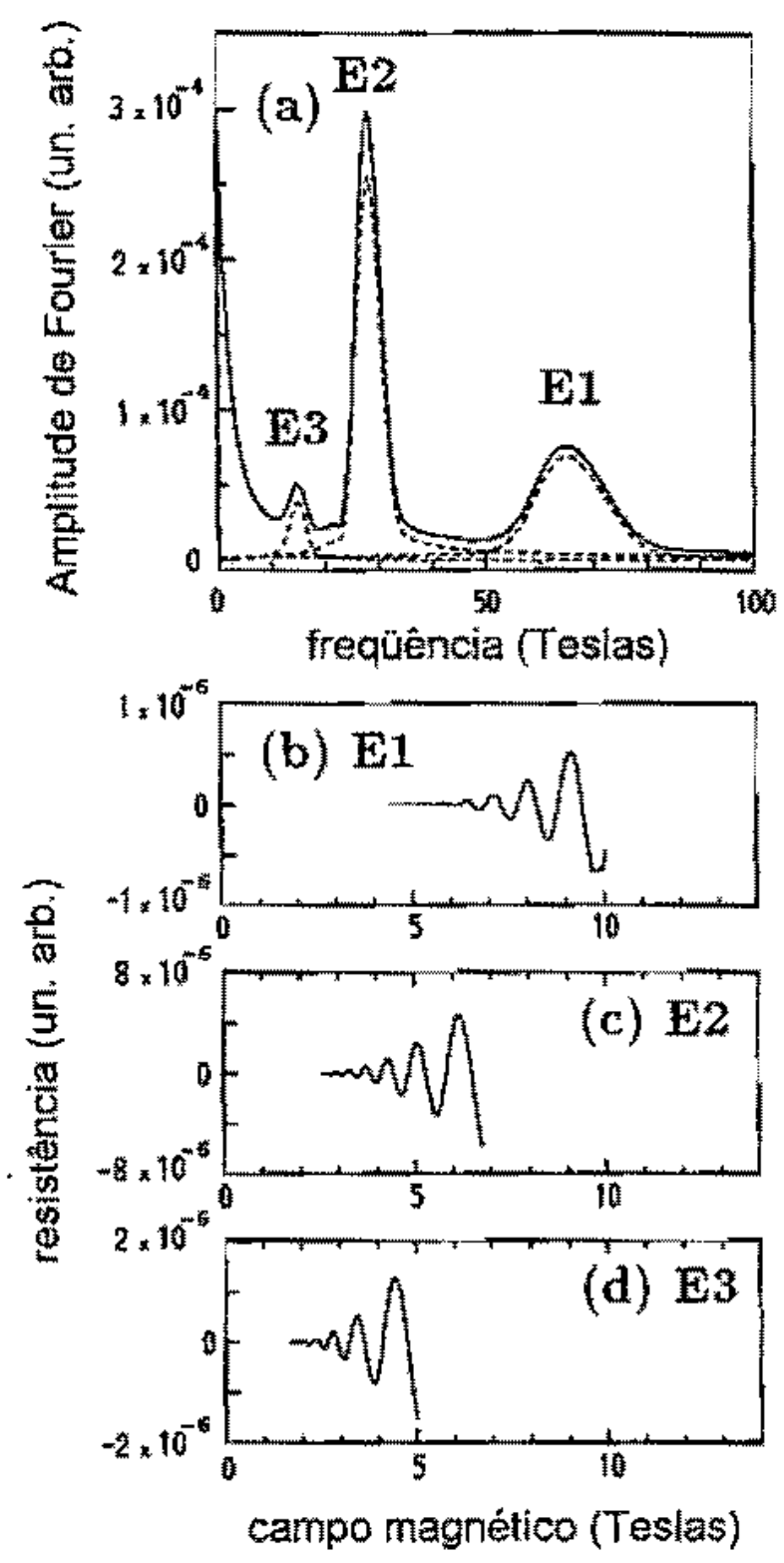

Figura 7.3: (a) Transformada de Fourier do espectro de SdH para a amostra 196; as linhas tracejadas mostram a transformada te Fourier filtrada utilizada para isolar cada um dos picos detectados; (b)-(d) mostram as oscilaçoes isoladas correspondentes is minibandas E1, E2, $€$ E3, respectivamente.

A Figura 7.3 mostra a transformada de Fourier da curva de $S d H$; 2 s linhas tracejadas mostram a transformada de Fourier flltrada, com os parâmetros to filtro de banda passante ajustados para isolar cada um dos picos de Fotrier observados. Apos aplicaça do filtro, todos os passos que conduziram à transformada de Fourier claquela irequência isolàda foram revertidos: a transtormada de Fourier inversa foi obtida $e$ as oscilaçöes na maguetoresistencia 
foram integradas numericamente. As Figuras $7.3($ b)-(d) mostram as componentes oscilatónias isoladas obtidas para amostra No. 196. As componentes oscilatórias abrangem uma gama menor de campos do que o intervalo medido $(0-14 \mathrm{~T})$ devido a que um intervalo nas extremidades (cujo comprimento é inversamente proporcional ao FWHM do filtro de Fourier) é perdido devido a efeitos de extremidade (como pode ser visto na Ref. [j 1$]$ ).

\subsubsection{Estimativa experimental para as mobilidades quânticas}

A mobilidade quantica associada a cada uma dus minibandas populadas foi obtida através de um ajuste com a teoria da contribuiçầ das minibandas a magnetoresistência, isoladas do resto do espectro de $\mathrm{SdH}$ como descrito na Seção 7.1 .3 . As oscilaçôes individuais foram ajus" tadas à Eq. (5.37) quando a largura em energia da minibanda era pequena $\left(W_{n}<\phi_{n}\right)$ ou à Eq. (5.35) quando a largura da minibanda era nâo nula $\left(W_{n}<\phi_{n}\right)$. Os parânetros $W_{n}$, $\phi_{n}$ e $\epsilon_{n}$ utilizados na equaça de ajuste foram tomados como sendo aqueles dados na Tabela 7.2 . sendo a temperatura fixa em $4,2 \mathrm{~K}$, o mesmo valor da experiéncia. $\mathrm{O}$ único parâmetro restante, $\mu_{Q}$, fol ajustado de rnodo a que o melhor acordo fosse obtido com a experiêtucia.

Para ilustrar o procedimento de ajuste, as oscilaçoes individuais e as curvas ajustadas para a amostra No. 196 să mostradas na Figura 7.4 .

Um ajuste com a teoria. neste caso, conduziu a $\mu_{Q}(E 1)=410 \mathrm{~cm}^{2} / \mathrm{V}$ s. $\mu_{\mathrm{Q}}(E 2)=1320$ $\mathrm{cm}^{2} / \mathrm{V}$ s e $\mu_{\mathrm{Q}}(E 3)=3630 \mathrm{~cm}^{2} / \mathrm{V}$ s. Todas as outras amostras receberam o mesmo tratamento e os valores obtidos para as várias mobilidades quânticas graficados contra o periodo de dopagem podem ser vistos na Figura 7.5

\subsubsection{Comparação com a teoria e discussão}

Os resultados experimentais mostram que, part um determinado periodo de dopagem, a mobilidade quântica cresce com o indice da minibanda. As mobilidades qutantícas experimentais associadas ì̀ minibanăka individuais säo mostradas por pontos na Figura 7.5 em funçäo do período de dopagem $d$.

Para valores grandes de $d$, os poços adjacentes desacoplam-sez as mobilidudes quânticas para as minibandas obtidas para a amostra No. 164, a qual contérn un único poco, é graficada na Fig. 7.5 em $4=800 \AA$.

Quando o periodo diminui, a mobilidade na minibanda $E l$ permanece quase que inalterada. A mobilidade quântica experimental para a minibanda $\mathrm{E} 2$ năo apresenta uma dependência suave com o período de dopagem, o que é atribuido à ffutuaçüo na densidale de portadores nas amostras (ver a Tabela 7.1) e limitada precisäo dos valores experimentais das mobilidades. De qualquer modo, os dados experimentais graficados na Figura 7.5 mostram claramente que na regia $d<200 \mathrm{~A}$, a mobilidade quäntica da mintbanda $\mathrm{E} 2$ decresce à medida em que período de dopagern torna-se menor. Finalmente, a mobilidade quântica dos portadores na

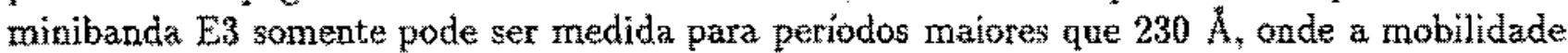
medida forneceu um valor de aproximadamente $3500 \mathrm{~cm}^{2} / \mathrm{V} s$.

As mobilidades quânticas téricas foram calculadas em função do período de dopageñ para concentraçoes de portadores de $N_{s}=4,3 \times 10^{12} \mathrm{~cm}^{-3}$ e $N_{\mathrm{S}}=5,4 \times 10^{12} \mathrm{~cm}^{-2_{*}}$; estes valores correspondem aos limites inferior e superior das concentraçoses de portadores livres nas amostras estudadas. As quantidades de entrada foram a energia de Fermi, o espectro energético das 


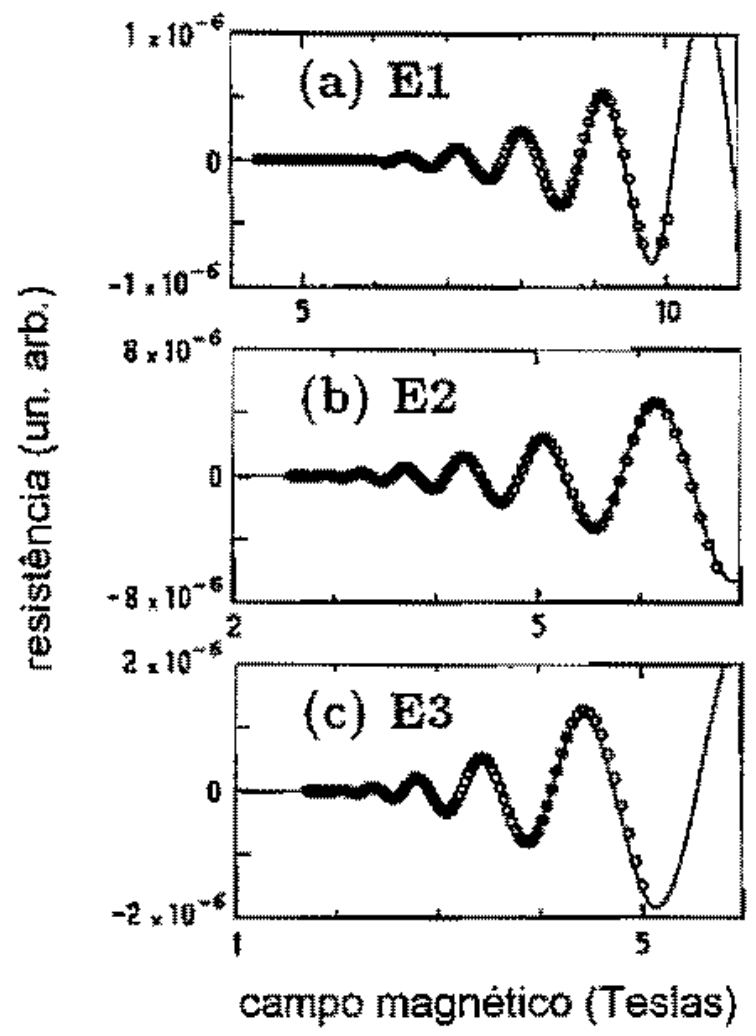

Figura 7.4; Oscilaçồs na magnetoresistência associadas com as minibandas individuais para a amostra 196. Os pontos representam as oscilacöes obtidas experimentalmente e as curvas cheias correspondem à teoria. (a) Oscilaçöes isoladas devido à minibanda fundamental, E1, e o resultado teórico pelo uso da Eq. (5.35); (b) O mesmo para a miabanda E2; (c) Oscilaçöes devidus a minibanda Es e o resultato teórico obutido pelo uso da Eq. (5.38)

minibandas e suas funçôes de onda, obtias a partir da soluçäo auto-consistente das equaçóes de Schrodinger e de Poisson. As mobilidades quanticas foram calculadas utilizando os resultados para mobilidades quânticas em sistemas periódicos (Seçäo 5.3), assumindo condiçōes periódicas de contorno num intervalo de quatro períodos te dopagem, incorporando nos cálculos apenas estados quãnticos pertencentes às três minibandas menos energeticas. Os resultados da teoria säo mostrados por linhas cheias na Figura 7.5 .

A Figura 7.3 mostra que para a minibanda $\mathrm{E} 1$, as mobilidades quânticas teónictas estão em excelente acordo com as obtidas experimentalmente. Para as minibandas excitadas $\mathrm{E2} \in \mathrm{E} 3$, existe uma concordância dentro de uma ordem de magnitude entre a teoria e a experiência, embora o acordo geral năo seja tăo bom como para a minibanda E1. Apesar disso, Eo nóvel como a teoria reproduz a característica principal da dependência da mobilidade quântica de $\mathrm{E} 2$ com o periodo $t_{,}$ou seja, um decréscimo na direçäo te periodos da super-rede menores. 


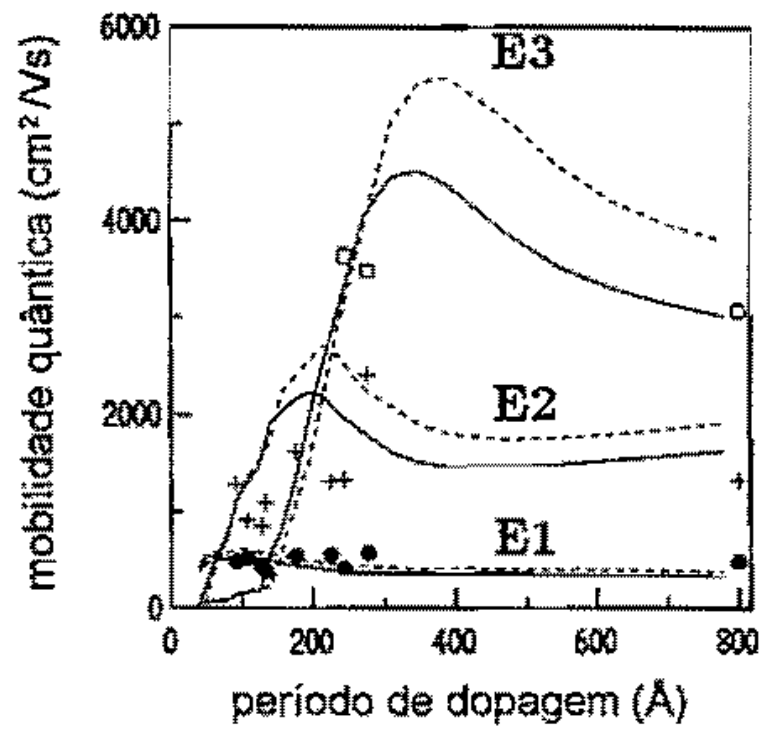

Figura 7.5: Mobilidade quântica em função do período de dopagern. Os círculos, cruzes e quadrados representam os resultados experimentais correspondentes às minibandas E1, E2 e E3, respectivamente; as linhas tracejadas e chelas säo o resultado teórico para $N_{\Im}=4.3 \times$ $10^{12} \mathrm{~cm}^{-2}$ e $N_{S}=5.4 \times 10^{12} \mathrm{~cm}^{-2}$, respectivamente.

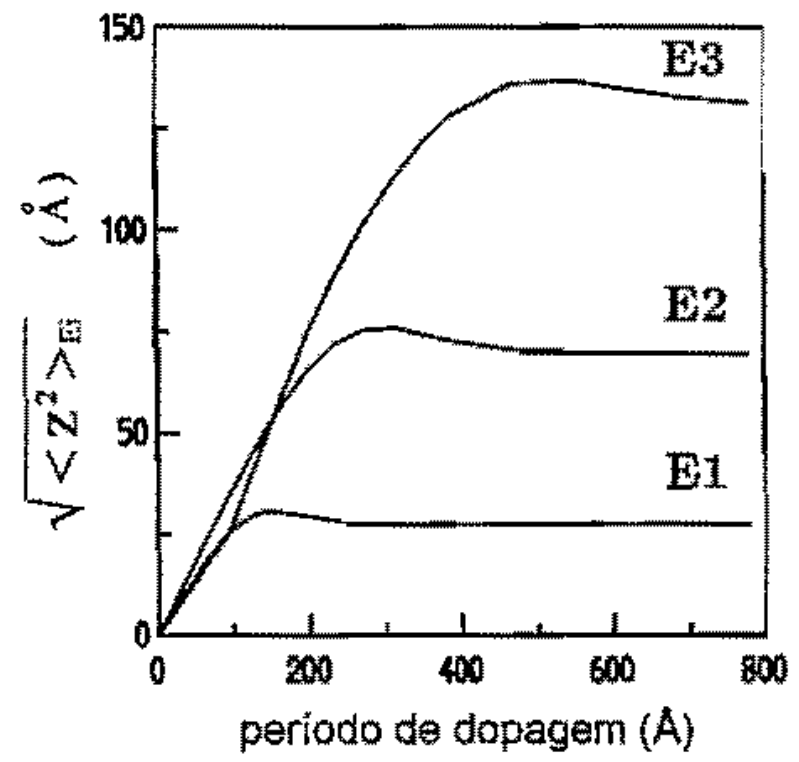

Figura 7.6: Distância média entre portadores confinados nas minibandas $E 1, E 2$ e E3 em funçäo do período de dopagern para una super-rede periódica $\delta$-dopada de InP com $N_{\mathrm{S}}=$ $4.6 \times 10^{12} \mathrm{~cm}^{2} /$ s. Os cálculos foram efetuados utilizando-se a Eq. (7.1).

Este capitulo pode ser sumarizado estabelecendo que, para um dado periodo da super-tede, 
a mobilidade quântica é maior para as subbandas mais energéticas e, quando o periodo diminut, as mobilidades quânticas diminuem. $O$ decréscimo nas mobilidades a medida em que o período diminui acontece quando $d \approx 300 \mathrm{~A}$ para a minibanda $\mathrm{E} 3$, mas somente quando $d \approx 200 \mathrm{~A}$ para a minibanda E1; para a minibanda E1, a teoria prediz um comportamento decrescente somente quando $d \approx 0 \mathrm{~A}$.

Estes resultados podern se explicados pela dependencia do comprimento de blindagem dos portadores com o periodo de dopagem $d$. Como mostrado no Capitulo 6 para amostras $\delta$ dopadas com uma única camada de doadores e para amostras $\delta$ dopadas polarizadas, a mobilidade é muito sensivel à distància mếdia entre a camada dopada e os portadores. A distância média entre portadores confinados na minibanda Ei e uma camada dopada colocada em $z=0$ pode ser estimada, neste caso, por $\sqrt{\left\langle z^{2}\right\rangle_{E i}}$, onde

$$
\sqrt{\left\langle z^{2}\right\rangle_{E t}}=N \int_{-d / 2}^{d / 2} \mathrm{~d} z z^{2}\left|w_{i}\left(k_{\text {rintura }}, z\right)\right|^{2}
$$

Um gráfico de $\sqrt{\left\langle z^{2}\right\rangle_{\text {Ei }}}$ para uma densiáade de portadores de $N_{S}=4,6 \times 10^{12} \mathrm{~cm}^{-2}$ é mostrado na Figura 7.6 .

Uma comparaçăo da Figuras 7.6 com a Figura 7.3 revela uma correlaçào surpreendente entre o andamento da mobilidade quăntica em una minibanda e a distância média entre seus portadores e camada dopada.

\subsection{Conclusōes}

As oscilaçöes de Shubnikov-de Haas foram medidas para supez-redes periodicamente $\delta$ dopadas de InP em funçäo do período de dopagem em amostras com densidades em torno $\sim 4.9 \times 10^{12} \mathrm{~cm}^{2}$ por camada dopada e periodos na faixa de 90 a $300 \mathrm{~A}$. Foi verificado gue cada minibanda manifesta-se no espectro de SdH através de uma única componente oscilatória, a qual corresponde à seça extrema da mini-superficie de Fermi correspondente ắnita de cintura. As oscilaçóes de carater quântico associadas as minibandas individuais foram isoladas do espectro de magnetoresistividade por técricas de Fourier. Das componentes oscilatórias individuais, a mobilidade quântica para cada minibanda foi estimada.

O modelo teórico desenvolvido apresentou um bom acordo com os resultados experimentais. As predicones teóricas do modelo mostram que as mobilidades crescem com o indice da minibanda e decrescem quando o período de dopagem diminui. $O$ começo dessa diminuiça ocorre em $d \sim 200 \AA$ para a minibanda $E 2$ abaixo de $d \sim 50 \mathrm{~A}$ para a minibanda $E 1$. A dependencia da mobilidade quântica numa minibanda individual em funçẵo da distância entre planos de dopantes mostra uma clara correlação com a mesma dependencia da funçăo da distância média entre seus portadores e o plano dopado. Isto demonstra que a distância média entre os portadores confinados e as impurezas é determinante no valor absoluto da mobilidade que pode ser obtida em sistemas $\delta$-dopados. 


\section{Capítulo 8}

\section{Mobilidades de transporte em sistemas $\delta$ dopados}

Seri descrito no corrente texto o formalismo do espectro de mobilidade, baseado num modelo serni-clássico de transporte eletrónico que foi desenvolvido por Beck e Anderson [72], em trabalho original, a partir de um desenvolvimento da equação de transporte de Boltzmanm por McClure[13]. Na notaça de McClure, as componentes do tensor de magnetocondutividade são expresses em séries infinitas, com termos individuais dependentes do campo magnético, da topologia no espaço de momentos e do tempo de relaxação en funçũo da energia das orbitas ciclotronicas.

A técnica do espectro de mobilidade foi aplicada com sucesso por Beck e Anderson na deter minaçäo aproximada das mobilidades de transporte e populaçăo de portadores em amostras de HgTe [74] e em hetero-estruturas de GaAs/AlGaAs [75]. Em outro trabalho [41, esta técnica é aplicada em sistemas $S_{1}: 3$ - - GaAs com bons resultados para as mobilidades de transporte.

Esse formalismo constituinse numa ferramenta para análise do fundo magnetoresistivo clássico podendo ser útil na determinatzo do número de portadores $N_{i}$ e respectivas mobilidades de transporte $\mu_{\mathrm{Ti}}$, Conforme será apresentado, a técnica do espectro de mobilidade por si só, näo permite avaliar diretamente as mobilidades de transporte em sistemas con múltiplas subbandas e a sua interpretação é dependente dos modelos para o espalhamento. A interpretação do espectro de mobilidade passa ser importante em altas temperaturas, já que as oscilacoes de SdH desaparecem quando a temperatura for superior a temperatura de Dingle das subbandas.

A teoria do espectro de mobilidade parte do modelo de Boltzmann para o transporte na aproximação de tempo de relaxação dependente da energia e, portanto, prevê a apenas a possibilidate do comparecimento de efeitos semi-clússicos no tensor de resistividade. $O$ modelo é valido, portanto, em regiôes de campo magnético da magnetoresistência aonde nâo comparecem efeitos quânticos, como as oscilaçồ $\$ \mathrm{dH}$ e magneto-resistividades anômalas.

Neste capitulo é apresentado un trabalho prelininar, ou seja, e säo disculidas as dificuldades associada à determinaço das mobilidades de transporte em sistemas $\delta$-dopados. Como será visto, a determinação das mobilidades de tramporte individuais nesses sistemas é fortemente dependente da disponibilidade de um equipamento capaz de manter temperaturas controladas acima de $4,2 \mathrm{~K}$ para a obtençäo das componentes do tensor de magnetoresistividade. 


\subsection{Populações e mobilidades individuais de transporte via medidas Hall}

A partir de medidas das componentes do tensor de resistividade $p_{x x}(B)$ e $p_{y z}(B)$, obtém-se as componentes do tensor de condutividade $\sigma_{z a n}(B)$ e $\sigma_{7 y}(B)$ pelas relaçōes

$$
\sigma_{x x}(B)=\frac{\rho_{x \neq}(B)}{\rho_{x x}^{2}(B)+\rho_{x y}^{2}(B)} \quad \text { e } \quad \sigma_{x y}(B)=\frac{\rho_{y x}(B)}{\rho_{x x}^{z}(B)+\rho_{y x}^{2}(B)}
$$

Numa estrutura simples, por exemplo num semicondutor degenerado com dopagem uniforme por impurezas doadoras rasas a $\mathrm{T}=0 \mathrm{~K}$, a banda de conduçäo está ocupada até a energia de Fermi. Por simplicidade, assumindo que o semicondutor tern a banda de conduçấo parabolica

$$
E=\frac{\hbar^{2} k^{2}}{2 m}
$$

conduz ao fato de que a superfície de Fermi associada é esférica. Pode-se assumir neste momento que o tempo de relaxaçảo $T_{T}$ da populaçäo eletrônica na superfície de Fermi é constante, já que a distribuiçăo de impurezas no cristal hospedeiro é uniforme. Portanto, o numero de portadores n e a mobilidade de transporte $\mu_{\mathrm{T}}$ podem ser determinados a partir das relaçóes conbecidas

$$
N=-\frac{1}{e R_{\mathrm{H}}} \quad \quad \quad \quad \mu \quad \frac{R_{\mathrm{H}}}{\rho}=-\frac{e \mathrm{~T}_{\mathrm{T}}}{m}
$$

onde $N$ é da densidade eletrônica total e $R_{\mathrm{ki}}$ é o fator de Hall.

As componentes do tensor de condutividade seräo, neste caso:

$$
\sigma_{z x}(B)=\frac{e N \mu_{\mathrm{T}}}{1+\left(\mu_{\mathrm{T}} B\right)^{2}} \quad \text { e } \quad \sigma_{x y}(B)=\frac{e N \mu_{\mathrm{T}}^{2} B}{1+\left(\mu_{\mathrm{T}} B\right)^{2}}
$$

o que resulfa em um fator de Hall $R_{H}$ e $\rho_{\text {tx }}$ independentes de $B$.

Em geral, os sistemas a serem estudados näo são tão simples assim, como apontado por Beck e Anderson [72], podendo ter superfícies de Farmi năo esféricas, com conduçào devido a portadores em mais de uma banda e a relaçäo de dispersäo de energia $E \times k$ pode ser não parabolica para as bandas, entre outros fatores.

A pratica mais comum encontrada no literatura é, a partir da dependencia en $B$ de $\rho_{z y}(B)$ e $\rho_{x x}(B)$, Cormular-se algumas hipóteses a respeito dos mecanismos de espalhamento, modelar-se $\mu_{\mathrm{T}}$ e ajustarmb as componentes do tensor de magnetoresistividade aqueles obtidas da equaçäo de Boltzmann consistentes com as hipóteses sobre $\mu_{\mathrm{T}}$. Beck e Anderson ressaltam ainda que. em geral, ajustam-se varios modelos para o mesmo conjunto de dados do tensor de resistividade e que essa năo-unicidade torna difícil a justificativa de um modelo fisico particular.

A interpretaçăo das medidas do tensor de resistividade ou condutividade proposta no tram balho de Beck Anderson, como será mostrado na próxima seçäo, e feita a partir de uma abordagem independente e conveniente do modelo fisico para uma estrutura particular. 


\subsection{Transformação do tensor de magnetoresistividade}

O formalismo do espectro de mobilidade é obtjio a partir da reformulação da equação de transporte de Boltzmann dada por McClure[73], a qual produz um resultado explícito para as componentes do tensor de condutividade $\sigma_{x x}(B)$ e $\sigma_{x y}(B)$ em funçăo da estrutura eletrônica de um determinado material e das mobilidades de transporte.

A dedução da expressão final de McClure para as componentes do tensor de condutividade nầo seră apresentada no presente texto, que limitar-se-á a apresentar apenas algumas noçōes encontradas no artigo da Ref. [73].

Para o entendimento da dedução do formalismo do espectro de mobilidade é necessário que seja introduzida grandezas de orígern topológica, $\mathcal{B}_{j}$, que são obtidas a partir das relaçōes de dispersão da estrutura de bandas đe um sistema físíco e estão relacionadas com as trajetórias ciclotrônicas nesse sistema. Suponha-se inicialmente que o espectro de energia de um sistema físico, por exemplo, de uma minibanda de uma super-rede 2D, seja dado por

$$
\varepsilon_{n k_{z} k_{\perp}}=E_{n k_{z}}+\frac{\hbar^{2} k_{\perp}^{2}}{2 m}
$$

com un campo magoético aplicado aplicado paralelamente ao eixo de crescimento, $B=B \hat{k}_{\mathrm{z}}$. Para definirmos a familia de trajetónias no espaço $k$, neste caso, basta que sejam especificados os vetores de onda $k_{\perp}^{2}$ e $k_{\varepsilon}$. A familia de trajetórias é definida então pela própria relaçäo de dispersäo fornecida anteriormente sendo $\varepsilon_{n \hat{k}_{k_{1}} k_{2}}$ constante.

Para a determinaçăo das componentes do tensor de condutividade é necessário o conhecimento dos coeficientes $B_{1}$ definidos como

$$
\mathcal{B}_{j}=\frac{1}{\sqrt{2 \hbar}}\left[\frac{d E_{i j}}{d k_{\perp}}+\frac{j}{k_{\perp}} E_{j}\right]
$$

onde $E_{j}^{z}$ é obtido a partir da expansão en série de Fourier da relaçăo de disperșão de energia (8.2) como

$$
\mathcal{E}_{n k_{s} k_{1}}=\sum_{t} E_{l}\left(k_{1}, k_{z}\right) e^{i k_{i}}
$$

onde $\theta$ to angulo polat associado $k_{1}$.

No caso particular de uma super-rede, Eq. (8.2), com o campo magnético aplicado $B=B \vec{k}_{z}$, os coeficientes de $B_{j}$ seräo, portanto,

$$
B_{i}=\frac{1}{\sqrt{2} \hbar}\left[\frac{\hbar^{2} k_{\perp}}{m}\right] \hat{\delta}_{j 0}=\frac{\hbar k_{\perp}}{\sqrt{2} m}
$$

Os coeficientes $\mathcal{B}_{j}$ determinam completamente o formato da órbitas ciclotrönicas e sằ obtidos a partir da relação de dispersão da banda. No caso particular de un gás de elétrons livres, apenas $\mathcal{B}_{0}$ não é nulo. Assumindo que o tempo de relaxação TT é constante em uma órbita ciclotrónica e que $\tau_{\mathrm{T}}=\tau_{\mathrm{T}}\left(E, k_{z}\right)$, MeClure deduziu que o tensor de condutividade[73] pode ser 
escrito como

$$
\begin{aligned}
& \sigma_{* x+2}(B)=\frac{e^{2}}{(2 \pi)^{3}} \int \mathrm{d}^{3} k\left(-\frac{\partial f_{\mathrm{s}}}{\partial E}\right) \mathrm{TT} \sum_{i=1}^{\infty} \frac{\left|B_{i-1}\right|^{2}+\left|B_{-i-1}\right|^{2}}{\left.1+\left(l \omega_{c} T_{\mathrm{T}}\right)^{2}\right)} \\
& \sigma_{x y}(B)=\frac{e^{2}}{(2 \pi)^{3}} \int \mathrm{d}^{3} k\left(-\frac{\partial f_{0}}{\partial E}\right)+\mathrm{T} \sum_{i=1}^{\infty} \frac{-i\left[B_{l-1} B_{-i-1}-B_{l-1}^{*} B_{-i-1}^{*}\right)}{1+\left(\left(\omega_{\mathrm{c}} T_{\mathrm{T}}\right)^{2}\right)}+ \\
& +\sum_{i=1}^{\infty}\left(\omega_{c} \tau T \frac{\left|B_{i-1}\right|^{2}-\left|B_{-i-1}\right|^{2}}{\left.1+\left(\omega_{c} \tau T\right)^{2}\right)}\right.
\end{aligned}
$$

onde $f_{o}$ é a distribuição de Fermi-Dirac para o gás de elétrons no equilhrio termodinâmico e $\omega_{c}$ é a freqǜtencia ciclotrônicá do gás.

As equaços $(9.3)$ e $(8.4)$ são as mais gerais possiveis para as componentes do tensor de magnetocondutividade. A equaçào $(8,4)$ pode ser simpliffcada utilizandonse uma referéncia comveniente de coordenadas, de formu a que a superficie de Fermi possua simetria de reflexäo em relaçäo a um plano de coordenadas no espaço de momentos[73]. Essa simplificaçăo permite, sem perda de generalidade, que a Eq. $(8,4)$ seja escrita como

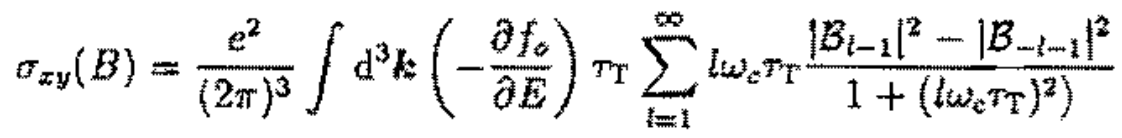

Assumindo que a frequềncia ciclotrônica proporcional a $B$, pode-se entöo definir uma massét ciclotrônica efetiva $m_{c}$ tal que

$$
\omega_{c}\left(n, E, k_{z}\right)=\frac{e B}{m_{c}\left(n, E, k_{*}\right)}
$$

e uma mobilidade $\mu \mathrm{T}$

$$
H_{\mathrm{T}}\left(n, E, k_{z}\right)=e \frac{m_{\mathrm{T}}\left(n, E, k_{z}\right)}{m_{E}\left(n_{4} E, k_{z}\right)}
$$

Em termo das novas variáveis, onde a referéncia funcional a $E$, $n$ e $k_{z}$ näo é maís utilizada por simplicidade de notação, as equaçöes (8.3) e (8.5) se transformam em

$$
\sigma_{x \pi}(B)=\frac{e}{(2 \pi)^{3}} \sum_{n} \int d^{3} k\left(-\frac{\partial D_{0}}{\partial E}\right) m_{c} \mu_{\mathrm{T}} \sum_{i=1}^{\infty} \frac{\left|B_{i-1}^{2}\right|^{2}+\left|B_{-i-1}\right|^{2}}{\left.1+\left(h \mu_{\mathrm{T}} B\right)^{2}\right)}
$$

e

$$
\sigma_{m y}(B)=\frac{e}{(2 \pi)^{3}} \int \mathrm{d}^{3} k\left(-\frac{\partial f_{o}}{\partial E}\right) m_{\mathrm{k} \mu_{\mathrm{T}}^{2}} B \sum_{i=1}^{\infty} l \frac{\left|B_{l-1}\right|^{2}-\left|B_{-i-1}\right|^{2}}{\left.1+\left(l_{\mu} \bar{B}\right)^{2}\right)}
$$

Pode-se agora definir um conjunto de funçöes de densidade de condutividade $\eta_{\mid}^{+}$e $\eta_{i}^{-}$como

$$
\eta_{t}^{ \pm}=\frac{e}{(2 \pi)^{3}} \frac{\partial f_{o}}{\partial E} m_{\varepsilon}\left(n, E, k_{*}\right) \mu \mathrm{T}\left(n, E, k_{z}\right)\left|B_{ \pm i-1}\right|^{2}
$$


tal que as equaçò $(8.8)$ e (8.9) ficam

$$
\begin{aligned}
& \sigma_{x x}(B)=\sum_{n} \int \mathrm{d}^{3} k \sum_{i=1}^{\infty} \frac{\eta_{i}^{+}+\eta_{i}^{-}}{1+\left(\mu_{t+1} B\right)^{2}} \\
& \sigma_{x y}(B)=\sum_{n} \int d^{3} k \sum_{i=1}^{\infty} \frac{\mu_{\mu} B\left(\eta_{l}^{+}-\eta_{t}^{-}\right)}{1+\left(\mu_{\mu} \mu^{-} B\right)^{2}}
\end{aligned}
$$

A caracteristica essencial do resultado modificado de MeChre [equacões (8.11) (8.12)] é que os elementos de condutividade săto expressos como somas e integrais sobre termos que tern a dependêneta de campo simples como expressada em (8.1). Para superfícies de Fermi com regiöes còncavas e convexas, $\eta_{i}^{+}$e $\eta_{i}^{\prime \prime}$ seräo näo nulos, resultando em termos de elétrons e buracos ra equaçäo (8.12). De fato, pode-se definir outro par de funçöes de densidade de condutividade $S^{ \pm}(H)$ por

$$
S^{ \pm}(\mu)=\sum_{n} \sum_{i=1}^{\infty} \int \mathrm{d}^{3} k \eta_{1}\left(n, E, k_{z}\right) \delta\left[\mu-\ell \mu \mathrm{r}\left(n, E, k_{z}\right)\right]
$$

tal que

$$
\begin{aligned}
& \sigma_{x x}(B)=\int_{0}^{\infty} \mathrm{d} \mu \frac{S^{(}(\mu)+S^{-}(\mu)}{1+(\mu B)^{2}} \\
& \sigma_{z y}(B)=\int_{0}^{\infty} \mathrm{d} \mu \mu B \frac{S^{4}(\mu)-S^{-}(\mu)}{1+(\mu B)^{2}}
\end{aligned}
$$

Finalmente, adotando a convenção de que eletrons têm mobilidade negativa e buracos mobilidade postzivo, de modo a que a condutividade em campo nulo seja positiva para elétrous e buracos, define-se $s(\mu)$ como

$$
s(\mu)= \begin{cases}S^{+}(\mu) & , \mu>0 \\ S^{-}(|\mu|) & , H<0\end{cases}
$$

e chegawse a

$$
\begin{aligned}
& \sigma_{x x}(B)=\int_{-\infty}^{\infty} d \mu \frac{s(\mu)}{1+(\mu B)^{2}} \\
& \sigma_{x y}(B)=\int_{-\infty}^{\infty} d \mu \frac{\mu B s(\mu)}{1+(\mu B)^{2}}
\end{aligned}
$$

ou

$$
\hat{\sigma}(B) \simeq \sigma_{z x}(B)+i \sigma_{x y}(B)=\int_{-\infty}^{\infty} \mathrm{d} \mu s(\mu) \frac{1+i \mu B}{1+(\mu B)^{2}}
$$

As Equaçōes (8.18) e (8.19) são o resultado de Beck * Anderson que corresponde à projeçăo do espaço $\hat{\sigma}(B) \times B$ no espaço $s(\mu) \times \mu$. Como póde ser apreciado no decorrer do desenvolvï mento, essa transformada depende da topologia no espaço de momentos, da massa dos elétrons 
e da própria temperatura do material envolvido, além do particular modelo para os tempos de relaxaçäo.

Por conseguinte, como salientado por Beck e Anderson, a funça s(j) näo pode ser determinada univocamente, mas pode-se determinar uma funçäo $S(\mu)=\max [s(\mu)]$ que para cada $\mu$ fornece o máximo valor fisicamente aceitável de $s$ compativel com o particular conjunto de dados de $\hat{o}(E)$, como será visto na seçäo seguinte.

\subsection{O espectro de mobilidade}

$O$ desenvolvimento matemático para a determinaţão da função envoltória $S(\mu)$ é bastante simples embora matematicamente extenso, estando bastante claro o desenvolvimento no artigo de Beck e Anderson [72]. 0 presente texto limita-se apenas ao esclarecimento dos pontos cruciais desse artigo que conduzem ao espectro de mobilidad $\$(\mu)$.

$O$ artifício matemático para a obtenção do espectro de mobilidade vem do aplicaça do teorema de Krein[72] ao problema presente, o qual afrma que deve baver pelo menos urna solução fisica $s(\mu)$ (funcionalmente, para todo $\circ \mu$ a função envoltória tá tal que $S(\mu) \geq s(\mu)$ ) se e somente se a matriz associada $A$, dada por

$$
A_{\gamma \beta}= \begin{cases}\sum_{i=1}^{N}\left(\sigma_{x x}\right)_{k}\left(C_{R}^{-1}\right)_{k, \gamma+\beta) / 2} & ,(\gamma+\beta) \text { par } \\ \sum_{k=1}^{N}\left(\sigma_{x y}\right)_{k}\left(C_{1}^{-1}\right)_{k_{+}(\gamma+\beta-1) / 2} & ,(\gamma+\beta) \text { impar }\end{cases}
$$

nảo for definida negativa, ou seja, näo tenka auto-valores negativos. Na exułąăo $(8,21),\left(\sigma_{x x}\right) k$ e $\left(o_{x y}\right)$ são os elementos de condutividade em campos $B_{k}$ e $N$ é múmero de valores de campo magnético onde as metidas foram efetuadas. $C_{R}^{-1}$ e $C_{l}^{-1}$ säo matrizes $N \times N$ inversas de $C_{R}$ e Cix

Considerando que o valor das condutividades näo incluem o valor de campo nulo, os ele mentos de $C_{R}$ sato definidos pela funçằo geratriz

$$
\sum_{j=1}^{N} C_{R_{j k}} x^{2(j-1)}=\prod_{j=1, j \neq x}\left(1+x^{2} B_{b}^{2}\right)
$$

e os elementos de Ci por

$$
C_{l i k}=-C_{R j k} B_{k}
$$


Caso o valor para as condutividades em campo nulo seja considerado, sendo $B_{1}=0$, 0 algoritmo para a obtençăo de $C_{Y}$ é

$$
\begin{aligned}
& N \leftarrow N-1 ; \\
& C_{i j k} \leftarrow-C_{j(k+1)}^{R} B_{k+1} \\
& C_{l}^{-1} \leftarrow \text { inversa }\left(C_{t}\right) \text {; } \\
& \text { for } \mathrm{j}:=1 \text { to } \mathrm{N} \text { do } \\
& \text { begin } \\
& \text { end; } \\
& \begin{array}{l}
C_{I}^{-1} \leftarrow 0 \\
C_{1}^{-1}{ }_{j 1} \leftarrow 0
\end{array} \\
& \text { for } \mathrm{j}=1 \text { to } \mathrm{N}-1 \text { do } \\
& C_{I}^{-1}+C_{1}^{-1}(i-1)
\end{aligned}
$$

O espectro de mobilidade pode sen entảo gerado a partir da relação

$$
S(\mu)=\prod_{i=1}^{N}\left[1+\left(B_{i} \mu\right)^{2}\right]\left\{\sum_{i=1}^{N} \frac{\left[\sum_{j=1}^{N}(-\mu)^{j-1} Q_{j i}\right]^{2}}{\lambda_{i}}\right\}^{-1}
$$

onde $\lambda_{i}$ são os autovalores de $\mathrm{A}$ e Q e a matriz ortonormal cujas colunas são os autovetores de A.

A idêia básica da inclusăo dos autovalores e autovetores da matriz $\mathrm{A}$ yem da noção de que o conjunto de dados $(B) \times B$ ser físicamente plausivel ou não. De acordo com Beck e Anderson[72], para verificar-se se um conjunto de dados éfísicamente plausivel ou näo, subtraem-se uma contribuiçäo elementar de condutividade, associada à densidade de mobilidade

$$
s\left(\mu^{\prime}\right)=s^{*} \delta\left(\mu-\mu^{\prime}\right)
$$

das componentes do tensor de condutividade. Ou seja, dos pontos originais $\sigma_{x x}(B)$ e $\sigma_{x y}(B)$ subtrai-se as respectivas contribuiçôs elementares de condutividade

$$
\begin{aligned}
& \sigma_{z z}^{z}(B)=\sigma_{z \pm}(B)-\frac{s^{\prime}}{1+\left(\mu^{\prime} B\right)^{2}} \\
& \sigma_{x y}^{\prime}(B)=\sigma_{z y}(B)-\frac{\mu^{*} s^{*} B}{1+\left(\mu^{\prime} B\right)^{2}}
\end{aligned}
$$

e verifica-se se os dados resultantes $\sigma_{x x}^{*}(B)$ e $\sigma_{x y}^{\prime}(B)$ sấo fisicamente plausiveis. Ou seja, assim determina-se matematicamente a funçäo envoltória $S(\mu)$ tida como a funçäo majorante de todos os modelos fisicos possiveis pura um conjunto de dados $a \times B_{1}$ ou seja, se o conjunto de dados $\sigma \times B$ foriundo de uma funçäo $s(\mu)$, tem-se que $S(\mu) \geq s(\mu)$ para todo o $\mu$. Matematicamente, 
o conjunto de dados é fisicamente plausivel se e somente se a matriz A não possuir autovalores negativos.

O procedimento numêtico para a obtença do espectro de mobilidade foi incorporado no programa SIMP, havendo sido testado primeiramente con dados gerados para $\rho_{x x}$ e $p_{x y}$ a partir da um modelo simples de vărios portadores com diferentes mobilidades de transporte e comparado com um ajuste simultảneo das componentes do tensor de magnetoresístividade com o mesmo modelo. Os resultados do espectro de mobilidade, tanto para os dados gerados quanto para uma amostra $\delta$-dopada, s落o mostrados nas Secoōes 8.5 e 8.6 , respectivitumente.

\subsection{A regiāo clássica da magnetoresistência}

Antes de se passar a discussão das steçōes seguintes, é mostrado nesta seção a região de campo magnético da qual é possivel a extráção do espectro de mobilidade. Essa região é denominada de "clássica" jâ que os resultados para o tensor de magnetoresistividade não apresentam efeitos quâtiticos como as oscilações de SaH, a magnetoresistência negativa e of efito Hall quântico, näo previstos pela formulação de Boltzmann para o tensor.

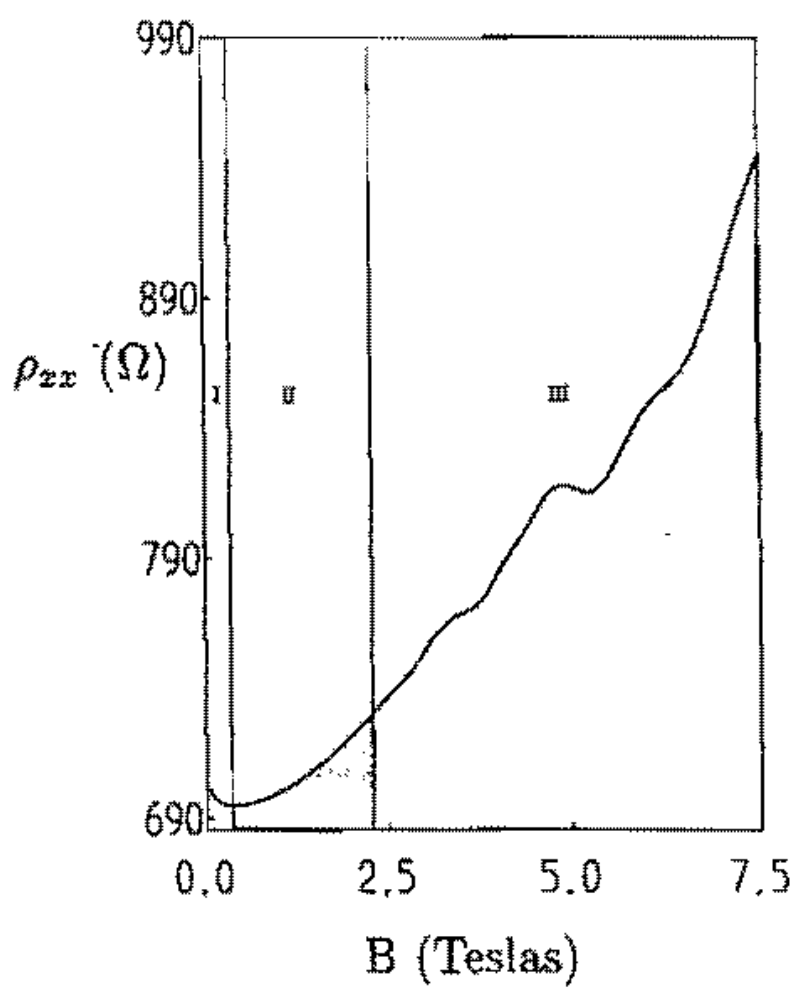

Figura 8.1: Componente $\rho_{x x}$ do tensor de resistividade para um poco o (amostra MAR124). Regiắ I - manifestação da magnetoresistência negativa. Reğão II - regiño clássica, aonde näo

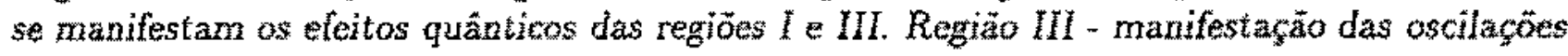
$S d H$.

Essa regiào está compreendida, em amostras b-dopadas, entre as regióes de baixo campo onde é visivel a manifestação da magnetoresistència negativa e a região de al to campo magnético 
aonde se manifestam as oscilaçoes de Shubnilkov-de Haas, como visto na Figura 8.1.

A assinatura da magnetoresistência negativa é claramente vista na Região I (Fig. 8.1), caracterizada por un decréscimo da resistividade en funçäo do campo magnético não previsto pela teoria clássica de transporte. O mecanismo que origina a magnetoresistencta negativa pode ser determinado, segundo Al'tshuler et al.[76], verificando a dependência em temperatura en campo magnético da região aonde esse fenômeno se apresenta. A determinação dos mecanismos que ocasionam tal fenómeno é objeto de controvérsia na literatura e não será discutido neste traballo. Alguma literatura a respeito pode ser encontrada na. Ref. [76] e na revisão de Leel77].

$\mathrm{Na}$ tegiăo III começam a surgir as oscilaçôes SdH correspondentes, neste caso, à terceira sub-banda ocupada. A determinaçäo das mobilidades de transporte via espectro de mobilidade, como já comentado, teräo de ser efetuadas utilizando os dados do tensor de resistividade nos carnpos da regiäo II.

\subsection{O efeito da posição e do tamanho dos contatos na obtenção do tensor de resistividade}

A fim de ser testado o efeito da posiçä̌o de contatos puntiformes na obtençào do tensor de resistividade e o formalismo do espectro de mobilidade, foi simulada uma experiencia com uma amostra zuadrada com duss populaçöes de elétrons nāo interagentes. Essa amostra hipotética tem como densidade de portadores $N_{1}=2 \times 10^{12} \mathrm{~cm}^{-2}$ e $N_{2}=1,3 \times 10^{12} \mathrm{~cm}^{-2}$, e como mobilidades de transporte $\mu_{T 1}=0,1 \mathrm{~m}^{2} / \mathrm{Vs}$ e $\mu_{T 2}=0,2 \mathrm{~m}^{2} / \mathrm{Vs}$

Os dados de $p_{x x}$ e $p_{\text {za }}$ foram gerados a partir do modelo

$$
\begin{aligned}
& \rho_{x x}(B)=\frac{\sigma_{x x}(B)}{\sigma_{x x}^{2}(B)+\sigma_{x y}^{2}(B)} \\
& \rho_{y x x}(B)=-\frac{\sigma_{x y}(B)}{\sigma_{x x}^{2}(B)+\sigma_{x y}^{2}(B)} \\
& \sigma_{x x}(B)=\sum_{i} \frac{e N_{i} \mu \mathrm{T}}{1+\left(\mu \mu_{\mathrm{T}} B\right)^{2}} \\
& \sigma_{x y}(B)=-\sum_{i} \frac{e N_{i} \mu_{\mathrm{Ti}}^{2} B}{1+\left(\mu_{\mathrm{Ti}} B\right)^{2}}
\end{aligned}
$$

que $\hat{e}$ urna representaça adequada do fundo magnetoresistivo para amostras con duas populaçò de elétrons năo interagentes.

Foi simulada urna experiencia onde foram situados quatro contatos na amostra sobre as diagonais do quadrado de lado unitário equidistantes de seus cantos segundo o parametro d (Figura 8.2). E conhecido que o metodo de van der Pauw para a determinação da componente $p_{x x}$ do tensor de resistividade fornece corretamente esse valor desde que os contatos sejam puntuais ou muito menore que as dimensöes da amostra, e que estejam situados em sua periferia. Na presentes simulaçäo:

- calculara-se as componentes do tensor de resistividade;

- assume-se que os contatos estejam na periferia; 
- calculam-se os fatores $F$ geométricos conforme estäo descritos no Apêndice, e multiplicamse as componentes do tensor por esses fatores:

- extraem-se as componentes $\rho_{x x}(B)$ e $p_{y x}(B)$ segundo o método de van der Pauw.

- deterninam-se $\mu_{n}$ e $N_{i}$ ajustando-se as componentes do tensor pelas expressöes (8.23) e pelo espectro de mobilidade

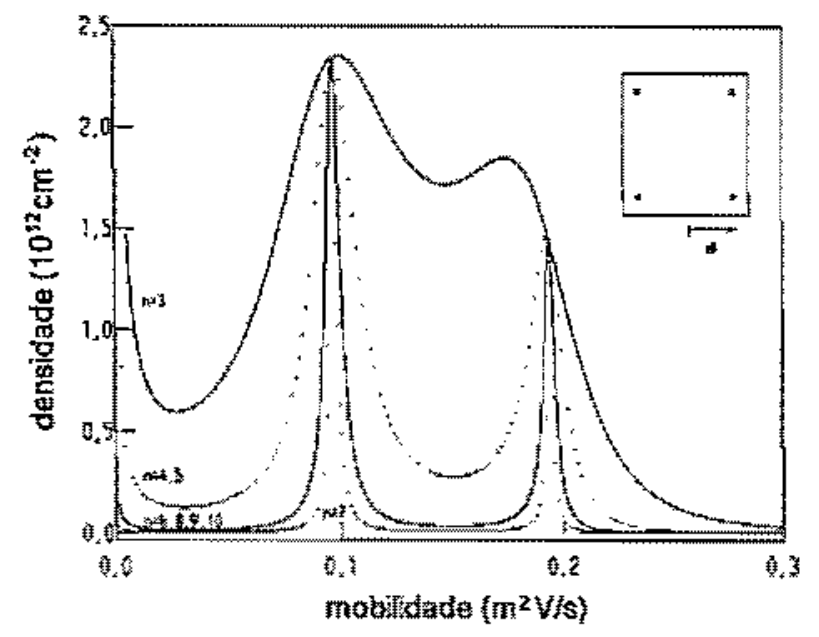

Figura 8.2: Evolução do formato do espectro de mobilidade com o número de valores de $\rho_{x x} e$ de $p_{y x}$ utilizados para a sua obtenção. Os rôtulos inseridos na figura representäm esse número utilizado, que foram tomados igualmente espaçados de 0 a 3 Teslas. A figura inserida é uma esquematizaçăo da amostra aonde é mostrado o parâmetro d

Numa situação extrema, o parâmetro d foi tomado como $d=0,37$. Se $d$ fosse 0,5 , o espectro de mobilidade consistiria de dois picos situados em $\mu_{T}=0,1 \mathrm{~m}^{2} / \mathrm{V}_{\mathrm{s}}$ e $\mu_{T}=0,2 \mathrm{~m}^{2} / \mathrm{V}_{\mathrm{s}} \mathrm{com}$ alturas $N=2 \times 10^{12} \mathrm{~cm}^{-2}$ e $N=1,5 \times 10^{12} \mathrm{~cm}^{-2}$, respectivamente.

0 espectro de mobilidade fornece o número máximo de portadores em função da mobilidade compativel com os dados do tensor de resistividade fornecido [72], para elétrons não interagentes (veja a Seçẫo 8.6). Pela figura 8,2 ve-se que a medida em que aumentamos o número de pantos (tomados igualmente espaçados no intervalo de 0 a 3 Teslas), os picos correspondentes a ambos os portadores da simulação tornam-se melhor resolvidos. A partir de um certo número de pontos tornados, a resoluçāo do espectro não melhora. Como observado por Beck e Anderson [72], isto é uma limitação da informação contida nos dados Hall dependentes do campo. Por outro lado, com o aumento do número de campos tomados dos dados simulados, a resoluçẫo dos picos do espectro oscila (embora o valor do pico permaneça aproximadamente constante) devido ao fato de que [72] para que melhor se resolva um deterninado pico oum determinado $\mu$, dados em $B=1 / \mu$ devern ser fornecidos. Neste caso, os dados que fornecem a função envoltốria mais estreita correspondem a 7 valores igualmente espaçados em $B$.

No que diz respeito ass valores fornecidos pelo espectro de mobilidade, estes são comparados nta tabela abaixo com os valores obtidos por um ajuste de mínimos quadrados simultâneo das equaçōes (8.23), mostrando um bom acordo. 


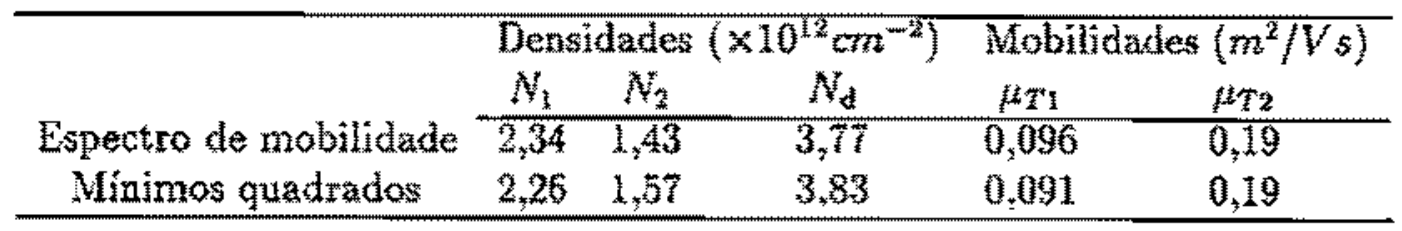

Na figura 8.3, comparam-se os dois ajustes efetuados mostrando que o espectro de mobilidade fornece um bon acordo com o metodo de minimos quadrados empregue.
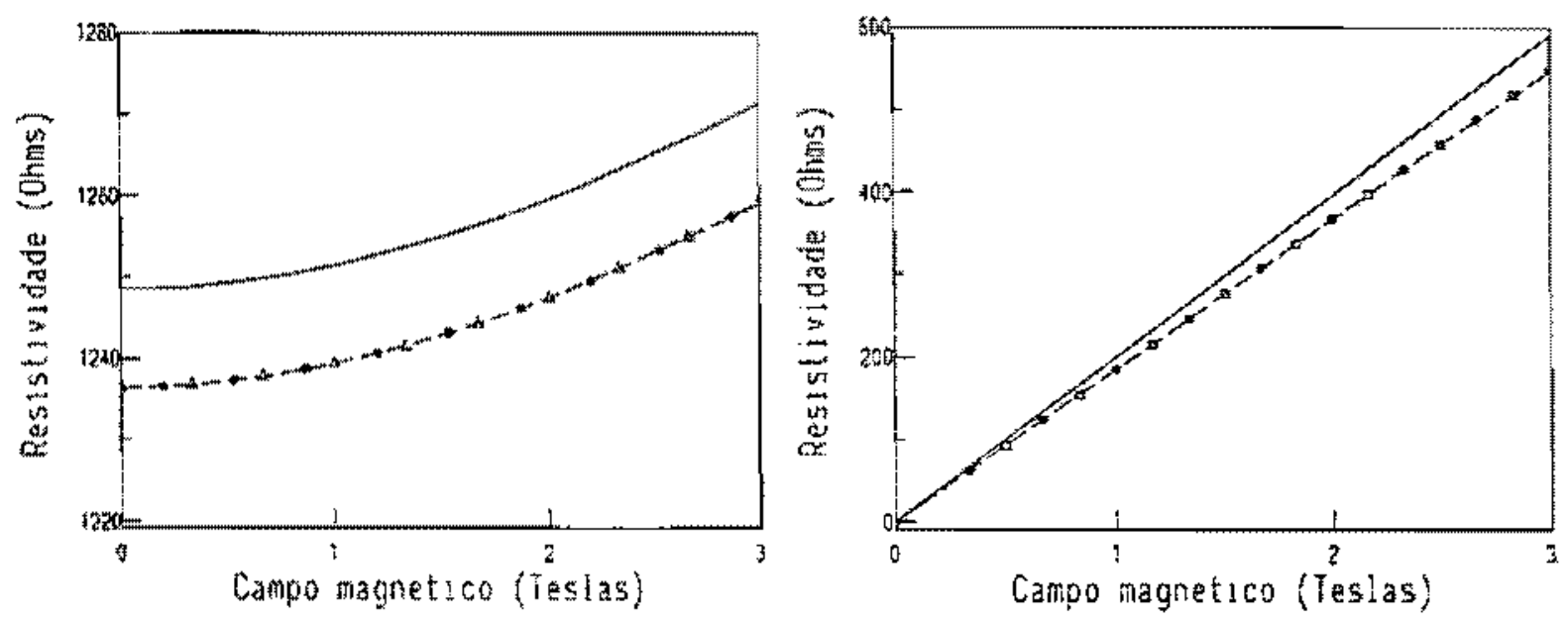

Figura 8.3: Ajuste dos dados de $\rho_{z z}$ e de $\rho_{z y}$ a partir de $\mu$ e $n$ obtidos pelo espectro de mobilidade (círculos) e pelo ajuste de mínimos quadrados (quadrados). A linha cheia corresponde à componente do tensor de resistividade obtida com os contatos na periferia da amostra enquanto a Jinha tracejada aos dados obtidos a partir da simulaça corn os contatos fora da periferia da amostras com parânetro $d=0,37$.

Como conclusão, o efeito da posiçă dos contatos deve ser considerado para uma obtençầ precisa das componentes do tensor de resistividade quando da utilização da técnica de van der Paww. Esta dif́culdade pode ser contornada utilizando-se a formulaçăo dada no Apendice.

\subsection{O tensor de condutividade em sistemas $2 \mathrm{D}$}

Nest seçẫo seräo apresentaods os resultados experimentais obtidos para as componentes do tensor de condutividade em uma amostra dopada de InP. Esses resultados serăo analisados pela técnica do espectro de mobilidade apresentada neste capitulo.

Os valores obtidos pelo espectro de mobilidade em sistemas $2 \mathrm{D}$ sera interpretados de acordo com a formulação de Siggia e Kwok[58] para o transporte em siztemas de múltíplas subbandas.

Os valores teóricos para as mobilidades de transporte foram calculadas pelo modelo RPA apresentado no capítulo 5 e comparados com aqueles fornecidos pelo espectro de mobilidade para a amostra estudada. 


\subsubsection{A interpretação do espectro de mobilidade em sistemas 2D}

As expressocs para o tensor de condutividade em sistemas 20 foran obtidas a partir da modelagem das mobilidades de transporte por Zaremba[is] a partir dos resultados de Siggia e Kwok[58] para sistemas com mais de um portadow, a $\mathrm{T}=0 \mathrm{~K}$. Zaremba mostra em seu artigo que, em geral, um sistema bimdimensional com $n$ portadores distintos intengentes com mobilidades de transporte $\mu_{\mathrm{T}}$ comportawse como um sistema de n portadores näo interagentes com densidades individuais $\hat{N}_{j}$ e mobilidades de transporte $\hat{\mu}_{T}$.

Zaremba deduziu que a matriz $\mathcal{K}$ da formulaçăo teónica do transporte an sistemas de múltiplas subbandas de Siggia e Kwok[58] pode ser diagonalizada e que o tensor de condutividade pode ser scrito como, en unidades atomicas efetivas,

$$
\begin{aligned}
\sigma_{x x}(B) & =\sum_{j=1}^{n} \frac{\hat{N}_{j} \mu_{T j}}{1+\left(\hat{\mu} T_{j} B\right)^{2}} \\
\sigma_{x y}(B) & =\sum_{j=1}^{n} \frac{\hat{N}_{j} \hat{H}_{T}^{2} B}{1+\left(\hat{\mu}_{j} B\right)^{2}} \\
\hat{\mu}_{T j} & =\frac{1}{\lambda_{j}} \\
\hat{N}_{j} & =\left(n^{1 / 2} \cdot u_{i}\right)^{2} \\
n^{1 / 2} & =\left(N^{1 / 2}, N_{2}^{1 / 2}, \ldots\right)
\end{aligned}
$$

onde $\lambda_{j}$ săo os autovalores da matriz $\mathcal{K}$ e $u_{j}$ é o autovetor de $\mathcal{K}$ associado ao autovalor $\lambda_{j}$.

Logo, de acordo com o modelo matemático de Siggia e Kwok, o espectro de mobilidade deverá apresentar um número de picos igual ao número de populaçóes de portadores presentes e centrados nas mobilidades aparentes $\hat{\mu}_{T}$ com altura $\hat{N}_{j}$. Portanto, para um particular sistema. com dois portadores, os elementos de matriz $K_{j i}$ devem ser calculados se desejar-se obter as mobilidades individuais de transporte.

\subsubsection{Resultados e discussão}

Para ilustrar a importância do modelo teónico na determinação das mobilidades individuais de transporte, efetuaram-se medidas do tensor de magnetoresistência em uma amostra contendo um únco poco a $\mathrm{T}=20$ e $120 \mathrm{~K}$, em campos que iam de 0 a 6 Teslas e a $\mathrm{T}=4,2 \mathrm{~K}$ em campos que iam de 0 a 14 Teslas. Foi fabricado na amostra uma máscara do tipo Hall bar e as medidas de magnetoresistencia a temperaturas altas $(20$ e $120 \mathrm{~K})$ foran efetuados pelo grupo do Dr. Koenraad.

Inicialmente, a amostra foi caracterizada a $4,2 \mathrm{~K}$ a fim de serem extraidos os parâmetros

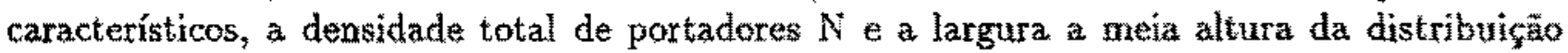
de doadores $\Delta_{\mathrm{d}}$. A partir desses parâmetros foi obtida a estrutura eletrônica autoconsistente da amostra a 20 e a $120 \mathrm{~K}$ e calculadas as mobilidades de transporte teórícas. Posteriomente, foram deteminadas, a partir do espectro de mobilidade e de um ajuste de minimos quadram dos simultaneo das componentes do tensor de magnetocondutividade à expressão (8.25), as mobilidedes e densidades aparentes para a amostra. No caso particular dessa amostra, näo fol 
possível a obtenção do espectro de mobilidade a $4,2 \mathrm{~K}$ porque a região clássica da magnetoresistividade é bastante estreita sendo essa região bastante aumentada para as altas temperaturas. Os resultados estão sumarizados nas Tabelas 8.1 e 8.2, e nas Figuras 8.4, 8.5 e 8.6.

\begin{tabular}{ccccccc}
\hline \multicolumn{6}{c}{ Calculados(Espectro de mobilidade) } \\
\hline $\mathrm{T}$ & $N_{1}\left(\hat{N}_{1}\right)$ & $\begin{array}{c}N_{2}\left(\hat{N}_{2}\right) \\
\times 10^{12} \mathrm{~cm}^{-2}\end{array}$ & $N_{3}\left(\hat{N}_{3}\right)$ & $\mu_{T 1}\left(\hat{\mu}_{T 1}\right)$ & $\begin{array}{c}\mu_{T 2}\left(\hat{\mu}_{T 2}\right) \\
\mathrm{m}^{2} / \mathrm{Vs}\end{array}$ & $\mu_{T 3}\left(\hat{\mu}_{T 3}\right)$ \\
\hline 4,2 & $1,48(-)$ & $0,34(-)$ & $0,07(-)$ & $0,182(-)$ & $0,429(-)$ & $1,12(-)$ \\
20 & $1,45(1,50)$ & $0,34(0,41)$ & $0,07(-)$ & $0,182(0,12)$ & $0,427(0,40)$ & $1,10(-)$ \\
120 & $1,11(1,24)$ & $0,26(0,50)$ & $0,11(0,19)$ & $0,220(0,12)$ & $0,445(0,45)$ & $-(0,99)$ \\
\hline
\end{tabular}

Tabela 8.1: Amostra 118. A partir das freqüências de $S d H, B 1=30,9$ e $B 2=7,16$ Teslas, a $T=4,2 \mathrm{~K}$, os parâmetros característicos dessa amostra foram obtidos como sendo $N=1,9 \times$ $10^{12} \mathrm{~cm}^{-} 2$ e $\Delta_{\mathrm{d}}=2 \AA$. A partir desses parâmetros, as densidades nas subbandas para as várias ternperaturas foram obtidas através do cálculo autoconsistente (Seçāo 2.1). As densidades e mobilidades aparentes, $\hat{N}_{i}$ e $\hat{\mu}_{T i}$, foram extraídas a partir do espectro de mobilidade. As mobilidades de transporte foram calculadas a partir do modelo RPA do Capítulo 5

\begin{tabular}{|c|c|c|c|c|c|c|}
\hline \multirow[b]{2}{*}{$\begin{array}{c}\mathrm{T} \\
(\mathrm{K})\end{array}$} & \multicolumn{6}{|c|}{ Espectro de mobilidade (Ajuste de mínimos quadrados) } \\
\hline & $\hat{N}_{\mathrm{I}}$ & $\begin{array}{c}\hat{N}_{2} \\
\times 10^{12} \mathrm{~cm}^{-2}\end{array}$ & $\hat{N}_{3}$ & $\hat{\mu}_{T 1}$ & $\begin{array}{c}\hat{\mu}_{T 2} \\
\mathrm{~m}^{2} / \mathrm{V}_{\mathrm{S}}\end{array}$ & $\hat{\mu}_{T 3}$ \\
\hline 20 & & $0,41(0,3$ & - & & $0,40(0,48)$ & - \\
\hline 120 & $1,24(1,13)$ & $0,50(0,49)$ & $0,19(0,33)$ & $0,12(0,12)$ & $0,45(0,33)$ & $0,99(0,85)$ \\
\hline
\end{tabular}

Tabela 8.2: Amostra 118. Tabela comparativa entre os valores determinados pelo ajuste de mínimos quadrados e pela obtenção através do espectro de mobilidade. 

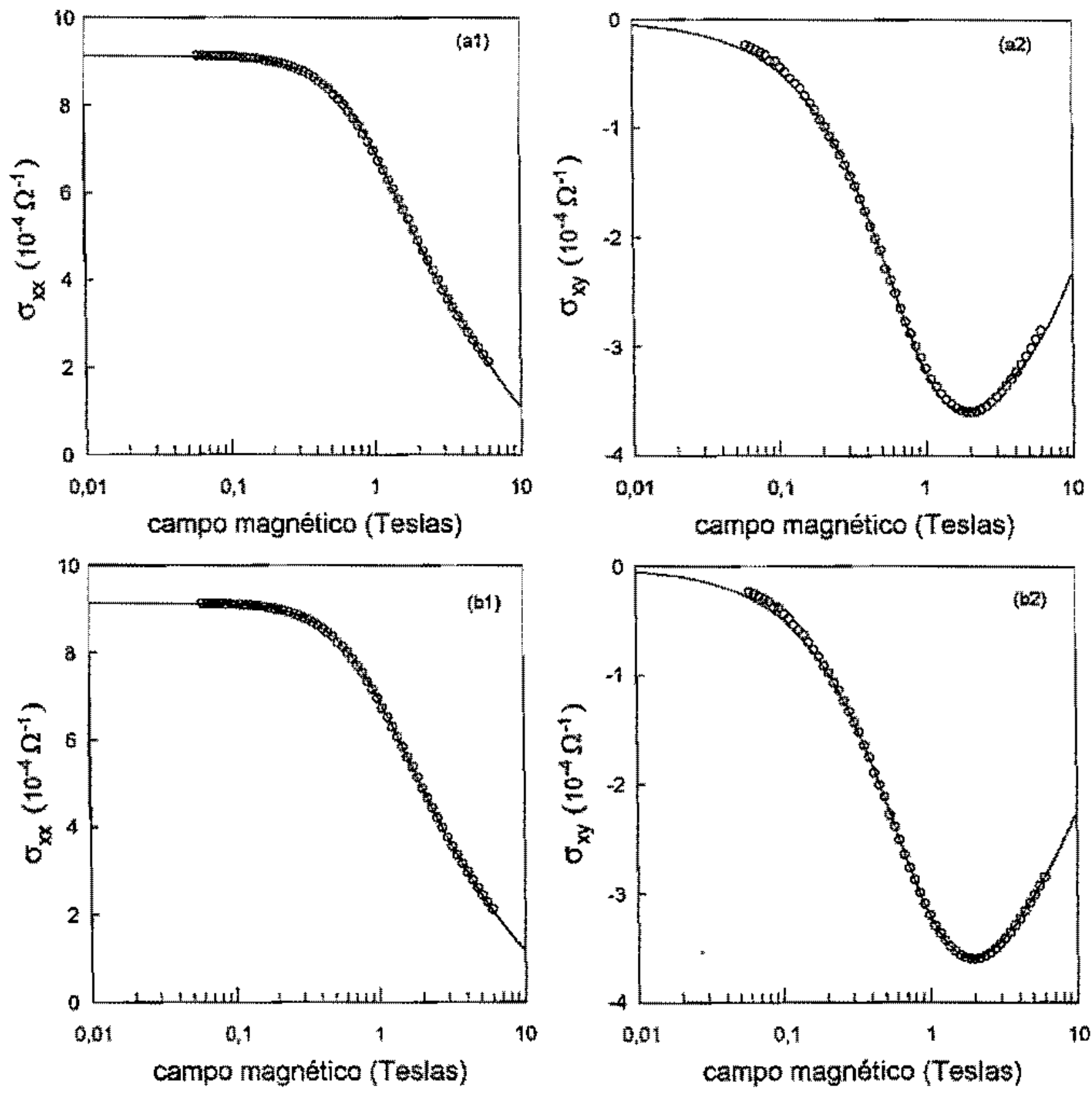

Figura 8.4: Ajuste do tensor de magnetocondutividade de um sistema com vărios portadores livres utilizando-se un método de minimos quadrados, a $T=120 \mathrm{~K}$. Foram utilizados 60 pontos logaritmicamente espaçados para cada componerte do tensor entre 0,06 and 6 Teslas. (aI) e (a2) Ajuste limitado a dois portadores livres; (b1) e (b2) 0 melhor ajuste permitindo tress portadores. A soma dos resíduos ao quadrado é de $1,25 \times 10^{-9}$ no primeiro caso e de $6,9 \times 10^{-10}$ no segundo caso.

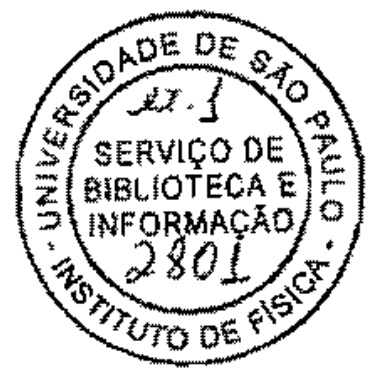



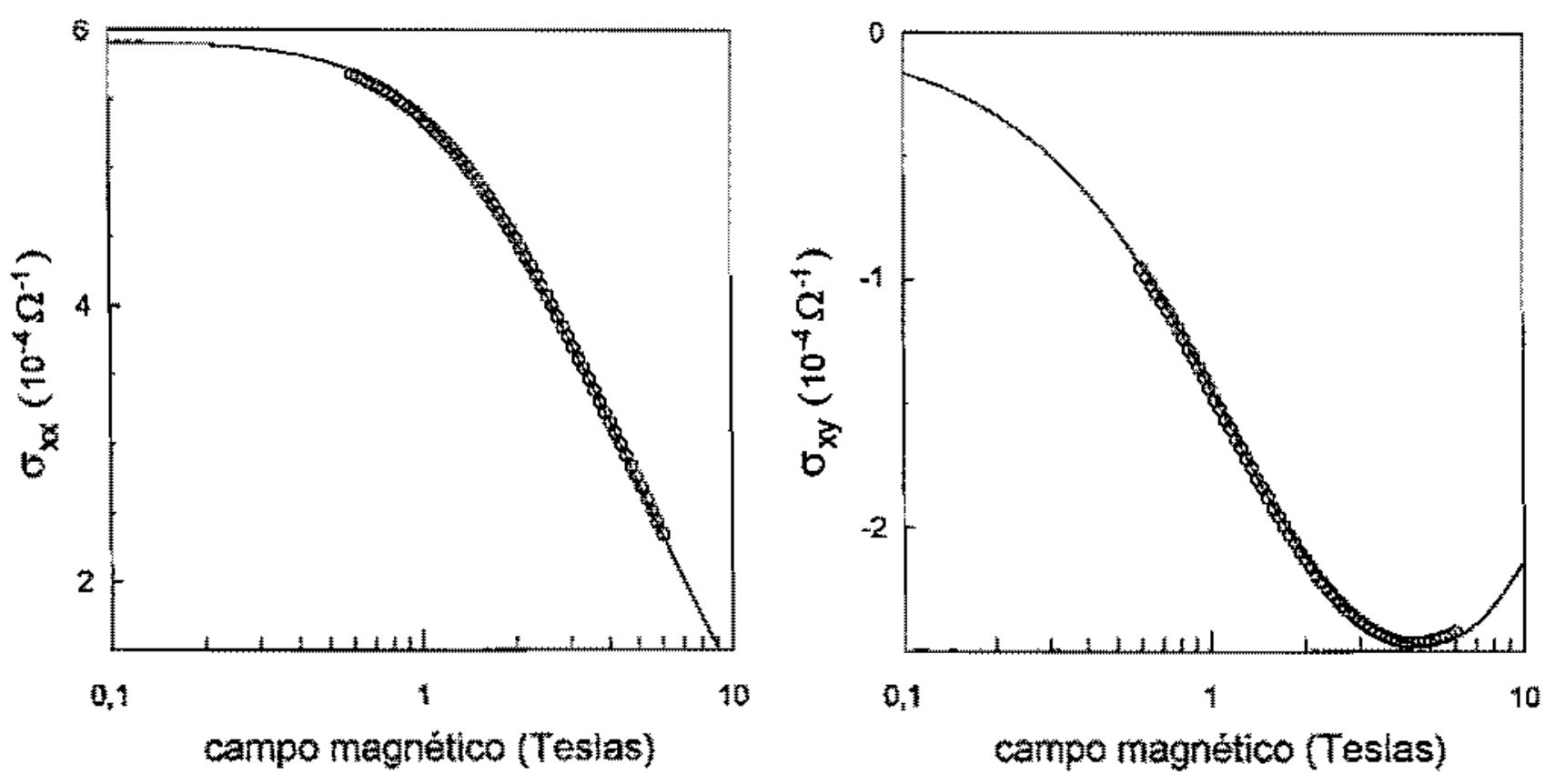

Figura 8.5: $O$ mesmo ajuste da figura anterior, a $T=20 \mathrm{~K}$, con 60 pontos logaritmicamente espaçados para cada componente do tensor entre 0,6 and 6 Teslas. 0 ajuste foi limitado a permitir apenas dois portadores. Nenhuma melhora foi observada permitindo mais de dois portadores livres no ajuste.
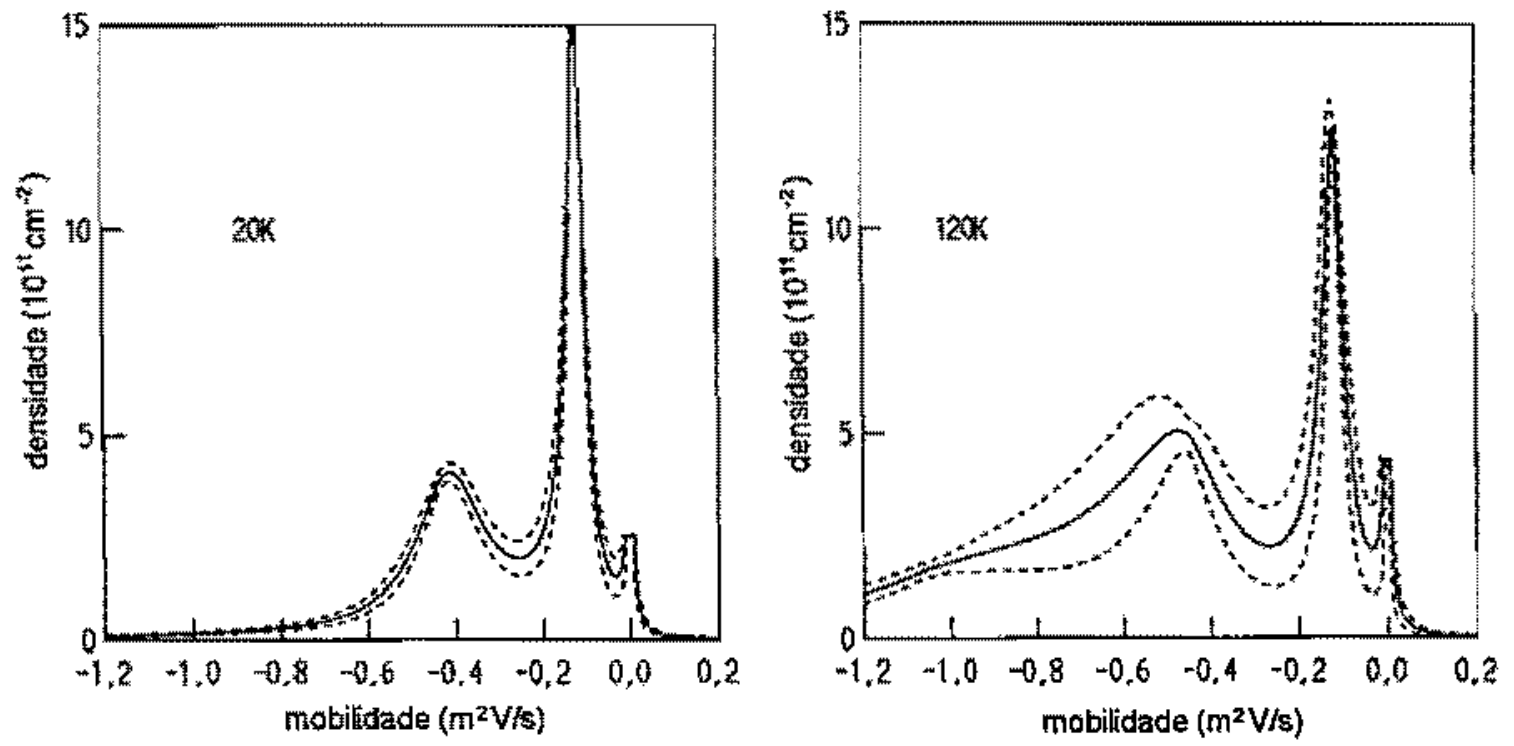

Figura 8.6: Espectro de mobilidade para a amostra 118 a $T=20$ e $120 \mathrm{~K}$. As linhas pontilhadas representam o desvio do espectro se for assumido um erro de $1 \%$ nas componentes do tensor de resistividade 
Os resultados da Tabela 8.1 mostram um bom acordo entre as densidades mobilidades calculadas e aquelas obtidas pelo espectro de nobilidade, para $\mathrm{T}=20 \mathrm{~K}$. Isso sugere que tanto as mobilidades e as densidades aparentes devem ser parecidas com as reais, devido a independencia linear das funçöes presentes no somatório da Eq. (8.25). Entretanto a discrepância entre as mobilidades $\mu_{T 1}$ e $\mu_{T 1}$ mostra que existe um forte espalhamento inter-subbandas entre a subbanda fundamental e a terceira subbanda, a qual näo é detectada a $T=20 \mathrm{~K}$. De fato, as mobilidades para a segunda subbanda permanecem praticamente inalteradas devido a ausència de espalhamento inter-subbanda, Isto indicativo que as mobilidades de transporte dependem do recobrimento entre funçós de onda de subbaudas com a mesma paridade. Por outro lado, o acorilo entre densidades piora à medida em que a temperatura aumenta. Como fato surpreendente, cabe notar-se o acordo entre as mobilidades na terceira subbanda, que apesar de não serem detectadas a temperaturas maís baixas, a tendencia mostrada é de convergencia para o valor de $\mathrm{T}=120 \mathrm{~K}$. A partir dos dados calculados para o tensor de Siggia e Kuwok foi possível determinar as mobilidades aparentes, ou seja, aquelas que espectro de mobilidade apresenta. na posição dos picos. Esses dados năo são apresentados pois esse procedimento fornece valores näo fisicos para as mobilidades e densidades individuais, sugerindo este fato que o modelo para o calculo das mobilidades deva ser reinvestigado.

Na Tabela 2 é mostrado que existe um bom acordo entre os resultados fornecidos pelo espectro de mobilidade e aqueles fornecidos pelo ajuste simultäneo das componentes do tensor de magnetocondutividade, mesmo sendo desprezados os efeitos de temperatura na Eq. 8.25.

\subsubsection{Conclusōes}

Fol observado no decorrer de todo o texto que o modelo RPA produz uma descriçăo ade quada para as mobilidades quânticas e seria esperada uma boa descriçäo para as mobilidades de transporte. Se forem comparados diretamente os resultados obtidos a partir do espectro de mobilidade com os valores calculados para as mobilidades de transporte, ou seja, assumindo que o espalhamento inter-subbandas possa ser desprezado, mesmo assim existe uma concordancia aceitável entre os valores experimentais e teóricos.

Foi tentada a obtençäo das mobilidades e densidades aparentes a partir dos resultados teóricos obtidos para as mobilidades de transporte. Por um lado, o efeito de temperatura foi desprezado es resultados teóricos foram calculados tomando-se $T=0 \mathrm{~K}$. Por outro lado, as contribuiçoes zo espalhamento devidas as populaçoes acima do nivel de Fermi foram desprezadas. A soma destes fatores pode ter sido responsável pelo pouco sucesso dessa tentativa e abre perspectivas para a investigaçäo de sistemas 5 -dopados em altas temperaturas.

De qualquer modo, foi mostrado neste capítulo que a técnica do espectro de mobilidade é confiável e que a obtençăo experimental das mobilidades de transporte em sistemas $2 \mathrm{D}$ com múltiplas subbandas não é possivel sem um rnodelo térico para o espalhamento. 


\section{Apêndice - Sistema atômico efetivo}

Para o astudo das propriedades eletronicas de sistemas epitaxiais conveniente expressarernse os resultados tomandomse

- a carga do elétron (e) como unidade elementar de carga,

- a massa efetiva do elétron $(m)$ como unidade elementar de massa,

- e o rajo de Bobr efetivo ( $\left.a_{b}\right)_{\text {. }}$ ou o raio da órbita de menor energia de um "f́tomo de Hidrogènio" de massa reduzida nu num meio com constante dielétrica $\varepsilon$,

$$
a_{\mathrm{B}}=\frac{\epsilon \hbar^{2}}{m \kappa e^{2}}
$$

como unidade elementar de comprimento, sendo $k=\frac{1}{4 t_{0}}$ com $\epsilon_{9}$ a constante dielétrica do vácuo.

- O Hartree efetivo (H), ou a energia total do "átomo de Hidrogentio" acima citado,

$$
H=\frac{\hbar^{2}}{m a_{B}^{2}}
$$

como unidade elementar de energia,

A motivação dessa escolha deve-se a ģue, em analogia a sistemas de fifica atônica e molecular, as equaçóes mantém-se independentes do tipo de heteroestrutura considerada. En particular, para sistemas 6 -dopados, as propriedades ópticas e de transporte permanecem invariantes a menos do escalonamento do sistema de unidades em termos de massa efetiva e da constante dielétrica do cristal hospedeiro.

O sistema atômico efetivo pode ser construido de igual modo, efetuando-se a análise dimensional das grandezas acima definidas, como tendo

- a carga do elêtron $(e)$ como unidade elementar de carga,

- a massa efetiva do elétron ( $n$ ) como unidade elementar de massa,

- o rajo de Bohr etetivo $\left(a_{B}\right)$ como unidade elementar de comprimento

- e tempo efetivo $\left(\frac{m a n}{h}\right)$ como a unidade de tempo.

$\mathrm{Na}$ Tabela 8.3, exprimimos algumas unidades no sistema atômico com stuas equivalentes mais freqüêtes na literatura. 


\begin{tabular}{|c|c|c|c|c|c|}
\hline Grandeza & Unidade & Dimensăo & SI & $\operatorname{In} \mathrm{P}$ & GaAs \\
\hline m & massa efetivat & {$[M]$} & $m$ & $0.08 m_{0}[53]$ & $0,067 m_{0}$ \\
\hline$\varepsilon$ & constante dielétrica & - & - & $11,8[18]$ & 12,56 \\
\hline$a_{B}$ & raio de Bohr efetivo & {$[L]$} & $\frac{2 \hbar^{2}}{m \kappa n^{2}}$ & $77,96 \AA$ & $99,087 \mathrm{~A}$ \\
\hline $\mathrm{H}$ & Hartree efetivo & {$[M][L]^{2}[T]^{-2}$} & $\frac{h^{2}}{m e_{3}^{2}}$ & $15,67 \mathrm{meV}$ & $11,585 \mathrm{meV}$ \\
\hline$H_{o}$ & mobilidade & $\left.[M]^{-1}[T] \mid Q\right]$ & $\frac{\frac{a_{B}^{2}}{\hbar}}{\hbar}$ & $923,4 \mathrm{~cm}^{2} / \mathrm{Vs}$ & $1491,7 \mathrm{~cm}^{2} / \mathrm{Vs}_{\mathrm{s}}$ \\
\hline$B_{0}$ & campo magnético & {$[M][T]^{-1}[Q]^{-1}$} & $\frac{A}{a a_{0}^{2}}$ & 10,8 Teslas & 6,7 Teslas \\
\hline
\end{tabular}

Tabela 8.3: Constantes fisicas para oInP e GaAs

Apesar de que todos os resultados que seräo apresentados neste trabalho sejam efetuados dentro da aproxirnação de massa efetiva, vale ressaltar que, em alguns semicondutores do grupo III- $V$, a invariância de propriedades pode ser extendida se considerarmos também a correçäo de não parabolicidade do semicondutor hospederro, como mostrado por Johnson et al.[79]. Os autores da Ref. [79] mostraram que para semicondutores hospedeiros, de gap direto, do grupo IIf-V (nomeadamente $\mathrm{GaAs}, \mathrm{GaSb}$, InSb, InAs e InP), quaisquer propriedades (funçōes de onda, preenchimento de subbandas ou energias de subbandas) seräo independentes do material hospedeiro desde que medidas en unidades apropriadas, mesmo que tenhamos que considerar a näo parabolicidade. 


\section{Apêndice - Determinação das componentes de $\rho$ em geometria retangular}

Como já discutido anteriomente, o valor absoluto de pe importante se for desejada a obtençăo das mobilidades de transporte de um sistema $\delta$-dopado ou de outro tipo qualquer de sistema, ou seja, a determinaçâ das componentes do tensor fortemente dependente da geometria da amostra. O problema da geometria e minimizado quando opta-se pelo fabrico de uma máscara na amostra ser estudada, o que envolve processos de litografia, os quais nảo săo disponiveis baixo custo. Uima técnica amplamente utilizada na literatura para a obtençäo das componentes do tenso de resistividade é a lécrica de van der Pauu [17], que consiste no fabrico de quatro contatos puntifornes na periferia da amostra e conseqüente eliminaçäo da geometria através de duas medidas.

Duas limitaçoes evidentes da técnica de van der Pauw säo a näo precisäo da localizaçäo dos contatos na periferia sua näo puntiformidade. Na literatura, alguns autores abordaram esses problemas de modo a extenderem técnica de van der Pauw. De acorto com Chwang et al.[16], a correçäo nas componentes do tensor de resistividade para contatos näo puntiformes localizados na periferia de uma amostra quadrada é menor que $0,6 \%$, independentemente do formato dos contatos, desde que eles ocupem uma área menor que $1 \%$ da área total da anostra. Perlof[15] estudou a dependência da resistividade em campo nulo na posiçäo de contatos puntifornes situados em qualquer sítio de uma amostra retangular.

A dependência das componentes do tensor de magnetoresistência, até onde foi pesquisado na literatura, não foi estudada. Neste Apêndice ê calculada a dependência dessas componentes na posição dos contatos em amostras retangulares.

Em uma anostra de formato genérico, sujeita a um determinado campo magnético $B$, com quatro contatos situados en seu interior, uma corrente $I$ é aplicada entre dois contatos a a diferença de potencial $\Delta \nu(I, B)$ é medida entre outros dois. A expressăo mais geral para a diferença de potencial obtida nesta situaçã̃o é

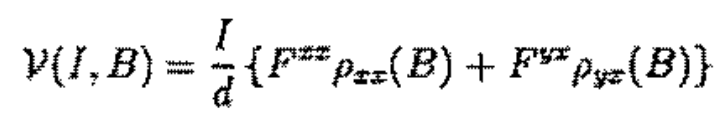

onde dé a espessura da amostrat $p_{4 x}(B)$ e $\rho_{y x}(B)$ säo as componentes do tensor de resistividade e $F^{ \pm x}$ e $F^{*}$ san fatores geométricos relativos as respectivas componentes do tensor, dependentes apenas da geometria da amostra da geometria dos próprios contatos. 


\section{Fatores geométricos em amostras retangulares com contatos puntiformes}

Para derivar uma expressăo particular para os fatores de correção, utillzaremos a técnica de mapeamento conforme utilizada por Perloff[15]. Esse autor deterninou o fator de correçäo geométrico para a componente transversal $\rho_{x y}$. Nésta seçâo apresenta-se brevemente o formalismo necessário para a obtenção dé correçöes para essa componente e também o resultado para a correçã geométrica de $p_{x y}$.

$O$ mapeamento é escolhido de tal modo aue um retângulo situado no plano xy seja conformemente mapeado para o semi-plano superior do plano zw.

As coordenadas (u,v) podem ser expressas em termos de funções de Jacobi elípticas $s n_{n} \mathrm{cn}$ e dn[62]

$$
\begin{aligned}
& u(x, y)=\frac{s n\left(x^{\prime}, m\right) d n\left(y^{\prime}, m_{1}\right)}{\Lambda} \\
& v(x, y)=\frac{\operatorname{cn}\left(x^{*}, m\right) d n\left(x^{\prime}, m\right) s n\left(y_{2}^{\prime}, m_{1}\right) c n\left(x^{\prime}, m_{1}\right)}{\Lambda}
\end{aligned}
$$

com

$$
A=c n^{2}\left(y^{\prime}, m_{1}\right)+m s n^{2}\left(x^{\prime}, m\right) s n\left(y^{\prime}, m_{1}\right)
$$

e

$$
x^{t}=2 K(m) \frac{x}{a} y^{t}=2 K(m) \frac{y+b / 2}{a}
$$

onde a e são as dimensões do retângulo.

O parâmetro mi satî́faz

$$
\frac{K\left(m_{1}\right)}{K(m)}=2 \frac{b}{a}
$$

ond $\mathrm{K}(\mathrm{m})$ é a intezal elíptica de primeiro tipo, definida por

$$
K(m)=\int_{0}^{\pi / 2} \mathrm{~d} \phi\left(1-m \operatorname{sen}^{2} \phi\right)^{-2 / 2} \mathrm{~d} \phi
$$

e

$$
m_{1}=1-m
$$

$O$ valor de $m$, funçäo da razão $b / a_{\text {a }}$ pode ser obtido através da expansão

$$
e^{-2 \pi / a}=\frac{m}{16}+8\left(\frac{m}{16}\right)^{2}+84\left(\frac{m}{16}\right)^{3}+992\left(\frac{m}{16}\right)^{4}+\ldots
$$

Na discussão a seguir, as coordenadas no espaço conforme de um ponto $\alpha$ são expressas sinteticamente na forma

$$
[u(x, y), v(x, y)]=\left[u_{a}, v_{\alpha}\right]
$$


Assumindo que a corrente entra pelo contato $\beta$ e sai pelo contato $\alpha$, a voltagem $\mathcal{V}_{\mu \nu}^{\alpha \beta}(B)$ é lida entre $\mu$ e $\nu$.

$$
\mathcal{V}_{\mu \nu}^{\alpha \beta}(B)=\frac{I}{d}\left\{F^{x x} \rho_{x x}(B)+F^{y x} \rho_{y x}(B)\right\}
$$

os fatores geométricos da Equação (8.30) $F^{x x}$ e $F^{y x}$ serão dados por

$$
\begin{aligned}
& F^{x x}=\frac{1}{4 \pi} \ln \frac{a_{\nu \alpha} a_{\mu \beta}}{a_{\nu \beta} a_{\mu \alpha}} \\
& F^{x y}=s_{\nu \beta}+s_{\mu \alpha}-s_{\mu \beta}-s_{\nu \alpha}
\end{aligned}
$$

onde

$$
\begin{aligned}
& a_{\nu \alpha}=\left\{\left(v_{\nu}-v_{\alpha}\right)^{2}+\left(u_{\nu}-u_{\alpha}\right)^{2}\right\}\left\{\left(v_{\nu}+v_{\alpha}\right)^{2}+\left(u_{\nu}-u_{\alpha}\right)^{2}\right\} \\
& s_{\nu \alpha}=\frac{1}{2} \theta\left(u_{\nu}-u_{\alpha}\right)-\frac{1}{2 \pi}\left[\operatorname{atan}\left(\frac{v_{\nu}-v_{\alpha}}{u_{\nu}-u_{\alpha}}\right)+\operatorname{atan}\left(\frac{v_{\nu}+v_{\alpha}}{u_{\nu}-u_{\alpha}}\right)\right]
\end{aligned}
$$

sendo $\Theta$ a função de Heaviside.

A componente $F_{x x}$ obtida é idêntica àquela obtida por Perloff para campo magnético nulo. Adicionalmente, uma componente $F_{y x}$ é obtida quando da aplicação de um campo magnético uniforme.

A partir das propriedades de simetria do tensor de resistividade,

$$
\begin{aligned}
& \rho_{x x}(B)=\rho_{x x}(-B) \\
& \rho_{x y}(B)=-\rho_{x y}(-B)
\end{aligned}
$$

e partir da expressão de $\mathcal{V}_{\mu \nu}^{\beta \alpha}(B)$ dada pela Equação (8.30), isolam-se finalmente as componentes do tensor como:

$$
\begin{aligned}
& \rho_{y x}(B)=\frac{\mathcal{V}_{\mu \nu}^{\alpha \beta}(B)+\mathcal{V}_{\mu \nu}^{\alpha \beta}(-B)}{2 I}\left(s_{\nu \beta}+s_{\mu \alpha}-s_{\mu \beta}-s_{\nu \alpha}+\right)^{-1} \\
& \rho_{x x}(B)=\frac{\mathcal{V}_{\mu \nu}^{\alpha \beta}(B)-\mathcal{V}_{\mu \nu}^{\alpha \beta}(-B)}{2 I} \frac{4 \pi}{\ln \frac{a_{\nu \alpha} \alpha_{\mu \beta}}{a_{\nu \beta} \alpha_{\mu \alpha}}}
\end{aligned}
$$

Este resultado estabelece que, para amostra com quatro contatos são necessárias duas medidas para que as componentes do tensor de resistividade sejam isoladas. As expressōes acima fornecem, para contatos situados na periferia da amostra, os resultados

$$
\begin{aligned}
& \rho_{y x}(B)=\frac{\mathcal{V}_{\mu \nu}^{\alpha \beta}(B)+\mathcal{V}_{\mu \nu}^{\alpha \beta}(-B)}{2 I} \\
& \rho_{x x}(B)=\frac{\mathcal{V}_{\mu \nu}^{\alpha \beta}(B)-\mathcal{V}_{\mu \nu}^{\alpha \beta}(-B)}{\mathcal{V}_{\mu \nu}^{\alpha \beta}(0)} \rho_{\circ}
\end{aligned}
$$

onde $\rho_{o}$ é a resistividade da amostra em campo nulo. 


\section{Bibliografia}

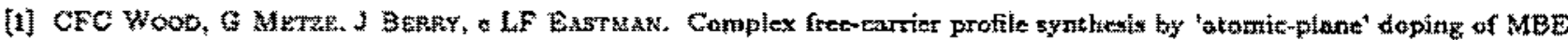

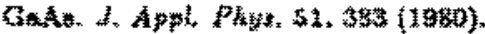

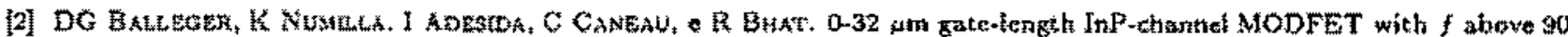

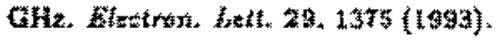

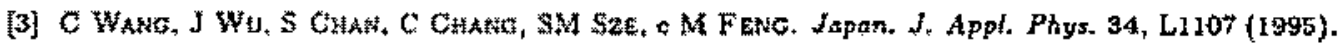

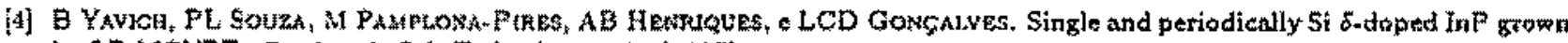
by L.P-MOVPE. Semieond. Sei. Temks:d, 12, 481 (1987).

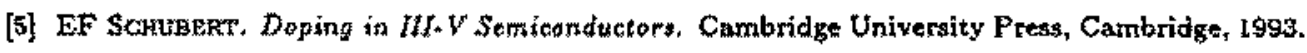

[6] EF Schutext. Semicond. Stmimetals 40,1 (1994).

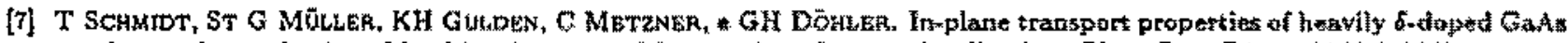
$n-i-p-i$ superłatticen: Motzl-insulator transition, weak and atrong tocalization. Phys. Fev. B 54, 13980 (1996),

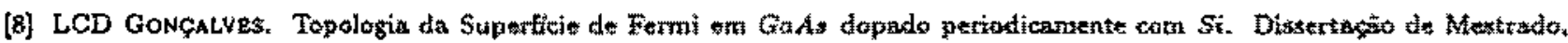
Universidade do Saro Pato - IFUSF, 129\%,

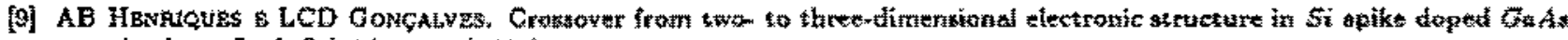
superiatices, Sutf. Sti. 305,343 (1994).

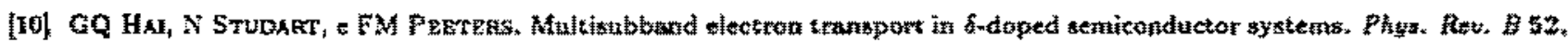
$8363(1095)$.

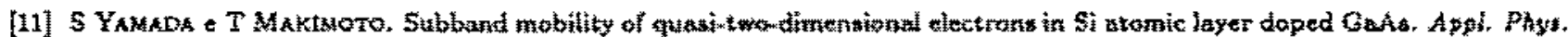
Extat, 57,1022 (1030).

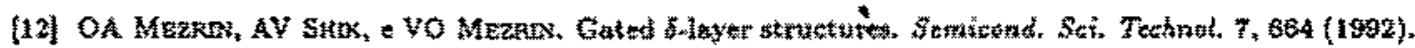

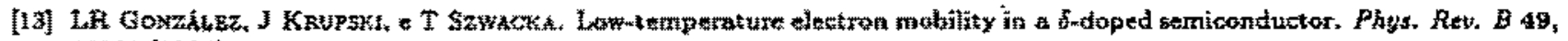
11111 (1904),

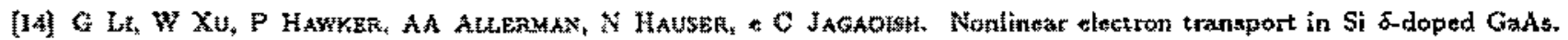
Supesiatt. Mienostruet. 17,55 (1985).

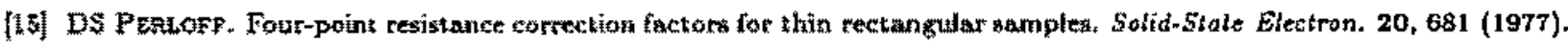

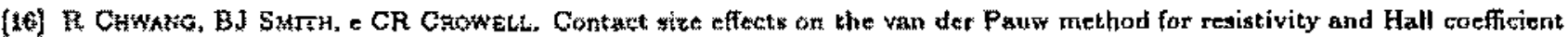
measurement. Selta-State Electrom 17, 12.t7 (1574).

[101] LA VAM DER PAUW. A method of metsuring tpecifie resistivity und Hall effect of dises of arbitrary shapes. Philips Research Reports 18,1 (1958).

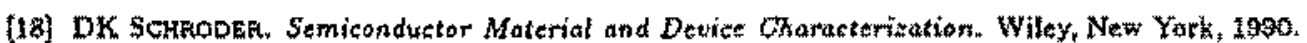

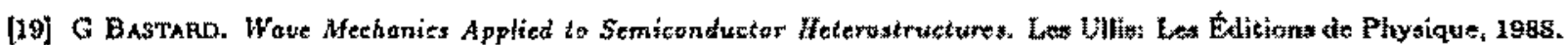

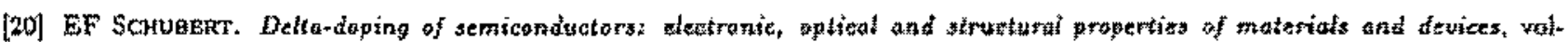

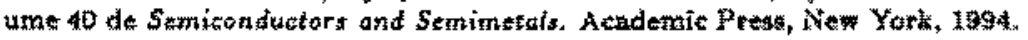

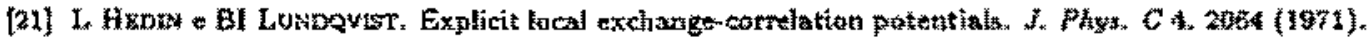




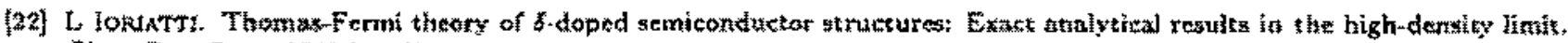

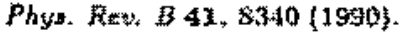

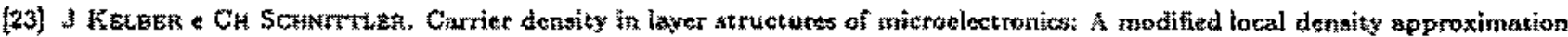

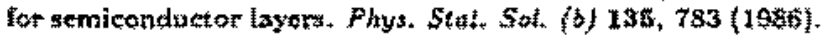

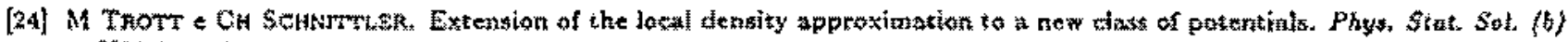
9. Ka

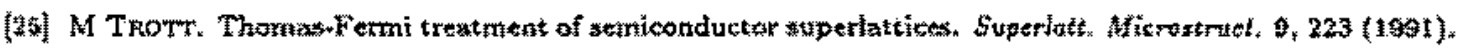

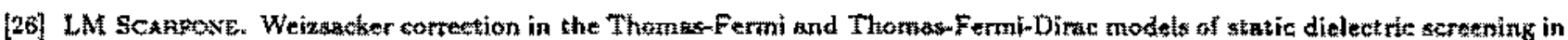

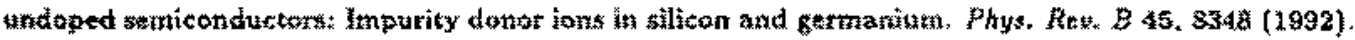

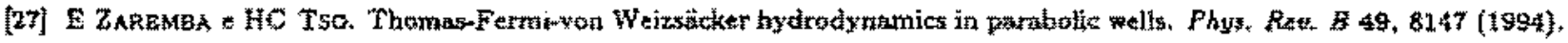

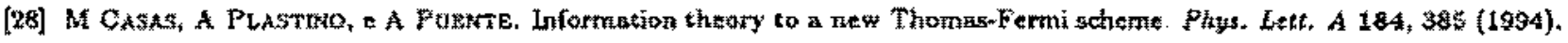

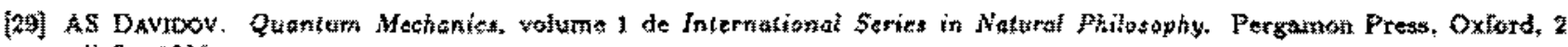
ediçäro, 190 .

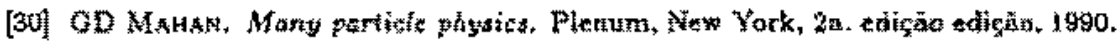

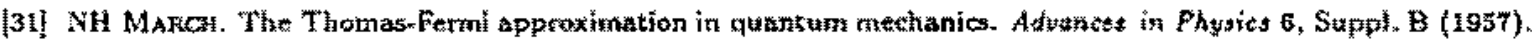

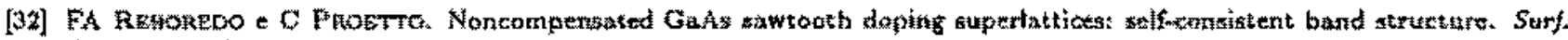
SEi. BI, 1633 (1952).

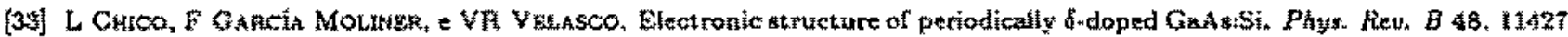
(1593).

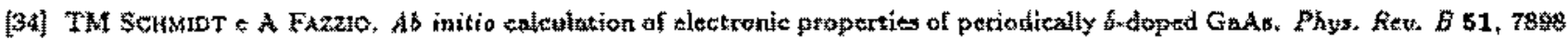
(1995).

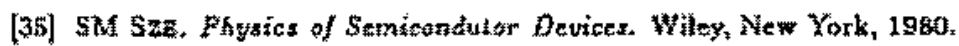

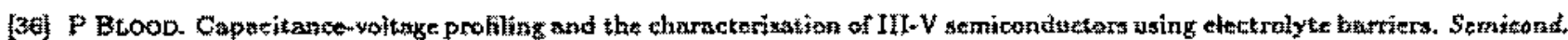
Set. Techinet. s. $_{7}(1986)$.

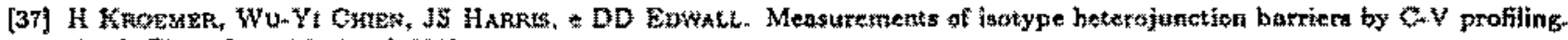

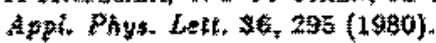

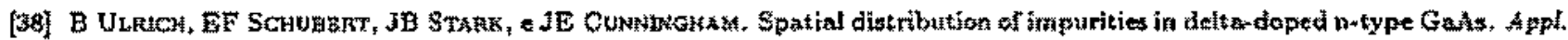

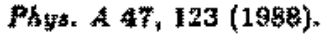

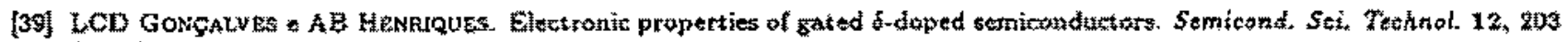
(1:97).

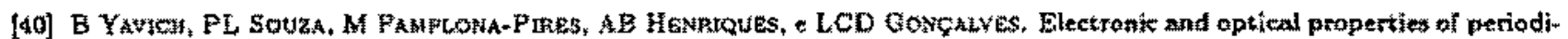

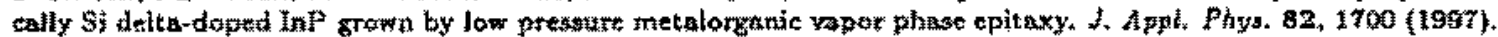

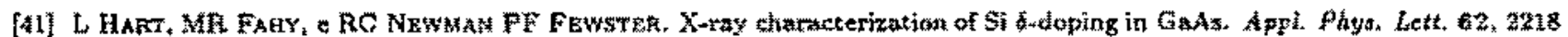
(1095).

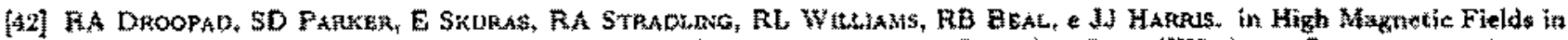

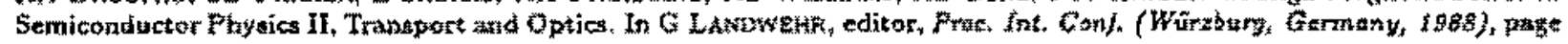
199. Ektlin, 1989. Springer.

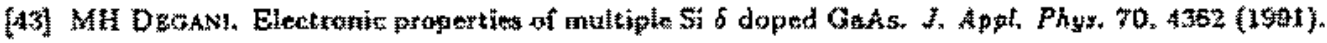

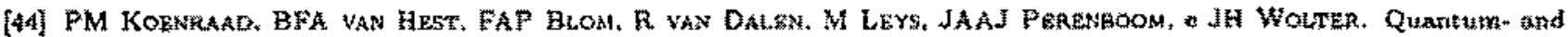

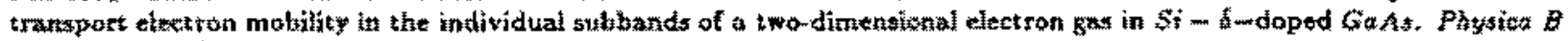
17\%, $435(1992)$.

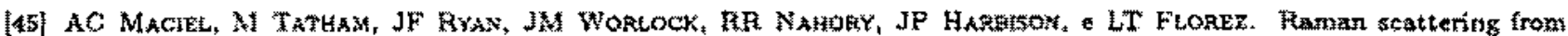

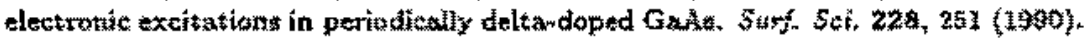




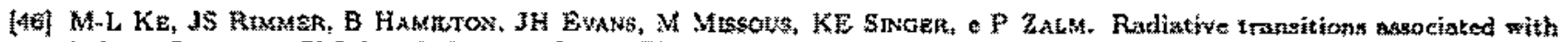
holo confinment at Si B-doped planns in GaAs, Pozs. Rev.

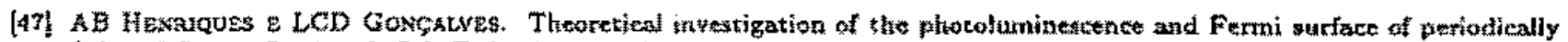

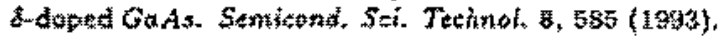

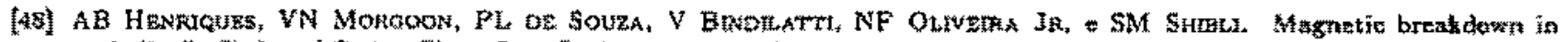

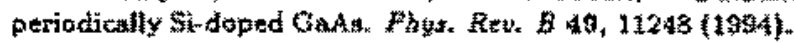

[49] A

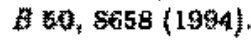

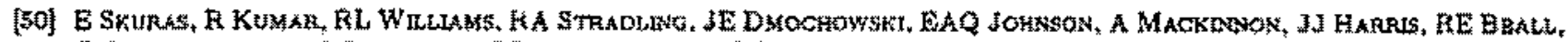

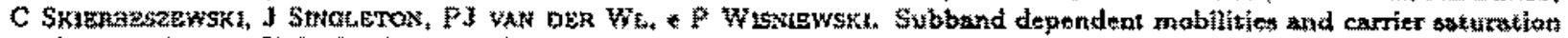

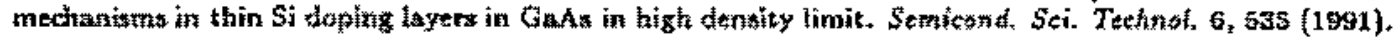

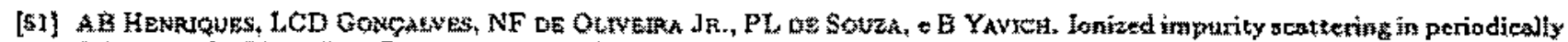

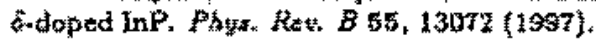

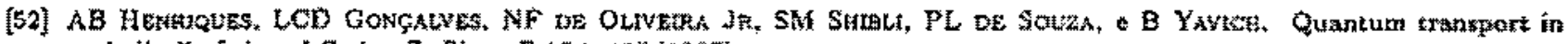

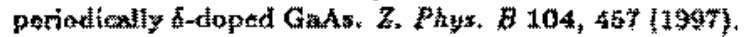

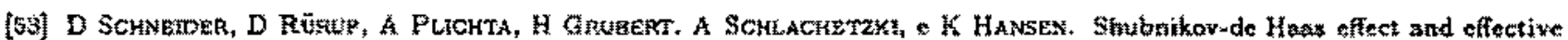

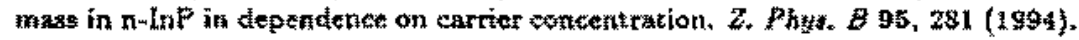

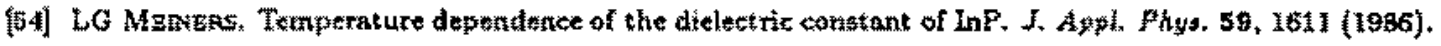

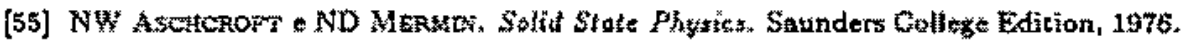

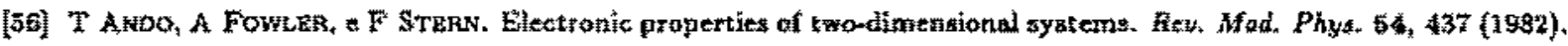

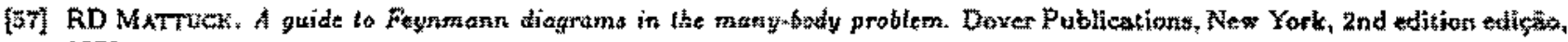
1992.

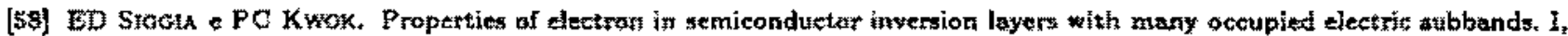

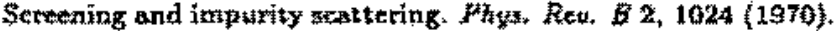

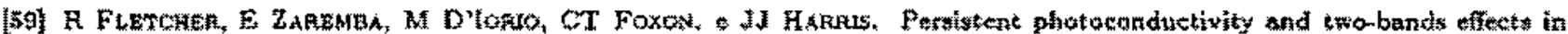

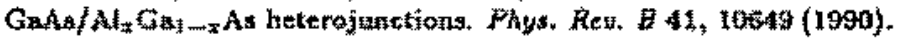

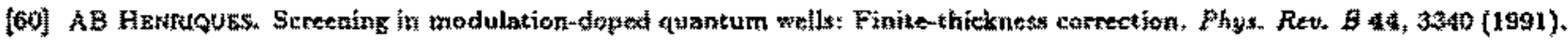

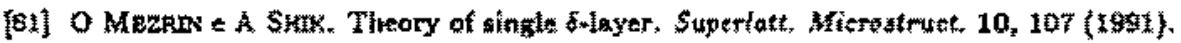

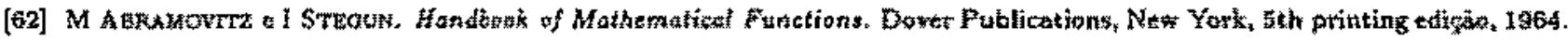

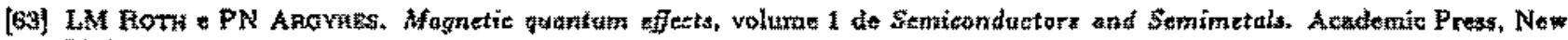
York, 1968.

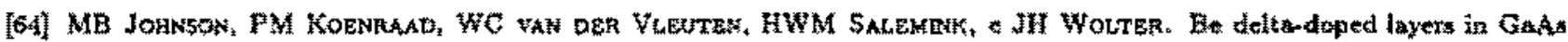

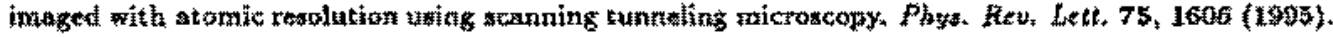

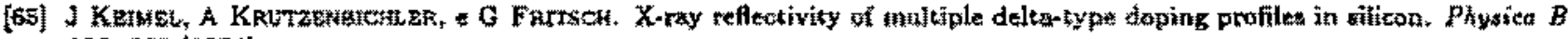
108, 2 (53 (1994).

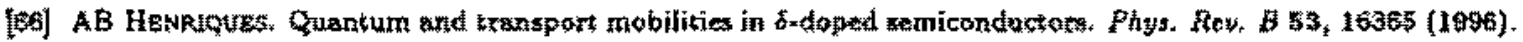

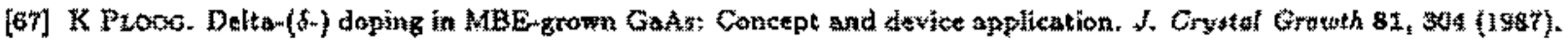

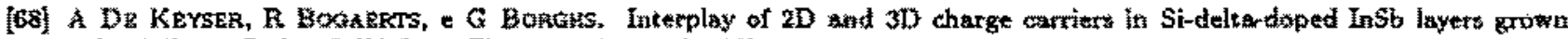

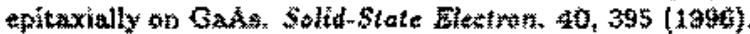

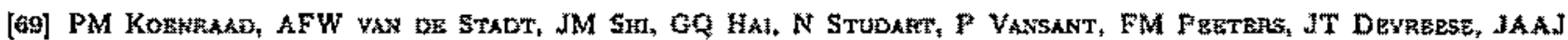

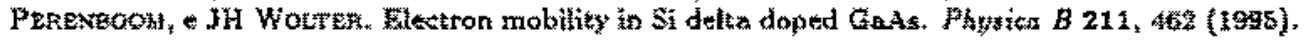

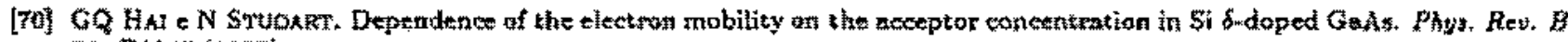
32. fi2245 (1995) 


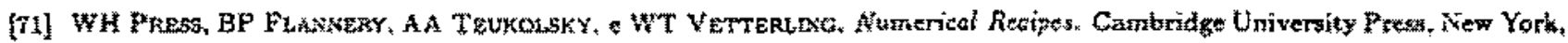
$198 \%$

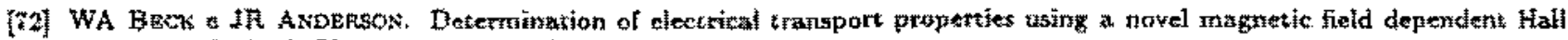

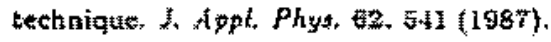

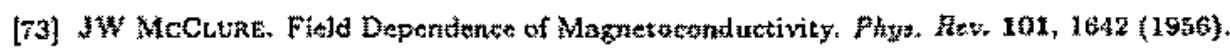

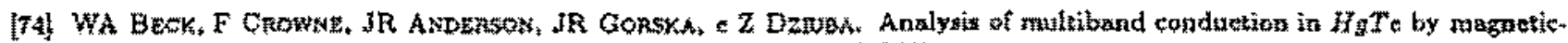

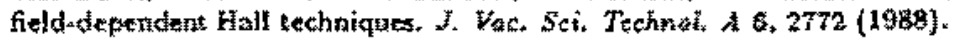

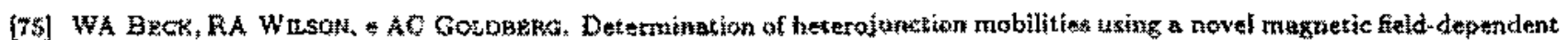
Hall technique. J. Crystat Growth $81,13(1987)$.

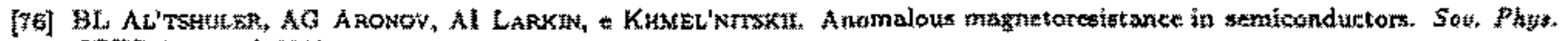

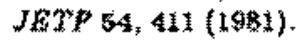

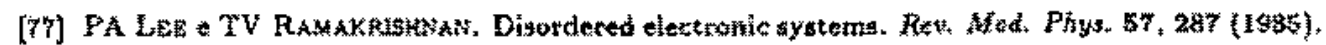

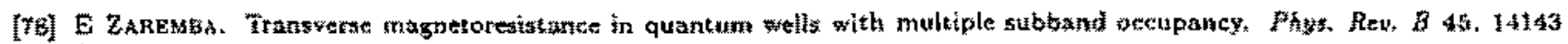
(1992).

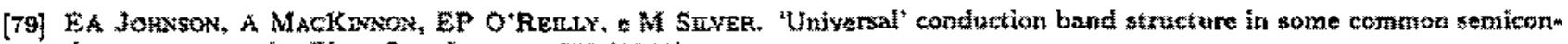
dyetor compounds. Fhys. Rev, Luth, 65, 752 (1090). 


\section{Trabalhos publicados}

Os estudos das propriedades eletronicas em super-redes $\delta$-dopadas, que deram origem a este trabalho, foram publicados nos seguintes periódicos e conferéncias, estando suas cópias anexadas ao final la tese:

1. AB HENRques E LCD GONGALES. Crossover from two to three-dimensional electronic structure in Si spike doped GaAs superlattices. Surf. Sei. 305, 343 (1994).

2. AB HENRIQUES, LCD GONCALVE, PL DE SOUZA, B YAVtCH. Sample parameters of degenerate semiconductor superiattices, Brazitian Joumal of Physics 26, 327 (1996).

3. AB HenRlQues, LCD Gongalves, PL DE SouzA, B YAVCH. Characterization of $\delta$-doped superlattices by Shubnikov-de Faas measurements. Semicond. Sci. Techol. 11, 190 (1996).

4. AB Henriques, LCD Gonçalves, V Bindlatti, NF OLVEIRA, JR., PL SOUzA, B Yavicu. Multisubband scattering in periodically delta-doped $\ln$ P. Prox. 23rd Intemational Conference on the Physies of Seniconductors (Berlin, Germany, 1996), paig. 2363, vol. 3. World Scientific.

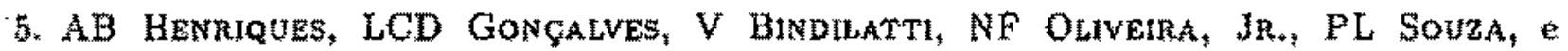
$B$ Yavich. Photoluminescence of periodically s-doped InP in high magnetic fields. Proc* 12th International Conference on Applications of High Magnetic Fields (Wurabury, Germany, 1996), păg. 629, val 2. World Scientific.

6. LCD Gonçalves e AB HeNRIQuEs. Electronic properties of gated $\delta$-doped semiconductors. Semicond. Sci. Technol, 12, $203(1997)$.

7. B YAVICH, PL SOUZA, M PAMPLONA-PIRES, AB HeNRIQUes, LCD GONGALVES. Single and periodically Si f-doped InP grown by LP-MOVPE. Semicond. Sei. Technol, 12, 481 (1997).

8. PL SOUZA, B YaVICH, M PAMPLONA-PIRES, AB HENRIQUES, LCD GONCALVES. Electronic and optical proparties of periodically $\mathrm{Si}$ deltandoped InP grown by low pressure metalorganic vapor phase epitaxy. I. Appl. Phys. 82, 1700 (1997).

9. AB Henrioues, LCD Gongalves, PL Sonza, e $B$ Yavich. Magnetic quantum effects in degenerate superlattices. Brazilian Jownal of Physics 27 A, 38 (1997).

10. AB Henriques, LCD GonÇAvEs, PL SOUzA, e B YaviCh. Capacitance-voltage profiling of periodically $\delta$-doped semiconductors. Brazilian Jotrnal of Physics 27A, 215 (1997).

11. LCD GONÇuLVE, AB HeNRloues, PL SOUzA, e B YAVICH. Characterization of periodically fmdoped semiconductors by capacitance-voltage profiling. Semicond. Sei. Technol. 12, 1 (1997).

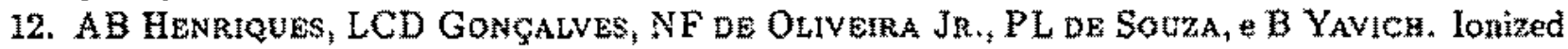
impurity scattering in periodically $\delta$-doped InP. Phys. Ret. $B 55,13072$ (1997).

13. AB Henriques, LCD Concalves, NF De Olvima In, SM SHal, PL de Souza, e B YaYion. Quantum transport in periodically 6 doped GaAs. Z. Phys. B 104, 457 (1997).

14. AB Henriques, S Obukhov, LCD Gongalves, PL DE Souza, $B$ Yaviek. Band gap renormalization in periodically delta-doped semiconductors. Phys. Stat. Sol. (a) 164, 133 (1997). 


\title{
Crossover from a two- to three-dimensional electronic structure in Si spike doped GaAs superlattices
}

\author{
A.B. Henriques*, L.C.D. Gonçalves

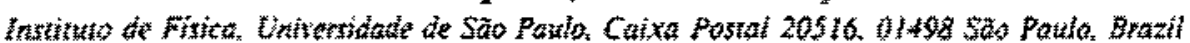

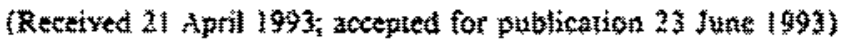

\begin{abstract}
Periodically 5 spike doped GaAs with the doping period in the range $100-830$. was studied by magnetoresistance measurements in tilted helds and by phococondustivity. The angular dependence of the Shubnikov-de Haas oscillations, in conjunction with a self-consistent calculation of the miniband strueture is used to construct the Fermi surface. When the doping period decreases, the superlattice potential weakens, and the magnetic breakdown of the superlattice Bragg reflection can be detected. Photoconductivity spectra are described by an absorption threshold at the Fermi energy, which is pushed upwards when the superiatice period decreases.
\end{abstract}

Spike doping is a technique which can be used to obtain carrier confinement in semiconductor microstructures. In spike doped GaAs, a sheęt of shallow donor atoms is localized within a few monolayers of the crystal. The carriers, released from the shallow donors, are confined by a $V$ shaped spact charge potential, a 0 well. In periodieally $S i$-doped GaAs ( $\hat{\delta}$-superlattice), sevm eral equaily spaced dopant sheets are introduced in the crystal. By varying the spacing between the dopam sheets, the strength of the interaction between adjacent $\delta$-wells can be uned, and the system can be taken from a set of diseon. nected two-dimensional systems for the widely spaced wells to an essentially anisotropic threedimensional system for the short period superlattice. The effect of an increasing coupling between adjacent wells when the superlattice period is made shorter has been deteeted by optical and magneto-transport studies of $\delta$-doped GaAs $[1-4]$.

* Corresponding author. Fax: $+\$ 5$ (1) 8140503
Periodically Si-doped GaAs grown by MBE was studied by Shubnikov-de Haas (SdH) measurements in tilted fields (0-9 Tesia) and by photoconductivity $(\mathrm{PC})$ at $2 \mathrm{~K}$. The samples werc grown by MBE by S.M. Shibli of the Instituto de Física da Universidade de São Paulo. The spacing between the dopant sheets was varied from 830 down to $100 A_{\text {; }}$ while the doping level per period was kept consiant at approximately $2.0 \times 10^{12} \mathrm{~cm}^{-2}$

First, the transwerse $\mathrm{SdH}$ spectra (fipld applied parallel to the growth direction) will be discussed. Fig 1 shows the inverse field Fourter transform for samples with a superiattice period in the range $830-100 \mathrm{~A}$. For the 830 , sample. the $\partial$-wells are disconnected, and three peaks are detected, which correspond to the occupancy of three subbands. The occupancy of the ground-state (EI) subband, which contains most of the electronic charge, is detected only as a weak peak in the Fourier spectrum, because of its relatively lower mobilizy due to the strong localization, or shor binding length, of 
the El electrons [5]. When the dowell spacing is decreased. the binding lengh rises and 50 does the relative strength of the peaks related to the ground-state miniband occupancy; simultaneously. the widths of the minibands inerease, while the number of populated minibands is reduced. For the 100 A sample, most of the electrons are in the ground-state miniband, which gives rise to a strong peak in the high frequency range of the Fourier spectrum.

The peaks $B_{i}$ in the Fourier spectra are the extremal cross sections $A_{i}$ of the Fermi surface in a plane perpendicular to the field diretion, in units of $h / 2 \pi e$. In order to interpret quantitatively the SaH data. in is necessary to know the shape of the Fermi surface, which se calculated self-consistently. The self-consistent procedure included the conduction band non-parabolicity and the exchange-correlation correction in the local density approximation. The input parameters were the superlattice geriod and the sheet carrier density per period. Details of the calculation procedure are given elsewhere [6].

The Fermi surface has the growh direction as its axis of symmetry, and can be represented by its rotationally symmetric cross section. The

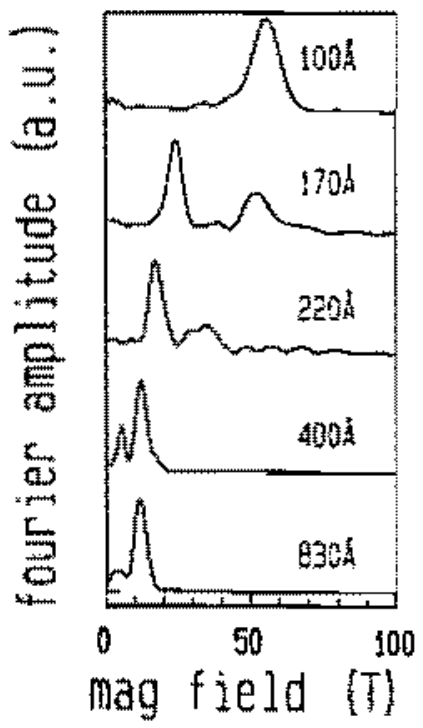

Fig- I. Fourier spectra of the experimental recordings of the

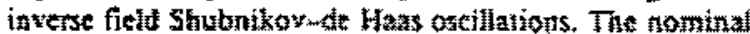

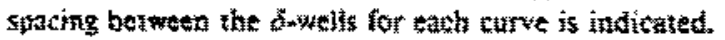

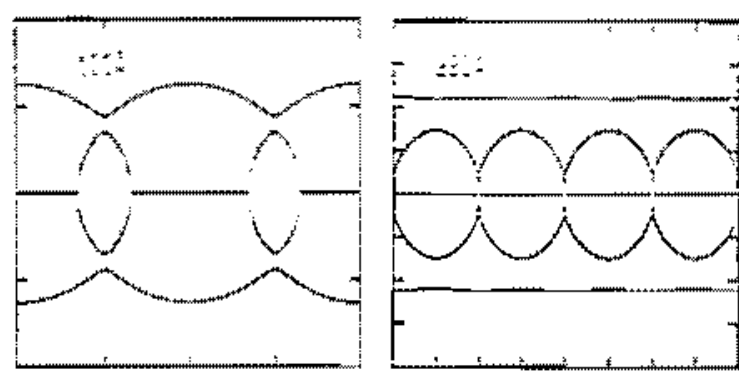

Fis. 2. Crows section of the Farmi surace of a d-supertantice

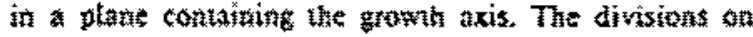

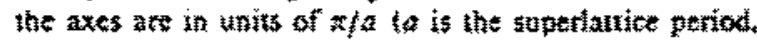
indicated for ath struteture:

Fermi surface for the 100 A superlattice is shown in Fig. 2 in the extended zone scheme. The outer curve, recognized as a cylinder with periodically modulated cross section, is the Fermi surface for the El miniband, whereas the next miniband (E2) gives the lenswshaped surface centered around the minzone extremum.

If the superlatsice period is increased, the Fermi surface for the second miniband gradually swells until it opens at the center of the Brillouin zone, thus changing aradually from lens-like to the periodically modulated cylinder shape, and the third minitand (E3) starts to be populated, which gives rise to a new Fermi lens-like surface at the minizone center, as for the $220 \dot{A}$ superlattice, also shown in Fig. 2. Conversely, if the superlattice period is reduced from 100 $A$, electrons are transferred from the second to the first miniband, whose Farmi surface is nore strongly modulated, and ultimately closes.

The electronic minibands described by an open Fermi surface will contribute to the transverse $5 \mathrm{dH}$ oscillations with a "belly" and a "neck" frequency (whith become degenerate in the uncoupled swell limit) while the minibands described by a closed Fermi surface will be characterized by a single frequency. For an open (cylinder-like) Fermi surface, the extremal cross section in a plane perpendicular to the field direction will increase when the direction of the magnetic field is tilted and will be finite only below a critical tilt angle, $\theta_{*}$, above which oniy open orbits in $k$ space are allowed. For a closed (lens-like) Fermi surface. the cross 
section decterses when the neld is tilted.

These opposite tendencies can be observed in Fig. 3, which shows the Fourier transform of the SdH spectra evolution as a function of the angle berween the growth direction and the mag* netic field $(\theta)$. For the 170 and 220 a samples, a strong peak at low frequencies is displaced to the left when $\theta$ increases, whereas a weak peak at high frequency moves to the right. The low fre. quency peak corresponds to a partially filled second miniband, and the high trequency one is due to a filled ground-state miniband. For the 400 A structure, wo peaks are detected at low fre. quencies: the lower frequency one, which is displaced to the left when the sample is tilted, is ascribed to a partially filled $\mathrm{E} 3$ miniband. and the one that moves to the right is ascribed to a full E2 miniband. In the $830 \mathrm{~A}$ period structure, the peak positions scale as $\cos \theta$, as expected for a set of disconascted 2D systems. The $100 \mathrm{~A}$ structure shows a single ptak of constant frequency, which is indicative of a 3D electronic structure,

The anguiar dependence of the peak positions detected in the spectra of Fig. 3 is shown in Fig. 4 . Also shown by solid lines are the theoretical cross sections of the Fermi surface. In the numerical calculations, the superlattice period was taken equal to the nominal value, and the total sheet carrier density, $n_{3,}$, was adjusted to obtain the best asrecment between the salculated extremal cross sections of the Fermi surface and the frequencies $\left(B_{i}\right)$ for $\theta=0$. With the input parame. ters thus fixed, the exiremal cross sections of the Fermi surfaces were calculated for all till angle

Table 1

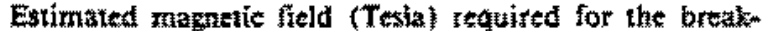
down of Dras teflection of the eicetrons in the E1, Ez ant E3 minuternests

\begin{tabular}{|c|c|c|c|}
\hline 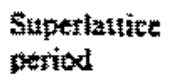 & EI & E2 & $\mathrm{E3}$ \\
\hline $100 \hat{A}$ & 1.74b & - & $w$ \\
\hline $170 \AA$ & 5.9 & $\rightarrow$ & $\ldots$ \\
\hline $220 \mathrm{~A}$ & 8.5 & $<1.0^{2}$ & - \\
\hline $400 \AA$ & 16.6 & 4.8 & 5.4 \\
\hline
\end{tabular}

Uteakdoth expected forn $h_{3} E_{F}>d^{2}$.

Experimental poins persist above $\theta_{e}$. interval $\left(0-90^{\circ}\right)$.

The calculated Femi surface extremal cross section dependence on blosely match the measured frequencies $B_{i}$, however, for some of the sampies. described by an open Fermi surface, agreement is only obtained below the critical tilt angle $\theta_{c}$. This is the case for the E1 Fermi sur. face cross section of the $100 \mathrm{~A}$ superlattice $1 \theta_{\varepsilon} \sim$ $\left.50^{\circ}\right)$, the E2 of the $220 \mathrm{~A}$ one $\left(\theta_{\mathrm{c}} \sim 60^{\circ}\right)$, and the E3 of the $400 \mathrm{~A}$ superiatice $\left(\theta_{c} \sim 60^{\circ}\right)$. Above these $b_{5}$, where no finite extremal cross sections for the corresponding Ferni surface miniband exist, the experimental curve persists.

The appearance of frequencies above the critical angle is interpreted in terms of a magnetic breakdown of Bragg reflection by the superiattice planes. The magnetic field strength required for an electron to cross a Bragg plane and transil between two minibands, separated by a gap of energy $A_{\text {, is }}$ in $w_{\mathrm{z}} E_{\mathrm{F}}>\Delta^{2}$, where $w_{\mathrm{t}}$ is the cyclouron frequency and $E_{\mathrm{F}}$ is the Furmi energy. The calculated magnetic tields required for the breakdown of Bragg reftection are shown in Ta ble 1 . and clearly support the hypothesis of magnetic breakdown.

The photoconductivity spectra at $2 \mathrm{~K}$ for the 170.220 and $400 \AA \delta$-superiattices in the energy range near the GaAs band-edge were measured and are shown in Fig. 5. The spectra are described by a smooth absorption onset, which blue-shifts when the superlattice period decreases; this is a consequence of the increase of the Fermi enargy [6]. The theoretical threshold for absorption from the $n$th hole mitriband, indicated by arrows in Fig. 5, was estimated by

$h \nu_{\text {threstiknd }}=E_{\mathrm{O}}+B G R-\mathrm{H}_{0}+E_{\mathrm{F}}+H_{\mathrm{nF}}$

where $E_{0}=1.519 \mathrm{eV}, V_{0}$ is the potential barrier between the wells, $E_{\mathrm{F}}$ is the Fermi tenergy measured from the bottom of the well. $H_{n \mathrm{FF}}$ is the hole energy at the Fermi wave vector, and $B G R$ w $-34 \mathrm{meV}$, as estimated for a 3D elect tron gas [7].

In summary, we have studied the magnetoresistance oscillations in GaAs $\delta$-superlattices in tilued magnetic fields. These can be interpred in terms of the shape of the Fermi surface, which 

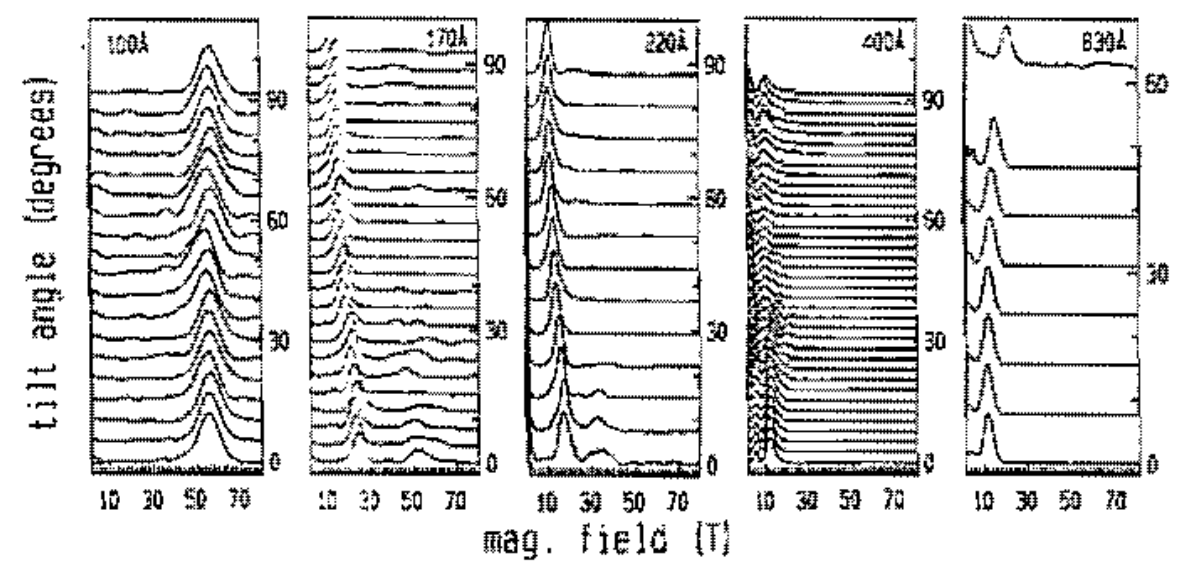

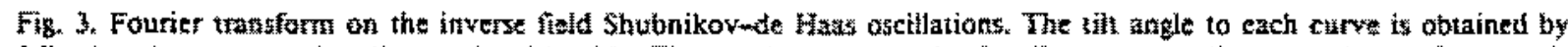

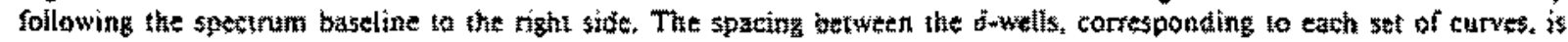
indiesied.
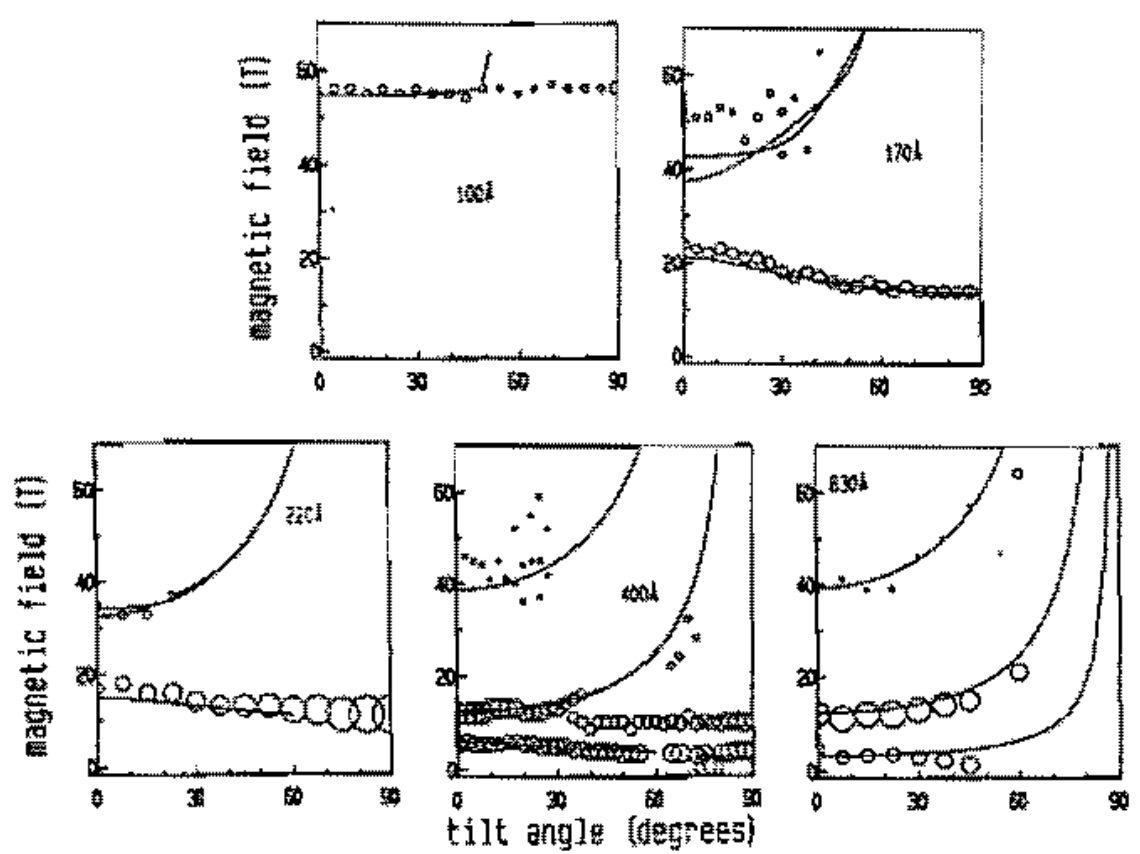

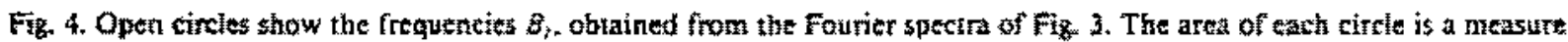
of the relative intensity of the Fourter peak, Solid lintes are the Fermi surface cross sections. obtained from the numetieal calcutastons. 


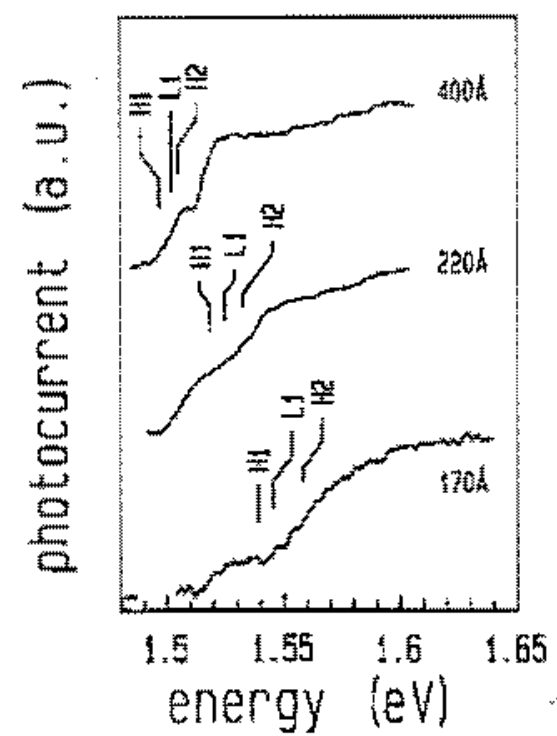

Fis. S. Photoconduxtivity spectra of periodically spike

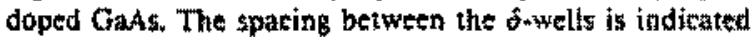
for each curve. Theoretical transition thresholds ate indi* cated by artows.

evolves progressively from the cylindrical shape in the uncoupled $\delta$-well limi, and approaches a sphere for the shor period superlattices. It is shown that the mannetic breakdown of Bradg teflection plays an important role in these systems, and for a doping period below $100 \mathrm{~A}$ the electronic structure is effectively three-dimentsional. Photoconductivity spectra were also measured, and the spectra obtained are consistent with the interpretation of the transport data. The model used for the analysis of the experimental results is simplified, since it does not take proper account of the effect of magnetic depopulation of the minibands [8], and also the effects of light on the self-consistent potential for electrons and holes and its consequences on the photoconductivity spectra [9].

This work is supported by the FAPESP Grant No. 91/3336-9 and the CNPa Grant No. $306335 / 88$.

\section{Reterences}

[I] F. Koch A. Zrenner and M. Zachau, in: Two Dimensional Systems: Physics and New Devices (Springer, Berlin, 1986) p. 175.

[2] R. Droopad, S.D. Parker, E. Skutas. R.A. Stratting. R.I. Williams, R, B. Beali and J,J, Harris, in: High Magnetic Fields in Stmiconduntor Physics If

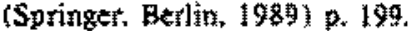

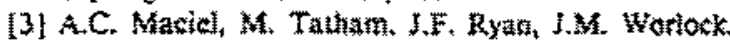

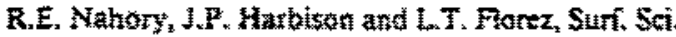
228 il 5901251.

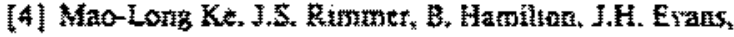
M. Missous, K.E. Sintar and P. Zalm, Pitys. Rey. B $45(1992\}\{4114$

[5] 5. Yamada and T. Kakimosov Appt Phys. Letc. 57 (1990) 1022 .

[6] A.P. Henriques and L.C.D. Gonçalvess. Semicond. Sti. Technol. 8 (1993) 58s.

[7] S. das Sama, R. Jalabert and S.R.E. Yans Fhys. Rev, B $41(1990) 8288$

[8] A. Zrenner. H. Reiwigets, F. Kachl, K Plogg and I.C Manan, Pats. Rev. B $33(1986)$ s60\%.

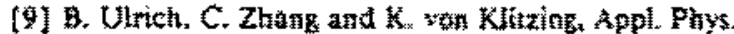
Letl. 54 (1989) 1133 . 


\title{
Sample Parameters of Degenerate Semiconductor Superlattices
}

\author{
A,B, Henriques and L,C.D. Gonçalves

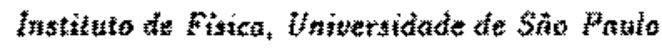

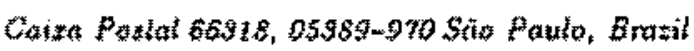 \\ P.L.de Souza and B.Yavich* \\ Centro de Estudos en Telocomunicaţöes \\ Pontificia Universidade Catolica, 20458 Rio de Jantion, Bnzil
}

Received 3n! 31, 1995

\begin{abstract}
The Shubnikov-de Hatas ostillations of InP vith a pertodical planat toping with Si were

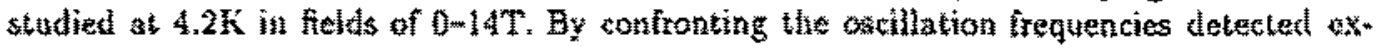
perimentally with the ones predieted on the basis of the effective mass approximation the carriter population of the superiattite minibands and the characteristic widith of the dopech layer wert obtained. The widlin of tlie toped layer obtained in this way is in good agreentent. witls the value obtained from $C V$ profiling measurements on the same structures.
\end{abstract}

\section{Introduction}

Semiconductors in which the dapant atoms are confined to a single ar a few monolayers of the semicon. ductor latice are of much technological importance duse to theit application in novel semicondactor devices $\left[{ }^{[1]}\right.$. In an ideal 6 -doped stperlattice $(\mathrm{SL}$ ) a monolayer of donor impurities is introduced periodically into the lrost crystal during the epitaxial growth process. The chanacteristic parametess of a 8 -doped superlattice sample are the density of tonor atoms in the doping layers,

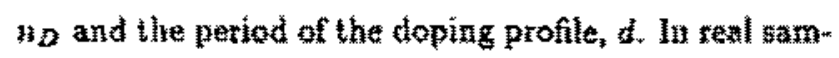
ples, thermal difusion of the donors atoms into the host rrystal rayy oceur; in this case the distribution of donor atoms along the growth direction can be approximated by a Gaussian function with a full width at half maximum $\Delta[1]$. The non-zero thickness of the donor layer is reffected upon the energy spectrum and miniband filling of the superlattice [N. In addition, the presente or background ionized impurities also las infuence on the electronit struchute lowever, these impunitios cta be netralized by illuminating the sample at low temperatures: after illumination the areal density of tree

\footnotetext{
-Permanent address: A.Fulsfte institute, 26 Polytechùich. taksya, 194021 St.Petersburg. Russia.
}

carriers per superlattice period can be taken as a good approximation ta ba equal to the density of donows, i.e. $n_{S}=n_{D}\left[a_{3}\right.$.

The characteristic parameters of a given $\delta$ - doped SL sample determine to a great extent its optical and electrical properties. For instance in GaAs, with an areal carrier density fixed at about $1.2 \times 10^{12} \mathrm{~km}^{2}$, when the doping period is decreased from 500 to $100 \mathrm{~A}$ the photoluminescente spectrum associated with the proence of the -1ayess changes from a narrow emission band with a eut-of energy near the bandmedge to 3 broad emission band wilh a cut-of energy about $60 \mathrm{meV}$ above the renormalized GaAs bandgap ${ }^{[4]}$ (set also (5]). Similarly, for a fixed doping level the absorption threshold is pushed upwards when the superlattice period is made shorten ${ }^{\text {[o) }}$, These observations are in good agreement with the theoretical calculations, wade in the effective mass approximation and using the chat-

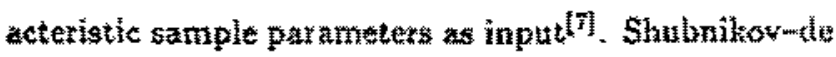
Hass experiments in tilted felds demonstrate the effect. of coupling between adjacent $\delta$-wells upon the shape of the Fermi surface $\left[\mathrm{l}_{\text {; }}\right.$, the extremal cross-section ay eas of the Fermi sutface and their dependence on the angle between the magnetic feld and the SL axis art 
also well reprotuced by the same theoretical modef Nhlus, parameters $i_{i}$ ns and $\Delta$ form the basis for the modelling of the electronie structure of a perlatice, and their knowledge is a presequisite for the understanding of the optical and electronic properties of a given sample.

The period of the o-doped supertatice can be es tablished accurately during the growth process; the remaining parameters the earrier density $\mathrm{n}_{5}$ and the spreading of the donor atoms 4 ) are more dificult to contral during the growth $h_{1}$ and should be established in dependently. For a sample with an isolated $\delta$-weil for equivalently $\mathrm{SL}$ of period large enough to uncouple the $\delta$-wells), in has been demonstrated that botin $n_{S}$ and $\Delta$ can be determined simultaneously from the semple's transverse Slubrikov-de Haas spectrum ${ }^{[t])}$. The procedure is based upon the linear dependence between the carrier population in a given subband and a frequency of oscillation in the magnetoresistance of the sample. For a supeslattice, however, the enetgy dispersion for movernent across the layers implies that the relation between the population of a given miniband and the corresponding oscillatory magnetoresistance frequency

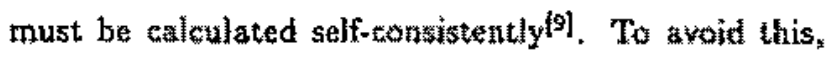
several authors have approximated the density of states for each miniband ly eitler a strictly two-dinensional or a three-dimensional form ${ }^{[5.11}$; tha sample parameters obtained in this way, however, are only approximate.

In this paper, we present results obtained on 6-doped InP superiatices obtained by Shubnikoy-de Faas and capaxitance-voltage (CV) measurements. By comparing the measured frequencies of escillation in the magnetoresistance to the values predicted by the self-ecnsistent calculations, the best fil values of $n_{S}$ and $\Delta$ are determined. The widtly of the donor layers, $\Delta$, obtanged from the analysis of the Shubaikorde Has (Stif) spectrar is in good agreement with the widt of the donor layer which is extracted from the capacitance-voltage profiling tor the same samples.

\section{Numerical procedure}

The electronic structure calcalations for the $\delta$-doped superiattice vet performed in the effective mass approximation by solving self-consistently the Sehrödinger and Poiston equations: details of the thesretical model and a description of the sequence of steps taken in the self-consistent procedure are described in Ref. [7]. Throughout this paper atornic units are used, whereby the units of length, energy and mass are

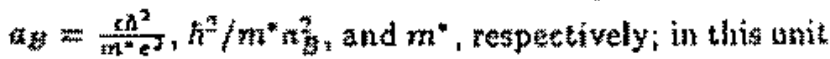
system the unit of magnetic feld is $B_{0}=\frac{k}{B_{3}^{*}}$. The dis* tribution of ionized donora can be approximated by a Gaussian hunetion ${ }^{[1]}$

$$
N_{D}(s)=n D \sqrt{\frac{4 \ln 2}{\pi \Delta^{2}}} \exp \left[-4 \ln 2\left(\frac{\Sigma}{\Delta}\right)^{2}\right]
$$

where $\Delta$ is the FWHM and is related to the diffusion coefficient $D$ according to $\Delta=4 \sqrt{D \tau \ln 2}$, where $F$ is the diffusion tirte. As the starting potential for the self-consistent iterations we tused the Thonas-Femi approximation for a single $\delta-$ well, $_{\text {; }}$ as given by lotiatti ${ }^{1}$ [12]:

$$
V(z)=-\frac{1}{2} \frac{\alpha^{2}}{(\alpha|z|+2 a)^{4}}
$$

where $\alpha=2 / 15 \pi$ and $z_{0}=\left(a^{3} \pi n_{s}\right)^{1 / 5}$,

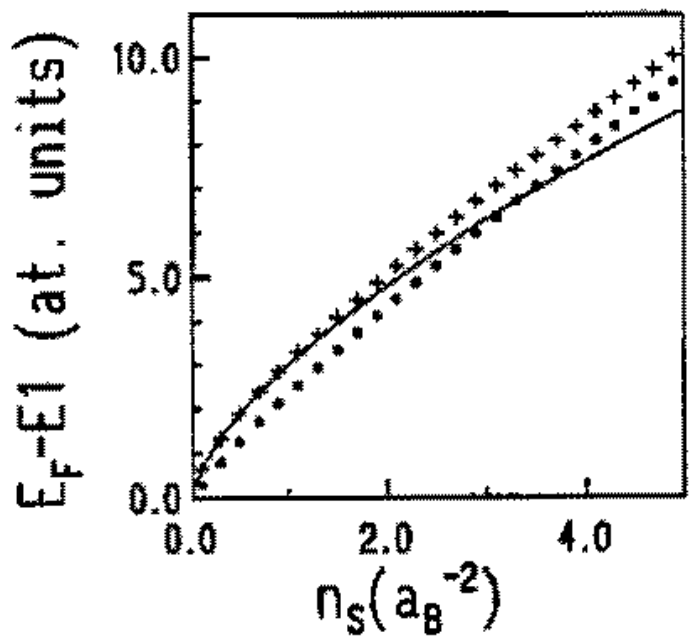

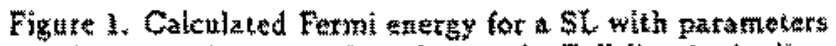

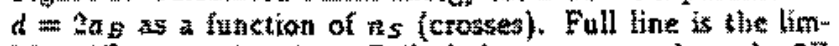
tung 30 appoximation. Futl circles correspond to the 3D

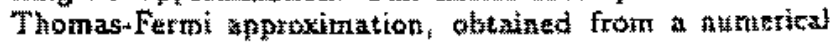
solution for the potential given by Ex. (1).

\footnotetext{
The factor $\frac{1}{2}$ arisex hate becatise of the wystem of units used.
} 
Fig. 1 shows the calculated dependence of the Fermi energy on the areal depsity ${ }_{5} 5$ for a $\mathrm{SL}$ of period $d=2 a_{B}$ and $\Delta=0.2 a_{B}$ (full thities). Also shown in Fig. 1 is the Fermi energy tependence on $\pi_{s}$ for inee electron gas, $z_{F}^{30}=\frac{1}{2}\left(3 \pi^{4} n_{5} / d\right)^{2 / 3}$ (full line), and the dapendence of the Fermi energy on $n_{5}$ in the two. dimensional Thomas-Fermi approximation (full cireles), obtained from a numerical solution to the Schrodinger equation with the confining potential given by Ea. (1). At low values of $n_{5}$, the wets are shallow and the coupling between neighboring wells is strong, so that $E_{F}$ follows the bulk dependence $E_{F}^{3}$. Át hizh concentrations the couphing between adjacent wells decreases, and the depenclence of $E_{F}$ ou ns approaclies the same linear dependence as the Thoms-Fermi approximation for an isolated towell. The $2 \mathrm{D}$ behayior at large $n_{5}$ Illustrates the point that at very high toping levels the b-wells are uncoupled event for very shot period SL's;

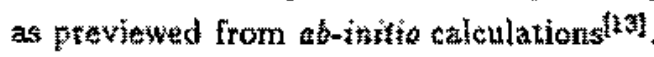

The connection betwen the output of the num merical calculations and the results of the thanswerse Shubnikov-de ladus measurements fwhen the magnetic field is applied parallel to the axis of the supertattice) is based upon the fact that if plotted against inverse feld the magnetoresistance ascillations of a-doped superiatitice display a sel of frequencies, $B i$,

$$
B i=\frac{A i}{2 \pi}
$$

where $i=1,2, \ldots$ and $A i$ is cross-tectional area of the mini- Perni surface of the $i-$ th electronic miniband (it); thas is each filled minitand there corresponds a period in the maghetoresistance oscillations. Farameters $n_{5}$, $d$ and $\Delta$ of a given sample are taken to be those that give the best simultaneous azrement between all the calculated and mestured SdH ostillation frequencias.

For an isolated well, Eq.(2) takes the familiar form $B t=\pi n_{S}^{i}$, where $n_{S}^{i}$ is the sheet carrier density in the inth electronic subband. By adjusting the input patameter $n$ s and $\Delta$ in the theoretical model until the predicted SAH frequencie agreed with the measured ones, Koostraal determined both the sheet cartier den. sity ayd the widh of the donor layer in GaAs with an isolated $\delta$-wel|[t|

Fig. 2 shows the calculated dependence of $B i$ on the sheet carrier density for an isolated $\delta$-well with $\Delta=0.1 a_{n}\left(\sim 10 \mathrm{~A}\right.$ for GaAs) (solit lines) and $\Delta=1.0 a_{0}$ (ailon for GaAs) (dathed lines). When the width of the donor layer in increaged, the 6 -... well becomes broader, consequently the energy difference between the mininum of the subbands decrease, resulting in a trans. Fer of electrons from the subband $E 1$ to $E 2$ and $E$. It is observed that the calculated SaH oseillation frequencies exhibit a substantial sensitivity to the width $\Delta$ : for a variation of $\triangle$ from $0.1 a_{B}$ lo $1.0 a_{B}$, at $n_{S}=2.0 a_{B}$ the change in the calculated frequencies $B 1$ is more than 0.7 at.unit. Consideriag that the Bi can be detectod experimentally with an accuracy of $\pm 0.2 \mathrm{~T}$ Tesias ${ }^{[3]}$, and taking the GaAs effective mass and dielectric constant to be $m^{\circ}=0.0605$ min and $\epsilon=12.6$, wespectively, it can be expected that the $S \mathrm{dH}$ analysis can produce an estimate of $A$ with as uncertainty of about \pm t $A$.

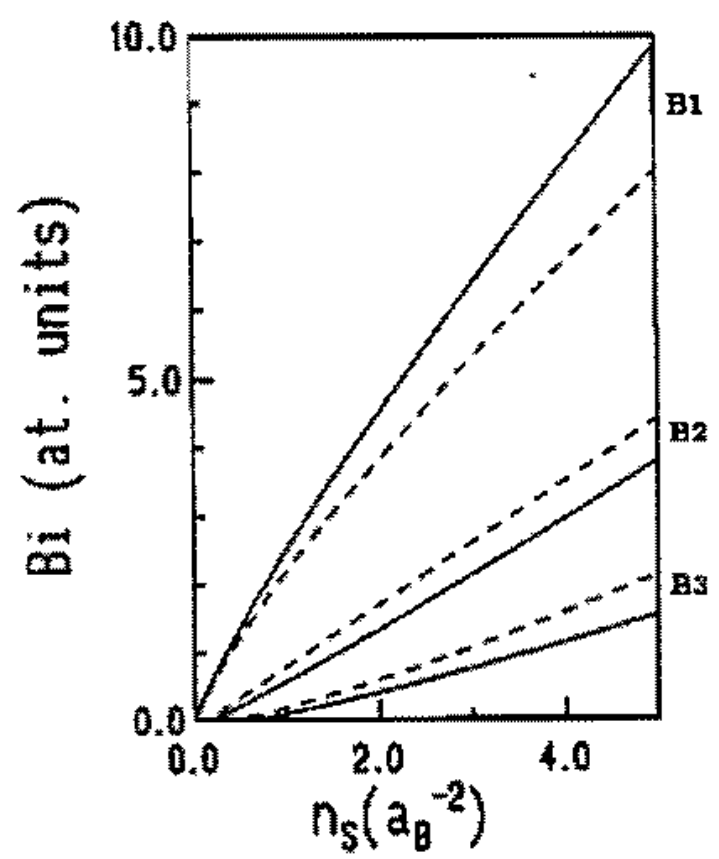

Figure 2. Galculated Sal oscillation frequercies $B i$ for an isolated 5 well. Full lines correspond to $\Delta=0.15$ and dasked linto ofo $\mathrm{A}=1.00 \mathrm{~g}$.

Fig. 3 depicts the calculated SdE frequenties $B i$ as a function of $n_{s}$ using a fixed value of the donor layer width, $\Delta=0.2 a_{g}$, for superlattice periods of $d=1.5 \mathrm{a}_{B}$ and $d=2,0 a_{B}$. As the superlattice period is made shorter, it is zequired a higher value of doping $n_{3}$ to populate the excited minibands; for this reason; the pariod $d$ is decreased, functions $B$ i(ns) for the exited minibands intersect the horizontal axis at higher walues of $n_{5}$. Fig. 2 and Fig. 3 demonstrate that the Sdf spectrum is sensitive to all the characteristic parame 
ters ( $n_{s, d}$ and $\Delta$ ) of a $b$-doped superlattiec, and it can in principle be used to estimate all the charateristic parametes of a given sample. In this paper, however, the petiod of the superlattice is obtained from CV measurements, and we limit our analysis of the Sdt spectio to extratet the parametars $n_{S}$ and $\Delta$ only.

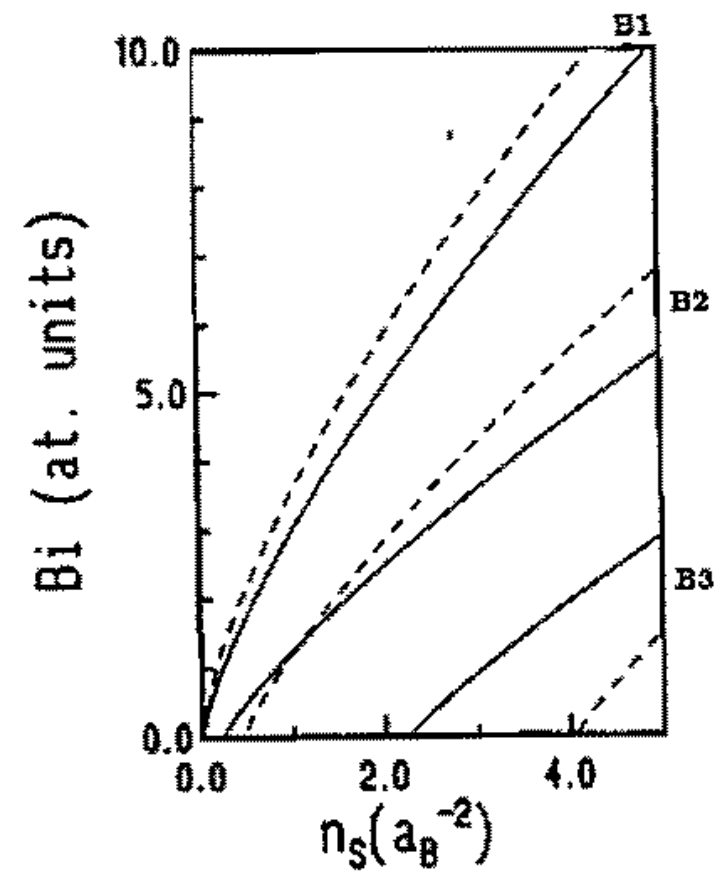

Figure ${ }^{3}$ Calculated SdH oscillation frequencies $B i$ for SL. with $d=2.0 a_{B}$ (full curve) and $d=1.5 a n$ (dasted curve).

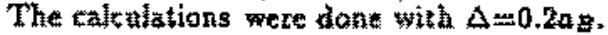

CV profles were calculated by resolving sulfconsistently the Schröedinger and Poinson equations for the superlattice under bias. The tapacitance of the system at a given bias is then determined atcording to $C=d Q / d V$, and the cy profiles were obtained from

$$
N_{C V}=4 \pi C^{3} \frac{d V}{d C}
$$

where $V$ is the external bias and $N_{C V}$ is the $C V$ cor centration, which occurs at a depth $z=1 / 4 \pi C$ from the surface of the sample.

\section{Experimental}

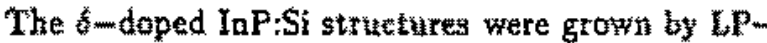
MOVPE in a AIX 200 reatetor. The source materi*sere $\mathrm{PH}_{3}(100 \%)$, timetilindium (TMI) and silane (SiL) as dopant. The InP epilayers were grown on (100) Fedoped InP sulstrates at $640^{\circ} \mathrm{C}$ and pressure 20 mbat with a growth rate of alrout $4 \mathrm{~A} / \mathrm{s}$. The structures consisted of a $0.4 \mu m$ thick undoped inf bufer layer, the doped structure, and a cap layer of $0.06-$ 0.07um thickness. During the growth the $\delta$-doped plane was sinterized after the TMll flow was bypassed and the surface was $\mathrm{PH}_{3}$ stabitized. "The planar doping was accomplished by introduang $\mathrm{SiH}_{4}$ in the gas pluste.

Hall measurements at $4.2 \mathrm{~K}$ were performed asing the van der Pauw technique, and the average Hall mobility was approximately $4000 \mathrm{~cm}^{2} / \mathrm{V} / \mathrm{s}$ for all samples. The Shubnikov-de Fas meastrernents were made using a four contact geombtry; the samples wers approxirnately square, with contacts in the corners. The magnetoresistance osellnations were studied at a fxed temperature of $4.2 \mathrm{~K}$ in magnetic fellds up to 14 Teslas. Measurements were done in the constant carrent movis, employing currents of $10-50 \mu \mathrm{A}$. Prior to the beginning of measurements the samples were itratizited with a ted LED with the purpose of neutralizing the background impuritits. CV measurements were periormed using a PN4300 profiler. By applying a reverse bias to the Sehottky contact on the surface of the sample and measuring the differeatial sapacitance, the aistribution of charge within a distante of $\sim 500 \mathrm{~A}$ from the aturface can be probed[1]. To probe distantes further from the surface, the sarmple was etched prior to the $\mathrm{CV}$ mea surernent.

\section{TV. Results and discussion}

We studied three $\delta$-doped In samples listed in Table I. One of these samples (No.144) contained a single 5-layer. The other two atmples contained $20 \delta$-layers; the sheet donor density in sample No, linl was approximately the same as in sample No.124, whereas sample No.120 hat a smaller doping level. Fig 4(a) shows the Shubnikow-de Foas spectum lor sample No.124, and (b) its inverse-field Fourier transtorm. The peats seen at $9.3,22.6$ and 65.6 Teslas correspond the otcupation of subbands $E 3, E 2$ and $E I$, respectively. As shown by Skuras ef aldst the widtin at half maximmm of a Fouriex patal can be sysaciated with the quantum no bility of the carriers in the corresponding suttand; the decreasing width of the peaks as we fo from $E$ lo $E$ ? and $E 3$ refect. an increasing mobility of the carriers, in

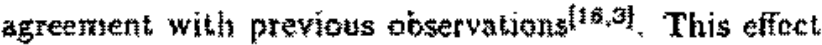
is responsible for a stualler tutertainty in the measuret 
Table [. Freçuency of the oscillations in the magnetoreststance of an average of 5 measurements at $4.2 \mathrm{~K}$. The values of $\mathrm{n}, 5$ and $\Delta$ and their uncertainties were estimated from the measured values of $B i$.

\begin{tabular}{|c|c|c|c|c|c|c|c|c|c|c|}
\hline 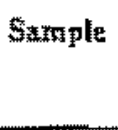 & $\begin{array}{l}\text { Number of } \\
\text { donor layers }\end{array}$ & 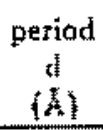 & BI & $\begin{array}{c}\text { Measazed } \\
\text { E2 } \\
\text { Tesias! }\end{array}$ & $B 3$ & $B 1$ & $\begin{array}{c}\text { Calculated } \\
\mathrm{z}_{3} \mathrm{z} \\
(\text { Testas) }\end{array}$ & $B 3$ & $\begin{array}{c}\left.\begin{array}{c}n \\
\left(10^{3}\right. \\
\left(m^{2}\right.\end{array} \mathrm{m}^{-2}\right) \\
\end{array}$ & $\stackrel{A}{(A)}$ \\
\hline 124 & 1 & - & $65.6 \pm 1,0$ & $32.6 \pm 6.9$ & $9.5 \pm 0.1$ & 65.2 & 25.4 & 9.3 & $4.94 \pm 0.05$ & $30 \pm 6$ \\
\hline 120 & 20 & 270 & $10.6 \pm 1.1$ & $8.1 \pm 0.3$ & - & 19.6 & B.l & - & $1.14 \pm 0.06$ & $53 \pm 15$ \\
\hline int & 20 & 400 & $64.4 \pm 1.5$ & $23.6 \pm 1.2$ & $11.3 \pm 0.3$ & 64.4 & 25.7 & 11.0 & $4.89 \pm 0.01$ & $39 \pm 7$ \\
\hline
\end{tabular}

peak position in the Fouriet transforth which ate associated to more excited minibands, as shown in Table I. In the SI, however, the electrons in the excited minibands are delocalized, and they interact simultaneously fith several conor layers, resulting that their quantum mobiltites are smallex than in the isolated o-well cased!n, consequently the Fourier peaks are broader and the uncertainty in their positions is larger, as Table I stowo
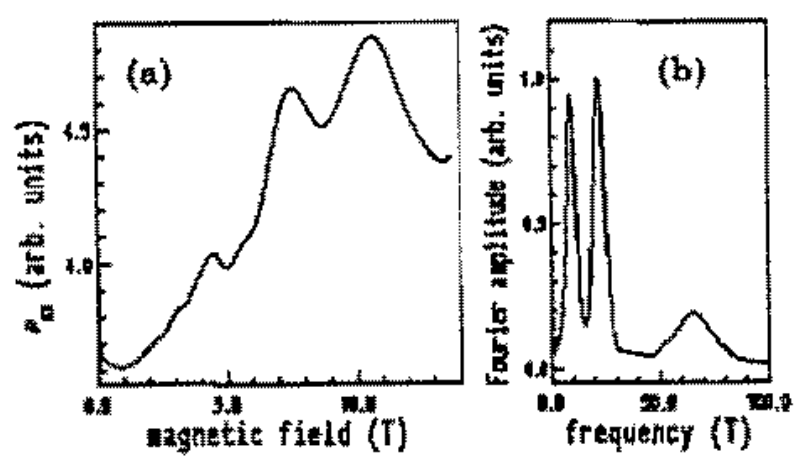

Fis field Fourie: transform (b) for sample No.124.

in order to tompare the experimental results to the theoretical calculations, the electronic effective mass and the dielectric constant for inp were taken to be equal to $m^{*}=0.0 \% m_{0}[18]$ and $c=11.8[19]$ tespectively. The values of $n_{s}$ and $\Delta$ for each sample were taken to be equal to thos that gave the least square deriation of the calculated to the experimemtal SdH frequencies, and the uncertainties in the values of $n$ s and 2 mere extimated from the experimental errors in the values of $B i$. The values of $n_{S}$ estimated from the Shubnikny-ile Hass measurements are in approximated agrement with the values of these parauneters est: mated from the conditions of growth. Table 1 summa- thes the results of the experiment and calculations for ali samples: a comparison of the measured Sat oscillam tion frequencies to the calculated ones is given, and the best-fit values of $\mathrm{n}_{\mathrm{g}}$ and $\mathrm{A}$ are shown. The grealer uncertainty in the estimated value of $\Delta$ for sample No 120 is due to the fact hat this sample has a lower doping level, and for this sample only two peaks are seen in the Fourier atansform of the Shubnikov-de Hatas oscilm lations.

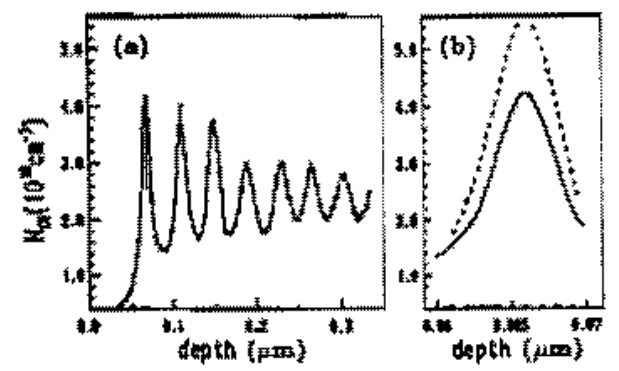

Figure s. CV prattut for sample No.121: (3) it the resull obtained by alternating etching of the sample and taking $C V$ weasurement (b) is a single CV acan whtst allows to probe the charge distribation arostud the first donot layer; the dashed line represertsts the thearetical CV spectrom astonextated by using the values of $n s$ and $\Delta$ oblained from the Stubnikoy-de Haass spectrath.

Fig. 5(a) show the CV profle for sample 121 ob" tained by alternating a CV medsurement and an etching of the sample repeatedly. From the CV profle the superlattice period is determined to be $400 \pm 15$ A. The CV profle show by the full curve in Fig. $5(b)$ was obtained by a single $C V$ tan of the sample whicl was etched prior to the beginning of the measurements. The dashed curve in Fig. $5(\mathrm{~b})$ is the theoretical $\mathrm{CV}$ spectrum for sample 121, generated with the sample parameters tyiven in Table I and by using Eq. 3 .

The width at hall maximum of the CV peak of Fig. $3(b)$ is $70 \mathrm{~A}$; the width of the theoretical spectrum, shown in Fig. by the dashed line, reproduce litis re.

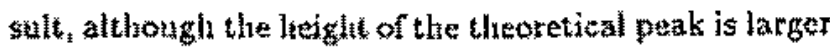


that obtained experimentally, Thus, the diaracteristhe witit of the donor layer estimated from the SdII spectrum is in quantitalive agreenent witls the valute estimated from the CV spectrum.

\section{Conclusions}

It was temonstrated that the Stubuikov-de lfats experiment can serve the purpose of determining the characteristic parameters of a the carriter distribution antong the superiatice mintbands; the width of the donor layer, and tie supertaltice period. In this paper we have linited the analysis of the Shubnikoy-de Haas spectrum to the estimate of the sihet carriet tensity, $s_{s}$, and the width of the donor layer, $\Delta$, and fixed the period of the superlattice at the value obtained from the $C V$ measursment. The value of $\Delta$ obtained fron the analysis of the Sali spectrum is in good agreenent with the value predieted by the $C V$ technique.

\section{Acknowledgement:}

We are grateful to Prof. N.F. Oliveira, Jo, for prom viding is the access to the high magnetic field facilthes of the LESBT/DFMT/IFUSP. The atthors atknowledge support by lAPESP, Project. No. 24/2155.9 and 04/5645-7, and CNPQ, Project. No. 306335/88 and $400935 / 93-7$.

\section{References}

1. E. F. Schubert, in Semieonductors and Sernimetats, edited by A. C. Cossard (Academic Press, Niesy York, 1994), Vol. 10, p.1.

2. M. H. Degani, J. Appl. Plyys. 704362 (1901).

3. P. M. Koenratad, B. F. A. van Hest, F. A. P. Blom, R. van Dalen, M. Leys,

I. A. A. J. Perenboom and J. II. Wolter, Physiea B $177_{*} 485$ (1922).

4. A. C. Maciel, M. Tatham, J. F. Ryan, A M. Worw lack, R. F. Nahoty J. P. Ilarbison and L. T. Florez, Surf. Sti. $228,251(1900)$.

5. We Ahao-Long, J. S. Rimmer, B. Ilamilton, J. H. Evaus, M. Missous, K. E. Singer and P. Zaim, Phys. nev, B 45, 14114 (1992).

6. A. B. litenriques and L. C. D.Conçalves, Surf. Sei. 305,343 (1994).
7. A. B. Henriques and L. C. D. Gonçalves, Stmicontl, Sci. Technol. 8, 585 (1993).

8. R. A Droopat, S, D. Parker, E. Skurat, R. A. Strading, R. L. Wilizams, R, B. Beall and J. J.

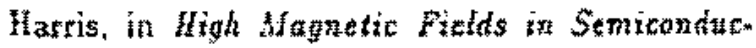
tor Ptastes 1I, Transport atud Optics, Proceedings of the International Conterence, Würzbutg, Ger" Inany, 1988, edited by G.Landiqehr, Springer Sethes in Solid State Sciences Y.8T (Springer-Yerlag, Betin, 1989), p. 199 .

9. A. B. Henriques, V. N. Morgoon, P. L. ile Soura V. Binditalui, N. F. Oliveira, Ir., and S, M. Sllibli, Phys. Rev. B 49, 11248 (1994).

10. A. Zrenner, H. Resinger, F. Koch and $\mathrm{K}$. Ploog, Procedings of the 17th International Conterence on the Physics of Semiconductors, San Francisco. 1984, edited by 3 . P. Chadt and $A$. Harrison (Springer, New York, 1984) p.325.

11. A. J. Dewdney, S. Holmes, H. Y.ti, M. Faly and R. Hurray, Superiattices and Mitrostrutures 14, 205 (1098).

12. L. Loriatti, Phys. Rev. 141,8340 (1900).

13. T. M. Sclimidt and A. Fazio, Phys. Rey. B $\mathbf{3 1}$, 7808 (1905).

14. A. B. Inenriques, Phys Rey. B 50, $\$ 058(1004)$.

15. E. Skuras, R. Kumar, R. L. Williams, IL, A. Stradling, J. E. Dmochoosti. E. A. Joluson, A. Mackinuon, J. d. Harris, R. B. Beal, C. Skiebbeszewski, d. Singleton. P. I.yan der Wel, and $P$. Wisnewski, Semicond. Sci. Tednol. 0 , 335 (1001).

10. S. Yamada and T. Makimoto, Appl. Plys, Lett. 57, 1022 (1900).

17. A. 3. Hetriques, V. Bindifatki, N. F. Oliveir J Jt, and S. M. Shibli, Proceedings of the Il th Enternational Conference on High Magnetic Fields in Semiconductor Physics, Boston, 1904 I World Scjentific, Singapore, in press).

18. D. Selmeider, D. Rürup. A. Plichta, H. Gruberi, A. Schlachetzki ant Is, Hansen, Z. Phys, B 75. 281 (1904).

19. L. G. Meiners. J. Appl. Phys. 50, 1611 (1086). 


\title{
Characterization of $\delta$-doped superlattices by Shubnikov-de Haas measurements
}

\author{
A 9 Henriquest, L C D Gonçalves, , P L de Souzał and \\ B Yavichty
}

I Instituto de Fisica, Universidade de Säo Pauto, Caixa Postal 6ta $1 \mathrm{~B}_{2}$

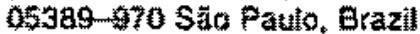

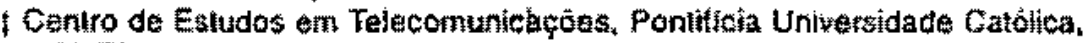
22453 Rio do Jangío, Eiazil

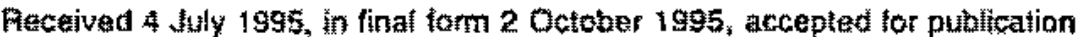
24 Ociober 1955

\begin{abstract}
Atwstract. The Shubrikov-de Haas oscifations of In $P$ with a poriodicat planar doping with Si were studied at $4.2 \mathrm{~K}$ in fields of $0-14 \mathrm{~T}$. By confronting the oscillation Irequencies detateded exporimentally with the ones prodicted on the basis of the eftective-mass approximation the carrier population of tha supertatice minibands and the characteristic width of the doped layer ware obtained. The widh of the doped layer oblained in this way is in good agreement with the vatue obtained from $C-V$ profiting measurements on the same structures.
\end{abstract}

\section{Introduction}

Senitunduttess in whith the dopunt athms are confined

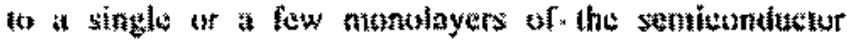

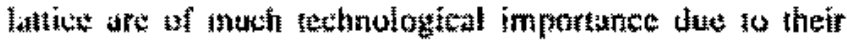

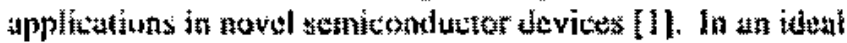

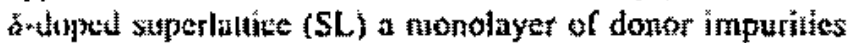
is intrexduced periodically into the host crystil during ite

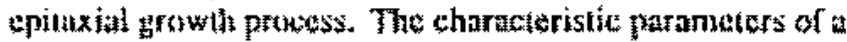
5-deaped seapertaltice sample are the densily of dener atoms in the doping bycrs, th, and the period af the doping

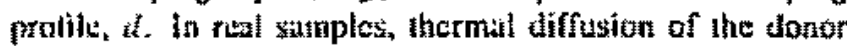

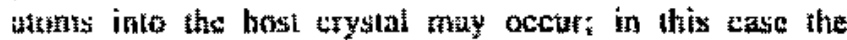
distribution of utumer atoms along the growth threction can

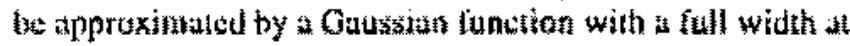
half luyer is rollewtet in the enefgy spexirum ant minthal

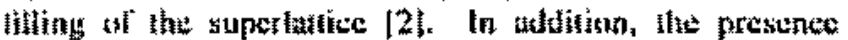

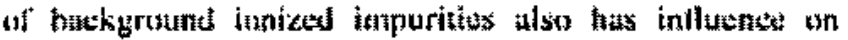

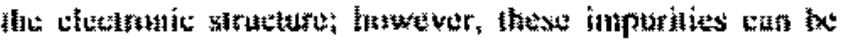

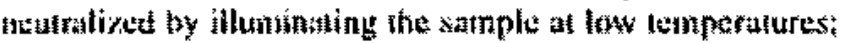

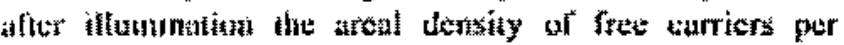
3.

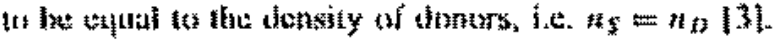

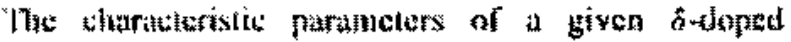

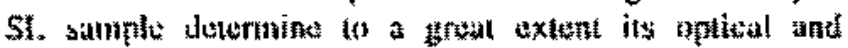

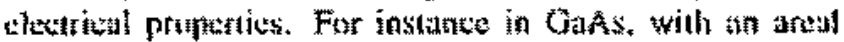

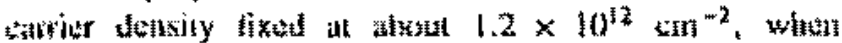

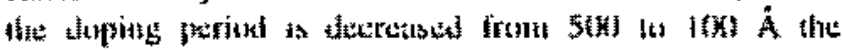

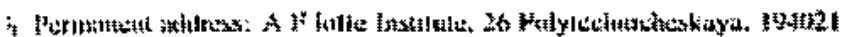

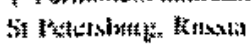

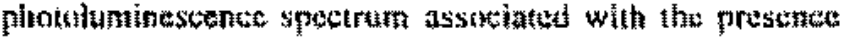

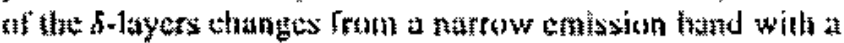

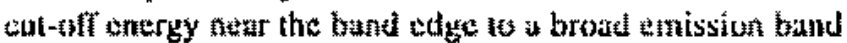

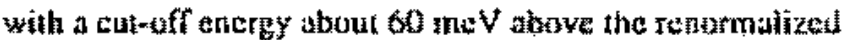
GaA: handgap [4] isee also [5], Similarly. for at fixted doping twel the absuption thresholl is poshed upwards

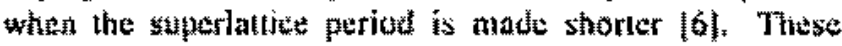
obstryations ane in goot agreconen with the lheortitiol talculatens, mate with the effectiventass thptoximation and using the charateristic sample paramelers as input [7].

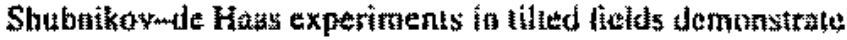

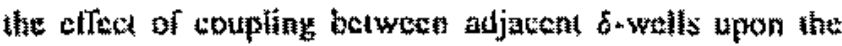

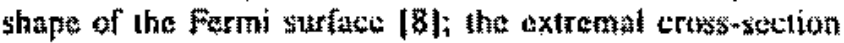

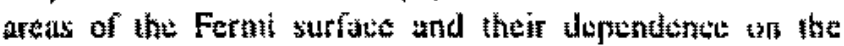

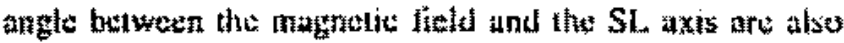

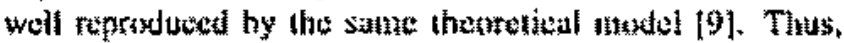

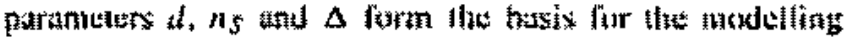
of the thextront strteture of a kanwiedge of them is a prerecalisite fur the understanding

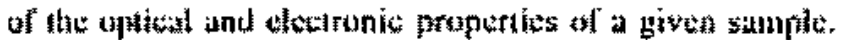

The perios of the s-donet superfatiles sin be

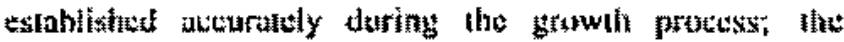

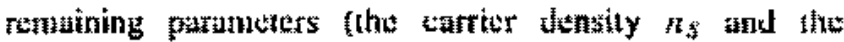

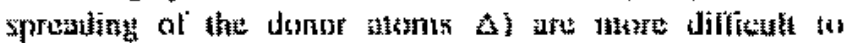

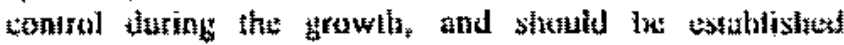

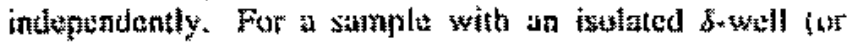

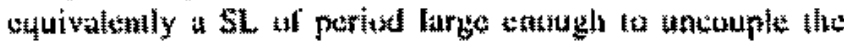

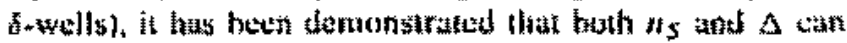

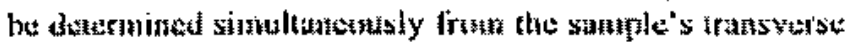

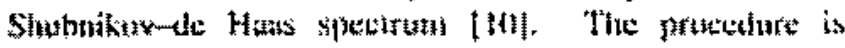

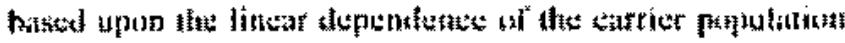




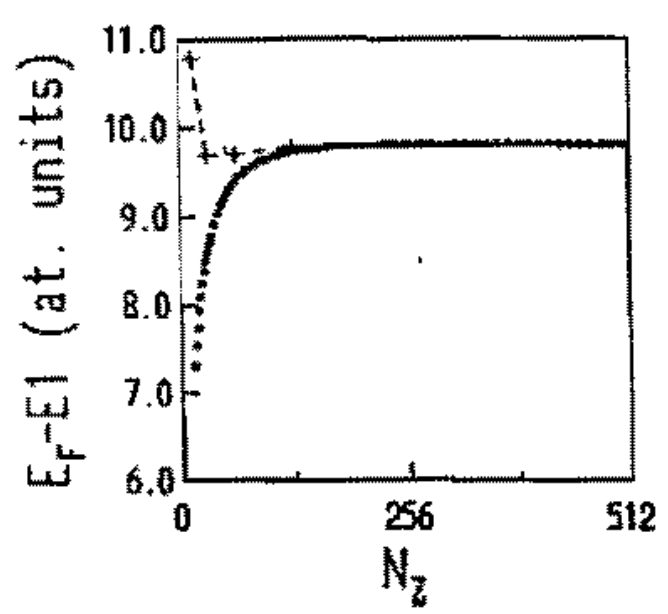

Figure 1. The calculated Farmi antorgy rolative to the ninimum of the sublaten E1 as atuction of the number of plans ways in the disctate Foturier expansion of the confining gotential (crosses) for an isolated neutral $\delta$-well with $a_{S}=5 a_{s}{ }^{*}, d=12 a_{\theta}$ and $\Delta=0.1 a_{B}$. Full circles represent the restits obtained by the tomatemmatrix method.

to a gives subhand on the Irequency of astillation in

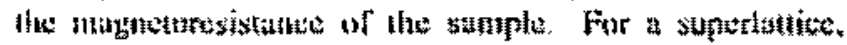

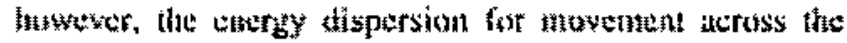

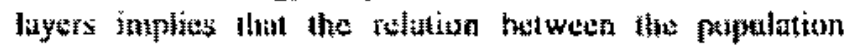

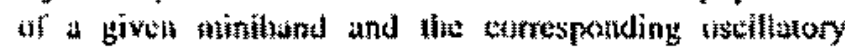
magnelutusisiante freguenty must he talletated self

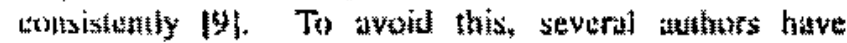
apmoximiated the detasity of stales tor eath ninibatal

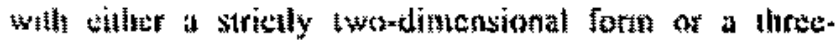

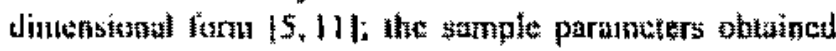
in lilis way. laswever, are only appraximate.

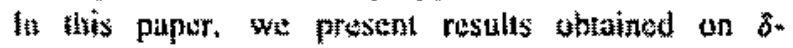

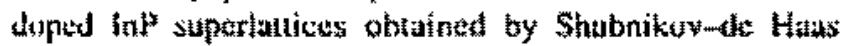

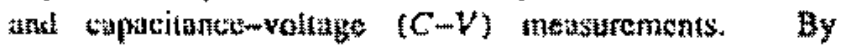
ctumparing the measured ftequencies of oscitlation in the Dimgntorestatance to the values prediclad by the sell-

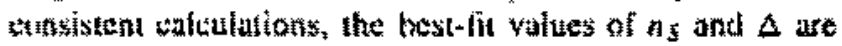

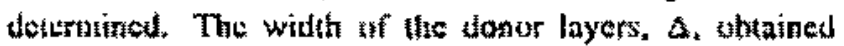

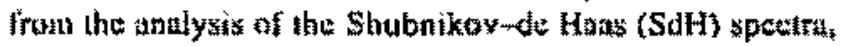
is in wand ayrectnen wh the width of the tonor fiyer

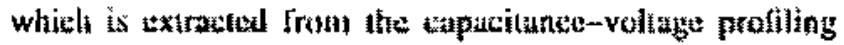

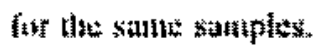

\section{Numerical procedure}

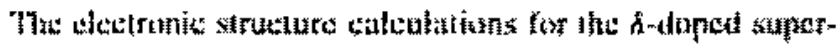

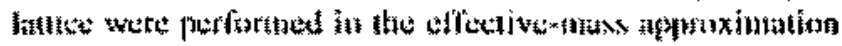

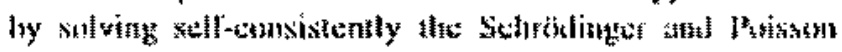

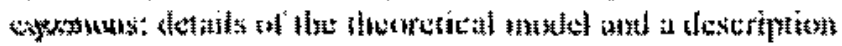

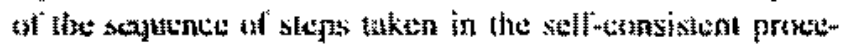

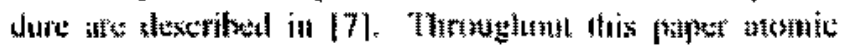

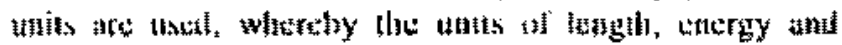

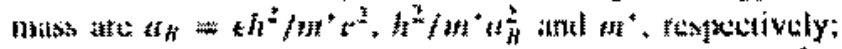

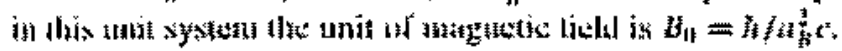

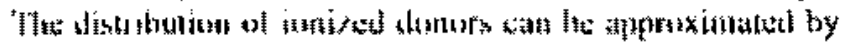

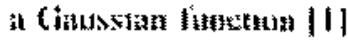

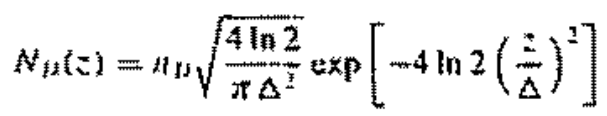

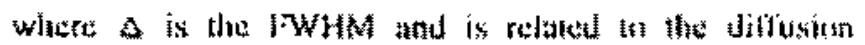

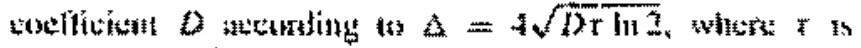

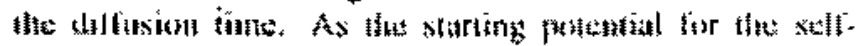

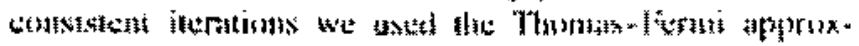

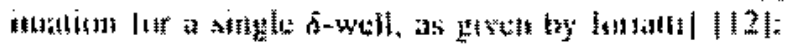

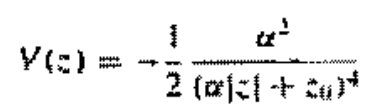

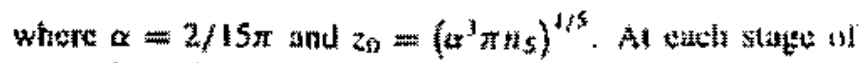

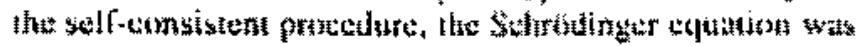

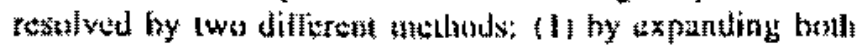

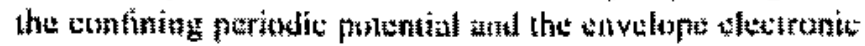
Ways function in a tistercle Fuarior seties ant solving to

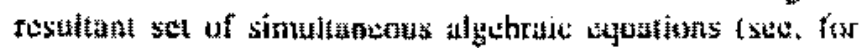

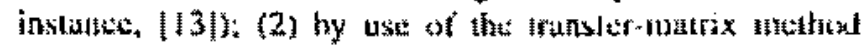

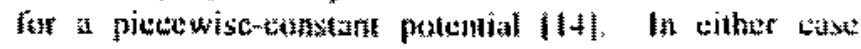

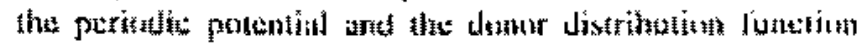

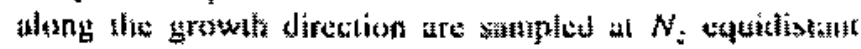

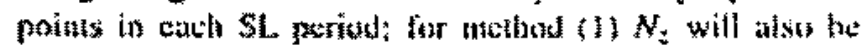
equal tal the number of plane waves ased in lito Fourier

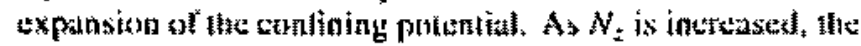

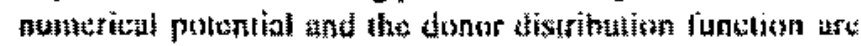

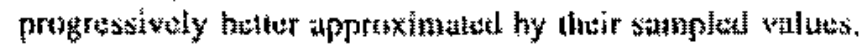

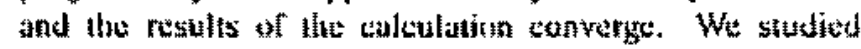
the subvergence as a fonetion of $N_{2}$ tot a highly doped

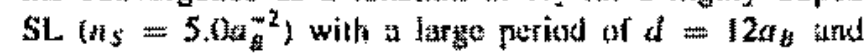

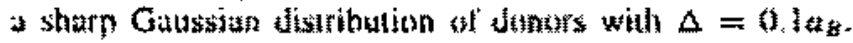
For sach piramelors unly the electrons is manihunds above

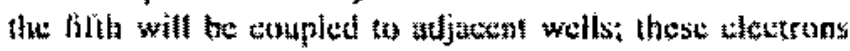

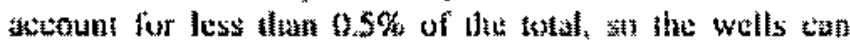

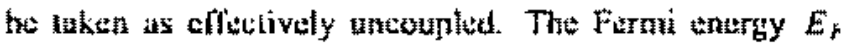

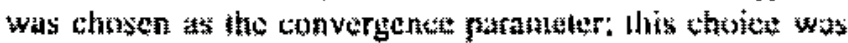
based upon the voservation that $E_{f}$ is very sensilive an any thangsas in the shope af the polential wells, suaking it an ideal single pataneder for the sonvergence dest. The

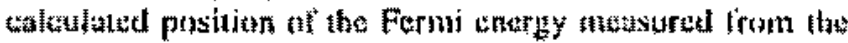

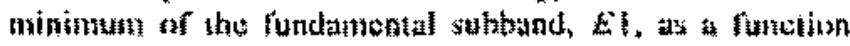
af slic number $N_{2}$, is shuwn in ligure 1 . Crosses an figur: 1 represen the statutions by the fouret expansion

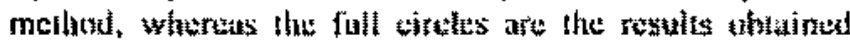

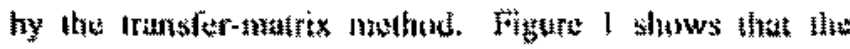

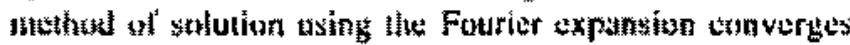

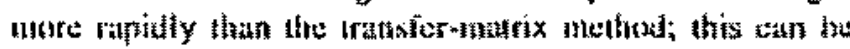

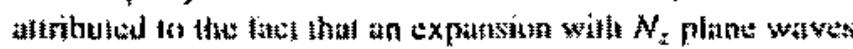

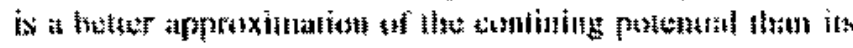

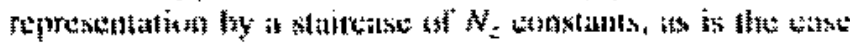

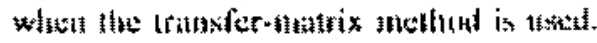

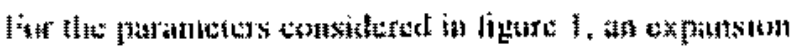

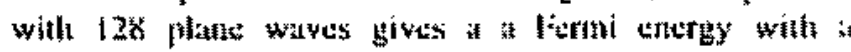

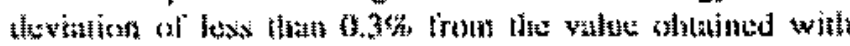

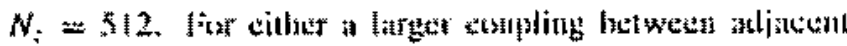

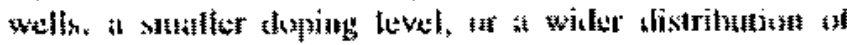

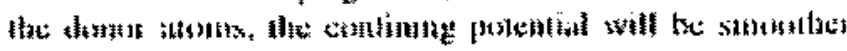

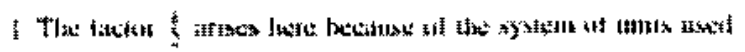




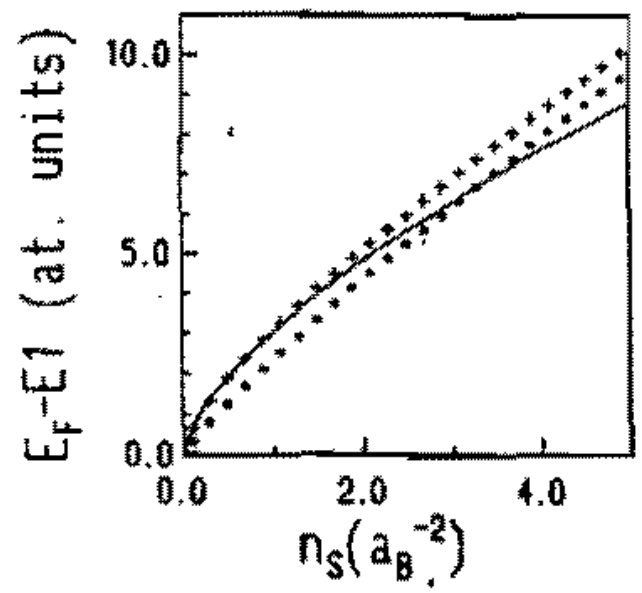

Figure 2, The calculatad Femi energy for a st with paramelets of $2 a_{g}$ as a function of $n_{S}$ (crosstas). The full line shows the limiting 3D approximation. Full circles correspand to the 2D Thomas-Fermi approximation. obtained from numerical soluifon lof lhe polential given by equation (1).

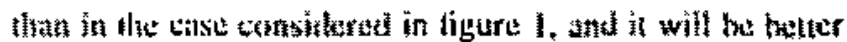

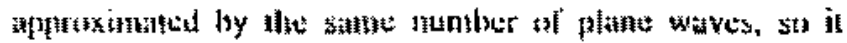

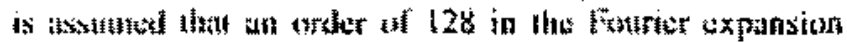

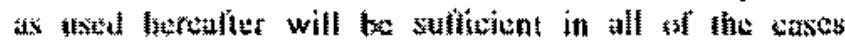

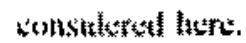

Fingus 2 shews the calculated dependurece at the

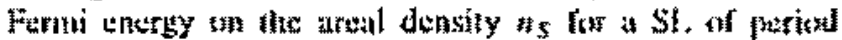

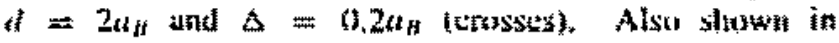
liguse 2 is the Formil energy depentences on $\|_{5}$ for

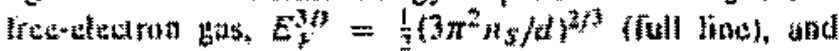

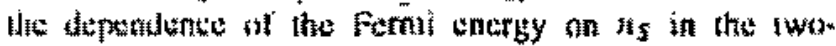

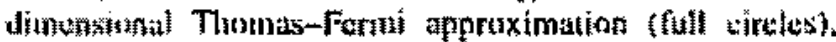

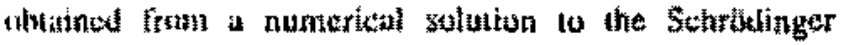

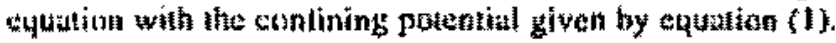
Al low yalues al ats, the wolls isto shallow and lote coupling hetwoten nelighbouring wells is strong to $E_{F}$. follows the

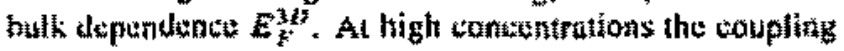
butwats wdjutent wells decrenses. and the depundente of

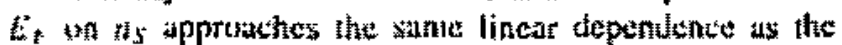
Themato-Fernit approximation for an isolated

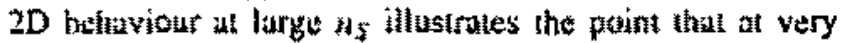

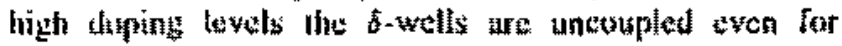

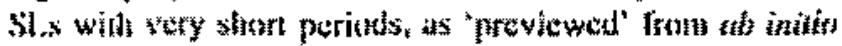
takculariass $\mid 15)$

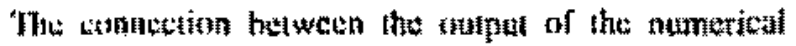

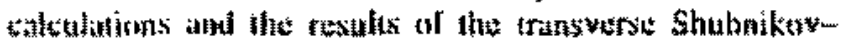

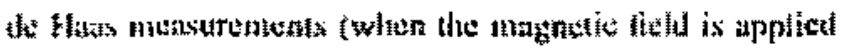

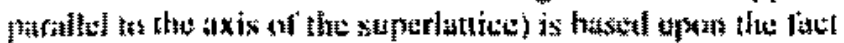

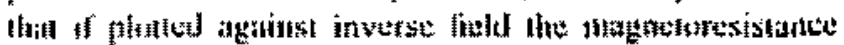

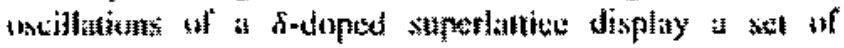

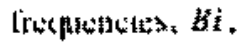

$$
B i=E E_{i}-E t
$$

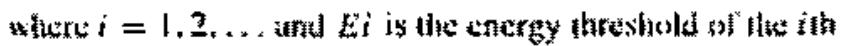

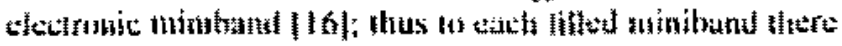
2:

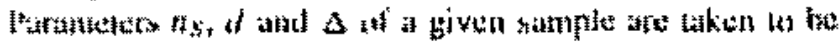

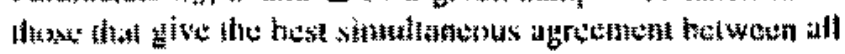

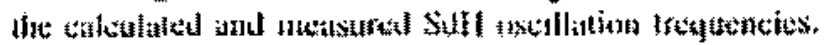

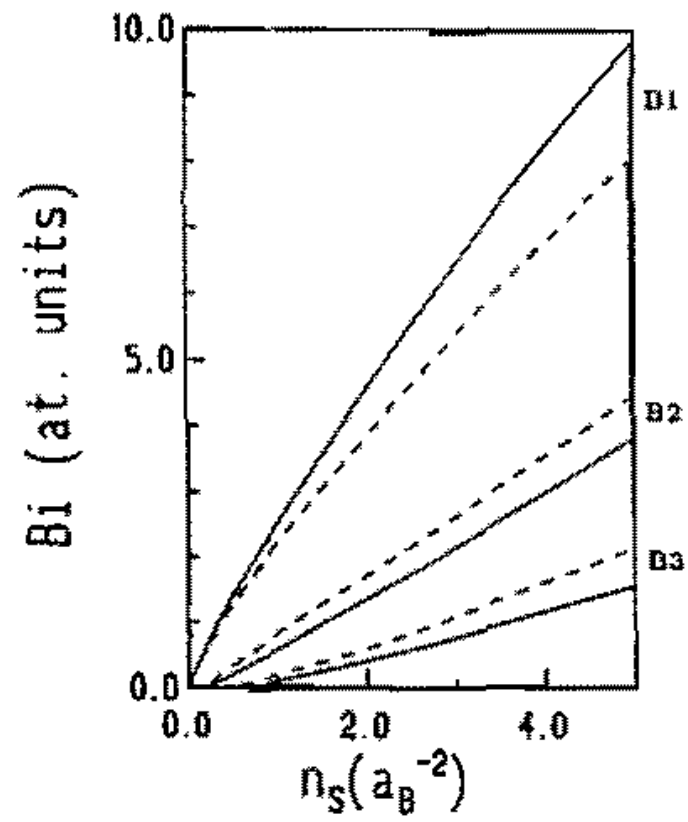

Fiqure 3, Calcuated SdH oscillation frequencies Bi lor an isolatad $s+$ well. Full lines corretapond $19 \$=0.1 a_{4}$ and dashed lines to $E=1.0$ a

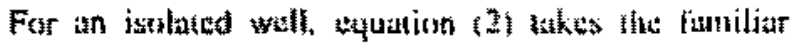

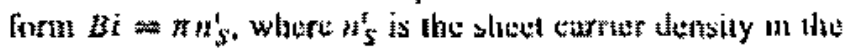

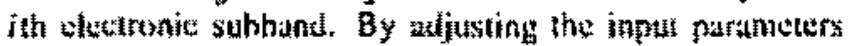

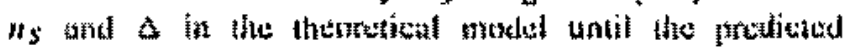

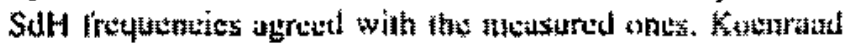

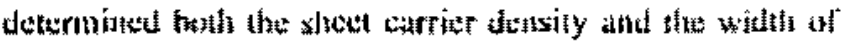

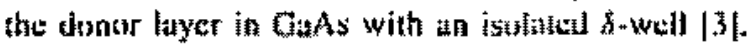

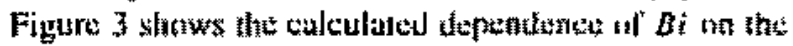

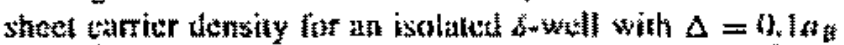

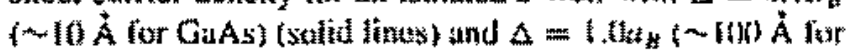
GaAst fushed linusị. When the sidth al the donor layer

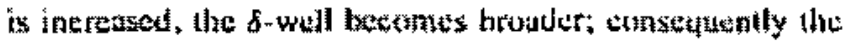

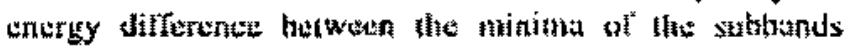

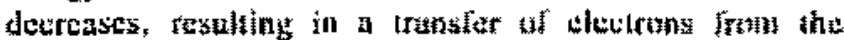

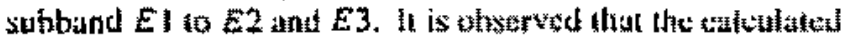

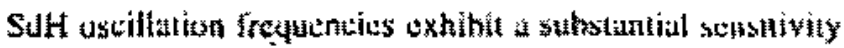

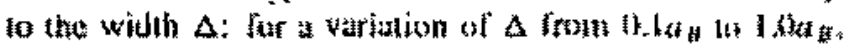

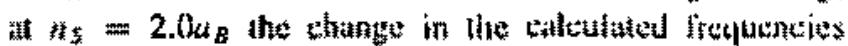

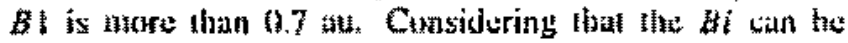

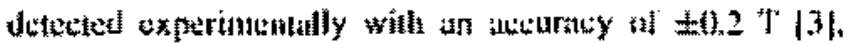

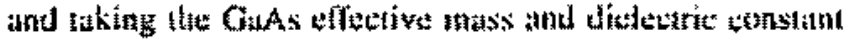

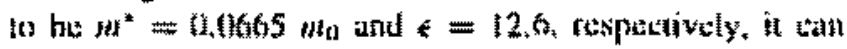

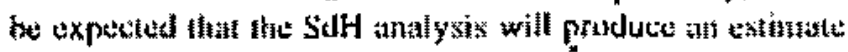

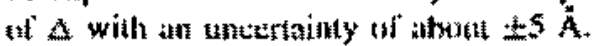

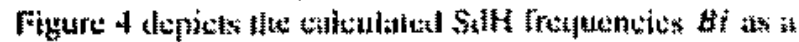

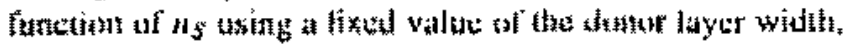

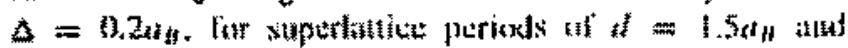

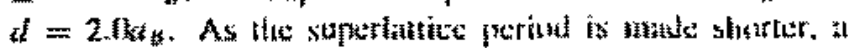

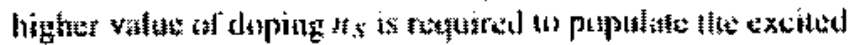

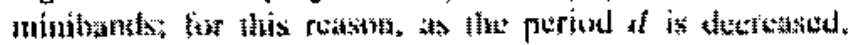

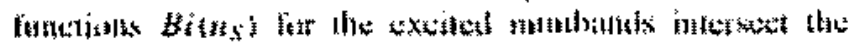

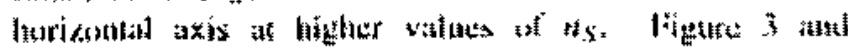

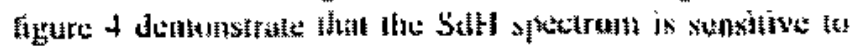

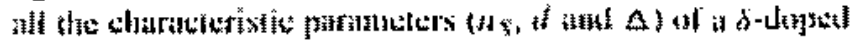

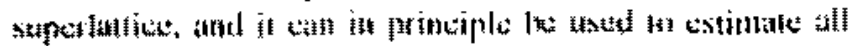




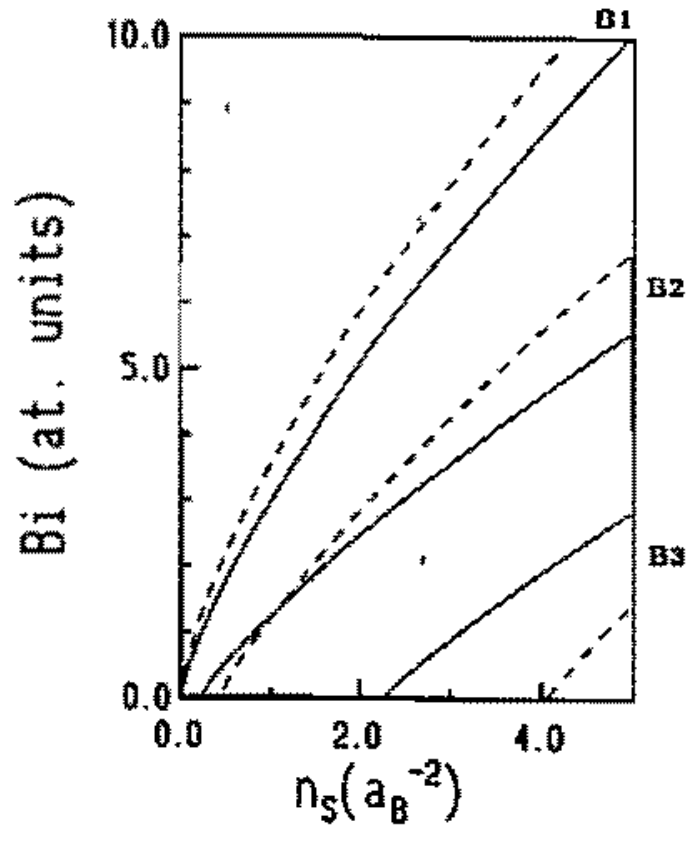

Figure 4. Calculated SdH oscillation trequencies Gi tor a Si. wilh $d=2.0 a_{B}$ (full curve) and $d=1.5 a_{a}$ (dashed curve), The catculations were done with $\Delta=0.2 a_{s}$.

of the thurationistio parameters of a given sammple. In this

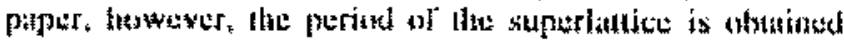

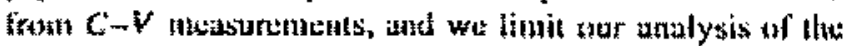

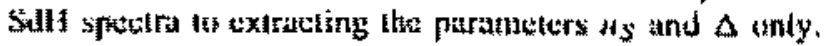

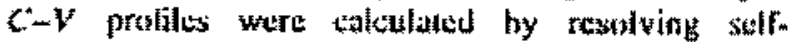
consistenly the Sthridinger and Poisson tatuations for the

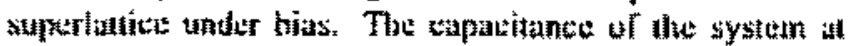

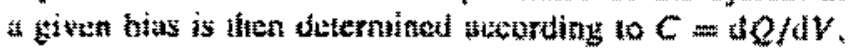

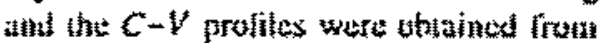

$$
N_{C Y}=4 \pi C^{3} \frac{\mathrm{d} V}{\mathrm{~d} C}
$$

where $V$ is the exiemal bias and $N_{0}$ is the $C$

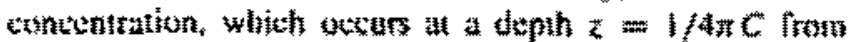
the surfotes the the simple.

\section{Experimental detaits}

Tht $\delta$-doped InP:Si sirueluras were grown by LP-MOVPE

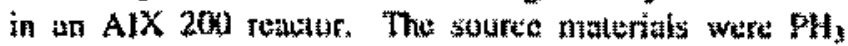

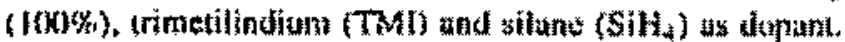

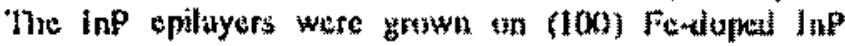

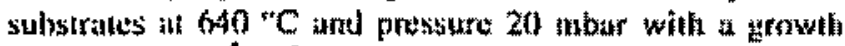

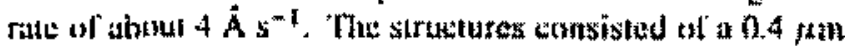
thist undoped InP huilter layer, the derpet strusturt. and at

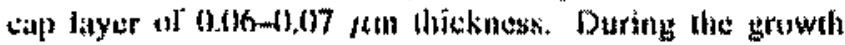

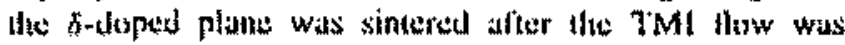
hypassed attel the surface was PH, stabilized. The planar topoug was attontplished by introtucting $\mathrm{SiH}_{4}$ in the gas phese. The comentrotion of SiH, was the sidne for all runs,

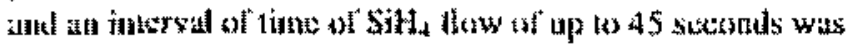

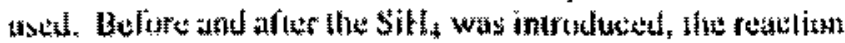

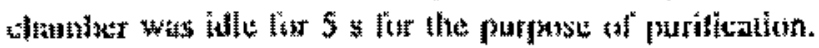

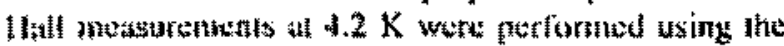

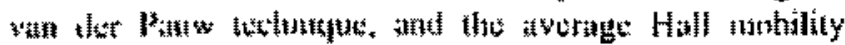
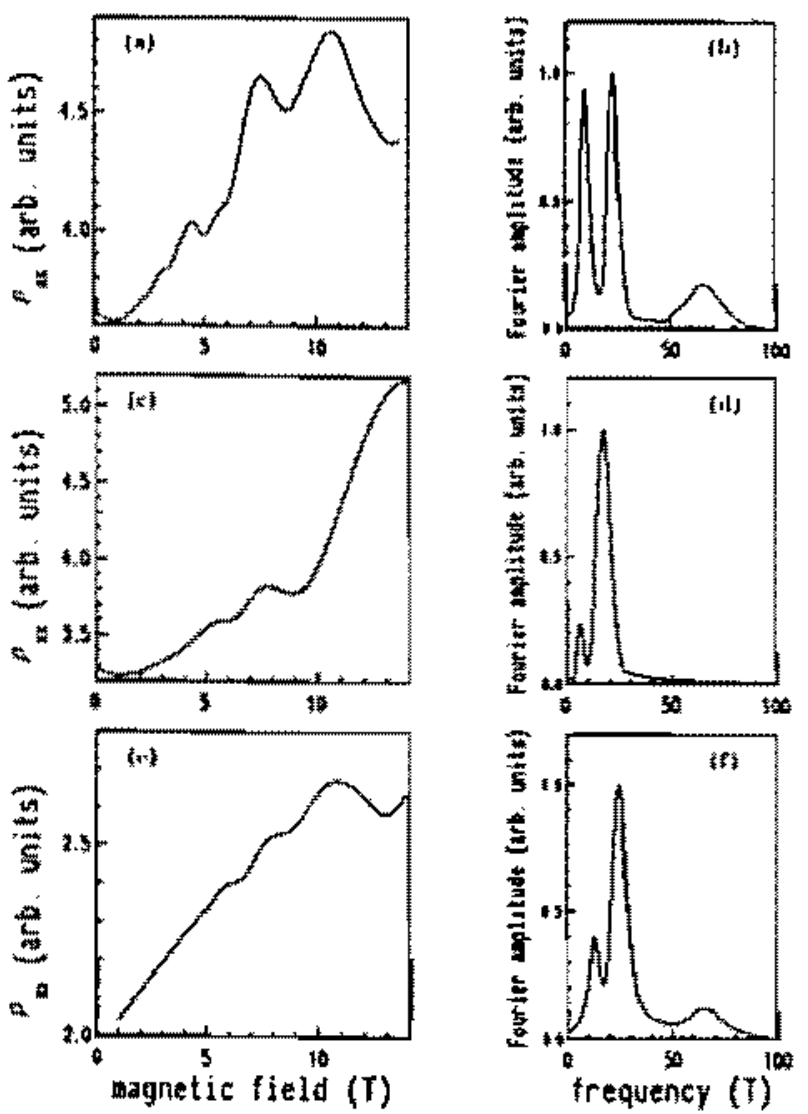

Figure 5. The Shubnikov-de Haas specirum (a) and its inverse-field foutier transtorm (b) for sample No 124. (c). (d) The same, but for sample No 120. (e). (1) The same, but for sample No izl.

way anproximaldy $4030 \mathrm{~cm}^{2} V^{-1} s^{-1}$ for all satuples.

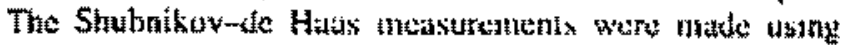

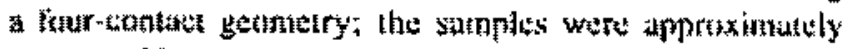

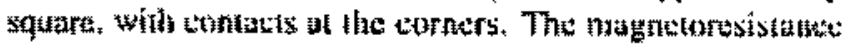

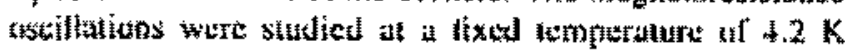

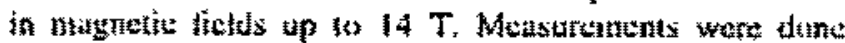

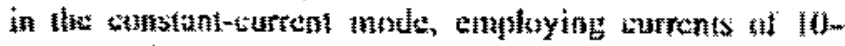

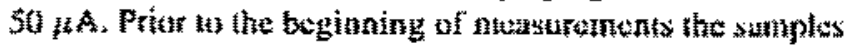

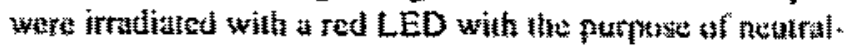

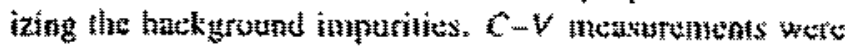

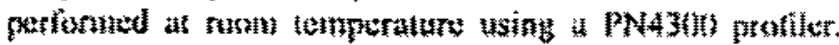

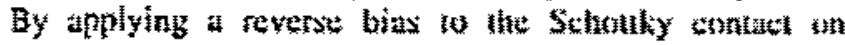

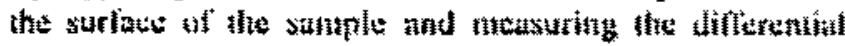

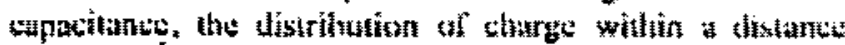

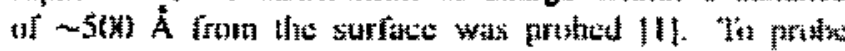

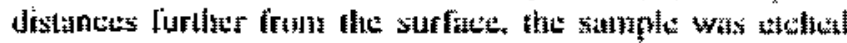

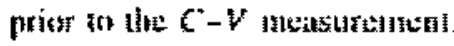

\section{Fesults and discussion}

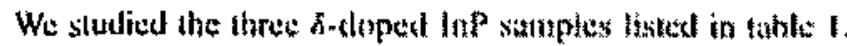

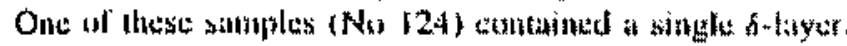

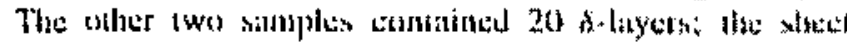

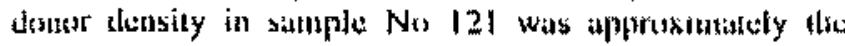

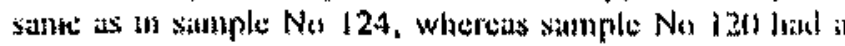

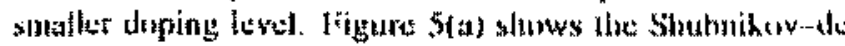

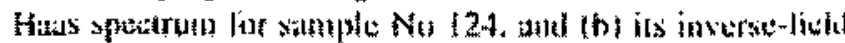




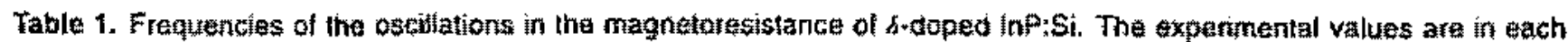

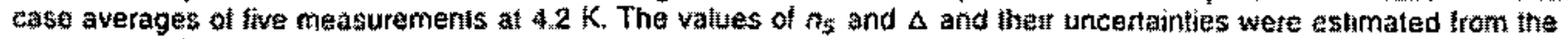
meacured yalues of 8 .

\begin{tabular}{|c|c|c|c|c|c|c|c|c|c|c|}
\hline \multirow[b]{2}{*}{ Sampla } & \multicolumn{2}{|l|}{. } & \multicolumn{3}{|c|}{ Measured } & \multicolumn{3}{|c|}{ Calculated } & \multirow[b]{2}{*}{$\begin{array}{l}n_{S} \\
\left(10^{1 k} \mathrm{crn}^{2}\right)\end{array}$} & \multirow[b]{2}{*}{$\begin{array}{l}\Delta \\
{[\hat{A})}\end{array}$} \\
\hline & $\begin{array}{l}\text { Mumber of } \\
\text { donor liayers }\end{array}$ & $\begin{array}{l}\text { Period, } \\
\text { (A) }\end{array}$ & $\begin{array}{l}8 \overline{11} \\
(\mathrm{~T})\end{array}$ & $\begin{array}{l}B 2 \\
(T)\end{array}$ & $\begin{array}{l}83 \\
{[T]}\end{array}$ & B1 & $\begin{array}{l}82 \\
(T)\end{array}$ & $\begin{array}{l}0.3 \\
(T)\end{array}$ & & \\
\hline $\begin{array}{l}124 \\
120 \\
121\end{array}$ & $\begin{array}{r}1 \\
20 \\
20\end{array}$ & $\begin{array}{l}270 \\
400\end{array}$ & $\begin{array}{l}65.6 \pm 1.0 \\
19.6 \pm 1.3 \\
64.4 \pm 1.9\end{array}$ & $\begin{array}{r}22.6 \pm 0.5 \\
2.1 \pm 0.3 \\
23.6 \pm 1.2\end{array}$ & 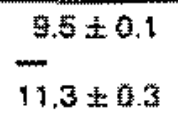 & $\begin{array}{l}65.2 \\
19.6 \\
44.4\end{array}$ & $\begin{array}{r}25.4 \\
8.1 \\
25.7\end{array}$ & $\frac{9.3}{11.0}$ & $\begin{array}{l}4.94 \pm 0.05 \\
1.14 \pm 0.00 \\
4.89 \pm 0.01\end{array}$ & $\begin{array}{l}30 \pm 6 \\
33 \pm 15 \\
39 \pm 7\end{array}$ \\
\hline
\end{tabular}

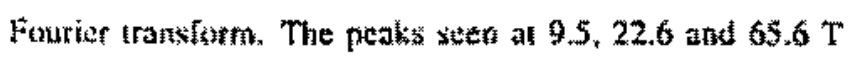

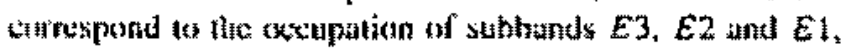

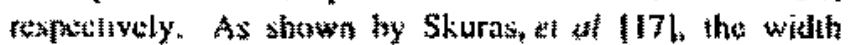

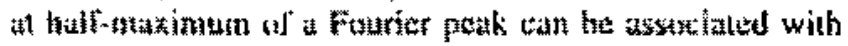

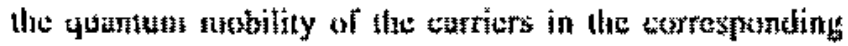

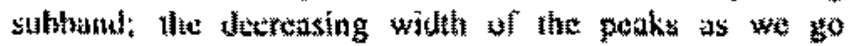

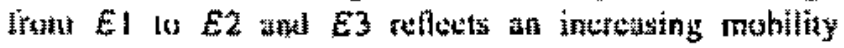

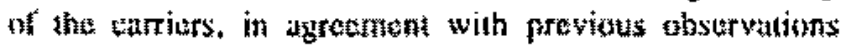

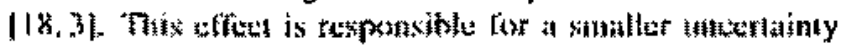

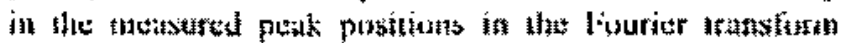
whith are associated with imere oxetted ainibands,

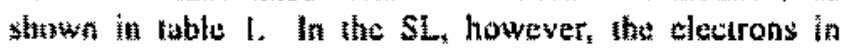

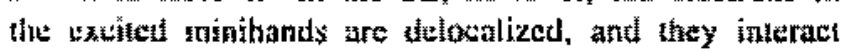
simulinuousty wifh scvers tonor layers, tesuling in their

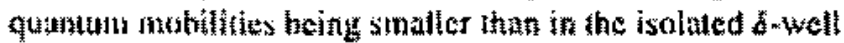

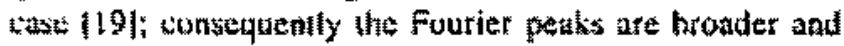

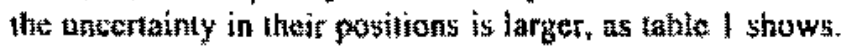

In order is compare the axperimental results to the theorutiol tolculatums, the clettrunte elloctive mass and

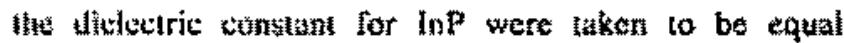

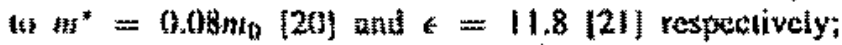
using the shew cartict dersity per superlutice period, nts, and the spread of the donor laysers, $\Delta$, as input fumatiters, the heowelical frequentics expected to be wesn in the Shubnkov-de Has spectrum, Bi, were Laltulatud numariwally. The input parameters $\eta_{n}$ and $\Delta$ ) in the rumertual calculations were varied until the tulculated SoH frequencies agreed whth the frequencies seten experimentaly. The valuex of $n_{5}$ and $\&$ for eact sumple were taken to bo equal to those that gave the leusi-square deviation botween the calculated and the experimenal Soll requencits. The uncenainties in the values of $n g$ and $\mathrm{a}$ were sstimaled from the experimental trrors in the exporianental yolutes of $B i$. Thbole I simmarizes the resultx of the experiment and caltulaions for all 3amples: a compurison of the meatuted Sall oscillation

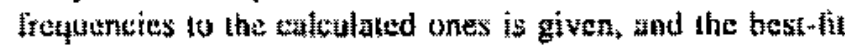

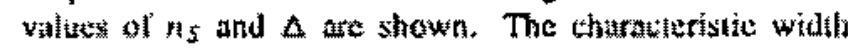
at the aloped layers testimated from the antysts of the

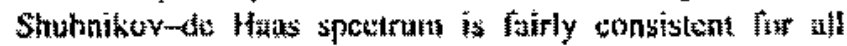
sumples. The sightly ligher valus of $\Delta$ and its groater

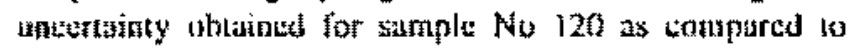

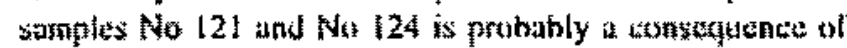

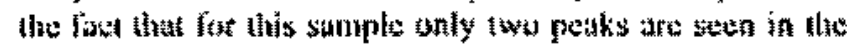

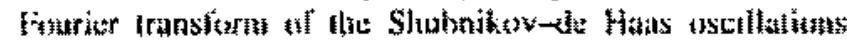

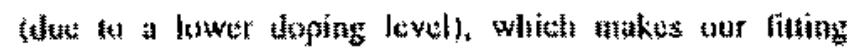

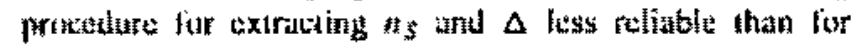

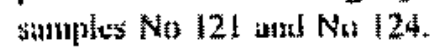
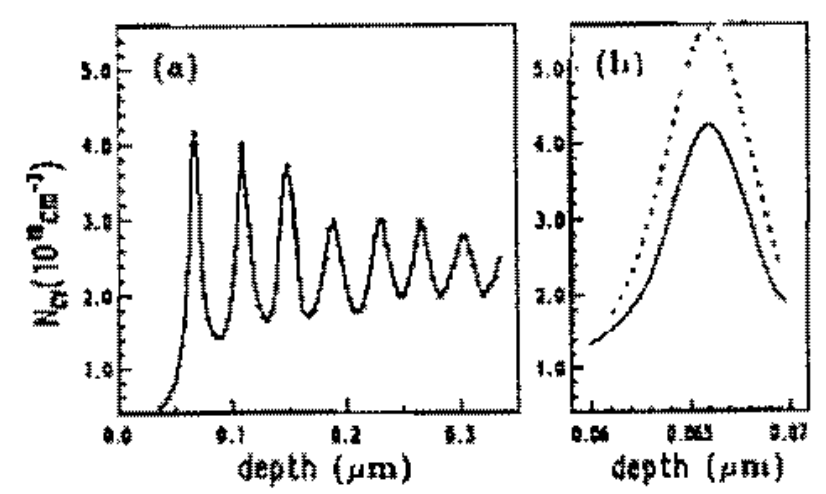

Figure 6. The 0 - 1 protid for sample No 121: (a) shows the result obtained by altemating etching of the sample and laking a $C-W$ measurement; $(b)$ shows a single $C-V$ scant which allows us to probu the chatg distribution around the Sirs! donat layer; the dathed line represents the theoretical $C-V$ spectrum generated by using the valuess of $n s$ and $\Delta$ obtained from the Shubnikavide Haas spectem.

Figure ti(a) shows the $C-V$ profle for sample 121 obtatinet by alternating $C-V$ measurtanent awd ath stching of the sample repetatedly. From the $C-y$ profile the stiperiatice period is determinet 14 bs $400 \pm 15 \mathrm{k}$. The C-V profile shown by the full curve in figure gat was oblatinet from a sisgle $C-V$ scan of the tample whith was etched prior to the beginning of the mensorements. The dashed curve in figure $6(b)$ is the theoretical $C$-n spetront for sample 121, generated with tho sample parameters given in zable 1 and by waing equation (3). The discrepanty between the experimental and theoreticul absolute values of Ney shown in figure t(b) nay have its origin in the fact that the $C-Y$ measurements were pertioned at room feraperature, while the Shubnikovm te Hats menturements were fakcm at $4.2 \mathrm{~K}$, and $n_{3}$ may show some depundence as a tuncium of lemperature, Anather possible stares for this discrepanty may he connected with the etching prowedure

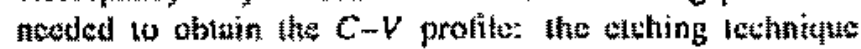
introtutes an uncertainty in the area of the sebuttky contwa

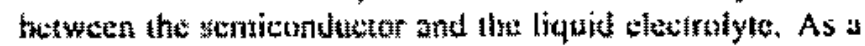

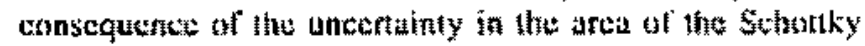

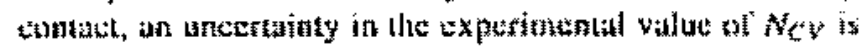

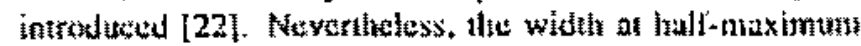

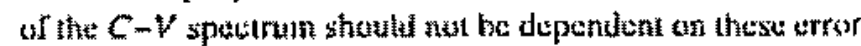

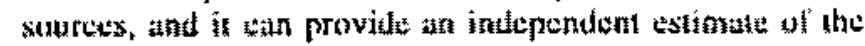

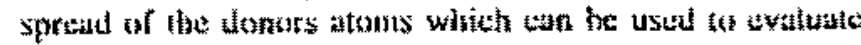

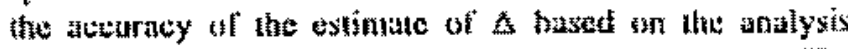

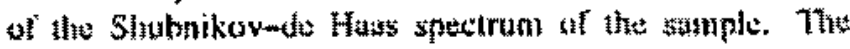




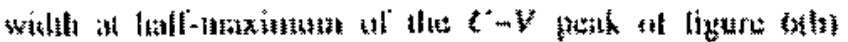
落

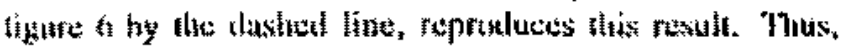

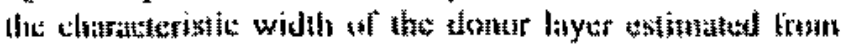

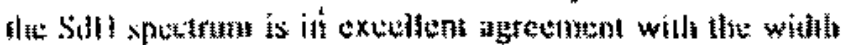

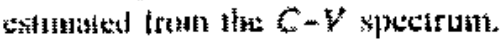

\section{Contusions}

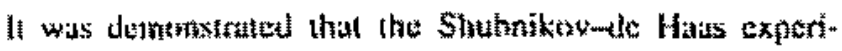

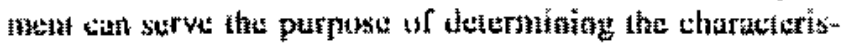

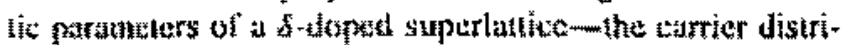

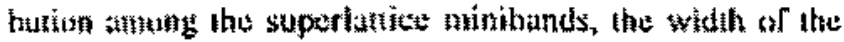

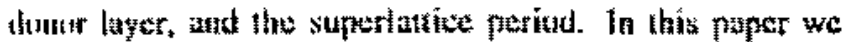

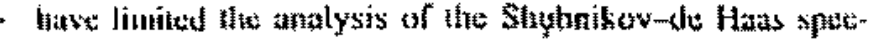

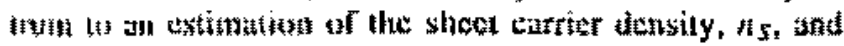

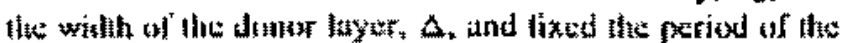

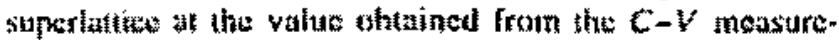

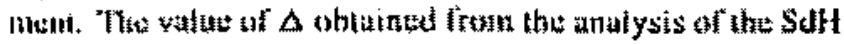

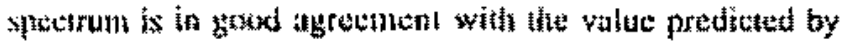

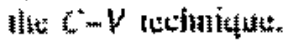

\section{Acknowledgments}

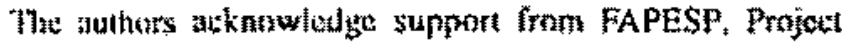

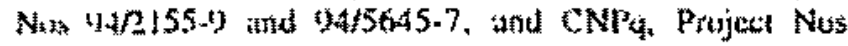

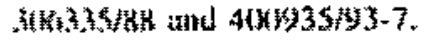

\section{Paferences}

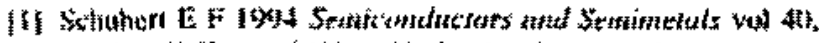

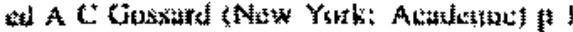

It) J

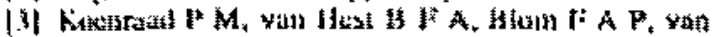

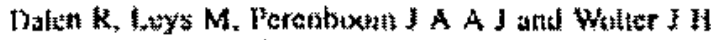

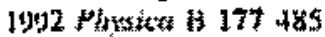

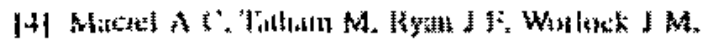

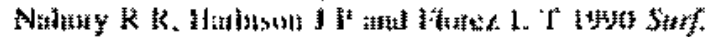
Sic. 228: 251

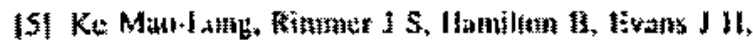

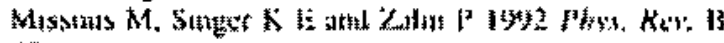
4314114

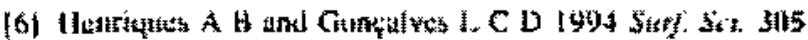
343

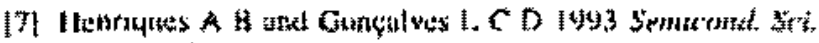
Teithed. 8535

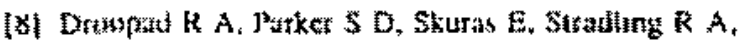

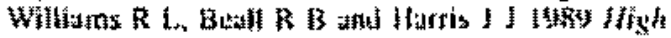

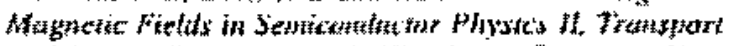

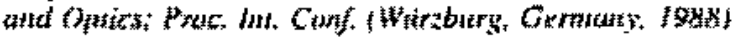

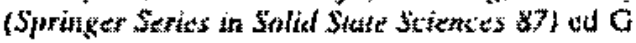

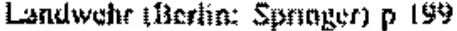

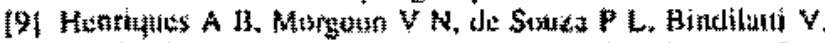

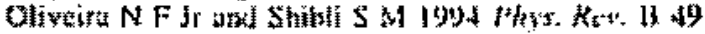
11248

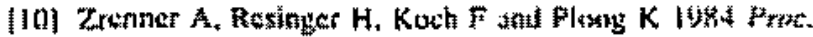

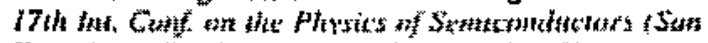

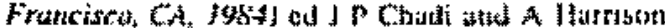
Hew York: Springer) 1325

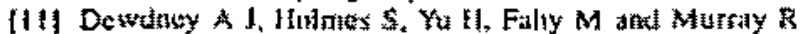

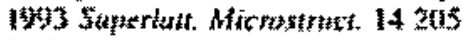

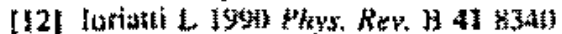

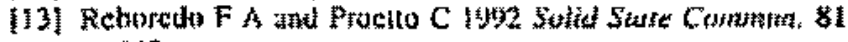
163

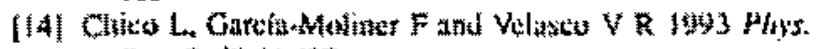

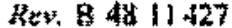

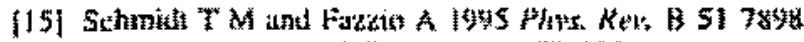

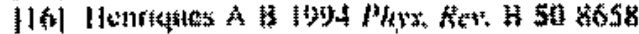

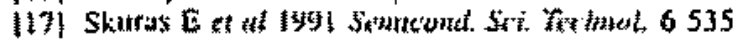

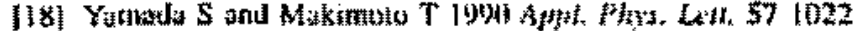

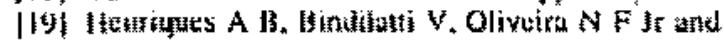

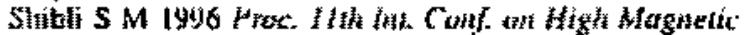

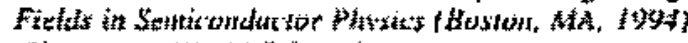

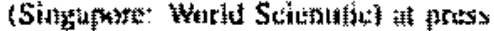

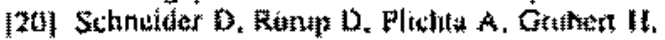

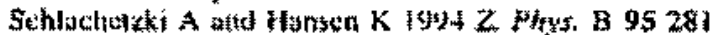

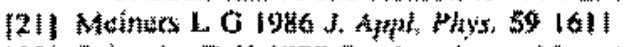

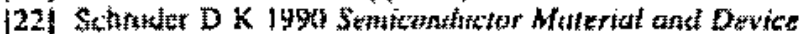

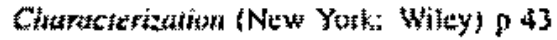


Trabalho apresentado na 23 rd International Conterence on the Physics of Semiconductors, Berlin, Juho de 1996 ; Aceito para publicaço em livro da Editura "World Scientific", Singapore

\title{
MULTISUBBAND SCATTERING IN PERIODICALLY DELTA-DOPED InP
}

\author{
A.B.HENRIQUES, L.C.D.GONÇALVES, V.BINDIIATT, N,F.OLIVEIRA, JR \\ Instituto de Física, Universidade de Säo Paulo \\ Caza Postal 66918, 05989-970 Säo Paulo, Brazil \\ E-mail: ahenriques@if.usp.br \\ and \\ P.L.SOUZA, B.YAVICH* \\ Centro de Estudes am Telecomunicaşōes, Pontifitia Uabersidade Catolica \\ Rta Marquès de Sän Vicente àv \\ $22453-900$ Rio de Juntion, Brastil
}

\begin{abstract}
The Shubrikoxde Haas (SdH) oscillations of InP with a periodieal planar doping with Si were studied below $30 \mathrm{mK}$ and in felds of $0-35 \mathrm{~T}$ produced by a hybrid rnagnet. The lon temperatures and high felds employed allowed to isclate well defined magnetoresistance oscillatory components. The ateal density of free carriers extracted from the $S d F$ curves was obtained to be $4.9 \times 10^{12} \mathrm{~cm}^{-2}$ for both samples. The distance between doping planes and the width at halfmaximum of the doping layers were obtained from capacitancenvoltage profile measurements. Experimental results show that the quantum mobilities decrease when the doping period is made shorter. This is in qualitative agreement with the theoretical estimates made using a model based on the Coulomb interation of free carriers with ionized donors, whereby the screening of the impurity centers is treated in the random phase approximation (RPA).
\end{abstract}

Single layer delta-doped semiconductors are obtained by doping one crystal plane of the host crystal lattice with shallow donor atoms. In periodically delta-doped samples, equally spaced planes of the host material are doped with donors: such samples present an enhanced conductivity compared to the single deltardoped ones, which is advantagecus for device applications ${ }^{1}$. Understanding the way in which sample parameters influence the carrier mobility in these systems is of fundamental importance. In this work we report a study of the carrier mobility in periodically Si delta-doped InP by SdH measurements.

The samples were grown by LP.MOVPE, by which means Si delta-doped InP with a sharp doping profile can be obtained ${ }^{2}$. In order to study the carrier mobility as a function of the distance between dopant sheets. two samples were selected with same

-Also at: A.F.Ioffe Institute. 26 Polytechnicheskaya. 104021 St.Petersburg, Russia 
density of $4.9 \times 10^{12} \mathrm{~cm}^{-3}$ tree camiers per doped layer. Sample 124 had a single, whereas sample 121 had 20 doped layers. To determine the widh of the doped layer and the doping period for the periodically doped sample, the capacitance-voltage (CV) profile for both samples was measured. The donor atoms were found to be distributed within a layer of width of $35 \AA$ and the doping period of sample 121 was obtained to be $400 \mathrm{~A}$. The magnetoresistance measurements were made with the samples mounted inside the mixing chamber of a plastic dilution refrigerator located within a 35-T hybrid magnet ${ }^{3}$, using a 4 -wire automatic $A C$ bridge and employing excitation currents under $1 \mu \mathrm{A}$.

In periodically delta-doped semiconductors each miniband manifests itself in the SdII spectrum with a separate osclllatory component, whose frequency is determined by the belly' extremal cross section of the mini-Fermi surfacet. The dependence of the amplitude of the magnetoresistance oscillations on the intensity of the magnetic field and temperature is given by

$$
\frac{\Delta R(B, T)}{R_{0}}=\frac{X}{\sinh X} \exp (-\pi \Gamma / \hbar \omega)=\frac{X}{\sinh X} \exp \left(-\pi / \mu_{Q} B\right)
$$

where $X=2 \pi^{2} k_{B} T / \hbar \omega, \Gamma$ is the full width at half maximum of the energy levels, and $\mu_{Q}=\frac{n}{m *}$ is the quantum mobility. At temperatures below $30 \mathrm{mK}$ and for helds of intensity higher than $1.5 \mathrm{~T}$, l.e. the conditions under which oscillations in the magnetoresistance vere observed, the thermal broadening factor, $X / \sinh X$, differs from unity by less than $0.01 \%$, hence the quantum mobility can be determined from the slope of a plot of $\ln (\Delta R)$ versus $1 / B$. Each oscillatory component was isolated from the rest of the magnetoresistance spectrum by bandpass filtering in the Fourier domain, and the quantum mobility was obtained by fitting the dependence of $\ln \Delta R$ on $1 / B$ with a straight line.

Figure 1 shows the results of the SdH measurements for sample 124. Results of the experiments are summarized in Table 1. Table 1 shows that he mobility of the electrons in an excited miniband decreases when the doped layers are brought closer together; moreover, the reduction in mobility is greater for a more energetic miniband. This effect is not unexpected, given that a more energetic miniband is described by a more extended electronic charge. As the distance between the doped layers is made shorter, the carriers in the excited subbands will begin to interact with charged impurities in the neighboring doped layers, which means an enhancement of the Coulomb scattering process, and hence a lower quantum mobility.

In order to describe quantitatively the evolution of carrier scattering with the doping period, the quantum mobility in the individual minibands was calculated for samples 124 and 121 in the frame of the RPA approximation, as lescribed elsewherex. In this model. the quantum mobility of an electronic subband is given by $\mu Q=\mathrm{er} / \mathrm{m}^{*}$, where $*$ is the quantum lifetime of the electronic state at the Fermi energy: which is calculated by using the Fermi golden ruie. Calculations vere made using a structure with the parameters given in Table 1 ; for the periodically doped sample, the number of 
doped layers was taken to be 4 in orier keep the computational time within reasonable limits. The theoretical quantum mobility of a miniband was taken to be equal to the mobility of the lowest energy subband from the set of subbands which originates the continuous miniband in the limit of an infmite number of doping periods.
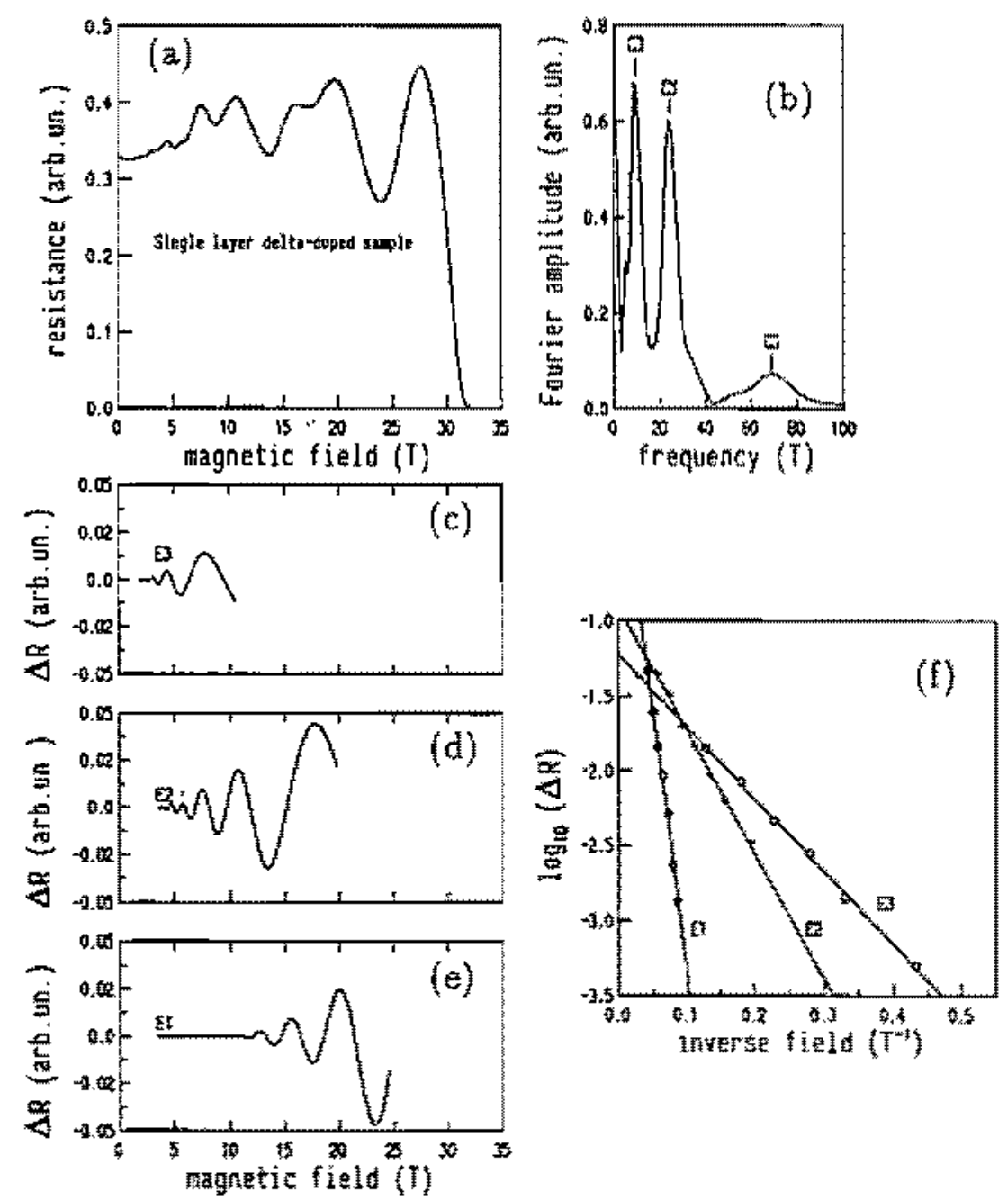

Figure 1: (a) SdH spectrum for sample 124; (b) Fourier transform of the SAH spectrum plotted against inverse magnetic feld; (c)-(e) Oscillations due to individual minibands; (f) Plot of $\log _{10} \Delta R$ against $B^{-1}$ for the oscillations shown in (c)-(e).

Following the notation of Ref. s, the impurity form factor vas taken to be

$$
F_{i}\left(q, z_{2}\right)=\sum_{i=1}^{4} \int_{-\infty}^{+\infty} g\left(z_{1}-z_{i}\right) e^{-i\left|z-z_{1}\right|} e^{-q\left|z^{2}-z_{1}\right|} d z_{1}
$$

where $g(t)$ is a nomalized Gaussian function of full width at half maximum of 35 . which describes the donor distribution in each doped layer. In every other aspect 
Table 1: Carrier concentration determined from the analysis of the SdH $\left(n_{S A H}\right): \mu_{Q}^{S d H}$ was determined from the individual oscillatory components in the SdH spectrum: $\mu_{Q}^{\text {theory }}$ is the theoretical estimate of the quantum mobility.

\begin{tabular}{|c|c|c|c|c|c|}
\hline Sample & Subband & $\begin{array}{c}\text { Period } \\
(\AA)\end{array}$ & $\begin{array}{c}\mathbf{n}_{S d H} \\
\left(\mathrm{~cm}^{-2}\right)\end{array}$ & $\begin{array}{c}\mu_{Q}^{S d H} \\
\left(\mathrm{~cm}^{2} / V_{s}\right)\end{array}$ & $\begin{array}{c}\mu_{Q}^{\text {theory }} \\
\left(\mathrm{cm}^{2} / \mathrm{Vs}\right)\end{array}$ \\
\hline 124 & $\begin{array}{l}\mathrm{El} \\
\mathrm{E} 2 \\
\mathrm{E} 3\end{array}$ & $\infty$ & $\begin{array}{l}4.9 \times 10^{12} \\
3.2 \times 10^{12} \\
1.3 \times 10^{12} \\
0.4 \times 10^{12}\end{array}$ & $\begin{array}{l}385 \\
1640 \\
2820\end{array}$ & $\begin{array}{l}454 \\
1540 \\
4020\end{array}$ \\
\hline 121 & $\begin{array}{l}\mathrm{E} 1 \\
\mathrm{E}_{2} \\
\mathrm{E} 3\end{array}$ & 400 & $\begin{array}{l}4.9 \times 10^{12} \\
3.2 \times 10^{12} \\
1.2 \times 10^{12} \\
0.5 \times 10^{12}\end{array}$ & $\begin{array}{l}478 \\
1050 \\
1550\end{array}$ & $\begin{array}{c}454 \\
1490 \\
2950\end{array}$ \\
\hline
\end{tabular}

the theoretical quantum mobilities were obtained by following the steps described previously'; results are shown in Table 1. Results of the theory show that the effect of doped layer proximity upon the the miniband's quantum mobility increases with the energy of the miniband, in qualitative agreement with the experimental results.

\section{Acknowledgements}

Calculations were performed using the computation facilities of the Laboratorio Central de Computação Avançada do Centro de Computação Eletrônica da Universidade de Säo Paulo (LCCA.CCE-USP). This work was supported by CAPES, Grant No. AEX0654/96-5, CNPq, Grants No.306335/88 and 400935/93-7, and FAPESP, Grant No. $94 / 2155.9$ and $94 / 5645-i$.

\section{References}

1. E.F.Schubert, in Semiconductors and Semimetals, edited by A.C.Gossard (Academic Press, New York, 1994), Vol.40, p.1

2. B.Yavich, P.L. de Souza, M.Pamplona Pires, W.M.Mendes, A.B.Henriques and L.C.D.Goncalves. Proceedings of the 1996 International Conterence on MOVPE, Cardiff. U.K. (unpublished)

3. N.F.Oliveira J, V. Bindilatti, E.ter Haar, R.V.Martin and E.McNiff. Cutchosiounk $J$ of Phys. 46. 2704 (1996)

4. A.B.Henriques, Physs. Rev. B 50, 8658 (1994)

5. A.B.Henriques. Phys. Rev. B 53.16365 (1996) 


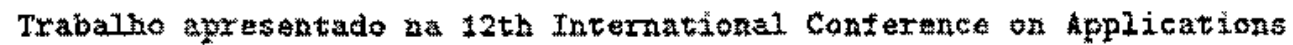

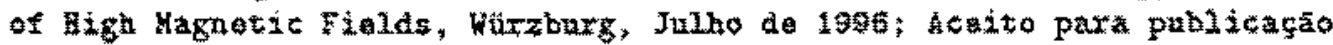

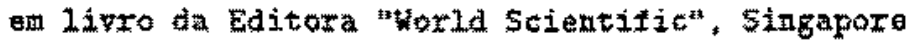

\title{
PHOTOLUMINESCENCE OF PERIODICALLY DELTA.DOPED InP IN HIGH MAGNETIC FIELDS
}

A.B. HLERIQUES, L.C.D. GONCALVES, V.BINDILATTI, N.F. OLIVEIRA, JR. Instituto de Fisicu de Universidade de 5 öo Paula

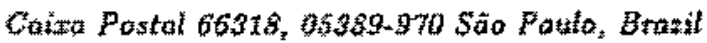

\section{P.L. SOUZA, B. YAVTH}

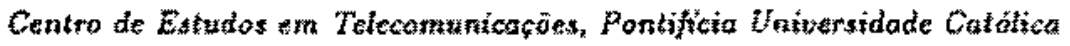
20.453 Rio de Jaturat Brazil

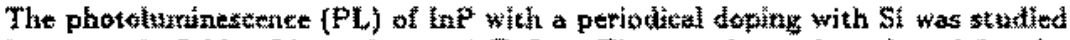
in magnetic feldz of intensity 0-15 Telias. The set of samples selected for the experiments had a doping period varying in the range 100-300 $t$ and a fixed shect corrier density per doping period of approximately $4.3 \times 10^{1 / 2} \mathrm{~cm}^{-2}$. A very

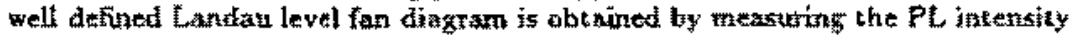
at a fixed wavelength as a function of atoplied magnetic field. The anmples wert

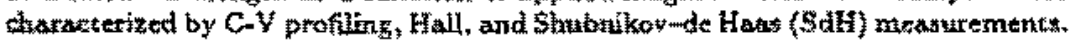
On the bastis of this characterination the cheoretional Landau fan level hisagran was

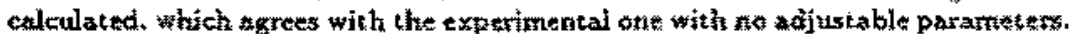
The oscillator strengzh of the phoronactited holes with the individual mínibands is discusesed.
\end{abstract}

In a-type periodically delta-doped semiconductors equally spaced shetets of the host crystal are doped with shallow donots. In such systems the catriers released from the donor atoms are confined by a self-consistent periodic po* sential which gives rise to a miniband structure. The existence of a miniband strueture has been demonatrated by $\mathrm{PL}$ 1, and by SdH measurements $3,4,5$. From the theoretical point of view it is predicted that under a magnetic field applied perpendiculat to the dopant steets each miniband will develop a single series of weakly defined landau levels". It should be possible lo detect the formation of the Landau levels optically, however, optical experiments in high magnetic fields on periodically doped stmiconductors have not been reported, whith is probably a consequence of the strong electron-impurity interaction in these systems ${ }^{7} z_{3}, y_{1}$, which leads to a broad (unresolved) Landau strueture

The delta-doped InP struetures fere grown by LP-MOVPE at the Centwo de Estudos erm Telecomunicatôtes of the Pontifieia Universidade Catolica. The very high quality of the samples is demonstrated by their Hall and CV spectra, 


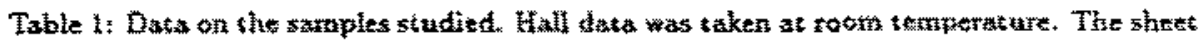

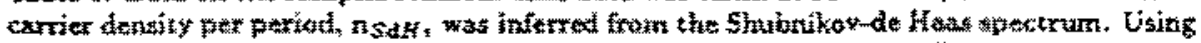

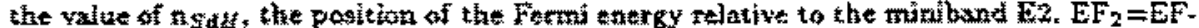
E2, is est thated from a selfoconsistenc selution of Poisson and Sthrotioget equations for the strutctidure ${ }^{13}$.

\begin{tabular}{|c|c|c|c|c|c|}
\hline Sample & Period $(\mathrm{A})$ & $\mathrm{n}_{\text {HaH }}\left(\mathrm{cm}^{-2}\right)$ & $\mathrm{n}_{5 \mathrm{dH}}\left(\mathrm{cm}^{-2}\right)$ & $\mathrm{EF}$ & $\mathrm{EF}-\mathrm{E2}$ \\
\hline 199 & 246 & $4.1 \times 10^{+2}$ & $4.3 \times 10^{\mathrm{2}}$ & 1.436 & 0.0373 \\
200 & 176 & $4.2 \times 10^{12}$ & $4.2 \times 10^{12}$ & 1.44 & 0.0435 \\
\hline
\end{tabular}

which showed that the donor atoms are spread over not more than two monolayers of the host trystal "1. The doping periodicity was also extracted from $\mathrm{CV}$ measurements; Table 1 summatizes the results. PL was detected using an unfocused low power laser beam; the bandpass of the spectrometer vas fixed at $<1 \mathrm{meV}$. Light was conveyed to the sample, and collected fron the sample by using an optickl filber bundle. SdH mextruternents were made in the constant current mode, using the wan der Pauw method, and the Joule heat distipated on the sample was less than 10-20pW.

Figure 1 shows the near band-edge PL as a function of the magnetic field intensity for sample. 200 at $4.2 \mathrm{~K}$. The weak structure seen is due to the development of Landau levels in the E2 miniband. This is demonstrated by the concomitance of the oscillations in the PL intensity at a fixed photon energy as a function of applied magnetic field and the SdH oscillations, as Figure 2 thows. The SdH ostillations are dominated by the tarriers occupying states in the E2 miniband, which have a higher mobility than carriers from the fundamental $\mathrm{El}$ miniband due to a smaller overlap of the Ea charge density with the impurity layers ${ }^{10}$. The foutier transform of the Sdll ostillations gives the fundamental field $B F(E 2)=32.3 T$; using this value, and also the periodicity and donor layer width extracted from the CV profile, the electronic structure of the sample can be modeled ${ }^{2}$, and the results of the theory are given in Table 1 . In Figure 2 the photon energy was fixed at $h \nu=1.445 \mathrm{eV}$, which was chosen so as to lave the oscillations in the PL intensity in ohase with the SdH ostillations. which determines the position of the Fermi energy relative to the photoexcited holes to be $1.445 \mathrm{EV}$. Esing the value of $\mathrm{EF}-\mathrm{E} 2 \mathrm{~g}$ given in Table 1 , the energy position of the electronic miniband relative to the photoxcited holes is obtained to be 1.4015. The Landau level diagram for the E2 miniband can then be drawn, as shown in Figure 3 . In order to check this result, the position of the Landau levels as a function of the magnetic field intensity should be measured optically. To determine the field dependence of the Landau levels, the PL intensity rtas 
measured as a function of the fteld at a fixed photon energy; this iz stown in Figure 4. The peaks shown obtained from Figure are shown as solid circles in Figure 3 , giving an excellent agreement, with the theoretical lines.

Assuming that the holes have only a weak dispersion and that the electronhole oseillator strentzh is energy independent, under weak excitation the zerofield PL lineshape will be given by

$$
l(h)=D(h v) f(h, T)
$$

where $D(E)$ is the dexsity of states (DOS) of the minibands and $f(E, I)$ is the fermi-Dirac distribution. The DOS function was caleulated using the parameters given above, and the results are shown in Figure $\overrightarrow{2}$. At lower energies, the DOS function oxershoot the experimental curve, indicating that the overiap of the EI miniband wave function with holes is weak.

\section{Acknowledyments}

Thus work was supported by CAPES, Grant No. A EXo654/96-5, CNPa, Grants No.306335/88 and 400935/93-7, and FAPESP, Grant No. 94/2/4 and $94 / 5645 \mathrm{~m}$.

\section{References}

1. A.C.Maciel, M.Tatham, I.F.Ryan, J.M.Worlotk, R.R.Nahory, J.P. Harbison and L.T.Florez Surt Sct. 228. 251 (1090)

2. Ke Mao-Long, J.S.Rimurner, B.hamilton, 1.H.Evans, M.Missous, K.E.Singer and P.Zalm. Phys. Rev. B 45, 14114 (1992)

3. F. Koth A.Zrenner and $\mathrm{M}$ Zachan, in Two-dimensional systems; phyzics and new devices, edited by G.Bauer. F. Kuchar and H. Heinreich (Springer. Berlin. 1986), p.175.

4. A.B.Henriques and L.C.D.Gongalves, Strf. $S c k, 305,343$ (1994)

5. A.B.Henriques V.N.Morgoon, P.L,de Souza. V.Bindilatti, N.F.Oliveira, Jo, and S.M.Shibli, Phos. Rev. B 49, 11248 (1994)

6. A.B.Henriques, Phys, Rat B 50, 8658 (1904)

7. S.Yamada and T.Makinoto Appi. Fhys Let. 57, 1022 (1900)

8. P.M.Koentand, B.F.A. van Hest, F.A.P.Blom. R.tan Dalen, M.Leys, J.A.A.J.Perenboom and J.F. Wolter, Physica B 17 7\%, 485 (1992)

9. A.B.Henriques, V.Bindilatti $\&$ N.F. Olyeira Jr, in High Magnetas fietds in the Phystcs of Semicond tuclors, edited by D. Heiman, (World Stientific, Singapore, $19959, \mathrm{p} .604$

10. A.B.hentiques. Phys. Reu B at press (1096) 
Tigure 1

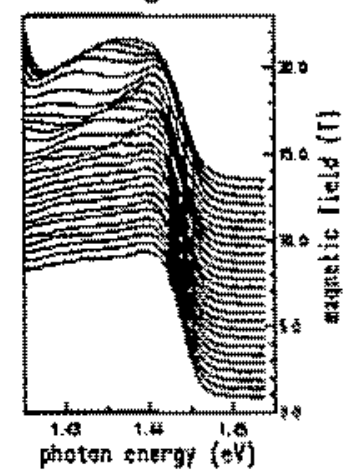

Figure 4

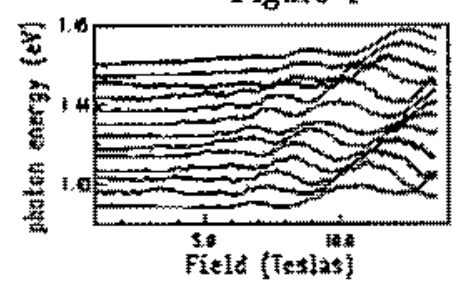

Figure 5

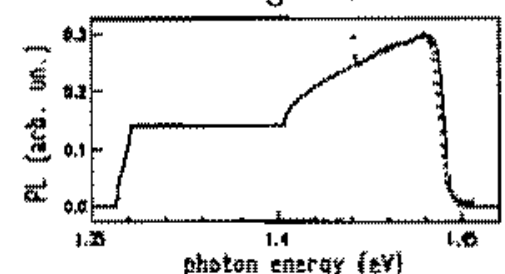

Figure 2

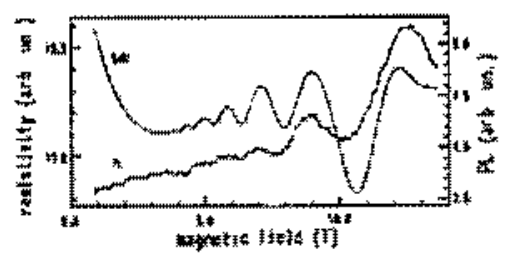

Figure 3

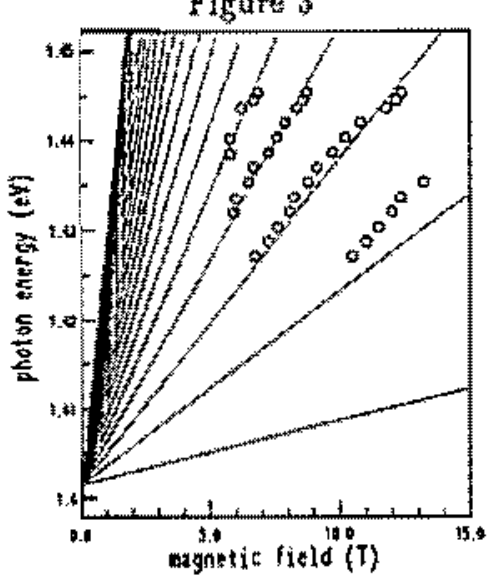

11. B. Yavich, P.L. de Souza, M.Pamplona Pires, W.M.Mendes. A.B.Henriques and L.C.D.Conţalves, Proctedings of the 1906 International Conference on MOVPE, Cardiff. U.K. (unpublished)

12. A.B. Henriques and L.G.D.Gonçalves, Semicond. Scki Technol. 11, 190 (1996)

13. A.B.Henriques, L.C.D.Gonçalwes, P.L. de Souza and B.Yavich, Semicond. Sci. Technol. 8, 585 (1993) 


\title{
Electronic properties of gated $\delta$-doped semiconductors
}

\section{C D Gonçalves and $A B$ Henriques}

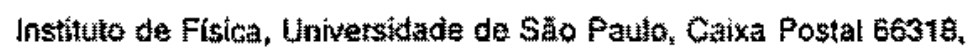
05390970 Săo Paulo, Braztil

Fectived 2 September 1998 , in final lom 1 Novernber 19g6, axcepted for putication 15 Novernter 1900

\begin{abstract}
The quantum and transpor subband motilities as lunction of appliad bias were cakculatad for a gated s-toped semiconductor. The electronic spectra (envelope wavehtuctions, subband energies and Fermi entergy) for the siructure under bias used as input in the calculations were obtained by either sotving self-consistently schedodinger and Poisson equatons of by solving the Schrotinger

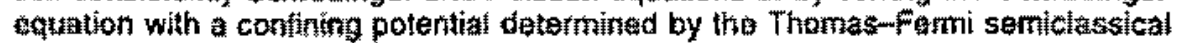
approximation. In the first case the screcring of the electron ionized impurity interaction was treated in the random phase approximation, whereas in the latter case the two-dimansional Twomas-Femti model of tcreening was tsed. Results show that allhough the semiclassicas approach oflers the advantage of greater simplicity, it describes reliably the carrief mobility in the fundamantal subband onty. The dependence of the mobally of carriers in individual subbands on applied bias corralates with the evolution with bus of the overap between subtand wavefunctions ond the doped-layer region.
\end{abstract}

\section{Introduction}

The s-doping echnique was originally devised 11 as a means to supply tre carriers for epitaxial semiconductor stnuctures. Since then, mach attention has been paid to S-doped systems due to their technological applicalions and interesting physical properites $[2,3]$. In a $z$-doped semiconductor shallow donors are localized in a few monolayers of a host crystal (for instance GaAs. In?. InSb). The electrons released from the donor atoms are confined by a $V$-shaped self-consistent potential well which splits the conduction band into a set of electrontc subbands which are described by watunctions whote localization around the doped layer decreases with the subband intex.

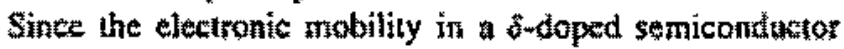
is determined by the Coulomb interaction of carriters with ionized donors situated in the doped layer, the dectuasing spatial localization leads to a mobility which increases with the subband index, has beten demonstrated both experimentally [4] and theoretically [5]. Meth effon has been devoted to inyestigating the mechanisms which limt the carrier mobiliy in sloped semicontuetors [5-10], the waterstaxting of whtel is of key impontance in finding ways of optimizing the transpon properties of these systems III!.

Theoretical calculations of the transport and quantom mobilittes of carriers in intividual subbands of a $s$-doped serniconducter bave alteady bewn performed using various levels of approximation. These calculations require as input the thectronte spectrum invelope wavefuntions for each subband, subbund energes and the Fenti cturgy) and the doping prafle. The carrier mobilily is obtained by using perturbation thatry with the strened Coulomb interacton between carriers and ionized donors taken 10 be the scattering mechanism. The atthors of reference [ 6 ] watd the semi-classical Thomas-Fem (TF) thery to obtain both the eletronic spectrum and the strmened Coulomb potential; in this model, the screering charge ant the doped layer are faten to be of zero thidkness, i.c. the two dimensichal (2D) limit is assumed. Recently, more realistic calculations have been performed the elecinonte structure was obtainet by solving selficonsistently Schrödintzer and Poisson equations, with inezsion of the exchange and correlation correction in the framework of the local density approximation, and the sareering of the clectronionized impurity interaction was treated in the raniom phase approximation $(5,7-9]_{\text {. }}$ This approsth allowed us to incorporate into the theory the widh and profile of the doping layer and the non-zero thickness of the sefening charge, and also the effect of scattering by ionized buckground impurities. A comparison between experiment and ineory showet that the quantum treatment can successfully predict the carier moblity in individual subbund [7]. In contrat, the semiclassical treatment, whereby the screening charge is strictly 2D, is not anticipaced to be quantitalively suitable, given that the nonzato bickness of the screening charge is an important ingrethent in the screening theory of quasi-2D systems (see, for instance. the pronounced effect of the finite thiskness of the wereening charge upon the binding enefyy 


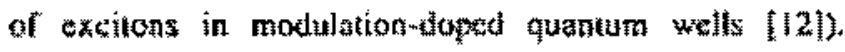
In principle, il is possible to beorgorate the non-zero thickness of the sereening charge into the scrichassteal

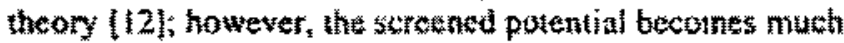
mare complicaled, thes decimating the main vintu of the semiclassical approach, i.e. its simplicity and somin analytizal formulationt.

For a gated $\delta$-doped structure. the tarrier mobility in the indivitual elcelronic subbunds so fil has been calculated only within the TF approatin [10l. The inturest in the tramport propentes of the gated sinumare womes from its technological applisutions, for instance in the s*

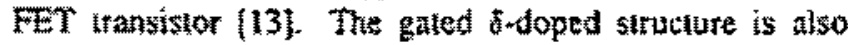
a convenient system to study the effects of the surface proximity upon the properties of the confined efecron gas [14], ance by applying a bias to the gated system the region near the surface can be depleted of carricts. It secms appropriate to extend the lull fiantum iratment to gated s-doped structures, which is the purpose of this inyeatigation. Wo calculated the mobilly of carters in indivitual subbands both in the framework of the TF model for he confining potential, along with a $2 \mathrm{D}$ TF stretsing charge (whien will be referred to hereafer as the $T-2 \mathrm{D}$ approximation), and in the frarnework of the quantum treatment. The reliability of the full yuantum treatment is assumed based on its success in describing

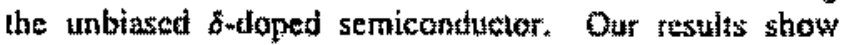
that altholgh the TF-2D molel presenis lhe advantage of greater simplicity antequires a smallst tomputational effor, it toes describe successfully the mobility of carriers accupying states beionging to the funtamanial subband only.

\section{Theory}

Our system will be modelled assuming that the positively charged donors. described by an ureal densily $N_{4,}$ are unifom ly thistributed in a single mondaytar of the host crystal, loeated in the plane $z=0$. The astumption of an ulimately hin doped layer is motivated by the ability of epitaxial growth lechniques 10 obian doped layers with a hickess of one or two monolayers $[15,15]$, and it simplifies the formalism and computational requirements. A sufficiently low doping density $\left(N_{d} * 10^{13} \mathrm{~cm}^{-2}\right)$ will be considered, so that the donor atoms can be taken to be uncorrelated. The prestnce of ionized background impurities in the structure is ignoted, in when case the electrical neutrality of the semiconductor is guaranted by taking $n_{5}=N_{4}$ where $n_{5}$ is the owerall sheet densily of cantined electrons in the 8 -weil. All restils we gresented in clfetive atomic units, hence the units of length. mass and energy are the effective Bohr radius $a_{a}=\epsilon \hbar^{2} / m^{n} k t^{2}$, the elfective mass $m^{*}$ and the effecive Hartree potential $h^{2} / m^{*} a_{i}^{3}$ respectively. The calmulated

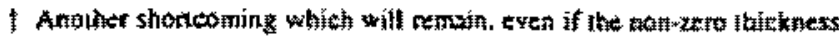

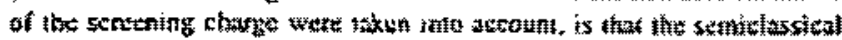

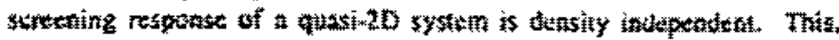

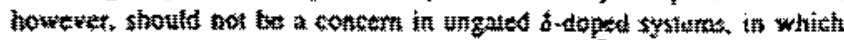

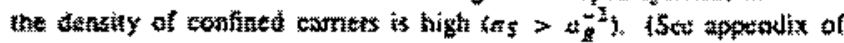
(4)

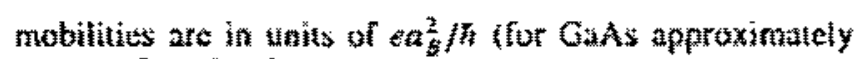
$\left.1500 \mathrm{~cm}^{2} v^{-1} \mathrm{~s}^{-1}\right)$. All calculations were mats as atming a sample temperature of $T=0 \mathrm{~K}$.

In atonic anits the giantum mobility of carrien in the it the electronic subband is eoual to the singlemparticte lifetime at the Fermi cnetgy, re( $i)$, which can be calcutated by using the Femi Gulden Rule. The resull is given by [9]

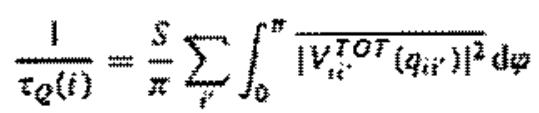

where $S$ is he area of the sample.

$$
4 i i^{\prime}=\left(k_{i}^{2}+k_{i^{\prime}}^{2}-2 k_{j} k_{\mathrm{j}} \cos \varphi\right)^{1 / 2}
$$

$k_{p}=\sqrt{2\left(E_{F}-E_{i}\right)}$ is the Fermi momentum for the ith subband, $E_{F}$ is the fermi energy, $E_{z}$ is the energy intesholal of the the subband, and

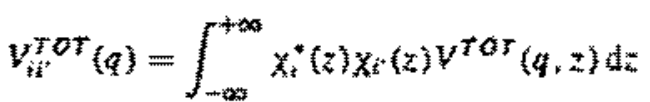

Whare $v^{\text {TOT }}(q, z)=\sum_{\text {a }} y^{\text {Tor }}(\rho, z) \mathrm{e}^{-\mathrm{itg}-z}$ is the $2 \mathrm{D}$ Fourier transform of the sereened electrostatic potential of the ionized impurities. In equation (1) the summation extends over filled subbarts only, and the overtine tepresents the statistical avernge over all possible impurity configurations.

The subband energy loteshold values, $E_{\text {at }}$ ant the corresponding single-particle wavelunctions $x_{n}(4)$ ate solutions of the Schrobinger equation

$$
\left(-\frac{1}{2} \frac{\mathrm{d}^{2}}{\mathrm{~d} z^{2}}+V_{c k n+f}(z)\right) X_{n}(z)=E_{n} X_{n}(z)
$$

where $V_{\text {ton }}(2)$ is the $\delta$ well potential profile.

The transpon mobility for carriers in the ith subband: 7. (t) ) can be obtained from the Boltzmann equation in the zelaxation lime approximation, which leads to a system of coupled linear equations (17)

$$
\sum_{i^{\prime}} K_{x i^{\prime}}+\tau_{T}\left(i^{\prime}\right)=\frac{k_{i}^{2}}{2}
$$

with

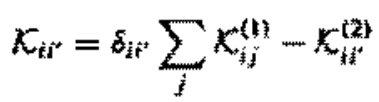

where

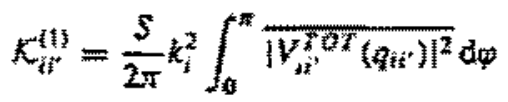

and

$$
K_{i j j^{\prime}}^{(2)}=\frac{S}{2 \pi} k_{i} k_{r^{\prime}} \int_{0}^{\pi} \overline{\left|V_{i^{\prime}}^{T O T}\left(q_{i k^{\prime}}\right)\right|^{2}} \cos \varphi \mathrm{d} \varphi .
$$

Equations (3) (6) were obtained stubband is ofestibed by an energy-dependent momentum

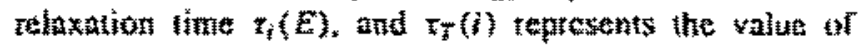
$r_{i}(E)$ at $E=E$.

In order to make a quantutative salculation of carrier mobilisy asing equations (1) and (3) - (6), a model for the coninning potential, $V_{e r n f}(z)$, as woll as for the sereened 
matental of the ionized impurities, $V^{\text {rot }}\left(\right.$ sa $\left._{3}, z\right)$, is needed. In the following sections. ihe cartien mobillty is oblained first from a full qumum trealmen. wheroby the tonlining potenial is obtained by solving Statodinger and Poisson equalions self-consistently and the screening tharge is

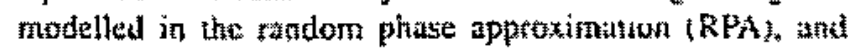
secont in the TF-2D approtiximation.

\subsection{Subband mobilities in the RPA}

In this case the contining potential is taken to bo given by

$$
V_{\text {stzin }}(z)=V_{H}(z)+V_{* x}(z)
$$

where $V_{H}(z)$ is the Hartee setfoconsistent potentital and $V_{x k}(z)$ is the exchange-correlation sorrection to the confining potential. which we used in the form parameirized by Hedin and Lundgrist [18]. The Hartre potential is oblained by selving self-consistanty culation (2) in conjumtion with the Poisson equation

$$
\frac{d^{2} V_{H(t z)}}{d z^{2}}=-4 \pi n(z)
$$

where $n(z)=\frac{1}{n} \sum_{1} E_{t}\left|x_{i}(z)\right|^{*}$ is the denvily of curriers confined in the sivwell.

For the biased structure, a Iration ${ }^{*}$ of the total electronic sheel charge dansity, $n_{5}$, will be transiorred to the gate placed al $z=-\alpha$. In this case oquition (7) will be stibjected to the boundary conditions

$$
\left.\frac{d V_{\operatorname{snn} f}(z)}{d z}\right|_{z=-d}=-4 \pi 5 n s
$$

and

$$
\lim _{t \rightarrow 0}\left(\frac{d V_{z e s f}([t \mid)}{d z}-\frac{\left.d V_{\text {tanf } f}(-1 z \mid]\right)}{d z}\right)=4 \pi n s .
$$

Althotgh the width and profile of the tistribution of donor atoms in the doped layer san be incorporated into the model [9], in the presen siudly we restrict ourselves to investigating the limit of a very narrow layer. In this cas the statistical ayerage of the RPA streened scattering potential will be given oy

$$
\begin{aligned}
& \overline{\left|V_{i i^{r}}^{\text {ToT }}(q)\right|^{2}}=\frac{n_{s}}{s}\left(\frac{2 \pi}{q}\right)^{2}
\end{aligned}
$$

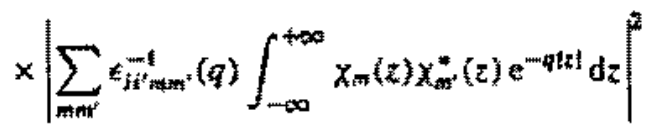

where $\varepsilon_{\text {it }}^{-*}(q)$ is the dielectric malrix, which is given by [17]

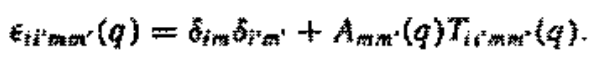

In the last equation $A_{m m}(q)$ is the independent responste particte density matrix and $T_{7 z^{*} \mathrm{ktm}}(q)$ is the Coulomb energy form fartor. The Coulom energy form factor is given by

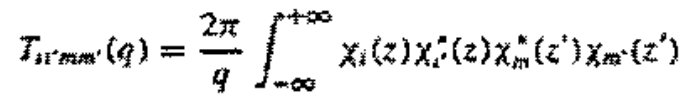

$$
\begin{aligned}
& x \mathrm{e}^{-4 \mathrm{z} z-z^{2} t} \mathrm{~d} z \mathrm{dz} z^{2} \text {. }
\end{aligned}
$$

If we neglect the small contributions to the dielectris matrix which arise trum subbants lying above une fermi level, $A_{\text {mom }}(4)$ will be given by $[9]$

$$
\begin{aligned}
& A_{\operatorname{man}}(q)=\frac{1}{\pi}-\frac{1}{\pi} \Theta\left(q-\left(k_{m}+k_{m}\right)\right] \\
& \times \sqrt{\left[1-\left(\frac{k_{m}-k_{m}}{q}\right)^{2}\right]\left[1-\left(\frac{k_{m}+k_{m}}{q}\right)^{2}\right]}
\end{aligned}
$$

where $\theta(z)$ is the Heaviside stop function,

The tarrier noblifies were calculated numerically by using zaquation $(0)$ in conjunction with equatons $(1)$ and $(3)-(6)$

Note that it the RPA approximation the lineslyape and with of the screening charge are reflected upon the screned potential through the dielectric matri* defined by equation (11), which depends on the electronic wavefunctions through ine coulomb energy fom factor of equaicun (12)

\subsection{Subbata mobilities in the TF-2D approximation}

The 8 -well profites tan be deternined asing the well known Tf semidtassical approximation. Seting the origin of the energy seale at the Fermi level, $E_{f_{3}}$, the TH differential equation for the sentening potential will be given by 110,201

$$
\frac{d^{2} V_{\operatorname{con} f}(z)}{d z^{2}}=-\frac{8 \sqrt{2}}{3 \pi}\left|V_{i \operatorname{son} f}(z)\right|^{3 / 2}
$$

where $z$ is the coordinate perpendicuiar to the deping plant: for a bistad struturte equation (I3) will be stbjeted the the same butndary conditions $(8)$ and $(9)$ as betore.

For $z>0$. the solution of the differentint equation is the "TF potentiat $[10,20)$

$$
V_{\text {cons } f}(z)=-\frac{1}{2} \frac{\alpha^{2}}{\left(\alpha|z|+4 z_{0}\right)^{4}}
$$

with $x=2 / 15$ 皒

$$
z_{0}=\left(\frac{\alpha^{3}}{x_{n}}\right)^{1 / 3}\left(1-s^{2}\right)^{-1 / 5}
$$

The depth of the potential sell, $V_{0,}$ is given by

$$
Y_{0}=V_{0}\left(1-s^{2}\right)^{4} t^{3}
$$

where $\overline{v_{0}}$ is litedepth for the unbiased structure $(e, g, z=0)$

$$
\bar{V}_{0}=\frac{1}{2}\left(\frac{x^{2} n^{2}}{x}\right)^{2 / 5} .
$$

Fot $z<0$, the potential is determined numerienlly from the differentiat edatition

$$
\begin{aligned}
& \frac{d V_{\text {cting }}(z)}{d z}
\end{aligned}
$$

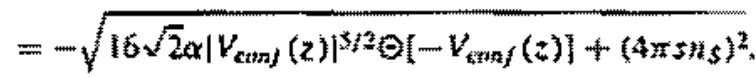

In the TF. $2 \mathrm{D}$ apptoximation the screened potential of a positively charged itapurity situated at $\left(p_{*}, 0\right)$ can be 
calculated for a soreaning charge lowatet al $\pm=0$, and the ratil is $[12,2\}, 2\}$

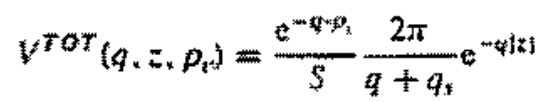

where $q_{x}=2$ is the TF screening wavevector, which ctarasterizes a density*tutetendent serecning tesponse of a 2D clcturanic charge.

In trids to calsulite the stobuat mobilities by using equation (I) and equarions (3) (6) it is necossary to

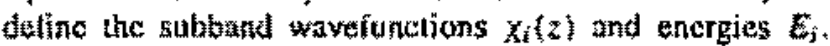
These were obtained by solving numerically equation (2) with the coofining polentulat laken to becteal to the TF approximaten (14). Using the watunctions oblained in this way the stativitical average of the sereened elcctrostatic potentinl over the distribution of posinively tharged donors can be culculated to obtain

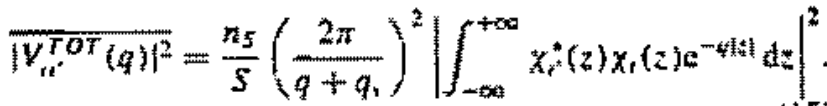

Sutatituting cquation (15) lato cquation (3) bnts abtains for $i=i^{*}$

$$
\begin{aligned}
& X_{i i^{\prime}}=-2 \pi{ }^{\prime \prime} s
\end{aligned}
$$

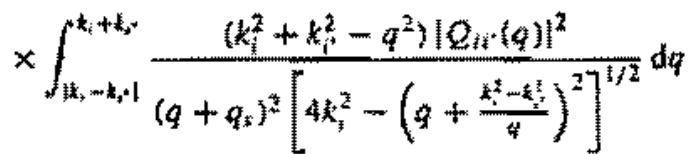

and the diugennt ciements

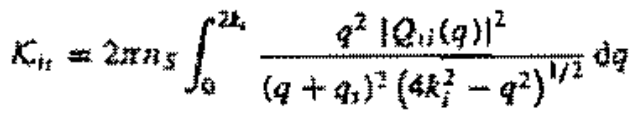

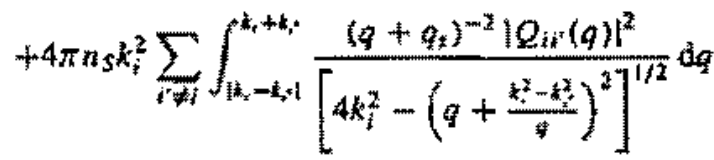

where

$$
Q_{i j}(q)=\int_{-\infty}^{+\infty} x_{i}^{\prime}(z) x_{j}(z) e^{-4[i l} \mathrm{d} z
$$

Equations (16) and (17) are in the form obtained by Mexrin and Shik 161 , and represent a converien form to talculate aumerically the tratsport and givantum mobilities of a subband by using refutons (1) and (3) of the previous secion.

In he TF-2D approxination the non-zero with of the screming chazge is not taken into accolnt, in opposition to the RPA approath. This difference can be appreciated from an examination of equation (15), which lests to a diogonal diclectrit multix

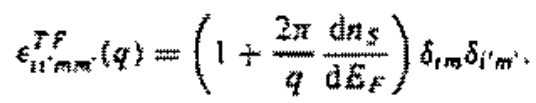

Equation (18) is independetal of the shape ot the screening

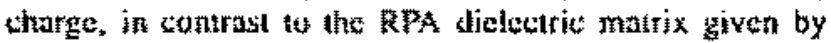
equation tilly. It is wett snown that the linit $q$ - of of the RPA lor a ditantum confined system will lent to the TF approximation for a strietly 2D sysim. Equation (18) can tx: obtuined by taking the Imat at $\rightarrow 0$ of the RPA equations whith laad to equation (II) (but not of equation (I) dircotly) and assoming $n \$=E_{F} / \pi$, whish is valid for a strictly 20 system.

\section{Results and discussion}

The quantum and transport mobifitics in individual

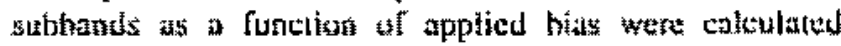
in bolh the RPA and TF-2D approximation for a seitoped semicontactor with donor concentrations $n_{S}=2,5$ and 10 $\mathrm{a}_{3}^{-2}$. Wo choose to represent the effect of bias through the fraction, $s_{r}$ of the tetal aumber of clectrons in the suructure, $n_{\text {s. }}$ which is transferred to the surface of the sample when a polential ditherence is applized berween the gate and the substrate. Results for the quantum and transpon mobtities as a funtion of 5 are shown in figure 1 .

First the resules for zefo bias whe be disclissed. The most rmarkable difference butwen the resulfs of the RPA and TF*2D appronches is that the RPA sutband mebilities increase with the subband index, while in the TF-2D calletation the subband mobilities are quanitatively similar. However, the mobility for cariers in the fundantatal subband, El. is approximalely the same in both calleslations. The outpot of the quanium treatment for

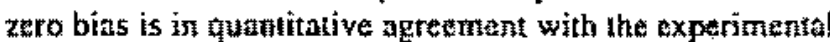

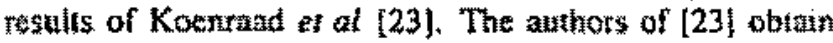
quanum mobilities in me th electronic sebtand, $\mu_{Q}\left(E_{i}\right)$

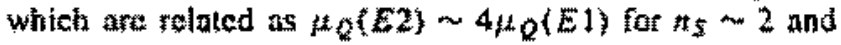
$\mu_{Q}(E 2)$ ma $3 \mu_{Q}(E l)$ for $n_{5}$ on 5 . These restits are wel] reproduce validily of the RPA approximation.

The calculations rely on two inpul quantities: th ditctronite spectrum and the screened clectrositic potential of the sheat of lonized impurities. We find tha?, for a donar layer of zero thickness as considered in this work. the electrontie spectrum obained by solving the Schrodinger equation (2) using the TF confining potential (14) is very bearly the same as he result obtained by solving sirnutianeously the Schrodinger and Poisson toquations; this finding is in agreentent with the conclusion of [20], where it is shown that at zere bias the TH confining patental of cquatian (14) yields results that are equivalent 10 those

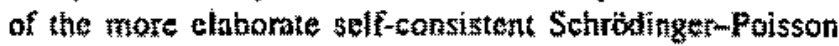
theory;

Thus the differences between the subband mobilities olwained by the RPA and TF 2D calculations cannot explainet by the tiffereneas in the electronic spectra and must be Iraced to the differences in the model for the screened electrostalic potentid used in each case. In the RPA model, the non-zero thickness of the screming charge is taken into accotent. This implies that the intensity of

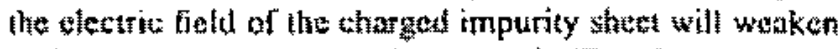
rapidly ats move away from $z=0$. Therefore electrons occupying states in more cnergetic subbands, uescribed by wavefurelions delecalized to a greater extenc, will be

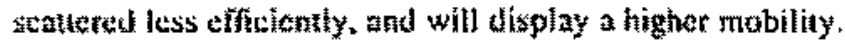

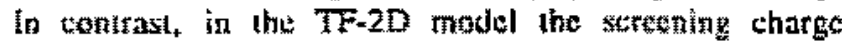
is ussumed to be of zere thickness, hence the electric tield of the charaed impurity sheet changes with : mutr 

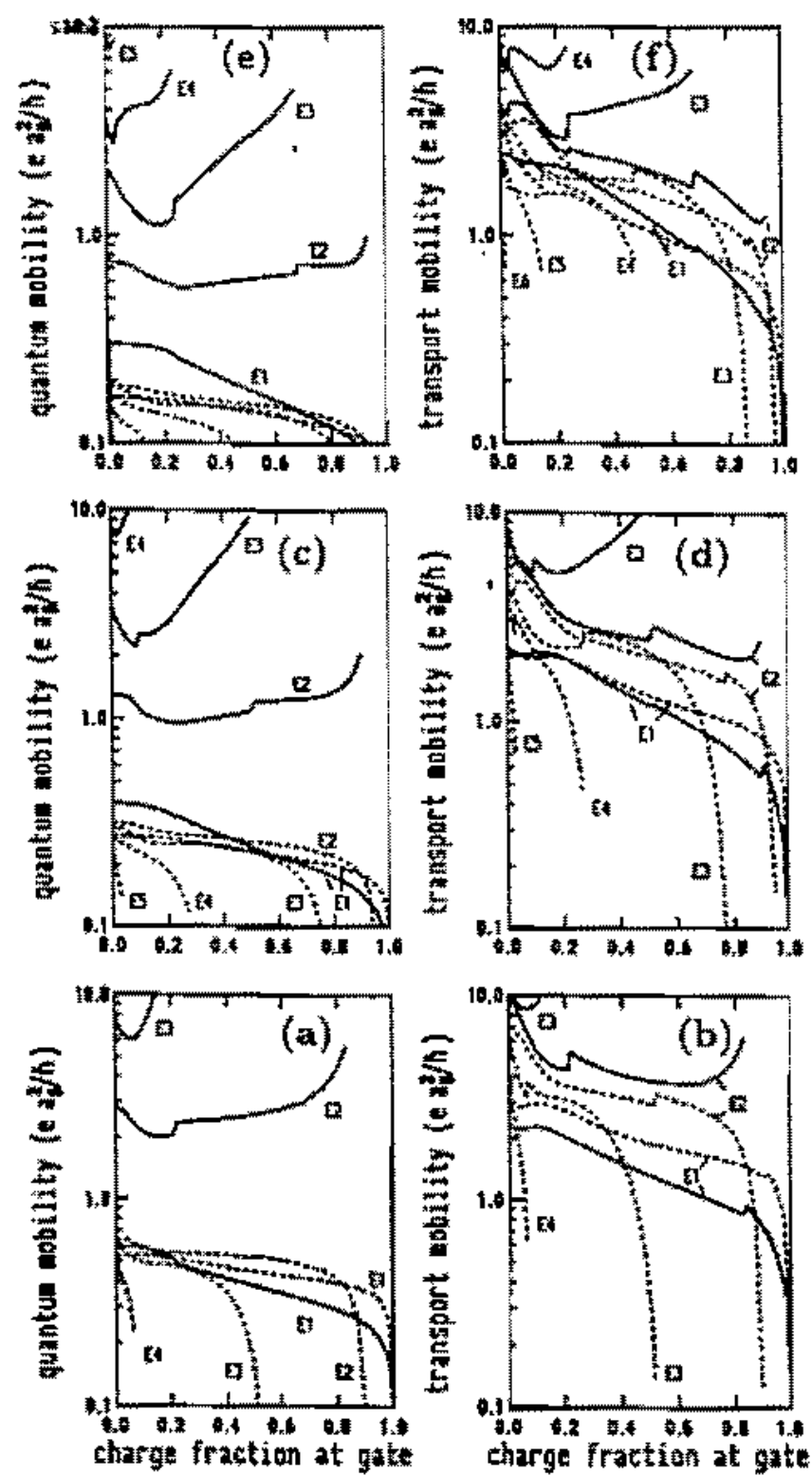

Figure 1. Calculated guantuwn and Iranaport mobintios for

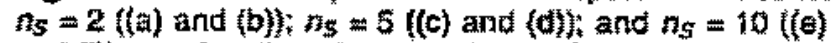
and (1)) as a function of the fraction sof the total number of carriers in the structure transterrad to the gate. Full curves corraspond to the the APA result, whereas dashed curves represent the result of the TH 20 approximation. Labeis inditate the subband index correspanding to each curve.

mote stowly than in the RPA model, and electrons in all subbonds are weattered with nearly equal effeiency and display similar mobilities. In other words, the mean distance belwen the electronic charge and the chatged impurity sheet is shown to a cruciat ingredient in the RBA motel, but not it the TF-2D approach. In fact. the TF-20 theory predicts that sometimes the mobitity decreases with the subband index, which is a conseduence of a decreasing fermi wavevector, which favours a higher stattering probabilily rate.

When ath external bias as applied, clactronic charge is transterret from the snmple. The tutermost subband is dopleted of touriers,

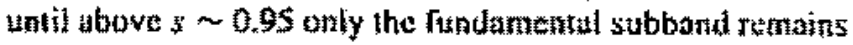
paptulated. Whenezen a stobland is depopulated of tartiers;

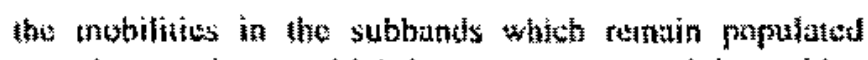
experience a jump, whth is a consequente of the sudust change in the density of states at the Fermi toncrgy: sucth jumps whll be attenualed at finte temparatures, when the energy range of conduting electrons is broadenet.

With increasing bias the colal denzily of electrons confuned in the well, $(1-s)$ ins decreases, which in the RPA motel implies that the screening capability of electrons contined in the $\delta$-well fecteases, hence the etectrostatic potential of the charged impurites betomes more intendet. whish means an intreatied scatering theisency and a liwter cartict mobility. This behayour (i.t. a tecreasing mobility with bias is sean is both transport and quantum subband RPA mobilitits in the range of small bias. However, at larger values of the bias the RPA mobilities in extited subbands incrosec. When bias is appliet, the high-enetgy subbands are tilted, dise to the fact that fte etectronic charge is repotled by the negative enarge on the surface of the sample. This is illustrated in flgute 2, which shows the $\delta$-well will $n_{s}=2.0$ and stbiand wayefunctions for zero bias and for $=0.25$. Ai zero biaz, the expectalion valutess are $\{z\}=0$ for all subbands. At $s=0,25$, the expectation value for the strongly bound elestrons in the $E$ l subthand experiences a small shit to $(z) E=0.05$, for the $E 2$ and

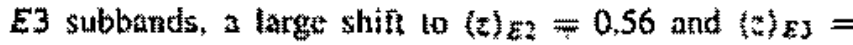
1.82, respectively, is oblained. Thus, with increasing bias electrons occupying sates in energetic subbands will move furtice nway from the impurity sheet. In the $\mathrm{RPA}$ modol such a spatial separation of electrons and impurtics implises that the mobiliy in excited subbands will increase with bias.

In [9] it was found that the electronic mobilizy in a subband $E_{i}$ correlates with the overlap of the

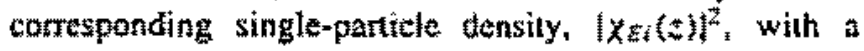
distribution fundion which tetermines the doped-layer profile. For donor layer of zero thickness is used in this work, such an overing will be given simply by $|\chi E(M)|^{3}$. Figure 3 shows the caleulated overiaps as a unction of bias for a $\mathrm{g}$-well with $n_{s}=2.0$. A compariton of figure 3 and figure I shows that there is clear correlation between the overlap $\left|\chi_{E_{i}}(0)\right|^{2}$ avolution with bias and the RPA mobility in subband $E_{i}$, i.t, when the oyertap increases, the mobility decreases, and vice versa. Such i correlation proves the point that the RPA mobitities are sensitive o the mean distance between the electronis charge and the doping layer.

In contrast, as figure $I$ shows, in the $T T^{*}+2 \mathrm{D}$ model the subband mobilties always dectense with applited bias; in this case. however, the screening length is density independent, thus the decrease in mobliny cannot bo attributed to a change in screening afficiency. As mentioned above. the TF-2D mobilities are tiso insensifite to the lecalization of the wavefunction, and heretore the tiling of the s-well has litte effect tapon the absolute values of the subband mobilities. The dectease in the subband mobilitits with bits obtained by the TF 20 model is dominated by the decrease in the Fermi wavevector as the onell is depleted. whith lwads to a hather scallering probability rate and hence lower mubilitics.

An attitional result of the theoretical tattulations is the average drilt mobilily, If aw. for transport pacallat to the deped layer. The averate drift mobility is given by 

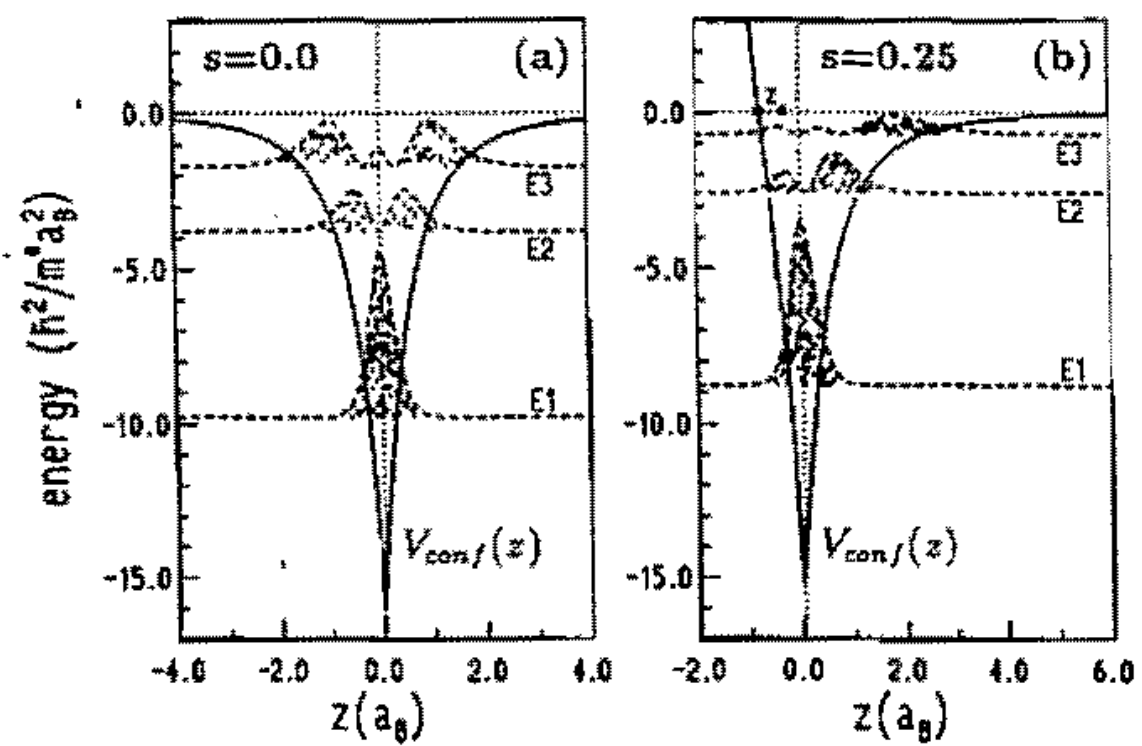

Figure 2. The contining 5 well obtained trom the TF-20 approximation fiul curve) for $s=0$ tal and $s=0.25$ (b). The origin of tha energy seale was chosen at the fermi energy. Eroken curves represent the electrontc chatge corresponding to the subsand indicated by a label.

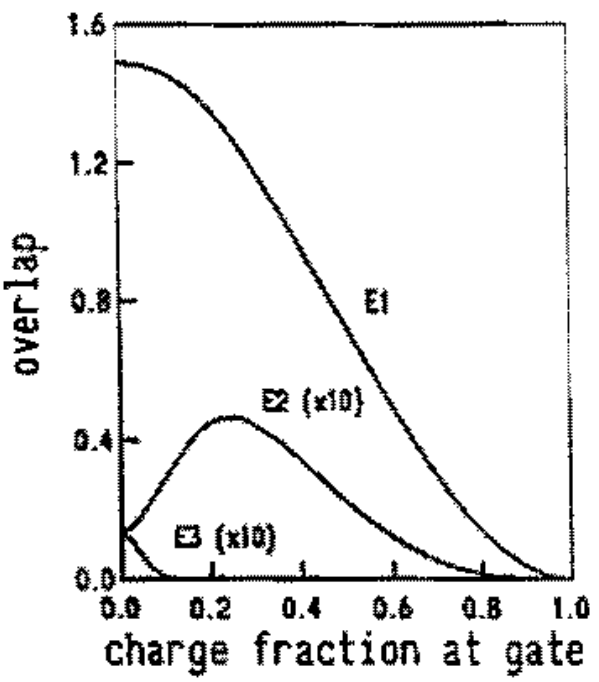

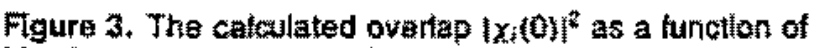
bias for $n_{s}=2$. Latols indicate the subland index. cortesponding to etech curve. The latetor by whith the calcutated overiap is muthiplied is inclicated.

the ayerage of the transport subband monility weighted by the deasity of carriers in the corresponding stuboand, $w_{A}=\sum_{i} H_{T}(i) E_{i} / \sum_{i} E_{i}$. Resolts of the calculation are shown in figure 4 as a function of applited bias; the full curve carresponds to the RPA with $n_{s}=5.0$ (for $n_{s}=2.0$ and $n_{S}=100$ the RPA nodel yields a similar result to that ohtained for $n_{S} \ldots 5.0$, and the avarage trift mobiuty curves are nol shown to avotid overlowding the figure); the average trin mobilities obtatned by the TF-2D model are shown for $n_{s}=2,0,3.0$ and 5.0 by the broken turves. If is interesting to observe that the dependence of avetage trifit irebility on bias is approximately the same in both metels.

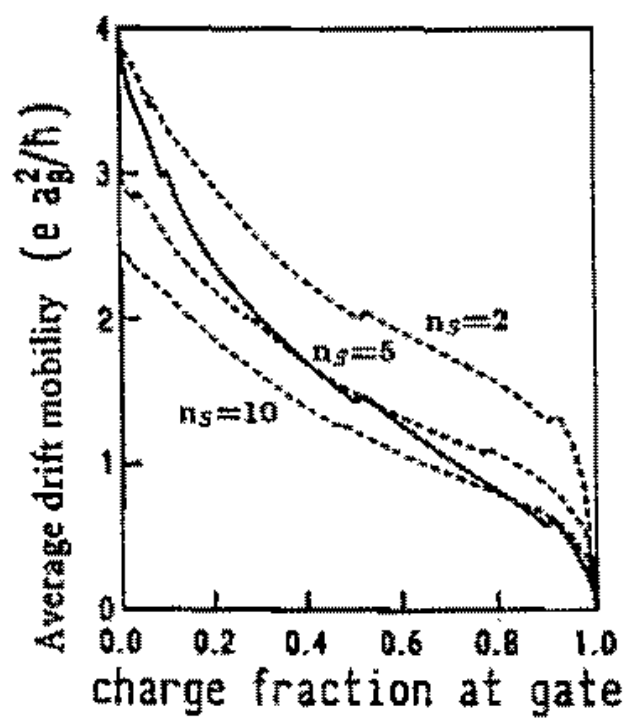

Figure 4. Catculated ayarage drite mobilites in the RPA model (full curve) and the TF-2D model (broken curves) as a function of applied bias. The lotal density of carriers in the stucture is inditated for each cure.

Since most of the lectronic charge in the well occupics states belonging to the fundamental miniband. the average drift mobilly will be dominated by the $E$ I mobully, which is similar in the RPA and TF-2D matels. This foct was observet in [6] whereby the authors show that the average drift mobility obloined whin the TF-2D madel campares

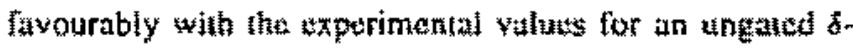
doped statuture. 


\section{Conclusion}

The quanturn and iransport mobititics in individual

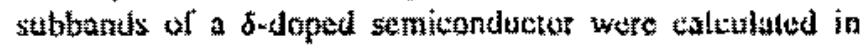
the RPA and the TF-2D afproximation as a function of external bias. Results of the TF-2D and RP theories agree for tut fundumantal subtond only, which is axplatined by the short binding length for wartiers in the rurtiamental subband. For excited stbbands, the nobilities intrase with hes subband index it the RPA approxination, whereas they remain nearly unchanged in the $T F=2 D$ model. This differente is due to the fact that in the RPA approximation the subband mobility 4 sery sensitive to the average distance belween the electronite charge and the scalleving centres, which is no the case in the TP + LD molel. Because the average urift mobility for transport parallel to the doped layer is dominated by cartets in the fundamental swbbant, the average dritil mobility in the TH-2D model agrees ressonably well with the RPA aretage drif motility. The output of the RPA calculation, which is assumed to remable due to the success of RPA theory in describing tabiased 8 -doped structures, shows that mobility depentence on bias correlates with the amoun of overlap betwect wayefunctions ant the region where donor aloms are situated.

\section{Acknowiedgments}

Calculations were performed using the fatifities of the Laboratorio Central de Computazaso Avancada do Centro de Computaçân Elctrontea da Universidute de Säo Paulo (LCC A CCE-USP). The anthors acknowledge suppont by FAPESP, Gram 94/2155-9 and Crant 9415645, CNPc, Grant 30633588 and CAPES.

\section{References}

[1] Wotd C E C. Metze G. Berry I and Enstman L F 1980 J. Apmil. Mys. 51383

(2) Schuber E F 1903 Doping in $/ H-Y$ Semiconductors

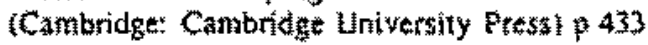

(31 Schutatr E F 1994 Semicond. Semínetoty 401

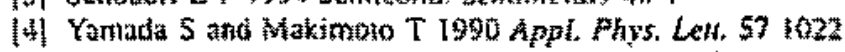

(5) Comalez L R, Krupstet 1 and Szwacka T 1994 Phys. Rev. B $4911 \| 11$

(6) Mezrin 0 and Shic 1991 Superiatt. Mictostmet. 10 107

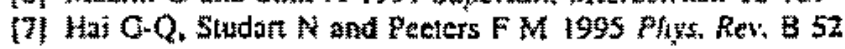
8363

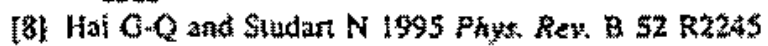

(9) Hentiques A 1996 phys. Rev. B 5316365

llo] Meatin O A. Shik A V and Mezrin V O 1992 semicond. s.ì. Tecinal. 7 654

III) Johnson M B. Kenraad P M, yan uef Vleuten WC and Salemint H W 1905 Phys. Rev. Left. 75 1606

[12\} Hebroques A B 199 i Phys. Rey. A 443340

[13] Ploog $\mathrm{K}$ 1987, Crystal Crowt al 304

(1) De Keyser A, Bogaertix and Borghs $C 1496$ solid-5iate sateran. 40395

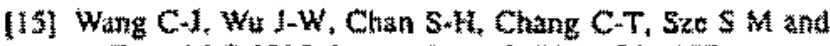
Feng M.5 1995 Japen. J. Appl. Phys. 341107

(16) Futsh B. Souza La Pires M P. Mendes W. Hentigues A B and Contratures L. C D 1996 \&. Crystal Growth

(1) Siggia E D and Kwok C 1970 Phys. Rev. B 21024

[181 Hetin $\mathrm{L}$ and Lundqvist 1971 L. Phys. C. Solud sate Phys. 4 theta

[19] Keys R W 1976 Comtanen. Solid State Fys. $7 \$ 3$

[20] toriati L. 1990 Phys. Rey. 418340

[21] Ando $T$, Fowite $A$ and Stern F logz Rev. Mod, Phys $\$ 4$ 437

221 Bastated O 1988 Wave Wechanics Applted to Semiconductor

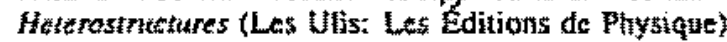

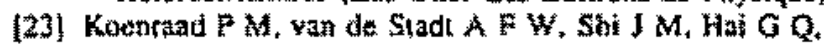
Stutlart N. Vonsani P, Peeters FM, Dextecse I T,

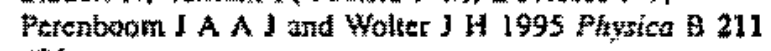
426 


\section{Single and periodically Si $\delta$-doped InP grown by LP-MOVPE}

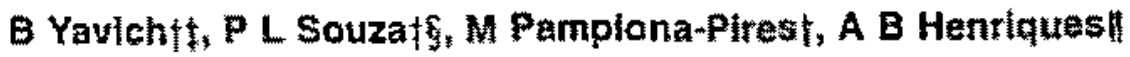 and $L \mathrm{C} D$ Conçalves\|}

I Centro do Estudos em Telecomunicaçoes, Fontiflcia Universidade Católica do

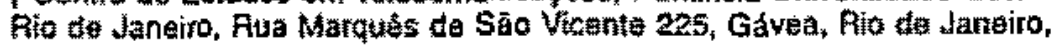
Fil 2245s.900, Brazil

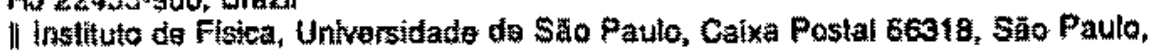
Sp 05389-970. Brazit

Feceived 10 Decomber 1996, accepted tor publicution 10 Jamary 1897

Abstract. Singlo and patodeally Si s-toped inP layors wote grown by LP-MOUPE

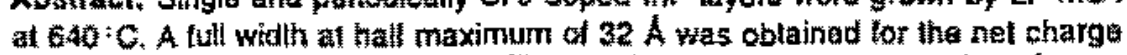
concentration profile for a sample with a peak nes ctrarge canceniration of

$1.8 \times 10^{18} \mathrm{~cm}^{-3}$. Numercal simulations showed that the impurities ara locallzed over less than inue lnP monolayer. No dopant difution ar segregation was

observed. The periodic sinctures, brown with barriers vanying trom 100 to $300 \mathrm{~A}_{2}$ all had nearly the same carrier sheet concantration per dopant layer and imputity locafization characletictics.

Since it was proposed by wood al in 1980 III the exdoping scehniguse which would ideally contint the dopants to single layer has coniributed much bolh to the understanding of fundamental propenties of $2 \mathrm{D}$ systems $\{2,3)$ and to the develoment of high-pertomance devices $[2-3]$.

Most of the work in this feld has been done on the GaAs and AlCaAs systems [3]. Ner charge distributitons with a fuli widin a hall maximum (FWHM) around $40 \mathrm{~A}$ for Si doped GaAs layers lave been measured by $C-V$ profiling. Such a charge distribution ituplies a dopart localization oyer 10 A or less, essentially remathing the itieal goal, Sminiar rexults have been obtained for AlGaAs.

Almost a decatie after the first wotk on GaAs, Di fortePoisson et al lol reported the abservation by $C+.+V$ protiling of Si $b$ doped InP layers whilh FWHM of 32 h. Si $\delta$-soped IncuAs layers wilh wery high cartior stect concentration have been grown by MOE [7]. Recently, Wang of ol [8] obtained extremely thin si s-doped layers in onlnt for HEMTs and non HBTs.

Periodically indoped layers, several s-doped layers separaled by the same distance, have raised much interest die to their great potential for unique device applicalions. Tranapan properties of somoped Si superiatices have

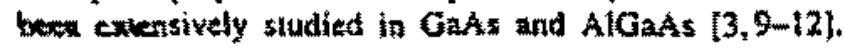
Such ytachare are very attraclive in the guest for high conducivity l13L. For applications and integration of devices operating at $1.5 .5 \mu \mathrm{m}$, knowledge of the properties

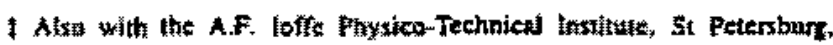
Rustiz.

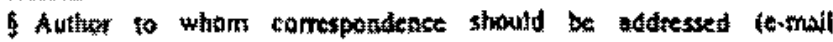

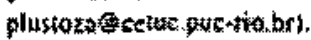

of butoped superlattices in InP-based materials is of paramount importancic.

In this commungution, results of a systemalic electrical characterization af single and difterent pariodically InP b-doped struetures are prestented and discussed for the first time. The samples wilh a single doping plane were grown with varying daping levels for studying he impurity lacalization. The periodictlly 8 -doped struclures have been designed to have lite same carries sheet concentration per doping plane. The possibilily of trowh of top guality sampies by low pressire metalorganic vapour phase epitaxy (LP.MOVPE) is demonstrated by the excetlent accord between the experimental tala and numerical simulation.

The 5-doped InP stmuciuses were grown at $640^{\circ} \mathrm{C}$ by L.P.MOVPE in an AIX 200 reactor at $20 \mathrm{mbar}$. The sturce materials were PH, (100\%), TMLA and $1 \%$ of Silt, diluted in $\mathrm{H}_{2}$. The total fow ratc, the TMln mole fraction and the VhII ratio used were $71 \mathrm{~min}^{-1}, 2.5 \times 10^{-6}$ and 360 respectively. The growth rate was $4.5 \mathrm{~A} \mathrm{~s}^{-1}$. The $\mathrm{Sill}_{4}$ ftux chosen was the one that produced the maximum doping tevel for a bulk sample (sample 204) but without reaching the saturstion reginte. since no signs of compensation could be detected. On (100) Fedoped In substrates. first a $0.3 \mathrm{~mm}$ thick undoped buffer layer wat grown, followed by eiher a single or periodic layer was deposited. The periodic structures are cornposed of 5 of 10 periods with banter thicknesses varying from 100 10300 A. The dopant plane for the sigule $\delta$-doped sumples was deposited turing a 5 to 40 srowth intermuption. Doping times longer that $30 \mathrm{~s}$ wased no increase in the doping concentration, while the mobility drepped. The optimined doping timte, 255 , was achieved for sample 18 ? 
Table 1. Electrical characteristics of the 8-doped structures. Experimental dala tor the investigated samples. The first colump

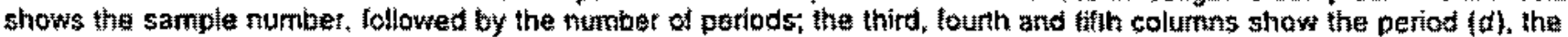

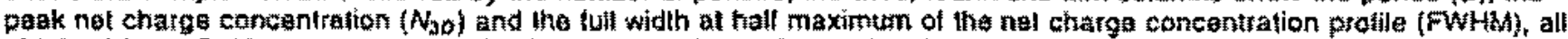

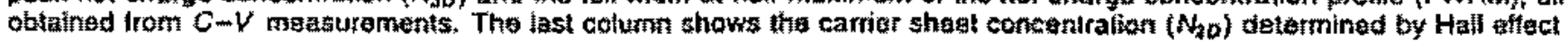
meastonements.

\begin{tabular}{|c|c|c|c|c|c|}
\hline Sample no & $\begin{array}{l}\text { Number ol } \\
\text { pariods }\end{array}$ & $\begin{array}{l}d(C-y) \\
(A)\end{array}$ & $\begin{array}{l}\text { Wo }(0-V) \\
\left(10^{14} \mathrm{~cm}^{-3}\right)\end{array}$ & $\begin{array}{l}\text { FWHM }(C-V) \\
(\text { A) }\end{array}$ & $\begin{array}{l}N_{30}(\mathrm{Hall}) \\
\left(10^{12} \mathrm{~cm}^{-2}\right)\end{array}$ \\
\hline $\begin{array}{l}204 \\
187 \\
164 \\
162 \\
165 \\
188 \\
194 \\
198 \\
197 \\
198 \\
296 \\
207 \\
200 \\
199\end{array}$ & $\begin{array}{l}\text { Bulk } \\
\text { Single } \\
\text { Single } \\
\text { Single } \\
\text { Single } \\
\text { Single } \\
5 \\
5 \\
5 \\
5 \\
10 \\
10 \\
10 \\
10\end{array}$ & $\begin{array}{l}\text { Bulk } \\
\text { Single } \\
\text { Single } \\
\text { Single } \\
\text { Single } \\
\text { Single } \\
22 \\
129 \\
222 \\
278 \\
107 \\
140 \\
176 \\
246\end{array}$ & $\begin{array}{r}9.0 \\
10.0 \\
8.0 \\
5.3 \\
2.0 \\
2.5 \\
18.0 \\
15.0 \\
13.0 \\
12.0 \\
12.0 \\
7.6 \\
9.0 \\
9.0\end{array}$ & $\begin{array}{l}35 \\
41 \\
47 \\
60 \\
76 \\
32 \\
\\
35\end{array}$ & $\begin{array}{l}6.0 \times 10^{10}\left(\mathrm{~cm}^{-3}\right) \\
4.4 \\
4.4 \\
4.2 \\
2.0 \\
1.1 \\
23.0 \\
21.5 \\
22.0 \\
21.0 \\
49.6 \\
52.0 \\
45.2 \\
41.5\end{array}$ \\
\hline
\end{tabular}

(Ste able 1). Therefore, this was the doping time chosen for the puriodic samples. Much longer doping times are requized when doping suturation is destred [14], The silane fux was always triggered 25 atter gowlo interruplisn and halled 2 s before the growth was resumed. Twe seconds pre and postodoping steps minimate the dopant memory effect and product ahrupt inteffaces at the same lime.

C-V measuromens wert performed uxing the elewtrochemical profiter PN4300 where a Schottky contact is formed between the semictonductar and the electralyte (HCL. $0.5 \mathrm{~mol}$. In the case of the periodic struetares the $C-V$ profiles were obtained by altwriting a newsuremont nat an ctch in order to detect he deeptr. layers in the sam. ple. Hall effect inga were taken at toom temperature vixing HL. 5500 equiqument.

Table I shows the results for he single 8 -doned samples (162, 164, 166, 187 and (89), (or the periolic siructures (xamples 194. 196-198 have five peribds while sampies 199, 200. 206 and 207 hate ten periods) and for il refetence lalk sample (204). $\mathrm{N}_{0}$ is the net charge concentration, FWHM is lis full widh al halt maximum of tose net charge disfrihution hoth obiained with $C-V$. Also, for the periodie somples. the period $d$ was measared by the $C-V$ profiling techrique. The carvier shest conceniration. $N_{42}$. shisined by Hatl eflect measutemerts, is in table 1, as well. Mobilites up to $2000 \mathrm{~cm}^{2} \mathrm{~V}^{m-1} \mathrm{~s}^{-1}$ at room lemperature suere intessurted.

The inser of ligure I shows a $C$ - profle (scatiered

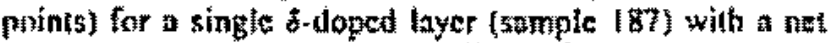
cilarge concentration of $10 \times 10^{16} \mathrm{~cm}^{-1}$ and a FWHM of 35 $\mathrm{A}$. Also shown on the same figtere is the theoretical $\mathrm{C}-\mathrm{y}$ protile (full curves). In ordat to ohlain a $C-y$ depletion profile. $\mathfrak{a}$ reverse hitas is apylied in the Schollky hartier an the surface of the semiconductor, and the differential

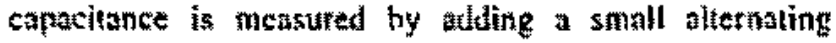
valtage to the teverse biss. The $C-V$ profice is then ahtalined by ploting lic $C-Y$ eancentration against the

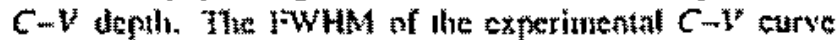
s deterumed by the planar lensity of Sil atums and the widh of the duster. When the dentity of mpurily atoms is known, the widin of the Si aistribution can be estimated by calcolating solf-contistently the theoreticat $C$-V profite with the width of the s.loyer as a varable inpul parameler. The lrue width of the 8 -layer is taken to he the theoretical value shich gives the $C-m$ profile in best agreement with the experimental one.

The C.V teshniqus: hes already been successfully applied to $\delta$-doped GaAs stmiconductor structures, as deseribed in [3] and 115]. Semuterl at al [15] have already demonstrated that the $C-V$ spectrum of a sudoped lyyer shows a peak with a FWHM which depends seasilively on the spatial localization of the depant monoritutes. If is also possible 10 determine the spread of the dopants in a s-doned structure with an accinacy within the lenth scale of the laltice constant of the host erystal 1161 .

ln the simulation reponted here, the Poisson and Schobdinger equations were solved self-consistemly within Ine Hartre approximation for the gated $\delta$.doned struclate 117]. The impritits wert axsumed to be distributed as a Gatessinn function. The differential capaciance was calculated assuming that transter of electrons from lite d-well to the Schottky barrier is the sole contritating mechanism. Olter contibutions at exceedingly stmall and are neglected $\{3$. The notusion of background accepiors with a density up to $2 \times 10^{14} \mathrm{~cm}^{-3}$ had no molizeable affesl on the calculated $C-V$ molite. "The ilopant concentration used was baken from the results of Hall measurements. shown in table $I$. One cleatly sces the excellent accord between experimental and simulated dota which was oblainted for a dopant distribution over $10 \%$ of the Bobr radius, namely $7.8 \hat{\mathrm{A}}$. This resull exclutes Jiffusinn of $\mathrm{Si}$ imanurities over more than lwo latuce ennstants, as Schubert el at IIS! have already shown to be the cate for MEE-grown Gahs al temperatures $\leq 550^{\circ} \mathrm{C}$. The linesianes afe reproduted with ercat prectiston.

The simulation fot the $C-Y$ preflits as a furtution

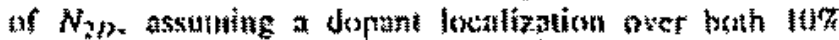

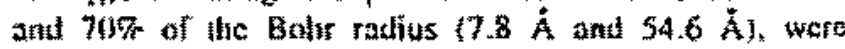




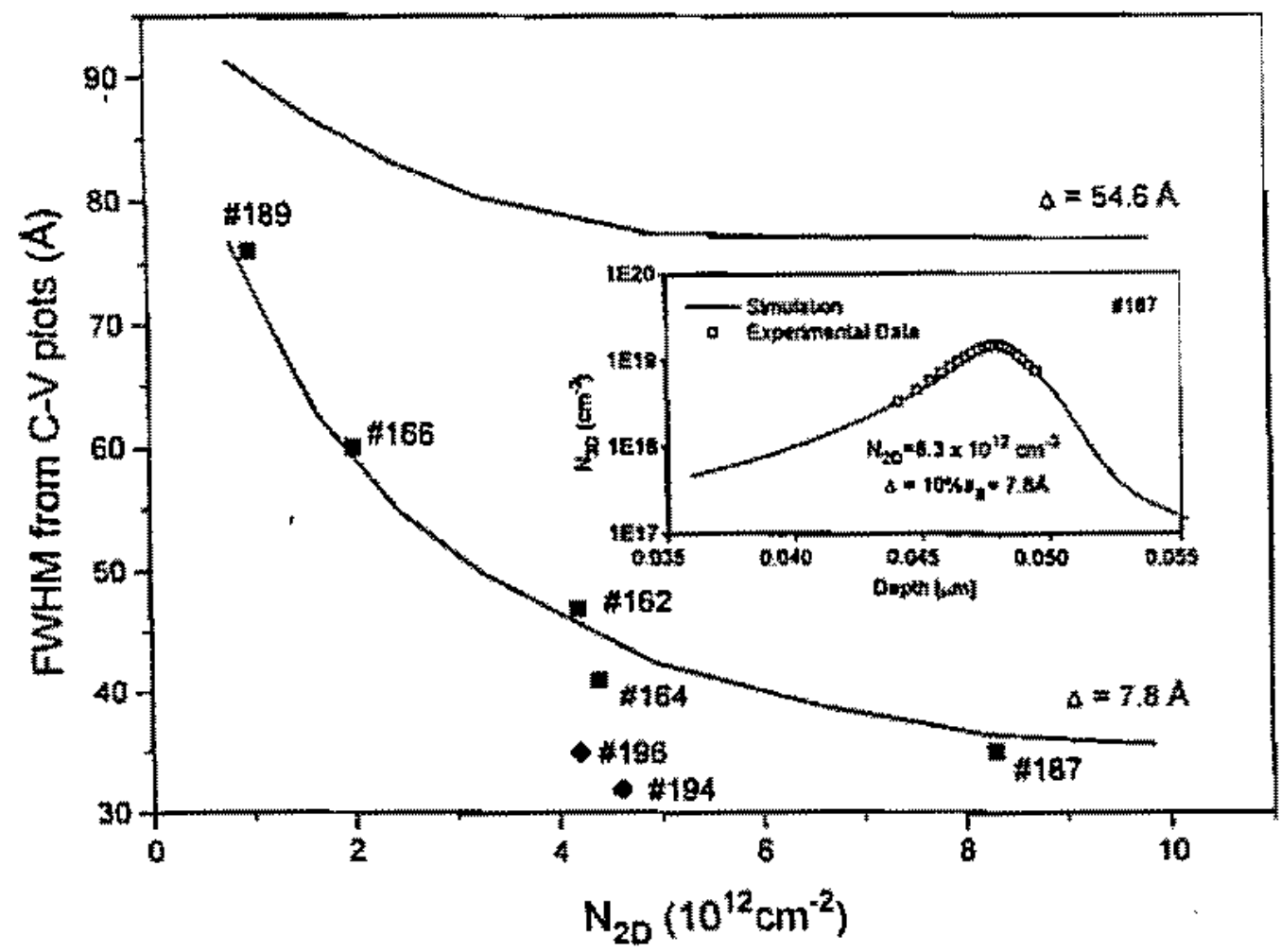

Flgurs 1. Full widh at hall maximum (FWHM) of tha $C-V$ plots as a lunction of the cartio sheet concentration. The

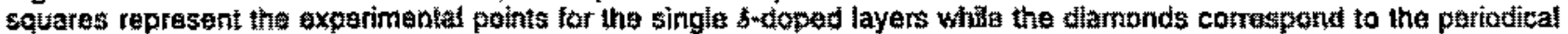

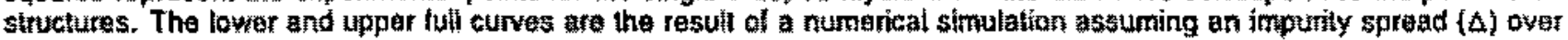
10\% and 70\% of the Bohr adius raspertivaly. The insert shows he not charge concentration as a function of depth for the

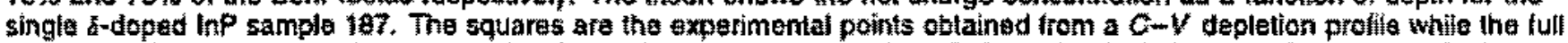
curve is a simutation assuming an imputity distribulion ( 1 ) over $10 \%$ of the Eotr radius (at). Included in the toputa ls the carriar sheat contentration obtained from Hall measuraments.

performad. The curves obtained for the FulM of the $C-V$ profiles as a function of $N_{M}$ are depicted by the full curves in figite 1. The experimental poins are included in the figure, where the squares represent he single fudoped samples thite the diamonds represent periodit suructures. Note that all the periodic samples have the same carrier sheet concentration per doped layer. The data points lie either on the simulated lower curve fimpunities localized over $7.8 \mathrm{~A}$ ) or below it, meaning thas the Sf copants are located at most over 8 . This implies that the dopants are confined to fewer than three monolayers of InP, showing that essentially no diffusion of 51 or surface segregrtion takes place even at the growth temperature of $640^{\circ} \mathrm{C}$. This is equivatent to the best fesults recently published for Gainp [8], for example. A simulation of the profile zeported by those althor zuealed approximately the same spatial localization for the dopants. This is in has been previously observed by Schubert at al [3, 15) at lower semperatures for MBE grown GaAs and by Di FortePoinsox at [6] for MOVPE-growa InP at $600^{\circ} \mathrm{C}$ and in contrast to the diffuston observed by Zenner ef al $\{18\}$.

In figure 2 one can observe a $C-V$ pratitle for lwo periodically doped stuctures wilh hive and ien periods separated by $92 \mathrm{~A}$ and $176 \mathrm{~A}$ respectively. The first doping plane is not resolved in lates $C-V$ profiles. The fel charge concentuation, $N_{30}$, is essentially the same as for the single layst. This profile is ohtantud by nlternatiog an stching step of $10 \mathrm{~A}$ with a measuremen. The etching procedure, however, introducts a brondening of the doping peaks. Thetefore, in order to more preciscly meatute the FWH, anolher piece of the same sample was ater to make a depletion pronle of the first doping patk whout trching. The same FWWM oblained for the xingle 8 -doped Jayers has been reproduced for the periodic structures, as stown in toble 1 and ploted in have 1 . A small becrease in the peak net charge concentration is observed as the dopant layer is located deeper in the sample. This effect is a conseguence of the etching technique. $\mathrm{As}$ one eqches the sample cown, a hole will be protuced and the clectrolyte that make the Schoiky barrier wh the semiconduclor will be in contact with the bollom of the hole and with the walls of the hole, as well. This effect will be tespensible for the observed damping is the net atage concentration. Also, in table 1, one notices that for wach set of periodic structures, $N_{3 p}$ decreases slightly as the barrier thickness increases. As the barrier gess laryer the value of $N_{3}$ approathes the value of $N_{30}$ for the single snlayer. This effect is most likely des to a contribution to the charge distribution Irom the neighbouring s-layers, this contribution being more stanificant the closer the neighbouring should keep in mind that the wavefunction extension of the Si $\delta$-layer in $\ln p^{3}$ is around $80 A$. Simple 207 is an exceplion possibly duse to a baxemout of the reacter which was done prior to us growth. The bake-out influences the 

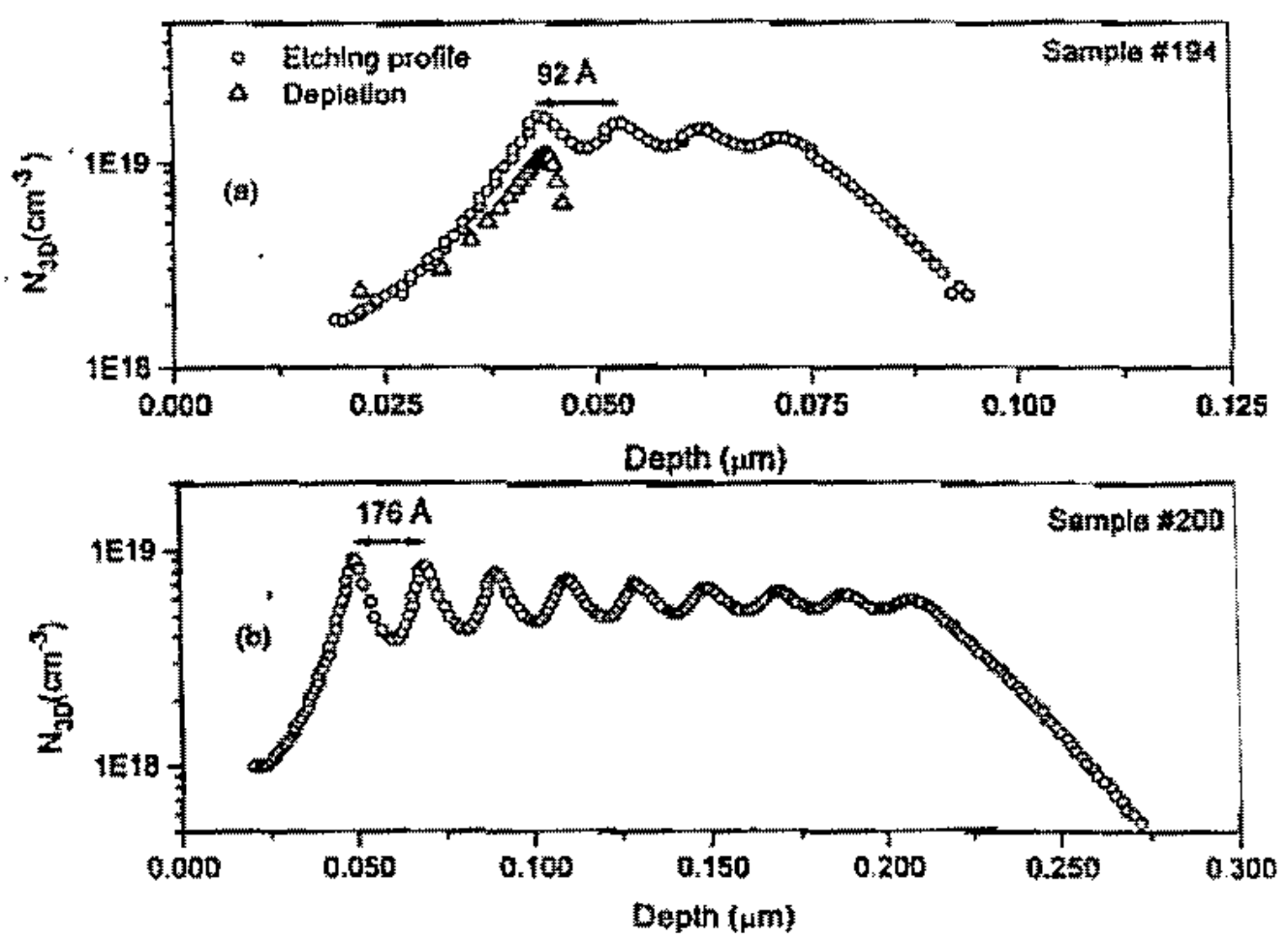

Figure 2. Net chafge concentration as a function of depth for two periodically b-doped samplas, namely 194 (plot (a)) and

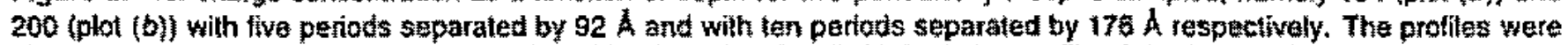
obtained from a $6-V$ atching profite. Incituded in plot $(a)$ is the $C-V$ depletion profle of the fitst doping plane, represented by triangless.

backgtound imfurity concentration.

In concluston, excellent quality $S i$ dayers of 8 A widh were grown by LP-MOVPE, showing that no diflusion takes place even at the relative high growth tempezalure of $640^{\circ} \mathrm{C}$. The FWHM of $N_{30}$ lecreases with incensing doping as expected for this $2 \mathrm{D}$ sysiem, clearly indicating the increasing confinement of carticts. Periodic structures with fye and ten periods were abtained with the same optimal imparity localization as the single tayers.

\section{References}

(1) Wood C E C. Metze G. Beryy J and Ezaztman L F 1980 1. Appl. Phys. 51 383

12) Ploog is. llauser $A$ and Fisher A 1988 Appl. Phys. A 45 233

[3] For a complete tevitw Schubert E F 1994 Semiconductors and semimetals vol sol, ed A C Gossard new York: Acalenicl p 1

[4] Jenng $Y$, Jeong D, Hong $w$, Canewu $C$, Bhal $R$ and Hiayes

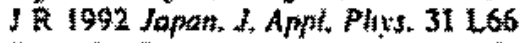

(5) Aalleger D C. Numatile K. Adesida 1, Cuneat C and Bhat R 1993 Etectmom. Lat. 291375
[6] Di Forte-Poisson A A. Brylinski C and Blondeau E 1989 1. Ampt. Phys, 66867

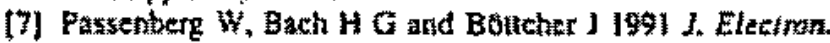
Mtater 2089

(8) Wang C, Whe ), Chan $\$$, Chang $C_{4}$ Ste $S M$ and Feng M 1995 Japan. J. Aprl. Phys. 34 Lillot

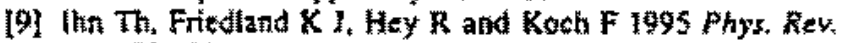
B 52.789

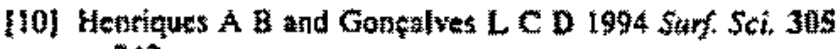
343

(11) Hetriques $A$ and Gonçalves L. C. D 1993 senicond Set. Technd. 8585

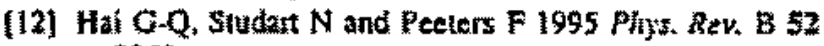
$\$ 363$

[13] Fo $Y$ and Wilander M 1995 J. Appl. Phy. 783504

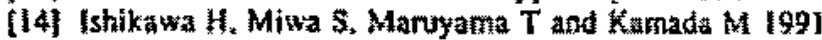

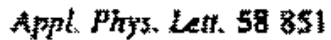

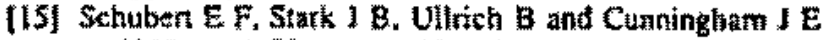
1988 Appl. Hys. LeIt. $\$ 2$ 1508

(16) Ulirich $\mathrm{E}$. Schubert E F. Statk I $\mathrm{B}$ and Cuntningham $\mathrm{E}$ lags Appt. Phrs. A 47123

[17) Gonçalyes Lo C a and Hentiques A 1987 Semiconat. Sei. Techol. 12203

[18] Zrenner A, Koch F and Ploo K 1987 Froc. 7hh lat. Conf. on the Electronic Propenies of $2 D$ systems (Sernta Fin) p 341 


\title{
Electronic and optical properties of periodically Si $\delta$-doped InP grown by low pressure metalorganic vapor phase epitaxy
}

\author{
P. L Souza, ${ }^{\text {a }}$ B. Yavich, ${ }^{\text {b }}$ and M. Pamplona-Pires

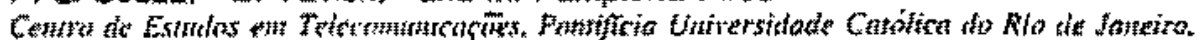

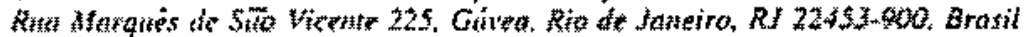

A. B. Henriques and L. C. D. Gonçaves

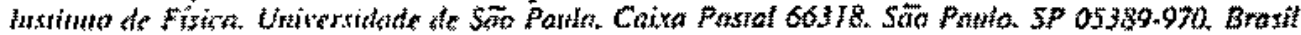

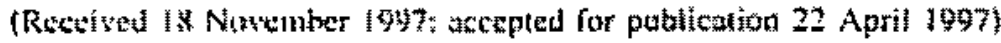

\begin{abstract}
A sertes of periodicaly Si $\partial$-toped inf sampies with 5 and 10 periods varying from 92 lo 278 , bas been investigated in terms of the transpon and optical properties. A reduction in mobility with dscreasing period was observed due lo he increasing overtag of the electrutic wavefunction with the various $\$$ in planes. $A$ broad band emission was telected for the pertodic struetures at energies higher than the lnP band gap. The culoff energy for this band decreases with the period and this

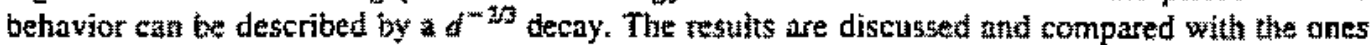
For GaAs aviluble in the linerature. 1997 American hastitute of phistcs.
\end{abstract}

[SOD? $1-8979(97) 03515.9]$

\section{INTRODUCTION}

In 1980 Wood af al.' proposed geowth intertuption dur ing the usping procedure of semiconductors in orter to achieve the planar dopant loenalization over onty a few angstroms. Since then this techntinut attracted ffe attention of many resentchers and the confinemere of dopants to essents finly a single layer contributed much both to the understand ingef fundarnental properties of two-dimenstional systems. its well as to the development of thigh perfomance

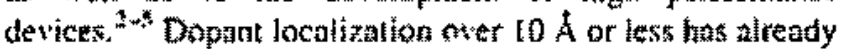
been oblained for a single 3 it doping plantio in Gas. AlGaAs. inP." InGaAs, and Galnp, loyers. Since this imputily distribution can be described by a Dirac's $\delta$ func.

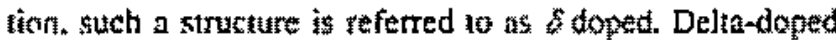
smiples were grown by molectiar bearn epitaxy st temperatures equal on betow $550^{\circ} \mathrm{C}$ to atoie diftusion of imptrinies.

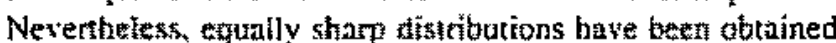
al so by metalorganic yapor phinse epitax the growth temperature ean be considerably higher, 600 7 fol $^{2}$. This result was very encoutaging since with MOVPE it is possible to grow componnds with both As ind $P$.

The success achieved with the single sodoped layers

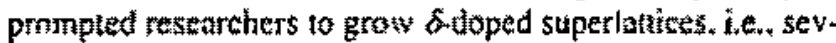
erat s-doped layers separated by the sane ditunce. Such sytutens have two unique properties if the period is smaller

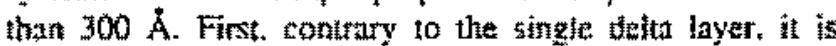
possible to daserve luminescence due to the periotic potential introtaced in such strutitures. Single delta doping layers create a $Y$ "shlaned potental stutch confines the electrons but reputis the holas. In case of a periodically b-toned structure mittitunds nay he formed so that botes and electrons are allowed to have spatially osertapping wavelumetions and op. fateil transitions may oecur. In additen, the combination of

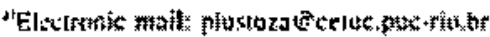

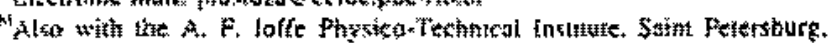

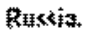

several doped pianes can lead lo strtetures of extremely high conductivity which are partictalaty interesting for hinth speed devices.

Thansport and optical properites of doped Si superlat tices have been stensitely studied in GaAs and

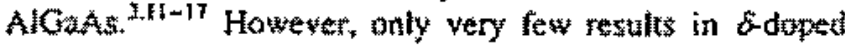
superiattices in InP based materials have been

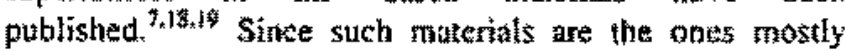

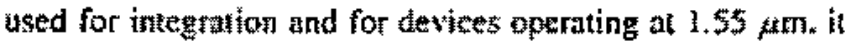
is imperatiye that data on the optical and transpor properties of whoped supertautces in these materials become available.

In this article the restlis of a systemaic investigation of the mobility and photolutninescence (PL) characteristics of a series of $\mathrm{Si}$ - 2 loped InP supertatices as a function of the superlattice period is reported.

\section{EXPERTMENTAL DETALS}

The $\delta$ doped inP structures were grotwn at $640^{\circ} \mathrm{C}$ by low pressure meltiongaic vapor phase epitaxy in an AIX 200 reactor al 20 mbar with a growth rate of $4.5 \mathrm{~A} / \mathrm{s}$. The source materials were $\mathrm{PH}_{3}(100 \mathrm{~h})$. TMln, and $1 \%$ of $\mathrm{SuH}$ diluted in $\mathrm{H}_{3}$. On (100) Fentoped $\mathrm{mP}$ substrates, first a 0.3 um thick undoped buffer layer was grown. followed by either a single of periodical silayers. and finally a $550 \dot{A}$ cap lay was deposited. The periodical straxtmes are composed of 5 or 10 periods with bariers thickness varying from 100 to $300 \mathrm{~A}$. The utopart layers tere deposited durinz a $25 \mathrm{~s}$ growt intertyption. The silane flux was always trigered $2 \mathrm{~s}$ after growth intertuption and hated 2 bofore the growa

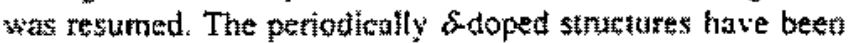
desiened to hate the same shect carrier concentration per coping plane. A scheme of the samples used in strown in Fig. 1 .

C-1 measurements were partormed asing the electrochemital protiler PNa300 where a Schoulky contact is formet beween the semintonductor and the blectrolyte [HCL, $0.5 \mathrm{~mol}$. In the of the pertodite structures the 


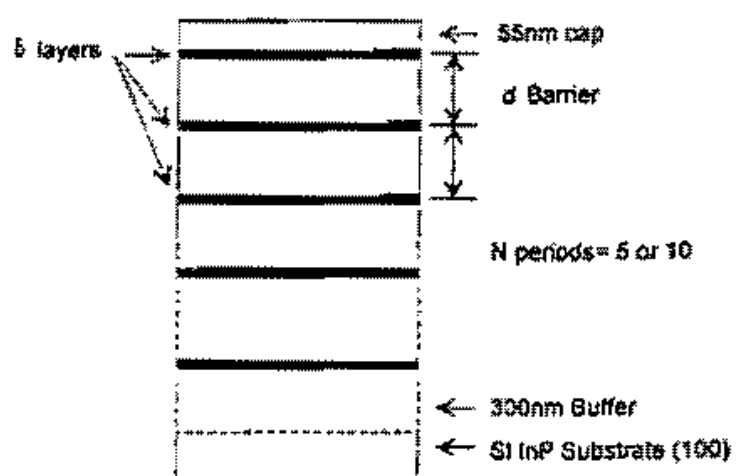

FIC. 1. Seben the $\delta$ doping supetiatice samples.

C.- y profles were obtaint by alternating a moasurement and at esch in order to defest the deeper hayers in the sample. Hall effect data were taken at room temperature using a $\mathrm{HL}$. 5500 equipment. Secondary ion mass spectroscopy (SMIS) measurements were periomed in Cameca MMS4F for detemining the depth profite of the atomic distribution. Oxym getr with energy of $3 \mathrm{KeV}$ and current 0.4 HA was used as primary ion. The scanned ares was $500 \times 500$ um $^{2}$ and the analytical ions were collected from the central area of diamefer zutal to $10 \mu \mathrm{m}$. Quantification of the compositional pro fles was done referring to implanted standards.

The PL measuremants were pertorned using the $\$ 14 \mathrm{~nm}$ line of an Ar laser for excitation. The signal was tispersed by a $250 \mathrm{~mm}$ monochromator and detected by a Ge nitrogen cooted photodetertor. The excitacion power densily vatied

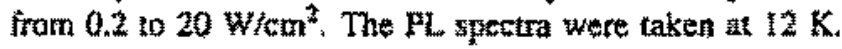

\section{RESULTS AND DISCUSSION}

\section{A. Electronic Transport}

Figure 2 stows the depth protile of both the nationge concentution and $\mathrm{Si}$ atomic concentration for sample 200 , which contains 10 periods. mexsured by $C$ - $V$ (aeprestnted by dots) and SMS (represented by the solid line), respettively. One clearly sees an excellent agreement between the

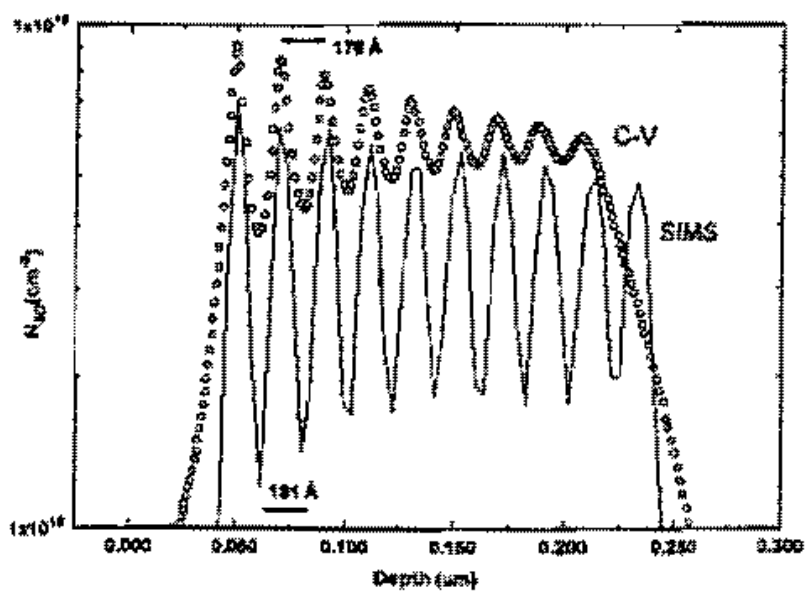

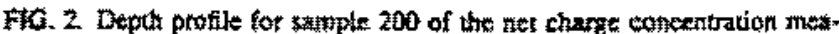

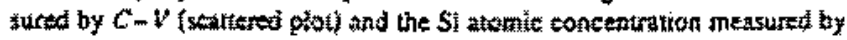
Sthes (solid tine plot).

two technigues. in terms of the period of the superlantite. As for the impurity concentration, at tirst sight, the integrated impurity toncentration measured by SIMS serts much lower than the integrated charge dentity datemined by $c-\vec{v}$. However, the observed width of the different pestiss in the $C-V$ pronle in Fig. 2 is not the real width of the Si atomite distribution as published elsewhwr:" The $C-V$ profle is obtaind by atternating an elching step of $10 \mathrm{~A}$ with a neasurement. The tehing procedure, however, introduces a broadening of the doping peaks. Therefore, in order 10 mart precisely neasure the full with at half-maximum ifwHM). anounter piece of the same sample was used to malke a depletion profile of the first doping peak without etching. The FWHMs uns obtained are ineluded in Table L. The net charge titutributions observed in our samples correspond to an atomic tistribution of around $8 \AA^{7}$, as determined by sol $\psi_{m}$ ing seif-consistently the poisson and schrödinger equations within the Hartre approximation for the gated soped structare. ${ }^{3,5}$ Exthellant agrecmont between the simuluted and measured $C-V$ profiles was oblained when a toparl focal-

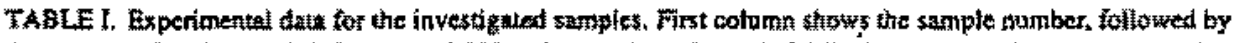

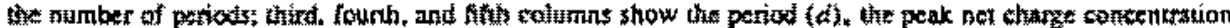

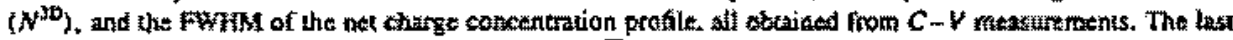

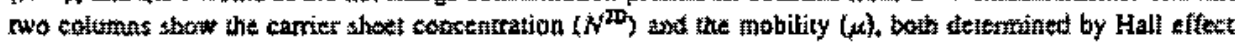
mataturements.

\begin{tabular}{|c|c|c|c|c|c|c|}
\hline Sample No. & 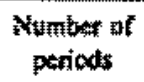 & $d \underset{\text { 隹 }}{d C^{\prime}}$ & 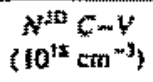 & 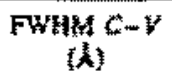 & $\begin{array}{c}N^{* \mathrm{D}} \text { Hall } \\
\left(10^{1+} \mathrm{mi}^{-3}\right)\end{array}$ & $\left(\cos ^{2} x\right)$ \\
\hline 204 & Bulk & Salut & 9.0 & & $6.0 \times 10^{10}$ & 1300 \\
\hline 187 & Single & Single & 10.0 & 35 & s. & 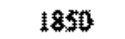 \\
\hline 164 & Wingle & Single & 0 & 41 & 4.4 & 1630 \\
\hline 154 & 3 & 92 & (s.6. & 32 & 23.0 & $\$ 430$ \\
\hline 198 & 5 & $12 \%$ & 15.0 & & 21.5 & 1580 \\
\hline 197 & 5 & 223 & 13.0 & & 23. & 170 \\
\hline 教范 & 5 & 278 & 120 & 35 & 210 & 1860 \\
\hline 205 & 10 & 106 & 120 & & 48,6 & 事科到 \\
\hline 207 & to & 133 & 7.6 & & 520 & 1520 \\
\hline 200 & 50 & 176 & 90 & & $45 \times 2$ & 1780 \\
\hline$\$ 9$ & to & $\hat{2}$ & 9.0 & & 41.5 & 2000 \\
\hline
\end{tabular}




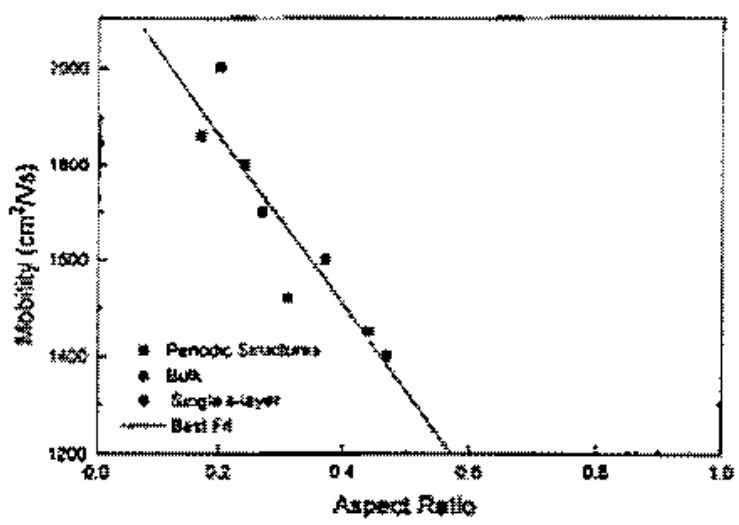

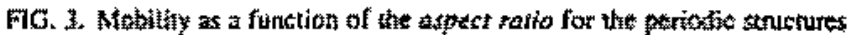
(A) for the tould sample 204 (O).

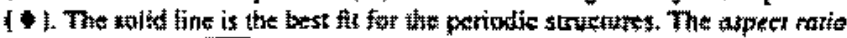

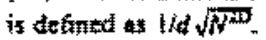

zation over 10 of the Bohr radius was assumed. The atomic localization over less than three monolayers indicates that Si diffusion can be nemected. Neverthetess, the SIMS curves zevel a much broader atomic profile. The lange width of the impurity peaks detected by SIMS are due to the resoItution limit of the apparatus used which is of the order of 30 1. The calculated area for the forst patal in the SDMS pronte is $4.9 \times 10^{12} \mathrm{~cm}^{-2}$ white for the $C-V$ profile it is $3.6 \times 10^{12}$ $\mathrm{cm}^{-2}$. The wifference in the real atomic concentration de-

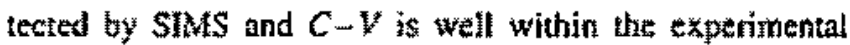
error of both techniques. The profiles also demonstrate the excellent uniformity acheved in the InP barriers' width or the period of the superlattices. The slight disctepancy of 5 between the period measured by both $C-V(176 \mathrm{~A})$ and SIMS (181 A) is within the resolution of the techniques. The first grown doping plane is not resolved in the $C$ - y profle. The line shape is not the same in the two profites of Fig. 2 , as expected, since the two technigues reveal differcht paramexers, i.e. sharae and atom distributions.

Table 1 shows ine tala extracted trom the $C-V$ profles and from the Hall effect measurements for samples 204 ta bulk reference sample), 164, 187 (samples with a single dopant plane), 194, 196, 197, 198 (superiattices with 5 periods), 199. 200.206, and 207 (suparlattices with 10 perrods). In Tahle $1, d^{30}, C-V$ and FWHM are the period, the net charge concentration and the full width at hall-maximum of the net charge distribution, all determuned from the $C-y$ protites. $N^{20}$ and th are the net sheet carrier concestration and the mobilizy both measured by Hall effect experiments.

As mentuted before, one of the highlights of the Seoping strpertatices for applictions is the highter mobility for high doping levels which can be achieved compared to bulk structures. One way of examining this characteristic is by plotung the mobility of the periodic stmuctures as a function of the secalled aspect ratio. The aspect ratio is tefined 2s the mean slistance between the si atoms in the plane divided by the period or $\mid / d \sqrt{N^{42}}$. This data is ploted ${ }^{4}$. Fig. 3. where the squates reptesent the experimental points and the straight solid line is the best fit. The diamond represents a single telta layer. sample 187 (aspect ratio is zero since the period is infinity) and the black dot represents the bulk lay sample 204 faspect motio is one sinte the distance betwe the dopant atoms in the plane is the same in any of the th directions: As the period increases the mobility increa approaching. In the limit of $a+\infty$, the mobility of a sin $\delta$ layer. If ane extrapolates the best fit to the equival three-dimensional system, meaning aspect rato equals this would inply in a sample with a nat charge concentrat of $1 \times 10^{2 \mathrm{k}} \mathrm{cm}^{-3}$ and mobility of only $440 \mathrm{~cm}^{2} N \mathrm{~N}$. The val of this bulk molvility cannot be sirectly measured sin $N^{30}+1 \times 10^{21} \mathrm{~cm}^{-3}$ is above the solubility limit of Sin in This resul indirectly attests that with $\hat{b}$-doped strutures 0 can achice moch higher mobilities than with bulk mater for the same sfieet catrier concentration.

The wave function extension of the si $b$ layers in InP round 80 A. As the period gets smaller the increasing over of the electronic wave function with the doped planes pi duces a mote fficient scattering leating to a decline in mobiliry. The trop in the mobility for the periodic struetus agrees with restits recentiy published for Si \&doped GaAs Henriques el al. ${ }^{19}$ have shown that the gitanum mobil decteases for the pertodite choped stractures. this effert ing mort drastic for the higher energy mitubands. It shot be noted that a reduction of the quanum mobility implies a lower transport mobility. as well. in yiew of this affe when desigaing high speed devices, one should consituter compromise between using a pertodic structure, insteat of single a-doped layer, in arder to increase the conductivi and the consequent decrease in mobility. In case a period structure is desired. Hen the period stowate be carefur chosen.

Compating the mobility for the two samples whth single Erdoping layer, it should be mentioned that sarmp 164 was grown with a different phosphine seurce which ha a higher background impurity leyel. The presterce of imp rities unimentionally introdiced during growth, indicate also by PL measurements, thould be the reason for the low mobility presented by sample 16 compared to sarmple 18 The data on ample 164 are shown in Table I becouse is b essentially the same sheat carrier density as each dopa plane in the superlatice structures. In the next session, whe the Pl. results will be presented. the spectrun of sample it will be compared wath those of the doping supentatices.

\section{Optical Properties}

The photolumintescence spectrat al $12 \mathrm{~K}$ of the sing ondoped sample 164 and of the periodic strumbars are show in Fig. 4 . The single $\&$ doped spectrum, as expected, is sim lar to the spectrum of good quality undoped inf. The $P$ FWIM of the near band edge emistion at $1.417 \mathrm{eV}$ f sample 187 is around $7 \mathrm{meV}$ and for sample 164 is larg probably due to the incorporation of undesirable impurite as mentioned in the previous paragraph" The undoped It layers grown under sirnilar conditions present a PL FWH of 3 meV at the same femperuture and excitation power des sity. The near band edge perat for the samples investigate involves more than wo excitonic emissions as it was show by a fitting procedure using three and four gaussians, ind ating the presence of different bound excitons. No sign 


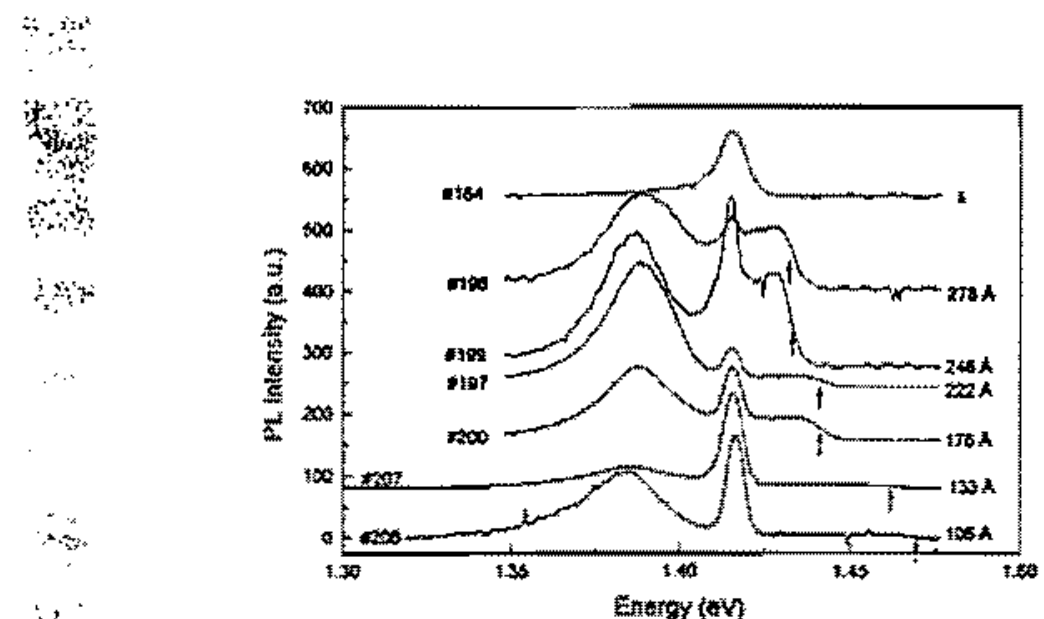

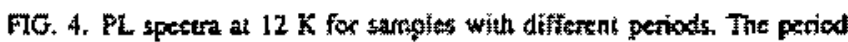
and sample numbers are incloded in the hature. The arrows show the curoff energy for the differeat samplex. The cutoff entergy was chosen as the eoexgy for which the pL intensity of the brosd bund dreps to half of its maximum valute.

the dela layer potential well is observed for the single s-doped samples since the well confints the electrons but repels the holes. Hence, hure is no gverlap between the holes and the confined elatrons. Two oher emissions, ane at lowar and one at highte anergy whin resget to the near band edge peak, are observed in the spectra of the periodic structures. The low enerpy one located around 1.39 at at 0.2 W/cm ${ }^{2}$, is attributed to a donot-aeceptor transition since it shifts to higher energies with increasing excitation power density. This type of behavior with the excitation power den. sity ean also be observed in coping superiatices of the $n-i-p-i$ upe when the period of the superattice is of the order of $600 \mathrm{~A}$ as reported by schuben et al. ${ }^{3}$ However, for short periods ( 100 to 250 h), as reported here, one would expect no changer in the atsisston energy for an increase in the excitation power density In addition, highter excitation power densites favor the near band efige emission indicating that this impority band saturatex. This emission is not related to the presucte of the doping superlattice.

The striking aeabute in these spectra is the presence of the high energy PL broad band emission which strows a difw ferent cutof energy for the different samples and whose in ensity relative to the near band edge peak declines as the period is reduced. This high energy PL emission is attributed to the trantition between electrons at the Fermi energy and confined hales in the doping superlatice regian. The high

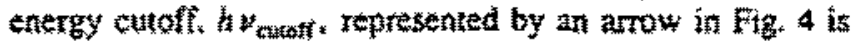
siven by:

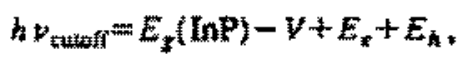

where $V$ is the effective $V$-shaped potential. $E_{e}$ is the stect tron Furmi energy measured from the bonom of the $V$ poten: tisl. and $E_{h}$ is the confinement energy for the holes measured from the top of the $V$ potential. ${ }^{13.16 .17} \mathrm{~A}$ band diagram is shown schematically in Fig. 5 to help one in understanding this discustion more easily. Both $E_{*}$ and $E_{k}$ should increase with decreasing period, consequently increasing ho ctrot. as it is obsaryed in this investigation. For the spectril shown in

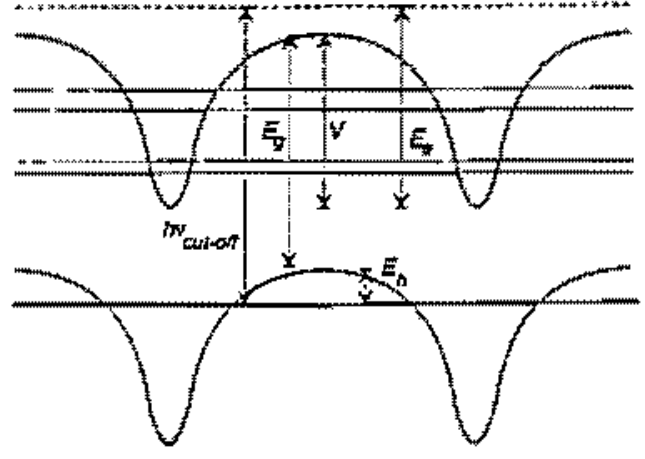

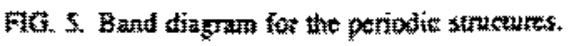

Fig. $4, h v_{\text {sutglf }}$ is between 20 and 57 mev above the near band edge emission. Similar retults have been reported for GaAs. ${ }^{16}$

The cutaff energies from Fig. 4 are plotted as a function of the period in Fig, 6 and are represented by squares. The bethavior of $h v_{\text {cusot }}$ as a function of the period of the superlatuce should follow a $d^{-2 / 3}$ depentence in the case of short periods as if will be shown briow. In this case, the system

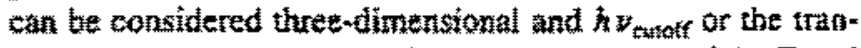
silton cutoff energy is then given by the postiton of the Fermi entegy for he system, which can be writen as:

$$
h v_{\text {cutoff }}-A=\frac{\hbar^{2} k_{F}^{z}}{2 m^{*}}
$$

where $A$ is the energy offset, $k_{k}$ is the Fermi wave vector, and $m^{*}$ is the effective mass. On the other hand, $N^{3 D}$ equals the total occupied yolume in $k m$ spesce $\left(4 \pi k_{F}^{3} / 3\right)$, divided by the volume of each aceupied state, $\left.(2 / 2 \pi)^{3}\right)$. Thus,

$$
N^{3 D}=\frac{4 \pi k_{k}^{3}}{3} \frac{2}{(2 \pi)^{3}}
$$

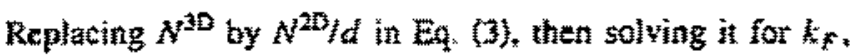
and finally substiuting it in $\mathrm{Eq}$. (2), onte obtains:

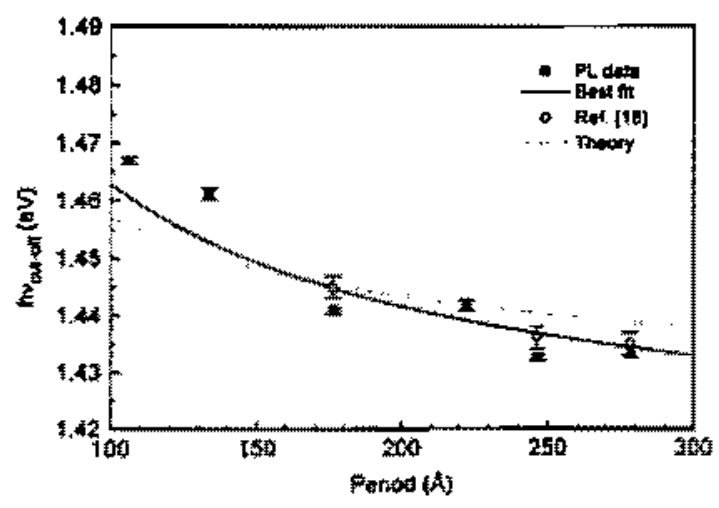

FG. 6. Plot of the cutofl catrgy $h v_{\text {tuth }}$ as a function of the period. The experimenial data repoced nete are represented by $(\boldsymbol{l})$ and the data trom Ref, is are tepsesented by (Q). The solid and dasthed lines represent the

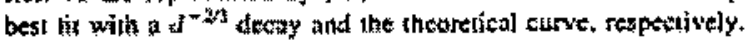




$$
\left.h_{\text {cutofil }}-A \frac{\hbar^{2}}{2 m^{*}} \mid \frac{3 m^{2} N^{20}}{3^{2}}\right)^{2 n}
$$

It should be pointed ont tha the approximation $N^{30}$ $=N^{20}$ Id is only valid for a smaller or equal to the Bohr radius. ${ }^{13}$ which in this tase is 78 . $\mathrm{A}$. Only under this condition can the systern be considered the edirnensional and the Fermi surface is indeed approximately spherical. in tact. it is khown In Raf. 12 that the electran gas is effectively isotropic as it is in bulk nuaterial when the period is of the order of 100 1. The reduction in the period of the superlattice is equiva. lent to an increase in the number of eitectons in a threedintensional system. 1.e., it implies a raste of the Fermi thrgy and consequently an increase of the cutoth entrgy. Simulations of the Pl. spectra for GaAs doped samples showing an energy choif above the energy bata zap of the host matcrial which increases with the decrease in the period have been already reported.

In Eq. (4) all the paraneters, except for the period, are constats for the superfattices investigated, therefore. $h v_{\text {cutont }}$ $=d^{-25}$. This dependence is depicted by the solid curve in Fig. 6. where the constant $A$ and the coefficiemt of $d^{-2 / 3}$ were best fit. The expenimemol data can clesily be fit to a $d^{-2 / 3}$ behavior cyen for periods larger than 80 . On the other hand, the fitting parameters camnot be totally accounted for

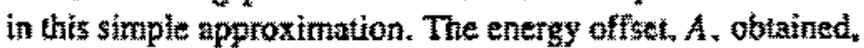
i.e., the entrigy in the limit of $d \rightarrow \infty$, was 1.40 eV at 15 meV below the expected InP band gap at $12 \mathrm{~K}$, postribly diue to band gap renommalization effects. ${ }^{20}$ The coefficient of $d^{-2 / 3}$ obtained in the fitting procedure is $50 \%$ highor than the calculated valtue in Eq, (4). Such slight discrepancy is positively surprising if one considers that the rubstivation of $N^{3 D}$ by

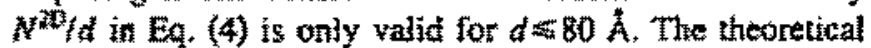
curve whe $A$ is substituted by the InP band $\mathrm{gap}$ and the

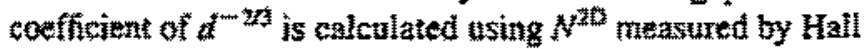
effect is represented in Fig. 6 by the dashed line. The close agrement between the expcrimental waltes and the simple predicted $d^{-23}$ trend indicates that for many purposes and applications such an approximation can be atcurate enough. A more complete and precise modeling of the problem, inclading effects such as band gap renotmaization, for example, is beyond the scope of this paper.

Also inclided in Fig. 6 and reprexented by diamonds are the valutes of the cutof energy as detemined from a combimutton of Shubnikov-de-Hans meazurements and photon energy emission as a function of applied magnetic ficld. This technigue together with som preliminaty results have been published eisewhere. ${ }^{18}$ One clearly cbserves that the bends detemined in this investigation and by the method of Ref. 18 coincide. The energy at which the intensity of the high enw wrgy broad band drops to half of its raximum value was

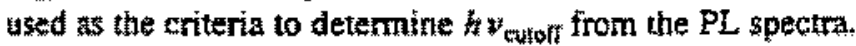
Some atwernatny may be introduced by this choice of crite-

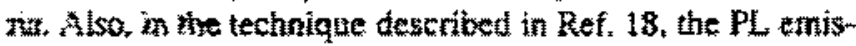
sion intensity as a function of magnetic held is measured for

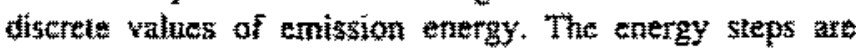
around 2 meV, which should Introtuce an etror in the evaluw ation of the transition calray.

Another important feature which can be noted in the spectra of Fig. 4 is that the high energy band becomes less interse refalive to the near band edge emission as the period of the superathice diminishes. Structures with very large pe. riod, $d m=$, present practically no overiap betwent the clectron and the hole watufunctions. As inc pertod is made shorter, but stall maintaining some deture of a swodimensional tharacter, the localized electun and hole stave functions will gradually overfap increasing the optical transition cross section. On the other hand, if the pertod is turthe reduced, the system moves from a iwomdimensional to 2 three-dimensional situation, where minibands are formed anc the wave functions are spread out. Consequently, the relative intensity of the high energy broad band woutid first increase reaching a maximum for a cotical period. and then, wouk drop as the period is continuousiy reduced. Actording th this, the samples investigated here would belong to the rangr where the systern has already gone through a maximum fo the ufigh energy PL emission relative intensity and it i gradually losing its two-dimensional character as the perios is made shorter. This behavior is consistent with the assump tion used in the previous discussion, namely, that the eiec fron gas is isotropic and that the Edoping superlattice systems investigated have a predominanty thee-dimensiona character. The maximum in the relative intensity of the broas band emistion should occu for a critical period, $d_{x} \leqslant 278 \mathrm{~A}$. This transtion from two-dimenstonal to three-dimensionat behavior bas already been observed for $\mathrm{CaAs},{ }^{\text {ta }}$ A simina yariation of the broad band emission intensity with the period has been predicted in GaAs, ${ }^{13}$ however, in that case. $d_{\leftarrow}$ was found to be between 50 and $100 \mathrm{~A}$. Further investigation is required for a better quantitative understanding of this phenomenon.

\section{IV. conclusion}

A systematic investigation of nobility and photolumi. nescence characteristics of Si Butoped lnP superlattices has been carried out as a function of the period. Samples with 5 and 10 periods have been grown with great uniformity as demontstrated by both $C-V$ and SMMS measurements. $A$ re* dixtion in the mobility with decreasing period of the super. lattices for the same sheet carrier concentration per doping plans has been observed. This effect is qualitatively 2 w. piained by the overing of the elestronic wavefunction with the neighboring doping planes.

The photoluminerecnes spextra for the superiatices in vestigated presented a high energy brotd band whose cutoff energy varies, in a simple approximation, with the period of the stuperatutice as $d^{-2 / 3}$. This behayor can be understowd as the dependence of the fermi level position on the barrier widh for the different sampies. The increase in the intensity of this broad band with increasing period can be qualitatively explained by a two-dimertsional to three-dimensional trans: tion. 


\section{KNOWLEDGMENTS}

Dr. B. Bef from the A. F. loffe Institutes Saint Seters. g, Russia has kindly periomed the SIMS measturntus. is work has been tonacially stipponed by HNEP, PES, CNPA. FAPER, and FAPESP.

E. C. Wood. G. Metze. J. Berty, and L. F. Eustoman, I. Appl. Ptyst. 51, 17 (1)

Bow. M. Hauser, and A. Fishor, Appl. Fhys. A 45, 233 (1988),

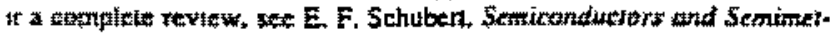

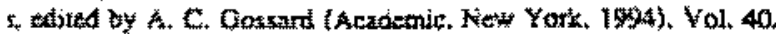

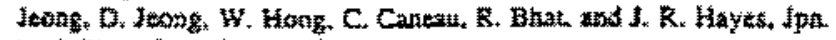
Appl. Foys. 31. LAs (1992).

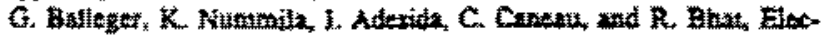

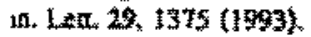

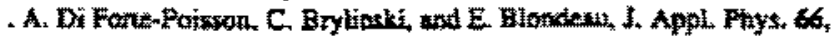
(7) (1989)

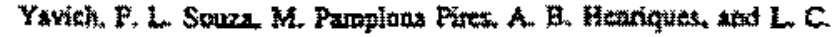

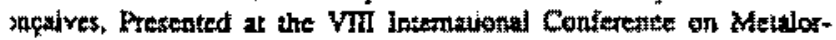
aic Vapor Ptase Eppiaxy, Cardiff, UX, fune 1906: B. Yavich, P. L uxz. M. Pamplone Pires, A. B. Henriques, and L. C. Ciongalves, Semni. 5tit. Tetringi. 12, 481 (1997).

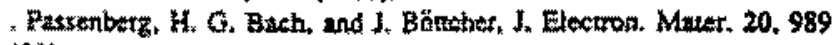
11.

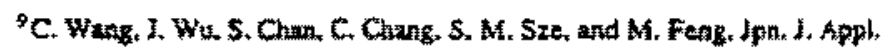
Phy, 34, LII0) (1995).

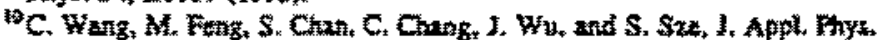
79, 8054 (1)

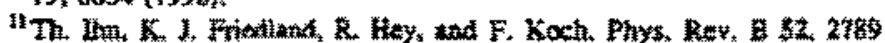
(1995).

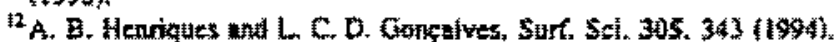

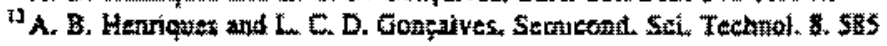
(1993).

14 A, B. Henriquess L. C. D. Gonçaives, P. L. Souza and B. Yaviob, Sezticond. Sei. Tethnol. 11, 190 (1996).

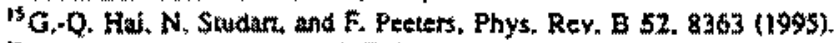

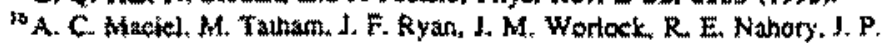

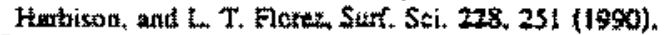

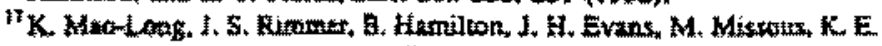

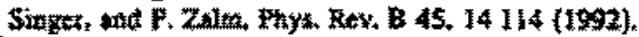

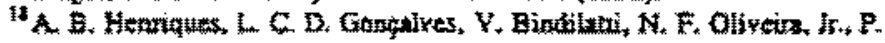

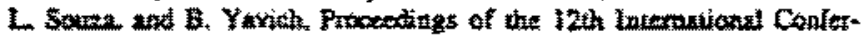

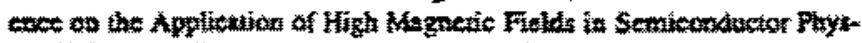

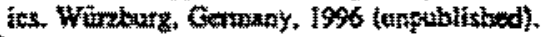

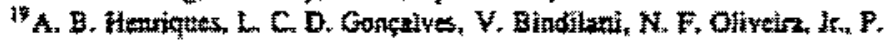

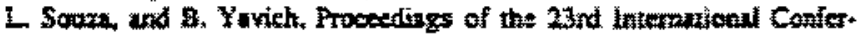

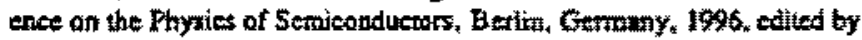

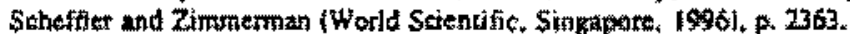

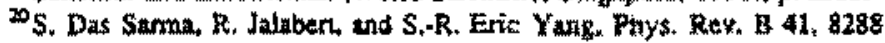
(15\%0). 


\title{
Magnetic Quantum Effects in Degenerate Superlattices
}

\author{
A.B.Henriques" ${ }^{1 *}$ L.C.D.Gonçalves ${ }^{1}$, P.L.Souza ${ }^{2}$, and B.Yavich ${ }^{2}$ \\ It Intituto de Fisica, Universidade de Sấo Paulo \\ Caiso fostal 66918, 05915ng70, sâo Paulo, Brazt
}

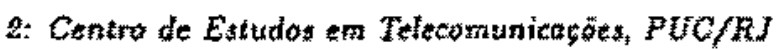

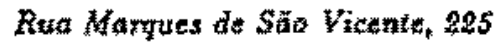

22453-900 Rio de Jenetro, Enzzil

Received Fobruary 2,1997

\begin{abstract}
The denaity of states for an effective mass electron gas confined by a superlattice potential in the presence of a quantizing magnetic field applied patallel to the growth axis was modelled using a tight-binding approximation for the superlattive dispersion. The magnetoostillatory behavior of the density of states the Fermi energy is analyzed. The brosdening of the energy levels due to ionized impurity scattering was calculated using the W.PA for the sereened Coulomb interaction in periodically $\delta$-doped samples, and results support the con* clusion that in such systems only the belly cross sectional areas of the minim Fermi surfate will contribute to magneto-resistance ostillations. The theory is used to interpret experimental results and allows to deduce important sample parameters from the Shubnikov-de Haas experiment.
\end{abstract}

\section{Introduction}

Semiconductor superlattices can be doped with impurities so as to obtain a degenerate system. For stch superlattice it is important to assess the carrier density and mobility, which are crucial parameters in respect to the optical and transport properties of a given sample. Because of the fact that often more than one miniband is populated with carriers, the conductivity takes place in several ninibands, which differ laxgely in mobility, and the interpretation of the classical Hall experiment becomes unreliable. An alternative procedure to characterize the samples is to study their Shubnitov* de Haas (SdH) effect. At low temperatures, degener. ate semiconductor superlattices exhibit an oscillatory magnetoresistance, which encodes such fundarnental information as the carrier distribution among the superlattice minibands and the broadening of the electronic entergy levels which arises as consequence of carriter seattering. For a degentrate system, in a collision-free picture, the magnetoresistance oscillations are periodic if plotted in $1 / 8$ ( $B$ is the intensity of the external magnetic field), and each frequency of escillation, $B_{i}$. is associated with an extremal cross sectional area of the Fermi surface, $A_{i}$, according toll

$$
B_{i}=\frac{\pi}{2 \pi c} A_{i}
$$

Figure 1(a) shows schematically the mini-Fermi surface for a superlatice with two occupied minibands, and E2. The artows show the extremal cyclotron orbits at the Fermi surface for a magnetic field applied along the growth axis, $k$, The fundamental miniband. El, tontains two extzernal cross sections, a belly and a neck. and miniband $E 2$ is described by a single extremal cross section. In this case the Fourier spectrum of the inverse field magnetoresistance should be described by three amplitude peaks, two peaks associated with miniband $E 1$ and a single lower frequency peak associated with miniband $E_{2}$, as shown schematically in Fig. $1(b)$. The miniband structure shown in Fig. l(a) can be attained, for instance, with a superiattice of composition In $s_{1-z} 5 b_{2} / I n S b$ la), for a sample with a Hall mobility of $27,000 \mathrm{~cm}^{2} / \mathrm{Vs}_{\mathrm{s}}$ the Fourier spectrum of the SdH

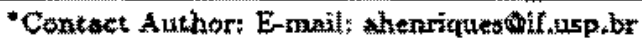


oseillations displays three well resolved peaks: two associated with the miniband $E 1$ and one associated with E2. The same mini-Fermi surface topology of Fig.1(a) can be achieved with semiconductors (GaAs (3) or InP [4] doped periodically with sheets of Si; in this case, however, only two peaks ate seen in the magnetoresistance. The b-doped systems are described by a much lower Hall mobility of about $4,000 \mathrm{~cm}^{2} / \mathrm{Vs}$ due to the efficient scattesing of carriers by fonized impurities. It is well known that in a lower mobility system the SdH oscillations will be associated with broader basds in the Fourier spectrum (5). Therefore the obvious interpretation is that in the periodically $\delta$-doped system, in opposition to the higter mobility lnAs $_{s_{1}} \mathrm{Sth}_{x} / \mathrm{InSb}$ system, as e consequence of the lower mobility, the belly and neck peaks cannot be resolved separately, but instead give rise to a single oscillatory magnetoresistance component. Nevertheless, in order to intexpret quantitatively the Shubnikov-de Hass spectrum, it is required to gain a formal understanding of the effects of broadening of the electronit energy levels upon the magnetoresistence oscillations.
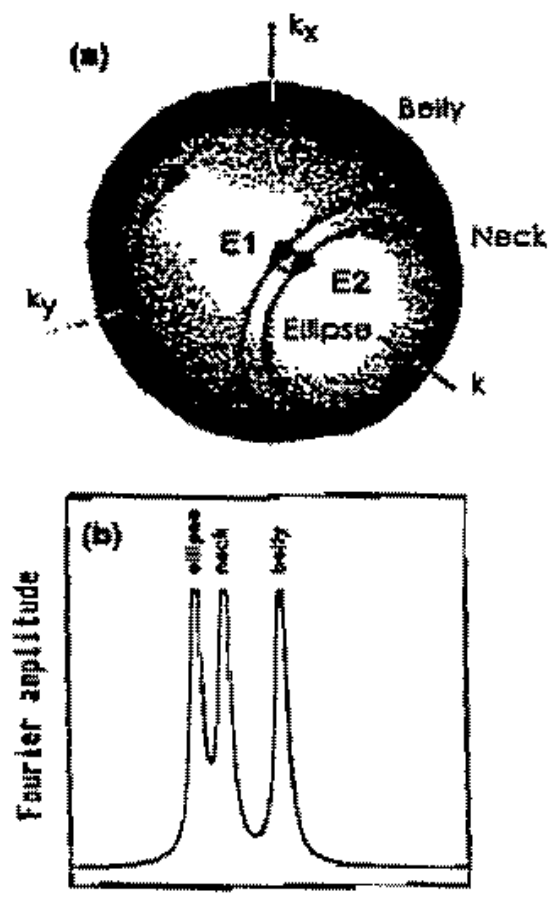

frequenty of oscillation

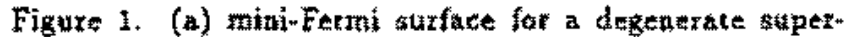
lattice with two pogulated mintbands; atrows sow the extremal cyclatran orbits in $\$-s p a c z$ for 3 magnetic held applited paratel to $k$; (b) Schematic representation of the

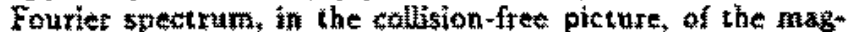
netorestistance ascillations ansociated with a mini- Formi nur face struterure as in $(\mathrm{aj}$.
11. Tight-binding model for the Shubnikov-de Hoas oscillations

We will consider the isolated magnetoresistance contribution from an electronic miniband, described by a dispersion law according to the tight-binding approximation (we use effective atomic units, whereby the unit of mass, distance and entrgy are $m^{*}, a_{z}=t \hbar^{2} / m^{*} \kappa c^{2}$ and $H=h^{2} / m^{\prime \prime} a_{B}^{*}$, respectively)

$$
E\left(k_{1}, k\right)=\frac{1}{2} k^{2}+\frac{\Delta}{2}(1-\cos k t)-k \frac{\Delta}{2}(1-\cos 2 k d)
$$

where $k_{1}$ and $k$ are the wave vector somponents perpendicular and parallel to the growth axis, respectively, $\Delta$ is the width of the miniband, $d$ is the period of the superlattice, and $\dot{t}$ is a small dimensionless constant which is a measure of the amount of serond-neighbor interaction in the tight-binding dispersion law. It readily follows from Eq.(1) that Alled minibands, for which the Fetmi energy $\phi_{0}$ is greater than the miniband width $\Delta$, will be described by a Fermi surfate of the shape of the corrugated cylinder as is the Fermi surface section associated with $E$ i shown in figure 1 (a).

Under an applied magnetic field parallel to the axis of the superlatitice, the ixmplane motion will be quantized fato Landau levels, giving rise to an energy spectrum

$$
\Sigma_{N}(k)=\lambda_{N}+\frac{\Delta}{2}\left(1-\cos (k d)-t \frac{\Delta}{2}(1-\cos 2 k d)\right.
$$

where $\lambda_{N}=B(N+1 / 2), N=0_{1} 1_{1} \ldots$, is the energy of the Landau levels, and the efiects of spin-splitting have been neglected. The density of states can be calculated to give (considering $c=0$ for simplicity)

$$
D(E, B)=\frac{B}{\pi^{2}} \sum_{E} \frac{\theta\left(E-\lambda_{N}\right) \Theta\left(\lambda_{N}+\Delta-E\right)}{\sqrt{\left(E-\lambda_{N}\right)\left(\lambda_{N}+\Delta-E\right)}}
$$

where

$$
\theta(z)=\left[\begin{array}{ll}
1 & \text { if } x>0 \\
0 & \text { otherwise }
\end{array}\right.
$$

is the Heaviside step function. Eq. (1) shows that in the collision-free limit ecla Landau level contributes to the density of states with two singularities at the 
entrgies $\lambda_{N}$ and $\lambda_{N}+\Delta$. In real systems, the Landau levels will be brokdened tue to potential fuctuations, scattering by impuritits, phonons and other seat* teting mechanisms [b], A full calculation of the den-

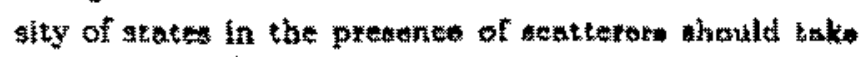
into account the physical nature of the broadening mechanisms, and the absolute value of the level width can be a complicated function of energy (see, for ia* stance, Ref.[7]]. However, as far as the interpretation of magneto-osciliatory phenomena is concerned, the rnain aspect of the broadeaing of the energy levels is that two energy levels can be distinguished only if their energy separation is greater than their level broadening, and this should not be fundamentally dependent of the exact lineshape of the broadeaing function. A simple way to see heuristically the efiect of the broadeaing on the density of states is to assume energy levels described by Lotentzian functions. The ostllatory magnetore sistance contribution from the miniband can then be calculated through [s]

$$
\frac{\Delta p_{x=}}{p_{0}}-\frac{X}{\sinh X} \frac{D\left(\theta_{1} B\right)}{D_{0}\left(\phi_{0}\right)}
$$

where $\phi$ is the position of the Fermi level under an applied magnetic feld, and $X=2 \pi^{2} T / B_{1} T$ is the temperature in units of $\hbar^{2} / k_{B} m^{*} a_{B}^{2}$. By a standard procedure?" me substitute (1) in (2), make use of the Poisson summation formula ${ }^{[0]}$. To take into actount the broadening of the energy levels, the expression obm tained is conyoluted with a Lorentzian function of semlwidth at half-maximum $\gamma$, and the final result is [11]

$$
\begin{aligned}
& \frac{\Delta p_{z=}}{\rho_{0}} \sim-\frac{X}{\sinh X} e^{-\alpha u}\left\{2 J_{0}(\beta u) \cos \omega u\right. \\
& \left.+\$ \in \operatorname{Sm}\left[e^{-i \theta \mathrm{x}} \Phi(1 / 2,2,2 i \beta u)\right] \sin \omega u\right\},
\end{aligned}
$$

where $u=1 / B, \alpha=\pi / \mu_{Q}, \mu_{Q}=1 / 2 \gamma$ is the quantum mobility, $\beta=\pi \Delta$, and $\omega=2 \pi(\phi-\Delta), \Phi(\alpha, \beta, z)$ is the degenerate hypergeometric function.

A Fourier analysis of Eq. $(3)^{[11]}$ shows that in order for the belly and neck frequencies associated with a filled electronic miniband to be resolved as separate peaks, the broadening of the energy levels must be smaller than the width of the miniband. i.e. $\gamma<\Delta$; otherwise, a single magneto-oselllatory camponent will be detected. In the latter case, the exat frequency of magnetoresistance ascillations will depend on the amount of second neighbor interaction, $\xi_{i}$ within the tight-binding model used for the dispersion law.

It should be pointed out that the existence of two magneto-oscillatory components, the belly and neck. san be iraced back to the two Van Hove wingulastitiwn associated with a given miniband, the $M_{0}$ singularity at the miniband threshold and the $M_{1}$ singularity at the miniband top, respectively [12]. Thus, under large broadening conditions, $\gamma>\Delta$, the $M_{0}$ and $M_{1}$ singtwlarities will not be manifested separately in the density of states, hence a single magnetoresistance oscillatory component will be manifested in the Shubnikov-de Haas experiment. Another way of weakening the oscillatory component associated fith the neck orbit is to reduce the energy minigap which separates the top of the miniband from the hreshold of the miniband of higher energy. If such a minigap, which we will denote by $G$. is smaller than $\gamma$, then the Van Hove singulatity $M_{1}$ will be effectively removed, and the magneto-oscillatory component associated with the neck oxit will not manifest itsel experimentelly.

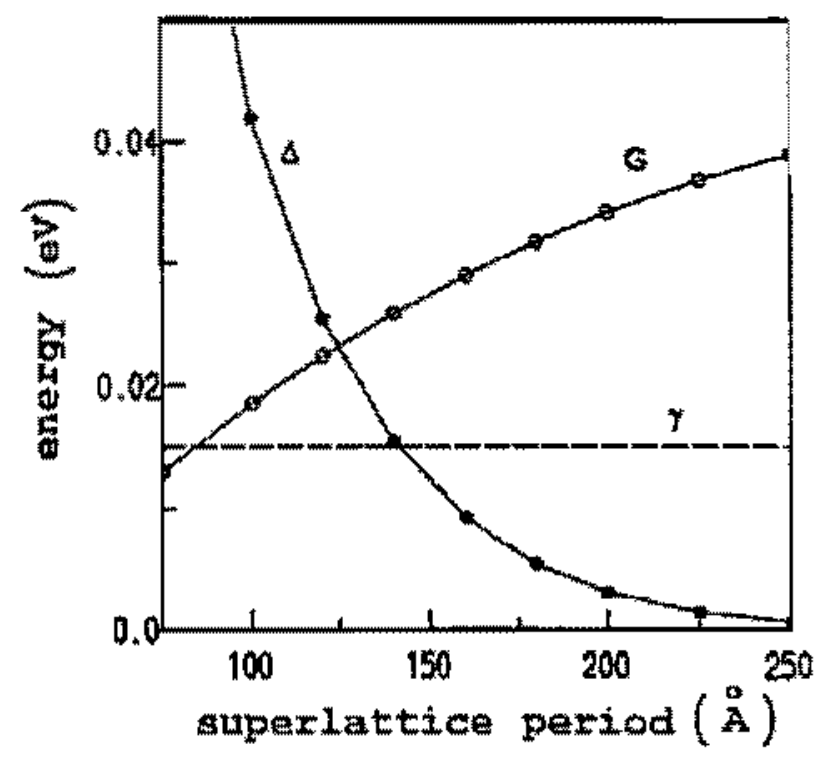

Figure 2. Energy width (A) Eor müband $E$ (full circles).

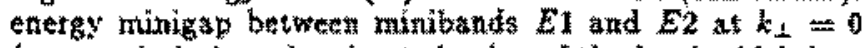
(empty circles), and extimated value of the leyel width in

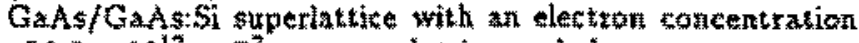
of $2.5 \times 10^{12} \mathrm{cmi}^{-2}$ per superiatitice period.

The conclusion to which we arrive is that the belly and neck orbits will be detected experimentally only if the broadening of the energy leyeis is sufficiently small, i.e $\gamma<\Delta$ and $\gamma<\theta$. Consider the fundamental minihand $E I$ in a periodically deltadoped system, whose

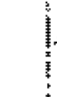


characteristic level width is $\gamma \neq 15 \mathrm{meV}$ in GaAs for a density of irnpurities of $2.0 \times 10^{12} \mathrm{~cm}^{-2}$ per superlattice period [13-15], If we were to detect the belly and neck orbits separately, the doping period of the systam would have to be reduced so as to couple adjacent vells to an exsent whth would make the $E$ l miniband energy width, $\Delta$, larger than 15 meV. However, seltconsistent calculations of the miniband structure [16] show that along with the increase of $\Delta$ there is a decrease of the minigap, $G$, and if $\gamma \sim 15$ meV then the condition $\gamma<\Delta$ and $\gamma<G$ is only tatakly satistied in a auzow range of doping periods $100 \mathrm{~A}<d<150 \mathrm{~A}$, see fiz.2. This makes the perspective of observing the magneto-oscillatory components associated with the belly and neck extremal orbits as separate oscillations in periodically 5 -doped systems tnlikely. In contrast, in compositional superlat tices such as the systern $\operatorname{lnA}_{1-x} \mathrm{Sb}_{x} / \mathrm{InSb}_{1}$ the thickness of the layexs can be chosert so as to incresse $A$ while maintaining $G$ constant, whith justifies the experimental observation of the bally and neck cross sections as separate maznetoosciliatory components in this case.

\section{Mixiband quantum mobilities ta the RPA}

The motel developed for the lineshape of the mag* netoresistance oscillations as a function of magnetic field intensity applied perpendicular to the confining layess, developed in the previous section, relles on the assumption that all of the Fermi energy electronic states of a given miniband are described by a broadening funetion of a fixed semi-width at halfmaximum w. This assumption is useful to give an approximate descrip. tion of the magneto-ascillatory phenornens in degenexate superlattices, however, in reality the scattering probablity of electron from a given quantum state will depend on the wave function of the inithal electronic state. Frorn the theoretictal standpoint, calculations of the widths of energy levess in samples with a single $\delta$-hoped layer has been calculated using either sine Thomas-Fermi model $[\mid 7-19]$ or the tandom phase approximstion (RPA) ${ }^{(18-23)}$ to desaribe the screened interaction between confined cartiers and ionized imputities. The theoretical calculations made in the frame of the RPA show good quantitative agreement with experimental estimates ${ }^{20,24)}$, while the agreement is poorer when a 2 -dimensional Thomas-Fermi model of screening is used (see discussion in Ref.[23]). More recently, a calculation of the electronic mobilities in periodically delta doped samples has been attempted [25]. For the pertodically delta-doped semiconductor, the theoretical quantum mobility calculation is based on the same input quantities as the mobility theory for semiconductors with a single -doped layer, i.e., electronic energy spectum and wave functions, and a model for the screened alectrostatic potential of ionized impurities. The basic novelty is the electronic wave functions, which for a periodically f-doped system describe Bloch states, whereas for a semiconductors with a single $\delta$-layer the ways functions describe state which are spatially localized around the doped layer. Our calculations wert made using the RPA model for the screened Coulomb interaction between carriers and ionized donors; this choice was motivated by the success of the RPA theory in describing the carriet mobility in $\delta$-doped materials with a single 8 -doped layer.

When electrons are confined by a potential which is periodic along one axis (the frowth direction $z$ ), as oceurs in a semikonductor with a periodical deltedopint, the electronic states ate quantized into superlattice rinibands of energies $E\left(n, k_{2}, k\right)$;

$$
E\left(n, k_{1}, k\right)=E_{n}(k)+\frac{1}{2} k_{L}^{2}
$$

where $k_{\downarrow}$ and $k$ are the wave vector components petpendicuiar and parallel to the growth axis, respectively, and $E_{n}(k, z)$ is the miniband dispezsion. In order of increasing energy, we will denote the succession of minibands as $E 1, E 2, E 3, \ldots$ The electronic states corresponding to the energies $E_{n}(k, z)$ are described by the wave functions

$$
\Psi_{n}\left(\bar{k}_{\perp}, k, \vec{p}_{1} z\right)=\frac{e^{i \bar{k}_{L}-b_{k}}}{\sqrt{S}} x_{n}(k, z)
$$

where $S$ is the area of the sample, $\chi_{n}\left(k_{1} z\right)=$ $z_{n}\left(k_{t} z\right) \epsilon^{i k x}$, and $u_{n}(k, z)$ are Bloch functions notmalized to the length of the superlattice. Functiont $\chi_{n}\left(k_{,} z\right)$ are the solutions of the Schrodinger aquation

$$
\begin{aligned}
-\frac{1}{2} \frac{d^{*}}{d z^{z}} \chi_{n}(z)+\left(y_{k}(z)+\right. & \left.z_{s z}(z)\right\} x_{n}(k, z) \\
& =E_{n}(k) \chi_{n}(k, z)
\end{aligned}
$$

where $V_{r s}(z)$ is local density approximation for the exchange-correlation correction to the confining potential, whith was taken to be equal to the form due to 
Zedin and Lundavist $\mid 2$,

$$
V_{s e}(t)=\frac{1}{\pi a F_{*}}\left[1+0.7734 t \ln \left(1+z^{-1}\right)\right)
$$

$a=(4 / 9 \pi)^{1 / 3}, r_{s}=\left[\frac{1}{4} \pi n(z)^{-1 / 3}, x=r_{n} / 21\right.$, ant $V_{n}(z)$ is the self-consistant Hartree potential, which is obtained from s numerical solution of the Poisson tans* tion

$$
\frac{d^{2} V_{g(z)}(z)}{d z^{2}}=4 T\left[n_{d}(z)-n(z)\right]
$$

where $n(z)$ is the density of ionized donor: $n(z)=$

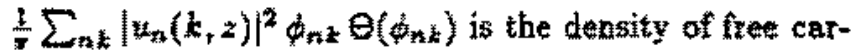
Nitus, $\phi_{n k}=\phi-E_{n}(k), \phi$ denot the Fumi energy and $\theta(x)$ is the Heaviside stop function.

The scattering rate of electrons from a jiven quaw tum state for $T=0 K$ can be obtained from the Fermi golden rule, taking the Coulono interaction betreen dectrons and ionized impurities to be the scattering mechninism. By using the wave functions given by Eq. (4), and conyidering the scattering procses of carriers at the Fermi surface, one obtains for the quantum hetime of the state $k$ of the nth electronic miniband (in atomic uaits, the quantum lifetime equals the quantum mobitity $\mu_{Q}$ ):

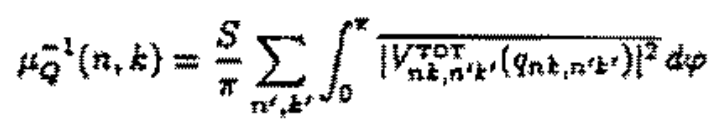

where the summation extends over the quantum states

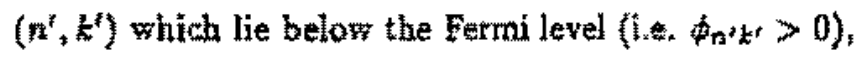

$$
g_{n k, n^{\prime} k^{x}}=2^{1 / 2}\left[\phi_{n k}+\phi_{n^{k} k^{z}}-2 \sqrt{\phi_{n k \phi_{n} k^{k}}} \cos \psi\right]^{1 / 2}
$$

the integration variable $\varphi$ is the angle of scatteting formed between yectors $\vec{k}_{1}$ and $\vec{k}_{\perp,}^{\prime}$ and

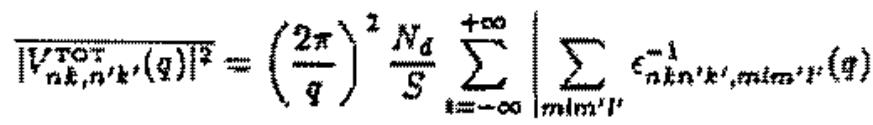

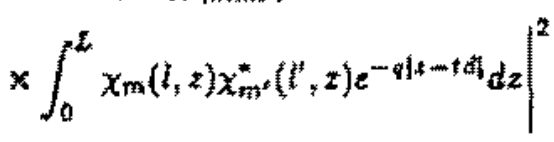

reprents the atatistical average of the matrix elements of the two-dimensional Fourier transiorm of the scat. tering potential. In the latter equation the summation extends over all the electronic energy lutels, $N_{A}$ is tite areal density of single charged tonor atoms in each dop ing period, tistributed along the $z$-direction in a plane of zero thickness; $d$ is the superlattice period, $L=N$ d

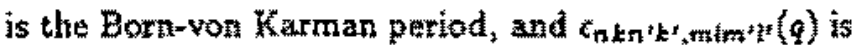
the dieletric matrix hiteh is given by

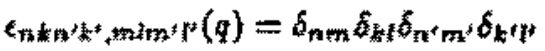

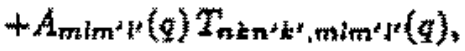

with $A_{m m}$ (n) $(a)$ being the independent response particle density matrix, given in the Appendix of Ref.[27],

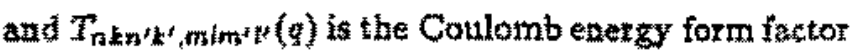

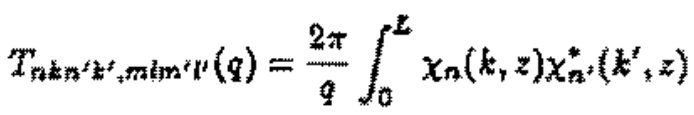

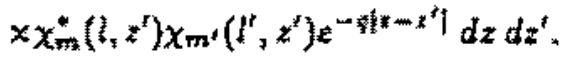

Results of the theotrical calculations reveal[128] that the width of the eneryy levels cortesponding to the neck orbit state fat the extreme of the mini-grillowin zone, $k=$ Th, for miniband $k 1)$ is always greate than the energy width of the levels asscciated with the belly or bit state of the same miniband (at the center of the

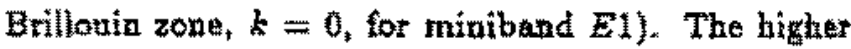
efficiency of the scattering by ionized impurities of elettrons in the neck orbit state is a consequence of to their greater proximity to the shets containing the ionized impurity atoms than ectrons in the belly orbit state. In the prestnt context this ratt implies that the impact of energy level byadening will be greater upon the $M_{1}$ singularity, zather than the $M_{0}$ one. This pro vides atw support to out earlier conclusion (sete prevous settion) that the neck extremat orbit should not manifest itself expeximentally, zherefore the single os clllatory component observed in association with eack superlatice miniband in periodically $\delta$-doped systems should be associated with the cross sectional area emw braced by the belly orbit.

\section{Expeximental}

The $\delta$-doped structures were stown at $640^{\circ} \mathrm{C}$ by L.P-MOVPC in an AIX 200 reactos at 20 mbut with a $\mathrm{PH}_{3}(100 \%)_{\text {. TMIn and }} 1 \% \mathrm{SiF}_{2}$ dilutad in $\mathrm{H}_{2}$. On (100) Fe-doped InP substrates, first a 0.3 um hick undoped buffer was grown, followed by a periodically 3 -doped In $\mathrm{P}$ layex, and finally a $300 \mathrm{~A}$ cap layer mas deposited. The pericdical structutes are composed of either or 10 period: with a spacing varying from 90 to 300 A. The dopant layers were deposited during a 
25 sec growth interruption. The silane fiux was triggered two seconds after growth interruption and halted two seconds before the growth was tesurned.

In order to determine the widuh of the doped layer and the doping period, the capatitance-voltage profile (CV) was measured for each sampie, using an electrochemical profiter PN4300. The Shubnikov-de Elaas experiment was cartied ouk in a supereondueting magnet. The sample was placed in liquid Fe at 4.2K. The ragnetoresistance measurements piere made in constant current mode, employing currents of $\sim 10 \mu k$, and using a four-contact geometry; the arnples were approxim mately square, with contacts in the corners. The magnetoresistance oscillations were measured in magnetic fields of intensity up to $14 \mathrm{~T}$.

\section{Results}

The overall sheet cartier contentration, ns, for each sample was extracted from an analysis of lts Shubnikovm de Haas spectrum. Figure 3 (a) show the magne toresistance spectrum for sample No. 196, and Figure 3 (b) shows the Fourier transform of the SalE oscil lations plotted against inverse field. Prior to taking the Fourier transform, and with the motive of teducing the unwanted background of monotonous magnetoresis tanse, the magnetoresistance curves were differentiated. Each of the peaks sen in Fig. 3 (b) cortesponds to a belly arbit of one of the populated minibands; the peak positions determine the belly extremal cross sectional areas of the minimermi arratuce in units of $n / 2 \pi e$.

To determine ns it was necessary to solve selfconsistently Schrödinger and Poisson equations (Eq. (5) and $\mathrm{Eq}_{\mathrm{q}}(6)$ for for sample. In the calculation, the doping period was fixed at the valne determined by the $\mathrm{OV}$ mensurement, and the $\mathrm{Si}$ stoms were taken to be diatributed according to a Gaustian futation with a full width at half maxirnum of $8 K$ as deduced from the $\mathrm{CV}$ spectrum ${ }^{23 !}$. The only additional parameter in thin calculation, the carriez concentration is, was vasied until all theoretical trequencie of magnetoresism tance oscillation, i.e. thos cortesponding to the belly crosssections of the mini-Fermi surface, approximated simultaneously all of the frequenciea of oscillation seen in the experimental Shubnikov-de Has spectrum. (It should be pointed out that such procedure will incotporate into the final zesult of $n_{5}$ those carriers in the outer minibands with a low density population, which are beyond the sensitivity of the Shubnikoy-de Hass spetrum). The procedure used to determine $n_{5}$ is described in more detail in Ref $\{4\}$. Results of the analysis of the $C-V$ spectra and of the Shubnikov-de Haas oscillations are summarized in Table 1.
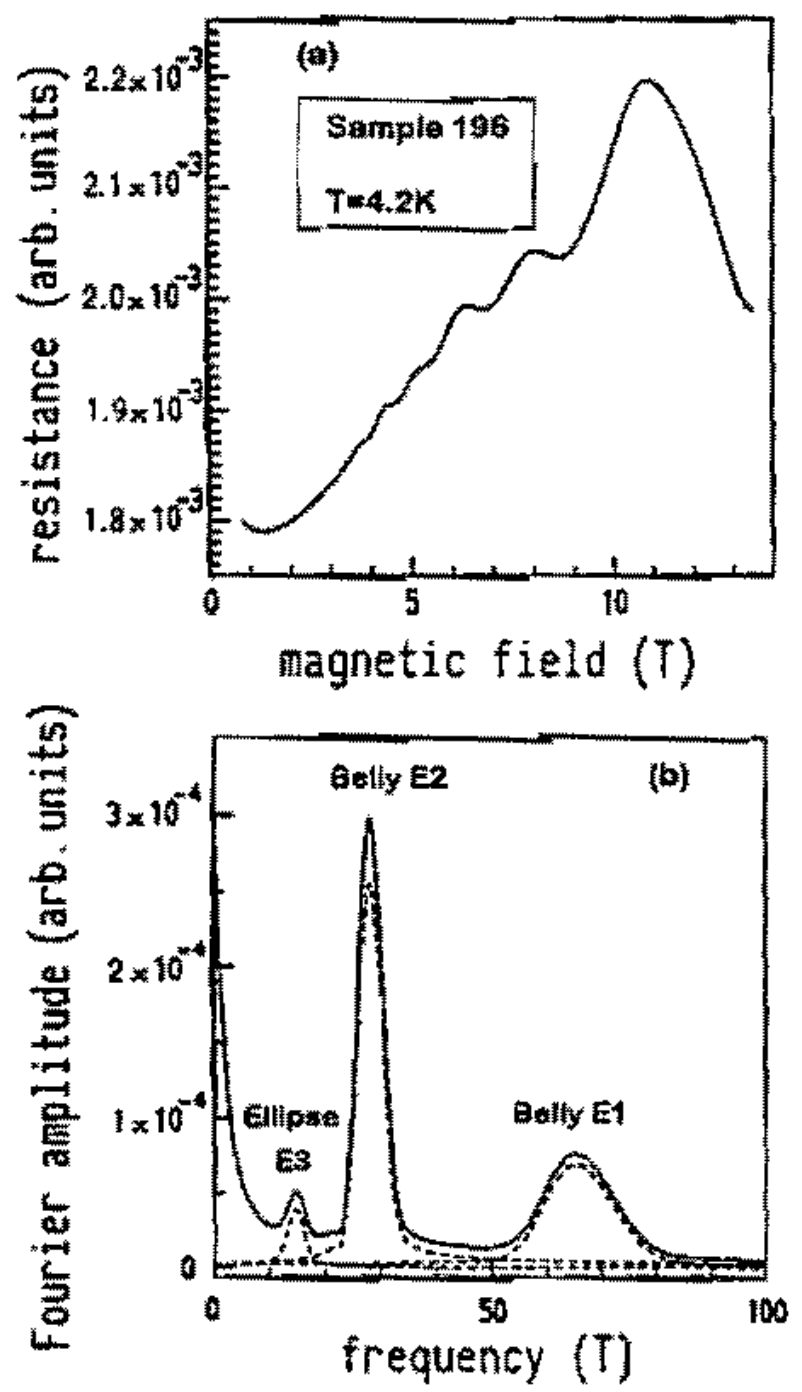

Fiture 3. (a) Stubnikovmde Mads specarum of $3 a m p l e ~ 196:$ (b) Fontier transtarm of the Shubnituovol Has spectrum plotted in $1 / \mathrm{B}$ for wampio 196 . The trequencies of ogrilla. tion assaciated with the belly abits are indicatet. Dashed

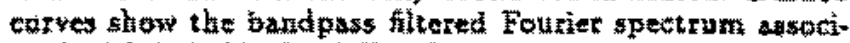
ated whith individuat minitadids.

The very good agreement seen between theory and experiment in Table 1 is an indicasion that the assumption that only belly extremal cross sections of the miniFermi surface can be detected experimentally in period ically $\delta$-doped systems is torrect. Moreover, the same assumption leads to excellent agteenent between the 
experimental and theoretical periods of the magnetooscillatory components for a magnetic field applied at tilted angles respective to the axis of the superlattice $[30,3]$.

Table 1: Parameters of the samples studied. The doping period $d$ was obtained from the $\mathrm{C}-\mathrm{V}$ spectrum of the sample. $B_{E i}^{S d H}$ and $B_{E i}^{T A}$ symbolize the experimental and theoretical frequencies of oscillation associated with the belly orbit in $k$-space. The overall carrier concentration $n_{S}$ shown gives the best agreement of theory with experiment.

\begin{tabular}{|c|c|c|c|c|c|c|c|c|c|}
\hline \multirow[t]{2}{*}{ Sample } & \multirow{2}{*}{$\begin{array}{l}\text { No. of } \\
\text { periods }\end{array}$} & \multirow{2}{*}{$\stackrel{d}{(A)}$} & \multicolumn{3}{|c|}{ SdH Experiment ( $\mathrm{T}$ ) } & \multicolumn{3}{|c|}{ Calculated (T) } & \multirow{2}{*}{$\begin{array}{c}n_{S} \\
\left(\mathrm{~cm}^{-2}\right)\end{array}$} \\
\hline & & & $B_{E 1}^{S C H}$ & $B_{E 2}^{S a h}$ & $B_{E 3}^{S a h}$ & $B_{E 1}^{T h}$ & $B_{E 2}^{T h}$ & $B_{E 3}^{T h}$ & \\
\hline 194 & 5 & 92.0 & 85.5 & 43.1 & - & 86.3 & 42.3 & $=$ & $4.27 \times 10^{12}$ \\
\hline 206 & 10 & 107 & 89.7 & 47.9 & 一 & 90.3 & 48.7 & 一 & $5.08 \times 10^{12}$ \\
\hline 198 & 5 & 128 & 74.9 & 38.6 & - & 75.4 & 40.2 & - & $4.50 \times 10^{12}$ \\
\hline 207 & 10 & 133 & 80.7 & 46.0 & - & 79.2 & 46.2 & 一 & $5.08 \times 10^{12}$ \\
\hline 200 & 10 & 176 & 62.2 & 32.2 & - & 63.8 & 32.4 & 9.1 & $4.27 \times 10^{12}$ \\
\hline 197 & 5 & 225 & 73.7 & 33.8 & - & 73.7 & 34.9 & 17.0 & $5.38 \times 10^{12}$ \\
\hline 199 & 10 & 245 & 73.1 & 25.9 & 11.1 & $\mathbf{7 5 . 6}$ & 27.2 & 11.2 & $5.26 \times 10^{12}$ \\
\hline 196 & 5 & 278 & 65.4 & 28.1 & 15.0 & 68.2 & 28.4 & 15.9 & $4.98 \times 10^{12}$ \\
\hline 164 & single & - & 69.6 & 24.0 & 6.8 & 70.8 & 24.5 & $6 . \bar{T}$ & $5.07 \times 10^{12}$ \\
\hline
\end{tabular}

The quantum mobility associated with each of the populated minibends was obtained from a fit with theory of the minibands' contribution to the magnetoresistance, isolated from the rest of the Shubnikov-de Haas spectrum by Fourier filtering techniques as described in Ref. [25]. The individual oscillations were fitted using equation (3) when the miniband energy width was narrow $\left(\Delta_{n}<\phi_{n}\right)$. Parameters $\Delta_{n}$, $\phi_{n}$ and $\epsilon_{n}$ used in the fitting equation were fixed at the values deduced from the self-consistent calculations, and the temperature was set to $4.2 \mathrm{~K}$ as used in our experiments. The only remaining parameter, $\mu_{Q}(n)$, was adjusted for best agreement with the experiment. To illustrate the fitting procedure, the individual oscillations and the fitted curves for sample 196 are shown in Fig.4; a fit with theory in this case yielded $\mu_{Q}(E 1)=410 \mathrm{~cm}^{2} / V_{s}, \mu_{Q}(E 2)=1320 \mathrm{~cm}^{2} / \mathrm{Vs}$, and $\mu_{Q}(E 3)=3650 \mathrm{~cm}^{2} /$ Vs. All other samples underwent the same treatment, and the quantum mobility values deduced are plotted against doping period in Fig.5.

Experimental results showed that at a fixed doping period the quantum mobility increases with the index of the miniband. The experimental quantum mobilities associated with individual minibands are shown by dots in Fig. 5 as a function of the doping period $d$. At large values of $d$ adjacent wells become uncoupled; the quantum miniband mobilities obtained for sample 164 , which contains a single $\delta$-layer, is plotted in Fig.5 at $d=800 \AA$.

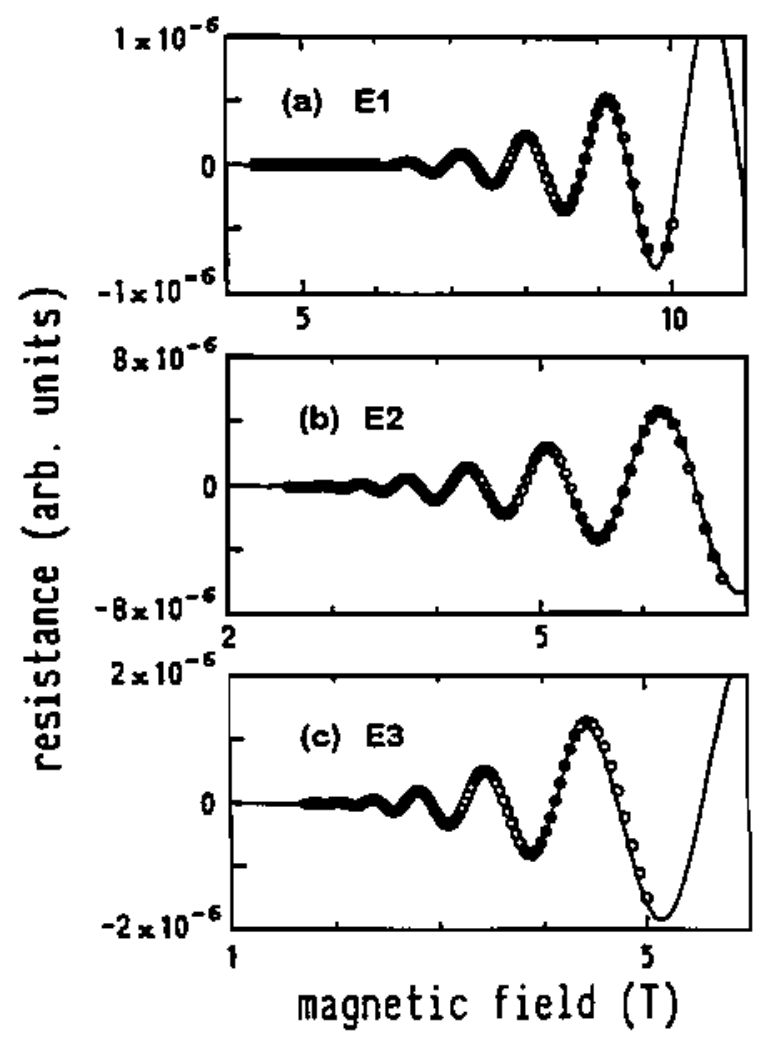

Figure 4. Magnetoresistance oscillations associated with individual minibands for sample 196. Dots represent the oscillations obtained experimentally and the full curves correspond to the theory. (a) Isolated oscillations due to miniband $E l$ and theoretical result by use of Eq.(3); (b) and (c) Same for minibands $E 2$ and $E 3$, respectively. 


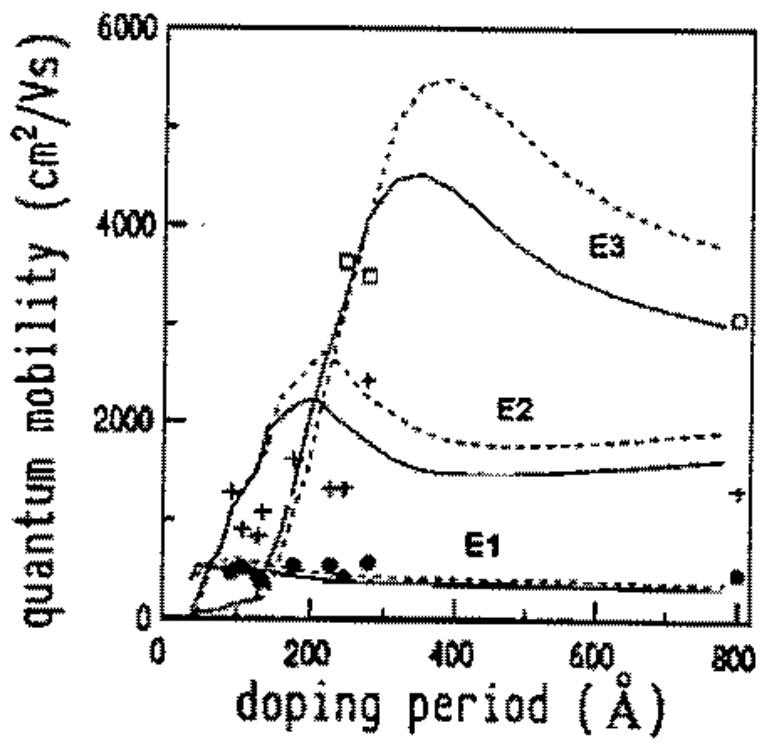

Figure 5. Quantum mobility as a function of the doping pexiod. Circles, crosses and squares reptesent the experimental results corresponding to misibands $E^{2}, E_{w}$ and $E 3$, respectively; dashed and full lines depict the theoretical nesults for $n \mathrm{~s}=4.3 \times 10^{12} \mathrm{~cm}^{-2}$ anta $n g^{3}=5.4 \times 10^{12} \mathrm{~cm}^{-2}$, tespectively.

When the period is made shorter, the mobility it miniband El remains neariy unchanged. The experimental quantum mobility in minibant $E 2$ does not show a smooth dependence on the doping period, which is attributed to the fluctuation in carrier deasity in the samples (see Tabie 1) and to the limited atcuracy of the experimental values of mobility. Nevertheless, the experimental data ploted in Fig.5 shows clearly that in the region $d<200 A$ the $E 2$ quantum mobility do cteases when the doping period is made shorter. Finally, the quantum mobility of catriets in miniband $E 3$ could only be measured for periods greater than $230 \mathrm{~A}$, in which range the measured mobility attains a value of approximately $3500 \mathrm{~cm}^{2} / \mathrm{Vs}$.

\section{v. Conclusion}

A theoretical model for the lineshape of the Shubnikoy-de Haas spectrum in dezenerate semiconductor supeslattices was presented, which allows for at grantitative stimation of the implications of the relstiva absolute valses of the broascriting of the energy levels, miniband width, and energy minigaps. The Shubaikov-de Haas oscillations were measured for penodically 6-doped InP an a funetion of the doping period in samples with a density of carriers around $-4.9 \times 10^{23} \mathrm{~cm}^{2}$ per doped layer and doping period in the range $90-300 \mathrm{~A}$. Each miniband manifests itself in the SaH spectrum through a single cosclilatory conmponent, which can be associated to the belly extremal otbit of its mini-Fermi surface. The quantura oscillations associated with individual minibands ware isolated from the underlying magnetoresistance spectrum by Fourier techniques. From the individual osciliatory componeats, the quantum mobility for each miniband was estimated.

A theory for the quantum mobility in periodically o-doped semiconductors was developed, which yields a fair agrement with the experimental results. The theoretical model predicts tisat the mobilities will increase with the miviband index, and the mobilities decrease when the doping petiod stade shoter. The onset of the decreasing behavior occurs at $d \sim 200 \mathrm{~d}$ for miniband $E_{2}$ and below $d \sim 50$ for miniband $E 1$.

\section{VIr. Acknowledgements}

Calculations were perforned using the facilities of the Laboratorio de Computação Cientifica Avançada da Universtdade de São Paulo (LCCA-USP). A.B.H. ac. knowledges support by FAPESP, Grant Na. $94 / 5645-i$, and $\mathrm{CNPq}$, Grand No. $306335 / 88$.

\section{References}

1. C.Kittel, Qtanium Theory of Solids, Wiley, Hew York (1963).

2. Tan Le, A.G.Vorman, W.T.Yuen, L.Har, I.T.Ferguson, J.J.Harris, C.C.Philips, and R.A.Stradling, Surk Sei, 305, 337 (1994).

3. A.B.Henriques, V.N.Morgoon, P.L.Sonza, $V$.Bindilatti, N.F.Oliveira Jr. and S.M.Shibli, Phys. Rer. B 49, 11248 (1994).

4. A.B.Henriques, L.C.D.Gonçalyes, P.L.Souza and B.Yavich, Semitond. Sei. Technal. 11, 190 (1986).

5. E.Skuras, R. Kumax, R.L.Williams, R, A.Stradling, J.E.Dmocliowski, E.f Johnson, A.Mackinnon, J.J.Harris, R.B.Beall, C.Skirbeszewshi, J.Singleton, P. wan der Wel and P. Wisniewski, Senicondi. Sei. Technol. 6, 335 (1991).

6. E.Gonik, NATO Adunced Siudy Instituts, Seres B: Phystcs 57, Plenum, New York (1987), p.365. 
7. T.Aado, A.B.Fowler, and F.Stem, Rev, Mod. Phys, 54,424(1982),

8. P.T.Coletidge, R.Stoner, and R.Fletcher, Phys. Rev. B 39, 1120 (1989),

9. L.M.Roth and P.N.Argyres, Semicond. Sernimetm als 1, 159 (1966).

10. R.Courant and D. Hzilbert, Methods of Mathematim cal Physics, vol. I, Interstience, New York (1053), $\mathrm{p}, 76^{\circ}$

11. A.B.Henriques, Phys. Rey, B 50, 8658 (1994)

12. G.Bastard, Wave Mechanics Applied to Semiconductor Beterostructures, Les Edations de Physique, Les Ulis (1988).

13. A.B.Henriques, V.Bindilatti, and N.F.Oliveira, 3r. High Mognetic Fields in the Physics of Semim conductors, World Scientific, Singapore (1995), p.804.

14. S.Yamada and T.Makimoto, Appl. Phys. Lett. $57,1022(1990)$.

15. P.M.Kounrad, B.F.A. van Hest, F.A.F.Blom, R. van Dalen, M.teys, J.A.A.J.Perenboom and J.E. Wolter, Physica 177, 480 (1992).

16. A.B.Hentiqutes and L.C.D.Gonçalves, Semicond. Sei. Technol. 8, 585 (1903).

17. O.Mezrin and A.Shik, Superiattices Microstruct. 10, 107 (1901).

18. O.A.Mezrin, A.Y.Shik and Y.O.Mezrin, Semi- cond. Sci. Technol. 7, 664 (1992).

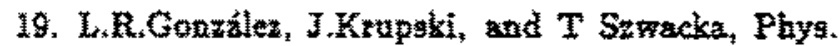
Rev, B 49, 11111 (1994).

20. G.Q.Hai, N.Studart and F.M.Peetets, Phys. Rev. B $52,8363(1994)$.

21. G.Q.Hai and N.Studatt, Phys, Rey, B 52, R.2245 (1994).

22. A.B.Henriques, Phys. Rev. B 53, 16365 (1996).

23. L.C.D.Gonçalyes and A.B.Fenriques, Sernicond. Sci. Technol. 12, 203 (1997).

24. P.M. Koenraad, A.F.W. van de Stadt, J.M. Shi, G.Q. Fla, N.Siudart, P. Vansant, F.A. Peters, J.T. Devreese, J.A.A.J.Perenboom and J.H.Wolter, Physica B 211, 426 (1985).

25. A.B.Henriques, L.C.D.Gonçalves, N.F.Oliveira, Jr., P.L.Souza and B.Yavich, Physical Review B (1997) (at press).

26. L.Hedin and B.Lundquist, J.Phys. C; Solid State Physics 4, 2064 (1971).

27. R.Fletcher, E.Zaremba, M.D'Iorio, C.T.Foxon and J.J.Harris, Phys. Rev. B 41, 10649 (1990).

28. A.B.Henriques (unpublished).

29. B.Yavich, P.L.Souza, M.Pamplona-Pires, A.B.Eenriques and L.C.D.Gonçalves, Semicond. Sci. Technol. 12, 481-484 (1997).

30. A.B. Eenriques and L.C.D.Gonçalves, Surf. Sci. 305,343 (1994). 


\title{
Capacitance-Voltage Profiling of Periodically $\delta$-doped Semiconductors
}

\author{
A.B. Henxiques ${ }^{1 *}$ L.C.D. Gonçalves ${ }^{1}$, P.L. Souza ${ }^{2}$, and B. Yavich ${ }^{2}$

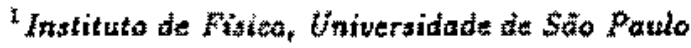 \\ Caixa Postal 68518, OS\$15.\$70, São Palio, Braxi?

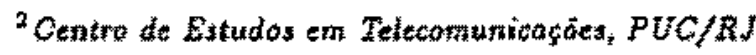

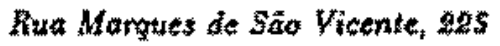 \\ 22452, 200 Aio do laneira, Erazil
}

Received February 2, 1957

\begin{abstract}
The capacitanteroltage (C-V) profiles of periodizally Si- $\delta$-doped InP samples were meav sured, which are described by a succession of equally spared peaks, with a spacing which is nearly equal to the intended doping period. The theoretical $\mathrm{C}-\mathrm{V}$ spectra for periodically Si-b-doped semiconductors were calculated fot various value of $b$-doping datsisity, doping period, density of background impurities and temperature. Analysis of the data indicates that the spacing between the peaks seen in the expetimental C-V spectrum is a reliable measure of the true doping period of the sample. The practical limitations of the G-V technique when applied to perjodically b-doped semiconductors are discussed.
\end{abstract}

\section{Introduction}

The sapastance-voltage (CV) profiling tehnique was originally developed to determine the spatial distrim bution of impuriti in aemiconductor heterojunctions and is describer in steadard textbooks (Bee, fox example, Ref.[1]). The C-V technigite can also be applied to semiconductor systems with quantum-confined carriers $[2,3]$, such as Si-f-doped semiconductors, in which case it is demonstrated that an analyais of the C-V spectrum can be used to determine the localization of the Si impuritien with an aceuracy within the lemgth stale of the lattice constant of the host ctystal [4]. In ordez to obtain a C-V spectrum a nuvetwe bime in applied to tha Schotiky contact made on the aurface of the semitonduetor, and the differential capacitance, $\mathrm{C}$, is meanured by adting a small alternating voltage to the reverse bate Using effetive atomic units, whereby the units of length, energy and mass are the effective Bohr radiut, $a_{B}=\epsilon \hbar^{2} / m^{*} e^{*}$, the effective Hartree, $\hbar^{2} / m^{*} a_{S \text {, }}^{2}$ and the effective Inass, $m^{*}$, respertively, the $C V$ spectum is defined as the plot of the CV concentration,

$$
N_{C V}=4 \pi C^{3} \frac{d V}{d C}
$$

against the CV depth,

$$
z_{C V}=1 / 4 \pi C ;
$$

and for f-doped semiconductors it is desctibed by $\mathrm{s}$ bell-sinaped curve. The physical processes that determine the shape of the C-V spectrum san be understood from a brief discussion. When a revarse bias is applied, electronic charge wansterred from the confining well to the Schottiy contatet. If we take the intensity of the electric field which exists between the Sckottky con" tact and the $\delta$-layer to be of an approximately conmant value, it followa from elementary electrostatice that $x_{C V} \sim L+$ where $L$ is the distance between the surface and the $\bar{c}$-layer and $\bar{z}$ represents the position expectation value of the electronic charge. Thetefore the fuactional dependence of $N_{C V}$ on $z \mathrm{CV}$ can be approximate by $N_{C V} \sim d V / s a c v$, and the shape of the $C V$ gpectrum will be determined by the dependence of $d \bar{z} / d V$ on the bias $V$. At small values of $V$,

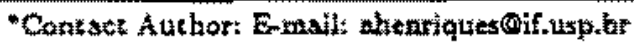


increases rapidly due to the contributions from high enargy subbands, which are described by a large bind. ing length, and ate very sensitive to the intensity of the external electric field. At intermediate values of $V_{*}$ only subbands which are strongly bound to the s-layer remain populated, and the dependence of $z$ on $V$ becomes weaker. Finally, at still larger values of $V$ the binding strength of the confining potential vanishes, meaning that $\bar{z}$ will again increase rapidly with $V$. Such ateplike dependence of $z$ on $y$ leads to a bell-shaped $C-V$ spectrum. The width at half maximum of the $\mathrm{C} V$ spectrum will be proportional to the width of the voltage step, $\Delta V$, in which the intermediate bias regime is fuifilled. For broad $\delta$-layers, $\Delta V$ is larger than for narrow ones, given that for a broad $\delta$-layer the confining $\delta$ well is wider, hence there are more electrons occupyin high energy subbands, meaning that a larger bias will be required to achieve the intermediate regime than for narrow b-layers.

It follows that the width of the $\mathrm{C}-\mathrm{V}$ spectrum of a o-doped semiconductor refiects the localization of the impurities in the f-layer. If the density of impurity atoms is known, the width of the s-layer can be timated by calculating self-consistently the theoretical C.V spectrum [4]. In such a calculation, the width of the clayer is a variable input parameter; the true wionth of the o-layer is taken to be equal to the pararneter value which ladis to a theoretical $\mathrm{CN}$ spectrum in best agreement with the experimertal one $[5,6]$.

In this wotk we extend the C-V spectrm analysis to periodically b-doped semiconductots. The CVV spectrum was measured for pexiodically Si 5 -doped InP, and ostillntions are sean whose pexiod are very nearly equal to the inteaded doping period. Theoretical $\mathrm{CW}$ specter for various doping densities and dopiag petiods were calculated, showing that the period of the oscillations sare an accurate messure of the doping periodicity. The effects of tempezature and presence of background impurities upon the theoretical CV spectrum were also sorditad.

\section{Experimental}

The $\delta$-doped InP structures were grown at $640^{\circ} \mathrm{C}$ by LP-MOVPE in an AIX reactor at 20 mbar with a growth rate of $4.5 \AA / \mathrm{sec}$. The source materials were
$\mathrm{PH}_{3}(100 \%)$, TMun and 10 of $\mathrm{SiH}_{4}$ diluted in $\mathrm{H}_{2}$. The total flow rate, the TMin mole fraction and the V/III fow ratio used were $7 / \mathrm{min}, 2.5 \times 10^{-6}$ and 360 , respectively, On (100) Fe-doped InP substrates, first a $0.3 \mathrm{~mm}$ thich undoped buffer layer was grown, followed by a periodical deposition of 8 -layers, and finally a 5 ton cap layer was deposited. The periodical structures were composed of 5 periods with a nominal batIier thickness of 280,250 and $100 \mathrm{~A}$. C-Y spectra were messured at room temperature using an electrochemical profiler PN4300 where a Schotky contact is formed between the electrolyte (HCl-0.5 mol). The density of Si impurities in each b-layer was approximately equal to $4.5 \times 10^{12} \mathrm{~cm}^{-2}$ in all samples, as estimated fron Shubnikov-de Haas measurements [7].

\section{Results}

Fig. 1 shows the experimental $\mathrm{C}-\mathrm{V}$ spectra for the three samples studied. The $C-V$ spectra are described by a set of peaks with a constant spacing which is approximately equal to the nominal spacing between the $\delta$-layers. Note also that when the spacing between the $\delta$-layers is made shorter, the peaks seen in the $\mathrm{C}$-V spectrum are less well resolved.

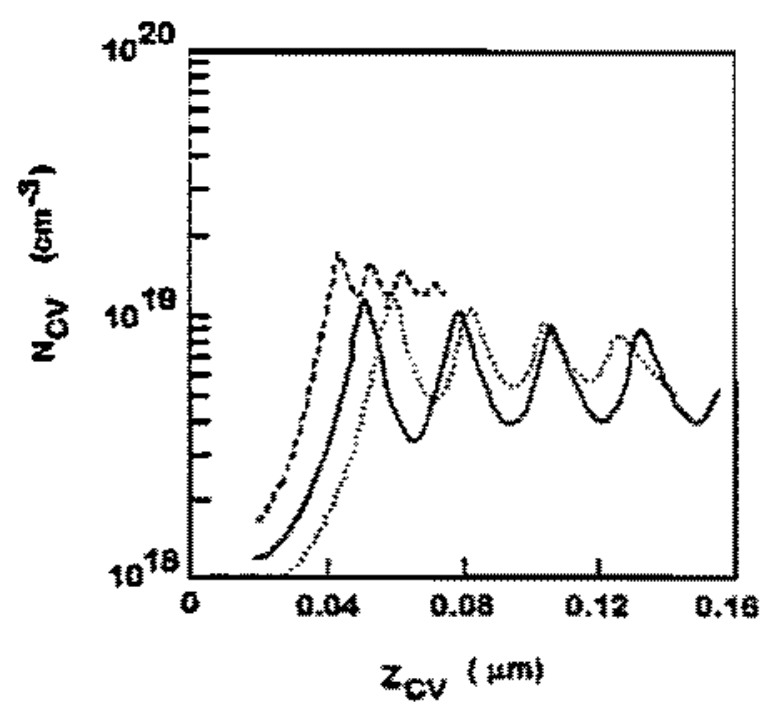

Figure 1. Expeximental C-V apectra of the pericedteally

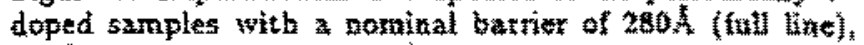
250) (dotned line) and 100. (dabked line).

To interpret the expezimental CV spectra, the oretical C-V spectra were generated by solving seliconsistently Schrödinget and Poisson tquations for the $\delta$-doped structure under bas (for a full description 
of the self-consistent procedure see Ref.[8]). We considered a structure with 5 equally spaced doping layers, and 25 electronic subbands were included in the calculations. The impurities were assumed to be distributed according to a Gaussian function; the width of the doped layer was fixed at the vaiue of 0.2 ag (approximately $15 \AA$ for $\operatorname{In} \mathrm{P}$ ). The input parameters in the calculations were the doping period $d$, the areal density of impurity atoms in each doping layer, $N_{d}$, the volume density of background acceptor impurities, $\Lambda_{a}$, and the temperature of the structure. The diferential capacitance was calculated by using equations $(1 a, 1 b)$.
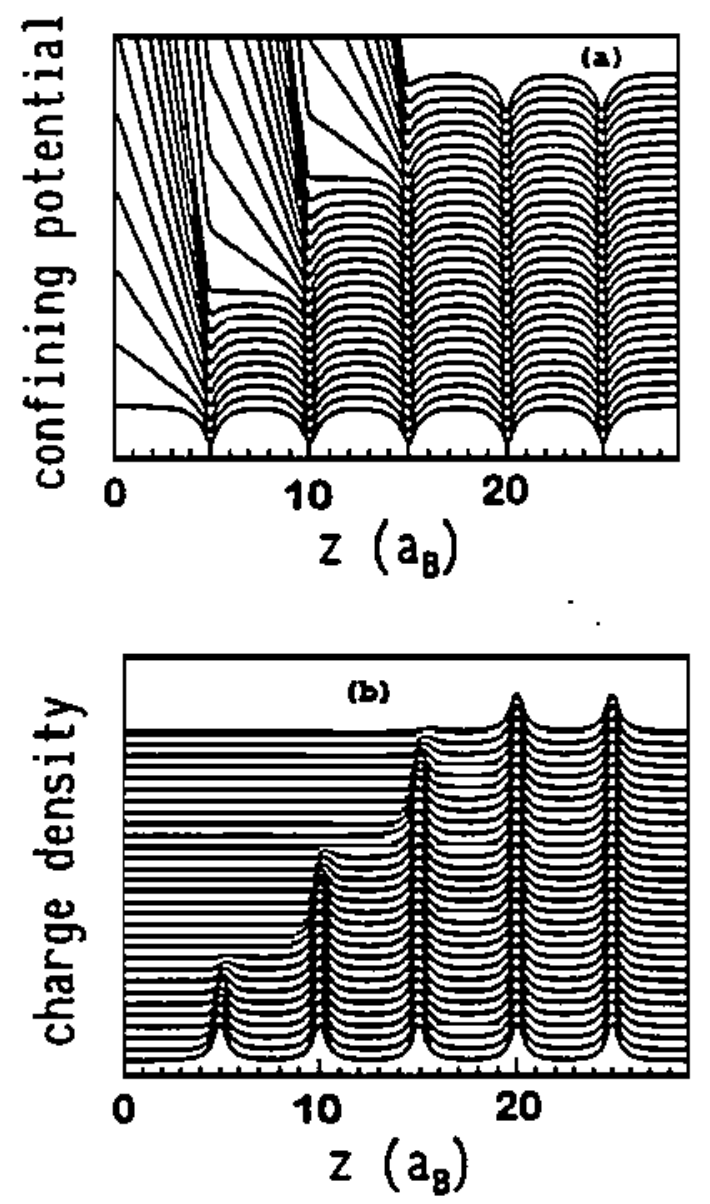

Figure 2. (a) Dependence of the self-consistent confining potential of a periodically $\delta$-duped semiconductor on the bias applied; the lowest curve corresponds to zero-bias and the uppermost curve corresponds to maximum reverse bias. The parameters were fixed at $N_{d}=8.0 a_{B}^{-2}, d=5 a_{B}$ and $\mathrm{T}=300 \mathrm{~K}$. The Schottiky contact is located at $z=0$; (b) Same dependence for the electronic charge density confined is the structure.

Fig. 2 shows the confining potential and electronic charge distribution, obtained from the self- consistent solution of Schrodinger and Poisson equations as a function of aplied bias for a periodically $\delta$-doped structure with parameters $N_{d}=8.0 a_{B}^{-2}\left(1.3 \times 10^{13} \mathrm{~cm}^{-2}\right.$ for $\left.\operatorname{InP}\right)$, $d=5 a_{B}(390 \AA$ for $\mathrm{InP}$ ) and $\mathrm{T}=300 \mathrm{~K}$. Fig. 2(a) and 2(b) show that, when the applied bias increases from zero, the semiconductor structure is progressively depleted. Notice, however, that the applied bias depletes first the $\delta$-well nearest to the suriace; the next well starts to be depleted only when the first well has been completely depleted of carriers. This suggests that it will be possible to approximate the $\mathrm{C}-\mathrm{V}$ spectrum of a periodically $\delta$-doped semiconductor by the superposition of $\mathrm{C}-\mathrm{V}$ curves associated with independent single $\delta$-doped structures, with $\delta$-layers located at distances $L, L+d, L \div 2 d, \ldots$ below the surface of the sample.

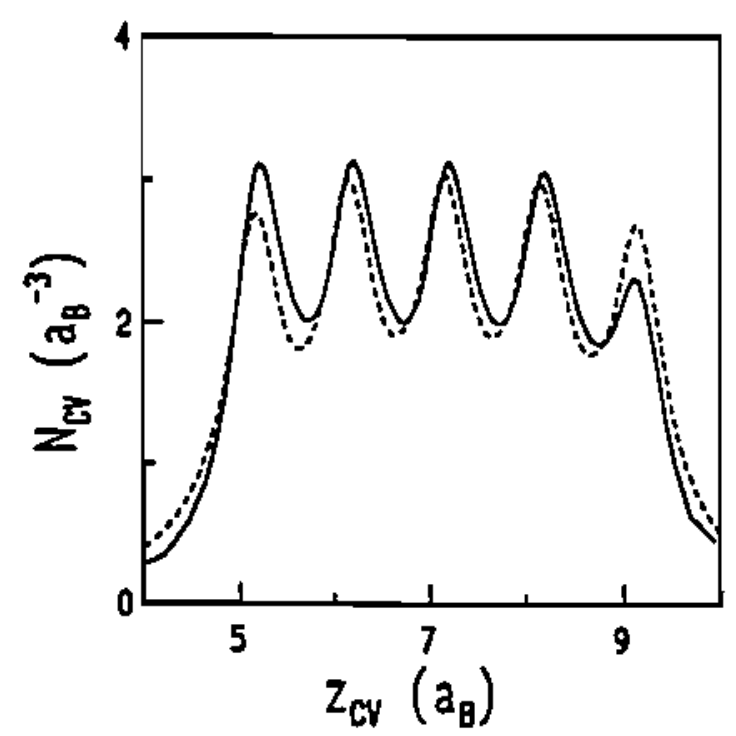

Figure 3. Calculated CV spectrum of a periodically $\delta-$ doped sample with parameters $d=a_{B}$ and $N_{d}=2.5 a_{B}^{-2}$ at $300 \mathrm{~K}$ (full curve). The dashed eurve represents the linear combination of theoretical C.V curves, associated with single $\delta$-doped samples with the same parameters, but with the $\delta$-layer located at distances $L, L+d, \ldots$ below the surface.

In order to test whether this assertion is valid for periodic structures with a strong coupling between adjacent welis [9], the C.V spectrum of a structure with a shorter period and lower doping density, $d=a_{B}$ and $N_{d}=2.5 a_{B}^{-2}$, was calculated and it is shown in Fig. 3 . Also shown in Fig. 3 by the dashed line is the C-V spectrum obtained from the superposition of $\mathrm{C}-\mathrm{V}$ curves associated with a single $\delta$-layer located at $L, L+d$, .... The similarity between the full and dached curves in Fig. 3 is striking. This leads to conclude that the doping period inferred from the $\mathrm{C}-\mathrm{V}$ spectrum will be equal, within a very good approximation, to the doping period of the structure, even in the limit of short-period 
periodically o-doped semiconductors. If the spacing betwen impurity layers is larger than the full width at balfmaximum (FWHM) of the C $\mathrm{V}$ peak associated with each single 6 -layer, than the $\mathrm{C}-V$ spectrum of the periodic structure will be described by a succession of pexals, the spacing becween which is an accurate meat sure of the doping period $d$. In opposition, if $d$ is less than FWHM, individual peaks will bot be tesolved.

To study the effect of temperature upon the $\mathrm{Cr}$ spectrum, it was calculated for a structure with o very short doping period, $d=0.5 a_{s}$, for $T=10 \mathrm{~K}$ and $\mathrm{T}=300$ K. Results are shown in Fig.4. It ean be seen that the spectrum calenlated for $\mathrm{T}=1 \mathrm{OK}$ presents distinct oscillations, whereas the oscillations are smeated out for $T=$ $300 k$. The explanation for a loper resulution at a higher ternperature lies on the fact that whes the temperature is increased, higher energy subbands become populated with electrons, which, by the reasoning exposed in section I leads to broader C.V peaks.

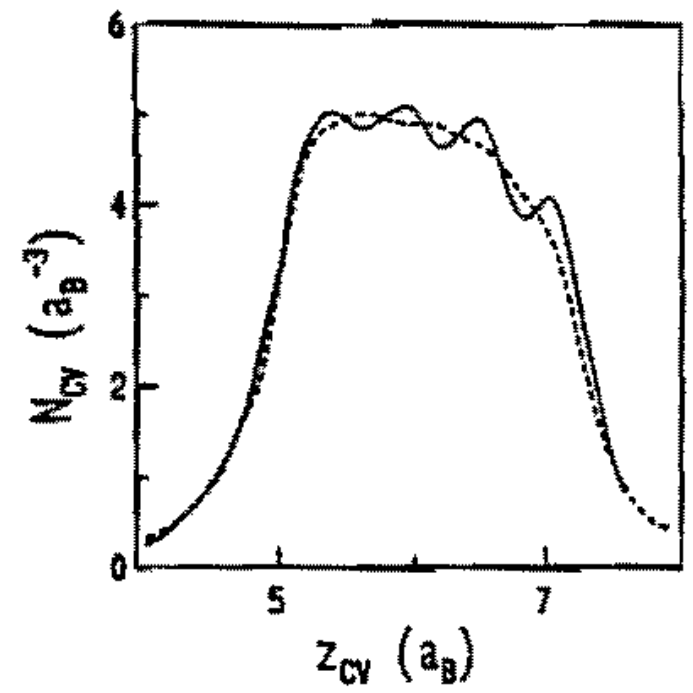

Ejgure 4. Calculated Cy spectrum of a periodically s-

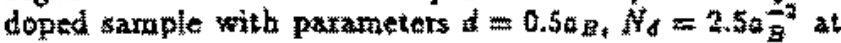
10\% (inll curve) and 300K (dashed carve)

Finally, we considered the efferts upon the shape of the $\mathrm{C}-\mathrm{V}$ spectrum which arise from the presence of background ionized acreptor imputities, unformly diswibuted in the 8 -doped semiconductar structure with a deasily $N_{a}$. The C $V$ spectrim was calculated for a structure with $N_{A}=8 a_{B}^{-2}$ for $N_{a}=5$ and $N_{s}=$ $10^{-4} a_{b}{ }^{9}\left(2.1 \times 10^{14} \mathrm{~cm}^{-3}\right.$ for InP). The spectrum cal. culated for the structure at $300 \mathrm{~K}$ was almost identical for both background impurity eoncentrations, whereas it was slightly sharper if the temperature of the structare was assumed to be $10 \mathrm{~K}$.

IV. Concluston

It was shown that the $C-V$ technique can be used reliably to determine the distance between impurity layers in periodically -doped semiconductors. The $\mathrm{CV}$ spectum of the periodical system can be described, to a very good approximation, as a linear combination of CV curves associated with a sequence of independent single 8 -doped samples in which the depth of the doped layer is increased by the distance between the impurity sheets. The CV techrique can be useful to determine the doping period only as long as the doping pariod is larger than the FWHM of the C.V spectrum associated with an individual impurity layer. Thermal effects were studied and show that the C-V peaks become broader when temperature is increased. The presence of background impurities has only a minor effect on the shape of the C-V spectrum, and should have a practical meaning only at low temperatures.

\section{References}

1. \$.M. Sze, Physics of Semiconductor Dewates, Wi[ey, New York (1980).

2. P. Blood, Semicond.Sci. Technol, 1, 7 (1086).

3. H. Kroemer, Wu-Yi Chien, I.S. Harris and D.D. Edwall, Appl. Phys. Lett. 36, 295 (1980).

4. B. Utrich, E.F. Schubert, J.B. Stark, and J.E. Cunningham, Appl. Phys. A 47, 123 (1988).

5. E.F. Schubert, Semicond. Semimetals 40, 1 (1994).

6. B. Yavich, P.L. Souza, M. Pamplona-Pires, A.B. Hentiques and L.C.D. Gonģalves, Semicond. Sci. and Technol, Letter to the Editor, (at press).

7. A. B.Henriques, L.C.D. Gonçalves, N.F. Oliveira, J., B.L. Souza and B. Yavich, Physical Review B (at press).

8. L.C.D. Gonçalyes and A.B. Hentiques, Semicond. Sti. Technol. (at press).

9. A.B. Hentiques and L.C.D. Gonçalves, Surf. Sci. 305,343 (1994). 


\title{
Characterization of periodically $\delta$-doped semiconductors by capacitance-voltage profiling
}

\section{C D Gonçalvest, A B Henriquest, P L Souzaț and B Yavichł}

Insituto de Fisica Universidade de S落o Paulo, Caixa Postal 66318, 05315.970 Săo Paulo, Brazil

1 Centro de Estudos en Tolecomunicaços. Pontificta Universidade Católica, Rua Marques de Sấo Vicente, 225 t253-900 Fio de Jantito, Brazil

Fectived 20 May 19s7, in final form 25 July 1997 , accepted for publication 5 Augusi 1997

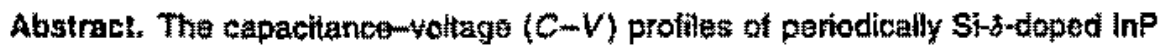
samples were measured, and these are doscribes by a succession of equally spaced peaks, with a spatiol periodicity which closely matches the intended toping period. Theoratical $C-V$ spectra for periedically $S j-\delta$-doped semiconductors ware calculated. Analysis of the data indiwates that the spacing between the peaks soun in the axpentmental $C-V$ spactum is a reliable measum of the true toping period of the sampte. The $\mathrm{C}-\mathrm{V}$ spectum of the periodically s-doped semiconductor is well approximated by a linear combination of $c-v$ curves tor isolated sudoped layers located at successive positions of analogous layers in the periodically z-doped sample. The practical limitations of the $C-V$ technique when applied to periodically toped semicontuterors are discussed.
\end{abstract}

\section{Introduction}

The capncitance-voltage (C- $\nu$ ) profiting techntque was originally developed to determine the spatial distribution of impurtites in semiconductor heterojunctions and is describut in siandard textbooks (see, for example, [1]). The $C-V$ technique can alse be applied to semiconductor systems with quantumeconfined cartiers $[2,3]$ such as $\delta$ doped semiconductors, in which ease it is demonztrated that an analysis of the $C_{-m} y$ spectrum can be used to atemine the localization of the impurtites in the $s$ layer with an accuracy within the lengit seale of the lattice constant of the host crystal [4]. In order to obtain a $C-V$ spectrum a reverse bias is applied to the Schotlky contact made on the surface of the semiconductor, and he differential capacitance, $C$, is measured by adding a small altemating voluge to the reverse bias. Using effective atomic units. whereby the units of length. energy and mass are the affective Bohr radius, $a_{b}=\in h^{2} / m^{*} z^{2}$, the effective Harme aphoximation, $k^{2} / m^{*} a_{g}^{2}$ and the effective mass. $m^{*}$, respectiwely, the $C-V$ spectrum is defined as the plot of the $C-V$ concentration

$$
\hat{N}_{C v}=4 \pi C^{3} \frac{d v}{d C}
$$

against the $\mathrm{C}-\mathrm{V}$ depth

$$
z c y=1 / 4 \pi c
$$

and for 5 -doped semiconductors it is deseribed by a bellw shaped aurve. The physical processes that determine the shape of the $C-Y$ spectrum can understood from a brief discussion. When a reverse bias is applied, tectronic charge is transferred from the conting well to the Sehouky conact. If we take the intensity of the electric ficld which exists between the Schotky contact and the $\delta$ layer to be of an approximately constant value, it follows from elementary electrostatics that $z c y+L+w_{3}$ where $L$ is the distance between the surface and the layer and $\bar{z}$ reprextents the position expectation value of the electonic charge, mescated from the centre of the o layer. Therefore the shape of the $C-V$ spectrum will be determined by the depentience of $\mathrm{d} z / \mathrm{d} V$ on the saias $V$. Al stanl values of $V, \bar{z}$ incretses rapidy due to the contributions from high" metrgy subbands. which are described by a large tinding length and ato very sersitive to the intensify of the anternal electric ficld. At intermedtate values of $V$, only subbands whith are strongly bound to the $\delta$ layer remain populated, and the dependente of $\bar{z}$ on $V$ becomes weaker. Finally. at still larger yalues of $V$ the binding strengh of the

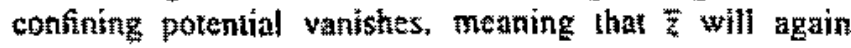
increase rapidly with $\psi$. Such a step like degendence of $z$ on $V$ leads to a bell-shaped $C-V$ spetrum. Since cbanges in $z$ are moch smailer than $t$, the position of the $C-V$ peak will approximate the distance from the surface to the S-toped plane. As shown by Schuber, the widh of the $C-V$ peak measures the spatial exten, $\Delta z$ z, of the singlew purticle wavefunction of the ground state. Since $\Delta z z_{1}$ 
depends on the width of the $\delta$ layer, it follows that the withl of the $C-V$ speetram of a $\delta$-doped semiconductor reterts the localization of the impurities in the stayer. If the areal densiyy of impurity atoms is known, the with of the 8 laysy can be zstimated by calculating sclif-consistenty In theoratical $C-V$ specirum 4 , In such a ealculation, the with of the a layer ts a vatable input parameter: the true wick of the s layet is taken to be equal to the parameter value which leads to theorelical $C-Y$ spectrum in best agrement with the experimemal one $[5,6]$.

In this work we extend the $C-V$ spectrum analysis to periodicilly dodoped semiconductors. The $C-Y$ spectrum was measured for periodically Si-diboped InP, and oscillations are seen. Theoretical C-y spectra were calculated. demonsuating that the periods of the oscillations seen experimentally are an accurate measure of the doping periodiciry. We atso study the range of sample parameters (doping level and period) in which the C.M (ochnique is useful to measure the doping period $d$.

\section{Experimental details}

The 8 -doped InP structures were grown at $640^{\circ} \mathrm{C}$ by metaloxide yapour phase epitaxy (LP.MOVPE) in an AIX reactor at 20 mbar with a growth rate of $4.5 \AA \mathrm{s}^{-1}$. The source materials were $\mathrm{PH}_{3}\left(100 \%\right.$ ). TMin and $1 \%$ of $\mathrm{SiH}_{4}$ diluted In $H_{2}$. The soial fow rate, the TMln moie fraction and lie VIII fow ratio used were 7 i min' $2.5 \times 10^{-1}$ and 360 respectively. On (100) Fexdoped Inp substrates, first a 0.3 an hick undoped butfer layer was grown, followed by a periodical deposition of $\delta$ layers, and finally a 550 A cap layer was deposited. The periodical strutututes were composed of five equally spact o layers with a nominal barice thickness of 280,250 and $100 \%$

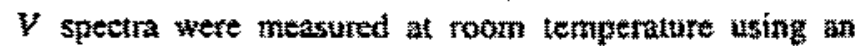
electrochemical profiler PN4300 where a Schothy contact is fomed between the semiconductor and the electrolyte (HCl-0.5 mol). The density of Sil impuritim in each layer was approximately equat to $4,5 \times 10^{12} \mathrm{~cm}^{-2}$ in all sumpies,

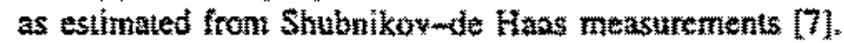

\section{Results}

Figure I shows the expermentel C-M ppecto for the the simples studied. The $C-V$ spectra are described by a sel of peaks with a constant spacing which is approximately equal to the nominal spacing belween the $\Delta$ layers. Note also that when the spacing between the lnyers is made shorter. the poaks swen in the $C$ - $y$ spectrum are less well resolved.

To interpret the experimental $\mathrm{C}-\mathrm{V}$ spectra, theoretical $C-V$ spectra were generated by solving self-consistently Schrödinger and Poisson equations for the d-doped structure under bias for a full description of the self-consistent procedure see [8]). We considered a structure with five equally spaced doping layers, and 25 electronic subbands were included in the calculations. The inpurities were astamed to be distributed aceording to a Gatssian function: the whth of the doped layer was fined al a value of $0.20_{0}$ (approximately $15 \mathrm{~A}$ for InP). The inpul paramelers in

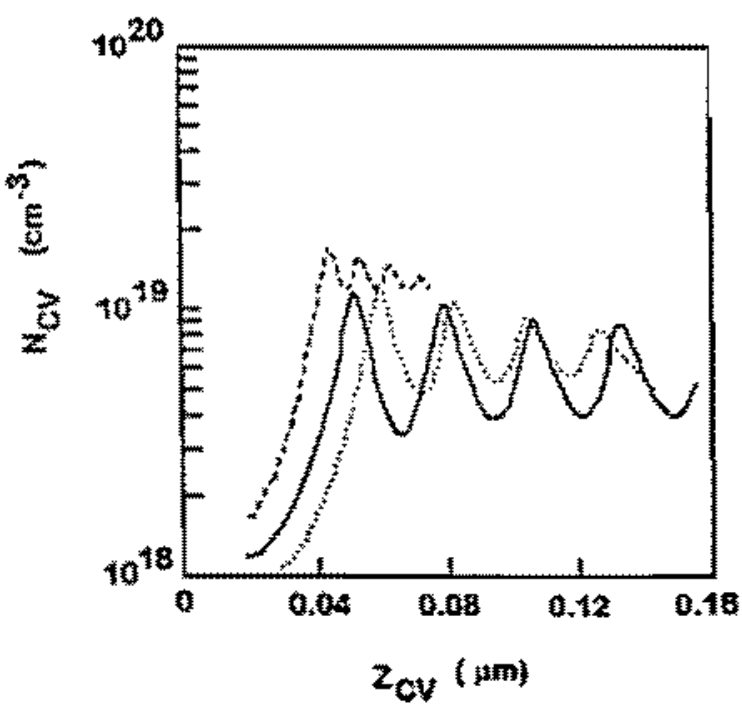

Figure 1. Experinental $C$ - $y$ spectra of the periodically sudopad samples with a nominat barrier of 280 A tull curva), 250 A (dotted curve) and $100 \mathrm{~A}$ (dashed curvel. The carrier tensity is aporoxinately equat to $4.5 \times 10^{12} \mathrm{~cm}^{-2}$, in each soping period, lor al samples.

the calculations were the doping period, $d$, and the areal density of impurity atoms in each doping layer, $N_{d}$. We also studied the effects of background acceptor impurities of volume densities in the range $N_{g}<10^{-4} a_{g}^{-3}\left(N_{\alpha}<2,1 \times\right.$ $10^{14} \mathrm{~cm}^{-3}$ for $3 \mathrm{n} P$ ). However, $C-V$ spectra showed ainost no dependence on the density of background acceptors, and the calculations shown here were made for $N_{a}=0$, thus electrical netutrality of the structure requires $n_{s}=N_{d}$ where $n_{s}$ is the areal densily of confined electrons. The C-V profiles were calculated by using equations (ia) and (lb).

Figtre 2 shows the confining potential and tectronic charge distribution obtained from the reif-consistent solutions of Schrödinger and Poiszon equations as a function of applied bias for a periodically 1 -daped strueture with parameters $N_{d}=2.5 a_{s}^{-2}\left(4.0 \times 10^{12} \mathrm{~cm}^{-2}\right.$ for InP), $d=a_{B}(79 \mathrm{z}$ for (nP) and $T=300 \mathrm{k}$. Figures $2(\mathrm{a})$ and 2 (b) show that, when the applied bias increases from zero, the semiconductor structure is progrestively depleted. Notice, however. that as bia is increased hist the $f$ well nearest to the surface becomas depleted the next well starts to be deplated only when the previous one has been empliet. This indicates hat the 6 -.

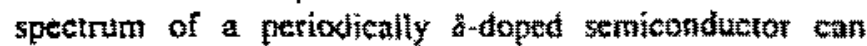
be approximated by the superpogition of $\mathrm{C}$. curves associated with independent single stoped structures, whith 5 layers located al distances $L, L+L, L+2 k t, \ldots$ below the surface of the sample; thus the spacing betwen the $C$ $V$ peaks will be equal to the distance beiween adjacent $f$ layers. As figure 2(c) shows. the superpostition of displaced $C-V$ curves associated with single d layers approximates very well the $C-V$ spectrum for the periodically 3 onoped structure.

However, it will only be possilble to resolve separate $C-V$ peaks if their spacing is larger than the full width at half maximum (FWHM) of the $C_{m} V$ peak associated with an individual $\delta$ layer. Assuming the spacing between $C-V$ 

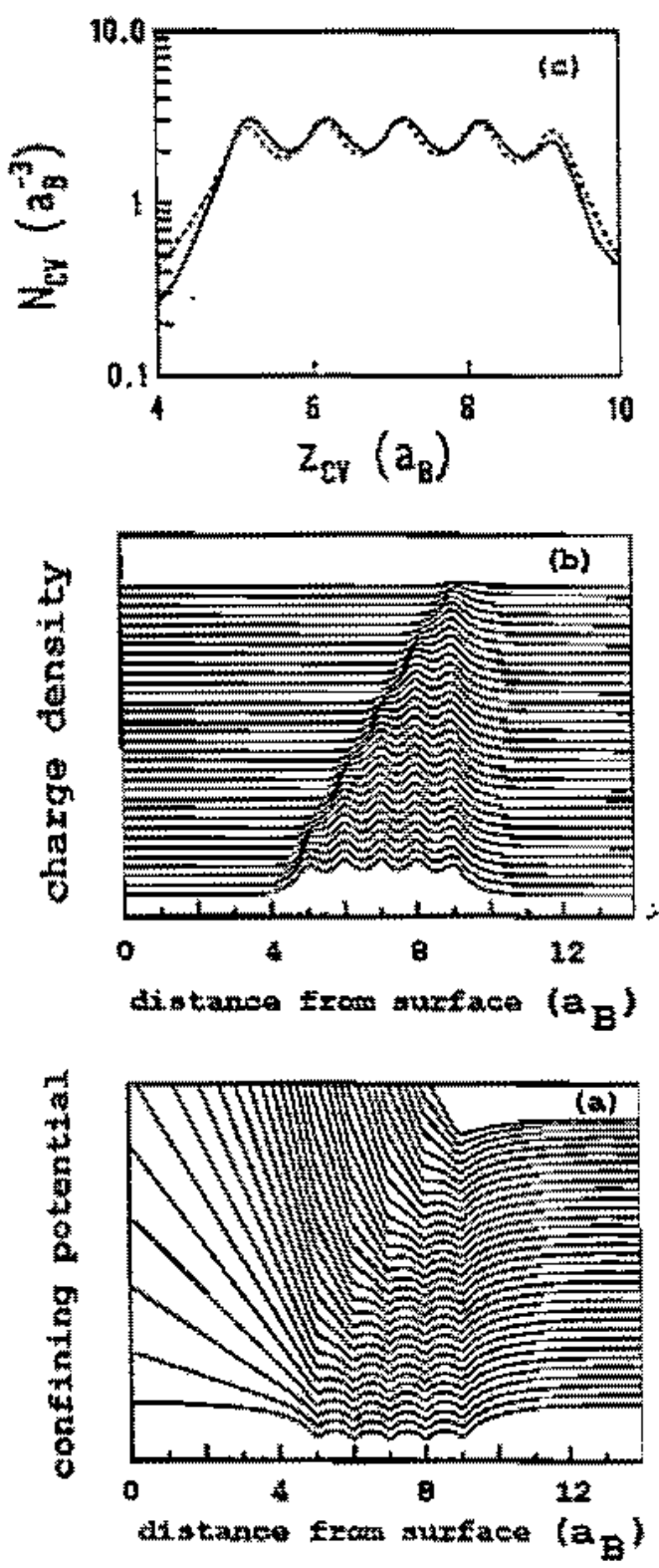

Figure 2. (a) Dependence of the self-consistent contining potential of a periodically s-doped semiconductor an the bias applied; the lowest curve corresponds to zerombias and the upparmost curve corresponds to maximum reverse

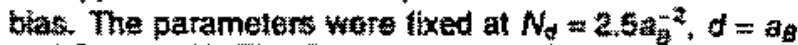
and $T=300 \mathrm{~K}$. The sehottiky contact is loceted at $z=0$; (b) the same dependence for tha elextronic change dertsity confined in the structure; (c) the calculated $C-V$ spectum lor the same structure (solid cunve). The dashed curve represents the sum of theoretical $C-V$ surves associated whth singte $\delta$ doped samples with the sama parameters, but

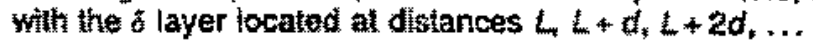
betow the surface.

peaks to be cqual to the doping period of and the FwhM of an individual $C-V$ peak equal to the spatial localization of cleatrons in the grount-state subband. $\Delta z_{\text {zal }}|5|$, to nbserve escillations in the $C-1$ spectrum the following condition must be satisfied

$$
d>\Delta z_{k i}
$$

Notice also that in this range of doping periods, the coupling between eiectrons localed in adjacent weits and belonging to the ground-state miniband is weak. In this case the ctrarge depletion of the structure under bias is a sequential prosess (i.e. a given well begins to be tepleted only when all weils before it haye been depleied), which by the arguments given above guarantees that the distance between $C-V$ peaks is a good measure of the doping period of the periodically $\delta$-doped semiconductor.

The spatial extent of the ground-state wavelunction, $\Delta z_{E}$, depends upon two main sample parameters: the sheel density of electrons in each well, $n_{5}$, and the width of the distribution of donor atoms in the $\&$ tayer, $\Delta$. For an ideal $\delta$ hayer of zero thickness $(\Delta=0)$. the extent $\Delta z_{E}$ can be estimated by use of the Bohr-Sommerfeld quantization rule (in effective atomic units)

$$
\int p(z) d z=2 \pi\left(n+\frac{1}{2}\right)
$$

The energy of a bound state, $E_{n}$, can be obtained by substituting $p(z)=\sqrt{2\left(E_{*}-V(z)\right)}$, where $V(z)$ is the known equation for thenfining potential. The spatial extent of the nth state is equal is the distance between the classical turning points and the nth state, which are determined by the condition $V(z)=E_{n}$. In the proximity of the $\delta$ sheet the confining porential can be approximated by $Y(z)-2 \pi n_{s}|z|$; in this approxirtation the spatial extent of the ground state $n=0$, which we denote by the label E1) is found to be

$$
\Delta z_{\text {EI }}=\left(\frac{3 \pi^{1 / 2}}{2^{5 / 2}}\right)^{1 / 3} n_{S}^{-1 / 3} \text {. }
$$

Therefore for sharp 1 layers the condition for the $C-V$ spectrum to display an oscillatory structure, whose period is equal to the spacing between the $\delta$ layers, will be

$$
d>\left(\frac{3 \pi^{1 / 2}}{2^{3 / 2}}\right)^{2 / 3} n_{s}^{-1 / a}
$$

In summary, it was shown that the $C-Y$ spectrum of the periodically $\delta$-doped semiconductor can be described, to a very good approximation, as a linear combination of $C-V$ carves associated with a sequence of independent single $\delta$-doped samples in which the depth of the doped layer is increased by the distance between the impunty sheets. For the three Si co-doped InP structures considered. and with a given doping strength of $4.5 \times 10^{12} \mathrm{sm}^{-2}$, the doping periods obtained from the $C-V$ spectra were found to be 92.225 and $280 \mathrm{~A}$, which are in close agreement with the intended doping periods of 100,250 and $280 \hat{A}$ respectively.

The $C-V$ technigate can be useful to determine the doping period only as long as the doping period is larger than the FWHM of the $C-V$ spectrum associated with an individual impurity layer. The techique should apply to a strueture with an arbirary number of previods and doping strengeth; electric breaktown can he avoided if $C-V$ mexsurements are mate in the etching mode. Nosice, however, that the etching procedure introduces a brostening of the C-M peaks (see [6] for details), as a consequence of which the experimental $C-V$ specirum will display only a linite number of oscillations associated with the $\delta$ layers nearest to the surface of the sample. 


\section{Acknowiedgments}

This work was supported by Conselho Nacional de Desenvolvimento Científico e Tecrológico, Grant No CNPq 306335/88.

\section{References}

[1] Sze S M 1980 Physics of Semiconductor Devices (New York: Wiley)

[2] Blood P 1986 Semicond. Sci. TechnoL 17

[3] Kroemer H, Chien Wu-Yi, Hamis $J S$ and Edwall D D 1980 Appl. Phys. Lett. 36295

[4] Ulrich B. Schubert E F. Stark J B and Cunningham J E 1988 Appl. Thys. A 47123

[S] Schubert E F 1994 Delta-doping of semiconductors: electronic, optical and structural properties of materials and devices Epitaxial Microstructures ed A C Gossard (New York: Academic) p 1

Schubert E F 1994 Semicond. Semimerals 40

[6] Yavich B. Souza P L. Pamplona-Pires M. Henriques A B and Gonçalves L C D 1997 Semicond. Sci. Technol. 12 481

[7] Henriques A B. Gonçalves L C D. Oliveira N F Jr, Souza P L and Yavich B 1997 Phys. Rev. B 5513072

[8] Gonçalves L C D and Henriques A B 1997 Semicond. Sci. Technol. 12203 


\title{
Ionized impurity scattering in periodically $\delta$-doped InP
}

\author{
A. B. Henriques, L. C. D. Gonçalves, and N. F. Oliveira, Jr. \\ Instituto de Fisica. Universidade de Säo Paulo. Caixo Postal 66318, 05315-970 Sāo Paulo. Brazil \\ P. L. Souza and B. Yavich \\ Centro de Estudos em Teleconunicą̧öes. Pontificia Universidade Católica. \\ Rua Marques de Sāo Vicente 225. 22453.900 Rio de Juneiro. Brazil \\ (Received 5 November 1996)
}

\begin{abstract}
The quantum mobility in the individual minibands of $\operatorname{lnP}$ with periodic Si $\delta$ doping was estimated from the Shubnikov-de Haiss spectra of the samples, meusured at $4.2 \mathrm{~K}$ in hields of $0-14 \mathrm{~T}$. The set of samples studied had a sheet density of $S i$ atoms of about $4.9 \times 10^{12} \mathrm{~cm}^{-2}$ in each doped luyer, and a doping period in the range $90-300$ A. A theoretical model for the 4 tantum mobility in individual minibands was developed. and theoretical estimutes of the quantum mobility are in reasonable agreement with the experimental values. It is observed that at a fixed daping period the yuantum mobilities increase with the index of the miniband, and the quantum mobility in an individual miniband decreases when the doping period is made shoner. The dependence of the quantum mobility on the miniband index and doping periodicity currelates with the dependence of the mean distance between electrons and the doped layer on the same quantities. These results demonstrate that in $\delta$-doped semiconductors the binding length of the quantum-confined electronic sharge is a very importin parameter, determining the carrier mobility which can be attained in these systems. [S0163-1829(97)01119-3]
\end{abstract}

\section{INTRODUCTION}

Semiconductors in which the atoms of the dopants are concentrated around a single plane of the host crystal lattice have important technological applications and display interesting physical properties. ${ }^{1.2}$ Using epitaxial growth techniques such as metal-organic vapor phase epitaxy (MOVPE) and molecular-beam epitaxy, planar doping (or $\delta$ doping) with silicon has been accomplished for various III-V semjconductors, for instance, $\mathrm{GaAs} . \mathrm{Al}_{x} \mathrm{Ga}_{1-x} \mathrm{As}$, InSb, and InP. In semiconductors doped periodically with sheets of $\mathrm{Si}$, the carriers released from the shallow donor $\mathrm{Si}$ atoms are confined by a periodical space charge potential, which splits the continuous conduction band of the host semiconductor into a set of electronic minibunds. The conductivity parallel to the doped layer is dominated by carriers contined in such minibands: these carriers interact strongly with the charged jonor atoms located in the doped regions, and this interaction consists the mechanism which limits the carrier mobility in $\delta$-doped systems. ${ }^{3-5}$

From the theoretical standpoint, calculations of the electronic mobility in samples with a single $\delta$ layer have been made using either the Thomas-Fermi model ${ }^{6-8}$ or the random-phase approximation (RPA) (Refs. 8-12) to describe the screened interaction between confined carriers and ionized impurities. The theoretical calculations made in the frame of the RPA show good quantitative agreement with experimental estimates. ${ }^{9.11}$ while the agreement is poorer sthen a two-dimensional Thomas-Fermi model of screening is used (see Ref. 13 by some of the authors). However, to the best of our knowledge a calculation of the electronic mobilities in periodically $\delta$-doped samples has not yet been attempted. and this is the purpose of the present study. For the periodically $\delta$-doped semiconductor. the theoretical quantum mobility calculation is based on the same input quantities as the mobility theory for semiconductors with a single $\delta$-doped layer, i.e., electronic energy spectrum and wave functions, and a model for the screened electrostatic potential of ionized impurities. The basic novelty is in the form electronic wave functions. which for a periodically $\delta$-doped system are described by Bloch states. whereas for a semiconductors with a single $\delta$ layer the wave functions describe states which are spatially localized around the doped layer. Our calculations were made using the RPA model for the screened Coulomb interaction between carriers and ionized donors; this choice was motivated by the success of the RPA theory in describing the carrier mobility in $\delta$-doped materials with a single $\delta$-doped layer.

\section{THEORY OF MINIBAND QUANTUM MOBILITIES IN THE RPA APPROXIMATION}

In this section effective atomic units are used, whereby the units of mass, length. and energy are the effective mass $m^{*}$, the effective Bohr radius $a_{B}=\epsilon h^{2} / m^{*} \kappa e^{2}$, and the effective Hartree $H=\hbar^{2} / m^{*} a_{B}^{2}$, respectively. For InP, we assume $m^{*}=0.08 m_{0}$ (Ref. 14) and $\epsilon=11.8$, $^{15}$ which gives $a_{B}=78 \AA$ and $H=15.7 \mathrm{meV}$.

When electrons are confined by a porential which is periodic along one axis (the growth direction $z$ ), as occurs in a semiconductor with a periodical $\delta$ doping. the electronic states are quantized into superlattice minibands of energies $E\left(n, k_{1}, k\right)$,

$$
E\left(n, k_{\perp}, k\right)=E_{n}(k)+\frac{1}{2} k_{\perp}^{2},
$$

where $\vec{k}_{\perp}$ and $k$ are the wave-vector components perpendicular and parallel to the growth axis, respectively, and $E_{n}(k, z)$ is the miniband dispersion. In order of increasing energy, we will denole the succession of minibands as $E$ l. 
$E 2, E 3, \ldots$ The electronic states corresponding to the energies $E_{n}(k, z)$ atw descabed by the wave functions

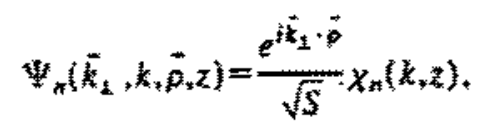

where 5 is the area of the sample. $\chi_{n}(k, z)=n_{n}(k, z) z^{\text {iz* }}$, and $w_{n}\left(k_{2},\right)$ are Bloch hinctions nomalized to the langth of the superiattee. fonctions $\chi_{n}(k, z)$ are the solutions of the Schrödinger equation

$$
-\frac{1}{2} \frac{d^{z}}{d z} X_{n}(z)+\left[V_{H}(z)+V_{z G}(z)\right] X_{n}(k, z)=E_{n}(k) X_{n}(k, z)
$$

where $V_{x i}(z)$ is local density approximation for the exchangewtorrelation comection to the conting potential. which was taken to bequal to the fom due to hedin and Lundquist:

$$
V_{x \in t}(z)=\frac{1}{\pi \alpha r_{m}}\left[1+0.7734 x \ln \left(1+x^{-1}\right)\right]
$$

$\alpha=(4 / 9 \pi)^{t / 3}, r_{x}=[4 / 3 \pi n(z)]^{-1 / 3}, x=r_{s} / 21$, and $V_{H}(z)$ is the self-consistent Hartre potential, which is obtained Inom a numerical solution of the poisson equation

$$
\left.\frac{d^{2} y_{u(z)}}{d z^{2}}=n[n d z)-n(z)\right]
$$

where $n_{d}(z)$ is the density of lonized donors, $n(z)$ $=(1 / \pi) \Sigma_{n k}\left|z_{n}(k, z)\right|^{2} \phi_{m k} \theta\left(\phi_{n k}\right)$ is the densily of fre carm ners, $\phi_{\text {mi }}=\phi-E_{\text {m }}(k)$, $\phi$ denotes the Fermi energy, and

$$
\theta(x)= \begin{cases}1 & \text { if } x>0 \\ 0 & \text { otherwise }\end{cases}
$$

is the Heaviside step function.

The scattering rate of electrons from a given quantum seate for $T=0 \times \mathrm{X}$ can be obtained from the Fermi golden rute, taking the Coulomb interaction between electrons and ionined impurities to be the scattering mechanism. By using the wave functions given by Ea, (I), and constitering the scattering processes of carritrs at the sermi surface, for the quanIum lifetime of the state $k$ of the nth electronic miniband (in atomic units. the guantum lifetime equals the quantum nobility $\left.\mu_{0}\right)$, one obtains

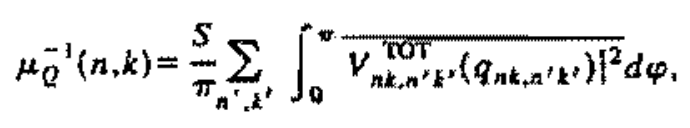

where the summation extends over the quantum states $\left\{n^{+}, k^{\prime}\right)$ which lie below the fermi level $\left(i, e_{* *} \phi_{*^{*}} z^{*}>0\right)$,

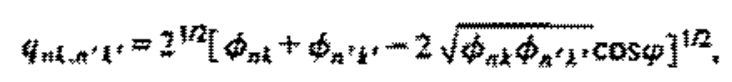

the integration variable th the angle of seattering formed betweten vector $\vec{k}_{i}$ and $\vec{k}_{i}^{\prime}$, and

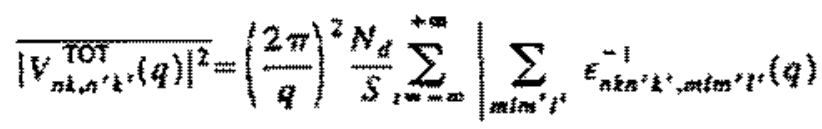

$$
\begin{aligned}
& \left.x \int_{0}^{n} x_{m}(1, z) x_{m}^{*},()^{*}, z\right)\left.e^{-\frac{3}{4} z-y d t} d z\right|^{2}
\end{aligned}
$$

represents the statistical average of the matrix elements of the two-dimensional Fourier transfom of the scattering pom tential. In the latter equation the summation extends over all the electronic energy levels. $N_{d}$ is the areal densily of single charged donor atoms in each doping period, distributed along the $z$ direction in a plane of zero thickness: $d$ is the super" lartice period: $N d$ is the Barn-yon Kaman period: ant

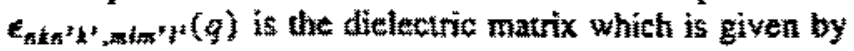

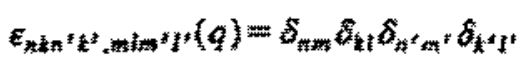

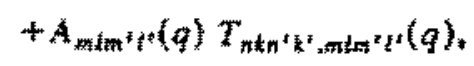

with $A_{\text {mim'in }}(q)$ being the independent response particle density matrix, given in the Appendix of Ref. 17, and $T_{n+n^{\prime} k^{\prime}, m i m^{\prime} l^{\prime}}(q)$ is the Coulomb energy form factor

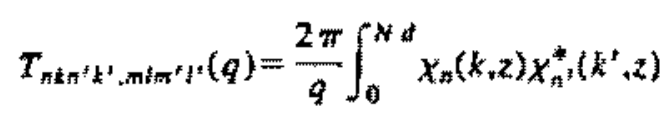

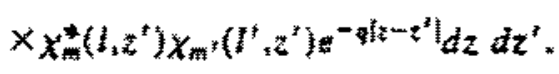

In ordar to lest the theory, a comparison with the quantum mobility obtained experimentally is neded. The guanum mobility of carriers in indivioual minibunds can be extracted from the Shubikov-de Hats (sdH) spectrum. As shown in Refs. I8 and 19, in a semiconductor superlatice each miniband manifests itself in the SaH experimert as a separate set of otcillatory components. Every miniband can be assigned to one of three categories: those of wwo-dimensional character and vanishing bandwidth. $\boldsymbol{A}_{\mathrm{ft}}=0$; these of quasi-two dimensional character, deseribed by a small dispersion and narrow bandwidth, $\Delta_{n}<\phi_{n}$, and these eficetively threedimensional, $\Delta_{n}>\phi_{n}$, where $\phi_{n}$ represents the energy distance between the Fermi level and the threstold of the miniband.

The contribution to the magnetoresistance of a miniband whase batainidth is smaler then fts Fermi energy, i.e. $a_{n}<\phi_{*}$ will described by ${ }^{13}$

$$
\begin{aligned}
& \frac{\Delta \rho_{x \Psi}}{\rho_{0}}-\frac{X}{\sinh X^{-\alpha} v} e^{-\alpha J_{0}\left(\beta_{n} u\right) \cos \omega_{n} u} \\
& +8 \epsilon_{n} \operatorname{Im}\left[e^{-i \beta_{n} \mathrm{~L}} \Phi\left(1 / 2,2,2 i \beta_{n} u\right)\right] \sin \left(\mu_{n} \mu\right\}
\end{aligned}
$$

where $X=2 T^{2} T / B, T$ is the tempervture in units of

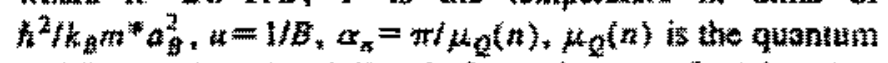

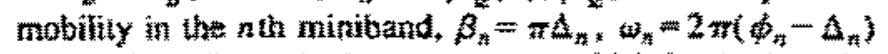
and $\epsilon_{n}$ is a dimensionless parameter whtch is obuaned by futing the numerically calculated dispersion law $_{*} E_{n}\left(f_{3}\right)$, to the expretsion

$$
E_{n}(k)=\frac{\Delta_{n}}{2}(1-\cos k d)-\epsilon_{n} \frac{\Delta_{n}}{2}(1-\cos 2 k d) .
$$


Equation (5) was obtained assuming the quantum mobllity to be constant within a minitand. Note also that when the spact ing bewween the doped layers is mate very large $(d-\ldots, 00)$, the width of the minibands decreases $\left(\Delta_{n}{ }^{m} \rightarrow 0\right)$, and Eq. (S) takes the familiar form associated with an electron gas confined in two dimessions: ${ }^{20}$

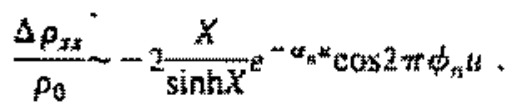

In the most general wase, Eq, (5) will be chanacterized by wo oscillatory components, tespetive to the "belly" and "neck" extremal orbits of the minin- Femi surface associated

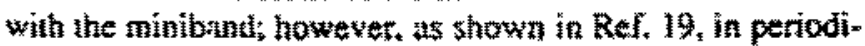
cally o-doped systents the next orbit is not defectable. This conclusion is betsen upon the observation that in order for the neck orbil to be detectable, the energy $\%$-level broadening mus be smatlet than the miniband with and atso smaller than the minigap to the higherwentergy mintoand. However, in periodically $\delta$-doped systems these two condilions are never met simulaneously. hence each miniband will munifest itself with a single oscillatory componen due to the belly orit. This assertion leads us to conclude that in the case of periodically s-doped semiconductors the quantum mobility appearing in Eq. (S) pertains to the belly orbit state. Therefore if we wish to test the quanturn mobility theory developed above. the quantum mobility obtained from a fit of $\mathrm{Eq}$. (5) to the experimental data should be compared to the output of Eq, (4) at the wave vewtor sssociated with the belly orbit (i. $=, k=0$ for minibands $E 1, E, \ldots, \ldots$ and $k=\pi / d$ for minibands E. E. E.,...).

For those mintbands whose bandwidth is larger than the Foni energy, when $\Delta_{n}>\phi_{n}$, the magnetoresistance oscillations can be approximated by the usual expression associaled with an twrestrained fre electron gas in three timensicus, ${ }^{\text {at }}$

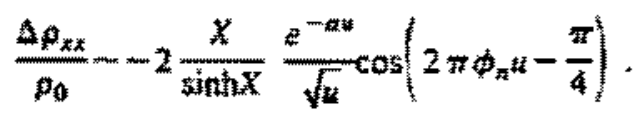

The quantum mobility in this case can similarly be oblained by fiting Eo. (8) to the isoluted magnetoresistance oscilla* ony component.

\section{EXFERIMENT}

The 8 -doped structures were grown at $640^{\circ} \mathrm{C}$ by low pressuremMVPE in an AIX 200 reactor at 20 mbar with a growth rate of $4.5 \mathrm{~A} / \mathrm{s}$. The source materials were PH, (IOO\%), TMin (crimethyl indium), and $1 \% \mathrm{SiH}_{4}$ dituted in $\mathrm{H}_{2}$, on $(100)$ Fe-doped in $\mathrm{P}$ substrates. first a 0.3 . fmm thick undoped butfer was grown. followed by a periodiw

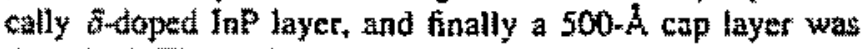
depositet. The pertedical structures are composed of either five or ten periods, with a spacing varying from 90 to $300 \mathrm{~A}$. The dopart tayers were deposited during a 25-s growth in. fertuption. The silane flux was triggered 2 after growth internption, and hatted $2 \mathrm{~s}$ before the growth was resumed. In orter to detcmine the widh of the loped layer and the doping priot. the capacitance-volage prothe $(C \cdot$ ) W was measued for each sample, using an electrothemieal profier PNit300.
The Shubnikov-de Hass experinent was carried ou in a superconducting magnet. The sample was plated in liguid He at $4.2 \mathrm{~K}$. The magnetoresistance meastrements were made in the consunt-current mote employing cturents of $-10 \mu A$. and using a four-contact geometry: the samples were approximately square. with contacts in the comers. The magnetoresistance otcillations were rastured in magnetis tields of intensity up to $14 \mathrm{~T}$.

\section{RESULTS}

We obtained an experimental estimate of the quantum mobility in of the poptated minitands by using a sequential proxess, which contsised of the following steps: (1) determination of the characterstic widh of the toped layer and of the doping period (2) determintwion of the shest eir-

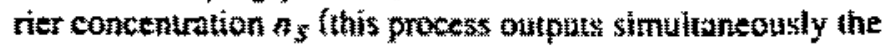

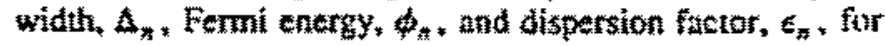
all minibands taken into considerationt: 13 isoloton of the

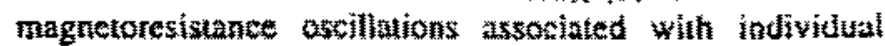
minibands: and (4) detemination of the quantum mobility of a populated miniband by fiting the appropriate equation [either Eq. (5) or (7)] to the isolated magnetomoscillatory component, with the taxumum mobility being the single fitting parameter. In what follows ench of these steps is described in more detail.

\section{A. Determination of the characteristic doping layer width und doping period}

It has been shown by Ulitich ef $a l^{22}$ that the $C \cdot V$ spec: trum of a sidoped semiconductor is very sensitive to the spreading of the impurity atoms. In order to estimate the characteristic width of the doped layer in our samples, we proceeded in the following way. Sample No. 187 with a single si o layser was grown under the same growth conditions ased for the periodically sudoped samples. In order to take advantage of the fact that the $C$ - $V$ technique presents a highter resolutiton for 4 hightr sheet concentration of contined amerrers, sample No. 187 was more highly doped than the ather samples used in this work. The aneal density of con" frret carrier in this sample was obtained from the Shutankoy-de Haas spectrim by following the prescription described in Ref. 5. Using the density of catriers obtained from the \$dH spectran, theoretical $C$ - $V$ profiles were generated by resolving self-consistently Schrödinger and Pois. \$on equations for the structuse under bias; in the calculation of the $C$. $Y$ spectrum, the doped layer was assumed to bo of Gatssian profile, and the width of the Gaussian was varied until the theoretical $C \cdot V$ spectrum achieved best agreement with the experimental one. A more detailed description of the $C-V$ technique and theory is presented in $\operatorname{Re} f .2$. Figure 1 shows the $C-V$ spectrom for sample No. 187. The theoretical curve shown in Fig. I was calculated assuming the donor layer to be of widih $8 \AA$. and it reproduces very well the experimenal $C-V$ spectrim. This demonstrates that $\$$ it atoms in the sodoping layers in our samples ar sprwad over not more than $2 \mathrm{ML}$ of $\operatorname{InP}$.

To defermine the doping periods of a sumple. its $C$ - $Y$ aptetrum was measured. As an example, the $C$. spectrum for sample No. 200 is shown in Fig. 2. The $C \cdot V$ contentrat lion, $N_{C+y}$. presents oxpllations as a function of the $\mathrm{C}$

\section{5




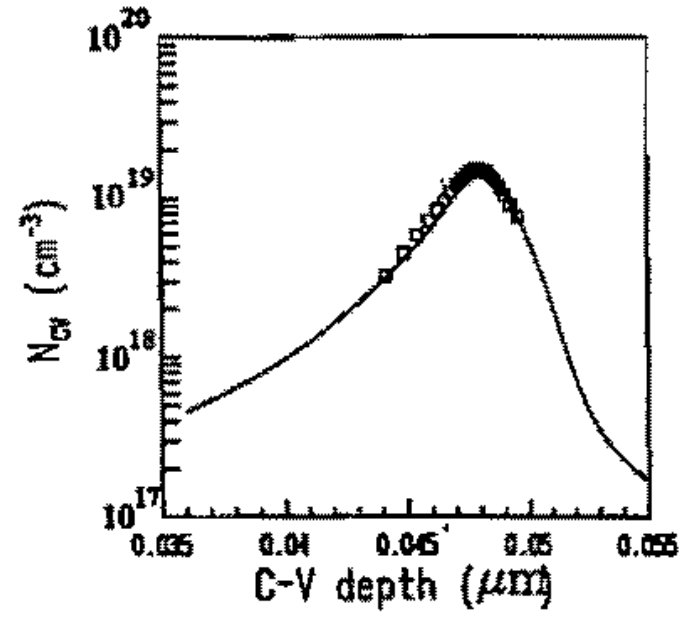

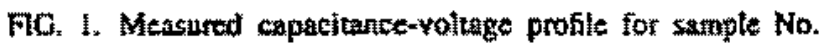
187 (squtare tots) for $T=300 \mathrm{z}$. The theoretical $C \times V$ spectum (full

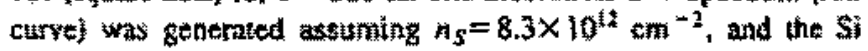
atom distributed accorting to a Gaussian funetion of full whth at hatf maximum af 8 .

deptit, zr.y. The oscillations seen in Fig. 2 display s periodieity of $176 \mathrm{~A}$, which we take to be sual to the doping period of this stweture: the doping periods obtained in the same way are shown in Table I for all samples stuatied.

\section{B. Determingtion of the carrier poputation wnd miniband parameters}

The overall shext carrier concentration $n_{5}$ for each sample sas extracted from an analysis of its Shubnikov-de Hass spectrum. Figare $3($ a) shows the magnotoresistance spectram for sample No. 196, and Fig. $3(\mathrm{~b})$ shows the Fouriter urans" fartin of the SdH ascillations plotted agoinst the inverse field. Protr to taking the Fourier transtorn, and with the motive of educing the umwanted background of monotonous magnetoresistance, the magnetoresistance curyes were differendi ated. Each of the peaks seen in Fig, $3(\mathrm{~b})$ corresponds to a belly otbit of one of the populated minibands; the peak po. sitichs tetermine the belly extremal cross sectional areas of the mini-Fermi surface in units of $h / 2 \pi t$.
To determine $n_{s}$ if was necessary to solve salfconsistenty Sxhroxinger and Poisson equations [Eqs. (2) and (3)) for each sample. In the calculation. the doping period was fuxed al the value detemined by the $C-V$ measumemt. and the Si atoms were taken to be distributed according to a Gaussian function with a full width at half maximum of $A$ as deduced from the $C V$ specirum, The only additional parameter in this calctlation, the camer concentration ns. was varied unill all theoretical frequencies of magnetoresistance oscllation, i.e. those comesponding to the belly cross sections of the mini-Fermi surface, approximated simultaneousty all of the frequencies of oscillation seen in the experimental Shtbnikov-de Haas spectrima. (It should be pointed out that such a procedure will incorporate into the final result of $n_{5}$ those carriers in the outer minibands with a lowideasity population, which are beyond the sensitivity of the shubnikov-de Hans spectram). The procedute used to detemine $n_{S}$ is descritsed in more detall in Ref. 23. Results of the analysis of the $C \cdot V$ spectra and of the Shubnikov-de Haas oscillations are summmrized in Table I.

For samples with a period lest than men 200 guanum oscillations associated with miniband $E 3$ were nto observed. This is an indication that in this range of doping periods the minigap between mintoands $E 2$ and $E 3$ is less than the brondering of the energy levels, meaning that for all pracical purposes minibands $E 3$ and $E 2$ merge into a singte tenergy bund. Unter these circumstances only the belly orbit associated with miniband wall be manifested by magne. toresistance oscillations which will follow the threedimensional behavior tescribed by Ea. (8). At still sborter pertads $(d<150 \mathrm{~A})$, mitiband $\mathrm{E}^{3}$ becomes depieted of corriers.

In addition to the concentration of free carriers, the selfcansistert calculations also cutpet the fermi energy $\phi_{n}$, the width $\Lambda_{n}$, and the dispersion factor $\varepsilon_{n}$ for all minibands; the parameters obtained are displayed in Table II.

\section{Istation of contributions of individual minibands to the anagnetoresistance}

Individual oscillatory components sepered from the rest of the magnetoresistance spectrum by applying a Fourier Gauszian bandpass filter: the bandpass fliter parart:

TAELE I. Paramaters of the samples studited. The dopinz period $d$ was obtained from the $C$ - Spectrum

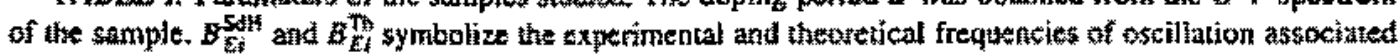
with the belly orbit in $k$ space. The overall currier concentration $n$ shown gives the best agreement af theory with experiment:

\begin{tabular}{|c|c|c|c|c|c|c|c|c|c|}
\hline \multirow{2}{*}{$\begin{array}{c}\text { Sampie } \\
\text { No. }\end{array}$} & \multirow{2}{*}{$\begin{array}{l}\text { Na. of } \\
\text { pariads }\end{array}$} & \multirow{2}{*}{$\begin{array}{c}d \\
(\mathrm{~A} \\
\mathrm{t}\end{array}$} & \multicolumn{3}{|c|}{ SdH Experiment $(T)$} & \multicolumn{3}{|c|}{ Calctolated $(T)$} & \multirow{2}{*}{$\begin{array}{c}n_{s} \\
\left(\mathrm{~cm}^{-2}\right)\end{array}$} \\
\hline & & & $\mathbb{E}_{E}^{\text {SUI }}$ & $B_{E 2}^{\text {S力a }}$ & $b_{\mathrm{E}}^{\mathrm{san}}$ & $B_{\varepsilon 1}^{\bar{z}}$ & $A^{\text {th }}$ & $B_{i:}^{7}$ & \\
\hline 194 & 5 & 92.0 & 85.5 & 43.1 & & 86.3 & 42.3 & & $4.27 \times 10^{12}$ \\
\hline 206 & 10 & 107 & 89.7 & 43.9 & & 90.3 & 48.7 & & $5.08 \times 10^{22}$ \\
\hline 198 & $s$ & 128 & 74.9 & 386 & & 75.4 & 40.2 & & $4.50 \times 10^{12}$ \\
\hline 207 & 10 & 133 & 80.7 & 46.0 & & 79.2 & 46.2 & & $5.08 \times 10^{12}$ \\
\hline $2 m$ & 10 & 176 & 62.2 & 32.2 & & 63.3 & 32.4 & 9.1 & $4.27 \times 10^{12}$ \\
\hline 197 & $s$ & 225 & 73.4 & 33.8 & & 73.7 & 34.9 & 17,0 & $5.38 \times 10^{12}$ \\
\hline 109 & In & 245 & 73.1 & 25.9 & H.1 & 75.6 & 27.4 & 11.2 & $5.26 \times 10^{12}$ \\
\hline 196 & $\$$ & 278 & 65.4 & 28.1 & 15.0 & 682 & 28 & I5.9 & $4.98 \times 10^{12}$ \\
\hline $10=$ & single & & 69.6 & 24.0 & 6.8 & 70.8 & 24.5 & 6.7 & $5.07 \times 10^{12}$ \\
\hline
\end{tabular}




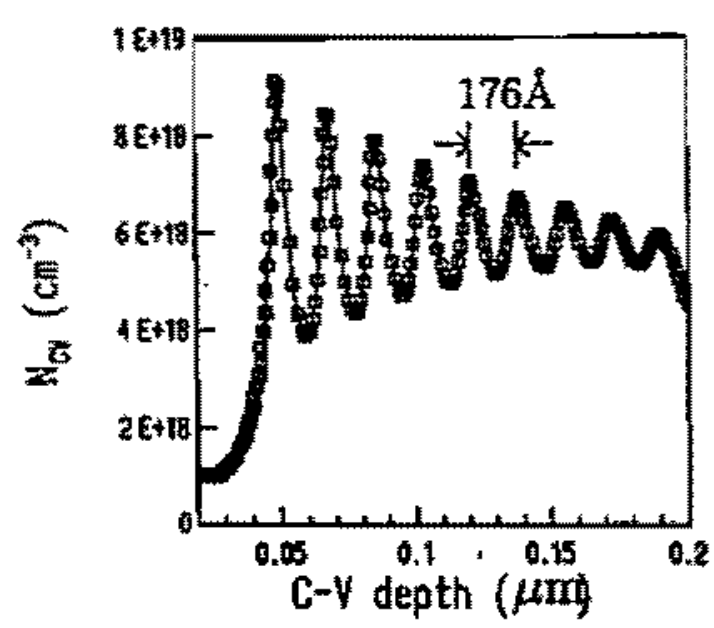

FG. 2. Capacilancs-voltage profite for sample No, 2M0. The periodicity of the peaks indicate that the doping period of this struxture is $176 \mathrm{~A}$.

eters were the peak frequency and full witth at half raxim mum (FWHM). This is illustrated in Figs. 4(a) $-4(d)$ tor sample No. 196. We have chosen sample No. 196 to exemplify the resuits of the Fourier filtering procedure because in this sample each miniband is associaled with one of the patterns which can be exhibited by the magneto-oscillatory components in periodically $\delta$-doped semiconductors: the fundamestal niniband $E$ | bears zero bandwidth and is thus Iwo dimensional, giving a magnetoresistance contribution which will obey Eq. (7); miniband $E 2$ bears a narrow band width $\Delta_{2}<\phi_{2}$, which corresponds to a dimensionality intermediate between 2 and 3 , and its magnetoresistance oscillations will obcy Eq. (5); and miniband E3, which has a large bandwidh $\Delta_{3}>\phi_{3}$ is effectively thee dimensional, implyw ing that its magnetoresistance oscillations will be described by Eq. (8). Thus sample No. 196 can serve the purpose of illustrating the Fourier fitering procedure and of the process of fiting individual oscillations with theory under all of the circtmstances which can occur.

Figure 4(a) shows the Fourier transform of the SdH curye: dashed lines show the flitered Fourier transtom, with band-

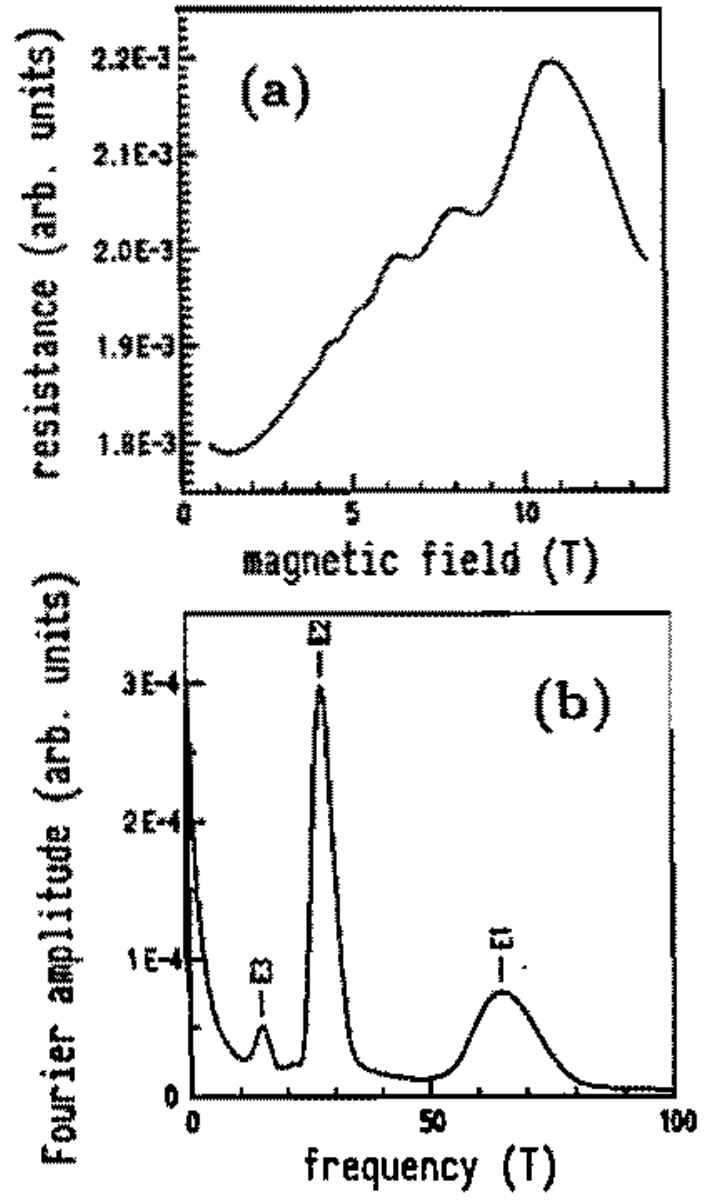

FIC. 3. (a) Shutrikov-de Haas spectrum of sample No. 196. (b) Fourier transforn of the Shutrikov-de hass spectrum plotted against $1 / 8$ and differemtiated for sample No. 196. The frequencies of oscillation associated with the belly orbits are indicated.

pass filter parameters adjusted to isolate one of the Fourier peaks seck. After the application of the bandpass filter. all steps leading to the isolated Fourier transform were reversed: an inverse Fouxier transformation was applied, and the mag. netaresistance oscillations were integrated numerically. Fig* ures $4(b)-4(d)$ shows the isolated magnetoresistance oscillav

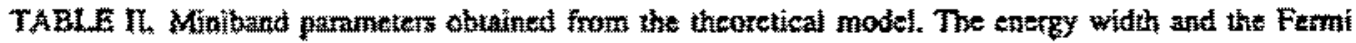

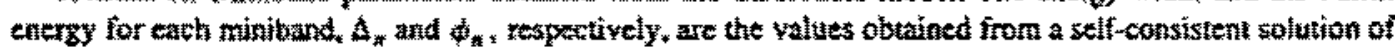

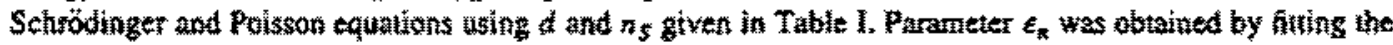

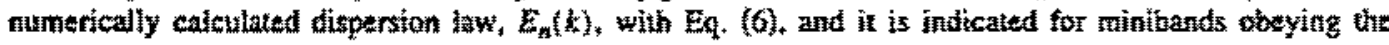
quasi-two-dimensiental betavior of Eq. (5).

\begin{tabular}{|c|c|c|c|c|c|c|c|c|c|}
\hline $\begin{array}{c}\text { Stample } \\
\mathrm{Na}\end{array}$ & $\underset{(m e V)}{\Delta_{1}}$ & $\begin{array}{c}\text { sit: } \\
\text { (meV) }\end{array}$ & $\varepsilon_{1}$ & $\begin{array}{c}\Delta_{2} \\
(\operatorname{meV})\end{array}$ & $\begin{array}{c}\phi_{2} \\
(\mathrm{meV})\end{array}$ & $\epsilon_{2}$ & $\begin{array}{c}a_{3} \\
(\operatorname{mov})\end{array}$ & $\begin{array}{c}\omega_{1} \\
(m, V)\end{array}$ & $\epsilon_{3}$ \\
\hline 194 & 43.7 & 127.0 & 0.21 & 1529 & 57.5 & & & D. & \\
\hline 206 & 25,4 & 13022 & 0.16 & 105.8 & 68.8 & & & 0.0 & \\
\hline 198 & 14.8 & 107.8 & 0.12 & 69.4 & 56.9 & & & Cot & \\
\hline 207 & $\|, 0$ & 1183 & 0.09 & $6 ! .0$ & 64.0 & & & 0.0 & \\
\hline 200 & 3.2 & 91.4 & 0.03 & 31.7 & 44.7 & & & 0.0 & \\
\hline 197 & 2.8 & 107.1 & 0.00 & 11.4 & 45.4 & & & 0.0 & \\
\hline 199 & 1.4 & 102.3 & 0.00 & 8.1 & 41.2 & 0.16 & & 224 & \\
\hline 190 & 0.0 & 95.5 & 0.00 & 4.6 & 35.9 & 0.11 & 19.9 & 19.0 & \\
\hline 164 & 0.0 & 96.7 & 0.00 & 0.0 & 37.2 & 0.00 & 00 & 11.4 & 0.0 \\
\hline
\end{tabular}



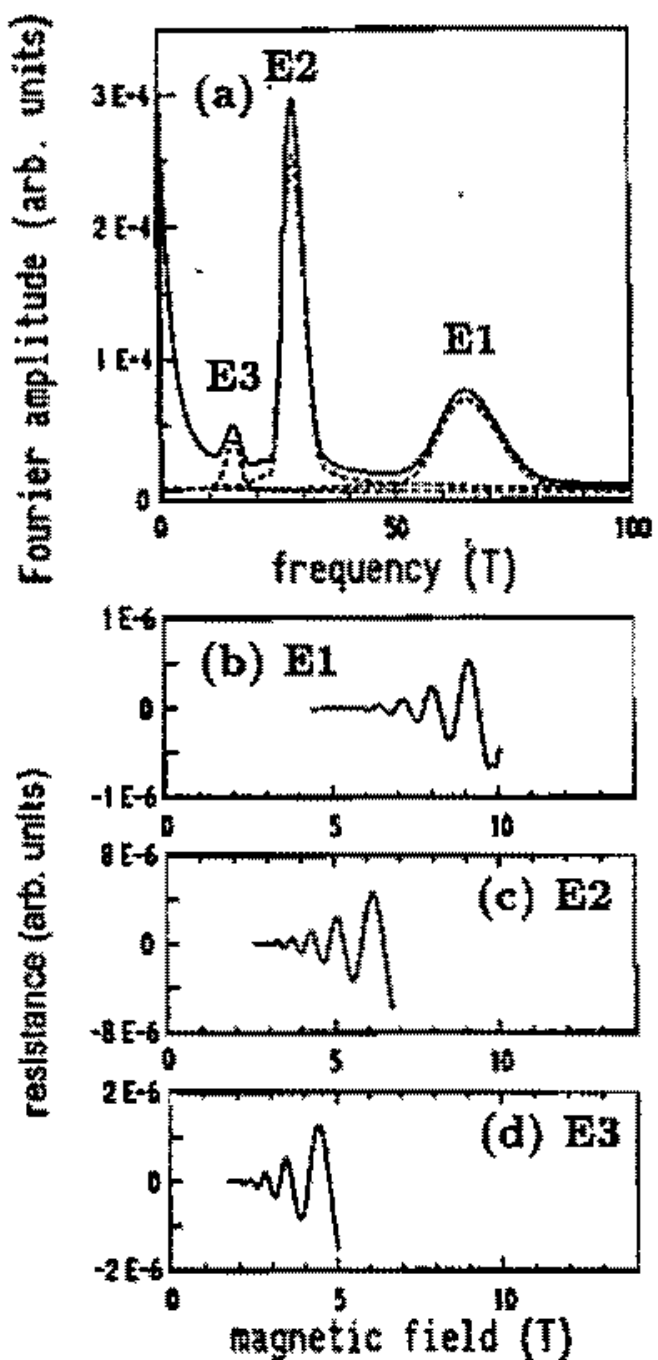

10. 4. (a) Fourier tratstom af the SdH spectum for sample No. 196; dashed lines show the filtersd Fourier fratsform usto to isolate each of the peaks detectedx (b)-(d) show the isolated aseil. lations doe to minibands $E_{1}, E_{2}$, and $E_{3}^{3}$, respectively.

tory components so obtained for sample No. 196. The isolated oscillations cover a smaller range of fields than the measured interval $(0-14 \mathrm{~T})$ because a certain interval at each end the length of which is inversely proportional to the FWhy of the Fouriat fiter) is lost die to end effects (sex, far instance, Ref, 14 I).

\section{Experimental estimates for the quantum montlites}

The quanturn mobility associtied with ench of the populated minibands was obtained from a fit with theory of the minibands' contribution to the magnetoresistance, isolated from the rest of the Shabnikov-de Haas spectrum as desoribed in Sec. IV C. The individual oscillations were hited wsing Eq. (5) when the miniband energy width wis narrow $\left(A_{n}<\phi_{n}\right)$, or Eq. $(8)$, when the thiniband with was wide $\left.\mid \Delta_{n}>\phi_{n}\right)$. Farameters $\hat{s}_{n}, \phi_{n}$, and $\xi_{n}$ used in the fitting equation were fixed al the values given in Table II and the temperature was set to $4.2 \mathrm{~K}$, as ased in our experimens. The only remaining pardmeter, $\mu,(n)$, was adjusted for best agreement with the experinent. To illustrate the thtting procedure, the individual oscillations and the fitted

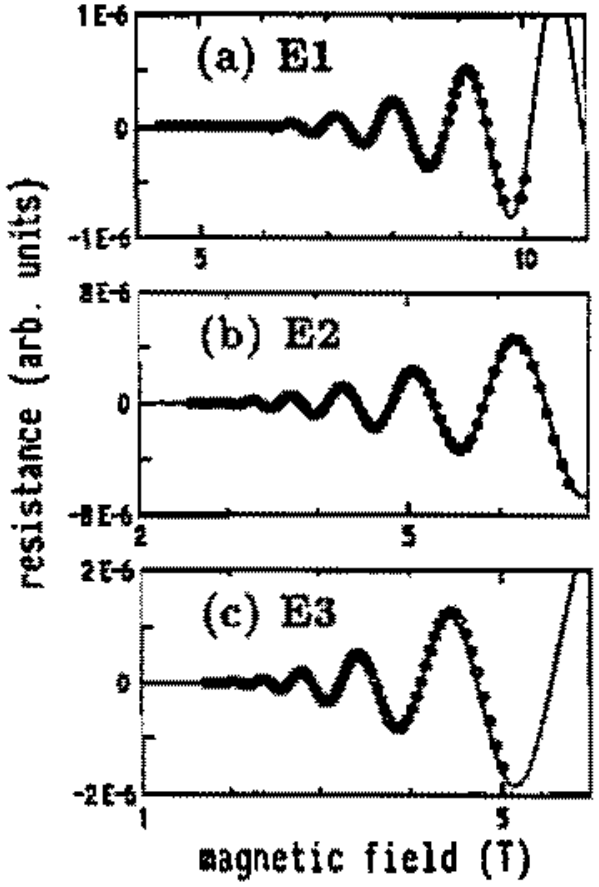

FG. S. Magnetorexistance oscillations assocjated with individual minibands for sample No. 196. Dots represent the oscilla. tons totained experimentally and the full caryes comrespond to the

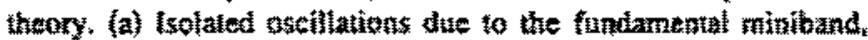
El and theoredeal result by us of Eq. (5). (b) Sume for miniband E2. (c) Isolated oscillations duc to miniband $E 3$ and theoretien resull obiained by use of Eq. (B).

curves for sample No. 196 are shown in Fig. $\$_{1}$ a tht will theory in this case yielded $\mu_{O}(E 1)=410 \mathrm{~cm}^{2} \mathrm{~N} \mathrm{~s}$. $\mu_{Q}(E 2)=1320 \mathrm{~cm}^{2} / V \mathrm{~s}$, and $\mu_{Q}(E 3)=3650 \mathrm{~cm}^{2} N \mathrm{~s}$. All other samples tnderwent the same treament, and the quan* sum mobilly values obtained are plotted against doping period in Fig. 6 .

\section{COMPARISON WITH THEORY AND DISCUSSION}

Experimental restits showed that at a fixed lophing period the quantum mobility increases with the index of the mini-

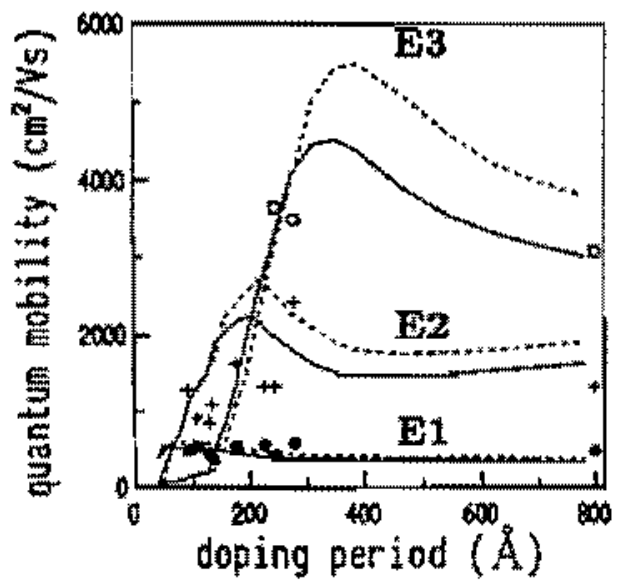

FIC. 6. Quantum mobility as a function of the topying period. Circles, crowsts, ata squares represent hte experimental resutis eot-

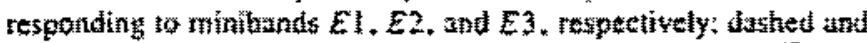
full lines depicl the theorelical resul for $n_{5}=4.3 \times 10^{\text {tz }}$ and $5.4 \times 10^{13} \mathrm{~cm}^{-2}$, respectively. 
band. The experimentul quantum mobilities associnted with indivitual minibands are sitswn by dows in Fig. 6 as a func" tion of the doping period $d$. At latge values of $d$ adjucen wells become oncoupled; the gatantum müniband motilitics obtained for sample No. 164, which contains a single s layer, is ploted in $\mathrm{Fig} .6$ al $d=800 \mathrm{~F}$.

When the periot is nate shorter, the mobility in miniband $E I$ remains nearly unzhanged. The experimental guantum mubility in miniband $E 2$ does not show a smooth dependence on the doping period, which is atributed to the fluctuation in carrier density in the samples (see Table 1) and to the limited accuracy of the experimental values of mobijily. Nevertheless, the experimental data ploted in Fig. 6 thows clearly that in the region $a+200$ \& the $E 2$ quantum mobillity decreases when the doping period is made shorter. Fintly, the quantum mobility of carriers in miniband $E 3$ could only be measured for periods grester than $230 \mathrm{~A}$, in which nnege the measured mobility attains a value of approximately $3500 \mathrm{~cm}^{2} \mathrm{~N}$.

The theoretical quantum mobitities were calculated as a function of the doping period for carrier concentrations of $n_{s}=4.3 \times 10^{13}$ and $5.4 \times 10^{12} \mathrm{~cm}^{-z}$, these values correspont to the lower and upper limits of the frec-crartier concentration in the samples studied. The inpul quantities were the Fermi energy, minituand energy spectrum, and wave functions, which were obtained from the solution of Sclirotinger and poisson equations as described in Sec. IV $\mathrm{B}$. The quantum mobilities were ealculated by using $\mathrm{Eq}$. (4), assuming periollic boundary conditions in an interval of four doping periods, ant incorporating inte the calculations only the quantum stale belonging to the three lowest energy minibands. Rew sults of the theary are shown by lines in Fig. 6 .

Figure 6 shows that for miniband $E 1$ the theoretion quanturn mobilites are in excellent agreenent with the experimental ones. For excited minibands $E_{2}$ and $E_{3}$ there is an order-ow-magnitude agutement between thery and experimen, although the overall agreement is not so good as for miniband $E I$. Neventheless, it is to be notied that the theory reproduces the main feature of the 22 quantum mobility dependence on $a_{3}$, way a decrease toward short stpertatice periods.

Ou inyestigation can be sumanarized by stating that, al 8 given superiatice pariod, the quantum mobility is higher in more energetic minibands, and when the period is matie shorter, the quxnmum mobilitites derease. The decreasing be havior coward shon superlatic periokis develops at $d-300$ $A$ for miniband $E 3$, bat only al $d+200 \AA$ for miniband E2; for miniband $E 1$, theory prediets a decreasing behavior only when $d<50 \mathrm{~A}$. These results can be explained by the depentence of the binding length of camriers on the doping period 4 . As known in Ref. 12 for B-doped samples with a single doping layer and in Ref, 13 for gated s-doped samples, the mobility is very sensitive to the mean distance betwe the imptrity layer and the charge carriers. The mean distance berwen tartiers contined in miniband $E i$ and an impurtity layer at $z=0$ can be estimated by $\sqrt{\left\langle z^{2}\right\rangle_{\varepsilon i}}$ where

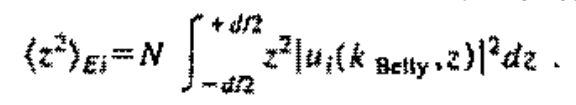

A piot of $\sqrt{\left(z^{2}\right)_{\text {g }}}$ for a cantar density of $z_{5}=4.6 \times 10^{12}$ $\mathrm{cm}^{2} N$ is shown the Fig. 7 . A comparisten of Figs. 7 and 6

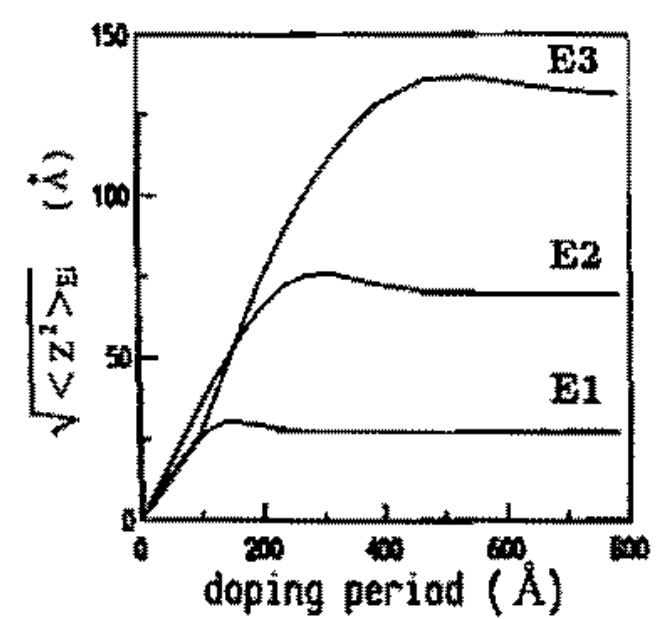

FIO. 7. Mean distance berwert carriers confined in minibands E1,$E 2$, and E3 35 a fonetion of the doping period for periodteally

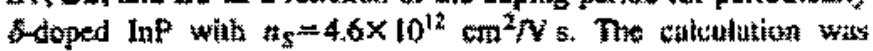
that using Eq. (8).

shows that there is an outstanding correlation betwetn the quantum mobility in a mintwand, and the mean fistance befween ifs carriers and an lompunity sheet.

\section{VL. CONCLUSION}

The Shubniko for periodically $\&$-doped InP as a function of the doping period in samples with a density of carriers arount $-4.9 \times 10^{12} \mathrm{~cm}^{2}$ per doped layer and foping period in the range $90-300 \mathrm{~A}$. It is verified that each miniband manilesis itself in the Sall spectum through a single esclilstory componen, which correspontes to the belly extremal orbit of its minü Ferni surface. The quantum oscillations associated whil individual minibands were isolated from the underlying mognetoresistance spectrum by Fourter techniques. From the individual oscillatory components, the quantum mobility for cach minibant was estimaled.

A theorelical model for the quantun mobilily was devel. oped, which yieks a fait agreement with the experimental resuls. The theoretical model predicts that the mobilities will increase with the miniband index, and the mobilities secrease when the doping period is made shonter. The onsel of the decreasing behavior octus at $d-200 \mathrm{~A}$ for miniband $E 2$, and besow $d-50$ \& for niniband $E 1$. The dependence of the guantum mobility in an individual miniband on the distance belween dopant sheets shows a salient correlation with the same dependence of the mean distance between is carriers and the doped layer. This demonstrates that the mean distance between confined carriers and inpantites is the ditu teminam of the absolute value of cartier mobitity which can bx achieved in buloped systerns.

\section{ACKNOWLEDGMENTS}

Calculatons were performed using the facilities of the

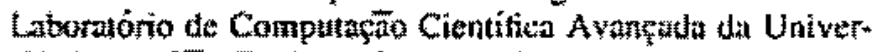
sidade de São Paulo (LCCA.USP) A.B.H. ackrowladges suppor by FAPESP, Grant No. 945645-7, and CNPq. Gran No. 306335188. 


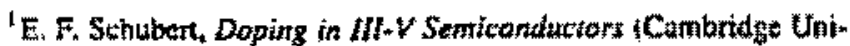
versity Press, Cambridge. 1993 , p. 433.

${ }^{2}$ E. F. Sthuber, in Epilaxial Micrustructures, edited by A. C. Cossard. Semiconductors and Semimetuls Vol, 40 (Acudetric Press. New York, 1994), p. 1.

${ }^{3}$ R. Droupidi, S. D. Parker. E. Sktras, R. A. Stradling, R. L. Wilbans, R. B. Beali, and 1. J. Harris, in High Nugnetis Fields in

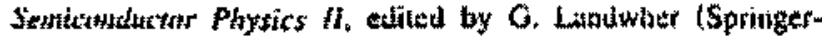
Veriug. Berlin, 1989). p. 199.

45. Yamula and T. Makimole, Appt. Pays. Lett. \$7, 1022 (1990).

'P. M. Kixemsad, B. F. A. van Hesl, F, A. Hlom, R, val Daten, M. Leys, I. A. A. 1. Perenkoon and 1. H. Wotidr. Physicu B I7, 485 (1992).

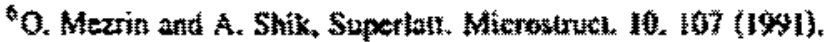

${ }^{7}$ O. A. Mezin, A. V. Shik, and V. O. Metrin, Sernicond. Sct. Technol. $7_{3}, 654(1992)$.

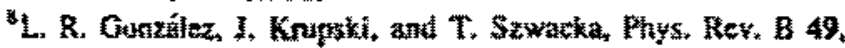
1111 (1994).

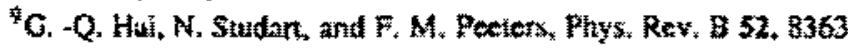
[1994];

${ }^{10}$ G. -Q. Hint and N. Studart, Phys, Rev, B \$2, R2245, (1935).

"P.M. Koenrad, A. F, W, yan de Stadu, J. M. Shi, G. Q. Hai, N. Sividun, P. Vansuni, F. M. Peeters. 1. T, Devreese. I. A. A. J. Perenbusm, and I. H. Woluer. Physien a 211. 426 (1495).

${ }^{12}$ A. B. Henriques, Phys. Rev. A 53,16365 (1596).
"3. L. C. D. Gonçalves and A. D. Hentiques, Stmicond, Sti. Technol. 12. 205 (1997).

${ }^{1}$ D. Schneider, D. Kürup. A. Pitelun, W. Ontuert. A. Sthaitheizki, and K. Hansen, Z. Phys. 85.281 (1994)

${ }^{15}$ D. K. Schroder, Semicontustor Material and Davice Charater. ization (Wiley. New York, 1990), p. 43.

${ }^{16}$ L. Hedin and B. Lundayist. J. Phys. C 4, 2064 (197),

${ }^{17}$ R. Fletcher, E. Zaremba, M. D'lorio, C. T. Foxen, and J. J. hiatris, Phys. Rev. 841,10649 (1990).

${ }^{ \pm 8}$ A. B. Henriques and L. C. D. Gonçalves. Semieond. Sci. Technot. 8, 585 (1993).

${ }^{19}$ A. B. Henriques, Shess. Rey, 30,8658 (1994),

${ }^{20}$ P. T. Coleridge, R. Sioner, and R. Fletcher, Phys. Rev. B 39, 1120 (1989).

21L. M. Roth and P. N. Argyres, the Physits of III. Compounds, elited by R. Willarison and A. Setr, Setmicanducrors and Semi-

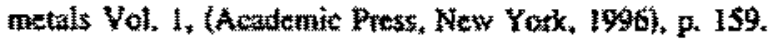

${ }^{22}$ 8. Ulrich, E. F, Schuber, 1, B. Stut, ant 1. E. Cunningham,

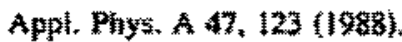

${ }^{23}$ A. B. Heqriques, L, C. D. Gençalves, B. L. Souta and B. Yavich, Semicont. Ser. Tentind. 11. 100 (196).

3W. H. Press, B. P, Fannery, A. A. Trukalsky, and W. T, Vetterling: Nuhericul Recrpes (Cambritige Universily Press. New

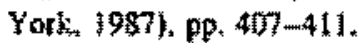




\title{
Quantum transport in periodically $\delta$-doped GaAs
}

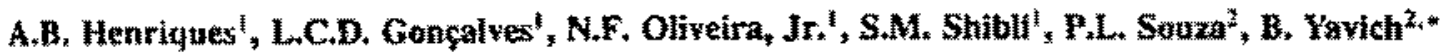

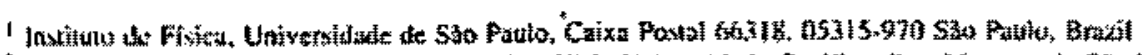

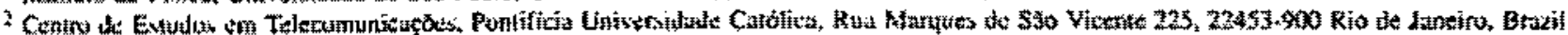

Retivivit: It Aptil igon

\begin{abstract}
The Shubnikov-de Hass spectra of GuAs sample: with a periodical doping with $\mathrm{Si}$ were meusured at $4.2 \mathrm{~K}$ using tields of 0. lat T. From the Shubnikov-de Has specm trun the quantum nobilities associaled with individual minibartods were tstimated for eacla sumple. The shet density of Si atoun in each doning plate was fixed approximalely $2.5 \times 10^{1} \mathrm{~cm}^{-2}$ in all semples and the doping period was varies in the tange $40-1000 \AA$. The quantum mobilities obwinted experimentally are compared with theoretical calcu bitionts using the fandon plase approximation to deseribe the stroned intertalion between electrons and charged impurtises. The theory kescribes quatitatively the results of the expentment, ite an increase of the quantum mobility with the index of the minibant, and a decrease in the mobility in all ninibands when the doping period is made shorter fwith a

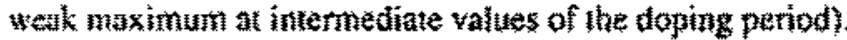
Whous possible improtements of the model are sutsested.
\end{abstract}

PACS: 73.20.0x: 73.50.J; 73.61,Ey

\section{Intraduction}

Planar. of $\delta$-doped semicondutlors have attracted interest in recent years in respect to their technologitenl toplication ant fundamental physics $[1,2]$. The etectronic structure of these systems can be modeled in the effective mass approximation $[3,4,5,6]$ which allows to explain the main characteristics of their opticil and transpor properties $[7,8]$. The spreading of the dopant anoms around the doped plame of the host crys" til bas been studied by various experimental techniques such as $X$-rays [9. 101. scanring lunneling microscopy [1 1] and capacitunce-voltage profling [12]. indicating that localizatitu of dopants within at most 2 monolayers of the host crys.

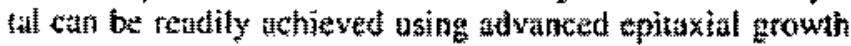
tachotques.

One important aspect of todoped semiconducters is that

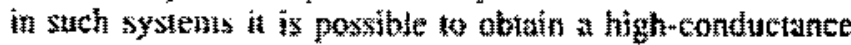

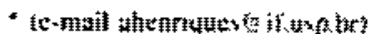

channel of electrons, which lavours their appliculion in electronic devices. The contituctance of the sample ean be enhated still further by introducing a number of extully spaced omtoped planes in the hosi crystal $\lfloor 1,2)$ fortod. icatly ondoped semicondustor. A releyunt pirsmeter of il

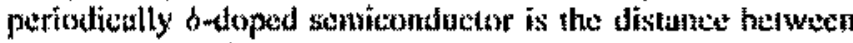
dopunt shects, $d$. At linge values of $d$, Itte $d$-wells ire intoupled, and electrons become fully localized around a given stheet with charged impurities; the mobility of these electrons is limited due to their strong Coulomb interaction with the impurty sheet. When $d$ is reduced, the coupling between b-wells increuses; an increasing amount of electrons will inferace simututateously with several impurity sheets, which results in a retuction of their mobility.

In the present work, we present an experimental study of the etcotron mability dependence upon the spacing betweat impunty layers in perictically b-doped GaAs. The sel of samples used had a nearly constant areal density of impurt. ties, with a doping period covering the range of 40 , $1000 \mathrm{~m}$.

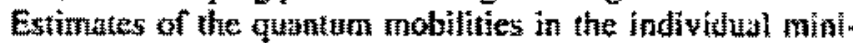
butus were made from the Shebnikoy-de hans (Sdh) specton of the sumples at $4.2 \mathrm{~K}$ in fields of $\mathrm{O}-14 \mathrm{~T}$. The experimental mobllites are compared with the theoretical yalues obutined by using the RPA theory developed tecently for the quantum mobulty of periodically b-doped semicontutetors (13).

\section{Experimental}

The $\delta$ doped structures were grown at a Varian CEN II MBE system. The substrate temperature was $540^{\circ} \mathrm{C}$ determined with an freon $V$ series pyromeler, whth the enitssivity ser at 0.70 . A ratio of $\mathrm{As}_{4}$ and $\mathrm{Ga}$ benrs equivalent pressure around 20 was chusen. These growth conditions ensure a $(2 \times 4)$ As stabilized surface reconsiruction during MBE growth. In all samples, a MBE undoped GaAs buffer layer was grown before doping. The growh rate for MBE was estimated to be $1.5 \mathrm{~mm} / \mathrm{h}$. According to these grow/h rates, the layer spacing was estimated, which was varied from $1000 \mathrm{~A}$ down $1040 \mathrm{~A}$. while the doping level per pertiod was kept constant in order to give concentrations of about $2.5 \times 10^{12} \mathrm{~cm}^{-2}$.

The Shumikoy-de Haas experiment was catried out

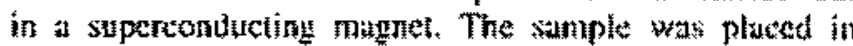




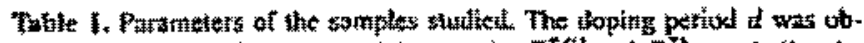

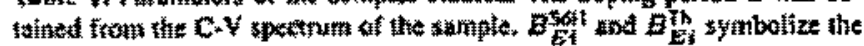

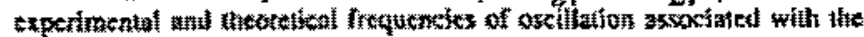

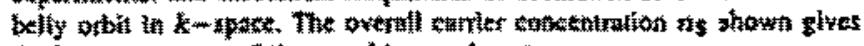

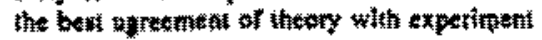

\begin{tabular}{|c|c|c|c|c|c|c|c|c|}
\hline \multirow[t]{2}{*}{ Simpte } & \multirow[t]{2}{*}{$(\mathbf{s})$} & \multicolumn{3}{|c|}{ 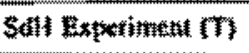 } & \multicolumn{3}{|c|}{ 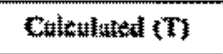 } & \multirow{2}{*}{ 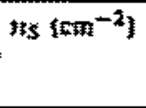 } \\
\hline & & 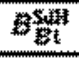 & 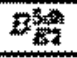 & 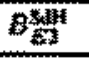 & \# & 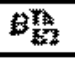 & $\mathrm{Ba}_{\mathrm{S}}$ & \\
\hline DNIE & 18 & 44.5 & 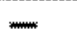 & $m$ & 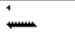 & - & س. & $1.93 \times 10^{12}$ \\
\hline tekn & 63 & 53.9 & m. & - & 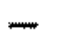 & - & سـ & $1.84 \times 10^{12}$ \\
\hline Det24 & 93 & 52.4 & - & $m$ & $m$ & - & سـ & $2.01 \times 10^{12}$ \\
\hline DNEI & 127 & 4. 3 & 21. & $-m$ & 41.9 & 21.7 & مسب & $2.34 \times 16^{12}$ \\
\hline LNat & 219 & 31,3 & 15.3 & $-m$ & 33.1 & 16.5 & تعد & $2.17 \times \mathrm{su}^{12}$ \\
\hline Dra32 & 389 & 39.6 & It).5 & 478 & 35.5 & 127 & 6.4 & $2.47 \times 19^{15}$ \\
\hline DN3\% & 611 & 41.5 & 10.2 & 2.3 & 36.5 & 131 & 4.5 & $2.37 \times 10^{13}$ \\
\hline DNM! & 950 & 45.3 & tIIst & s.jo & $35: 5$ & 11.7 & 3.8 & $2.48 \times 10^{12}$ \\
\hline
\end{tabular}

liquid the at $4.2 \mathrm{~K}$. The magnetoresistance measurements were made in constant cument mode, employing currents of $\sim 10 \mu \mathrm{A}$, and using sotr-eontact geomotry; the samplet were approximately square, with contacts in the corners. The magnetoresigtance oseillations were measured in magnetic, fieldis of iniensity up to $14 \mathrm{~T}$.

\section{Experimental determination of the minlband mabilitites}

As shown in $[4,5]$, in periodically $\delta$-doped semiconductors ench minibsnd manifests itself in the Shubnikov-de Haas spectrum (SdH) as a separate oscillatory component. The oscillatory contribution to the magnetoresistance from a mini" band whose bandwidth is smalier than its Ferni energy, l.e. $\Delta_{n}<\phi_{k,}$ will be [\$]

$$
\begin{aligned}
& \frac{\Delta \rho_{m z}}{p_{0}} \sim-\frac{X}{\sinh X} e^{-\alpha_{n} z}\left(2 \omega_{0}\left(\beta_{n} u\right) \cos \omega_{n} u\right. \\
& \left.+8 \epsilon_{n} 3 \mathrm{~m}\left[\mathrm{e}^{-i \beta_{n} \mathrm{u}} \Phi\left(1 / 2,2,2 i \beta_{n} t\right)\right] \sin \omega_{n} t\right] \text {, }
\end{aligned}
$$

where $X=2 \pi^{2} T / B, T$ is the temperature in unts of $n^{2} / \mathrm{Ag}_{\mathrm{y}} m^{*} a_{\mathrm{B}}^{2}, \mathrm{u}=1 / B, \alpha_{n}=n / \mu_{\mathrm{Q}}(n), \mu_{\mathrm{Q}}(n)$ is the quan" tum mobility in the nth miniband, $a_{n}=\pi \Delta_{n} \omega_{n}=$ $2 \pi\left(\phi_{n}-A_{n}\right), \epsilon_{n}$ is a dimensionless dispersion factor deter. mined by the coupling strength between neighboring wells and $\Phi(\alpha, \beta, \gamma)$ is the degenerate hypengeonetric function. The oscillatory magnetoresistance contributon from a mini" band whose bandwidth is larger than the Fermi energy, i.c. $\Delta_{n}>\phi_{n}$, can be approxinated by the usual expression associated with an unrestraiaed free electron gas in three dimensions [14]

$$
\frac{\Delta \rho_{x x}}{\rho_{0}} \sim-2 \frac{X}{\sinh X} \frac{e^{-a_{n} u}}{\sqrt{u}} \cos \left(2 \pi \phi_{n} u-\frac{\pi}{4}\right) \text {. }
$$

The carrier concentration, $n_{\text {s. }}$ was determined tor each sample from the frequencies detected in its Shubnikoy-de Haas spectrum, as described in [13]. In such a procedure, the Schrodinger and Poisson equations for the superlattice are solved simultaneously with ns as a variable inpul pararneter. The value of As $_{\mathrm{s}}$ is varied until the theorelical Sdft frequencies uchieve best ugreement with the experimental ones. Results of such an antlysis are summarized in Tuble 1 . In atlcition to the concentration of free carriers, the analysis of the

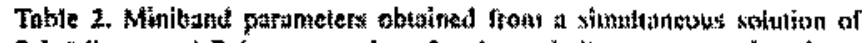

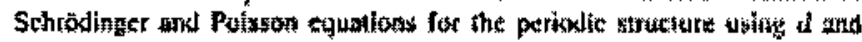

\begin{tabular}{|c|c|c|c|c|c|c|c|c|c|}
\hline Sample & $\frac{\Delta_{1}}{\text { fanctil }}$ & 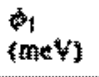 & 糙 & 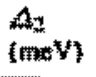 & $\begin{array}{l}\text { कx } \\
\text { ftrte }\end{array}$ & 1 & $A_{1}$ & (nize & $t$ \\
\hline atis & 158 & 168 & menn & 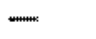 & 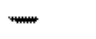 & . & 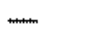 & $m$ & س. \\
\hline DNat & Iff:8 & Imen & 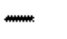 & mom & 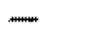 & 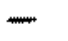 & 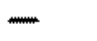 & - & - \\
\hline DN24 & 958 & 9.9 & 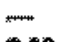 & $m_{1}$ & $=$ & سשس. & 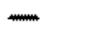 & - & $\rightarrow$ \\
\hline DN30 & 27.1 & 81.2 & 0.30 & 96.5 & 376 & س & $m$ & $-m$ & $\rightarrow$ \\
\hline DN26 & 3.7 & 375 & o.te & 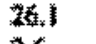 & 籍部 & 6.10 & 57.1 & D.8 & - \\
\hline DA432 & 6.6 & $6: 1,7$ & (c) & 党象 & anta & 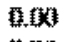 & 12.0 & 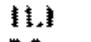 & $\rightarrow$ \\
\hline LN38 & an & 53.6 & ates & a. & 勧1. & 整践 & 1.6 & 7.8 & - \\
\hline D赫政 & $a$ & 61.5 & $0, \infty$ & 青象 & 20.3 & alo & 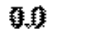 & 6.5 & - \\
\hline
\end{tabular}

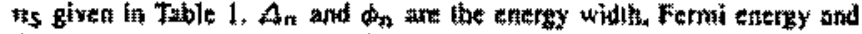

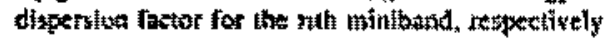

Shubuikow-de Hass spectrum also outputs the Fermi energy. $\phi_{n+}$ the width, $A_{3 *}$ and the dispersion factor, $\varepsilon_{n+}$, for all minibands: the paramelers so obtuinted are displayed in Table 2. To lsolate the oscillatory magneloreslstance associated with a giyen miniband from the rest of the Shubnikov-de has spectrum Fourier fillering lechniques were used. Figure 1 iflustrates this procedure for sample DN30. Figureta shows the raw magnetoresistance spectrum at $4.2 \mathrm{~K}$; Fig. 16 shows the Fourier transform of the SdH curve plotted against inverse field; dashed lines show the filtered Fourier transform, with band-pass filter parameters adjusted to isolate one of the Fourier peaks seen.

Prior to taking the Fourier transform, and with the motive of reducing the unwanted background of monotonous magnetoresistance, the magnetoresistance curves were differeniated. After the application of the bandpass filter, all steps leading to the isolated Fourier transform were reversed: an inverse Fourier transformation was applied, and the mag. netoresistance oscillations were integraled numerically. Figure led sfrows the isaluted oscillatary eomponents so obtained for sample DN30. The isolated oscillations cover a smaller range of fields than the measured interval $(0-14 \mathrm{~T})$ because a certain interval at each end the length of which is inversely propartional to the FWHM of the Fourier filter) is lost due to end effects (see, for instance, \{15).

The guantum mobiliky corresponding to a given mintbath yas estimated by fiting the isolated magnetoresistance ostillations associated with it by ejther (1) or (2), with the guantum mobilty being the single fitting parumeter. The indivitual oscillations were fitted using (1) when the miniband energy widit was namow $\left(\Delta_{\mathrm{n}}<\phi_{n}\right\}$, or $(2)$ witen the mini. band width was wide $\left(\Delta_{n}>\phi_{n}\right)$. Parameters $\Delta_{n}, \phi_{n}$ and $\mathrm{F}_{n}$ used in the fitting equation were fixed at the values given in Table 2 and the temperature was set $104.2 \mathrm{~K}$ as used in our experiments. The only remaining parameter, the quasn. tum mobilisy $\mu_{\mathrm{Q}}(n)$, was adjusted for best agreement with the experiment. To illustrate the fiting procedure, the individual oscillations and the fitted curves for sample DN30 are shown in Fig. Ic-d; a fil with theory in this case yielded $\mu_{\mathrm{O}}(E 1)=504 \mathrm{~cm}^{2} / \mathrm{Vs}_{\mathrm{s}}$ and $\mu_{\mathrm{Q}}(E 2)=1094 \mathrm{~cm}^{2} / \mathrm{Ns}$. All other samples underwent the same treatment, and the quantum mobility values obiained are plotted against doping period in Fig. 2. 

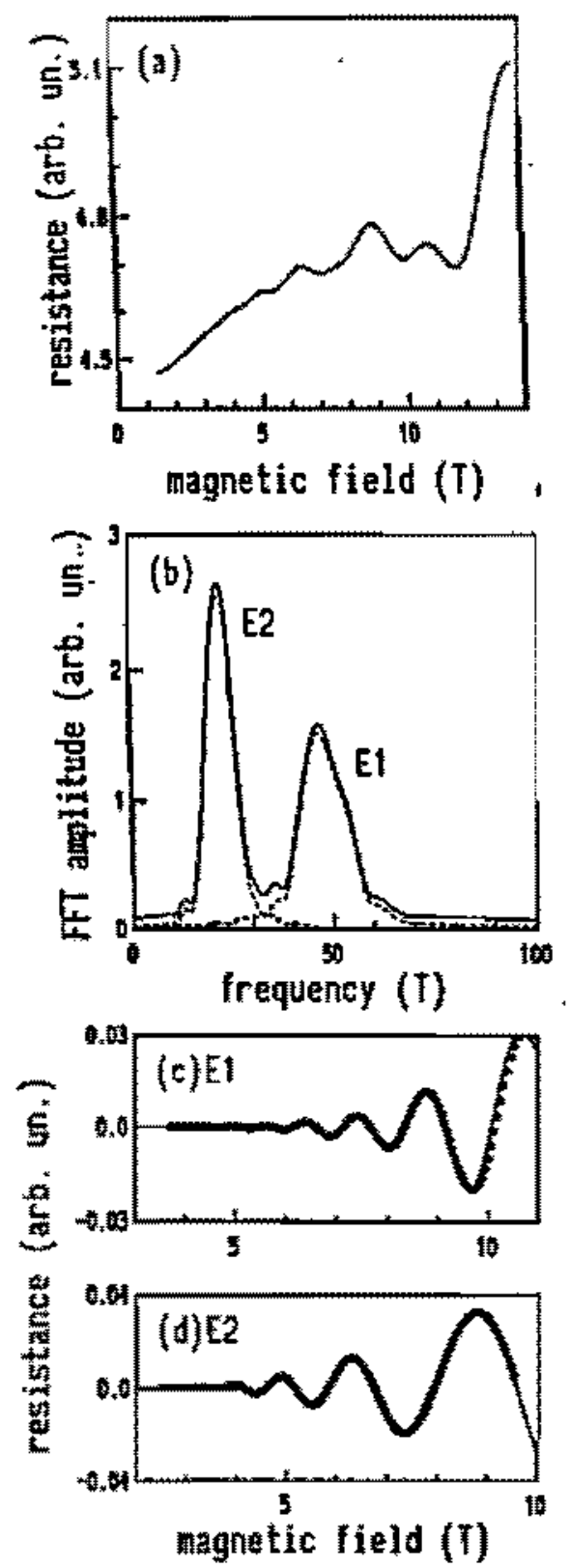

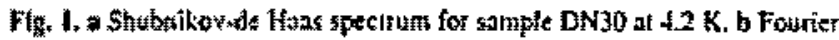

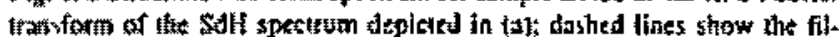

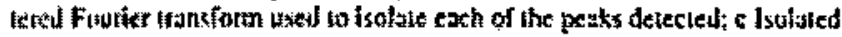

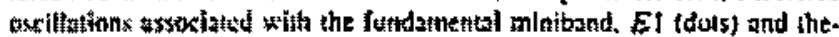

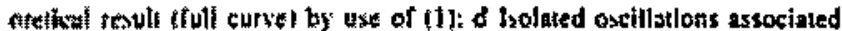

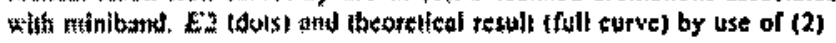

\section{Calculation of miniband quantum mobilitles in the $\mathbf{R} \mathbf{P}^{\mathbf{3}} \mathbf{A}$}

In this section effective ntomite units are used, whereby the units of mass, length and energy are the effeclive mass

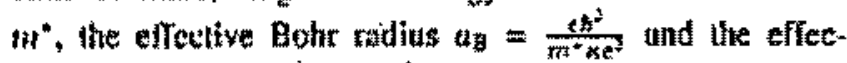

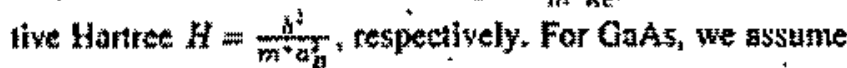
$m^{*}=0.057$ mitid $\mathrm{e}=12.6$, which gives $\mathrm{ag}_{\mathrm{g}}=99 \mathrm{~A}$ and $H=1 ! .6 \mathrm{meV}$.

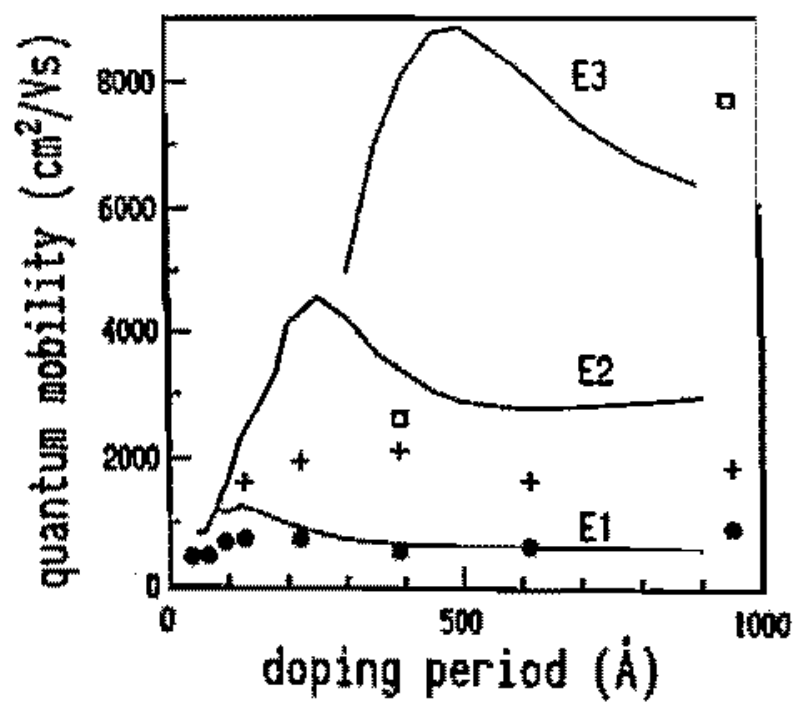

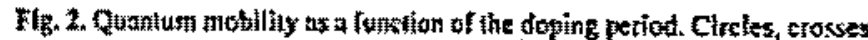

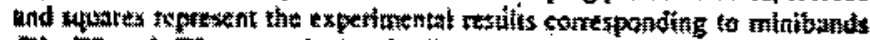

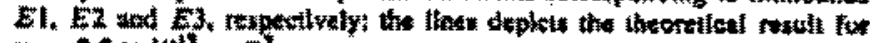
nt: $2.3 \times 141 \mathrm{con}$

The seattering rute of electrons from a given quantum - state for $T=0 \mathrm{~K}$ can be oblained from the fermi golden rule, thking the Coulomb interaction between electrons and ionized impurities to be the seattering mechanism. Considering the sctuttering processes of carriers at the fermi surface. one objains for the quionturn lifetime of the state $k$ of the the electronic miniband in the randon phase approximation (RPA):

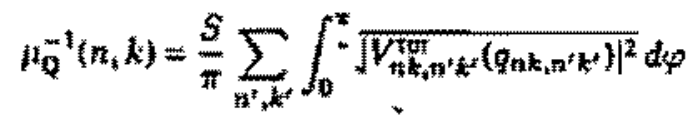

where the summation exteads over the quantum states $\left(n^{\prime}, k^{\prime}\right)$ which lie tolow the Fermil level (i.e. $\phi_{n^{\prime} k^{*}}>0$ ).

$$
q_{n k, n^{\prime} k^{*}}=2^{i / 2}\left[\phi_{n k^{\prime}}+\phi_{n^{\prime} k^{\prime}}-2 \sqrt{\phi_{n k k^{\prime} k^{\prime}}} \cos \varphi\right]^{1 / 2} \text {. }
$$

the integration vatiable $\varphi$ is the angle of scattering formed between vectors $k_{1}$ and $k_{1}^{\prime}$, and

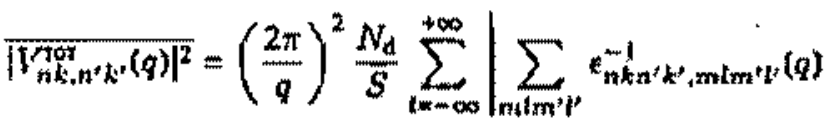

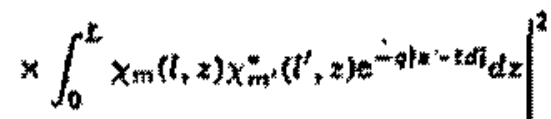

represents the statstical average of the marix elements of the two-dimentional Foutier teansform of the seatiering po. iential. In the latter equation the summation extends over all the eletronic energy levels, $N_{\theta}$ is the areal dersity of sin. gle charged donot nsoms in ach doping period, distributed along the $z$-tirection in a plane of zero thickness, $d$ is the superlatice period, $l=N d$ is the Born-von Karman period,

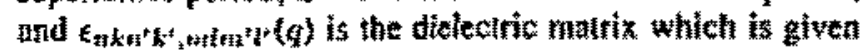
by

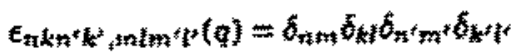

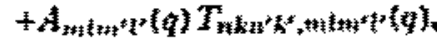




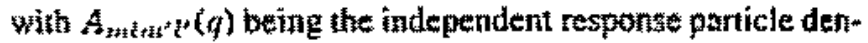
sily matrix, given an the Appendix of [16], and

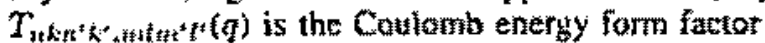

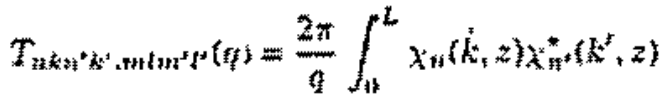

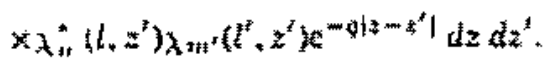

In these equinitions, $\chi_{+1}(k, z)$ represents the superlattice Bioch wave function in miniband $n$ at the wave vector $k$, obtatined from a valf-consisten solution of Schrottinger and Poissor sanuinons for the periodicully $\delta$-doped strumture, als destribed in $[4]$.

For comparison with the exptriment, resulis of the theoretical calculatons of the mintband çuantum mobilities obtilined through (3) at the waye vector $k$ associaled with the belly orbit $(k=0$ for minibands $E l, E 3$ and $k=\pi / 4$ for miniband E2) are showa by solid lines in Fig. 2 .

\section{Discussion}

The experimental quantum mobities askociated with indi: victual minibands are shown by dor in Fig, 2 as a fanction of the doping pertod t. The experiment shows that at uny doping period of the guatam mobility increases with the miniband index. At large values of $d$ the wells are uncoupled. and the results for the sumple with a period of a = 1000 A are similar to repors on the subband quan" tum mobilities measured for isolated sulvells [17]. As the distance belween neighboring welts is decreased, the mini* burut mobilities show a tentency to decrease. More exterided minibands show greater sensitivily to the coupling beiween adjacent welly when d is reduced from $1000 \mathrm{~A}$ to $400 \mathrm{~A}$ the mobility in mintband E.3 decreases almos: 4 foid. whereas less extended states E2 and $E 1$ show no bistuct change in

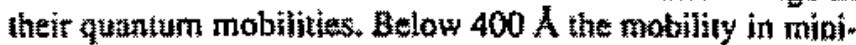

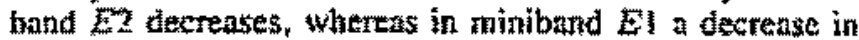
nubility is detected only below $a-100 \mathrm{~A}$.

Such a belavior of the quantum mobility is merprated in tems of the changes in the Cottomb interaction between electrons in a given miniband and the charged impurtites. Because of their longer meat distance to the impurity shetet. electrons in more energetic minibands are seatuered with less efticiency and display a higher quantum mobility. At large values of 1 , the wells are uncoupled, and electrons itteraet only with the charged impurtites around which they are tocatized. When of is decreased, the cotspling increases, and electrons begin to interact simulantontily with several impurity sheets, which redues their mobiliy. When $d$ is decreased from a large value, mote energetic subbands be. konging to adjucent wells begin to couple sooner than less sentratic ones, hente the onsel of a decreasing mobitity tovats $t=0$ in more energetic minibands occurs al jarger

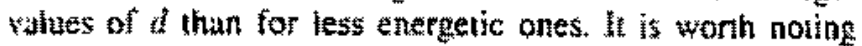
that when th 1 is reduced, the miniband mobitities attain a weak maximum before the rapid tecrease al still shorter values of t. Such a mobility enthancement has also been obserted in

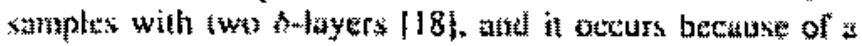
stmiller overlup bemeen the electronic change dunsity and

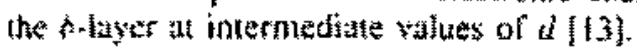

The theoretical quontum motwihtes were calculated as a function of the doping period for currier concentrations of $n_{5}=2.5 \times 10^{12} \mathrm{~cm}^{-2}$. Thu aunntum mobities were walm culated by using (3) assuming priodic (⿻) in wn interval of 4 doping periods: and incorpszating into the culculations only the quantum states belonging to the 3 lowest energy minibands. Resuls of the lheory are shown by lines in Ftg. 2. The theoretital quantum mobilities dix. play the same features as the experimental onts. $\mathrm{i}, \mathrm{e}$. an in* crease whithe ininiband index at a fixed specing between the twwells and is rapid decrease when $d$ is reduced below a certain value, whith is larger for more extended minibands. However, good atuntiulive agrement between theory and experiment octurs for the lowest entrgy miniband $E$ l only, and is not so good for the excited states $E_{2}$ and $E 3$. The discrepancy between heory and experiment can be linked to the restrictions mude in the theoretical calculations. Our numerical calcultions diti inelude only a fixed number of

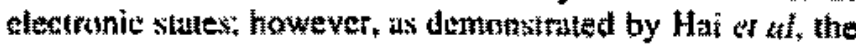
contributions to the dielectric matrix which arise from states thove the Fermi chergy leat on a relitction in the theoretical quantum mobitities, lise affect being greater upon the more exiended minibunds [17/1. Another relevant effect not accounted for in the theory is the finite width of the toped layers. which aiso leads to an overestimation of the cuanIum mobitities in excited minibands 119]. Finally, the eftects of non-purabolicity were ignored in the calculatons; given that the confinement energy for electrons at the Femi level is around 100 meV, the nen-parabolicity stowtd also contribute to a reduction in the theoretical values of quantum nubilitity.

\section{Conclusion}

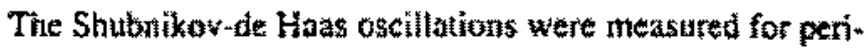
odically $\delta$-toped GaAs as a function of the doping period in samples with a dersily of carriers around $-2.5 \times 10^{\text {t? }} \mathrm{cm}^{*}$ per doped liyer and toping pertod in the range 40 - $1000 \mathrm{~A}$. The quantum oscillations axsocialed with individuat minibands were isolated from the background magnetoresislance spectrum by foorier techniques: From the individual oscillatory components, the quanum mobility for each mintband was estimated. It is obtaned that at a given stperlation pex riod. the guantum mobllity is higher in more energetic nimibands, and when the period is made shorter, the quantum mobilizes demreast. These results are explained it ans of the deperdence of the binding length of carriers on he doping period $a$.

Numerical calculations of the miniband quantum mobi:

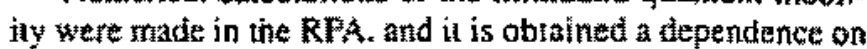
the doping periodicity in qualiative agrement with the experimental results. although the quantrative agreament is not futly satisfactory tor the excited minibands. Various limiling fuctors of the therry which could be improved upon were indicated.

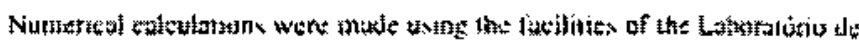

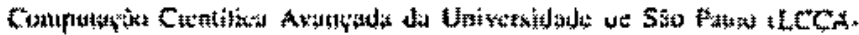

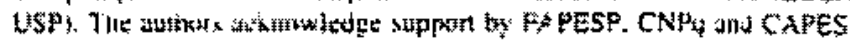




\section{References}

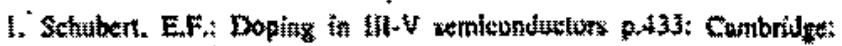
Combridue Univeriny Prow 1993

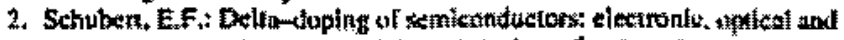

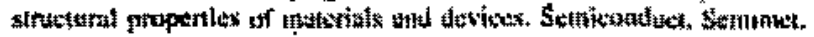

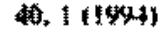

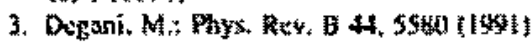

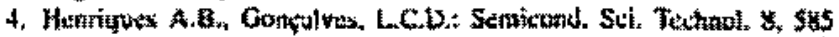
(1093)

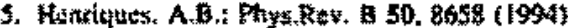

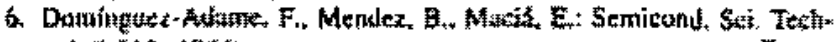

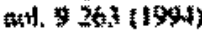

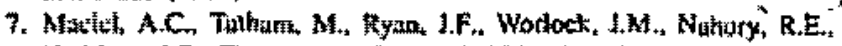

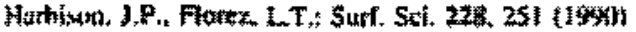

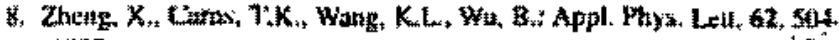
(16)3:

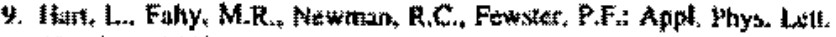
62. 2218 (19)

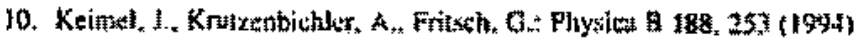

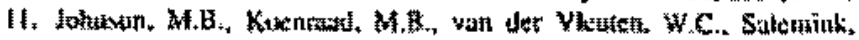

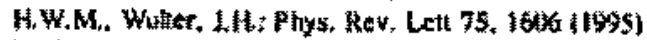

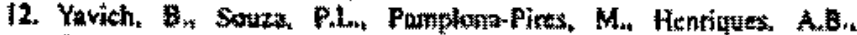

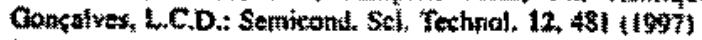

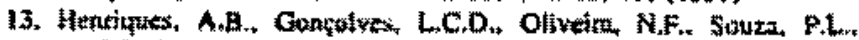

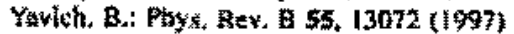

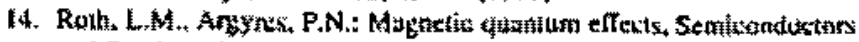
and Semintretils 1. 159 (196)

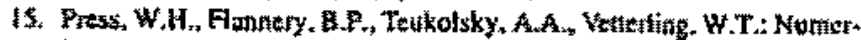

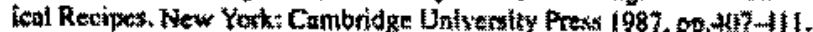

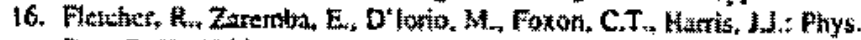

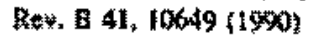

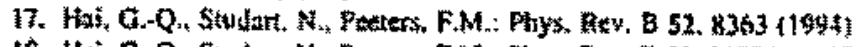

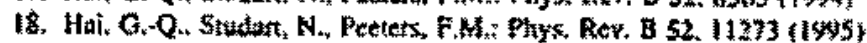

19. Henrikutus. A. A. Fhys. Fev, B 53, 16360 (1996) 
phise. stat. sol. (n) 164. $133(199 \pi)$

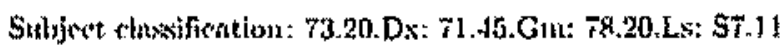

\title{
Band Gap Renormalization in Periodically Delta-Doped Semiconductors
}

\author{
A. B. Henriques (a), S. Oaukhov (a), L, C. D. Gonchlyes (a), \\ P. L. SOUzA (b), and B. YAVICH (b)
}

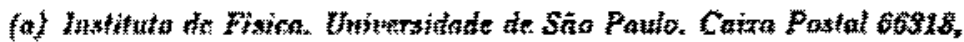

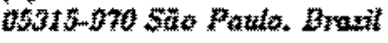

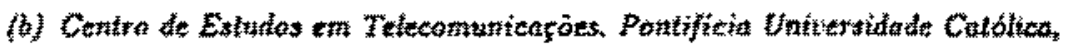

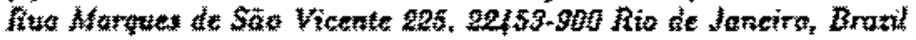

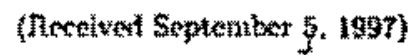

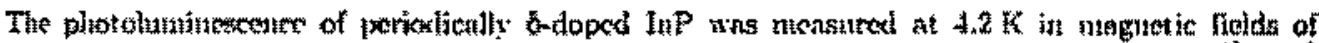

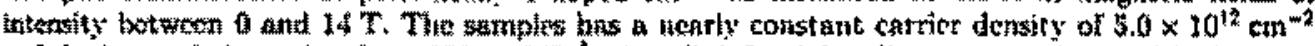
asd dopiag portol vatying from 130 to $243 \mathrm{~A}$. A well defined fan diagrath issociatod with the optiw

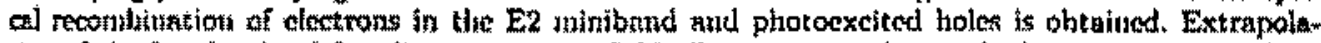
tion of the Landau level fan diagram to zero field allows us to estimats the band gap renormalizaw tion (BGI). The BGA decreases rapidiy when the period of the superlattice is increasert. The BCR observed cark be acrounted for by the density of non-confined (three-dimensionat) elections present in the structure.
\end{abstract}

Periodically ondoped semitondnctors fom a typa-Ii superlattice in which a high tentsity electron gas is confined by a periodic potential along the growth direction. The dimensonabity of the electronic structure can be twed between 2 and 3 by varying the spaceing betwen the $\delta$-sheets [1]. These properties makf periodically b-foped struetures an attractive syotem in whith to study many-body phenomenn as a function of the dimen simality of the electron gns ronthed in thes system, which is the purnose of the present study. Band gnp renormalization (BCI) is one guch effect. whisl contssts af the lower. ing of the single-particle energy atates due to exchange and correhation effects. The BCR is manifested in a band gap whith is narrowyer than obserced for the same non-fogentew ate matrinl [2]. For a homogenesus 3D szsten. theoretical calculations in the random phase approxination suggest that the BOH sariss like $n^{3 / 3}$ [2]. where $n$ is the particic

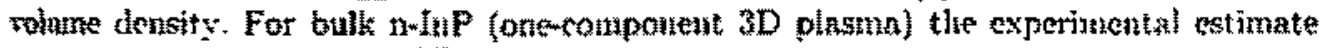
of the BGR at 4.2 k fits a $n^{1 / 3}$ dependence as follows [3]:

$$
\mathrm{BGR}^{30}(\mathrm{pV})=2.25 \times 10^{-\mathrm{s}}\left[\mathrm{n}\left(\mathrm{ctin}^{-3}\right)\right\}^{1 / 3} \text {. }
$$

If we now imagine the physteal system to be conpressed into a uarrow planar space thereby reducing its dimensionality froin 3 to 2) we would expect the BGR to increase, given the enhancement of Coutonb interaction between the charge carriers. This is in weed the casc: for a fixed interparticle separation. tle BGR is always greater in $2 D$ than in $3 \mathrm{D}$ (see [4] and references therein).

In this work we obtained an experimental stimate of the BGR in periodically \& doped InP. In order to extinite tlie BGR. we netsured the photoluminesence of the satmples at $4.2 \mathrm{~K}$ in magnetic fields of intensity between 0 ant $14 \mathrm{~T}$. The samples had 
Thble 1

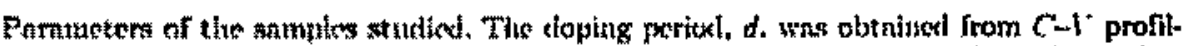

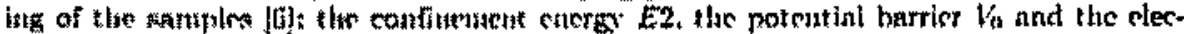

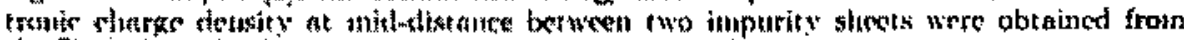

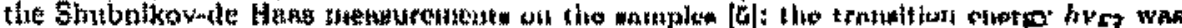
obtained by a fit of Ed. (2) to the experimental fan dingrarn: and the BGR was estimated through $\mathrm{Ea}$. (5)

\begin{tabular}{llllllll}
\hline sampie & $d(A)$ & $E 2(\mathrm{eV})$ & $V_{0}(\mathrm{eV})$ & $Q(d / 2) \mathrm{cm}^{-3}$ & hVG $(\mathrm{eV})$ & BGR $(\mathrm{eV})$ \\
\hline 207 & 133 & 0.104 & 0.092 & $2.30 \times 10^{15}$ & 1.400 & 0.037 \\
200 & 176 & 0.095 & 0.093 & $1.01 \times 10^{13}$ & 1.403 & 0.025 \\
199 & 245 & 0.118 & 0.130 & $0.55 \% 10^{18}$ & 1.400 & 0.017 \\
\hline
\end{tabular}

similar carrier concentrations (about $50 \times 10^{12} \mathrm{~cm}^{-12}$ ), which were measured from the Shubnikov-de Haas effect [5]; the doping period. $t_{4}$ was obtained from capecitunce-yolzage profles of the samples $[5,6]$; retults are stummarized in Table 1 . Also bhown in Trble 1 are

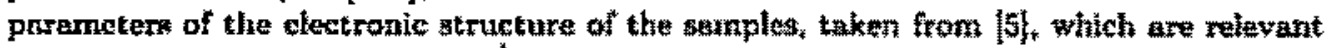
in the present context.

Fig. 1 shows the photeluminescence of the samples; broud 1 L emission detected above the bond top of bulk InP is due to eltctronic transitions between the confmed electron gas and photoexcited holes [?].

When a magnetic field is applied parallel to the growth tirection. the PL develops a veak Landau level structute, scan in Fig. 16 lor sample No. 200 . In order to better roive the

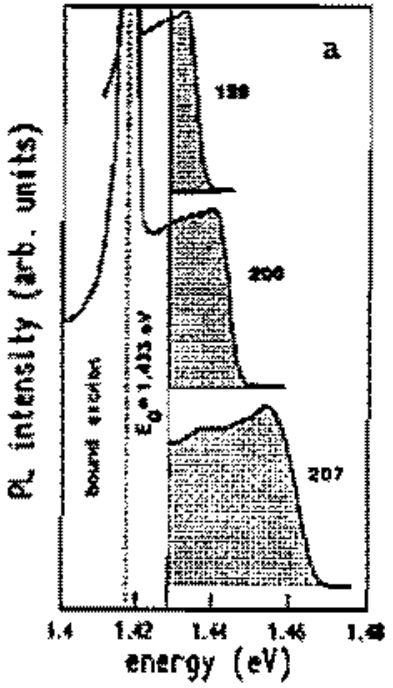

Fix: 1
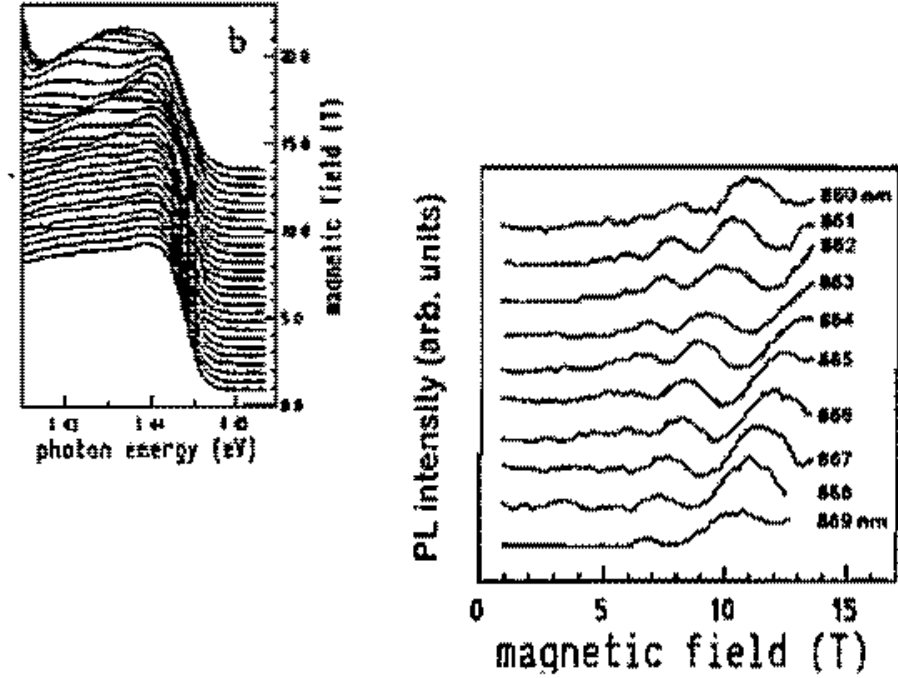

Fig. 2

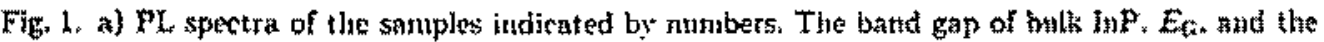

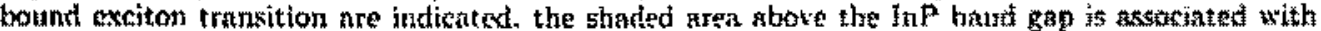

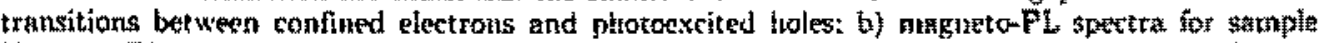
No. 200. The intenzity of the magnetic fielut corresponding to eack curve is obtained by following the baseline to the right hand side

Fig. 2. PL hatensity at hxed photon waveiength as a function of the nagnetic feld intensity tot sample No. 200 . The photon wavelength corresponoing to each curve is indicated 


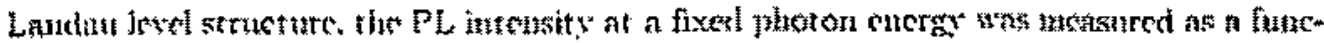

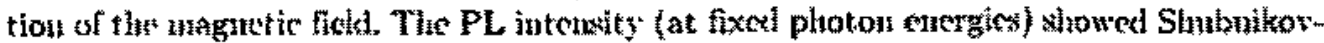

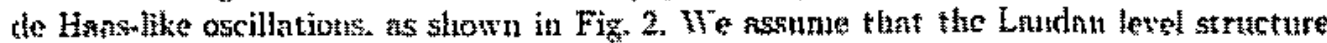

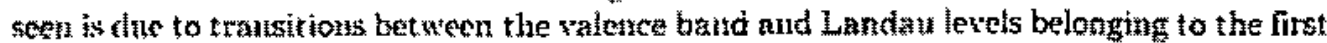

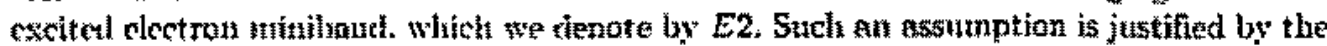

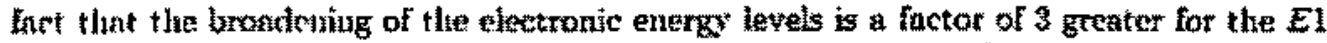

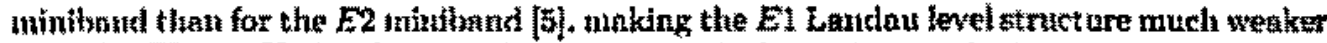

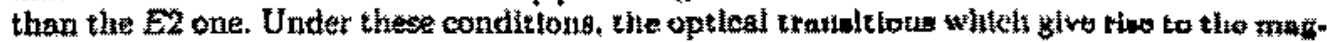

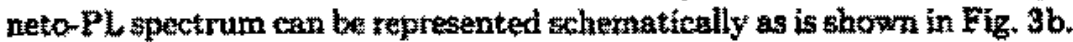

For a photon energy at at $h v_{0}$, the maxima in PL intensity determine the magnetic neld at which given $E 2$ Landau level croses energy by. Therefore, using the magnetom PL depicted in Fig. 2, the Landan level fan diagram can be bult and it is shown in Fig. 4 for all samples.

We will make the simplifying assumption that the BGR effect is described by a rigid saif of the conduction band towards the valence band, which is teaspnably accurate for the shortmperiod samples. According to the whematic xepresentation shown in Fig. 3, the Landau level tan diagram will be determined by the energies

$$
h v_{2}(N, B)=h v_{2}+h^{E}(N, B),
$$

where

$$
h_{\mathrm{E} z}=E_{\mathrm{Q}}-\mathrm{BGR}-V_{0}+E_{2} \text {. }
$$

$V_{0}$ is the hetght of the periodic potential, Ex is the confinement energy of the second miniband, and $\lambda^{E 2}(N, B), N=0,1, \ldots$, are the energies of the $E 2$ inandau levels. We approximated $\lambda^{(N, B)}$ by

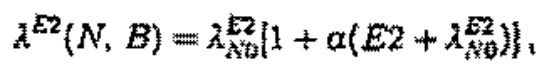

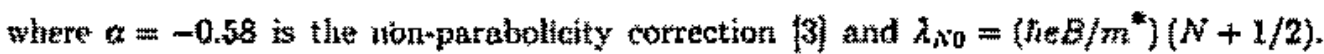
The holes are assumed to be localized a likely source of hole localization are the fluctua tions in the electrostatic potentid of the ionized point impurities which are distributed within the b-layers. The experimental Laadau levels (dots in Fig. 4) were fitted sinultaneously using Eç. (2) with hitg being the single adjustable parameter. The enery sep-

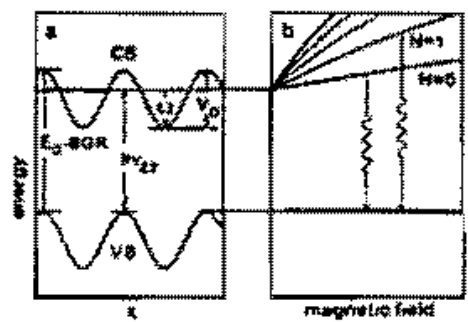

Fix. 3

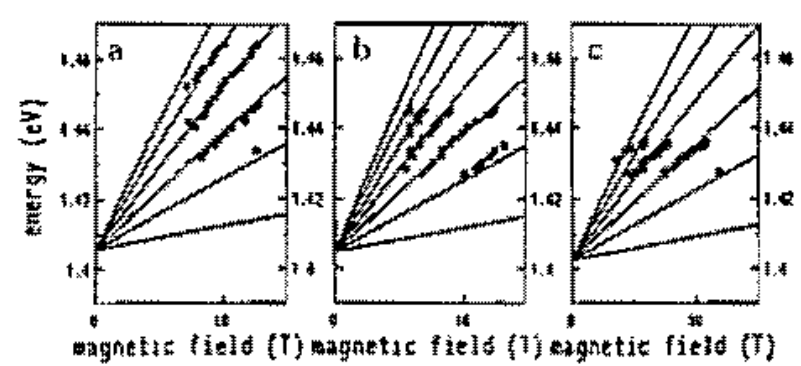

Tis.

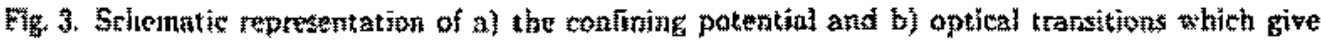
nix to angneto-PL spetrum

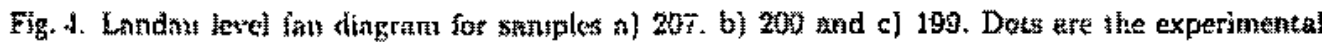

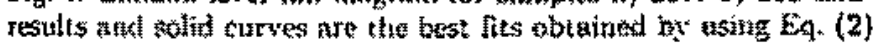




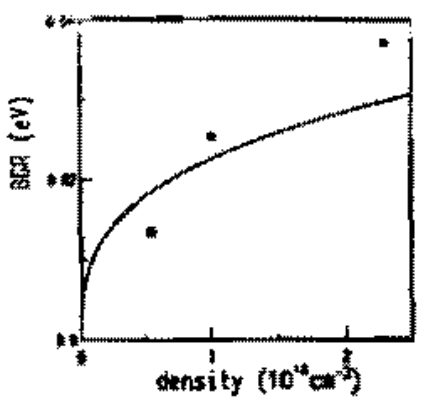

Fig. 3. Dats cortespunt to use BGR given in Table 1. Thie solid carve is given by Eq. (I)

aration, $h w_{\mathrm{E} z}$, yielded by the fit, deternines the BCR to be given by

$$
\mathrm{BGR}=E_{\mathrm{C}}-V_{\mathrm{4}}+E_{2}-h_{\mathrm{E2}} \text {. }
$$

where $E_{G}=1.433 \mathrm{eV}[3]$. and the values $V_{0}, E 2$ were taked trom Table 1 for each sample.

The BGR obtaned in this way is show in Table 1 . We can that the BGR decresses when the superinttice period incresses; in other words, as the dimensionulity of the electron gas progreses from' 3 to 2 , the BCR decreases. This behnviour is exactly opposite to our earlier reasoning that in a 2D system a larger BGR should be observec. This apparent contradiction is explained by the type-n character of the stperlattice lomed by doping a semiconductor periodically: lectrons and holes are confined in alternate layers and thus are spatially separated. For a shortwpriod superlatkice the electrouic structure is $3 \mathrm{D}$, and we expect the experimental $\mathrm{BGR}$ to agree with the result of Eq. (1). However, when the doping period is large, photo-excited holes and electrons will become uncorrelated due to their spatial separation. Our experimental values of BGR can be explained solely by the contributions arising from 3D electrons in the structures. From a self-consistent solution of the Schrôdinget and Poisson equations for each sample. with the sample parameters taken tron $|5|$, we obtained the spatial density of elextrons along the axis of the superiattice. $g(z)$. The value of the electron density at niddedistance between s-layers. i.e. the exact position were the photo-excited holes are loceized. is shown in Table 1 for all structures. The BGR as a function of the electron density in the position of tha lole is plotted ist Fig. 3: the solid curve corresponds to Ex. (1). The aerenent with BGR predicted by En. (1) is an indication that in periodically

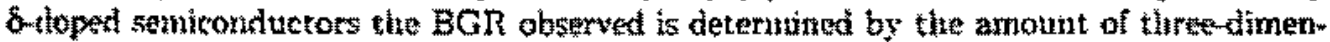
sional (unbornd) electrons present in the structure.

Acknowledgement. This work was supported by Conselto Nacienal de Desenvolwimesto Cientifico e Tecnológico. Grant No. CNPBg a $306335 / 88$.

\section{References}

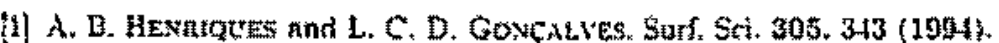

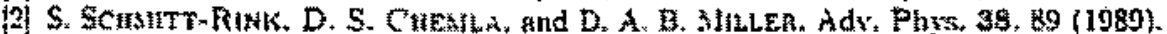

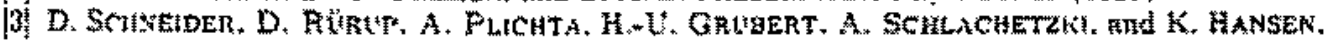

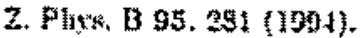

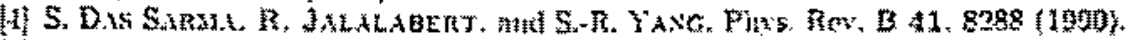

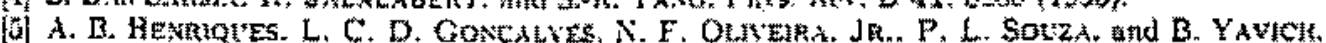

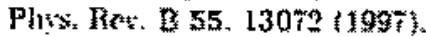

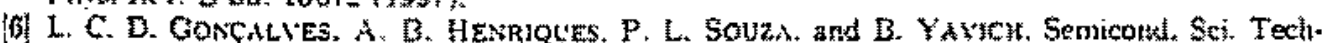
minl., Bress.

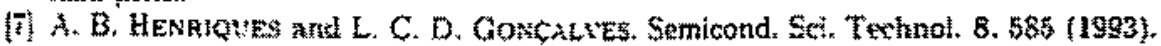

